


\section{A N U A LS}

FOR

StUdents OF MEDICINE. 


\title{
COMPARATIVE ANATOMY
}

\author{
AND
}

\section{Physiology.}

RY

\section{F. JEFFREY BELL, M.A.,}

PROFESSOR OF COMPARATIVE ANATOMY AT KING'S COLLFGE.

\section{ILLUSTRATED WITH 229 ENGRAVINGS.}

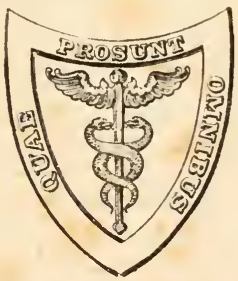

PHILADELPHIA :

LEA B ROTHER \& CO.

(Late Henry C. Lea's Son \& Co.) 


$$
11686
$$


To

\title{
SEPTIMIUS W. SIBLEY, F.R.CS.,
}

\author{
AS A LITTLE TOKEN OF RESPECT
}

FOIR THE

SKILL AND SYMPATHY WITH WHICH HE EXERCISES

HIS BENEFICENT ART. 



\section{PREF A C E.}

THE reader who is sufficiently acquainted with the progress in vertebrate physiology during the last phase of physiological methods, and who knows how scattered and incomplete are the investigations which have been made by the same kind of physical and chemical inquiries on invertebrate animals, will not expect to find in the present volume any complete statement of the physiology of animals, in the sense in which that term is now used. Such observations as have been made without especial reference to the vital processes of man are, for the most part, very valuable and suggestive; but the time to write a textbook of Comparative Physiology, as we now understand it, has not yet arrived.

All that I have attempted to do in this little book has been to illustrate the details of structure by a notice of such experimental inquiries as I have convinced myself, or have adequate reason to believe, are, in their broad outlines, correctly stated. I have much more attempted to make use of what were long since called the experiments that Nature makes for us, by 
referring to, sometimes perhaps insisting on, the dif. ferent methods by which similar results are attained by different animals. That which I have most constantly kept before myself, and which I hope the student will faithfully bear in mind, is, that there las been an evolution of organs as well as of animals, and that he who desires to understand the most complicated organs must first know the structure of such as are more simply constituted.

In pursuit of this object, I have written about organs rather than about groups of animals; but $\mathbf{I}$ have added an index in which the various parts of an animal are collected under the head of its name; so that the student who desires to use this manual as a zoological text-book will have no difficulty in selecting the portions of the chapters which bear on a particular form or set of forms.

I have departed a little from the ordinary method of writing a handbook, in somewhat plentifully interspersing the names of my authorities for various statements. I have done this, not only because it recommends itself to my sense of justice, but because zoological science is just now advancing so rapidly that many observations and. suggestions have to be incorporated, even in a text-book, before they become the general property of zoological workers. My indebtedness to the personal teaching and the published writings of Professor Ray Lankester must be 
by no means thought to be limited to the statements with which his name will be found to be connected; indeed, I owe him more than I can well express.

I have been careful to acknowledge the source whence the illustrations are taken, and I have to return my thanks to the Publication Committee of the Zoological Society; to Professor Flower, who only added one more to a number of acts of personal kindness when he generously put at my disposal all the wood-blocks which were in his own possession; and to those other friends who have allowed me to copy figures from their works.

As this manual is written on lines that are rarely followed, I shall be greatly obliged for any suggestions as to its improvement, or for corrections of any errors which may have found their way into it.

\section{F. JEFFREY BELL.}

King's College, May, 1885. 



\section{ONTENTS.}

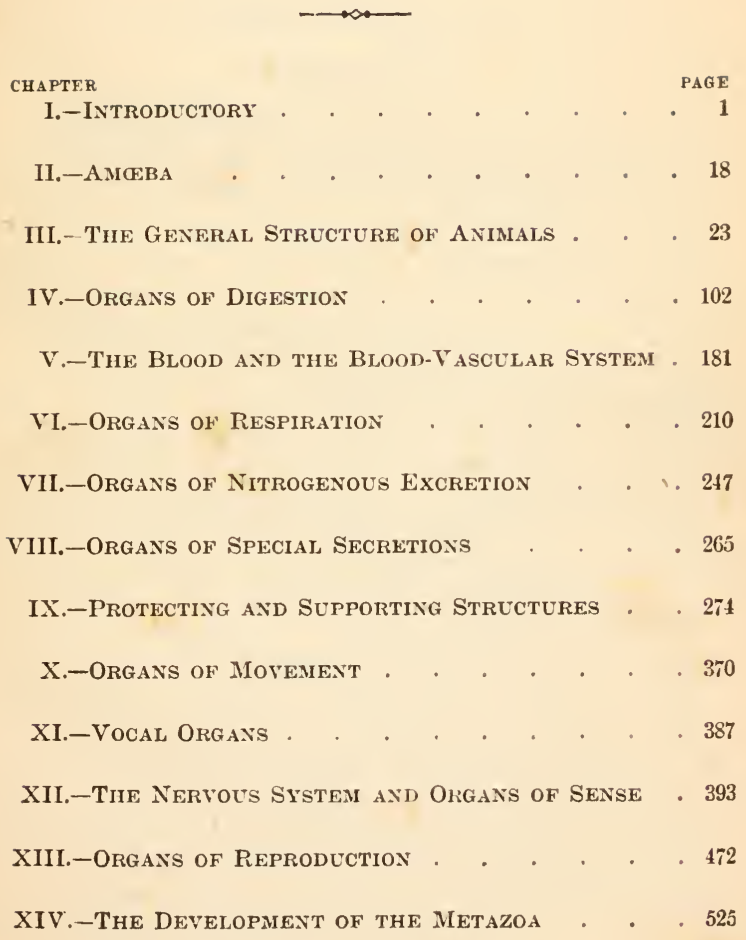




\section{Comparative Anatomy AND Physiology.}

\section{H A P T E R I.}

INTRODUCTORY.

Comparative anatomy is the science of the structure of animals, considered in their relation to one another; comparative physiology deals with the functions of the parts of which these animals are made up, and, by examining different forms that present various kinds of activities, it throws light on the essential properties of living matter.

The study of animals is but a part of the wider science of the study of organised matter generally, the science of biology, which takes plants as well as animals for the objects of its investigations. Under the head of biological studies we have, therefore, to group (a) those which regard organisms as working machines, capable of performing various functions; these studies are physiological, whether animals or plants be separately or simultaneously examined; (b) in the second place, the parts of which the organism is made up may be investigated, and our studies are then said to be anatomical, if we concern ourselves with isolated types, as does the student of human anatomy; or they are morphological, when we compare organisms and their parts one with another, and try to draw out the significance of isolated facts, and to learn their bearing on the general scheme of the organisation of living matter.

$$
\mathrm{B}-16
$$


The present work is concerned only with Animals; but, as there is a fundamental resemblance between Plants and Animals, it is in the first place necessary to enquire into the characters and modes of activity of living matter, pure and simple, without any question as to whether it be animal or vegetable.

\section{LIVING MATTER.}

Animals and plants have at least this in common, that they are both fashioned out of a material which, in all its essential characters, is common to them both ; and, whether one would be a zoologist, or student of animals, or a botanist, or student of plants, it is, in the very tirst place, necessary that he should have some clear and exact comprehension of what are the characters and what are the modes of action of that primary fashioning substance which forms the material basis of living creatures, and which is known as protoplasm. The fact that the sciences of zoology and botany have to do with this "physical basis" of living matter separates and distinguishes them at once from such studies as chemistry or physics, with which the phenomena of life have no necessary connection.

Living is distinguished from not-living matter by several important and easily recognisable characters. It would seem to have a fundamental and characteristic composition; it has the power of continuing to exist by taking into (nutrition), and making part of itself (assimilation) other living or even not-living matter. Nutrition and assimilation lead to growth, and this growth is succeeded by a stage in which the additional material obtained is used for the purposes of reproduction. After a time a living organism may be seen to be unable to withstand the action of the surrounding forces in the midst of which it has lived, grown, and reproducerl itself; in other words, its activity diminishes and 
diminishes, until at last it dies. From this dead matter, living material can never, by any process now known to us, be produced; for, so far as we know, living matter can only proceed from other living matter.

As the chemist is only able to acquire definite information with regard to the chemical composition of living matter by the use of certain treatments which deprive it of life, we cannot speak with certainty of more than the broad outlines of its composition; but this, at least, may be said: in living matter (protoplasm), the four chemical elements, oxygen, hydrogen, nitrogen, and carbon, are always found, and with them there would seem also to be associated small quantities of sulphur and phosphorus. It is possible, if not certain, that protoplasm is a compound of a number of the so-called proteid bodies, and it is quite certain that what chemists call its " atomic composition" is very high. One of the most complex bodies known to us is that constituent of the brain which is called protagon; and its "atomic composition" has been determined to be $\mathrm{C}_{160} \mathrm{H}_{308} \mathrm{~N}_{5} \mathrm{PO}_{35}$, or no less than 509 atoms. When such a body is active, fresh chemical changes are always taking place within it; it is in a condition of unstable equilibrium; the result of such change, so far as it affects the living matter, is loss or waste; in addition to this, living matter is always taking up fresh oxygen, and forming carbonic acid, of which it has to free itself. These activities combined require, as may be supposed, the addition of fresh material from without; that is to say, living matter demands food. The food so taken in may or may not be similar in composition to the organism itself ; but, as the living creature has wasted through all its parts, the fresh material has not merely to be taken in, it has also to be assimilated. When a crystal, placed in a solution of its own material, grows, it does 
so by merely laying on the fresh molecules outside those already formed; protoplasm, on the other hand, makes the fresh food, which may or may not, indeed need not, have the same composition as itself, an essential part and parcel of itself.

In the next place we observe, that while a crystal under the conditions just now mentioned will grow so long as it is supplied with matter of similar chemical constitution, living matter only grows when assimilation goes on at a quicker rate than destruction or waste. Save for the difficulties of experimenting, there is no reason why all the sulphate of copper in the world should not $(\alpha)$ be brought into one huge crystal, and $(\beta)$ so remain. It is not so with living matter ; for every organism there appears to be a limit of growth, and when that is reached, all the succeeding matter assimilated goes for a different purpose. The organism, ceasing to grow, begins to reproduce its kind, and, in the very simplest cases, produces an individual exactly similar to itself. This act of reproduction appears to be, next to sustentation, the primary work of every organism, and when that is completed, we often observe that the parent organism begins to lose its activity ; it becomes the prey of other living organisms; or, undergoing gradual decay, the complex mass of albuminous matter, which we call protoplasm, and associate with life, falls away into constituent molecules of a less high degree of chemical complexity.

Assimilation, growth, reproduction, death, are, as here explained, four phases in the history of living matter which at once and sharply distinguish it from crystalline or other dead material.

Nor is this all; if we set one crystal against another of similar composition, or if we try to rouse or stimulate a crystal, we get no response. With living matter the case is very different; roused either by 
some apparent friend or enemy in the water, or by a touch from our needle, as we observe it under the microscope, a mass of living matter will be found to be irritable. In consequence of this irritability it undergoes some change converting latent into actual energy, and this is most frequently and most easily seen to be some change in space, or in the relations of its parts; these are due to what is known as the contractility of living matter. In other cases, the production of heat, light, or electricity, is the expression of irritability.

We have next to observe, that within the area of any given mass of protoplasm, there may be movements of its parts; some of the granules seem to stream in a more or less regular course between those on either side of them, in a way which can best be unclerstood by supposing the observer to be raised above and to be able to note the movements of a great crowd of passengers in a busy street; some move faster than and overtake others, some collect into more or less small crowcls; others, having moved onward for a certain distance, turn asicle or turn back. This streaming movement of protoplasm is highly characteristic, and affords a proof that the problem of the motile activity of protoplasm can only be explained by the study of the parts of which it is made up.

Lastly, thin layers of non-granular protoplasm are sometimes to be observed gliding over firm bodies; by these means the whole mass is enabled to progress in a forward direction.

The study of streaming movements shors us that the constituent particles do not move around any fixed point, but freely as the particles of a fluid substance. So far as we can see, these movements are not the result of any external cause; did we choose to allow that a simple mass of protoplasm had a "will," we might well call them "spontaneous" or "voluntary;" 
without going so far, we must allow that they appear to be due to the protoplasm itself; they are selfmoved or automatic.

Living matter, then, is irritable and automatic; irritability finds expression in contractility, or in the production of such forces as heat, light, or electricity.

With regard to its general physical and chemical characters, we have to note that it is possessed of great cohesive powers, and yet is very extensile; it does not mix with water, but it swells by imbibition; it may expel the contained fluid in the form of rounded vacuoles, and bubbles of gas are sometimes apparent in it. It is ordinarily colourless, and refracts light more strongly than water; it is in most, and probably in all cases, slightly alkaline in reaction.

Before we leave the general consideration of protoplasm, we must point out two foreign elements which have to be considered. The first of these is the presence in protoplasm, as we ordinarily observe it, of various more simple chemical compounds, which have the form of granules; these, which may be fatty or starchy bodies, are conveniently grouped together under the head of metaplasm; they may be regarded as owing their origin to the changes that are constantly taking place in the molecular constitution of the protoplasm, or, in other words, as waste products not yet eliminated.

The second is a general motion of a protoplasmic mass, especially when of particularly small size (e.g. bacteria); this movement of the body as a whole is not a vital, but a purely physical phenomenon, as may be demonstrated by the simple experiment of rubbing up a little gamboge in a drop of water, when exactly the same movement is to be observed. This approximation and separation of small particles is a phenomenon which has attracted the attention of the physicist, by 
whom it must be explained; it was, howerer, first observed by an eminent botanist, and is consequently known as the Brownian morement.

The term cell is not unfrequently applied to every separate mass of living matter, but, in consequence of the associations connected with this term, it is better to make use of the more elaborate tlıough perhaps more intelligible nomenclature which enables us to distinguish between the difierent characters of "elementary organisms." When attention was first directed to these objects, the botanist observed that in each mass of protoplasm there was a portion which, by various characters, could be easily distinguished from the rest, and which might be very appropriately spoken of as the nucleus; in addition to this, he saw that the outer portion of the protoplasm was enclosed as in a wall; he spoke, therefore, of the whole as a cell, with a cell wall, and a contained nucleus.

Later on it was found that the protoplasm (or "sarcode," as it was originally called) of animals was not to be distinguished from that of plants, and it was then also seen that it was only in very rare cases that this animal protoplasm was enclosed in a cell wall. Thereby the very first conception of a cell was destroyed, but the name was still retained as a convenient term.

Still later researches revealed the at first astonishing fact that organisms could and did exist in which that specially modified portion of the protoplasm which had been called the "nucleus" was, to all appearance, altogether absent; some naturalists, and especially some physiologists, now regard the nucleus as no essential part of the cell. On the other hand, it seems better to recognise in our nomenclature the present conditions of our knowledge, and to use for the "elementary organism" some other definite term than that around which so many battles have 
been fought, and with which, perhaps, no few superstitions are or have been connected.

We will, therefore, follow those who have agrsed to the suggestion of Prof. Haeckel, and will use for the elementary organism, whether or no provided with a nucleus, the useful and suggestive term of plastid. This plastid, or unit of organic structure, is composed of protoplasm; it may be without a nucleus, when it is a cytod (or cell-like body), or it may have within it a denser mass, which is very feebly, if at all, contractile, the nucleus; in which case it is a cell. This nucleus is ordinarily provided with one or more smaller nueleoli, and, possibly, always has a distinct investing membrane. It would appear to have a special chemical composition, inasmuch as while a cell when treated with a ten per cent. salt solution leaves a precipitate, no such precipitate is stated to be found when a cytod is subjected to the same reagent. The body so precipitated has been called nuclein.

Protoplasm, then, is presented to us in the form of plastids, and these plastids may either be without (cytods) or have (cells) distinct nuclei. All organisms are composed of one or more cells, or, in other words, are either unicellular or multicellular: The former, as much as the latter, are capable of exhibiting all the essential phenomena of life.

\section{TISSUES AND ORGANS.}

When we examine the different stages in the history of a developing animal, or compare a series which commences with low and passes through more highly developed forms, we find a gradual increase in the complexity of the parts; of this we have already had an example in comparing the cytod with the cell, and we shall observe it in every chapter of this work. This increase in complexity is termed the process of differentiation. 
In making a general survey of animals we find that the lowest consist only of simple cells ; later on, the cells are found not to live an independent existence, but to be associated one with another, and different groups of cells are seen to be differentiated in various ways. The result of this is that sets of cells come to have different characters (some are contractile, others irritable, and so on), and these different sets are what are known as tissues; secondly, we observe that these tissues become connected with one another in different proportions and relations, so as to give rise to those parts of the adult which take on particular duties, and are known. as organs.

Looked at in a general way, and without taking any notice of exceptional cases, we observe that there are tissues in an animal which are not found in a plant; these, which are distinguished as the animal tissues, are such as have a relation to movement or sensation; in other words, the muscles and nerves are animal tissues. On the other hand, plants preserve, protect, and sustain themselves, and the corresponding tissues in animals are always spoken of as the vegetative; of these we may find convenient examples in that outer layer of the body which is spoken of as epithelium, or that supporting tissue which is known as bone.

The classification of organs is a little more complex, but it will be convenient to give it now, so that time and space may be saved in the future.

In the first place it is clear that the regetative functions fall under three great heads; an animal has to care for itself, to adapt itself to or move through its surroundings, and to reproduce its kind. And, in the second place, it is just as obvious that it has to perceive what is going on around it, and to act accordingly. We have, then: 
(1) Organs of internal relations.

i. Protective.-Examples: Skin, shell.

ii. Nutritive.-Examples: Digestive tract (nutrient); heart and blood-vessels (circulatory).

iii. Parifying.-Gills, lungs (carbonic acid); kidneys (nitrogenous products).

(2) Organs of external relations.

iv. Loconmotor.-Limbs, etc. (compounded of skeletal and muscular tissues).

v. Prelnensile.-Limbs, etc. (compounded of skeletal and muscular tissues).

vi. Offensive.-Teeth, claws, electrical, odorous organs.

(3) Reproductive.

(a) Germ-producing glands : testes, ovaries, which are essential.

( $\boldsymbol{\beta})$ Copulatory : penes, etc., which are accessony

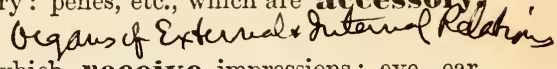

(a) Organs which receive impressions; eye, ear, etc., brain.

( $\beta$ ) Organs which stimulate other organs ; brain.

\section{METHODS OF COMPARISON.}

When an anatomist has acquired a positive knowledge of a certain number of selected forms of life, he proceeds to convert his empirical acquaintance with facts into science by reasoning upon the information which he has acquired. In this operation he makes great use of the fertile method of comparison, remembering the words of Buffon, "Ce n'est qu'en comparant que nous pouvons juger." Like things, however, must be compared with like, or confusion will inevitably result. We must, therefore, lay down certain rules to guide us in these kinds of enquiries, for, though no one would attempt to compare a heart with a ling, many would, at first, more willingly compare the leg of a man with that of a cockroach, than the fin of a perch with the wing of the sparrow; yet the latter is the more justifiable proceeding. 
The reason for this is plain, the moment we clearly understand what object the comparative anatomist has before him ; it is that of coming to some general conclusions as to identity or community of structure; for this purpose, then, he is not to compare parts that have the same function, but those that are formed in the same kind of way. The physiologist, on the other hand, looking at organs as parts of a machine, examines together those that do the same thing. When we compare parts morphologically, we must not be content merely with an analogy between them, we must be careful that there is a homology or real resemblance.

The first criterion of homological parts is their development from similar embryonic structures; such are the wing of a bird and the leg of a horse. But a further question now arises; why have these wings and legs, which in their completed condition are so different from one another, a similar structure in the embryo? The answer to this is given by the doctrine of descent, which supposes that the bird and the horse had in the past a common ancestor, provided with limbs simpler in structure than those of either bird or horse, but having essentially that which they have now, or which they have had, and from which they are both derived; a true and complete homology of parts is, then, only to be found between animals which have had a common ancestor provided with the part to be compared. This complete homology may be conveniently spoken of as homogeny (Ray Lankester).

It is very necessary to have before the mind this idea of community of descent, because we shall constantly meet with cases in which, with a very close resemblance in structure and mode of development, there is not a complete identity in descent. For example, all mammals and all birds are provided with four 
cavities in their hearts : two auricles and two ventricles ; but it is certain that, whatever was the animal that was the nearest common ancestor to the two, it had only one ventricle. The right and left ventricles of the hearts of birds and mammals are, then, not homologous in the sense of being homogenetic; they have been acquired independently by the two groups, in consequence of certain physiological needs; they are the result of similar modifying forces, and are homoplastic, but not homogenetic parts.

\section{DEVELOPMENT.}

The last point to which the student must be introduced is one of the very greatest importance. If we study the animal kingdom throughout, we find that, starting from the simplest mass of protoplasm, we are gradually led to the complex and elaborate structural and functional arrangements which are found in so highly organised an animal as man himself. If, on the other hand, we study the developmental history of a highly organised form, we find that it starts from a simple mass of protoplasm, the egg, or ovum, as this plastid is called; this cell gradually becomes more and more elaborated, and takes on the more complex arrangement which may be seen in its parent; we observe, that is, that not only are there a number of stages in the different representatives of the animal world, but that there are also a number of stages in the structural history of every individual; and we may go yet a step farther, and say that in a broad and general way there is a complete parallelism between the two.

The results of the investigations and considerations which flow from a study of the facts here indicated are best expressed in an aphorism, which may at once be laid to heart, and which will be abundantly proved by a study of development and comparative anatomy : 
"The history of the individual is a compressed epitome of the history of the race."

Those, therefore, who desire to obtain a complete knowledge of animals or, indeed, of any one animal, must not be contented with an account of the anatomy of the adult; they must direct their attention also to its development, and become the students of Embryology, while they must no less take care to study the history of the animal, or of its allies, in the past ages of the world, or to know something of its

\section{Palaeontology.}

These two branches, Embryology and Palacontology, are of the greatest assistance in an endeavour to obtain some clear idea of the morphology of animals ; but a weapon no less sure and no less important is that of comparison, by means of which similar parts in different organisms are studied and explained; no better aid to safe judginent can be afforded, and it must be used unceasingly and unsparingly.

\section{EVOLUTION.}

The great maze and mass of facts which are found in works on zoology or comparative anatomy are hardly to be held together without the bond of philosophy; the grouping of facts, and, still more, the grouping of animals, must be always more or less unintelligent, mechanical, and artificial, unless we make some use of some kind of explanation. That which we shall use here will be founded on the belief that there is a blood relationship, or relationship by descent and inheritance, between every member of the animal kingdom; and that, were it possible to know all the facts, we could make a genealogical tree for animals, which should be as exact and definite as the family tree which is drawn up by the genealogist or the herald. That division of biology which busies itself with genealogical problems is known as Phylogeny. 
All the steps in the differentiation and elaboration of organised beings are examples of that process of evolution, which, when based on a belief in the existence of a blood relationship between animals, is known as the doctrine of descent. In an attempt to understand how this has worked, we make reference to two different series of facts. We have, in the first place, to make certain generalisations as to the way in which the differences have been brought about, and we have, in the second, to consider what are the essential properties of living matter which may be regarded as the determining factors in the evolution of organised material.

The generalisations made from a number of ob. served facts may, if this definition be borne in mind, be called the laws of evolution; they have been thus enunciated by Professor Huxley :

(1) There has been an excess of development of some parts in relation to others.

(2) Certain parts have undergone complete or partial suppression.

(3) Certain parts, which were originally distinct, have coalesced.

Let us apply these laws to a concrete example, and select for study the fore-foot of a camel. In the more primitive mammalia there were five fingers or digits, each connected by a metacarpal or palm bone with the wrist, and these five sets of digits and metacarpals were of subequal size. In the hoofed group of animals the first of these, or thumb, disappeared, as in the case of the modern pig; the two that were now outermost, the second and fifth, became smaller and smaller, as in the sheep or deer, and finally, as in the camel, disappeared altogether. Here we have various stages of law 2. This loss of the outer was accompanied by an increase in the size of the median digits and metacarpals (law 1), and in the more or less complete fusion of 
the third and fourth metacarpals one with the other (law 3); the result of this last process being the formation of a bone which at its lower end only gives any obvious indication of its primitively double nature.

The characteristics of protoplasm which appear to be the deterynining factors of evolution, are (1) its power of producing an organism like to itself; and (2) the fact that no child or parent, or any two children, are exactly similar one to another. The first of these principles is known as that of heredity, the second as that of variability. It is obvious that the second principle only comes into action because of the differences in the surroundings of every individual plastid ; the greater the homogeneity of the surroundings, the greater the likenesses between the plastids. The law of heredity may consequently be compared to the first law of motion (Gasquet).

Organisms, therefore, tend to resemble their parents, but, being more or less differently affected by surrounding media and objects, diverge more or less from the parent stock; the greater the differences in environment, the greater the differences between parent and child. This is a fact so well known to us all that we need not enlarge upon it here.

\section{ANIMALS AND PLANTS.}

While the conviction that there is an essential unity between animals and plants may be taken as one of the most important results of modern biology, we have to note that along the two lines of organisation the constituent protoplasm has, on the whole, developed special characteristics. In other words, we are not able always to say definitely whether a given unicellular organism is an animal or a plant ; but we can always with certainty point to the differences which distinguish a rose from a bee. 
Thus the form (1) of a plant is diffuse and arborescent, that of an animal oblong and rounded. A plant lives on (2) carbonic acid and mineral salts, but an animal requires albuminoid foods. These foods are in the plant taken in (3) by the porous tissues, and there is no distinct mouth as there is in all but the lowest, and in the majority of parasitic animals. The secretions (4) of a plant are non-nitrogenous, while some of the waste products of an animal always contain nitrogen. In their habits (5) we find that plants are fixed, and animals locomotive. And, lastly, (6) as to the characters of their cells, we find that plants have a cell wall formed of that ternary compound which is known as cellulose, while the wall of an animal cell, when present, is derived directly from the cell protoplasm.

To nearly all the statements now made an exception may be found: thus (1) cacti and fungi are certainly not arborescent or diffuse, while polyps as certainly are. (2) Fungi appear to require some more complex compound than merely carbonic acid and mineral salts, but such a body as ammonium tartrate will give the nourishment required; every animal known to us requires albuminoid food, and dies when deprived of it. (4) It is quite true that plants do not give off nitrogenous excreta ; but their protoplasm, it must always be remembered, is capable of forming them; on the other hand, all the excreta of an animal are not nitrogenous; Ascidians (and, if they are truly animals, some of the Cilio-flagellata) form cellulose. The latter and some low worms have been observed to form starch, and sugar is a ternary compound formed by various animals. The well-known Volvox offers (j) an exception to the statement that plants are fixed, and polyps and, to a large extent, stalked Echinoderms, to the statement that animals are locomotive. Lastly, some of the lowest plants, such as Myxomycetes, have their protoplasm naked, while the just-mentioned 
Cilio-flagellata have cellulose in their cell-walls. and the so-called matrix of cartilage cells does not appear to be directly formed from the cells themselves.

This enumeration of differences or resemblances is, after all, unsatisfactory, and will, with the progress of knowledge, come, no doubt, to be regarded as misleading; for the present, it will not fail in its object of impressing on the student the broad and general characteristics of animals and plants as we now know them ; but there must be added to it a reminder that among the higher members of the Droseracer we find plants $(\alpha)$ whose leaves have in some forms the power of movement when excited; $(\beta)$ the glands of their leaves are able both to digest and to absorb animal matters; and $(\gamma)$ the normal electrical current is, when these leaves are irritated, disturbed in the same manner as is that of a contracting animal muscle.

The general relation of animals to plants is well shown in the following table (Brass):

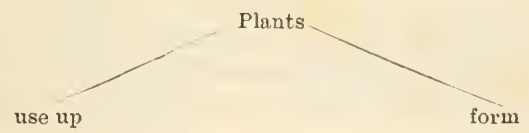

carbouic acid, water, nitrates,

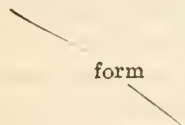

oxygen, carbohydrates, fat, allumen,

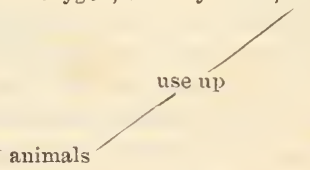

The fact that, in sunlight, green plants (that is, plants containing chlorophyll) give off oxygen has led some to think that plants take in carbonic acid and exhale oxygen ; but plants as much as animals give off carbonic acid as a waste product. If or when an animal contains chlorophyll grains, it as much as a plant will give off oxygen under the influence of sunlight.

$$
\text { C- } 16
$$




\section{CHAPTER II.}

\section{AMCEBA.}

IT has been wisely said that "the highest laws of our science are expressed in the simplest terms in the lives of the lowest orders of creation" (Paget); and it will be well, therefore, to commence our studies with a close investigation into the characters of one of the simplest of living animals.

The word Amoelba is a generic term, * which is applied to a number of forms, which have in common the following characters; they are more or less minute specks of nucleated protoplasm, without any wall or membrane limiting their surface, and they are capable of pushing out processes of their body substance from any part or point of it. They are sometimes as much as one-hundredth of an inch in cliameter, but they in all cases require the assistance of a microscope of high powers for their satisfactory study.

If we place one on a glass slide, and, after allowing it to become used to its new position, examine it under the microscope, we shall at once see how appropriate is the name that has been given it. Its form is never constant for more than a few moments together, as we can best demonstrate by making a sketch of its shape once every minute for some five or six times.

These changes in form are, we know, expressions of the irritability and contractility of the protoplasm.

* The possibility that a number of so-called Amœebæ are stages in the life-history of animals or plants does not affect the question here dealt with. 
Looked at more closely, we see in it evidences of differentiation of structure; the mass, small as it is, is not homogeneous; the outer portion is denser and
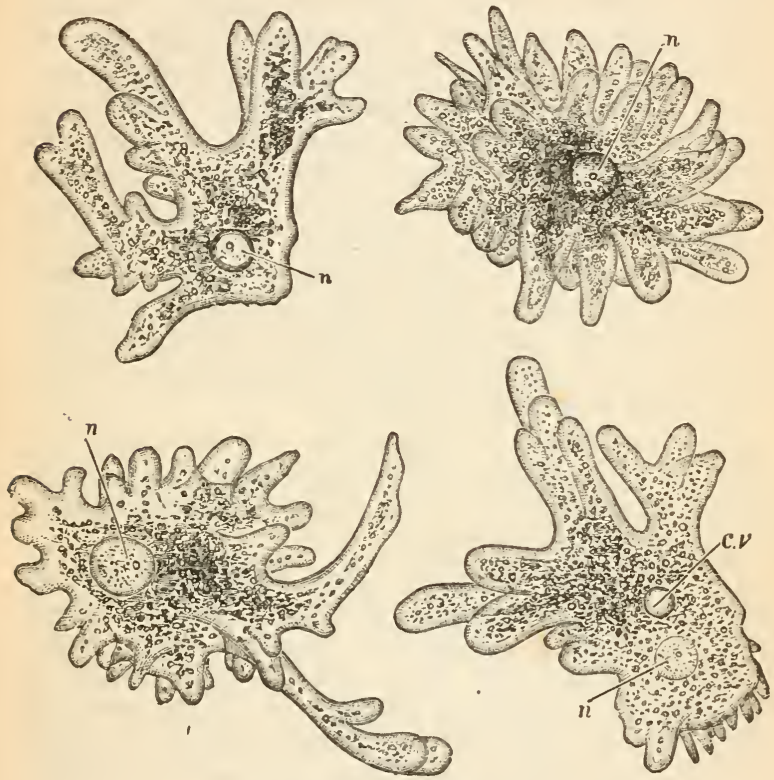

Fig. 1.-Amœta.

$n$, Nuclcus ; $c v$, contractile vacuoles.

clearer (Fig. 1) than the inner, which is more fluid and granular. Although these two portions are not sharply marked off from one another, it is convenient to have definite names by which to distinguish them, and we will speak therefore of an ectosarc, and an endosarc. Within the endosarc we see a diskshaped or rounded body which retains its form, while 
the protoplasm around it is changing; this is the mucleus $(n)$, and within it is a smaller body, the little nucleus, or mucleolus. In the ectosarc we have to observe a space which opens slowly, and contracts rapidly; its power of contraction may be seen to be independent of that of the general mass of protoplasm. This space (the contractile vacuole, $c v$ ) appears, though we cannot speak with certainty, to be a kind of pump, whereby water is taken into and forced out of the body; the water that enters must bring with it a certain quantity of oxygen, which is a prime necessity of every living organism, whether it be plant or animal; while the water that is forced out of the body must carry with it a certain quantity of those waste products which always appear when a living body is in active function.

The contractile vacuole, then, would appear to effect for the amcba the two processes of respiration and of purification, which, in higher animals, are performed by definite organs.

It will at once be noticed that there is no special point by which food enters, or what is useless in that food escapes from the amoba; in other words, there is neither mouth nor anus. But it will almost as soon be seen that this naked cell has no need of either the one or the other; it flows around the food it needs, and it flows away from the waste or useless matter which is of no further use to it.

Just as there is no special inlet for the food, so there is no part of the cell which can be said to be especially digestive in function. We can best see what happens to the food when it is a green-coloured plant; when such is under observation we find that it gradually breaks up within the amœba, that it gradually loses its green colour, and finally disappears; if it be a diatom that has been flowed around, we may observe in time that the undigested case will be 
left behind. The cell, then, of which the amoba consists, is capable of taking in food, and of making it part of itself ; it can, in fine, effect all the operations of nutrition.

The flowing around food is only an expression of that general locomotor activity of the amœba which finds a more general expression in those remarkable. changes in form to which we have already directed attention. These, when studied in detail, are found to be effected in the following fashion. At some point of the body where the contour is smooth and rounded a little knob of ectosarc may be seen to be protruded, and to widen ont as it increases in size; the cavity in its interior which is thus formed becomes filled with endosarc which flows into it. The protrusion is at first broad or lobate, and it may so remain; or it may increase in length and diminish in proportionate breadth, or it may eren become branched at its free extremity. Such an out-pushing of the substance of the naked cell is spoken of as a pseudopodium (false foot). When, as often happens, several small pseudopodia, or one or a few of large size are given off close to one another, and if the pseudopodia are not at the same time protruded from the opposite surface of the cell, then the whole mass follows the pseudopodia, and there is a general movement of the amœba; at such a time we can distinguish an anterior from a posterior end.

The amoba, then, feeds, grows, and moves about, takes in oxygenated water, and gets rid of waste material; exhibits, in fine, all the essential phenomena of internal and external relation; it does not exhibit anything more than a general irritability, but as it does answer to stimuli from without, it presents us with a copy, as it were, of the changes that occur in ourselves when we are acted on by external stimuli. It performs all the actions that are essential to our 
idea of an individual living for itself. But it does more than this; it performs also the function that is necessary for the continuance of the species of which it is a representative. It reproduces itself.

In the simplest case the act of reproduction is effected thus; the nucleus elongates, becomes constricted in its middle, and divides into two. As this division is being effected the surrounding protoplasm becomes divided into two masses, each of which accompanies one half of the nucleus. As a result of this process we have two individuals where before we had one, and they differ only from the amœba which we have been previously studying by their smaller size; as our first amœba has altogether disappeared, it is, to all practical purposes, dead; and we have, then, in this, the simplest condition of reproduction, the death of the parent absolutely cotemporaneous with the appearance of a new generation. This process of reproduction is that which is known as fission.

Another method is also observed in the amœba, which may be regarded as a modification of that of fission. A small portion (bud) of non-nucleated protoplasm is gradually separated off from the rest of the mass; this increases in size, and develops within itself a new nucleus, so that it becomes exactly similar to its parent, which, in this case, continues to exist. Here we have reproduction effected by budding, or gemnation.

Notwithstanding all the functions performed by this minute mass of protoplasm, it will be observed that there is nothing in the cell to which we could correctly give the name of an organ. We are in the presence of life, but hardly of organisation. 


\section{CHAPTER III.}

THE GENERAL STRUCTURE OF ANIMALS.

BEFore proceeding to a comparative account of the structure and functions of the organs of different animals, it will be necessary to introduce the stuclent to the broader characteristics of the groups into which the animal kingdom has been divided. What follows in this chapter is to be regarded as having that aim alone; it is in no way to be looked upon either as a classification of animals, or even as an introduction to it, and it is to be used rather as a kind of guide to the relative position of any animal that may be mentioned in the succeeding chapters. So far as is possible in the necessities of the case, it has been so prepared as to linder rather than to aid the student in any attempt to commit to memory a system of classification ; for it is certain that there is nothing less fruitful in good result than a parrot-like acquaintance with what is only a compressed epitome of the more certain results of zoological enquiries, but which, it is to be remembered, may at any time be profoundly modified by further investigation. What is called a classification of the animal kingdom is nothing more or less than a précis of our knowledge at a given moment, and, at its best, ean never be more than relatively correct.

On the other hand, the sketch that follows may be of use as indicating the general course of development, taken along different lines by different kinds of animals.

'The simplest animals essentially resemble an 
Amøba in this particular, that, for the whole period of their lives, all the functions of the organism are $\times$ performed by a single cell; and, even where cells remain collected into a colony, each individual member of that colony performs all its own duties, and affords no assistance to the rest; there is no division of labour.

In the higher animals a very different phenomenon is seen; here again the whole organism is, indeed, composed of cells or cell-derivates ; but, howsoever complex it may become, it starts always on the cycle of its existence under the form of a single cell. This cell, which is known as the ovum or egg-cell, undergoes a series of divisions by means of which, two, four, eight . . . . cells are produced, and these become arranged in definite fashion, and take on more or less well-defined functions. Here, then, different parts of the organism have different duties, or, in other words, there is

\section{$x$ division of labour.}

The first or lower group of organisms are asso-

= ciated together as the Deotozoa; the second, or those that come after them, form the division of the

= ILetazon. Did we desire to use less objective terms, we might adopt for these groups the corresponding

$=$ terms of Cytozon and Histozon (Maupas), which conveniently direct attention to the essential difference in the cells of the protozoan, and the tissues of the metazoan organism.

In attempting to arrange either of these divisions, we are met at once by the fact that the changes which have taken place in organisms have been in two lines or directions; there las been progress, and there has been degeneration. The former we shall find to be more intimately associated with a free and active life, and a ready power of adaptation to changed circumstances ; the latter to a fixed and often to a parasitic mode of existence. 


\section{PROTOZOA.}

For our purposes we shall find it convenient to divide the Protozoa into three great groups, one of which has become degraded by parasitism; these are the Sporozoa, of which the best known division are the Gregarinida ; the others, one of which is distinctly higher than the other group, may be called the Sarcodina and the Infusoria.

Of the Sarcodina, the best type is the common Anocha, which we have already studied ; like it, all the members of the group move about and take in their food by means of those movements of the protoplasm of the cell which result in the formation of pseudopodia, and they reproduce themselves either by division or by budding.

In the Infusoria the amœbiform character is lost, and the cell has and retains a definite form; the ectosarc ordinarily sheds out a structureless membrane. This encloses the softer protoplasm which makes up the rest of the organism, giving off delicate processes which make their way through the limiting membrane; these processes, or cilia, are typically developed, are portions of protoplasm which retain their contractile power, and form the chief means of progression. Owing to the presence of the covering membrane or cuticle, it is necessary that there should be at some point an opening in the cell (cytostome), by means of which food may, at any rate, enter; this opening is ordinarily spoken of as the month; in addition to it there is sometimes a second orifice developed, which has the function of an anus (cytoproct).

The third division of the Protozoa are the degraded parasitic forms, of which the Gregarine is an excellent example. Though these cells are covered in by a distinct membrane, there is no orifice or 
mouth by which the food can enter; living as they do in the digestive tract or other cavities of the bodies of higher animals in which nutritious matter is abundant, they obtain such food as they require by the mere

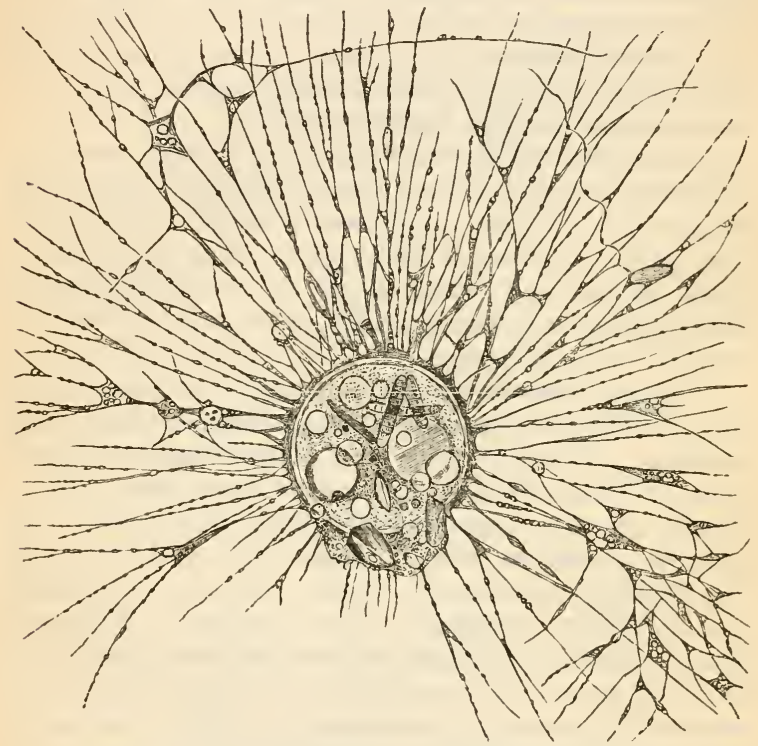

Fig. 2 A.-Gromia, showing the test and the protruding protoplasm.

physical process of osmosis. Similarly, having ceased to lead a free life, and abiding now in closed spaces, they have lost the cilia which were possessed by the infusorian and exhibit instead a slow serpentine movement which is effected by the ectosarc.

The Sarcodina are conveniently divided into three great divisions : 
I. Rhizopoda; example: Amoba, Gromia, Nummulites.

II. Heliozoa ; example: Actinophrys (Sun animalcule).

III. Radiolaria ; example: Acanthometra, Chilomma.

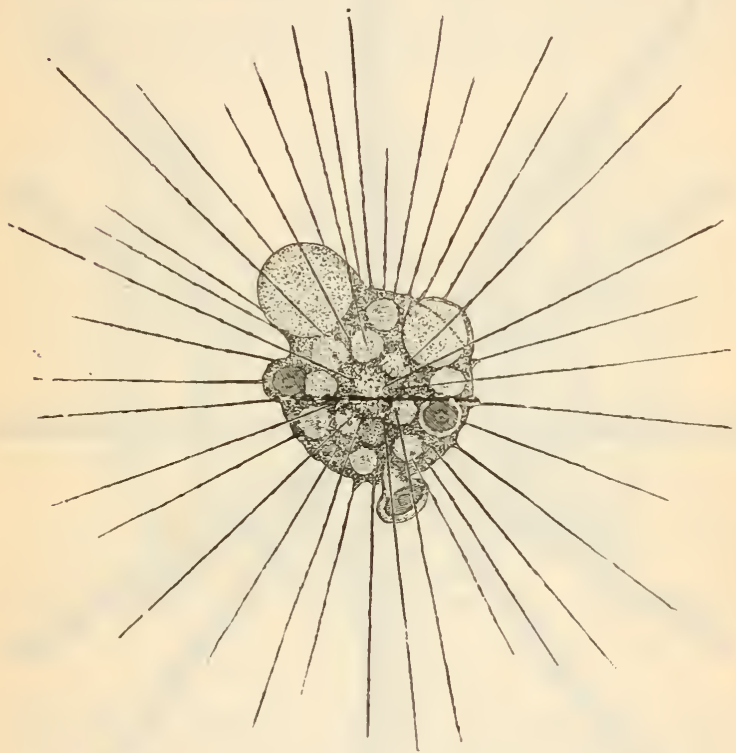

Fig. 2 B.-Actinophrys sol, showing the vacuolated ectosarc, the finely granulated endosarc, the nucleus, contractile vacuole, and pseudopodial filaments. (After Leidy.)

Leaving out of our consideration those simple and incompletely known forms in which no nucleus is developed in the protoplasm (Monera), * we may distinguish the naked Amœba-like Rhizopoda from those

${ }^{*}$ It is possible that in such forms the nuclear substance is diffused through the protoplasm (Gruber). 
in which a covering or test is developed; this test may be chitinous (Gromia), or chitinous and calcareous, or, in rare cases, siliceous; and it may have either

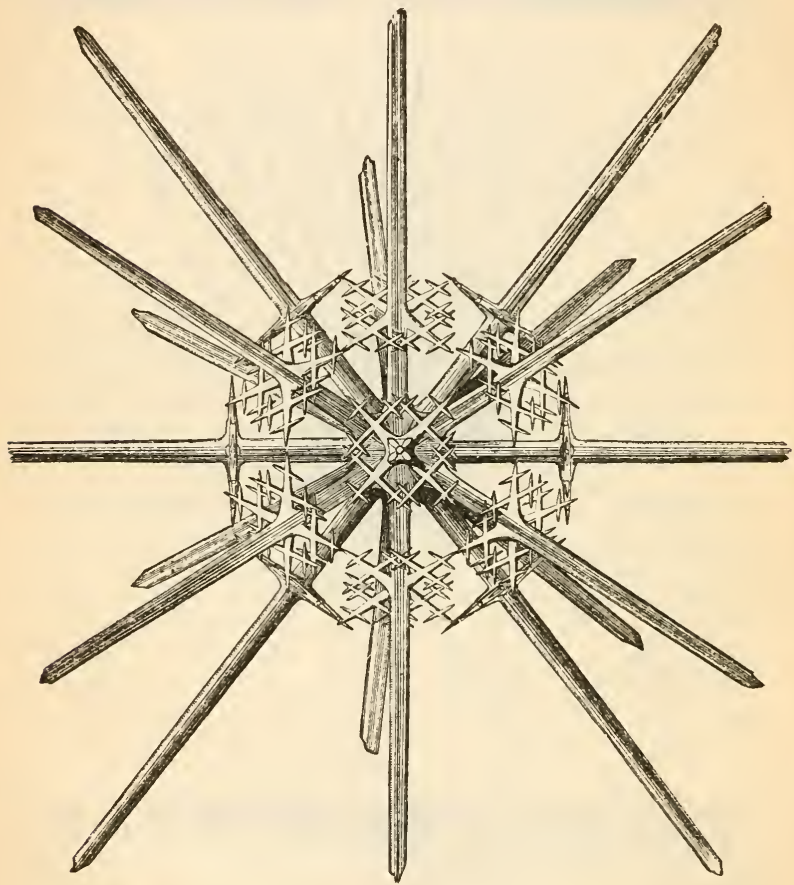

Fig. 2 c.-Xiphacsntha, showing the siliceous skeleton. (After W. Tromson.)

a single large orifice (Fig. $2 \mathrm{~A}$ ), or the test may be perforated with a number of holes (Foraminifera), and may attain to a large size (Nummulites), and great complexity of form. 
The Heliozoa either have the body naked or a siliceous skeleton is developed; the body is very commonly spherical in shape, while the psendopodia (Fig. 2 B) are fine, alter but little in form, and rarely anastomose with one another ; lastly, the IRadiolaria (Fig. 2 c) have a chitinous "central capsule," around which flows the protoplasm, and with which there is
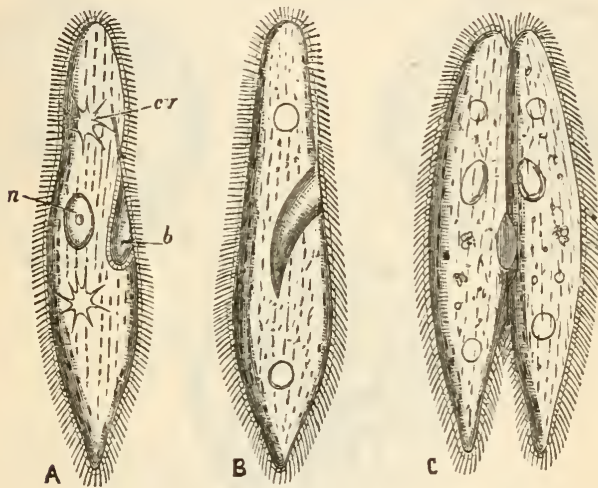

Fig. 3 1.-Paramacium aurelia; $\mathrm{A}$, from the side; $\mathrm{B}$, from below ;, two in conjugation.

$n$, Nucleus ; $b$, mouth; $c v$, contractile vacuole.

ordinarily connected a delicate and often elaborate slliceous skeleton. The pseudopodia are less constant in form than in the Heliozoa, and enter into anastomoses with their neighbours.

The Infusoria are ordinarily ciliated, but in some (Flagellata) the cilia are replaced by a single long whip-like process of protoplasm (flagellum) (Fig. 3 II.), and in others which are parasitic on (ectoparasitic) the bodies of other infusorians, the cilia are lost and replaced by tentacle-like sucking tubes (Fig. 3 inI.). 
I. Ciliata, as Paramœcium, Vorticella, and others; the cilia are either regularly distributed over the cell, and are, for the most part, subequal in size (Paramœcium) (Fig. 3 I.); or some are much larger than the rest (Stentor); or the cilia are ordinarily confined to a spiral circlet around the mouth (Vorticella), and are only occasionally found on other parts of the

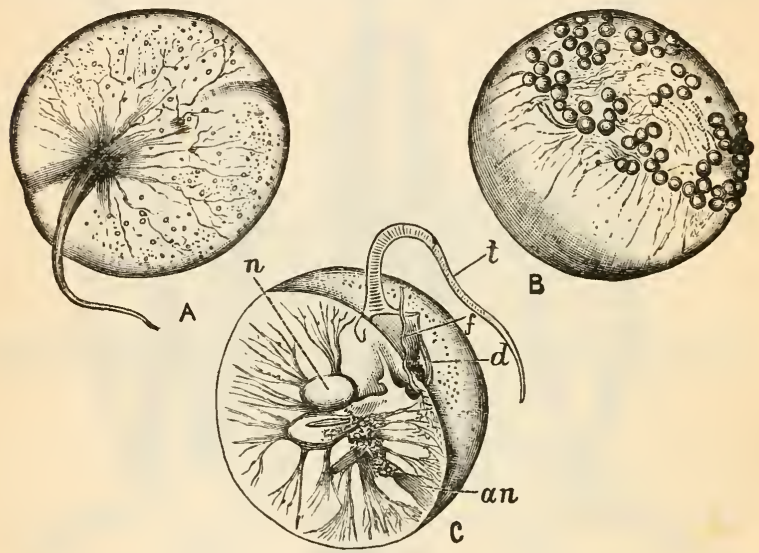

Fig. 3 Ir.-A, Noctiluca miliaris; B, with buds ; c, section. $n$, Nucleus ; $f$, flagellum; $t$, tentacle ; $d$, denticle ; $a n$, anus.

body; or, finally, they may be limited to the so-called ventral surface (Euplotes); in the Peritricha, as the group to which Vorticella and its allies belong is called, there is often an elongated aboral stalk, which sometimes exhibits a remarkable power of rapid contraction.

II. Flagellata ; a number of forms are grouped by some writers under this head; of such as are almost indubitably animal, Noctiluca (Fig. 3 II.), the animalcule which causes much of the diffused phosphorescence of the sea, is one of the best known. 
III. Suctoria: in these parasites (e.g. Acineta, Fig. 3 III.), the mouth is lost and the sucking tubes protruded from the protoplasmic mass serve to convey food into the body. A study of their development reveals the interest. ing fact that they commence life as ciliated embryos, and suggests the idea that they are descended from ciliate infusoria.

The Sporozoa will, for the purposes of this book, be represented by the Gregarinida. The forms best adapted for study are the gigantic Gregarine found in the intestine of the lobster, and remarkable for being, though but

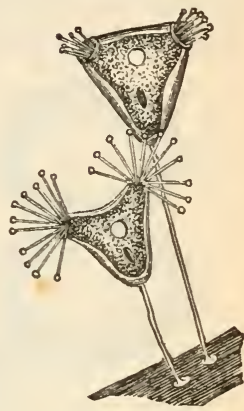

Fig. 3 IIr. - Acineta tuberosa.

a single cell, as much as two-thirds of an inch in length; and the much smaller species found in the

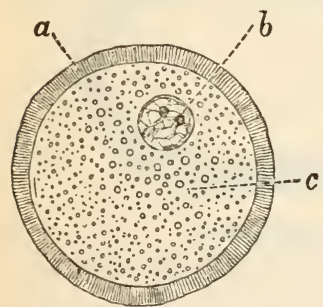

Fig. 4.-Ripe Ovum of Cat. (After Klein.)

$a$, Envelnpe ; $b$, nucleus ; $c$, protoplasm. testicular reservoirs of the earthworm.

\section{II.-THE MIETAZOA.}

STRUCTURE AND EARLY HISTORY OF THE EGG-CELL.

The key to the structure of the higher animals, or Metazoa, is to be found in a knowledge of the early history of the egg from which, as has been already. said, they all arise. This cell, when mature, consists of a mass of protoplasm (Fig. 4, c), with a central nucleus (b), and contained nucleolus, and in most, though not in all cases (Hydra), it has a definite investing membrane $(a)$. Under normal circumstances this egg-cell is fertilised 
(by the male element (chap. xiii.), and then commences to undergo a process of cleavage, or division. It first divides into two cells, which are, in the simplest cases, equal in size; each of these again divides, so that there

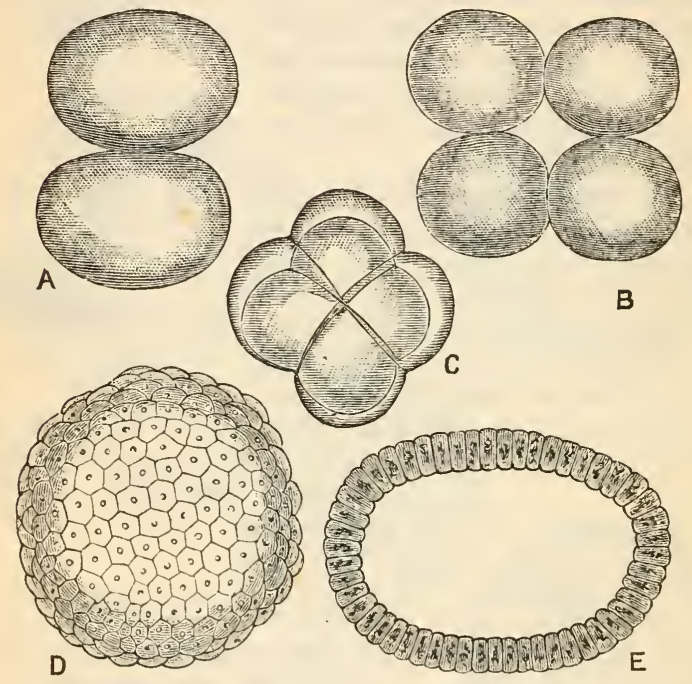

Fig. 5.-Segmentation of Amphioxus.

A, Stage with two equal segments; B, with fonr; C, with eight; D, segments enclosing a segmentation carlty ; $\mathbf{E}$, somewlat older stage in optical section. (After Kowalevsky.)

are four, then eight, and so on. After a time the process of segmentation (Fig. 5) comes to an end, and then we have a mass of segments, which are either closely applied to one another, and so have a kind of mulberry-like appearance (hence the name of usorula applied to this stage); or, as is more common, the segments separate from one another during the process of division, and give rise within to a space, 
the segmentation cavity; the cells bounding this cavity then undergo a further change, by means of which the single becomes replaced by a double layer, one of which is interior to the other.

This two-layered condition is brought about in one of two ways; either the cells of one half of the sphere are pushed into the contained space, and, by approaching the other half, more or less completely obliterate the segmentation cavity, or the cells undergo a transverse and concentric cleavage, by means of . which each cell becomes two, and the single is converted into a double layer. Whether the former process (that of in vagination)

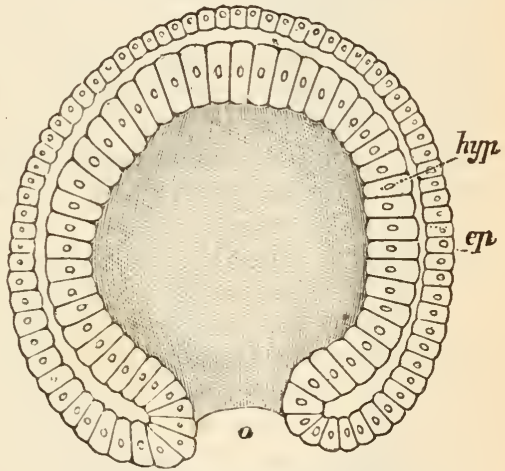

Fig. 6.-Diagram of a Gastiula. $o$, Blastopore ; $e p$, epiblast ; hyp, hypoblast.

or the latter (delamination) takes place, the celllayers are regarded as comparable, and receive the same names ; the outer is known as the epiblast (Fig. 6, ep), the inner as the hypoblast (hyp). Similarly the contained cavity, which is clearly the segmentation carity in the latter mode, and an altogether new formation in the former, is spoken of as the archenteron, while the narrow opening to the exterior is the blastopore $(o)$. The whole organism is now said to be in the Gastrula stage (Fig. 6).

No known animal remains at quite the low and undifferentiated condition of a Gastrula; and, indeed, D-16 
in most cases yet another germinal layer, as the epiblast or hypoblast is respectively called, is developed between the two we know already. It is appropriately spoken of as the mesolblast; it arises in various modes, into the distinctions of which we need not enter here; it will suffice for us to know, that in all the higher Metazoa the greater part of the organism is fashioned out of it.

In all cases the outer and inner layers undertake the functions which their position entails on them; the cells of the epiblast become converted into the parts which cover in and protect the rest of the body, and give rise also to those organs by means of which the organism becomes acquainted with what is going on around it, sensory organs and nervous system. The hypoblast remains always in connection with the cnteron, or digestive tract, forming the lining of its walls, of the glands that are therein developed, and of such outgrowths as may arise from it. In the lower divisions of the Metazoa the mesoblast does not take any large share in the formation of the organs; it remains in a more or less indifferent condition. In the higher forms it becomes quite the most important layer in the body, taking on as it does the duty of developing the skeleton, the muscles, the blood, and vascular system, the excretory organs, and the connecting tissues; it always, also, becomes primarily cleft or divided, so that a cavity is developed within it; this is the true body cavity, or colom, and all animals that possess it may, whether they secondarily lose it or not, be spoken of as the Calomata.

The acolomate Metazoa are the sponges (Porifera), and the great group to which belong hydra, the jelly-fishes, and the sea-anemones (Coelenterata). The simplest sponges show hardly any advance on the typical Gastrula, the amount of mesoblastic tissue developed being small; but they are remarkable at 
once for a character which sharply distinguishes from all other animals. It happens to many Gastrulæ that, their blastopore closing up, they develop an investment of cilia on their epiblast, and swim about for a time freely in the water; but these cilia are confined to the outer surface. In the sponges it is otherwise, the ciliated cells early become internal to the nonciliated, and some are retained throughout life in the so-called "ciliated chambers." When we come to examine into the activity of a living sponge we find no advance on that of a Protozoon, save so far as the division of labour is here first clearly seen ; we find, that is, that the multicellular organism feeds, grows, respires, reproduces itself, and dies; and we find, too, that, like many Protozoa, it forms for itself firm supports in the way of a skeleton, but we find no cells that are specially sensory, and none that are obviously muscular; there is the general irritability and contractility

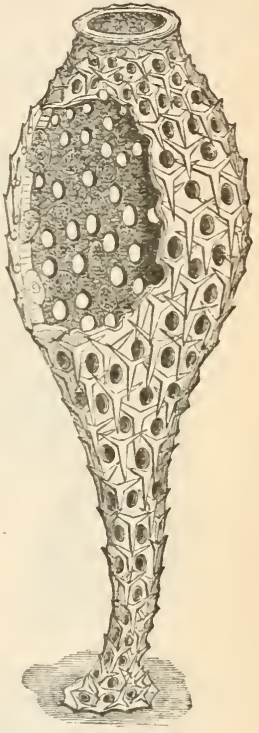

Fig. 7.-Calcareous Sponge. Ascetta primordialis. (After Haeckel, $\times 50$ diams.) which living protoplasm always exhibits, but there are no special organs for either function.

The Porifera, or sponges, fall into the following divisions :

1. Myxospongiae, in which there is no hard skeleton ; e.g. Halisarca.

2. Calcispongiae, in which a support for the body is furnished by calcareous spicules; e.g. Ascon, 
Leucon, Sycon. The commonest British form is ordinarily known as Grantia. (See Fig. 7.)

3. Silicispongiae, in which part of the skeleton is made up of spicules of silica; e.g. the common fresh-water sponge (Spongilla), Chalina, Euplectella.

4. Ceratospongiae, in which the skeleton is
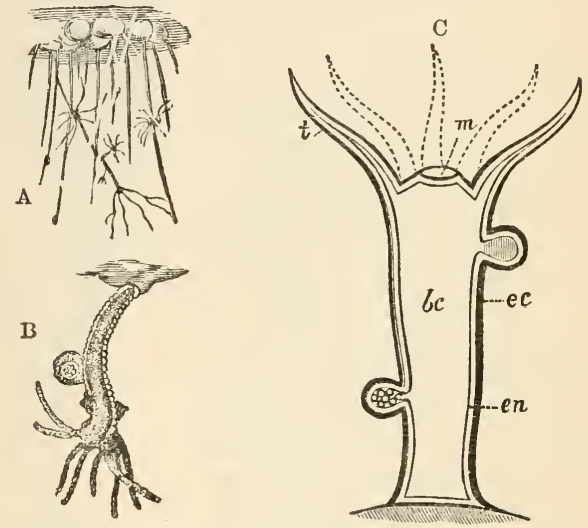

Fig. 8.-A, Hydra viridis, attached to Duckweed; B, a Single Specimen magnified; c, Hydra in Diagramatic Section.

$e c$, Ectoderm ; en, endoderm ; $m$, mouth ; $b c$, enteric cavity ; $t$, tentacles.

completely horny or fibrous, and devoid of siliceous or calcareous spicules; e.g. the bath-sponges (Euspongia).

In the Colenterata it is otherwise; in many forms both nervous and muscular tissues are to be recognised not only by the aid of the microscope, but by the activity of these animals, and by their reactions when subjected to physiological experiment.

Henceforward, then, we have to do with forms which possess, in some shape or other, all the essential tissues of even the most complicated 
organisms; differentiation will lead to greater subdivision of labour, and greater complexity of structure, but all the materials are, even so low in the grade of animal life, ready to our hand.

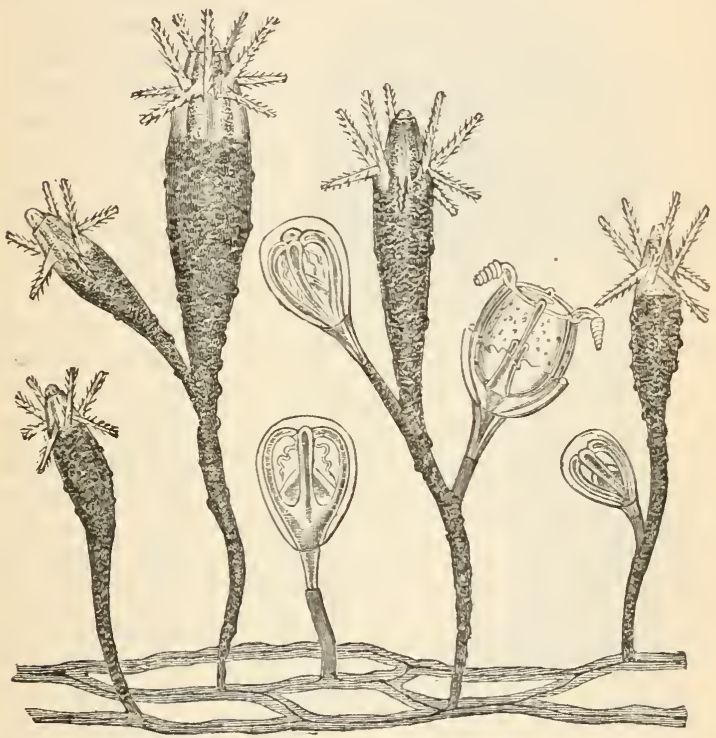

Fig. 9.-Pevigonimus vestitus, showing Trophosomes and Gonosomes (After Allman.)

A coelenterate animal, then, is one in which the archenteron of the gastrula, even when secondary outgrowths are developed from it, remains always as the only cavity in the body, in which the mesoblast is but imperfectly differentiated, but in which organs of offence, locomotion, and sensation are added on to the structures of the original gastrula form. 
In its simplest known condition, e.g. Hydra (Fig. 8), a Cœlenterate has a terminal mouth $(\mathrm{m})$ which leads into a digestive cavity $(b c)$, and around

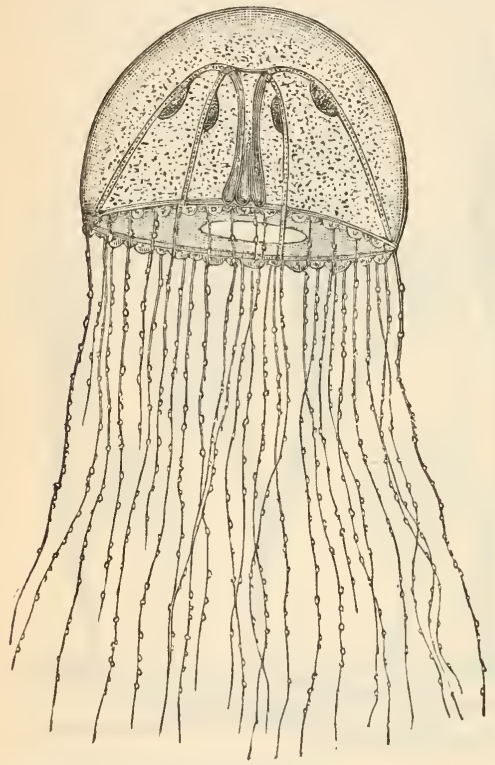

Fig. 10.-Figure of the Medusa of a Hydroid. (After Hincks.) which tentacles $(t)$ are develo ped ; these tentacles, which serve as organs of prehension, sensation, and offence, are hollow, continuations of the enteric cavity passing into them. There is no second orifice to the enteron, and reproduction is effected either by gemmation, or by the formation of ova and spermatozoa.

In the more complicated members of the group the hydriform body gives off buds, and becomes one of a colony (Fig. 9); and the separate "persons" of this colony are connected together by a common trunk, which is hollow within, and continuous with the enteric cavity of each person; in the simplest stage of these colonial formations each person performs the same duties, but in the more complex different 
persons take on different duties; when these, again, are at their simplest stage, we find that while some nourish the colony (trophosomes), they take no share in reproducing it; this office is performed by other persons (gonosomes), which depend for their nourishment on the neighbouring trophosomes. Division of labour among the persons of the colony may go still farther, and groups become formed of which some have nutrient, others locomotor, others protective, and others prehensile or offensive functions (Siphonophora; e.g. Portuguese man-of-war) (Fig. 12). Where the Cœlenterate is fixed, we observe, in one division, that the generative persons become free-swimming, and, while retaining the essential characters of the division, become greatly altered in form, in adaptation to their new mocle of life; such persons are spoken of as Medusae (Fig. 10). Finally, we find that, in some cases, the fertilised ovum of a medusa gives rise not to a fixed hydra-like body, but directly to a medusa form. The tentacles are set round the mouth in a circle, and the parts of the body are similarly arranged in a fashion of symmetry, which is called

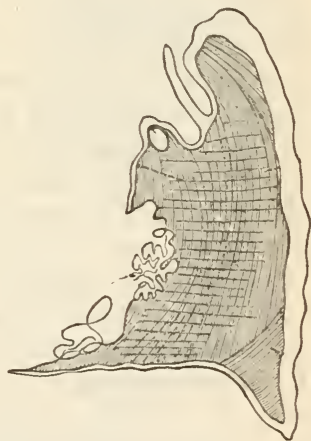

Fig. 11.- Longitudinal section through Sagartia parasitica, showing a meseuteric septum with the body wall to the right, and the enteric wall to the left. (After O. and R. Hertwig.) (See Fig. 54.)

radial; where, however, the free mode of life has obtained for a long period of time, we sometimes find that there is only one axis of the body on either side of which exactly corresponding parts are to be found; in other words, a bilateral 
takes the place of a radial symmetry; e.g. Venus' girdle among the Ctenophora. (See Fig. 16, page 46.)

The Coelenterara fall into two well-marked divisions, Hydrozon and Anthozoa; in the former the mouth is placed on a projecting oral cone, while in the latter it is sunk below the level of the oral circlet of tentacles, and the cavity developed from the enteron, and separating its wall from the body wall, is traversed by partitions (mesenteric septa) (Fig. 11), of which a certain number extend across the whole of the cavity, while others only project for a shorter or longer distance into it.

\section{CELLENTERATA.}

A. Hydrozoa.-The hydrozoa fall into two wellmarked divisions, in the first of which the medusa form, when developed, always has an infolded rim of the body running round the inner edge of the mouth of the bell (velum). In consequence of the presence of this fringe it may be spoken of as the Craspedote division; in it the sense organs are never protected by any lid or cover, and they are therefore known as the Naked-eyed Meduss (fymmophthalmata), and as the generative sacs never form projecting pouches, they are by some spoken of as Cuvptocarpa.

I. Craspedota.-The Craspedota fall into three groups; in the first the organism is always hydriform, or the nutrient persons are hydriform, and the generative medusiform, or the organism is always medusiform. They may, therefore, be called Hydromedusae. Examples of these are : Hydra, Cordylophora, Hydractinia, Sarsia, Oceania.

In the second group we have those colonies of hydriform persons in which the common stem becomes richly impregnated with calcareous salts, and they therefore may be known as Hydroid Corals or Hydrocorallina. Such are Millepora and Stylaster. 
In the third group we have those freeswimming colonies to which reference has already been made as examples of the highest form of division of labour: they are called the Siphomophora, and Velella, Diphyes, Physalia, and Physophora (Fig. 12) belong to this group.

\section{Scyphomedusae.-}

In the second great division of the hydrozoa we have the forms which are best known as the Medusæ, or jellyfishes par excellence. With one exception, they all pass through a stage which, at first somewhat hydriform in appearance (Scyphistoma-stage), is remarkable for undergoing transverse division; each of the segments so formed separates and forms an independent medusa. When adult they are always medusiform in appearance, and, as they rarely have a velum to their disc, they are

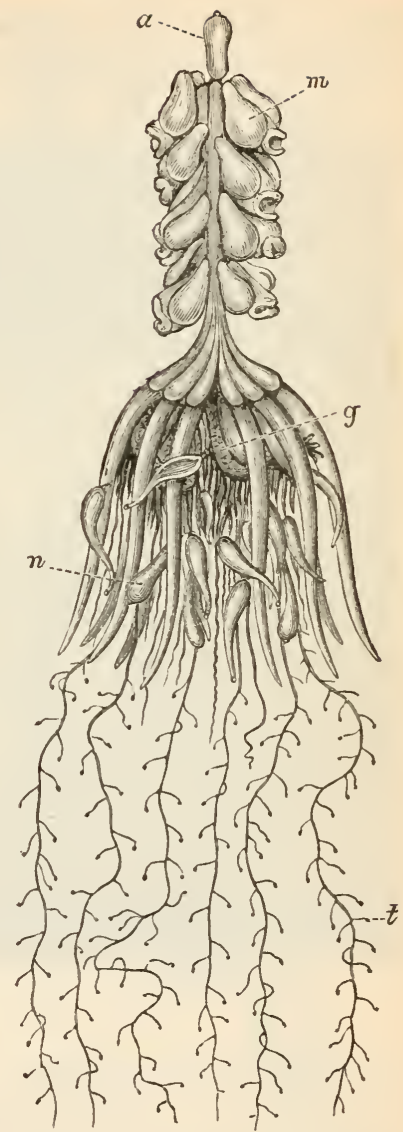

Fig. 12.-Physophora hydrostatica.

$a$, Air-lyladder : $m$, nectocalsx ; $g$, generative persons: $n$, nutrient persons (in the form of sucking tules); $t$, tentacular persons. (After Cuvier.) 
42 Comparative Anatomy and Physiology.

often spoken of as the Acraspedota; the term Steganophthalmata refers to the fact that their senseorgans are placed in protected recesses on the margin

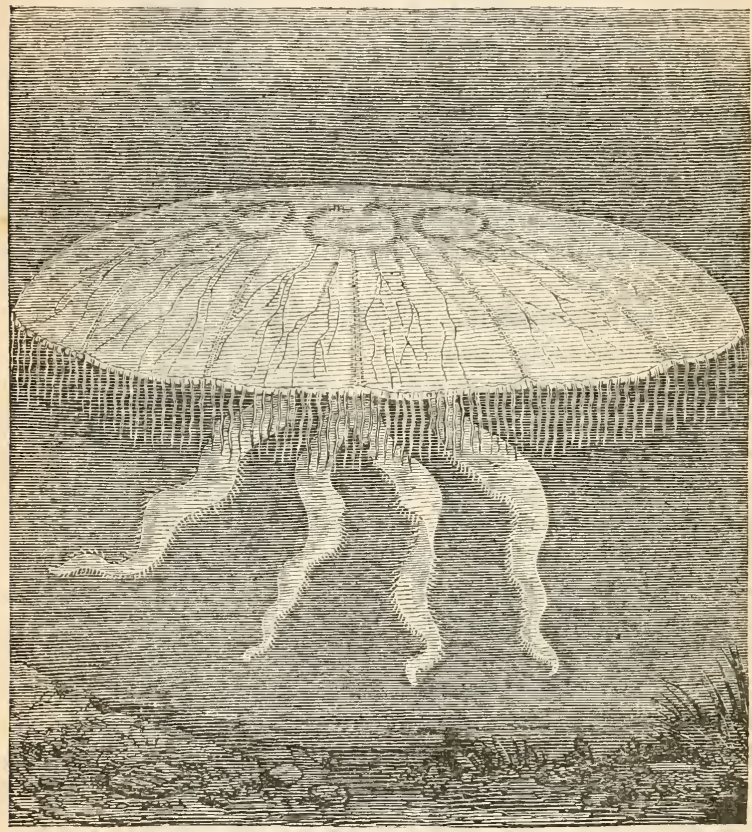

Fig. 13.-Aurelia aurita.

of the disc (covered-eyed medusæ), and that of Phanerocarpa must be altered from its original significance to mean only that the generative glands are large and obvious. They are ordinarily free, but Lucernaria is fixed; the common Aurelia (Fig. 13) is a typical example of the group, while Rhizostoma is 
an example of the forms in which the original mouth is lost, and replaced by a number of small apertures developed on the long arm-like outgrowths of its lips.

B. Anthozoa.Among the Anthozoa we find the seaanemones and the great bulk of those colenterates which form coral.

. According as they possess eight, and eight only, or six, or some multiple (often a large one) of six, we divide the Anthozoa into the Octactiniae, and the Iexactiniae.

\section{The Octactiniae} have never more than eight tentacles, and these are flattened and serrated at their edges. In Alcyonium ("dead men's fingers") calcareous spicules are scattered in the borly ; in Tubipora ("organpipe coral ") the spicules collect and form a continuous tube for each polyp (Fig. 14 A) ;

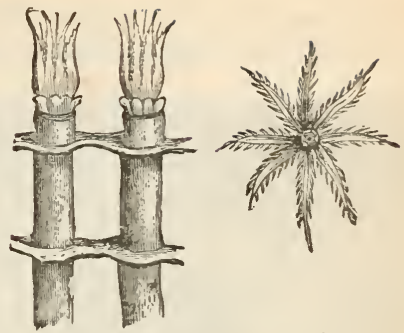

Fig. $1+$ A.-Tubiposa musica.

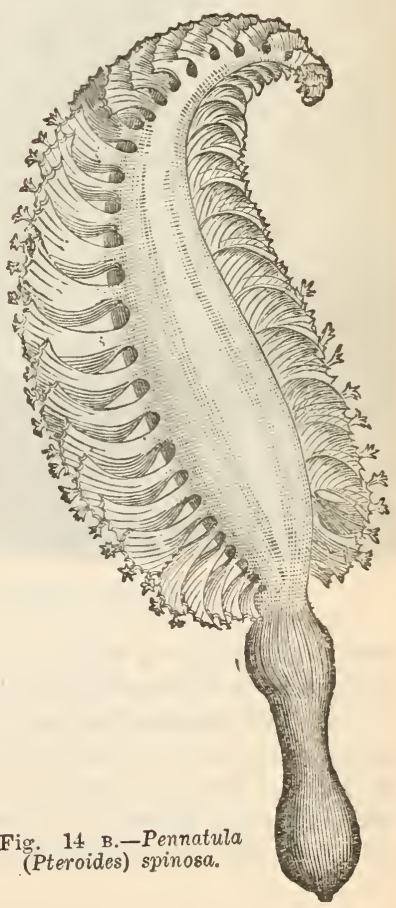




\section{Comparative Anatony and Physiology.}

in the sea-pen (Pennatula) (Fig. $14 \mathrm{~B}$ ), the tissue which connects the polyps together is horny, in the noble red

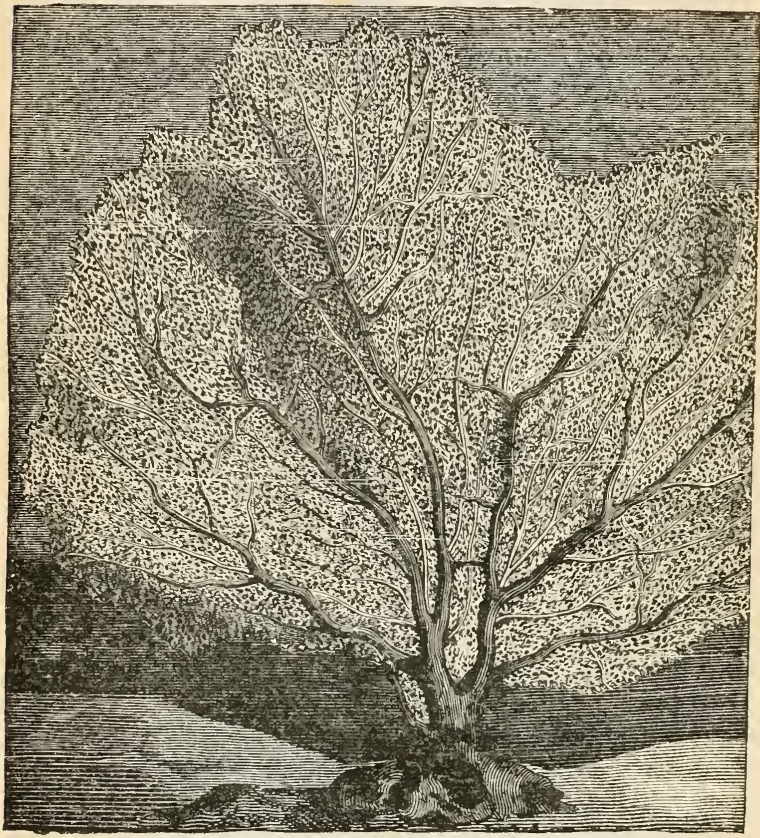

Fig. 14 c.-Gorgonia flabellum.

coral it is calcified, while in the sea-fans (Gorgonia) an elegant hard network is developed (Fig. $14 \mathrm{C}$ ).

II. The Hexactimiae; the six tentacles or multiples of that number are filiform, and their edges smooth. Some, like the common sea-anemone, remain single throughout life, but, in most, buds are given off, and a colony is formed. The deposition of 
calcareous salts often gives rise to large masses of "stony" coral, of which the brain-coral (Mrandrina) is a good example; in other cases (e.g. Fungia) the septa are alone calcified.

There still remains a division of the Coelenterata which, though it has been definitely placed by some naturalists with the Hydrozoa, and by others with the Anthozoa, is possibly an independent group; in these, the eight canals derived from the enteron run at equal distances close to the surface of the body, and along these there are formed bands of cilia, which have, in consequence of their comb-like appearance, gained for these forms the name Ctenophora. The glassy globe called Cydippe (Fig. 15) is found on our own shores, while Venus' girdle (Cestus veneris) is an example of that acquired bilateral symmetry to which we have already referred (Fig. 16).

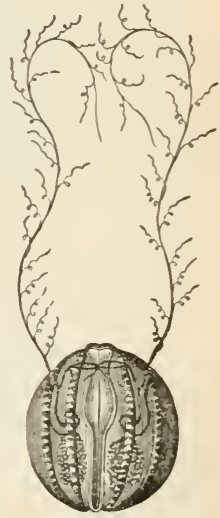

Fig.15.-Cydippe pileus.

\section{THE HIGHER METAZOA.}

In the remaining Metazoa a cavity distinct from the archenteric cavity becomes developed, and the mesoblast becomes the seat of those important changes, by means of which nearly all the tissues of the body are derived from it. In the midst of this mesoblast a cavity arises by cleavage or fissure, or from the archenteron there are given off out-growths which, in time, become shut off from the parent space, and occupy the middle of the mesoblast. The carity formed in either of these ways is spoken of as the body cavity or calom, and the result of its appearance is 
that the mesoblast becomes separated into two layers, one of which applies itself to the epiblast, and the other to the hypoblast; in this way we get the somatopleure and splanchnopleure of

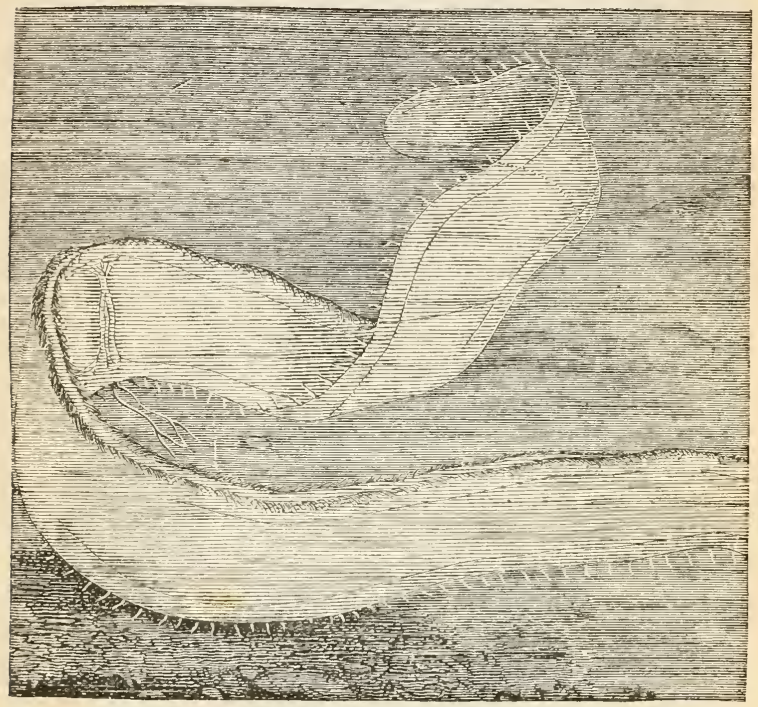

Fig. 16.-Venus' Girdle (Cestus veneris).

embryologists. All the Metazoa that possess this body cavity may be spoken of collectively as the Colomata. In some cases the colom remains throughout life in a very rudimentary condition, and in a few it cannot be said to be developed at all, while in others it would seem to have heen lost by degeneration. According to its mode of origin, as an out-growth from the enteron, or by cleavage of the mesoblast, it is spoken of as an enterocale, or a schizocole. 
The archenteron ordinarily closes up, so that the blastopore disappears; a fresh mouth, and in most cases also, an anus, are developed at either end of the tube; these are lined by inpushings of the epiblast; the epiblastic pits, deepening and elongating, finally become continuous with the original or archenteric cavity, which is, it will be remembered, lined by hypoblastic cells. In a fully developed digestive tract we have now to distinguish three regions : (1) a mouth passage (stomodoum) which is lined by epiblast ; (2) a mid-intestine (mesenteron) lined by hypoblast; and (3) an anal passage (proetodoum) lined again by epiblast.

The greater number of the Netazoa are free animals, and no doubt the ancestors of all the terrestrial were aquatic forms; organisms moving freely in such a medium as water would clearly have one end which was anterior and one which was posterior, and as these would be differently affected by the water through which they moved, the one end would become differently constituted to the other'; the anterior end would be that at which food would be taken in, and at which the prey or an enemy would be first met. This end would then be primarily the sensitive end, and we find that it is here that sense organs of various kinds are best developed. In other words, we have henceforward to look for a definite region, specially sensitive in function, developed in front of the mouth ; this may be called the praestomium.

On either side of the moring body the water would exert equal pressure, and the two sides would come to exhibit similar characters, or bilateral symmeny would hecome apparent. In shallow waters one aspect of the body would be more exposed to the influence of light than the other, and we should therefore distinguish between an upper or dorsal and a lower or ventral surface. 
The origin, then, of the higher Metazoa is to be looked for in an animal in which an anterior end with a præstomium is to be distinguished from a posterior end ; in which the two sides are similar to one another, and the dorsal slightly different from the ventral surface. Forms of this kind are still to be found among the lowest Worms.

Various organs must, of course, be developed within such an organism; in the simplest cases some of the cells of the hypoblast retain the power possessed by the Amœba of taking solid food into the substance of their own bodies; the organism being small, no special means of circulating the nutriment thus obtained are required; and, just as in the Amœba, respiration is carried on by the general surface of the body, and by the water brought in with the food. On the other hand, even in Amœba, we found a contractile vacuole, and we may, therefore, well suppose that in this complex of cells there must be some special means for the removal from the body of its waste nitrogenous products. At any rate, the mesoblast is on either side channelled by a delicately walled canal which has openings into the spaces in the mesoblast, and communicates by a pore with the exterior. As the organism is to give rise to cells from which other organisms are to arise, some part of its body must be set apart as generative cells; in the simplest cases these are mere masses of cells in simple pouches, which pass directly into the water.

Of the cells in the region of the prestomium some will be more particularly modified for the reception of impressions from the outer world, and will form a rudimentary mervous mass, with which a few nerve-fibres will be connected; as the creature is capable of moving from place to place, we have, further, to look for the presence of muscular

\section{tissuc.}


The lowest Metazoa are grouped into a somewhat heterogeneous mob, which is known as the division of the Vermes or Worms. Of these the lowest are the Flat-Worms.

A. Platylielminthes.-Of the three divisions of flat-worms, two are degraded by parasitism; such are the divisions to which the tape-worms (Tænia), and the flukes (Distomum) belong.

I. The Turbellaria are the simplest forms, and are free living; the body is soft and small, covered with cilia, and without an anus; the entrance to the digestive tract is often provided with a proboscis, and the generative apparatus may be simple, or may be greatly complicated. A distinct cœlom is not always apparent (Accela), or it may become secondarily obscured. The enteric tract is straight, or branched. Planaria, Dendrocœlum, and Mesostomum are examples of this division.

II. The Trematoda are flat-worms that have taken to a parasitic mode of life, but are by no means so profoundly modified as the members of the group next to be considered. They either live on the bodies of other animals (ecto-parasitic), like Aspidogaster, which is found in the gill chamber of the fresh-water mussel; in this case they exhibit no "alternation of generation." Or they live within the bodies of other animals (pento-arasitic), like Distomum hepaticum (the liver-fluke); in this case they pass different stages of their existence in two different animals. The ciliated covering is lost, and suckers are developed, which serve as organs of attachment, and, to a certain degree also, as organs of locomotion; the sexes are ordinarily united in the same individual, and the accessory parts of the generative apparatus are greatly complicated.

III. The Cestoda, or tape-worms, are flat. worms which are still further modified in accordance E-16 
with their constantly ento-parasitic habit of life, and they, like the endo-parasitic Trematoda, ordinarily pass through different stages of their development in different hosts. While the simplest forms, like the Caryophyllæus of the carp, exhibit no kind of jointing or division of the body, and Ligula has the jointing affecting only the internally placed generative organs, most consist of a more or less large number of joints ; Tænia echinococcus having three or four, T. solium about

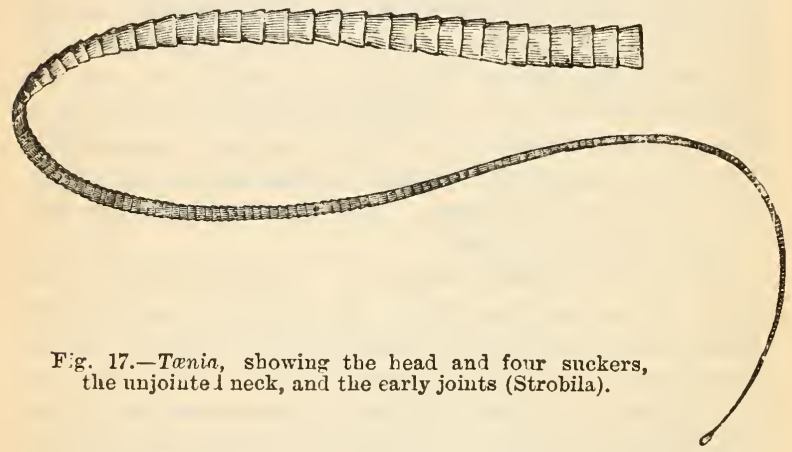

a thousand, and Bothriocephalus latus having, it is said, as many as 10,000 joints, and attaining to a length of twenty-five feet (Fig. 17). As these joints increase in size and approach maturity, the ova become fertilised, and commence to develop; on the joints breaking off and escaping to the exterior, the ova within are set free, and if eaten by the other host proper to the tape-worm, they go through the earlier stages of their development within its body. In these parasites the digestive tract is altogether aborted.

We have been carried away by these degraded forms from the general line of development; we return to it, however, only again to find ourselves confronted 
with a group, the great majority of the members of which are, in their sexual state at least, endo-parasitic. These are the round-worms or thread-worms (Nematohelminthes). They are remarkable, as compared with the soft-bodied Turbellarians, for the great development of that horny material which is, as chitim, so richly present in the integuments of many Metazoa. The intestine forms a straight tube, and is surrounded by a comparatively spacious body cavity. The whole body is; as their popular name implies, greatly elongated. Examples of this group are Gordius, Ascaris, Filaria, and Trichina.

More closely allied to the round-worms than to any other worms are the Acanthoceplna!i, of which Echinorhynchus (Fig. 18) is an example. They are internal parasites, which, like most tape-worms and flukes, live, at different stages of their

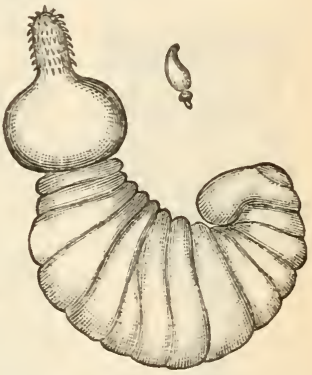

Fig. 18.-Echinorhynchus nodulatus (nat. size and enlarged). (After Busk.) life-history, in different hosts.

They are provided with a protrusible proboscis, which is armed with recurved hooks of considerable strength.

The Rotatoria or Wheel-Animalcules exhibit certain characters which we shall again meet with in the larval stages of some of the higher forms. The anterior end carries a disc, the edge of which is ciliated (this is the so-called "wheel-organ"), and in the centre of which the mouth is placed (Fig. 19). A special apparatus for comminuting the food is found in the stomach. The "water-vessels," or organs by means of which, in all probability, waste nitrogenous matters are excreted, are very distinct, and are provided with 
delicate branches with terminal orifices; the two vessels open into a special enlargement or bladder, the walls of which are contractile, so that the fluid stored up in it can be forced to the exterior. The sexes, as in Nematoids, are ordinarily separate, and the males can be distinguished from the females by their smaller size. Rotifer, Brachionus, and Melicerta are examples of the Rotatoria.

Most of the forms with which we have already

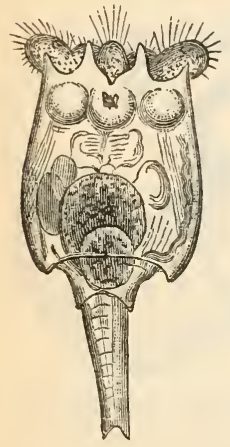

Fig. 19.-Brachionus; to show the Ciliated head-disc. had to do are small in size, and it will have been noted that, where the body attained, as in the case of certain tape-worms, to a considerable length, that body was not an individual whole, but was broken up into joints or segments.

In the great group of worms which we are now going to consider, this segmentation of the body is very distinctly exhibited, and affects not only the external form, but the great majority of the internal organs; this phenomenon becomes the more comprehensible when we learn that at one of its very earliest stages in development the mesoblast itself becomes regularly segmented. In the simpler conditions the segments, which we will henceforward call metameres, are, for the greater part, exactly similar in character, and only those at either end of the body differ much from the rest. Later on we shall see that, just as in the simpler animals, different parts take on different duties, and division of labour becomes as apparent among the metameres as it was in the various persons of the colonial Cœlenterata.

Now, also, we find that organs for which, in the smaller and simpler forms, there was no necessity, 
gradually become elaborated. The body is now too large be to able to do without an apparatus by means of which the nutrient material obtained by digestion, or the store of oxygen necessary for the actirity of the protoplasm of its constituent cells, may be carried about from part to part, and we have therefore a system of circulating vessels. In many, also, the firm covering of the body necessitates the development of special outgrowths into which the vessels pass, charged with the carbonic acid which is constantly associated with the activity of living protoplasm; in these outgrowths the blood gives up carbonic acid, and receives oxygen in its place; in other words, a respiratory is added on to a circulatory apparatus. In the majority, again, the body is too large to be able to move about without the assistance of special muscular processes or limbs, and these are not unfrequently strengthened and supported by those chitinous secretions which we call setae (bristles).

Elaborate and complex activities of such a kind as these require to be brought into relation with one another, or, in other words, to be co-ordinated, and performed in regular and systematic fashion; it is not now sufficient for the organism that there should be a præstomial nervous mass with some few nerve-fibres given off from it. Centres of nervous activity must be developed in rarious parts of the body, and we find, therefore, that collections of nerve-cells are found in different metameres; these ganglionic masses are connected together by fibres, and so it results that there runs down the ventral surface of the body a chain of ganglia. From each of these ganglia nerve-fibres pass to the muscles and other organs of the body, and to them there come other fibres which have one end in the skin, and which convey to the central apparatus 
some information of what is going on in the world around it.

General sensibility of this kind is, however, soon found to be insufficient for the needs of the organism; sight and hearing are possessed, no doubt, by lower forms, but we shall soon find creatures with elaborate eyes, and well-defined auditory organs, while obscure indications of an olfactory sense are, a little later, to be detected.

The organisation of the ringed worms or AnnuIata attains its highest degree of complexity in the free-swimming marine forms. Here the ringed body has on most of its metameres a single or double projection on either side (parapodium), from which there project a number of bristles (seta); at the anterior end, the tentacles are aided by a number of elongated feelers, and a pair of well-developed eyes, and sometimes, too, anditory vesicles are to be found there. The mouth is provided with strong horny denticulated jaws, which are moved by special muscles, and which serve to break up the food; different parts of the digestive tract take on different functions, and pouches, which may again be branched, sometimes appear at the sides. A fluid circulates through the body in a system of closed vessels, and some of these vessels have their walls provided with muscles by means of which the current, which is always regular in direction, is propelled onwards. At the sides of the body thin outgrowths of its wall serve as gills (branchia), and most of the metameres are provided with a pair of coiled tubes which open into the spacious cœlom, and also to the exterior; these are the renal organs (mephridia).

The division of ringed worms in which the setæe are numerous on each parapodium is called the Polychata; of these, some, like the sea-mouse (Aphrodite), Polynoe, and Nereis are free-swimming, 


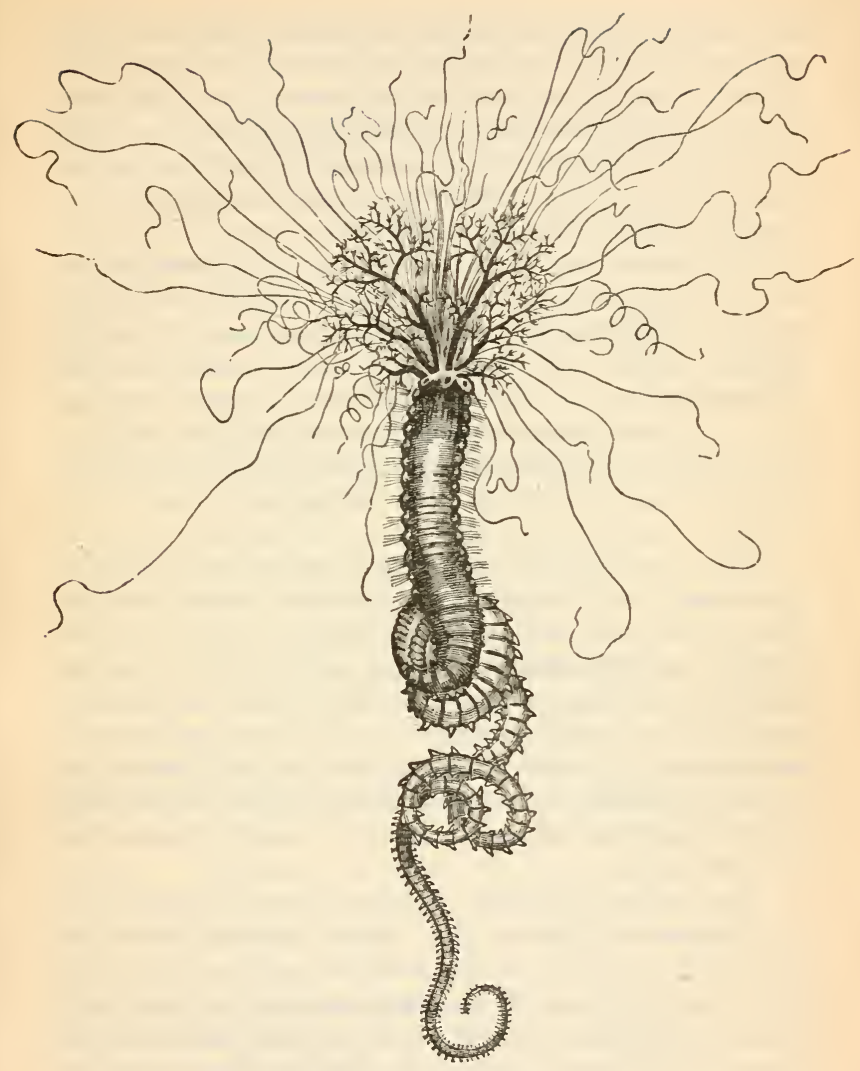

Fig. 2).-Terebella emmalina.

and form the group of the Vagantia; others give up their free mode of life and settle down like Sabella and Serpula into tubes; in these Tubicolae (Fig. 20), 
the hinder part of the body is less elaborately developed than the anterior, which can be protruded from the mouth of the leathery, sandy, or calcareous tube. The lowest forms of the division have no setæ at all, and Polygordius, which may be taken as the representative of the Achaeta, retains throughout life a circlet of cilia at its anterior end.

In another and lower division of the Annulata we find that the setæ are never more than eight at the most in each bundle ; and such forms may be distinguished from the Polychrta, and known as the Oligochata. Of these the best known form is the common earthworm (Lumbricus), but all are not, like it, terrestrial in habit; Nais and the blood-worm ('Tubifex) are inhabitants of fresh water.

Most appropriately, perhaps, associated with the Annulata, but exhibiting a number of characters that bring them into relation with the flat-worms, are the leeches or Hirudinea; living on the blood of other animals, as many of them do, they have the integument often developed at one or two points into suckers, by means of which they attach themselves to other anirnals, or to firm bodies, from which they can extend themselves to seize or attach themselves to their prey.

Most closely allied to the Annulata, but best kept in a separate division, are those marine worms of which Sipunculus is the best known example; for these the old term of Gephyrea may be retained, without prejudice to our views of the value of the ideas which gave rise to the name. The body exhibits no exterual segmentation; they are remarkable for possessing excretory organs of the kind found in the Annulata, as well as those seen in Rotifers; in some cases the anus is not at the hinder end of the body, but t!le intestine is so 
coiled on itself that its orifice comes to lie at the side, and in the anterior half of the body.

The difficulties arising from our imperfect knowledge, and the generalised characters of the lower forms which are associated together under the head of the Vermes, disappear, for the most part, when we rise above them in the scale of animal organisation.

No one, for example, can fail to see that a starfish is no close ally of a crayfish, or a snail of a frog; on the other hand, a sea-urchin and a starfish are as clearly allied to one another as is the crayfish to the crab, the mussel and snail to the octopus, and the shark to the frog, the pigeon, or the rabbit.

While the bases or origins of these several forms are obscure enough, the apex stands sharply out, and we inay compare the four series of forms of which mention has just been made to four great branches arising from a common trunk. Each of these branches may be called a phylum. In one the body wall becomes richly impregnated with calcareous salts, which sometimes form projecting spines, the original bilateral symmetry yields to an acquired radial one, and locomotion is typically effected by a special series of suckers connected with a system of water-tubes; this is the phylum of the Echinodermata or starfishes. In another the soft body becomes invested in and protected by a hard shell which is secreted by a special outgrowth of the body called the mantie; the ventral surface is drawn out into a muscular foot, and a series of delicate filamentous processes grow out on either side of the body; this is the phylum of the Mollusea, or shell-fish.

In yet another series we find a closer resemblance to the Annulata than is exhibited in any other of the higher phyla. Some or all of the metameres become provided with appendages, which are most often jointed, and one or more of these pairs of appendages 
become specially modified to the purpose of the mouth. This phylum, which we will call that of the Arthropoda, might, if constancy of nomenclature were not a matter of convenience, be more appropriately designated as the Gnathopoda (Lankester). Lastly, there is an important phylum for which, in the light of recent researches, it seems well to adopt some other name than the ordinary designation of Vertebrata. This phylum is remarkable for the development along the dorsal area of a rod, which, at first hollow, subsequently becomes solid, and forms a primitive and, in some cases, permanent support for the overlying nerrous system. In recognition of the presence of this cord we will speak of the phylum as that of the Chordata; here are included the degenerated Tunicates, the primitive and somewhat modified Lancelet (Amphioxus), and the great group of fishes, reptiles, birds, and mammals in which a vertebral column, more or less well developed, encloses and protects the spinal cord; these are the true Vertebrata (Balfuur).

It is a matter of little importance which of these phyla is first considered in greater detail, but, as the most aberrant are the Echinodermata, it is, perhaps, convenient to dispose of them first of all.

One of the best known types of the Echimo. dermata is presented to us by the starfish (Asterias), in which no bilateral symmetry is at first apparent in the adult, though it is quite well marked in the larva. There is a central rounded alisc from which are given off five rays or "arms;" in other words, we have the bilateral symmetry overshadowed by an acquired radial symmetry (Fig. 21). On the principles on which we have already worked, this mode of symmetry in a freely moving animal is not, at once, 
explicable. To understand it we must make use of the method of comparison, and appeal to palæontological evidence. When we do this we find that the oldest forms were, like the still extant Pentacrinus,

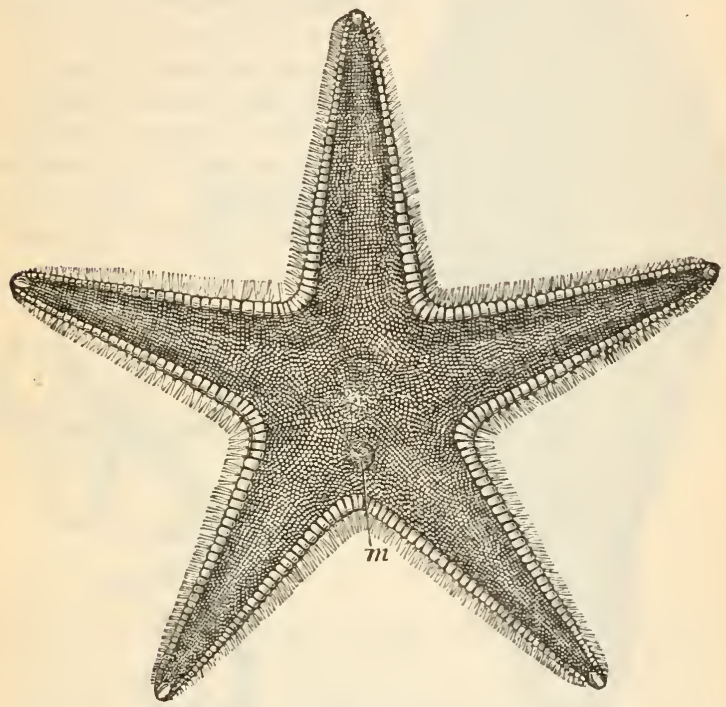

Fig. 21.-Astropecten irregularis. $m$, Madreporite.

fixed on a stalk (Fig. 22) ; in other words, the ancestors of the Crinoids being fixed forms had to develop their organs in different directions around a common centre, so that, from whatever point prey or enemy approached them, they would be prepared for and ready to meet them.

In the great majority of this group we observe for the first time among the cnelomate Metazoa a hard supporting structure to which we can apply the 
$6 \circ$

Comparative Anatomy and Physiology.

term skeleton; this skeleton consists of a large number of firm calcareous plates closely soldered

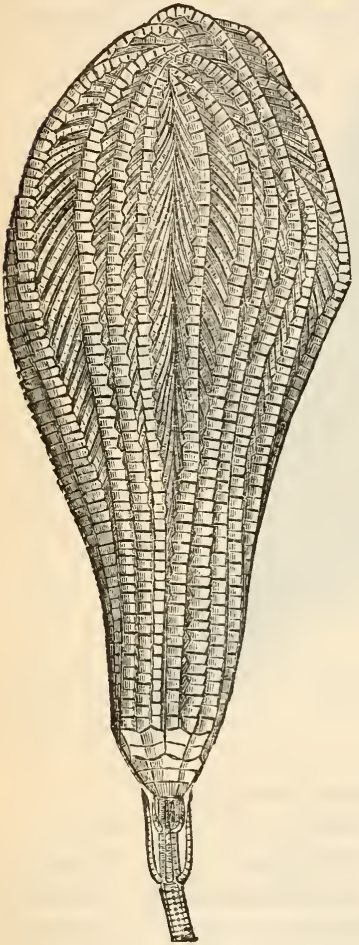
together. Within, or just outside, these plates there runs down every arm, or branch of an arm, a canal which contains water, and from this canal there are given off more or less delicate tubes (the so-called tube-feet) which are connected with the canal;

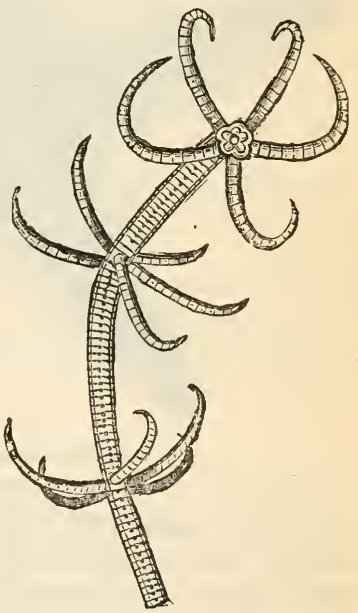

Fig. 22.-Pentasrinus Wyville-thomsoni. (After Wyville Thomson.)

all the canals communicate with one another by means of a ring which surrounds the mouth. Owing to the appearance presented by a dried starfish the earlier naturalists spoke of the areas in which these 
tube-feet were placed as the "walks" or ambulacra, and we may, therefore, speak of the ossicles or plates which specially support and protect the tube-feet as the ambulacral plates or ossicles. Accompanying the radial water-vessel is a nerve-trunk and

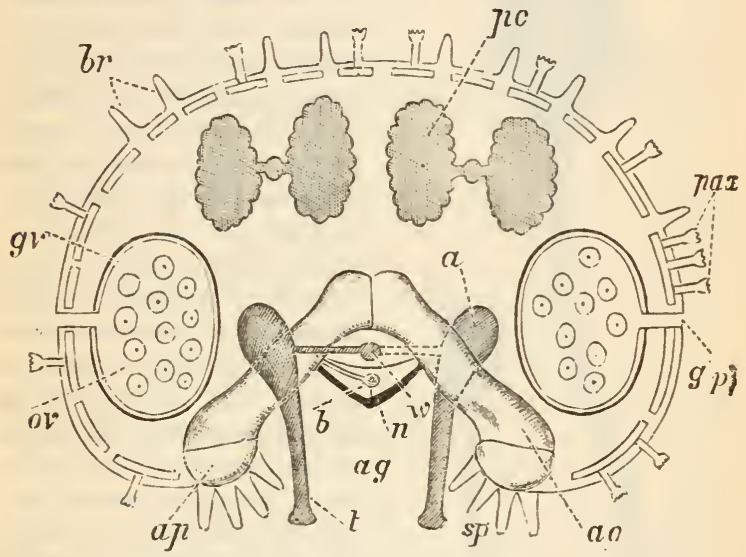

Fig. 23.-Diagram of a Cross-section of an Al'm of a Common Starfish (Asterias rubens).

on the left side the section is supposed to pass hetween $t$ tro of the ambulacral nesicles, hut on the right side through one of them $\left(a_{0}\right)$; $a g$, amhulacral groove; $n$, radial nerve; $b$, radial blond-ressel $; w$, radial water-yessel: $n$, anpullæ: $t$, tentacles or suckers : $a p$, adamlulacral p'ates : $s p$, spines: $p a x$, paxillæ, arising from limestone plates: or, nvary: $g p$, genital pore $g v$, genital hlond-ressel: $b r$, respiratory processes: $p c$, cæca of the intestine. (After P. H. Carnenter.)

a blood-vessel; while in the arm of the starfish we find also generative sacs, and processes of the digestive tract; all of which enter, like the water-system, into the cavity of the disc.

If, therefore, we make a transverse section (Fig. 23) throughout the arm of a starfish at a short distance from the disc we should cut through digestive, circulatory, ambulatory, generative and nervous 


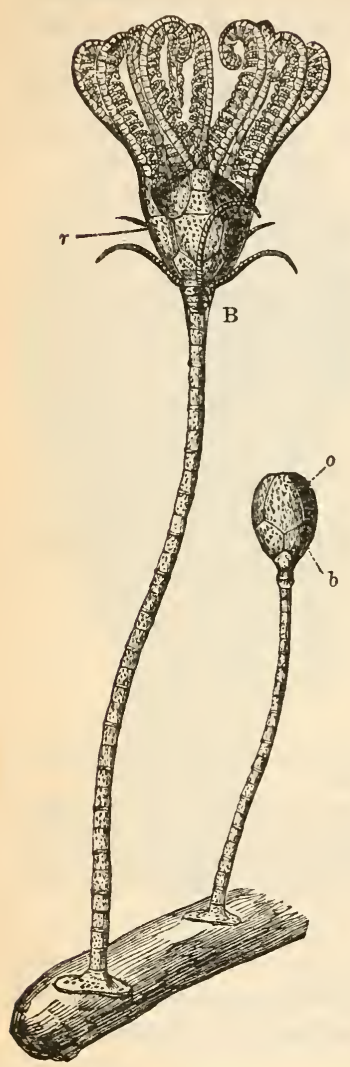

Fig. 24.-Pentacrinoid Larva of Antedon.

A, Quite young larra, before the opening of the cup, and the appearance of the radial plates; $B$, Nearly mature : $b$, basals : $o$, orals ; $r$, first radials. (After Carpenter.) organs, or should, in other words, have before our eyes representatives of all the more important systems of organs in the body. It is this phenomenon which has led to the theory once held by Cuvier, re-presented by Duvernoy, and, in our times, supported with much vigour by Haeckel, that the Echinoderm is a colony of bilaterally symmetrical metazoic animals which have become connected together by their anterior ends. It is more in accordance with the facts, as at present known to us, to suppose rather that the radiate form has been brought about by a return to a fixed habit, and that this mode of symmetry has been retained by inheritance. In those forms which stand farthest from the Crinoids the radial is again obscured by a secondarily acquired bilateral symmetry (Spatangus, Synapta); a close investigation into the char. acters of most members of the phylum enables us to distinguish a plane 
which exactly divides the body into two similar halves.

The Echinodermata are sharply divisible into two grades; in the lower of these the animal is either fixed by a stalk throughout life, or, as in the case of the Rosy Feather star (Antedon rosacea) of our own shores, the larva is fixed by a stalk (Fig. 24). This grade may be called that of the Pelmatozoa ; to it belongs the order of the Crinoidea, with others now extinct; representatives of it are Rhizocrinus, Pentacrinus, and Antedon.

In the organisation of these forms attention should be directed to the presence of the cuplike central portion; this calyx consists essentially of a central plate and two sets of alternating plates five in number; these are the basals and the radials.

In the higher grade of the Echinodermata, the Echimozoa, these plates are often obscured. In the regular Sea-Urchins (Echinoidea) the two sets of five plates can always be made out, but the central plate is excavated to make room for the anus; fire of the plates become perforated by the genital ducts (basals), while the other five (radials) are similarly perforated by the ocular tentacles. Cidaris, Echinus, Echinometra are examples of the regular Echinoidea; by Clypeaster and the flattened Laganum we pass to the edentulous Spatangidæ, where a secondary bilateral symmetry becomes very apparent.

In the true starfishes (Asteroidea), of which Asterias, Linckia, Oreaster, and Astropecten are examples, and in the Ophimoidea, of which Ophiura, Ophiocoma, and Ophiothrix are representatives, the calycinal plates are often obscured, and the ambulacral suckers are limited to the lower surface of the body and do not extend, as in Echinus, from mouth to apex; in the latter the ambulacra are covered in by a ventral plate, and in one dirision (that of the 
Astrophytida) the arms become more or less branched. Lastly we have the class of the IIolothuroidea, which are more nearly allied to the Echinoids than to the Asteroids; in these all signs of the calycinal system have disappeared, the calcareous skeleton is greatly reduced, and often consists merely of scattered and minute calcareous plates, which are sometimes altogether absent. In many cases the tube-feet cease to be arranged in five regular rows, and may, as for example in Synapta, disappear altogether; when this happens there remains no external character which speaks to the five-rayed ancestry of these extreme forms; in other words, here again external bilateral symmetry is re-acquired. Holothuria, Cucumaria, Synapta, are the best known examples of this group.

It is impossible to escape from the belief that the Arthropoda are more nearly allied to the Annulata than to any other group of the worms, but they are

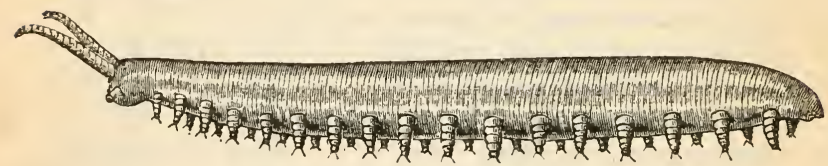

Fig. 25.-Peripatus capensis.

Showing the elongated bilaterally symmetrical body, with the ringed antenna, and the incompletely jointed paired aplendages with a pair of terminal claws.

sharply distinguished from them by the fact that, in all cases, one or more of the appendages of the body ure converted into organs which may be called mouthorgans, jaws, or guathites. Some idea of the primitive form may be gathered from Peripatus, which is the simplest Arthropod known to us. The body was elongated, distinctly bilaterally symmetrical, the præstomium was provided with tactile antennæ, and 
at the sides of the body there were a number of appendages which were only incompletely ringed, but the presence of which afforded evidence of metameric segmentation. The mouth was near, though not quite at, the anterior end of the body, and at its side were a pair of slightly modified appendages; the anus was posterior and terminal. The excretory organs were on the type of the Annulata, and were arranged metamerically. Peripatus may form the type of the Protracheata.

In all the remaining Arthropoda, some of which in all probability did not have a Peripatus-like ancestor, but have acquired a form similar to that of the descendants of such an ancestor, owing primarily to similar external conditions and similar necessities of life (homoplasy, see page 12), the appendages are distinctly jointed, so that the separate parts can be moved on one another ; the mouth is often some way from the anterior end, and excretory organs of the annulate type are never found.

In the simpler forms the greater number of metameres remain distinct, but in all divisions there is a marked tendency for the metameres at the anterior end to fuse into a head, and in some cases also into a thoracic region.

They are divisible into three great groups: A. Crustacea, B. Arachnida, C. Tracheata. In all three chitin is largely developed in the integument; and they are all, in addition, remarkable for the total absence of those delicate protoplasmic processes which we have learnt to know as cilia.

A. 'The great majority of the Crustacea are aquatic forms, and they either breathe the oxygen dissolved in the water in a vague manner (that is to say, no special respiratory organs are developed, and the exchange of gases is effected through the walls of the body), or they are provided with outgrowths of the F-16 
borly wall, which are known as gills or branchige; the presence of these has caused the name of Branchiata to be given to this division of the Arthropoda. The greater number of the segments carry a pair of appendages, and the great majority of these are, in the lower forms, exactly similar in character (Fig. 26, 5a). The metameres remain separate, and are

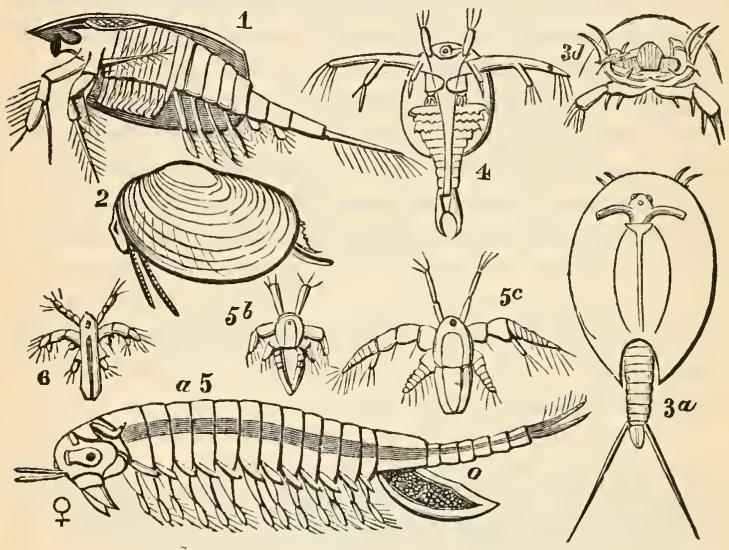

Fig. 26. - Various Branchiopoda.

1, Nehalia hipes (shell removed on one side); 2 , Estheria sp.; $3 a$, dorsal : $3 b$, ventral aspect of Lepidurus angassi ; 4 , larva of Apus canciformis ; $5 a$, adult female of Branchipus stagnalis ; $5 b, 5 c$, larvæ; 6 , larva of Artemia salina.

often very numerous; in the higher forms they tend, in a most remarkable manner, to be limited to about twenty, and the dorsal parts of the hard exoskeleton become fused in the anterior region (Fig. 27).

In all, the mouth is moved so far back from the anterior end of the body that two pairs of appendages (antenma) lie in front of it.

They are divisible into the Entomostraca, so called from the slight amount of fusion of the 
exoskeleton of the separate metameres, and the Malacostraca, which wore so called because their covering is soft as compared with the hard shell of the oyster or the snail. In both divisions we find members which have become parasitic in habit, and

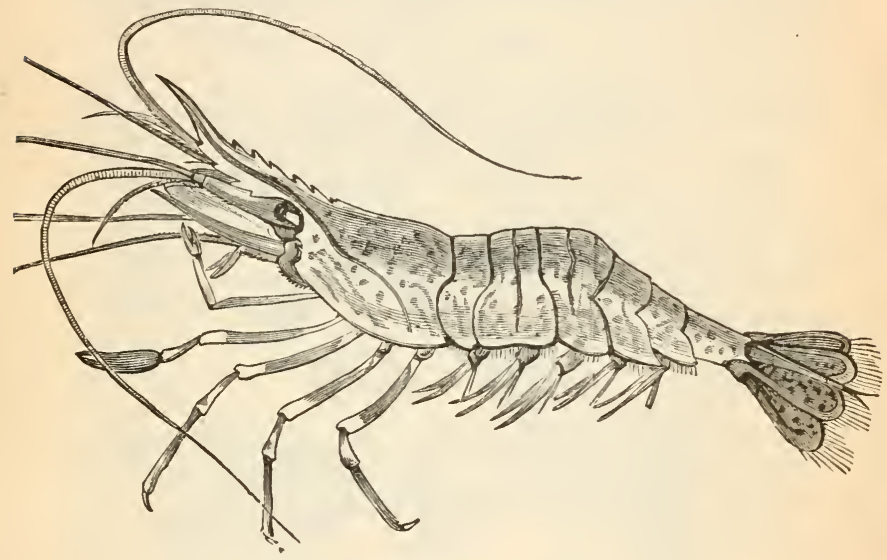

Fig. 27.-The Common Prawn (Palcemon serratus).

in which, consequently the characteristics of arthropod organisation are more or less modified and obscured.

In the Entomostraca we never have more than three pairs of appendages converted into Guathites, or jaws; the appendages behind the genital orifices never carry appendages (Fig. 26; 5a), and the young nearly always make their appearance as unsegmented larvæ with two or three pairs of appendages, of which two are constantly biramose (Nauplius larva) (Fig. $26 ; 4,5 b, 6$ ).

1. The Branchiopoda have, as their name 
implies, the function of respiration undertaken by some of the appendages ; the body is often provided with a fold (Fig. 28; 1, 2), which is derived from the dorsal portions of the anterior metameres, and forms a backwardly-directed free carapace. Such are Apus and Daphnia; Nebalia forms a link of connection with the Malacostraca.

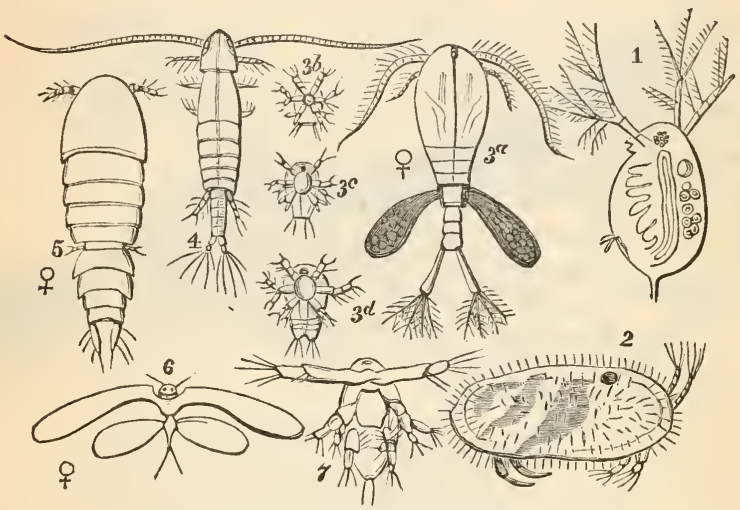

Fig. 28.-Various Entomostraca.

1, Daphnia pulex; 2, Candona hispida; $3 a$, adult female of Crclops quadricornis ; $b, c, d$, larvæ; 4, Cetochilus septentrionalis ; 5, Sapuhirina ovato lanceolata; 6 , Nicothoe astaci (parasitic on the gills of the lolster); 7 , Nallplins stage of copepod. (From Woodward.)

2. The Copepoda have a small stout body, covered by a carapace; one pair of the antennæ are large and oar-like (Fig. $28 ; 3 r$ ), and retain the primitive locomotor function that they had in the nauplius stage. Cyclops and Cetochilus are freeswimming forms ; some, like Sapphirina (Fig. 28 ; 5) are temporary parasites ; others, like Nicothoe(Fig. 28; 6 ), which lives on lobsters and crayfishes; Dichelestium, which is found on the sturgeon, and Lernæa, which lives on the cod and other fishes, are still more modified; 
while the extreme modification is seen in Argulus, a common parasite on the stickleback.

3. In the Ostracoda the carapace forms a completely bivalve shelly covering for the body, the abdominal region of which is greatly reduced. Cypris and $\mathrm{Cy}$ there are examples.

4. Although the Cirripedia are, when adult, greatly altered by their fixed or parasitic habit, they leave the egg as Naupliiform larvæ; these become attached by their anterior ends, and enclosed in ${ }^{\circ}$ sac-like mantle formed by the integument; this either remains soft, as in Alcippe, which lives in cavities, and is thereby protected, or undergoes calcification, when a greater or less number of plates become developed. The anterior region is either broad, as in the acorn shell (Balanus), or drawn out into a stalk, as in the barnacle (Lepas).

\section{The Centrogo-}

nida, or, as they are often called, IRhizocepliala, are usually found on the bodies of higher crustacea after the - nauplius stage is passed. They are endoparasitic,

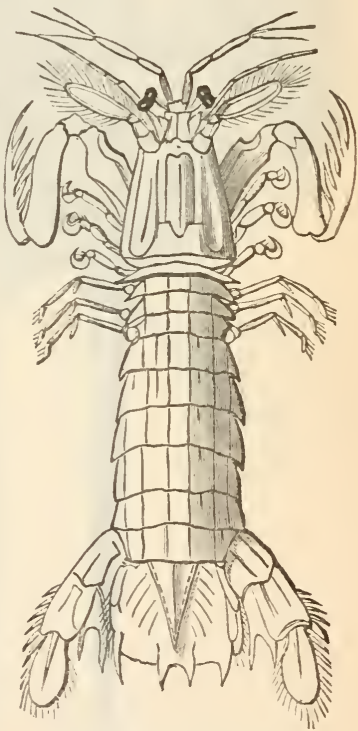

Fig. 29.-Siuilla mantis. and, later on, form a sac without limbs on the outer surface of their host's body. To this group belong Peltogaster and Sacculina.

B. The Ialacostraca have almost constantly 
twenty segments to their body, and all but one of these bear appendages; as many as six may be con-

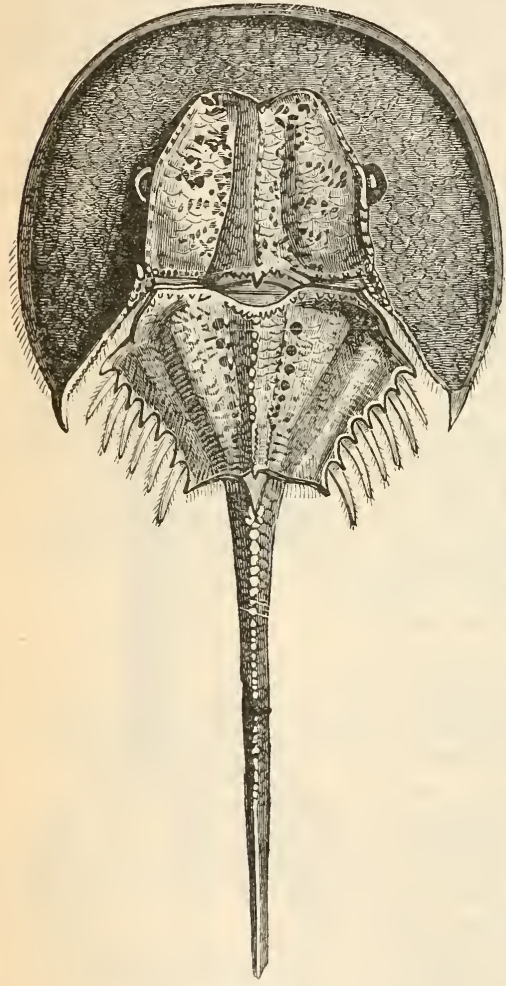

Fig. 30.-Limulus moluccanus. verted into gnathites, and the larva ordinarily, though not always, are set free at a later than the nauplius stage.

\section{The Pod-} opluthalmata are so called from the fact that their eyes are placed on stalks (Fig. 29); in them some of the dorsal portions of the thoracic metameres take part in the formation of a carapace. Such are cray fishes, lobsters, shrimps, and crabs.

2. The IIedrioplithalmata have the eyes sessile, and no carapace is developed; the

Amphipoda (e.g. sandhopper) are the least modified; some of the Isopoda (such as the wood-louse) are fitted to and do dwell on land, while the 


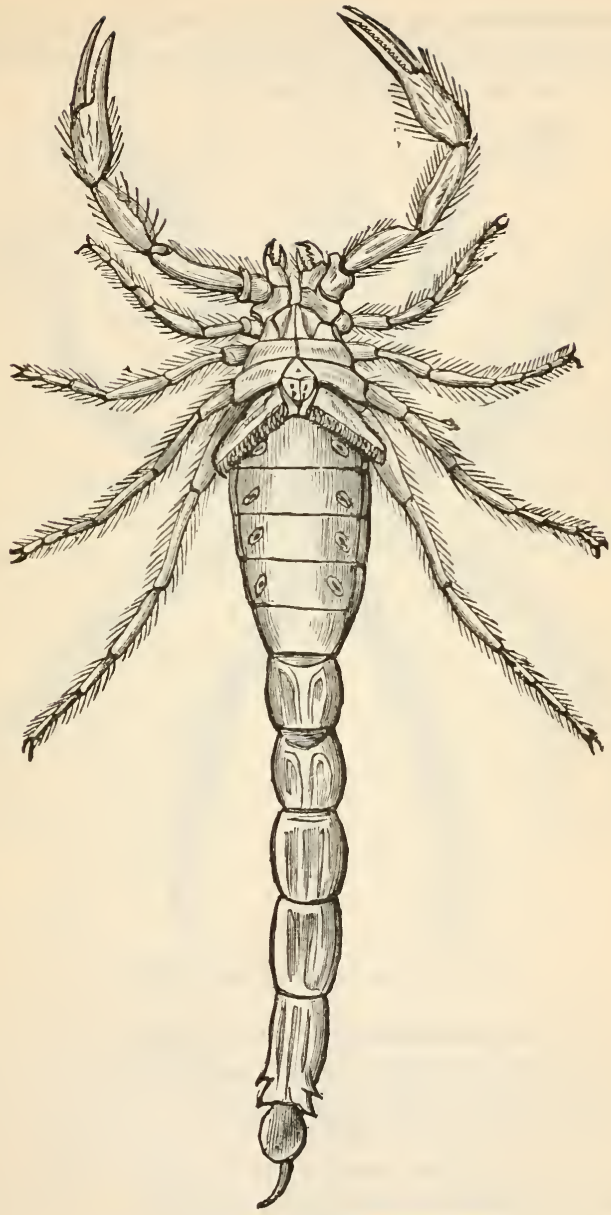

Fig. 31.-Scorpio nccitanus. 
Laemodipoda are modified by parasitism, and have the abdominal region rudimentary (e.g. Cyamus, which is found on the skin of whales).

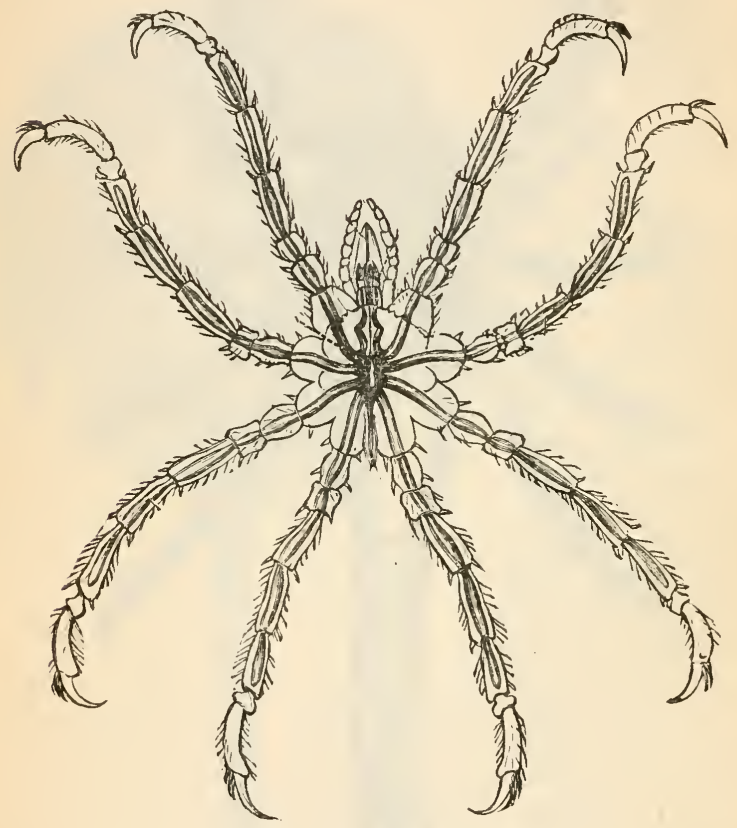

Fig. 32.-Ammothoa pycnogonoides.

B. The Arachnida are arthropods, in which the mouth is never placed so far back that any of the appendages become antennary organs; the second and succeeding four (at most) pairs of appendages have their basal portions ranged round the month, the functions of which these parts subserve. The free portions of the six anterior appendages take on various 
duties. Respiration is effected by flattened processes attached to the appendages behind the generative pores (which are always placed comparatively far forwards), and they either carry blood or contain air, or disappear and are replaced by tracheæ. The hinder part of the body never carries jointed appendages.

\section{H aemato-} bran uh iata.These are to-day represented by the king-crab (Limulus ; Fig. 30). In them the respiratory lamellæ contain blood, and the hinder portion of the bolly is fused into a single mass, while the terminal spine is of great length.

\section{Erob ran-} chiata.-Such are the scorpion (Scorpio ; Fig. 31) and the spiders (Mygale). In these the respiratory lamellæ are sunk into

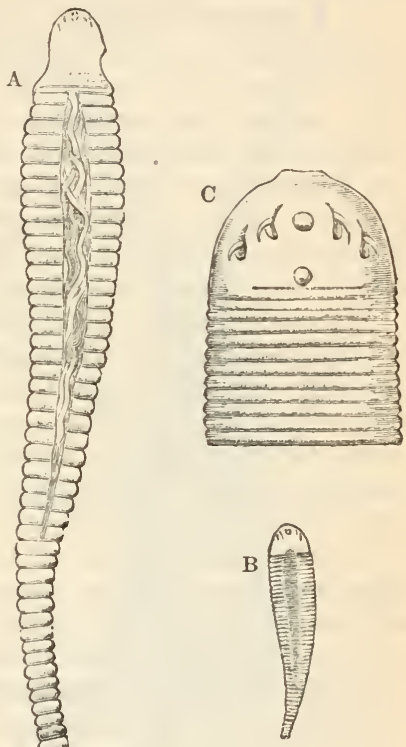
depressions of the body, and contain air (the so-called lungs or lung-books). The hinder portion of the

A, Female, nat. size; B. male, nat. size; 0 , head of nilale, enlarged.

Fig. 33.-Pentastomum tænioides. 
body is either elongated and distinctly jointed, with a short terminal spine, or is greatly contracted, and globose in form.

3. Lipobranchiata.-In these the respiratory lamellæ are lost, and if any special respiratory organs are developed, they are in the form of tracheal tubes. Here belong the Acarina (mites, ticks), with an unsegmented abdomen, and often a sucking mouth; the Pedipalpi (Harvestmen), with a segmented abdomen; and the Pycuogonida (no-body crabs), in which prolongations from the gastric cavity extend into the enormously long legs (Fig. 32).

Appended to this group, but considerably altered by parasitism, so that when adult they have elongated worm-like bodies, with but two pairs of mouth hooks to represent the appendages, are the Pentastomida, the best known example of which is the Pentastomum tænoides, which is found in the frontal sinuses of dogs' skulls (Fig. 33, A, B, c).

C. The third division of Arthropoda is that of the Trachcata; in them there is always one pair of antennæ in front of the mouth, the gnathites may be very profoundly modified; respiration is effected by means of air tubes (trachear), which are regularly arranged and richly developed within the body. They are divisible into a lower and a higher group, of which the former has comparatively few representatives; the other more than all the rest of the animal kingdom.

I. Myriopoda or Centipedes and Millipedes.In these most of the metameres are separate and distinct, or are united by pairs, and all are provided with a pair of jointed appendages. The mouth organs are not greatly modified ; they are all terrestrial.

II. I I cxapoda or Insects. - In the vast assemblage of forms associated under this head, the appendages of the adult are never functionally 
developed behind the region of the thorax; one pair of appendages form the præ-oral antennæ, and the metameres do not exceed twenty in number. They are sharply divisible into two great subdivisions, according as they are or are not provided with wings ; with the latter, of course, we must associate those in which wings are found in one sex only, or are rudimentary, or of whose ancestral existence (as in the case of parasites), we have sufficient evidence.

A. Aptera, or true wingless forms such as the springtails (Podura), and bristle-tails (Lepisma). In the simplest of these the mouth organs can work either from side to sicle, or from before backwards; the tracher, however well developed, and they are often only poorly so,

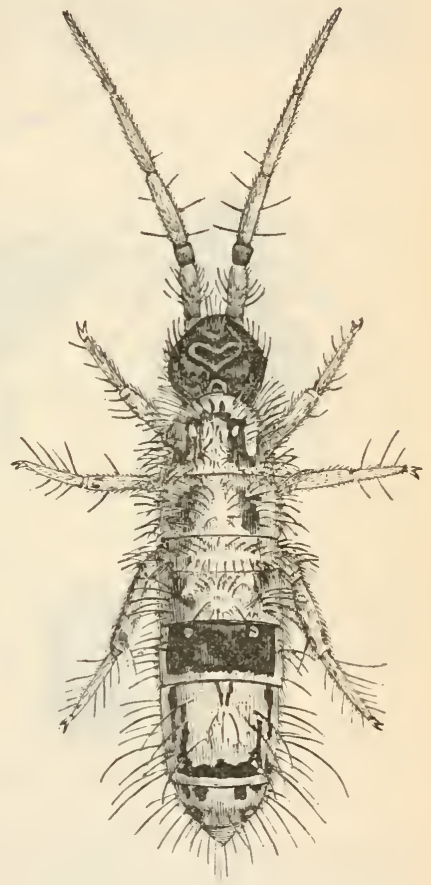

Fig. 34.-Orchesella cincta, enlarged. never anastornose with one another (Fig. 34).

B. Pterygota.-Here belong all the remaining insects, which are either winged, that is, provided with two pairs of membranous dorsal outgrowths in the region of the thorax, which can be moved by 
muscles and serve for flight; or one pair only is developed, or is developed in one sex only, or both pairs are more or less rudimentary. The organs of the mouth are adapted for biting and cutting, or for sucking, and the abdominal metameres are often more

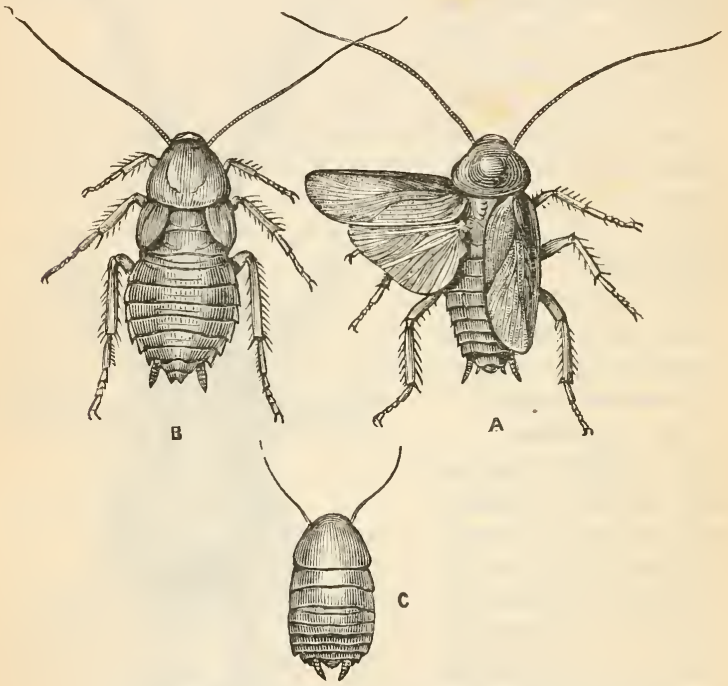

Fig. 35.-Cockroaches: A, Male ; в, Female; c, Young.

or less reduced ; the generative pores are placed far back, and respiration is always effected by tracheal tubes or modifications thereof.

a. Mandibulata. - In this series the mouth organs are adapted for cutting and biting, and move from side to side; or are converted into licking organs.

1. Orthoptera : cockroaches, grasshoppers, and locusts. -With the anterior pair of wings converted 
into wing covers, and the posterior often functional in the males only. No true metamorphosis (Fig. 35).

2. Nemroptera: dragon-flies, termites.-With two pairs of membranous wings. A true metamorphosis, or the life history consisting of three periods, an active larval, a quiescent pupal, and an active perfect or imagimal condition.

With this group may be placed the Trichoptera (caddis-flies).

3. Colcoptera : beetles, cockchafers, lady-birds. - Anterior pairs of wings converted into wing-covers; these are distinctly horny. True metamorphosis. order.

The parasitic Strepsiptera come nearest to this

4. The IIymenoptera (bees, ants) have the mouth organs adapted for licking, as well as for liting and cutting. Both pairs of wings functional. Metamorphosis complete.

B. IIaustellata.- In this series the mouth organs move from before backwards, or serve as stabbing or sucking organs.

5. I Iemiptera (bugs, aphides, lice). - Mouthorgans stabbing and sucking. Anterior pair of wings functionless; in parasites both may be rudimentary. Metamorphosis generally incomplete.

6. Diprera (flies, fleas).-Mouth organs stabbing and sucking; anterior wings functional, the posterior possibly represented by the small knobbed "balancers" (halteres). Metamorphosis complete.

7. Lepidoptera (butterflies, moths).-Mouth organs form a sucking apparatus, with no power of stabbing; both pairs of wings functional. Metamorphosis complete.

The Mollusca form a well-marked phylum, the essential characters of which would be represented in 
some such schematic Mollusc (Lankester) as that here figured. The oblong body is bilaterally symmetrical, and the præstomium, as in Peripatus, is provided with a pair of tentacles (Fig. 36, A, a); the mouth $(\mathrm{B}, o)$ is on the lower surface, and near, though not at the front end, while the anus $(m)$ is median, dorsal,
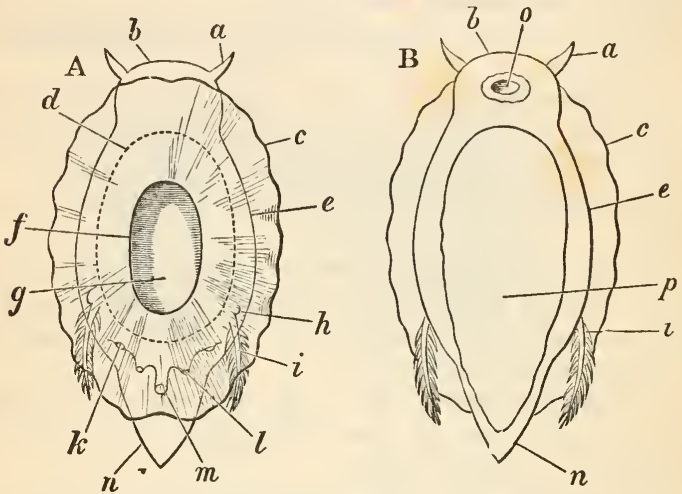

Fig. 36.-Diagrams of the Typical Structure of a Mollusc. A, from above; $B$, from below.

$a$, Tentacles of head $; b$, head; $c$, edge of mantle,$e$, outline of foot seen throngh the mantle, which is supposed to be transparent : $f$, edge of shell-follicle ; $g$, shell ; $h$, osphradium (Sprengel's olfactory organ); $i$, ctenidia (gills); $k$, generative orifice (paired) $; l$, aperture of one of the nephrtdia (excretory organs); $m$, anus; $n$, foot where it extends beyond the visceral mass; 0 , mouth ; $p$, plantar surface of foot. (After Ray Lankester.)

and posterior ; right and left of this anal opening we find the orifices of the excretory organs $(l)$, and near them those of the genital ducts $(k)$.

So far the creature presents no characters other than such as we might expect to find in any cœlomate Metazoon; in addition, there are four characters of greater significance. The ventral surface is produced into a more or less triangular muscular outgrowth, which is known as the foot; the dome-like dorsal surface, which contains the chief mass of the viscera, 
is protected by a hard body, the shell $(g)$, and this shell is derived from a primary shell-sac $(f)$; the walls on either side of the middle line of the body are produced into free folds, the pair of which make up the mantle, and on either side of the body there are given off comb-like processes (ctenidia) (i), which are ordinarily known as the gills. Indications of metameric segmentation are rare, and are only obscurely indicated in the majority of the cases where they are to be detected.

The Mollusca may be primarily divided into those in which the region of the head is reduced or lost, and those in which it takes on more special characters. The former are conveniently known as:

A. Lipocephala.-This division contains only the group of the Lamellibranchiata or mussels and oysters. In these the primitively single shell is divided into two bilaterally symmetrical halves, and the two divisions of the shell are only different (Oyster: Myodora) in size and character, when one side comes to be that on which the animal ordinarily reposes, or when it ceases to live in an upright position; the foot may, as in boring forms, be of considerable size, or it may be greatly reduced, as in the oyster, which remains for long periods at the same place.

This shell is brought together by special adductor muscles, of which two pairs are found in many adults, and have been observed in the young of some which (oysters) have only one pair in adult life. The ctenidia, which commence as separate ciliated filaments in two rows on either side, ordinarily undergo a large amount of fusion or concrescence, whereby they are converted into perforated plate-like structures which have, among others, a respiratory function. In some the mantle never extends beyond the limits of the shell, and these are the : 
I. Asiphoniata, such as the mussels and the oysters.

II. In others the mantle is produced into two more or less elongated siphons (Fig. 37, Siphoniata) and these siphons are either not retractile as in the cockle (Cardium), and the immense Tridacna; or the siphons can be retracted by special muscles (Simupalliata), as in Pholas, Solen, and Mactra.

B. In the higher division of the Mrollusea the

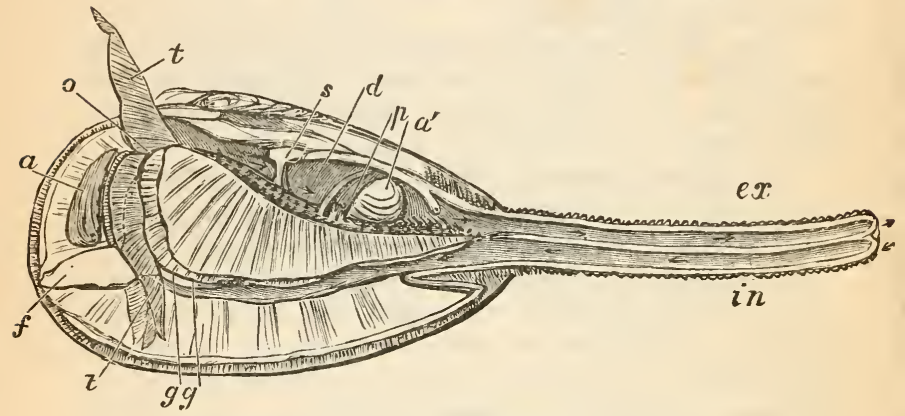

Fig. 37.-Mya arenaria, a Siphonate Lamellibranch.

$e x$, Excurrent; in, incurrent siphon; $a$, anterior ; $a^{\prime}$, posterior adductor muscle: $g g$, branchiæ ; $f$, foot ; $t$, Jabial tentacles ; $o$, mouth ; $s$, stomach ; $d$, intestine; $p$, muscle of the foot.

cephalic tentacles and eyes are retained, and within the cavity of the pharynx there is developed a special rasping organ or tomgue, the presence of which justifies the name Glossophora, which is applied to this series. In a number of these the foot becomes divided into three well-marked regions, but in the lowest group,

1. Gastropoda, the foot is ordinarily simple, and only constricted into three regions; it is broad and flattened. In a large number the body undergoes a twisting round its central axis, in consequence of which the two sides of the body come to be unequally 
or asymmetrically developed. The appearance of this torsion allows us to divide the Gastropoda into à lower or more primitive, and a ligher or more differentiated series.

a. Isopleura. - In these the two sides of the body are equally developed, and many of the characters of the primitive mollusc are retained unchanged. Here we have the Polyplacophora, represented by the Chitons, in which the shell is broken up into eight pieces arranged in a fashion to which it is difficult to refuse the name of metameric arrangement (Fig. 38) ; and the Neomeniidae, and the Chatodermatidae, in which the shell is represented by spicules only.

\section{B. In the Anisopleura we}

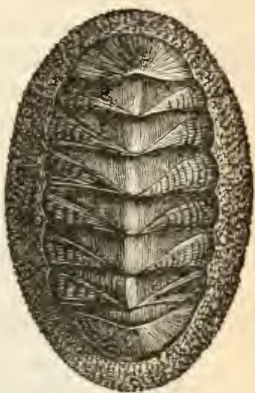

Fig. 38, - Chiton mag. nificus.

have an exceedingly interesting phenomenon; while the body undergoes torsion, the nerve-cords that run down the sides of the body may or may not be implicated in the change. Where they are not we have the Euthyneura, which either, like Aplysia and Doris, continue to breathe by gills the oxygen dissolved in water, or like the pond-snail (Lymnœus), the garden-snail (Helix), and the slug (Limax), have their gills aborted, and a breathing chamber or lung formed by the apposition of part of the edge of the mantle to the side of the body.

In the Streptoneura the nerve-cords are implicated in the general torsion of the body, and form a figure of eight loop; in the Zygobranchiata, of which the ear-shell (Haliotis) and the limpet (Patelli) are examples, the right and left gills become respectively the left and right, and are equal and $\mathrm{G}-16$ 
symmetrical ; in the Azygoloramchiata, such as Paludina, Dolium, the cowry (Cyprœa), and the whelk (Buccinum), the left gill and excretory organ become aborted ; some members of this division, the so-called Heteropoda, become modified to a free-swimming life, as Atlanta or Firuloides.

II. The ancient group of the Scaphopoda exhibits some primitive characters, but is specially

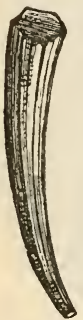

Fig. 39. - Shell of Dentalium elephanti. num. remarkable for its elongated elephanttooth-like shell (Dentalium) which is open at either end (Fig. 39).

III. The Pteropoda closely approach in many important characters the next succeeding group, but they are most conveniently kept separated from them. The anterior portion of the foot (propodium) surrounds the head, and the median part (nesopodium) is converted into a pair of flapping finlike organs by means of which these ordinarily minute creatures are enabled to swim about on the surface of the ocean. According as they have or have not a shell, they are called Thecosomata (Hyalea, Cymbulia), or Gymuosomata (Clione, Pneumodermon).

IV. The last and highest division of the Mollusca is formed by the Cephaloporla; the propodium is here produced into a number of long tentacular processes or arms, on which suckers are not unfrequently developed; the mesopodium of either side unites with its fellow to form an incompletely or completely closed siphonal tube, which serves as the chief organ of locomotion. The shell is external or internal, coiled or simple, or completely absent.

a. The ancient group of the Tetrabranchiata, to which many fossil forms belong, is represented to-rlay by a single genus, Nautilus; they receive their 
name from the possession of two pairs of gills, with which, an exceptional circumstance among Molluses, are associated two pairs of ante-chambers to the ventricle. The siphon is incomplete, the propodial tentacles are numerous and devoid of suckers; the shell in external, chambered, and coiled (Fig. 40).

B. The Dibranchiata have either eight arms as in the Octopus, or ten as in the squid (Loligo), or Sepia ;

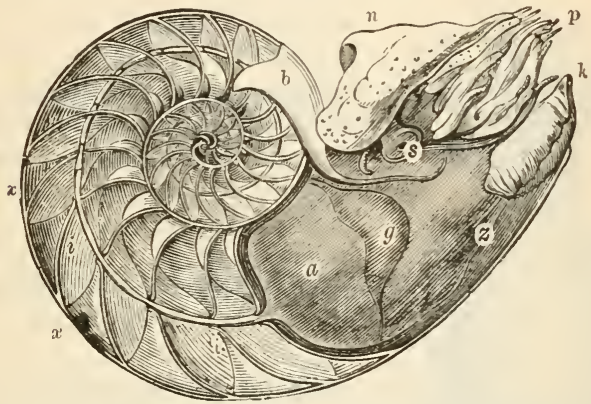

Fig. 40.- Section of the Shell of the Pearly Nautilus, showing the coil of chambers, and the animal in the largest, or that last formed $(z)$. $a$, Mantle; $b$, dorsal fold; $g$, shell-muscle; $i i$. Siphuncle; $k$, funnel or siphonal tube; $n$, hood; $p$, tentacles; $s$, eye; $x$, septa between the chambers.

there is only a single pair of gills and auricles, and the arms are provided with suckers (Fig. 41).

It has long been the custom to divide the members of the Animal Kingdom sharply into the two great groups of "Vertebrata " and "Invertebrata"; we have seen, however, that the most scientific separation is that into uni-cellular and multi-cellular organisms, Protozoa and Metazoa; and, next, that the lower Metazoa have no signs of that body-cavity or colom which becomes so well marked a part of the organisation of the higher forms; and, lastly, we have seen that the Echinodermata, the Arthropoda, and the 
Mollusca form three very distinct branches or phyla, the common ancestor of which is to be sought for only in a simple worm. Of equal value with these is another phylum, which may be most conveniently spoken of as that of the Chordata, distinguished from the rest by the association of two characters, the temporary or permanent possession of a rod underlying the central

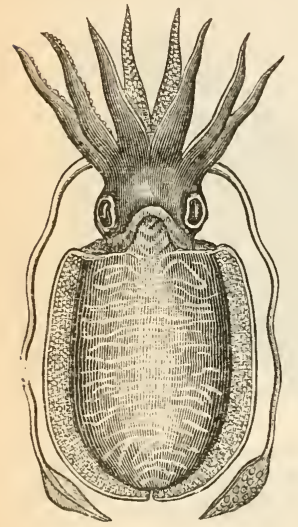

F g. 41. - The Common Cuttlefish. dorsally-placed nervous system, and the similarly temporary or permanent possession of clefts or passages at the sides of the head and neck, which open to the exterior (visceral clefts).

Either one of these characters may be seen in certain members of that heterogeneous mob, which, partly from the nature of things, and partly from the imperfect condition of our knowledge respecting them, must be retained in the group of Vermes.

Among, or standing near to, the Platyhelminthes, are some elongated, free-swimming, marine forms which are known as the Nemertinea. These worms are provided with a dorsal proboscis, which is enclosed in a sheath. The relations of this proboscis to its sheath are shown in Fig. 42 A, while Fig. 42 B exhibits in diagramatic form the relation of certain parts in one of the lowest of fishes (the lamprey); a comparison of the relations of these structures (proboscis and its sheath on the one hand, and chorda dorsalis on the other) with (a) the dorsal surface of the body and $(\boldsymbol{\beta})$ the digestive tract, reveals very striking resemblances, which come to be of still greater significance when we 
combine with them the knowledge of the fact that, in certain Nemertines, the nerve cords, instead of lying at the sides of the body, tend to take up a dorsal position. Whether or no Hubrecht is right in regarding the Nemertinea as giving us indications of where to look for the ancestral form of the Chordata, it is clear that we must sharply distinguish them from the group of the Platyhehinthes, with which they have
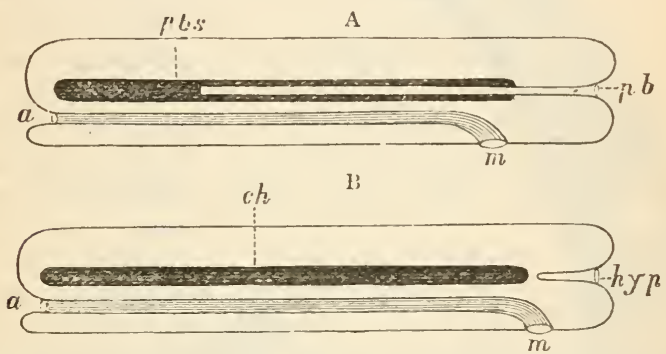

Fig. 42.-A, Diagram to sbow the relation of the proboscis ( $p b s)$ to the surface of the body and to the sheath of the proboscis $(p b s)$, in the Nemertinea; (B) diagram of Petromyzon (the lamprey) showing the hypophysis cerebri (hyp); the chorda dorsalis (ch); the mouth $(m)$; and the anus $(a)$. (After A. A. W. Hubrecht.)

been hitherto very closely associated. Lineus, Carinella, Polia, are examples of this group.

So, again, in another group of "worms," the Enteropneusti, the sole representative of which is the remarkable Balanoglossus (Fig. 43), the anterior portion of the enteron divides into a ventral and a dorsal portion ; the former retains its nutrient office, but the latter has chitinous lamellæ developed in its walls; between these clefts $(b r)$ appear, which finally open on the surface of the body ; blood-vessels are richly distributed to the walls of the arches, and the water taken in by the month passes through the clefts to the exterioi: In Balanoglossus, therefore, just as 
much as in a fish, we have gills developed at the sides of the anterior region of the digestive tract.

With regard to the Chordata, however, it is to be distinctly borne in mind that both these organ; (notochord and gill-slits) are to be found, and we may,

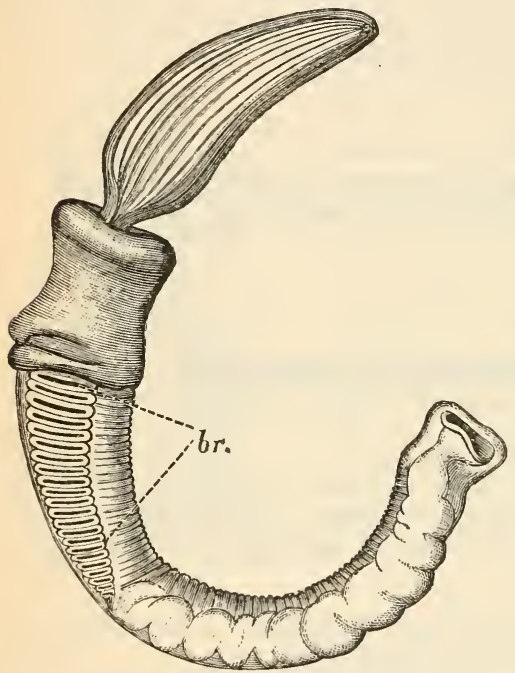

therefore, look for the ancestral or ideal Chordate in an elongated, bilaterally synımetrical, metamerically segmented animal, in which the central nervous system, dorsal in position, was supported by a rod of firm tissue, in which the sides of the borly and pharynx were perforated by gill slits ; and in which the mouth was Fig. 33.-Young Balanoglossus seen from the side. placed on the bi. Branchial slits; $\times 12$. (After Pagenstecher.) ventral surface, not far from the front end of the body. The Clnordata fall into three well-marked groups; in one degeneration has proceeded to an extent so considerable, that in many all indications of a chordate ancestor are completely lost; these are the Urochordata or so-called Tunicata. In another, many primitive characters, such as the original segmentation and the notochord, are retained unchanged, but in some few points 
there would seem to be degradation; these are the Cephalochordata; and, lastly, we have the true Vertebrata or Craniata.

A. Cephalochordata.-Of these the only example is the Lancelet or Amphioxus, in which the notochord, pointed at either extremity, extends from one end of the body to the other; the number of gill slits is very great, and they are covered over by an outgrowth of the body wall which grows down on either side, and unites along the ventral line, leaving a pore for the exit of the water (atrial pore). The original segmentation of the muscles of the body is not obscured; the mouth is over-hung by a projecting hood, and furnished with a number of tentacles (cirri); the liver is represented by a very slight, blindly ending outgrowth of the enteric tube, and renal organs are very obscurely indicated ; there is no centralised heart, and appendages are completely wanting. The eye is only a pigment spot, and no signs of an ear have been detected.

B. Urochordata.- In no division of the animal kingdom has the value of the study of derelopment been of more importance than in this, for it has revealed the presence of a notochord, and the essential resemblance between their gill clefts and those of the Cephalochordata; while in none has the application of the principle of degeneration (Dohrn; Lankester) been more instructive.

In but few forms is the notochord retained throughout life, and in these it is found in the tail only, Perennichordata (e.g. Appendicularia); in the rest, Caducichordata, the caudal notochord is present in the larva only, or is never developed at all ; in these, just as in Amphioxus, outgrowths of the body wall enclose the true sides of the body, and give rise to an atrial chamber, by whose pore the water of respiration, and often also the waste matters of digestion finally make their way to the exterior (Fig. 44). 
Some of the Caducichordata remain solitary throughout life, e.g. Ascidia, or Boltenia (which is remarkable for its long stalk); others become fused into a common colony, as Botryllus, Pyrosoma, colonies of which may be more than a foot long, and Salpa, the chains of which are sometimes several feet long.

C. In the true Vertebrata the anterior end of the central nervous system is enlarged into a brain, which becomes surrounded and protected by a cartilaginous capsule or shull; supporting and protecting arches, which finally become distinct vertebrae,

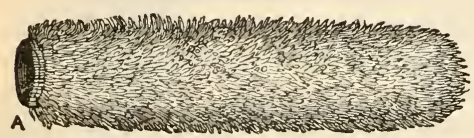

Fig. 44.-Pyrosoma; A, The atrial or excurrent opening.

are developed around and above the noto. chord, which, in the adults of the higher forms, is completely aborted. Optic, auditory, and olfactory organs are developed; there is a centralised heart and a distinct liver appended to the enteric tract. They are divisible into two groups, distinguished by the fact that, in the higher, an anterior gill-arch becomes modified to form jaws at the sides of the mouth.

a. Cyclostomata, or Round-Mouths; these are the lampreys (Petromyzon), and hags (Myxine). There is here no mandilbular arcli, no appendages in the form of limbs, and the olfactory organ is single and median. The hags are parasitic in habit.

B. Gnathostonata.-In this division all the remaining Vertebrata are included; in them an anterior gill-arch becomes mandibular, two pairs of lateral appendages are typically developed, and the nasal sac is double.

In all divisions of the animal kingdom we may observe groups which seem to stand near the ancestral 
forms, and others in which, a given complexity of structure having been attained, there is a profusion in the elaboration of the details. This truth is well exemplified in the groups of the Vertebrata.

\section{Ichthy-} opsida; these are the true Fishes, and the Amphibia (or frogs and newts). In them respiration is always effected by gills during some or the whole of their life, the heart never has more than three chambers, and there are always two aortic arches at least given of from it.

a. isces.

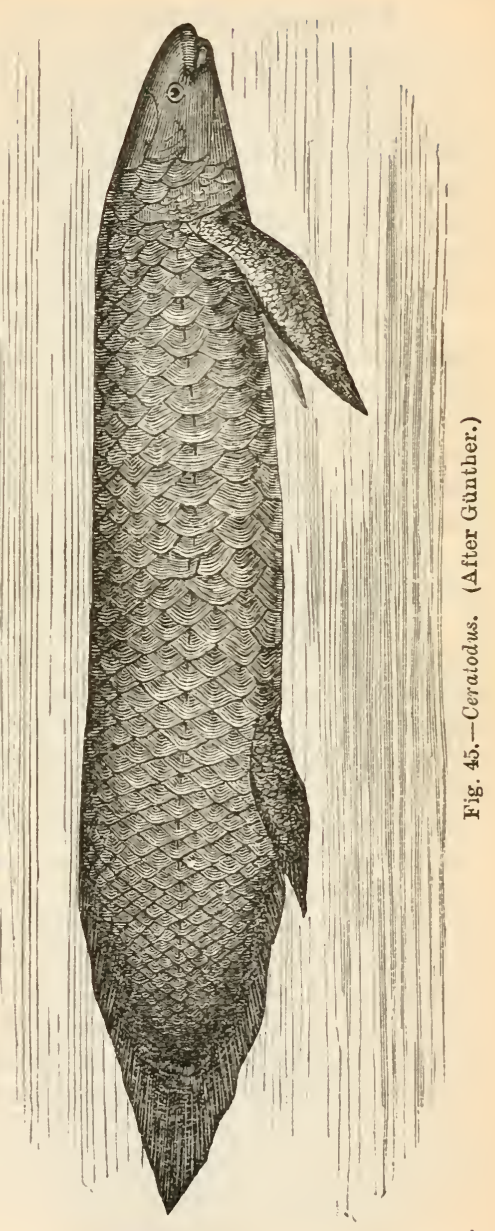


1. Elasmobramchii (sharks and rays).-In "cartilaginous fishes" the gill slits are, in the simplest, naked, i.e. not covered over by any fold (operculuun), neither the skull nor the jaws are ever protected by ossifications of the investing membrane (membrame bomes); the notochord has the outer sheath provided with rings of ossification, or distinct vertebræ become developed. The skin is either naked, or covered with calcified tooth-like papillæ.

2. Dipnoi; e.g. Lepidosiren, Ceratodus.-In these the cartilaginous brain capsule becomes invested by bones developed in the covering membrane, and the digestive tract gives off a single or incompletely divided air sac, which is more or less richly supplied with blood-vessels, and may undertake the office of a lung, the possession of which enables the fish to live in mud. The pectoral and pelvic fins are broad and paddle-like (Fig. 45), or elongated and filiform.

3. The Ganoidei and (1) Teleostei are the two groups of the Pisces in which we observe that elaboration of the details to which reference has already been made; a cod, a sole, or an eel stand almost as far from the primitive vertebrate as the snake, the hawk, or the bat. The former group retains certain more primitive characters which are only rarely or rudimentarily possessed by the latter; thus the arterial trunk (see page 195), which is muscular and contractile in Elasmobranchs, Dipnoi, and Amphibians, is so also in Ganoids, but is only incompletely so in some Teleostei (Butirinus); the spiral valve which is found in the intestine of Elasmobranchs is retained in the Ganoids, though not well developed in the Sturgeon and its nearest allies; it is lost in most Teleostei, though found in Butirinus (Stannius), in Chirocentrus, and perhaps represented in rudiment in the smelt (Huxley).

In both groups the ends of the gills are free, and 
the gill chamber is covered in by a bony plate, operculuna ; the renal ducts do not open into a depression (cloaca) common to them and the anus. In all Ganoids, and in one great division of the Teleostei, the air sac on the dorsal surface of the body opens by a duct into the œsophagus.

The recent Ganoidei fall into two divisions :

\section{a. Selachoi-}

dei ; * such are the Sturgeons (Acipenser) and Polyodon; in these the skull consists of persistent cartilage, overlaid by bones developed in the investing membrane; spiracles are persistent, and the body is either naked, or has bony plates developed in the dermis (Fig. 46).

* Chondrostei.

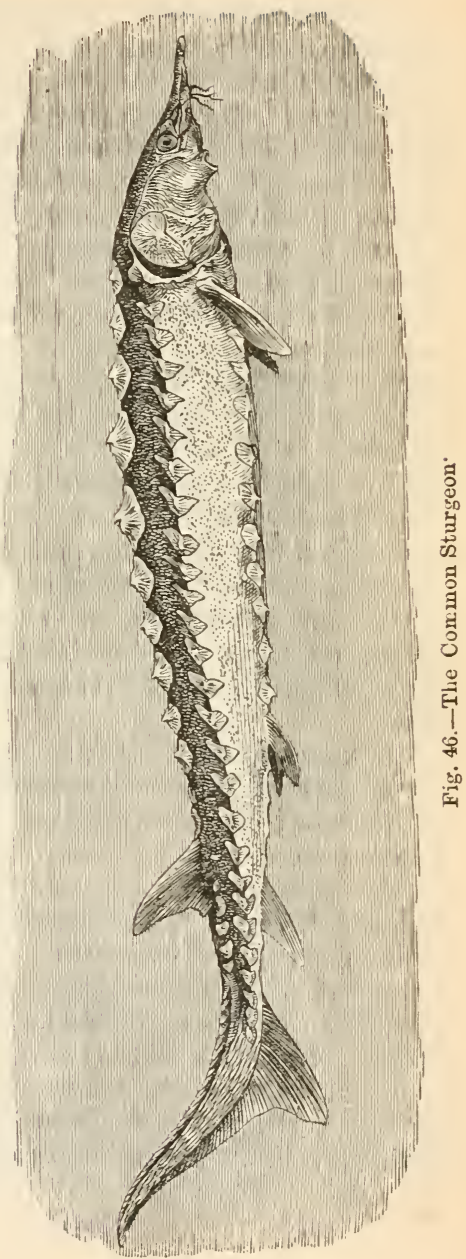


B. Teleostoidei; * represented by the North American bow-fin (Amia), and gar-pike (Lepidosteus), and the North African Polypterus; in these the hinder part of the cartilaginous cranium always undergoes ossification, the spiracles close up, or are covered by a bony plate, and the scales, which are never formed of true bone, are large, and may be covered by a layer of enamel. Vertebra are developed around the notochord.

The Teleostei, or bony fishes, always have ossified vertebral centra, and more or less of the primitive cranial cartilage is finally replaced by bone; scattered bony plates are developed in the dermis, or the integument is protected only by thinner scales, or the body is naked; they are divisible into:

a. Physostoni, where the air bladder, which is an outgrowth of the œsophagus, almost always remains connected with it by an open duct, and the hinder pair of fins, if retained, as in the salmon, are always abdominal in position; here we find catfishes (Silurus), carps, pikes (Esox), and salmons, as well as the finless eels.

R. Physoldisti. - In these the air bladder becomes shut off from the esophagus, or is aborted, as in the sole; the ventral fins, which are rarely abdominal (Notacanthus), are ordinarily thoracic or jugular in position; not unfrequently they are rudimentary or lost. The fin-rays are either all jointed as in the cod, or some are entire, as in the perch. Some forms are asymmetrical and flattened like the sole; some swollen and globular like the sun-fish ; some greatly elongated like the pipe-fish; some with a prehensile tail like the sea-horse; some have the body scaleless ; others, like Diodon, have erectile spines; some can live in semi-fluid mud (Ophiocephalus); 
some can make overland journeys, and go up inclined surfaces, if not trees, like Anabas; some can take leaps out of the water, like the "flying gurnards" (and the physostomous Exocœtus); some, like Chætodon, have a minute mouth, while the sword-fish has its upper-jaw converted into a powerful piercing organ, and another (Toxotes) has acquired the habit of throwing a drop of water at the insect it desires to obtain. Other examples might be given of the profusion of variation within the limits of Teleostean organisation.

Even the lowest of the Amphibia are distinguished from the highest of fishes, such as Ceratodus or Lepidosiren, by the fact that their fore and hind limbs are arranged on the same plan as in the higher vertebrata (see page 350), and these limbs terminate typically in five digits, so that, like the higher forms, they are pentadactyle; if, further, fins are developed, they never have fin-rays.

1. Urodela; in the lowest of these (Proteus, Menobranchus) (Fig. 47) external gills persist throughout life; in the next grade (Ampliuma, Nenopoma) the gills are lost, but the gill-clefts remain; while in the highest (Salamandra, Triton) the gills disappear in the adults, and the clefts close up. All retain the tail, which in the

2. Anura (or frogs and toads) is only found during the tadpole stage, when also respiration is effected by external or internal gills, which disappear in the adult, to be functionally replaced by lungs.

3. Caeciliae are still more modified forms, in which the limbs are lost, and the body is elongated and serpentiform.

The two higher divisions of the Vertebrata are the Sauropsida and the Mammalia, which may be grouped together as the Ammiota. They are characterised by the very early development of a 


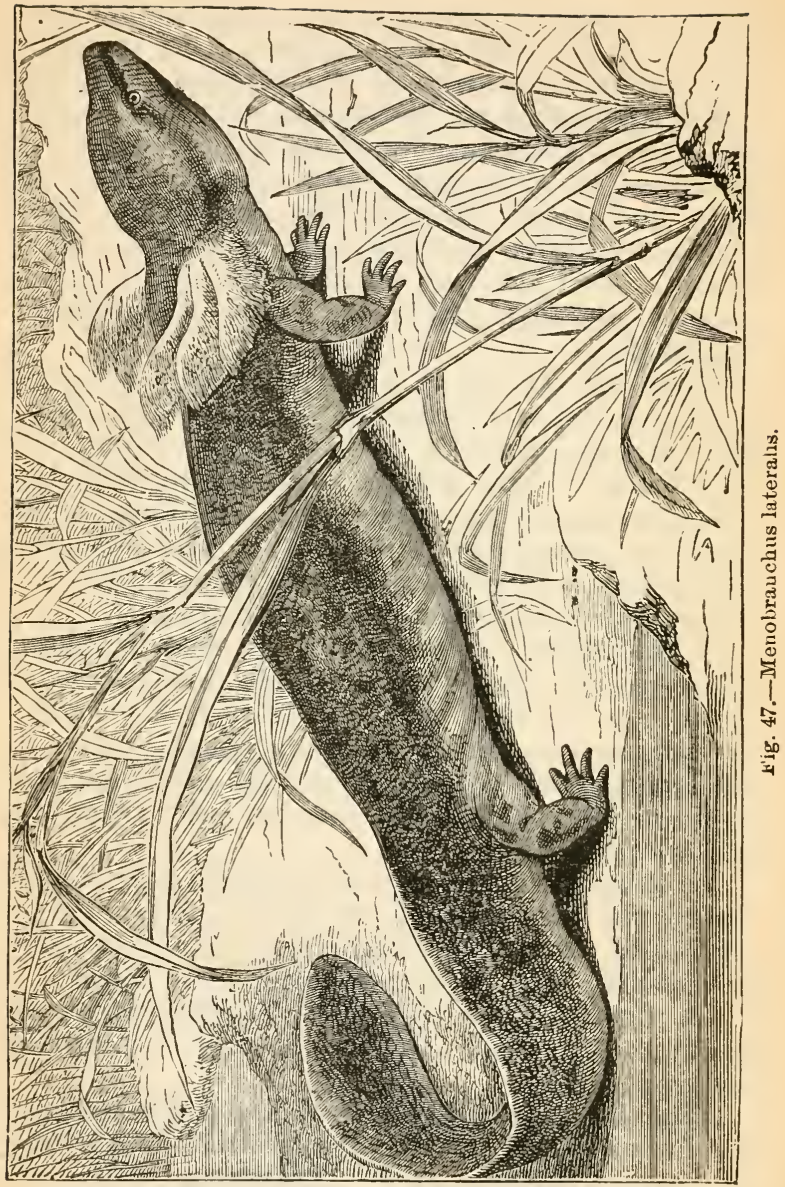


large sac-like structure similar in origin and primitive position to the bladder of the frog; this allantois takes on respiratory functions in the developing reptile or bird, and a nutrient one in the higher Mammalia. From either end of the body there grows out a fold, which passes over the body of the embryo and unites above it with its fellow; this fold, which is double, forms the amnion; the two layers of the amnion separating from one another give rise to a cavity between them which is more or less occupied by the allantois; in the Bird the allantois is comparatively larger than it is in the Mammal.

The differences between the Sauropsida, or reptiles and birds, and the Mammalia are well and sharply marked, and it is almost impossible to suppose that their common ancestor was not more amphibian than amniote in character. Thus, the Sauroids have scales or feathers, the Mammals hairs; the skull is always articulated to the atlas by a single condyle in the Sauroid, and by two in the Mammal; the quadrate bone, which is external to the ear in the Sauroid, is enclosed by the otic capsule in the Mammal; the red blood corpuscles of a Sauroid are, and of a Mammal are not, nucleated; the connection between the cerebral hemispheres of a Mammal is more intimate than in a Sauroid, and while the eggs of the latter are large, and provided with a quantity of yolk, those of the Mammal are much smaller, ${ }^{*}$ and nutrition is afforded to the young by milk, the secretion of certain modified tegumentary glands.

The recent investigations of palæontologists have

* It has been recently stated that the ova of the lowest Nammals are large, and that they are hatched outside of the body. This observation, coupled with the facts that certain fossil Reptiles (Theriomorpha) give well-marked indications of mammalian affinities, and that some Reptiles (e.g. some of the Amphisbænidæ) have the occipital condyle double, may necessitate a revision of current ideas as to the origin of the Mammalia. 
afforded us a complete series of intermediate stages between the reptiles and bircls, and they are justly united in the common group of the Sauropsida.

A. Reptilia. - Sauroids with horny or bony plates, but no feathers, with more than three digits in the manus, of which three at least bear claws, with at least three digits in the pes, and with unankylosed metatarsals. The blood is ordinarily cold, and there is at least one pair of aortic arehes.

1, 2. Lacertilia, or lizards, and Ophidia, or snakes, have the quadrate movable, the penis double, and the anus a transverse slit. Some of the Lacertilia, such as Lacerta (the common lizard), are the least modified of all Sauroids, and the Geckos retain a primitive character in the persistence of remnants of the notochord. Others are specially modified, like the flying lizard (Draco), others have ossified scutes approaching those of crocodiles (e.g. Cyclodus) ; Hatteria is remarkable for the possession of "uncinate processes" on the ribs (see page 346), such as are seen in crocodiles and birds. Some, like the blind-worm, lose their limbs, but all have a pectoral arch and a urinary bladder, both of which are absent from the Ophidia, in which the hind limbs are rarely present, and then are only short and inconspicuous. They are divisible into the Eurystomata, in which the mouth-cavity is capable of dilatation, and the Stemostomata, in which the facial bones are immovably connected with one another. Among the former we find vipers, rattlesnakes, and water snakes, which are venomous; and adders, boas, and pythons which are not so. Typhlops and Uropeltis are examples of the Stenostomata.

3. Chelonia, or turtles and tortoises. - In these the quadrate is immovably connected with the side of the skull, the penis is simple and solid, and the anal orifice rounded. The bony plates developed in 
the dermis are definitely arranged, and form a "carapace," which is generally, though not always (Trionyx), covered by horny epidermic plates, which form the "tortoise-shell." They exhibit a primitive character in the retention of the five digits in either limb, but diverge from the typical organisation in the loss of teeth; an interesting series of modifications, in relation to their mode of life, are exhibited by the limbs. In the tortoises, which are terrestrial, the digits are free; in the amphibian terrapenes there is a partial web, which is more complete in the Trionychidæ; while the marine Cheloniidæ have the digits completely covered by skin, so that they form flattened swimming fins.

4. Crocodilia, or crocodiles and alligator's, are the only reptiles in which the heart is four-chambered; like the Chelonia, they have the quadrate immovably connected with the side of the skull, the penis is simple and solid, and the anal orifice is rounded. The teeth are set in distinct sockets, and are never found on any bones but the maxillæ, premaxillæ, and dentaries. They have returned to an amphibious or aquatic mode of life, in correlation with which their feet are webbed, the nostrils can be closed, and the tympanic membrane of the ear covered over.

B. Aves, or birds, are Sauroids with feathers, with never more than three digits in the manus, or four in the pes ; three of the metatarsals are ankylosed with one another, and with the distal tarsal bone. The blood is hot, and there is only a single systemic aorta. All recent forms are toothless. Physiologically, if not also morphologically, the recent forms are divisible into :

I. Ratitae, in which the ventral surface of the sternum is broad and flattened, and the fore-limb does not form a functional wing; such are the ostrich and the cassowary.

$\mathrm{H}-16$ 
II. Cariuatae, in which the ventral surface of the sternum is typically provided with a median keel, and the fore-limbs may serve as functional wings. Among them we find the singing birds, parrots, owls, eagles, geese, pigeons, and gulls ; and here, as among the Teleostei, we find the most varied elaborations in the details of a structural organisation, which is, in its essential points, extraordinarily similar throughout the group. The extinct Odontornithes (e.g. Hesperornis) were true birds with teeth in their jaws.

The Mammalia, or last division of the Vertebrata, are all distinguished from the Sauropsida by the possession of two occipital condyles, and by the fact that the single aortic arch is the left and not the right member of a primitive pair. They are all more or less hairy, and have mammary glands; the quadrate becomes the malleus among the auditory ossicles, the blood is hot, and the red blood corpuscles

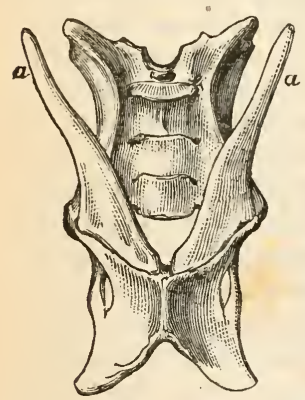

are without a nucleus, while the cerebral hemispheres liave a corpus callosum. (See page 426.) They exhibit three well-marked grades of development :

A. Prototheria (Ornithodelphia), in which the mammary glands are without teats, the young are not nourished within the uterus of the mother by means of a placenta, the Fig. 48.-Pelvic Arch of epipubes (see page 348 ) are Echidna, showing the Epi- large, and the corracoids
pubes $(a, a)$.

duck-bill (Ornithorhynchus) and the Echidna (Fig. 48), which have so far diverged, like the Chelonia, from 
the primitive type, that they are without true teeth.

B. Metatheria (Didelphia). - These are the Marsupials; they have true teats, but no placenta ; the epipubes are large, but the coracoid rudimentary. The Marsupials exhibit a great range of variation and structure among themselves; some are carnivorous, like the Opossum, the Dasyurus, and the Thylacine; others herbivorous, like the kangaroo (Macropus) and the wombat (Phascolomys).

C. Eutheria (Monodelphia). - Here stand the rest of the Mammalia, which, without any known exception, have teats, a placenta, rudimentary or no epipubes, and a rudimentary coracoid. The least differentiated are the Insectivora (e.g. hedgehog, mole), to which are most closely allied the Chiroptera (bats), and the Rodents (rat, rabbit); in these the yolk sac takes a larger share in the formation of the placenta than it does in other mammals.

The Edentata form, at the present day, an isolated group, represented by the sloths, anteater's, and armadillos, by the pangolins (Manis), and by the ant-bear (Orycteropus). The hoofed animals, or Ungulata, form a well-marked division, in which the group of the even-toed forms (Artiodactyla), such as the pig, deer, and cow, is very distinct from that of the odd-toed (Perissodactyla), such as the tapir, rhinoceros, and horse. With the Ungulata, the coney (Hyrax) and the elephant may be associated (Flower). Of aquatic forms, the Cetacea, or porpoises, toothed whales, and whalebone whales seem to stand nearest to the Ungulates. Of the attinities of the other aquatic mammals, the Sirenia, or manatee and dugong, we can only with confidence say that they are not with the Cetacea. The true Carnivora are the dogs, cats, and bears, and with these are closely allied the walruses and seals. 
By the almost universal consent of zoologists, the highest "order" of the Mammalia is that of the Primates; of these, the lowest suborder is that of the Lemuroidea (of which some naturalists would make a separate order), the highest that of the Anthropoidea, which is divisible into five "families," the highest of which is the Hominida, represented by the single genus IIomo.

While Man is said to be the highest of animals, it is not to be forgotten that in the other divisions of zoologists there are forms in which structural characters are at least as perfectly elaborated, when we bear in mind their ancestral history and the relation of structure to function. The horse, the whalebone whale, the woodpecker, or the boa constrictor, are, to cite only a few examples, forms in which structural organisation is as, if not more, complete, and as differentiated as it is in man.

There remain to be considered very briefly several groups of animals which, in the present state of our

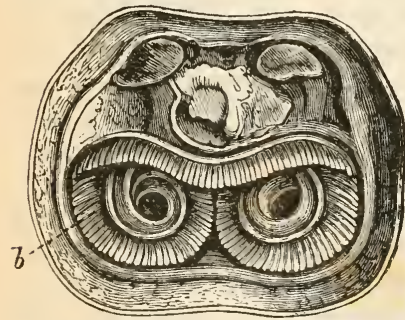

Fig. 49.-Crania anomala. $b$, Arms. (After Davidson.) knowledge, cannot be satisfactorily placed with any of the great phyla which we have just been describing. Of these the more important are :

\section{Brachiopoda.}

-These were placed by earlier naturalists with the Mollusca, from which, however, they are to be distinguished in consequence of the segmentation of the larva, the dorsal and ventral positions accupied by the two 
unequal valves which make up their shell, and by the characters of their nervous system. The so-called arms (Fig. $49 ; b$ ) are outgrowths of the præ-oral disc of the larva, at the edges of which the tentacles or cirri are set. This great development of their arms is to be correlated with the fixed habit of the adult.

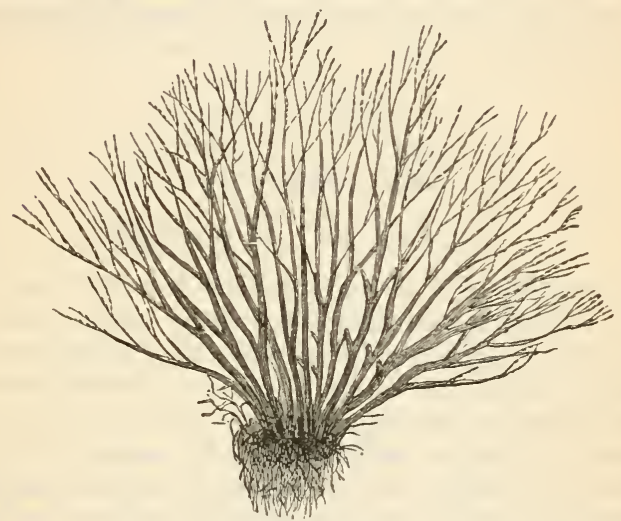

Fig. 50.-Bugula purpurotincta. Nat. size. (After Hincks.)

Terebratula and Lingula (which is stalked) are examples of this isolated and geologically ancient group.

2. The Bryozoa have likewise been placed with the Mollusca; they are clearly degenerate forms which, by the characters of their larvæ, appear to have been descended from an ancestor common to them and the Chrotopoda. Balfour has suggested that they become fixed by their præ-oral lobe. They live in colonies, and are the forms that are popularly known as sea-mats or sea-mosses (Fig. 50).

3. The Chaetognatha (as represented by Sagitta) are forms that have relations to the Chrtopoda and 
to the round worms, but differ from them remarkably in the mode of development of their body cavity, which is an enterocele.

4. Myzostomum is a form with some points of resemblance to the Chrtopoda; its characters, however, are still obscure, partly, no doubt, on account of its having taken to the habit of living parasitically on Crinoids, on which alone it has as yet been detected.

\section{CHAPTER IV. \\ ORGANS OF DIGESTION.}

THE activity of a living organism has for one of its chief results destruction and loss of tissue; this loss can only be made up for by the act of taking in fresh material from the outer world. In the necessary nutrition of an organism, we find that the first process is that of digestion, by means of which substances foreign to the organism become assimilated to it, and are rendered capable of being absorbed, and of passing into that stream whence the different parts of a body take, as they require, the food which is needed to make up the losses caused by their several activities. Organisms are, in other words, metabolic.

It is to be carefully borne in mind that the essential step in the nutrition of an animal is that of assimilation, and it, indeed, is the only process which obtains in the case of the lowest and simplest organisms. In other words, a simple mass of protoplasm, such as an Amœba, takes up from without food material into its own substance, and this, as we have already learnt, is effected directly; the material thus taken in is acted upon by the living 
protoplasm of the cell, which is capable of separating ont from the food such parts as are nutritious, and of converting them into protoplasmic matter; what is useless is discharged, or got rid of.

This direct mode of assimilation by a living cell is spoken of as intracellular digestion; it is the only mode of nutrition which is known to obtain in the Protozoa, but it is very important to observe that the phenomenon is by no means limited to that division of the animal kingdom; it ohtains alșo in various lower groups of the Metazoa, and even after a distinctly defined mouth has become developed. It is, therefore, associated with a number of characters which indicate an advance in the complexity of organisation; and, on the other hand, it is found also in forms which have, under the influence of a parasitic habit, become degraded as compared with their ancestors. The simplest mode of seizing food is observed in the Amoba, where the protoplasmic body seems to engulf its nutriment by flowing and closing around it. And this ingestion of food does not take place at any definite point in the body of the Amoba, but now at one spot, and now at another. When the form of the body becomes more definite, the protoplasmic processes act as organs by which the food is drawn towards the central body-mass.

A much more elaborated mode is to he seen in the ciliated Infusorians, where a definite orifice ("cytostome") acts as the sole entrance for food into the body; in many cases this so-called "mouth" has also an anal function, but in a few forms it has been distinctly observed that a second orifice is present; by means of this "cytoproct," the mndigested portion of the food passes from the body. The presence of a definite oral oritice is no doubt to be associated with the greater elaboration of the organisation of an Infusorian, and we find also that some 
of its most characteristic organs (the cilia) are specially modified in the neighbourhood of the " mouth." In other words, we have here the first sign of a correlation between the digestive orifice and the organs which are locally connected with it, and which are also in relation with the outer world. The cilia around the mouth of Paramœcium (Fig. 3 I.) are much longer than those which fringe the greater part of their body, and give rise to more powerful currents, by means of which food particles are floated towards the orifice.

Some of the ciliated Infusorians, such as Opalina ranarum and Anoplophrya are endoparasitic, and in these the mouth is lost (Fig. 51), as it is also in the Gregarinida, which live in cavities rich in nutrient matter, such as the intestine of the lobster, or the testicular re-

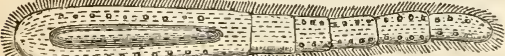

Fig. 51.-Anoplophrya prolifera. (After Claparede and Lachmann.) servoirs of the earthworm ; in such forms as these nutri.

ment enters into the substance of the cell by the mere physical process of diffusion or osmosis.

In the ectoparasitic Suctoria, where the mouth is likewise lost (Fig. 3 III.), processes of the body are drawn out into sucking tubes with knobbed ends; these tubes retain the extensile and contractile power of simple protoplasin, so that they are able to elongate themselves in such a way as to touch their prey, which is ordinarily a ciliated infusorian, and to contract themselves so as to draw the prey nearer. The knob is enabled to bore its way beneath the cuticle, and then, in the words of Stein, "a very rapid stream, indicated by the fatty particles which it carries, sets along the axis of the tentacle, and, at its base, pours into the neighbouring part of the body of the Acineta." 
No movement of the wall of the tentacle has been observed, and the cause of the production of this stream is still unknown.

As has been already observed, the simplest mode of digestion (the intracellular) is not confined to the Protozoa ; it has been observed in sponges, Cœlenterata, and the lowlier worms. A clear idea of what is understood by this method will be obtained from the consideration of a single case. When a section is made through the body walls of a Hydra we find that the endodermal cells vary considerably in size, and that, while some are provided with a singlelong flagellum, others are distinctly

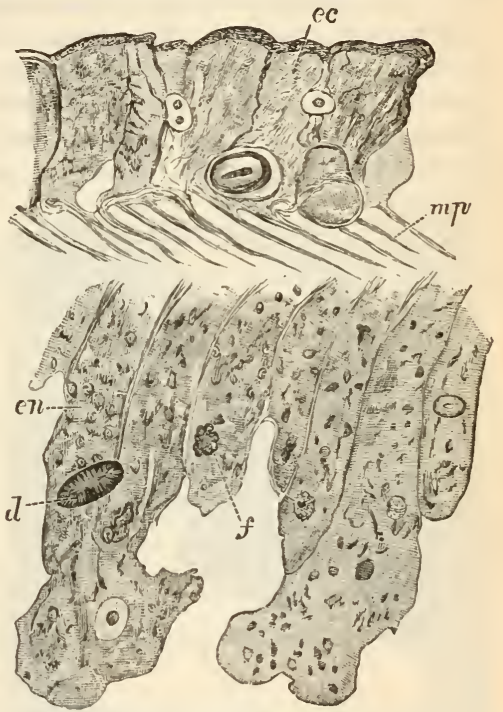

Fig. 52.-Longitudinal Section of the Body of a Hydra, killed in full digestion.

ec. Ectoderm; en, endoderm; $m p$, muscular processes; $d$, a diatom ; $f$, food particles. (After T. J. Parker.)

\section{a unoboid in}

form, and give off large pseudopodia (Fig. 52) ; within these cells dark-coloured granules of various sizes are to be detected, and these food-particles are sometimes found to be "half in and half out of the protoplasm" (T. J. Parker). In such a form, therefore, as the Hydra, there would not seem to be, as in Man and most of 
the Metazoa, any secretion poured out into the gastric eavity from the cells which line this space, but a number of the cells would appear to retain the power of separately assimilating the food material. Ubservation of these endodermal gastric cells shows that they vary considerably in size according to the fasting or well-fed condition of the animal; and we are entitled to suppose that these cells become smaller after the process of digestion, in consequence of their having given up part of their acquired material to the other cells of the body; cells which, be it understood, have

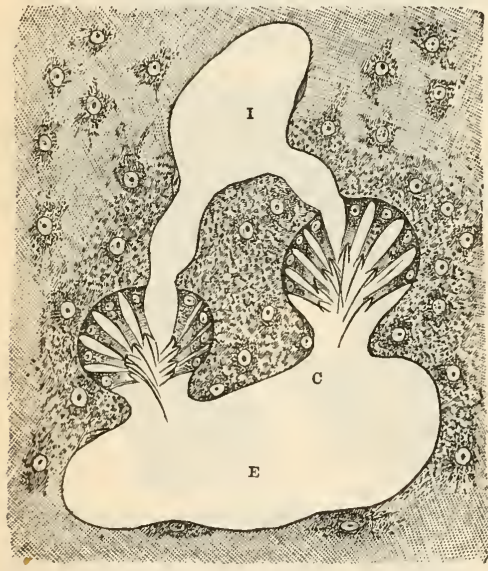

Fig. 53.-Flagellated Chambers (c) of Turkev Bath Sponge, showing the collared-cells and flagellum.

ז, Excurrent canals: I, Incurrent canals. (After Schulze.) lost the power of independently assimilating nutriment. We have here to do with nutrient cells, just as in the Colenterata (page 39) we observed nutrient persons (trophosornes)ina colony. A history, not unlike that of Hydra, may be told of a Sponge; but here, it is interesting to note, we have to do not with an amœboid ingestive cell, but with another form which, no less, has its representative among the Protozoa; we find, that is, a "collaredcell" taking the place of the amœboid cell (Fig. 53). In the "ciliated" or "flagellated"chambers which are found 
along the course of the canals which traverse the body of a sponge we find a single layer of cells, each of which is provided with a long whip-like process (flagellum), and has the free edge of its protoplasm converted into a collar-like fringe. By the action of the flagellum currents are set up around the cell, and directed to the space surrounded by the collar; these currents of water bear with them minute food-particles, which thus make their way into the substance of the cell. Such faagellate cells recall the Flagellate Infusoria, among the Protozoa. Finally, in the case of the lower worms, we have the evidence which is afforded by Mesostomum ehrenbergii, a Turbellarian which lives on the small Annelid Nais. In observations on intracellular digestion no method is more fruitful in its results than that which consists in feeding an animal with some finely-divided colouring matter such as carmine; Mesostomum, however, has been found to reject this substance, and the ingenious expedient had to be resorted to of first feeding the Nais with carmine, and then inducing the turbellarian to eat the annelid. This experiment, which was completely successful, afforded certain evidence as to the persistence of the intracellular mode of digestion in this animal, for a large quantity of the coloured material was found in its digestive cells.

The phenomenon of intracellular digestion has been now seen to be very widely distributed among the lower Metazoa, and observations are continually being made in confirmation of the facts here described. With a single exception, no observer has as yet seen any combination of this primitive method of taking in food with the more complex one of the presence of a set of cells which secrete a special gastric juice; we may expect, however, to find that the sharp distinction between the lower and the higher methods will be bridged over by other forms than the fresh-water 
Medusa (Limnocodium); in this remarkable creature the cells which line the mouth of the gastric tube have the function of secreting cells, while it is only in those that lie at the opposite end of the tube that the intracellular method has been observed (Lankester).

This power of intracellular digestion is not confined to the cells that line the gastric or endodermal cells; Metschnikoff has observed that some of the organs (nematocalyces) of the hydroid Plumularia may be fed with powdered carmine, when the dust will enter into the substance of the cells of the ectoderm, which, like the endodermal cells of Hydra, have retained the power of protruding pseudopodia. The mesoderm, likewise, in the form of the wandering cells of sponges, and in the larvæ of Echinoderms, where some of the organs disappear, or are not continued on into the structure of the adult, exhibits this same property. Even in the higher Metazoa the white blood corpuscles have been observed by Koch to have in their midst bacilli which they have taken into their own substance; and in inflammatory processes large connective tissue-cells may be observed eating up blood corpuscles, carmine granules, and pigment particles.

The lowest and simplest condition of the wall of the gastric cavity is to be seen in the lowest Cœlenterata, which present a far more primitive arrangement than do most of the sponges; there is, indeed, hardly a perceptible advance on what is found in the typical gastrula, and such as there is, is due to the presence of the tentacles around the mouth; the central, or axial sac, lined with endodermal cells, is continued into the tentacles.

If we bear this arrangement carefully in mind, we shall be able to refer to it the greater number of arrangements which are to be found in the higher Cœlenterates; we have, in other words, to look for an 
axial gastric cavity, with which there communicate passages or canals. The stomach may be enlarged in some, and diminished in other directions, and the canals may be greatly developed in number, and provided with outgrowths or pouches; but the essence of the arrangement is still apparent.

When, as so frequently happens, a number of hydroid polyps become connected with one another by a common trunk and form a colony, the gastric cavity of each polyp is brought more or less into relation with those of the rest; for each cavity is continuous with the canal which runs in the centre of the stem or trunk of the colony. and the cells which line this passage are provided with cilia. The facts that some polyps occupy positions more easily accessihle to food currents than others, and that the less fortunately situated can draw on thein tellows, lead, in a number of cases, to a division of labour, those best adapted for tho business of nutrition come to limit their activities to this important duty (trophosomes), while others. fed at their expense, devote themselves to the equally important duty of developing the generative products, and so take on the especial function of reproducing the species (gomosomes). The Stylasteridæ, on the other hand, afford us examples of zooids which, having ceased to be nutrient, have become reduced to mere tentacles, the duties of which they alone perform (dactylo-

\section{zooids).}

It is now necessary to direct attention to a portion of the gastric apparatus of Hydra, which was, for the moment, neglected ; the mouth of Hydra, or indeed of any hydroid, is not a mere space in the wall of the body, but forms a conical process, at the tip of which is set the orifice, so placed that when a hydra is looked at from the side, the mouth cone only can be seen, and the wide mouth itself is hidden.

If we pass now to the other extreme of the series 
and examine a free-swimming Medusa (Fig. 10) we find that the mouth and the stomach form a free projection hanging downwards, sometimes in the shape of a tube of some length; around this mouth we again find tentacles, and if we examine the first portion of the gastric apparatus we find it is widened out to form what may be called a stomach ; connected with this last there are a large number of canals which channel the substance of the disc of the umbrella, and carry into it the nutriment prepared by the gastric cells; these canals have, therefore, a circulatory function, and are, consequently, appropriately spoken of as the gastrovascular canals. They either run simply or are ramified, and are again brought into connection with one another by opening into a canal which runs round the edge of the umbrella; from this canal cavities sometimes pass into the tentacles which fringe the margin of the disc.

The tentacular processes set around the mouth are, often of considerable size, and are in certain forms broken up into a number of processes; in one group (that of the Rhizostomidr) this is carried to an extreme, for the oral tentacles take the place of the mouth, which, in the adult, is closed up, and they become provided with digestive cells and openings to the exterior ; so that in these forms a number of small secondary orifices take the place of the single large primitive mouth.

The other great division of the Cœlenterata, that of the Anthozoa, presents us at once with an important distinctive character; for the mouth is not placed on a projecting cone, but is depressed below the level of the surrounding platform developed from the body wall (Fig. 54). The second distinction is perhaps the more important; the tube into which the mouth leads is widely open at the lower end; in other words, we have here the appearance not of a system of canals 
channelling the surrounding tissue, but rather of a series of chambers separated from one another by narrow septa, while even these are perforated by two holes (Fig. 54 ; l).

The mouth is an elongated slit, which sometimes becomes constricted in its middle, so that we have essentially two orifices. On the ventral side of this slit a groove is often developed, which leads into the gastric cavity; the cells which line the sides of this groove (the "siphonoglyphe" of Hickson) (Fig. $55 ; s t)$, are ciliated, and by the action of these cilia the food is carried to the digestive region of the body; the presence of this groove or the size to which it is developed have been observed to vary with the size of the animal, or of the colony of which the polyp is a part; or, in

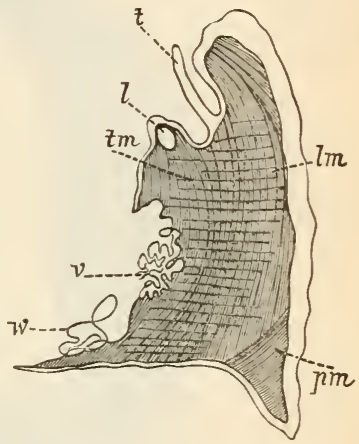

Fig. 51.-Section of Sagartia parasitica.

$t$, Tentacle; $l$, internal septal stoma; $l m$, longitudinal muscle $: t m$, transverse muscle; $\nu m$, parietal muscle $; v$, mesenterial filaments: $w$, Acontia. (After O. and R. Hertwig.)

other words, to depend upon the demand for food which is made by the Alcyonarian (Fig. 55).

The great size of this mouth slit, and the fact that it is often constricted in its middle, are of considerable importance as bearing on the early history and function of the blastopore, or opening into the gastrula; in simple or archaic forms, such as Peripatus, the blastopore is a greatly elongated slit which closes up in the middle, and forms the mouth at one end and the anus at the other.

In the Anthozoon Peachia the mouth slit is similarly converted into two openings, one of which 
has the function of an ingestive, and the other of an egestive passage (Sedgwick).

The walls of the digestive tract are not, as in the Hydrozoa, in direct contact with those of the body ; the

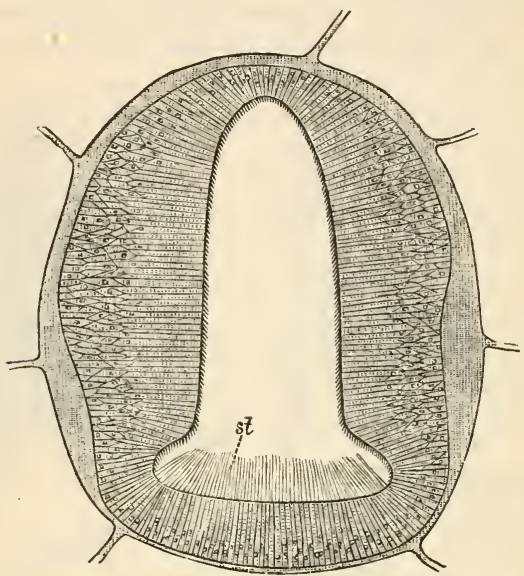

Fig. 55.-Transverse Section of a Polyp of Cologorgia plumosa, showing the long delicate cilia of the siphonoglyphe (st). (After Hicksou.)

intermediate space is traversed by delicate plate-like septa, some of which extend across the whole, and others only partly project into the perigastric cavity (Fig. 54). The axial gastric space communicates at its lower end with the compartments of the perigastric; and the septa project more or less inwards at this point. Along the free edges of these septa there are placed special filamentous structures, which are known as the Mesenterial filaments, the name of mesentery being applied to such septa as reach the walls of the gastric tube. The only physiological experiments yet made on those filaments are those of Krukenberg, which demonstrate that these constituent cells act on 
proteids by the method of intracellular digestion, and they appear to be the only part of the organism which is entrusted with this duty.

The Ctenophora have the spaces in connection with the axial gastric cavity narrowed to four canals, and there are two pores at the aboral pole of the body. There are never more than two long tentacles, and when these are lost, as in Beroe, the mouth is much wider than in the tentaculate forms.

For the rest of the Metazoa, with the exception of the already mentioned Turbellaria and Trematoda (e.g. liver fluke), the intracellular mode of digestion has not been observed. As in some of the Cœlenterata, we have a higher mode; the cells of the endodermal lining of the gastric tube liave now ceased to act independently of one another; certain of them are set apart for the function of secreting a ferment, which, passing from them into the digestive cavity, there acts upon the food; the albuminoids contained in it are converted into substances capable of passing through the wall of the intestine. Special salivary glands are, in many, developed for the purpose of converting starch into sugar. There is some evidence, however, that certain cells continue to take up nutriment into their own substance; even in the frog some of the cells of the small intestine have been observed to send out short processes into the enteric cavity (Thanhoffer), recalling thereby the amœboid cells and the intracellular mode of digestion which is seen in Hydra.

Among the flat-worms we need here only consider the Turbellaria and flukes, as the tapeworms obtain their nutriment in a very special way. (See page 177 ; Digestion of parasitic animals.) A mouth is always present, but is by no means constant in position, as it may be far forwards, at the middle of the body, or far back (Opisthomum). In a number there is 
a protrusible proboscis, formed from the anterior portion of the digestive tract; in some the moutl. does not lead into any distinct gastric space (Convoluta), or there inay or may not be a central space (Mesostomum); such forms, of course, obtain their nutriment by intracellular digestion. The tube, when distinctly formed, may be simple throughout, and blind at the end opposite the mouth; or there may be a muscular pharynx, and the tube may have a vent or anus. The tube may be bifurcated in its hinder part (some Trematoda), or may give off a large number of branches, which, as in the fluke, ramify through the body, and either end blindly, or communicate with one another; in the latter cases the gastric canals have also a circulatory function, just like the gastrovascular canals of the Medusæ. (See page 110.)

The Nematohelminthes have the mouth at one end of their elongated body, and the anus not far from the opposite end ; the digestive tube is perfectly straight, and is strengthened anteriorly by a deposit of chitin. The mouth, which sometimes (Gordius) disappears during the course of development, but not, curiously enough, until the worm has ceased to live an endoparasitic life, is only provided with circumoral bristles in such (Anguillulidæ) as never pass any part of their lives within other animals. Anteriorly the tube is often widened out, well supplied with muscles, and converted into a sucking apparatus.

The Earthworms afford an example of how an animal may atone for the absence of certain organs by what may be really regarded as artificial means; though they live on all kinds of food, and especially on leaves, they are without any organ by means of which their food may be broken up; to effect this they swallow small stones, which, acted on by the contraction of the muscles in the walls of that 
portion of their intestine which is known as the gizzard, are able to pound the food which has been taken into it; the sarne phenomenon is known to be observed in grain-eating birds. But this is not the only method by means of which the earthworm, with its unarmed mouth, is able to act on the so often dry food on which it lives; as Mr. Darwin pointed out, we observe in them a case of extra-stomachal digestion, which, so far as is known, is unique in the animal kingdom. Before proceeding to swallow its food, the worm bathes it in a fluid secreted by the glands of the mouth; this has not merely a lubricating, but a distinct chemical action, the contents of the cells and the starch granules being, in some observed cases, dissolved out before the leaves were taken into the mouth. The parts of the leares thus acted on seemed to be sucked into the month by the action of the muscular pharynx (Fig. 56) ; as the food passes down the completely straight intestine, it meets in the asophagus with the secretion of three pairs of calciferous glands, in which we find crystals or concretions of carbonate of lime. It would appear that these glands are first of all excretory organs, but the excretion seems to have a definite action on the food, and to prepare it for the action of the gastric juices.

The secretion of the cells of the intestine, by the action of which the

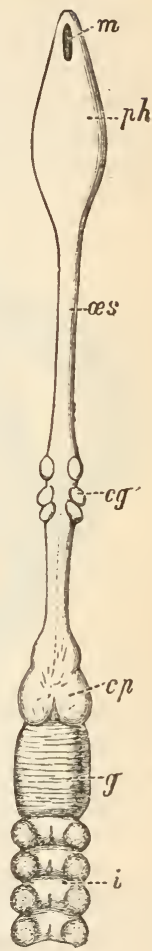

Fig. 56.-Diagram of the Alimen. tary Canal of an Earthworm. (After Ray Lan. kester.)

$m$, Mouth ; $p h$, pharynx; œe, œsophagus: $c g$, calcareous glands ; $c p$, crop : $g$, gizzard; $i$, in testire. 
food is brought into condition suitable for absorption, is unable to exercise its activity unless the food on which it acts is alkaline in reaction ; in other words, its activity is arrested in an acid solution. Now, the process of the decay of leaves is accompanied by the formation of several acids, which must necessarily be neutralised before the digestive fluids can act on the

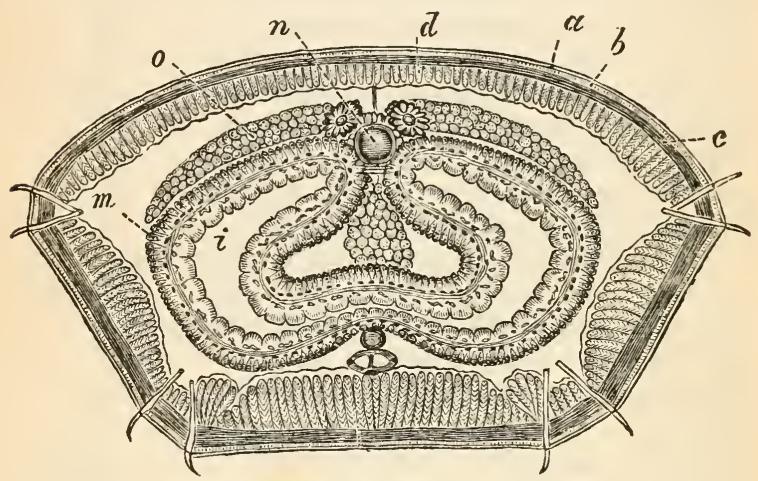

Fig. 57.-Transverse Section of Earthworm to show the Position and Relations of the Intestine.

$a$, Cuticle $; b$, hypodermis ; $c$, layer of circular muscles ; $d$, layer of longitudinal muscles $; i$, enteric cavity; $m$, "green layer"; $n$, dorsal vessel; 0 , "liver." (After Claparòde.)

ingested leaves; this neutralisation appears to be effected by the calcareous concretions on which the so-called humus acids readily act; the result of their union is an alkaline liquid.

Below the calciferous glands the œsophagus widens out into a crop, and this is succeeded by a gizzard, which is provided with powerful transverse muscles, and ordinarily contains, as has been already stated, small stones and grains of sand ; by the powerful contraction of its muscular walls and by the aid of these 
stones the gizzard becomes the organ of the earthworm in which the food is triturated, or ground up. Beyond the gizzard the intestine runs straight backwards to the anus, which is placed quite at the end of the body. In this intestine we first neet with a structure which will reappear in other groups, and affords us the first example of a method by which the absorbing capacity of the intestine may be increased with the greatest economy of space. A transverse section of an intestine reveals the presence of a fold which runs along the median dorsal line and projects into the enteric cavity. This is the so-called typhlosole, or blind tube. Around the intestine are a unmber of granular greenish cells (Fig. $57 ; \mathrm{m}$ ), which become specially aggregated together on the dorsal surface to form the so-called "liver" $(o)$; the function of this aggregation of cells is unknown, but it is undoubtedly misleading to apply to it a term of such definite significance as that by which it is known. This remark will apply also to the so-called livers of other invertebrate animals.

We may easily pass from the intestinal tract of the earthworm to those of the other ringed worms. The absolutely unarmed condition of the mouth is not, of course, to be expected in a blood-sucking or voracious form, and thus it is that we find the leech provided with three chitinous "jaws," hardened by a little carbonate of lime, the edges of which are minutely serrated, and which are provided with a special system of muscles by means of which they are able to work on one another ; so, again, one or more pairs of hard chitinous or even calcareous teeth are developed in the free-living marine worms; these, which are generally hooked and serrated on their concave edge, work from side to side. The earthworm is enabled to push its pharynx forwards when seizing food, but the voracious sea-worms can protrude their 
pharynx to some considerable distance and so give to it the function of a proboseis.

The region of the crop of the earthworm is, in the leech, specially modified in relation to the blood-sucking habits of that form; from either side it gives off as many as eleven tubes or blind diverticula, which occupy a very large proportion of the body cavity, and appear to serve as strainers of the watery portion of the blood which is pressed out through their walls. The development of crea is not, however, confined to the leech, for it is found also in the sea-mouse (Aphrodite), where the very numerous cæca are branched towards their free ends; in many other marine worms the intestine has a more or less sacculated appearance, owing to the tube being constricted at the points where the septa between the body-segments are developed.

The Geplnyrea contrast strongly with the Annulata so far as the arrangement of their intestine is concerned, for this, in place of being straight, is ordinarily coiled, and the anal opening is often found within the limits of the anterior third of the body. The most anterior portion of the tract has here, again, the function of a proboscis, and is sometimes surrounded by retractile tentacles; in Bonellia, a form which in adult life lives in mud or shells, the proboscis is of great length, and is divided into two lobes at its free end ; along the ventral surface of this organ there runs a ciliated groove which reaches to the mouth, and the whole apparatus is capable of being retracted with great rapidity.

The Rotatoria obtain their food from the currents of water which are set in motion by the cilia on their "wheel-organ" or disc; and comminute it by means of a system of hard parts which is placed in an anterior enlargement of the intestine, and consists typically of two hammer-like pieces which are set 
laterally, and are caused, by the contraction of the muscles connected with them, to work upon two centrally set pieces, which may be regarded as forming an anvil. Notwithstanding the minuteness of these forms, it has been possible to form some idea as to the character of the secretions of their digestive cells; red monads swallowed by them exhibiting a bright red colour in the stomach, thanks, apparently, to the acid reaction of the gastric juice of these forms; in the other parts of the intestine they have been seen to be of a dark or brown-red colour, owing to the neutral or alkaline reactions of the contents of that region (Cohn).

The characters of the digestive tract of the Rotifers present us with several instructive phenomena, for we find that in the males, which are always smaller than the fenales, the intestine is nothing more than a solid cord of cells, while sometimes there is in the females themselves an indication of degradation in the arrested development of the terminal portion of the gut, and the consequent return to the lower aproctous condition or stage in which an anus is wanting. Nor is this all ; while the males of Nematoid worms are distinguished from the females by having the generative ducts opening to the exterior by a passage common to them and the intestine, the Rotifer among Vermes presents an arrangement which is exceedingly common among the Vertebrata ; that is, the possession of an enlargement or cloacal chamber into which there open not only the digestive and generative tubes, but also the canals of the excretory system.

The fixed Bryozoa likewise obtain their food by means of the currents of water which they set in motion with the cilia that cover the surfaces of their protrusible tentacles; in a number the mouth is guarded by an outgrowth (epistome) which has a 
singular resemblance to the foot of Molluscs. (See page 78.) Though the epistome is probably a guard for the mouth in most of the Bryozoa that possess it, it is undoubtedly an organ of locomotion in the remarkable genus Rhabdopleura. The enteric tract is folded on itself, so that the anus is always near the anterior end; it is, indeed, placed either within (Endoprocta) or without the circlet of tentacles (Ectoprocta).

Among the Echimodermata, where the mouth is ordinarily placed in the centre of the disc, we find that there are either no masticatory organs, as in the Crinoids, or that the hard skeletal pieces are specially moditied in the region of the mouth to form the so-called "odontophore" of starfishes, or the various kinds of mouth papillæe which are found in the Ophiuroids. These are ordinarily said to have a masticatory function, but their small size ana feeble development justifies us rather in looking upon them as mere filters. In the regular Echinoids, or those in which the spherical form of the body is retained throughout life, a very elaborate system of pentamerally arranged parts is developed, the appearance of which, en masse, has given rise to the popular term of "Aristotle's Lantern." Each fifth part of this lantern consists of a hard tonth, bevelled at the free edge like that of a rabbit or a rat, so as to keep constantly a sharp free edge; this is supported in a framework, and connected by muscles with an arched piece (auricle) developed on the interior of the test. In Echinanthus and its allies this "dental pyramid" is less complex, and in the Spatangoids it has disappeared altogether; so that these last are reduced to living on such organic material as is to be found in the sand, which they scoop up by the aid of their spoutshaped mouths. Holothurians, likewise, are without any special dentary organs, though the walls of their 
œsophagus are ordinarily strengthened by the deposit of calcareous plates, which are sometimes very regularly arranged.

The walls of the intestines of Echinoderms are in all cases remarkably thin, and but feebly provided with muscular tissue, a somewhat remarkable arrangement, when we reflect that the movement of food in their digestive tract can be by no means aided by the pressure of their body walls on the enteric tube within.

In the Crinoidea the anal is always near the oral orifice, and is placed on a projecting cone ; in Holopus, as in some starfishes (e.g. Astropecten) and in all Ophiuroids, the anus is lost, so that here we have an example of the fact that the absence of an anus is not always to be regarded as a primitive condition. There can be no reasonable doubt that the Crinoids are older than the rest of the Echinoderms, and it is only in the most aberrant of these that we find an anus absent. Where an anus is present it is, except in Crinoids, placed typically at the opposite pole of the body to the mouth; but in the irregular Echinids we find a most interesting series in the way of modification; thus, in Rhyncopygus it is on the "back," but not at the apical pole; in Echinolampas it is at the edge of the test, where the upper passes into the under surface; while in Echinoneus it is quite close to the mouth, and, therefore, completely on the ventral surface.

The intestine is either saccular, as in the aproctous Echinoderms, or spirally coiled as in Crinoids and developing starfishes, or looped as in Holothurians; in the proctuchous Asteroids and in some Echinids it is provided with cæca, which in the former are paired, and extend some way down the cavity of each of the arms. These so-called "hepatic cæca" have been found to have on fibrin the action of peptic 
ferments, part of the fibrin being converted into peptones; and on starch that of salivary fluids. As in many other Invertebrata, the term hepatic has been applied to regions of the digestive tract, rather on account of the brown coloration of these regions, than from the definite experimental knowledge that their secretions have in any way the functions of a human liver. Some starfishes are capable of protruding the œsophageal portion of their intestine, and of engulfing prey, which they then draw into their bodies.

It cannot be too much insisted on that one of the most prominent characteristics of the Arthnropoda is the conversion of one or more pairs of its appendages to the service of the mouth; they become, in fact, mouth-organs (garathites), and are, from a physiological point of view, to be regarded as part of the digestive apparatus.

There is, perhaps, no investigation which can be more interesting than the study of the modifications undergone by these parts, whether we examine a single individual, such as the lobster, with its six pairs of mouth organs, or extend our survey over the whole series of arthropodous forms; in the one case we observe the modifications undergone by similarly constituted parts as they take on different parts in the duty of perforning a common function, and, in the other, we see a multitude of changes, conditioned by differences in affinity and in habit. The remarkable phenomena associated with the parasitic node of life of some members of this phylum will be considered later on. (See page 179.)

When we examine a lobster or a crayfish, we find that six pairs of appendages enter into the service of the mouth, and that in most of them we can make out the leading points in organisation, which are characteristic of a "typical" appendage. (See page 301.) 
There is, in other words, a basal portion and two branches more or less well developed.

Of all, the most modified is the first of the six, or mandible, for here the basal portion is very strong,
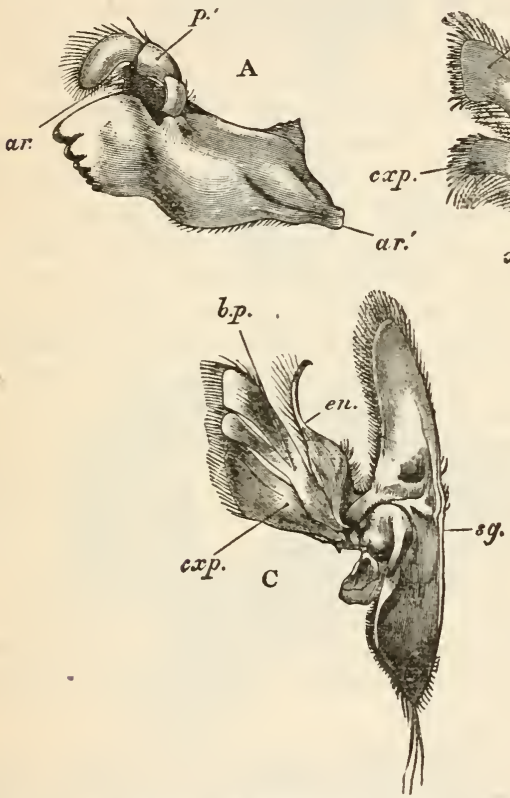

Fig. 58.-Mouth Organs of the Crayfish.

A, Mandible; B, flrst maxilla; $c$, second maxilla ; $b p$, basipodite ; en, endopodite ; $c x p$, coxopodite; $p$, palp of mandible; $s g$, scaphognat hite. (After Huxley.)

and gives rise to two toothed ridges; of these the lower projects farther than the upper, and has a more sharply serrated edge; of the two branches of a typical appendage, the endopodite is alone developed, and that feebly, for it consists only of three comparatively short joints (palp). 
From the appendage next behind, or first pair of maxillae, the outer branch, or exopodite, is still absent, but the basal portion is well developed, though not so stout or so strong as in the case of the mandible; both its joints are flattened out and provided with a number of bristles, which are als o present, though less numerous and not so strong on the unjointed piece which represents the endopodite. So far as the digestive process is concerned, the second pair of maxillae are still chiefly represented by the two basal joints of the typical appendage, the endopodite being still small and undivided, while the exopodite, though developed, has duties to perform in relation to the respiratory organs. (See page 225.) Behind the maxillæ we find three pairs of maxillipedes, or foot-jaws, the most posterior of which is the largest, and in a state of repose covirs over the five pairs of mouth organs that lie in front of it. In the two more posterior pairs we do not observe that increase in size or flattening out of the basal portion which we saw in the maxillæ; but in the first maxillipede the most important part is taken by the two lamellar joints, of which that portion is composed, while the endopodite consists only of two in the place of the five distinct joints which are found in the succeeding pairs.

All these appendages are so articulated to the walls of the body that they work on one another from side to side; it is clear that they can only cut or tear the food on which the great forceps have already seized, and, for the purposes of digestion, the food has to undergo a further comminution, comparable in a sense to that which is performed by the grinding, as distinguished from the cutting teeth of man.

The mouth, which is a narrow elongated slit, leads by a short wide gullet into a capacious stomach, divided into an anterior and a posterior chamber, and 
separated from the intestine, which lies behind it, by a filtering apparatus of valves and bristles. Within

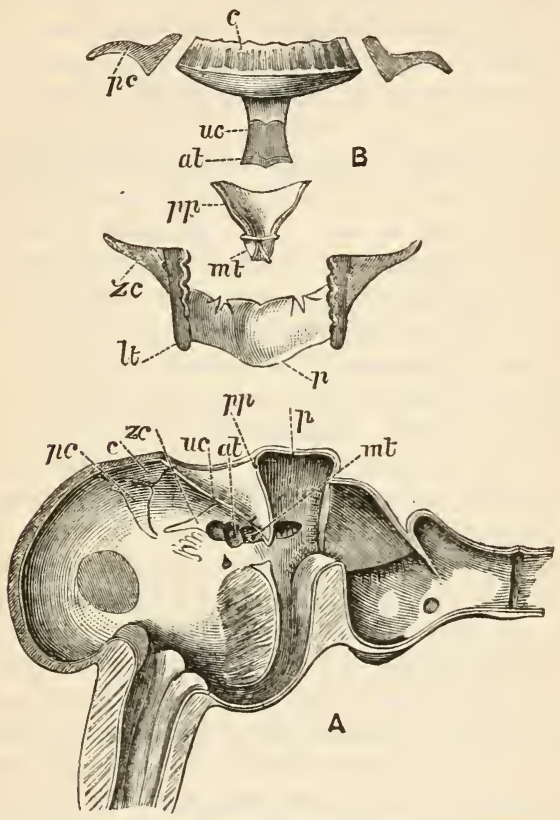

Fig. 59.-The Parts of the "Gastric Mill" of the Crayfish in situ (A), and disarticulated (B).

$c$, Cardiac ossicle ; $p c$, pterocardiac ossicle; $z c$, zygocardiac ossicle ; $l t$, lateral tooth : $p$, pyloric ossicle; $u c$, urocardiac ossicle with $(a)$ accessory tooth; $p p$, prepyloric ossicle with (mt) median tooth. (After T. J. Parker.)

this stomach there is developed a hexagonal framework of calcareous and chitinous pieces, some of which are provided with powerful grinding teeth. The fore (Eig. $59 ; c)$ and hind $(p)$ sides of the hexagon give off, the one forwards and the other backwards, an elongated ossicle $(u c, p p)$, each so placed in relation to 
the other that, when at rest, the two make an open angle towards the dorsal aspect, while the more posterior has at its lower edge a strong tooth $(m t)$ which takes a backward direction. To the fore and hind bars of the hexagonal framework there are attached strong muscles, which, by contracting, draw these two bars away from one another. This separation of the terminal naturally requires an approximation of the lateral faces $(p c, z c)$, two of which bear strong teeth. While these teeth are thus brought closer to one another, the angulated bar which connects the fore and hind pieces of the hexagon becomes straightened out; the result of this straightening is seen in the downward and forward movement of the tooth which is developed on the hinder median bar ( $m t)$ and which is thereby brought into closer relation with the approximating teeth on the side-pieces. (See Fig. 59.) This elaborate "gastric mill" must break up" the food-masses taken in by the crayfish; but, as if this were not enough, the hinder part of the so-called pyloric region of the stomach is provided with cushions covered with hairs, and longitudinal ridges with still finer hairs, which form a most efficient filtering apparatus. This may, from a physiological point of view, be compared with the sieve of hairs which lies at the entrance to the intestine of the fish-eating bird, the darter (Plotus).

As far as this filter the whole of the enteric tract will be found to have its inner face lined with chitin; the next succeeding portion, which forms the commencement of the delicate "intestine," has no such internal layer; but this in the crayfish, though not in the lobster, is quite short. On it there follows the remainder of the "intestine," and this will be found to be again lined with chitin.

When we come to ask ourselves why so much, yet not all, of the enteric tract of the crayfish is thus lined by the same dense body as that which forms the outer 
covering of a crayfish's body, we are compelled to turn to the history of development for an explanation. When we do this, we find that the epiblastic infoldings, which form respectively the stomodoum and the proctodoum, are carried very far inwards, and that only a small portion of the archenteron, or region primitively lined by hypoblast, remains in the adult organisation. The developing lobster, as compared with the developing crayfish, has a much shorter proctodeal invagination.

While it is absolutely true of all the animals here spoken of as Arthropoda that some of their appendages are converted into mouth organs or gnathites, the number is by no means always so large or the arrangements so complicated as those which we have just found to obtain in the crayfish. In Peripatus, for example, one pair only of appendages are modified to serve as jaws, which have the special function of cutting blades. In the Scorpion, where there are no appendages in front of the mouth, there are only two pairs specially adapted to the service of the mouth, and these have their free ends pincer-shaped, and not converted into cutting or biting organs ; this arrangement will be the more clearly understood when one remembers that these animals suck the juices rather than eat the tissues of their prey.

The differences between the Chilopodous and Chilognathous Myriopoda allow us to say little that is true of them both; in both, however, we see here, as in other parts of their organisation, characteristics of a less high degree of differentiation than those that obtain in the crayfish, on the one hand, or the cockroach on the other; there are two or three pairs of gnathites, and these are always jointed. One is often converted into a poison gland in the Chilopoda, and in them also, as in the scorpion, the basal portion of some of the succeeding pairs of appendages 
surround the orifice, and aid the work of the mouth.

In the lower crustacea (Entomostraca) we never find more than three pairs of appendages converted into gnathites, and these are, in a general way, comparable to the mandibles and maxillæ of the crayfish.

The true Insects or Arthropoda Hexapoda have, likewise, three pairs of mouth appendages, and these, again, are known as mandibles and maxillæ; but the mandible is never provided with the three-jointed "palp," which is found in the crayfish.

No series of structural changes in relation to the different modes of taking in food is more interesting than the really remarkable variations which are found in the size and shape of the gnathites of insects, and nowhere, perhaps, do we see more distinctly the influences of those two prime factors in organic evolution, heredity and adaptation.

As Meynert has pointed out, we find in winged insects two chief types of mouth organs; in some the mandibles are hinged on to the sides of the head, and the first pair of maxillæ have a less perfect articulation; sometimes, indeed, the latter merely slide on the sicles of the hard parts which bound the mouth; in others the mandibles and maxillæ are not articulated, but can be withdrawn inwards, or protruded outwards.

In the former the articulation is such that the gnathites work from side to side and are tit to act as cutting or biting organs; in the latter they can be pushed into an object or laid side to side, so that they form stabbing or sucking parts.

It is of supreme interest to observe that among the members of the lower grade of insects, or that in which wings are never developed (Aptera), the mouth organs sometimes (Campodea) remain in an undifferentiated or generalised condition; though not 
articulated to the sides of the head, they can bo moved by muscles from side to side, while, thanks to the absence of the articulation, they can be pushed out or drawn in ; they are, in fine, capable of acting either as cutting or as stabbing organs, and it is in them, therefore, that we must look for that indifferent arrangement from which both the mandibulate and haustellate type of mouth organs have had their origin.

The former is well seen in the ancient group of the Orthoptera, and is easily demonstrated by the familiar example of the cockroach. In this form it is quite easy to recognise the three pairs of gnathites which, in insects, form those organs of the mouth which are derived from modified appendages, the one pair of mandibles, and the two pairs of maxilla.

In front of the mouth there is an upper lip or labrum, which has the form of a movable flap; behind it lie the mandibles (Fig. 60 ; md), modified appendages, of which no part other than the basal remains, all signs of a palp having completely disappeared; these work from side to side, and have their inner edge strongly toothed, so that they act as efficient biting organs.

Behind these we find the first pair of maxillae, organs of some size and complexity; the basal piece or cardo $(c a)$ is articulated to the head, and has, at right angles to its long axis, the second joint or stipes (st); this can move in a lateral direction, and is continued forwards into a soft galea $(g a)$, and an internally placed lacinia $(l a)$, the inner edge of which is toothed, thongh not so strongly as the mandibles. Attached to the outer side of the stipes is the so-called palp.

The second pair of maxillæ are still further modified, presenting as they do confluence of the basal portions, which in most air-breathing Arthropods is J-16 
still more complete. The result of this fusion is the formation of a median piece, which is incompletely divided into two, forming the mentum $(\mathrm{m})$, and submentum; these, with the anteriorly lying

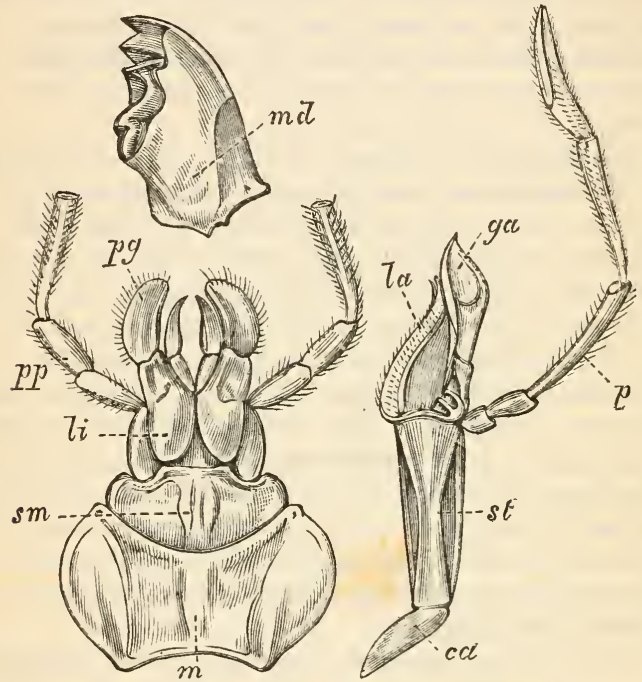

Fig. 60.-Mouth-parts of the Cockroach.

$m$, Yentum ; sm, submentum; $l i$, ligula : $p g$, paraglossa ; $p p$, palp of second maxilla; $m d$, mandibles; $c a$, cardo ; st, stipes ; ga, galea ; la, lacinia ; $p$, palp.

ligula $(l i)$ and paraglossa $(p g)$, make up the part which by entomologists is most unfortunately spoken of as the lower lip or Iabium; unfortunately, because it is formed from the modification of the proximal parts of an appendage, and is not strictly comparable to the labrum or upper lip, which is a part of the exo-skeleton of the head. The palp $(p p)$ of the second pair of maxillæ is smaller than that of the first. 
The mouth organs of the Neuroptera are strictly comparable to those of the Orthoptera; but we see an advance in the fusion of the lateral halves of the labium, while the biting mandibles are grooved on their inner face, and the first pair of maxillæ are slender, and are so arranged as to close the groore, and to give rise to a pair of organs which serve as tubes for the passage of the juices of the prey which they have first bitten.

In the allied Trichoptera (caddis flies) the mandibles are reduced to membranous rudiments, and the maxillæ and labium are closely united, and at their base come to be tubular in form.

In the Coleopter'a (beetles) the biting powers of the mandibles seem to reach the maximum of their development, and the labium has the mentum and submentum united into single piece.

In the Hymenoptera (bees and wasps) the mandibles still retain their biting function, but the maxillæ are modified to serve as licking and sucking organs; the ligula and the first pair of maxillæe are greatly elongated, and the latter apply themselves to the sides of the former, giving rise with it to a tubular apparatus, which comes into play after the elongated ligula (or its accessory piece) has licked up' the honey on which their possessor depends.

The conversion of the mouth parts into a sucking organ is most completely seen in the butterfly (Lepidoptera); the mandibles are reduced to mere rudiments, and the first pair of maxillæ are greatly elongated; the inner face of each of these last is deeply grooved, and the edge of the groores minutely denticulated in such a manner that, when one maxilla is applied to its fellow of the opposite side, it combines with it to form a closed tube; the labium is reduced, and its palps are often very small or evanescent. The sucking tube may 
become of considerable length when the Lepidopteron feeds on the honey of plants, such as orchich, in which the nectaries are at a considerable distance from the outer edges of the flowers; in, for example, Amphonyx, one of the Sphingidæ, the proboscis is nine and a quarter inches long, or about three times the length of the animal's body. In some Lepidoptera the proboscis is enlarged to pierce vegetable tissues,

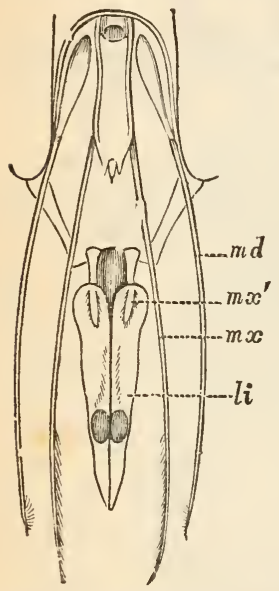

Fig. 61.-Month Organ of Nepa.

$m d$, Mandible ; $m x$, first pair of maxillø: $m x^{\prime}$, second pair (lalinm); $l i$, ligula. (After Savigny.) and, as in the orange-sucking Ophideres, it has externally the form and function of a bayonetshaped saw (F. Darwin).

In the blood- or juice-sucking 耳emiptera (bugs, aphicles) not only the mandibles but also the first pair of maxillæ are reduced to fine setiform processes, which, being moved by muscles, are enabled to serve as stabbing organs; they are ensheathed in the elongated labium (rostrum) the sides of which curve upwards in such a way as to produce a sucking-tube (Fig. 61).

In the Diptera (or flies and fleas), what were bristles in the bug now form sharp, cutting, lancet-like organs, and the second pair of maxillæ again form the suctorial tube ; in some cases (Pangonia) the proboscis is more than twice as long as the body.

Allied to various orders of insects are forms which, in correlation with their modes of life, have their gnathites still more considerably altered from the $\mathrm{Or}$ thopterous type ; thus, among the white ants (Termitidæ) the mandibles are functional in the so-called 
soldiers, but reduced in the workers; the Ephemeridæ or day-flies, which want to eat no food in the aduit stage, have the gnathites almost completely aborted. The Mallophoga, or so-called "Mandibulate lice," which are found on the skin of birds and mammals, and feed on their feathers and hairs, have the mandibles hooked and the maxillæ small.

Like the crayfish, the cockroach has a large portion of the anterior region of its digestive tract lined with chitin, and, like that form, it has also a considerable portion of the hinder region formed by the proctodeal invagination. The chitinous layer extends through the funnel-shaped pharynx, the narrower cesophagus, the crop-like enlargement, and the proventriculus; the last has the form of a truncated cone, and its walls are thick and well-provicled with muscles; its internal lining is raised up into ridges which serve as teeth, and between these ridges there are pouches. The next succeeding portion has no chitinous lining, and its anterior end has connected with it eight blind prolongations (the so-called pyloric carca), which are not all of the same length, and which vary in size accorcling to the periods of cligestive activity; it is, apparently, in this cavity that the food undergoes the changes which convert it into chyle, and the caca are only to be regarded as outgrowths which increase the capacity of the ventriculus. The intestine behind is lined throughout with chitin, and the smaller is separated from the wider portion by a valve; the whole tract ends in a terminal anus.

As may well be supposed, the different parts of the digestive tract present very different characters in the various groups of insects; in the mandibulate forms (Neuroptera, Coleoptera) the stomach is provided with a series of more or less powerful chitinous ridges, by means of which the food is comminuted; in the sucking insects the gizzard 
is aborted, but the crop is swollen out into a simple sac (bees), or into two hemispherical sacs (blowfly), or its attached portion forms a short narrow tube and its free part a swollen bladder-like enlargement (butterfly). This organ may extend far back into the abdomen, and, as it has thin walls and no muscular attachment to the body wall, its size is probably increased and diminished by the contractions of the linder parts of the body ; this so-called "sucking stomach" appears to act as a reservoir for food in the Diptera.

At the anterior end of the tract there open the ducts of the salivary glands, which are ordinarily developed in insects, but best seen in the haustellate forms; they vary greatly in form and size, and are by no means always confined to the function of digestive glands, as the mosquito, the bug, or the tse-tse fly are sufficient to bear witness. Many larvæ have well-developed glands which open just behind the mouth, and which secrete a body which in air hardens into a fine silky thread. Glands are often developed in the walls of the rectum or large intestine, and have a secretion which is frequently of a pungent, if not of a disagreeable, odour. The Malpighian vessels which are connected with the hinder portion of the tract and open into it are not digestive glands, but organs of renal excretion. (See page 256.)

We find a very different arrangement of mouth organs in the Mollusea to that which we have just been studying in the Arthropoda; the great majority are without any seizing organs of any kind, and the lowest, the Lamellibranchiata, have no means by which they can comminute their food; they live, therefore, on the minute organisms which are brought to them with the water of respiration, and which are felt for and guided to the mouth by the blunt "labial tentacles " that lie on either side of it. 
The rest of the Mollusca, or Cephalophora, are provided with a rasping organ, which lies on the floor of the pharynx, the odontophore. But, anteriorly to this, and at the edge of the mouth, there are one or more horny plates, with a sharp cutting edge; these are best developed in the cuttle-fishes, where they have the appearance of a parrot's beak turned upside down; in the nautilus these beak-like plates are calcified.

The characteristic organ of the digestire system of such Mollusca as have not suffered degeneration of the head is the just-mentioned odontophore. This consists essentially of an orerlying chitinous sheet, the surface of which is produced into a variable number of more or less sharp processes, the so-called teeth; this, then, is a rasping organ, or radulat. Underlying are connective and muscular fibres, and supports are afforded for it by the development beneath of masses of cartilage ; as muscles are inserted into the anterior and posterior faces of these cartilaginous supports, it is clear that, by their alternate contraction and relaxation, they will draw the radula backwards and forwards. The whole apparatus is developed in a blind diverticulum, lying on the ventral surface of the cavity of the mouth. The teeth, which may be very variously arranged, are greatly strengthened by the deposit of silica; and as they and the chitinous sheet are worn away they are replaced by the hinder part of the radula, which passes forwards on its bed; the replacement of the effete parts being effected, in other words, in a way comparable to that of the human nail. The radula is ordinarily divisible into a central piece, with a lateral piece on either sicle; the teeth on the former are spoken of as the rachidian teeth, and those on the lateral pieces as the uncini. The arrangement of these teeth varies very greatly, and, for the purpose 
of succinctly stating their numbers and positions, the following method of formulation is used.

The central teeth of the rachidian series are denominated by the sign 1 , when present, and 0 when absent; the admedian teeth by the signs $1,2,3 \ldots$, according to the number present; while the lateral teeth are noted by the sign 0 repeated as often as there are lateral teeth on either side; when the number of arlmedian or of lateral teeth is very large, the sign $x$ is used in place of $1,2,3 \ldots$, or 0 repeated. For example, when, as in Eolis, there are no lateral teeth, we write the formula 0.1.0 ; that of Amphisphyra, is 1.1.1; that of A plysia, 13.1.13; and that of Oncidium, 54.1.54 (Woodward).

The whole mass of the odontophore may be of considerable size, and, in the limpet, the radula is two or three times the length of the body; the number of separate teeth may be very great, as among the snails, where 167 transverse rows of 135 teeth each will give some twenty thousand teeth; in some species of Helicidæ, the aggregate exceeds thirtynine thousand $(39,596)$.

The teeth are sometimes large and hooked ; sometimes conical and upstanding; when the rachidian teeth are, as sometimes happens, absent, another part of the digestive tract may, as in the Bullidæ, be provided with calcareous plates which replace them functionally. In a few (e.g. Rhodope) the odontophore is lost.

In a number of cases, the muscles that move the radula are not confined to those that are inserted into the supporting cartilages, but there are others that pass to the walls of the head; the contraction of these is the cause of the licking movement which a protruded radula may be often seen to perform.

In some, especially slugs and snails, a hard horny plate is developed on the roof of the mouth cavity, 
and aids the radula in its work of trituration, just as the hard pad which takes the place of the upper incisors of the sheep serves as a resistent structure against which the lower incisors may bite.

At the sides of the anterior portion of the digestive tract glands of various forms are ordinarily found; these are known as salivary glana's; but the inappropriateness of the name is not only obvious from the observed fact that in the slug the secretion of these glands has no influence on starch, but is made the more striking so soon as we know that, in several genera, the secretion of these glands contains a comparatively large amount (nearly three per cent. in Dolium) of free sulphuric, and a smaller quantity of hydrochloric, acid. Further, we have to note that these buccal glands are found in marine as well as in terrestrial forms, whereas among the vertebrata the salivary glands are only well developed in terrestrial forms.

The intestine is considerably coiled; the œsophageal portion is sometimes produced into a "crop," as in Lymnæus or Octopus ; the succeeding portion may be simple, and have its walls thin or muscular, or it may be broken up into several chambers; in Scyllæa it is armed internally with horny cutting blades, and in Aplysia with blunt horny spines, behind which is an armature of sharp hooks. It is only behind such gizzard-like enlargements that the digestive ferments are secreted. The anal orifice is, in those Cephalophora that have lost their original bilateral symmetry, brought far forwards, and situated near the mouth, or is placed at the side of the body. Cæcal pouches or tubes are developed in various ways along the tract of the intestine, and some of them become charged with dark-coloured cells, and have been regarded as forming a "liver;" there is, however, no reason for associating with these structures the functions of the 
similarly named part in the Vertebrata; and, indeed, where best studied, they have been found to have rather the function of the pancreas. In the dibranchiate Cephalopoda a rectal crecum secretes an inky fluid, which was formerly used for writing and for the manufacture of sepia; this is the so-called inkbag. The secretions of the Octopus have been found to be all acid.

In the Lamellibranchiata (or Aceplaala) the odontophore is completely absent ; the intestinal tract is comparatively simple, but varies in the extent of its convolutions; in its walls, or in an appended crecum, is the so-called crystalline style or stalk, a transparent rod-like structure of unknown function. Its absorbent surface is sometimes increased by the development of a typhlosole, as in the earthworm, and the terminal portion very frequently passes through the dorsally-placed heart.

In all Chordata we observe that, as also in Balanogiossus, the anterior posterior of the digestive tract is primarily divisible into an upper and a lower portion, one of which serves as the means of passage for the water of respiration, and the other as the food passage. Postponing for the moment (see page 231) the consideration of the former, and insisting only on the significance of this arrangement as a leading point in the morphology of the Chordata, we observe that in the Tunicata the exclusively nutrient region of the enteric tract commences at the bottom of the respiratory part by a rounded or funnel-shaped opening; the tube, which varies in calibre in different parts, is often looped, and in such cases the anus comes to lie not far from the mouth.

Among the Chordata we find very simple arrangements of the digestive tract in the Cephalochordata; the mouth of the Lancelet is placed 
on the ventral surface of the body, not far from the anterior end, is over-hung by a hood, and supported by cartilaginous bars, which bear ciliated cirri, the gill-like appearance of which gained for the animal the misleading name of Branchiostoma. As these cirri are moved by muscles they are enabled to direct food to the mouth, and to serve as a filter against the entrance of sand and other useless or dangerous bodies. As in the rest of the lower Chordata, this mouth serves as the orifice of entrance for the water of respiration, which makes its way to the exterior through numerous spaces in the wall cf the more anterior region of the digestive tract. The part of the tract belind the gill chamber is of some width, and gradually narrows as it approaches the anus, which is situated on the ventral surface not far from the hinder end of the body. At its anterior end it gives off a forwardly directed short blind process, which is known as the liver. As in the Nemertinea, the enteric epithelium is ciliated. In the Urochordata a large part of the anterior region of the enteron is again converted into a respiratory chamber; and it is the succeeding portion only that is limited to the duties of a digestive apparatus. The tube varies in width in different regions and is ordinarily coiled on itself, so that the anal is not far from the oral orifice; the food passes into it along a groove which lies on the ventral surface of the respiratory chamber, the sides of which are ciliated, and the cells of which secrete a mucous substance which entangles the food and carries it into the œsophagus. The anterior orifice of the œsophagus is generally funnel-shaped, and provided with cilia; the succeeding portion has a diverticulum, which is spoken of as the liver, and it may be further provided with other glandular organs. In some cases the digestive tube is coiled into a closely compacted 
1 mass, as in the Salpidæ, where it forms the so-called "nucleus."

In those Vertebrates that breathe by gills the water of respiration enters by the mouth ; in the airbreathing forms the air enters the mouth by the nostrils, so that in their case also the most anterior portion of the digestive tract serves as an ante-chamber to the respiratory organs. Leaving these functions aside for the moment (see page 231) and confining ourselves to the mouth as a part of the digestive apparatus, we observe that it is rounded in shape in the lowest, the Cyclostomata (lampreys and hags), and merely supported by cartilages; in all the rest it is more or less slit-like, and a pair of branchial arches give rise to jaws (Gnathostomata). These jaws are either covered by connective tissue, or horny plates (tortoises, birds, monotremata), or, as in all Mammals, except the lowest and the whales, they are guarded and aided by movable muscular structures, which are known as lips. These aid in the taking in of food, or in retaining it when it has entered the mouth cavity; in the production of sounds, and especially of human speech; and they are an important factor in the production of the expression of the emotions.

In the vertebrate series we apply the term teeth to those hard bodies which are set in the mouth, and are developed from cells of epiblastic origin; in their simplest condition these organs are more or less simple spiny bodies, exactly comparable to the spines which are found on the skin of many sharks. Nor is the community a community of structure melely; from within the limits of the history of an individual it is possible to draw sufficient evidence to prove that there is a community of origin between what have been well called dermal demticles and what we call teeth. The accompanying figure, which represents a section of the lower 
jaw of a dogfish, at a stage previous to that at which any lip is developed, shows the direct continuity of structures, which, in the adult, seem to be very different from each other. When we consider the different relations to the surrounding parts which would be entered into by the spines that came to lie within the area of the mouth, we see at once that, by being brought into contact with the food the spines would be led to increase in size and strength ; but this increase in activity would be necessarily accompanied by a richer nervous and vascular supply; and this, reacting on the spines, would lead to

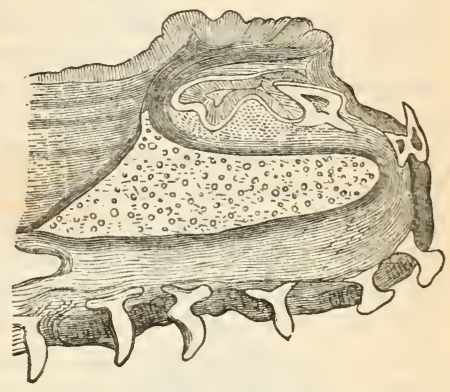

Fig. 62. - Section of Lower Jaw of young Dog-fish, showing the spines of the skin under the jaw, and the teeth above. (After C. S. Tomes.) greater differentiation, which has taken the form of greater definiteness in arrangement and structure.

In commencing, therefore, a review of the teeth of vertebrates, we find that we start with a generalised or non-differentiated condition; as we pass on we shall find that the teeth become more and more linited to certain bones, and diminish in number ; in other words, there is a gradual reduction. Concurrently with this, we have to note that, when a group of animals becomes especially adapted to a certain mode of life, or presents marked aberrations from the general plan of structure, they become cdentalous, or lose their teeth ; such, for example, are the pipefishes among Fishes, toads among Amphibia, Chelonia (turtles and tortoises) among Reptiles, all recent 
birds, the duckbill and the echiclna, and some of the whales among Mammals; this is a phenomenon not confined to Vertebrata, for it may be observed in the Spatangoids among Echinoidea, where the "Lantern of Aristotle" is altogether absent, and in the tubicolous Chrtopods, which have lost the strong jaws of their free-swimming allies.

In correspondence with the great diversity of mode of life and of details of structure among fishes, we note in that group the very greatest differences in the disposition and size of the teeth; seeing, indeed, here an excellent illustration of the law that commencing structures are subject to great variability. Here, too, we find an example of spines on the skin taking on the function of teeth; the true teeth, that is to say, the hard structures within the area of the mouth, are, in the saw-fish (Pristis), quite small and blunt; the sides of the enormous snout are, however, provided with large dermal spines, set at regular distances from one another, and each implanted in a special socket.

When well developed, as in the dog-fish, the teeth are set in several concentric rows; those of the outer are alone functional, and they, as all, are not attached to the jaw, but are only fixed in the covering membrane; this membrane appears to move over the surface of the jaw, and thereby the teeth which have been in use for a time are removed from the edge of the jaw, and the next succeeding series come to occupy their position, and to take on their function.

A large number of small teeth are likewise to be found in many bony fishes (Teleostei), and here, where a number of distinct bones are developed, we often find every bone within the mouth bearing teeth; as may readily be supposed, such teeth are generally of small size, and without any special masticatory 
function; indeed, in very many fishes the food is swallowed whole.

Owing to the fact that these Vertebrates are not able to put their fins to the duty of seizing their food in the way in which many higher formis use their anterior pair of limbs, the teeth may often be observer to have a special prehensile function. This power is sometimes developed to an extraordinary degree; all the numerous teeth in the mouth of the pike are directed backwards, and so prevent or oppose the escape of any prey which has been taken into the niouth; an extension of this arrangement has been described in the angler (Lophius), where some of the larger teeth in the front of the mouth are so attached to the edge of the jaw that they spring up again as soon as the food which has pressed them downwards into the mouth has passed them and entered the oral cavity (Tomes). By this means the prey is caught as in a trap.

Whe re the Fig. 63.-Lower pharyngeal Bone of Scarus, teeth are used for. the purposes of

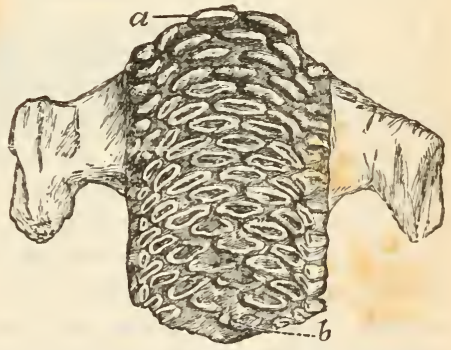
showing Teeth of different Ages. Two-thirds natural size. (After C. S. Tomes.) breaking up the food or the shell in which it is contained, they become of considerable size, as in the Wrasses ; in the parrot-Wrasses (Scarus) the teeth undergo fusion with their neighbours; in the sheep's-head (Sargus) the teeth in the front of the mouth are cutting organs, and those at the sides larger, and have their surface rounded, so that, as they move on one another, they act as grinders. Where a number of teeth are 
required they are not always confined to the bones of the skull; thus, in the just-mentioned Scarus, the lower pharyngeal bones unite, and they, like the upper pharyngeals, are armed with crushing teeth (Fig. $63)$; here, then, we have an instance of the bones of the branchial arches (see page 328), being tooth-bearing. Another example is afforded by the carp, in which fish the bones of the skull are all devoid of teeth, which are confined to the lower pharyngeals; these, as in the case of the incisors of the sheep or ox, do not work on upper teeth, but on a hard process, which, in the carp, is developed on the occipital bone of the skull.

In other fishes the teeth are exceedingly delicate, as in Chatodon, which has gained its name from the bristle-like character of these organs. In a few cases the teeth are placed in distinct sockets, as in the file-fishes, of which Balistes is an example; in Lepidosteus the socket is not complete, and the tooth becomes anchylosed to its walls.

Lepidosiren presents an arrangement not unlike that which is found in Rodents among Mammals, for the front edge of the teeth is harder than the rest, which therefore wears down sooner, and leaves a sharp cutting edge. In no group of the Vertebrata are these organs of greater value to the palæontologist than among Fishes, as the discovery in Australian rivers of Ceratodus, which had been thought to have been extinct since the time of the deposit of the older secondary rocks, is sufficient to bear witness.

In a few cases there are differences between the teeth of males and females, as in the skate (Fig. 64; $\mathrm{A}$ and $\mathrm{B}$ ) where those of the male are more pointed than those of the female.

In the male salmon, at the breeding season, the lower jaw is produced into stout hooks, and in correspondence with this the anterior end of the upper jaw 
is also enlarged, and the premaxillary teeth are four times as large as those of the corresponding region in the female.

Small and simple as are the teeth of most recent Amphibians, they are, as compared with those of most fishes, greatly reduced in number ; this, no doubt, is largely to be explained by the development of the
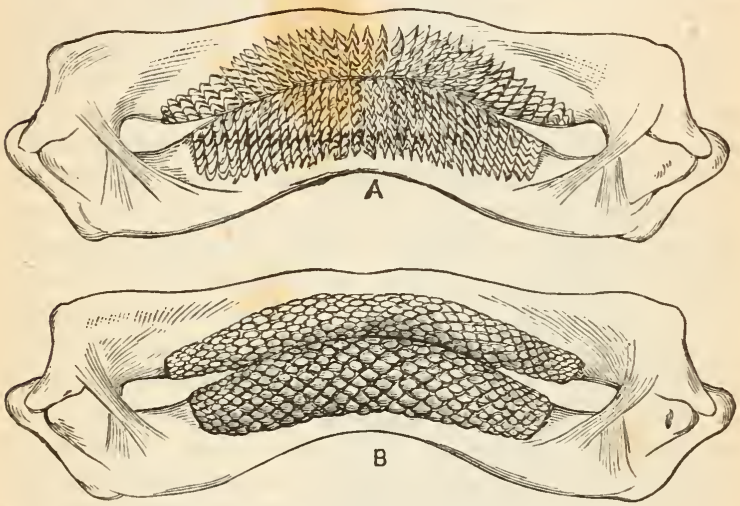

Fig. 64.-Teeth of Skate. A, Male; B, female.

fore-limbs into organs which are capable of seizing and holding the prey, or of pushing it into the mouth ; we find, too, that the great majority of the teeth are now found on the membrane bones (see page 329), at the sides of the mouth only; though, indeed, the frog has fine vomerime teeth, and other amphibians have them on the palatine, or the pterygoid bones.

Whether we pass now to the Reptiles or to the IVammalia, we get still more marked indications of this reduction; in all the latter which have teeth, and in all crocodiles and many lizards, teeth are found only on the lower jaw, and on the maxillæ and premaxillæ. $\mathrm{k}-16$ 
As may be supposed, the teeth of the crocodile are of great size and strength.

An instructive example of a quasi-edentulous condition is found in the lizard of New Zealand, which is known as Hatteria; the teeth at the sides of the jaw are not replaced when they are worn down, but the bone itself, which is exceedingly dense, takes on the function of a cutting organ. In forms which are permanently edentulous, like the tortoise or the pigeon, the edges of the jaws become invested in horn, the shape and form of which varies with the habits of the animal; in some birds (wild duck) the edges of the horny case become serrated and give rise to the appearance of tooth-like structures; in some cases (Odontopteryx) the edge of the underlying bone becomes denticulated ; these are adaptations to modes of life, and must be carefully distinguished from the actual possession of true teeth such as characterises a large group of extinct birds (Odontornithes).

Curiously resembling the arrangement of the turtle, and having, of course, much the same function, are the tough horny plates on the jaws of tadpoles; the history of these plates would, however, seem to be very different from that of the similarly disposed parts in the higher forms; that is to say, the beak of the tadpole, and, doubtless, the horny apparatus of the lamprey, are structures which preceded, and not succeeded, the possession of teeth.

A phenomenon similar to that seen in Lophius is to be observed in Suakes; here, again, the organs of prehension being absent, owing to the disappearance of the limbs (see page 96), the teeth are directed backwards ; when, therefore, living prey, such as a frog, has entered into the cavity of the mouth, it is prevented from escaping out of it by the erection of the teeth. Some snakes kill their food by constriction, and swallow it at leisure; others swallow it whole, and in them 
the bones of the skull are loosely connected with one another, and so allow of the enlargement of the cavity of the mouth ; others, finally, kill their prey by biting and simultaneously injecting poison into the wound. In these last (the venomous snakes) there may be several not very long teeth in the maxillary bone, or there may be but one maxillary tooth, which in such cases is long and movable. In the former the fangs are distinctly grooved along some part of their length, but the sides of this groove are sufficiently close to form a serviceable canal, along which the poison from the poison gland may make its way into the wound. In the latter the single large maxillary

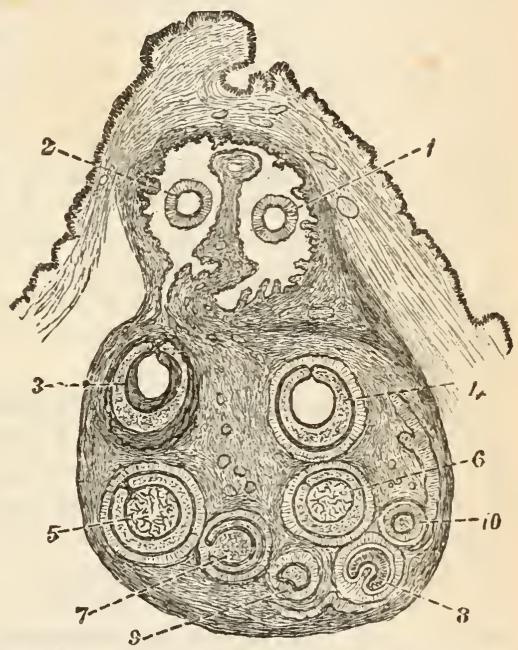

Fig. 65.-T'ransverse Section of the Poison Fang and Reserve Set of a Viper.

1, Tooth in use: 2 , the tooth which will succeed it : 3 to 10 , tooth-sacs numbered in the order of their succession. (After C. S. Tomes.) tooth appears, from the outside, to be solid and ungrooved; the real fact is, however, that the two edges of the groove have completely united to form a closed canal, the existence of which becomes apparent in a transverse section of the tooth; the opening of the canal is not placed quite at the tip of the sharp fang, but, just as in a subcutaneous injection syringe, the orifice is a little behind 
the tip which, as it were, guides and saves the poisonous fluid.

As a further aid to the more extreme venomous forms, which can only subsist by this mode of attacking their prey, and which are eminently liable to have their organ of offence broken in the act of "striking," the reserve teeth are arranged in a manner which seems to be unique in the animal kingdom. Instead of a single series of reserve teeth set in one and the same line with the tooth in active function, there are two rows, in each of which the pair of teeth are almost of the same age and grade of development. When, therefore, the active tooth is lost, that in the other line, which is lying beside it (Fig. 65), is ready at once to move forwards into a little different position, and to take on its function; by this means the fang is replaced with a minimum loss of time (C. S. Tomes).

When we come to the Mammalia, where, as has been already said, teeth are never found except in the mandibles, maxillæ, and premaxillæ, we are met, at the outset, with an arrangement of which, at present, it seems impossible to afford any altogether satisfactory explanation. There are never more than two sets of teeth, one of which is temporary or milk, and the other permanent; the teeth of these two sets differ in form, size, and number. In some cases the milk teeth are never of any use; such mammals may be conveniently spoken of as monophyodont, while those in which there are two sets may be similarly called diphyodont. At the same time it must be carefully borne in mind that that there is no sharp delimitation between these two groups. In marsupials and guinea-pigs there is only one milk molar; in the rabbit the milk incisors disappear before birth, and among edentates only one species (Tatusia peba) is known to have milk-teeth. 
The definite diphyodont arrangement is best seen in the higher Mammals.

The possession of this double series is not, however, the only remarkable character of the teeth of Mammals ; while there are only inconsiderable, if any, differences in the form of the teeth of any given fish or reptile, and such differences are characteristic only of small groups, we find that for a large number of Mammals, though by no means in all, the teeth in different regions of the mouth have distinctly and definitely different forms and function; (1) in the anterior portion we find sharp cutting teeth; (2) at the sides we sometimes see strong seizing or holding or offensive organs, and, farther back (3) we see that the upper surface of the tooth becomes widened ont and tuberculated so as to form a more or less suitable grinding surface. Looked at in a general way, these three kinds or forms of teeth may be grouped as (1) incisors, (2) canines, or (3) molars. The molars are spoken of in diphyodonts as premolars or molars, according as they are or are not preceded by milk or deciduous molars. Mammals with variously formed teeth are conveniently known as heterodonts; while a homodont dentition is ascribed to such forms as the edentates, or the toothed whales, in which all the teeth have exactly the same character.

When a homodont dentition obtains, the number of teeth in the jaws may be very great, some dolphins having as many as two hundred (Pontoporia); in the other forms the number of teeth is strictly limited, no known living mammal having more than forty-eight teeth (Megalotis).

In comparing the teeth of one heterodont with those of another, it is very convenient to make use of the set of symbols which make up the "dental formula ;" here the letters $\mathbf{i}, \mathbf{c}, \mathbf{p m}$, and $\mathbf{m}$, represent the different categories of teeth, while the fraction 
sign is used to represent the disposition in the upper and lower jaws. Making use of this method of formulation, we may represent the typical dentition of a heterodont mammal thus :

$$
i \frac{3.3}{3.3}, \quad c \frac{1.1}{1.1}, \quad p m \frac{4.4}{4.4}, \quad m \frac{3.3}{3.3}=44 \text {. }
$$

This is the dental formula of the low insectivorous mammal Gymnura.

The dental formula of man is :

$$
i \frac{2.2}{2.2}, \quad c \frac{1.1}{1.1}, \quad p m \frac{2.2}{2.2}, \quad m \frac{3.3}{3.3}=32 .
$$

And that of the cat:

$$
i \frac{3.3}{3.3} \quad c \frac{1.1}{1.1} \quad p m \frac{3.3}{2.2} \quad m \frac{1.1}{1.1}=30 .
$$

There are a number of certain modifications in the form or structure of the tooth which at once attract attention. While those Mammals, such as man, which bite their food have sharp incisors, those that gnaw it have the greater part of the surface of the incisors devoid of that hardest part of the tooth which is called the enamel, and so maintain an edge, the softer dentiae always wearing down faster than the enamel which is at the front and sides. The teeth which are set at the outer angles of the jaw (the canines) are especially large in those forms which seize on a living, and require to hold a struggling prey; and it is these organs which are most frequently converted into weapons of attack, though in the most prominent case of all, that of the elephant, the tusks belong to the incisor series. In the male boars (Suidæ), the canines attain to a considerable length, being in the Babirussa, an animal not so large as the 
domestic pig, from eight to ten inches long; they are often exceedingly sharp, and are capable of inflicting on those whom they attack severe and deep wounds. In the males of the anthropoid apes the canines are always much larger than in the females, and as they are not developed till later, we are justified in believing that they are sexual weapons of attack, by which the males are aided in fighting with one another for the possession of the females.

The molars again present us with indications of differences in the form. of the teeth corresponding to differences in the character of the food; at the same time, the very greatest care must be taken in estimating the kind of food from the form of the teeth, and at all times, where it is possible, the general arrangements of the alimentary canal must be steadily borne in mind. Four chief types may, however, be easily distinguished (1) carnivorous, (2) insectivorous, (3) frugivorous, (4) herbivorous. The molar or premolar tooth of the dog, which has, since the time of Cuvier, been distinguished as the carnassial, is modified to form a sharp blade, and is continued behind into a thick tubercle (Fig. $67 ; h$ ).

The typical insectivorous tooth is distinguished by the development of four or five sharp cusps (Fig. 66); in the frugivorous forms the cusps

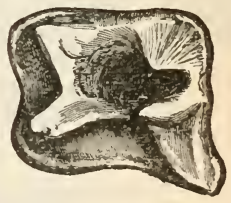

Fig. 66.-Molar Tooth of Hedgehog. are not so distinct, nor so sharp, and are more connected with one another by more or less distinct ridges.

The most essential point in the arrangement of the herbivorous or grinding molar tooth is the disposition of the several constituent tissues of which it is made up ; the large squarish solid structure, formed of pillars and ridges, is composed of enamel and 
dentine ;* as has already been said, these two tissues differ greatly in hardness; they will, therefore, wear down unequally and so give rise to a roughened surface well adapted for grinding. In addition to the
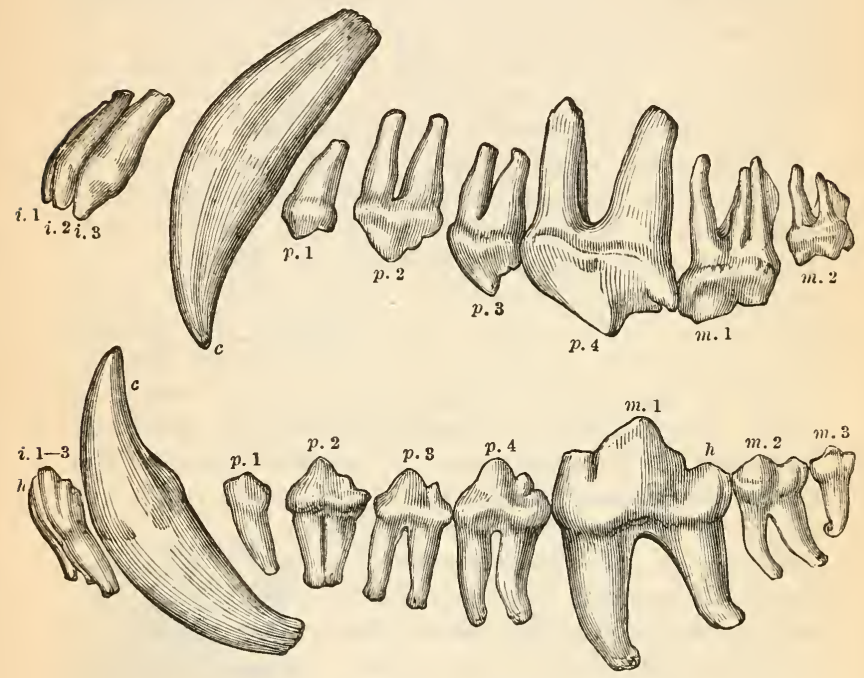

Fig. 67.-Teeth of Wolf.

$i 1$ to $i$, Incisors; $c$, canine ; $p 1$ to $p 4$, premolars ; $m 1$ to $m 3$, molars ; $h$, heel of the flrst molar or lower "carnassial" tooth.

outer investment of cement, we find it also filling up the interspaces (Fig. 68). In the Carnivora the lower jaw is so articulated to the skull as to be able to work from below upwards; in the herbivorous forms the jaw works from side to side.

Some of the Cetacea (dolphins, whales) are distinguished by the total absence of teeth, and the

* For an account of the minute structure of the teeth, see Klein's "Elements of Histology," chap. xxi. 
special armature of the mouth by "whalebone;" but indications are presented both by palæontology and embryology which are sufficient to justify us in believing that this order was primitively provided with a heterodont dentition. While the dolphin has a number of teeth in both jaws; the sperm-whale has we 11 -developed teeth in the lower jaw only; the bottle-nosed whale has never more than four functional teeth, and in the narwal (Mono(lon) it is the male only that has the ordinarily single tusk well developed; this may be as much as nine feet long. Among the whale-bone whales teeth are never more than rudimentary, but

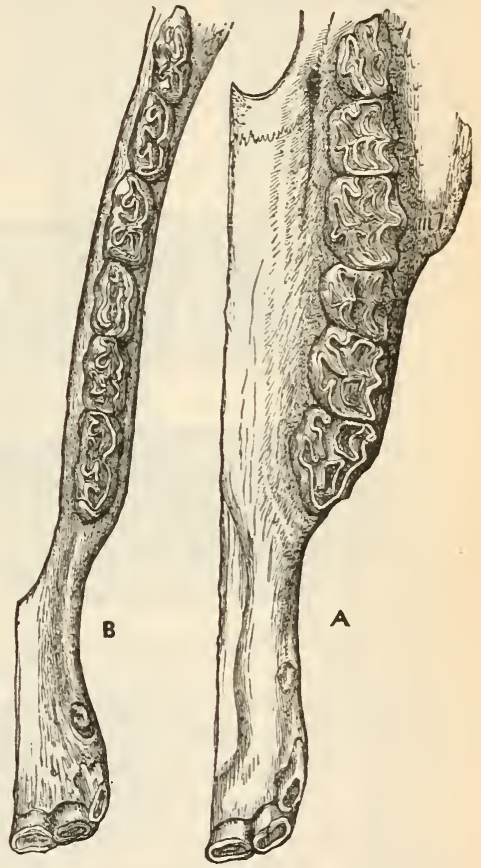

Fig. 68.-Teeth of Horse; A, Upper Jaw ; B, in the adult their Lower Jaw.

place is taken by plates of "baleen," which are set nearly at right angles to the axis of the mouth, and have their free ends frayed out into a number of stiff hairs, which make a most efficient strainer; the whale, in taking into its enormous mouth a 
quantity of sea-water, simultaneously takes in a large number of the smaller marine animals; raising its tongue it drives out the water, but retains behind the filter the food that came in with it (Fig. 70).

In all vertebrates, with the exception of some fishes and a few amphibians (e.g. Pipa), there is developed in the floor of the mouth a tongue, which owes its primitive origin to the mucous membrane which covers the branchial arches. It is never of
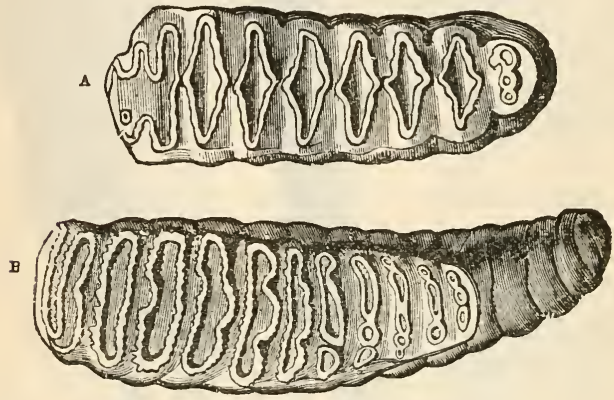

Fig. 69.-Last Molars of (A) African, (B) Indian Elephant.

large size in fishes, and in them is never supplied with muscular tissue as it is in the higher forms; in some cases it is provided with a horny sheath.

In many forms, as in some Amphibians (e.g. the frog), where it is attached by its anterior end to the symphysis of the lower jaw ; in Chamæleons, where it is knobbed at its extremity; and in various other lizards, where it is cleft anteriorly, as it is also in Ophidia, it is capable of considerable protrusion, and may be used as a prehensile organ.

Among Birds the tongue is protruded with great rapidity by the wood-pecker (Picidæ), and by the humming-birds (Trochilidæ), and sun-birds 
(Nectarinidæ). In the wood-pecker some of the hyoid

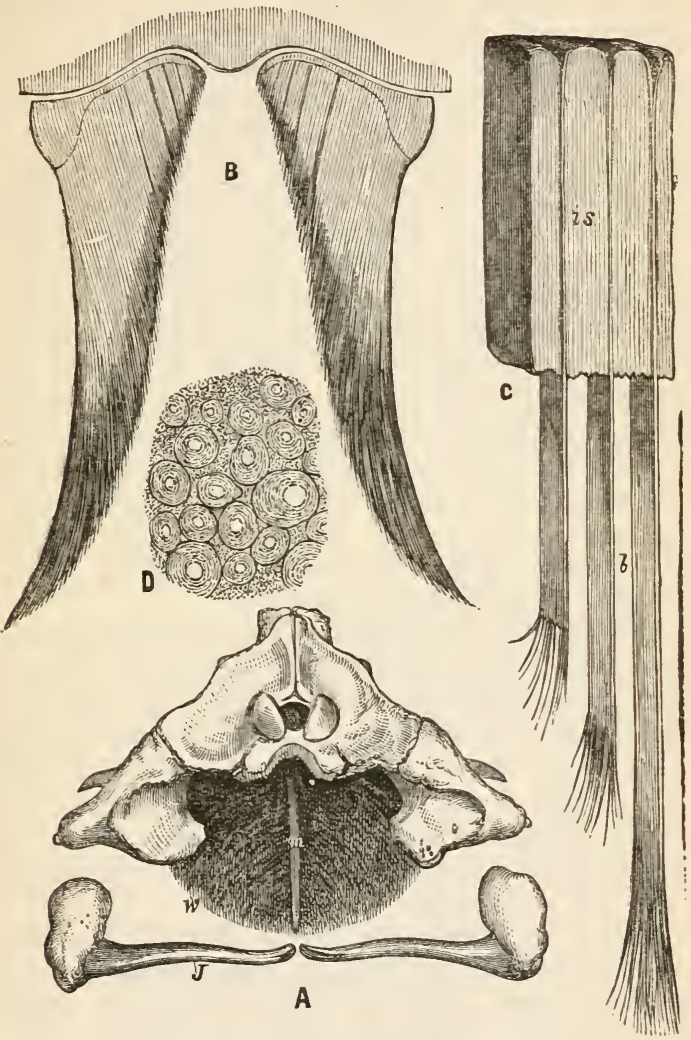

Fig. 70.-Figures to illustrate Position and Structure of the Baleen. (From Murie, after various authors.)

A, Hind view of skull of right whale; $w$, whale-bone; $m$, mesial ridge of palate ; J, lower jaw-hones; B, arch of baleen plates, as seen in cross section of the mouth; $c$, vertical section, showing the intermediate sulistance; is, baleen plates; $b$, frayed out at their free edges; $\mathbf{D}$, transverse section of whale-bone, magnifled. 
bones, or bones that support the tongue, are of considerable length, form a curve with its concavity forwards, and then, trending forwards, lie on the upper surface of the skull, and reach as far as the nasal region. Attached to these bones, and attached also to the anterior end of either mandible, is an extensor muscle, which lies on the inner or concave side of the loop; on its contraction the loop is drawn up, and as the only mobile point of the hyoid bones is that at which their anterior extremities are inserted into the tongue, it is clear that the upward movement of the bones must result in the forward movement of the tongue; in some other Picidæ the hyoid bones are movable in their sheath, but the result is the same. Essentially similar arrangements are to be seen in the humming-birds and sun-birds. The mechanical principle, that the longer the hyoid bones the greater the force and extent of the protrusion of the tongue, is supported by what has been observed in Picus as compared with Zosterops (Gadow).

The tongue, thus protruded, is in the woodpecker invested in a horny sheath, which ends in a slender point, and is provided on either side with backwardly directed prickles, which serve to draw from the holes in the wood the insects on which this bird feeds; their capture is aided by the slimy secretion of the salivary glands, which are compressed on the contraction of the extensor muscle. (Compare the account of the Great Ant-eater, page 160.)

In the sun-birds the horny part of the tongue forms two tubes; in the honey-eaters there may be as many as eight, and the inner or outer margins become frayed out into fine processes; in the humming-birds there are tubes, the edges of which are ordinarily entire. It has been pointed out by Gadow, that while the sucking in of honey is an easy process when there is sufficient fluid to fill the anterior 
opening of the entire tubes, air would, when there is not, rush in instead, and that the advantage of the frayed margins lies in the fact that the honey will ascend to the tubular portion by capillary attraction. It is important to note that these arrangements are of a homoplastic character, inasmuch as the hummingbirds are not close zoological allies of the sun-birds; in other words, we have here again an example of how similar structures are gained by forms which live under similar external conditions.

In the Parrots the end of the fleshy tongue is dilated, and, from its prehensile function, has been compared to a human finger; on its lower surface there is a broad nail-like horny plate, which is free at. its anterior border; in the brush-tongued parrots there are spinous papillæe on the upper surface, which stand upright, or project forwards when the tongue is protruded.

The tongue of Mammals is well provided with muscular tissue, so that it is not only protrusible (it is of great length in insectivorous forms like the ant-eater), but is capable of a licking movement; and in some, such as the lion, it is armed with strong horny papille that are of considerable assistance in removing flesh from bones. In man, in addition to the kind of functions just enumerated, it is of importance as an accessory organ of articulate language. In some manimals a tongue-like structure (the sublingua) is developed beneath the tongue; in the lemurine Galago (Fig. 71), the front end of this organ is provided with five stiff denticles, arranged in comb-like fashion, and having, apparently, the function of keeping clean the incisor teeth (Flower). In the dog, and some other Carnivora, the protrusible tongue is supported by a fibrous and muscular body, the so-called "Iytta," or worm of the dog's tongue.

The walls of the cavity of the mouth are provided 
with glands, which are outgrowths of the walls themselves; of these the most important and best known are the salivary glands par excellence; but these are only specially modified forms of the simple tubular, which, with the compound tubular glands, are alone found in the lower Vertebrata, and which have at first no other function than that of lubricating the tongue, the mouth cavity, and the food;

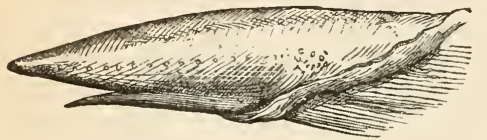
and they are, therefore, only feebly, if at all, developed in fishes.

In the Amphibia the most

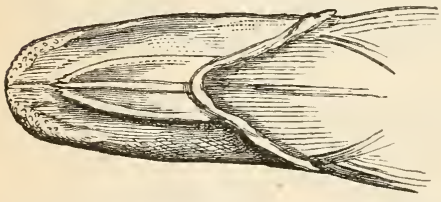

Fig. 71.-Side View and Lower Surface of the Tongue of a Galago. important is the intermaxillary or internasal gland (Wiedersheim), an idea as to the function of which is to be gathered from the fact that in the waterliving Axolotl it is but feebly developed, while in the metamorphosed and pulmonate form known as Amblystoma it is of much larger size. In this group, further, where the tongue is so often used as an organ of prehension, the lingual glands are well developed, and their secretion is driven on to the surface of the tongue with every contraction of that organ. In the chamæleons, which likewise catch their prey by the aid of their tongue, the labial and palatine glands are well developed; the median of these latter may be regarded as the homologue of the intermaxillary of the Amphibia. The glands that lie in the floor of the mouth are ordinarily well 
developed in the Lacertilia, and very richly so in the poisonous Heloderma of Mexico; in correspondence with the position of these glands the reptile is said to turn on its back when striking its prey (Fischer); the secretion of these submaxillary glands has certainly poisonous effects, but the blood of a guinea-pig killed by it does, unlike the blood of the victim of the bite of a colubrine snake, but like that of the victim of a viperine snake, coagulate after death (Fayrer). In the venomous Ophidia the poison is supplied by the labial gland, which lies along the edge of the upper jaw, and has its duct opening into the maxillary tooth.

The salivary glands are small in river tortoises, and absent in the marine Chelonia, and in the alligator, where the glands are confined to the tongue.

In Birds, again, lingual glands are well developed, but, as may be supposed, the labial are altogether absent; in the wood-peckers, where the tongue is protruded with great rapidity (see page 156), the sublinguals are enormously developed, and provide a sticky secretion, which acts like bird-lime.

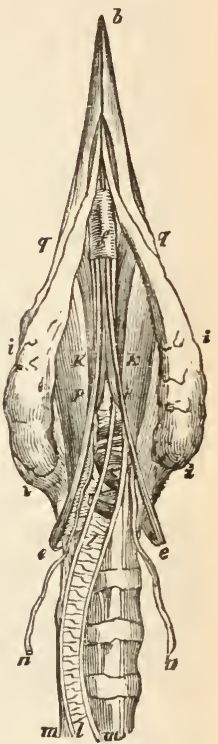

Fig. 72.-Head of Green Woodpecker seen from below, showing the large Sublingual Glands $(i, i)$, the Hyoid Bones (e), and the Base of the Tongue $(f)$. (After IIacgillivray.)

In the Mammalia, three pairs of large, ordinarily acinous, glands predominate over the smaller and more scattered buccal glands; these, from their positions, are distinguished as the parotid, submaxillary, and sublinguals. From our knowledge 
of the influence which the secretion of these glands has on starchy foods in ourselves, it is often thought that therein lies their prime function. Certain considerations seem to show that this is not a correct view ; in the Cetacea and other aquatic forms, and in the blood-sucking Desmodus, the glands are considerably reduced in size; the dog "bolts" his food, or, in other words, does not subject it to the influence, which is not exerted in a moment, of the salivary secretions; while the kangaroo, which dwells in the arid plains of Australia, has some of the glands of great size. It would seem, therefore, that the prime function of these structures is to afford a supply of water for the solid food, and a further physiological advantage is gained by the fact of this water being supplied at or near to the temperature of the mammalian body.

The well-known fact in human physiology that the secretion of the parotids is the most watery, and that of the submaxillary and sublinguals more viscid, is paralleled in comparative anatomy by the large size of the parotids in animals, such as ruminants, and other herbivorous forms, which masticate dry foods; and the great size of the submaxillary in such animals as the Echidna, or the ant-eater, which require a viscid fluid for the purpose of catching their insect prey. In the last-mentioned mammal some of the fibres of the stylo-hyoid muscle encircle the submaxillary ducts, which are thereby constricted when the muscle contracts, and in this way the ejection of the fluid is assisted (W. A. Forbes).

With the exception of the buccal cavity, the greater part of the enteric tract of a Vertebrate is developed from the archenteron, the proctodeal portion being, as a rule, exceedingly short. The general tract may be conveniently divided into the esophagus, stomach, intestine, and rectal portion; this last, in all except 
some Fishes and the higher Mammalia, opens into an epiblastic pit, the cloaca, into which there also open the ducts of the renal and generative glands. (See page 263.) Primitively, as in Amphioxus, this tract is quite straight, and has no definite outgrowths along any parts of its course ; later on it undergoes considerable nodifications; its anterior region gives rise to an outgrowth, which serves at first as an air bladder, and later on becomes converted into a pair of lungs, which serve as the definite respiratory organs of all higher vertebrates (see page 236 ) ; the stomach ceases to have its long axis parallel to the long axis of the body, and at the same time becomes enlarged and more or less complicated; the intestine buds off two glands of high physiological importance, the liver (only feebly, if really, represented by a crecum in Amphioxus) and the pancreas; the intestine becomes narrower anteriorly than it is posteriorly, so that one may distinguish a small and a large intestime; between these a blind outgrowth, or eacum, which in Birds is often double, is nearly always developed; while the inner face of the walls of part of the intestine is thrown into folds, whereby the extent of the absorbing surface of this region is very greatly increased.

So far as the intricacy of the tract is concerned, we find it to be a very general rule, not only in Vertebrates, but in all animals, that carnivorous, as compared with herbivorous, forms have a simpler enteric tract; thus, the gar-pike (Belone) has the intestine short and straight, and the herbivorous tadpole has a more complexly coiled intestine than the insectivorous frog; the proportion of the length of the intestine in the cat is to the body as from 3 to 5 times to 1 , while in the pig the proportion is as 12 to 1 ; so, too, the milk-fed calf has a much less complex stomach than the grass-eating and ruminating cow. 
In Amphibians and Reptiles the œsophagus is ordinarily wide, and but few adaptive modifications are to be noticed in it. Oligodon, an egg-eating snake, presents a remarkable arrangement. It will be easily seen that, were this animal to break in its mouth the eggs on which it feeds, the greater part of the conients would almost certainly escape. We find, however, that the teeth in the mouth are quite rudimentary, and that through the upper wall of the gullet there project the elongated inferior spines of several of the vertebræ of this region; the tips of these spines are coated with a substance of great hardness, and the eggs, after they have reached a position in which their contents can be safely disposed of by the animal, are broken by them.

The most important modification of the nesophagus is to be found in birds, and especially those that are grain-eating; there is here developed a considerable enlargement, the so-called "crop," which may not (cassowary), or may (pigeon), be provided with special glands in its walls. The object of the former arrangement would appear to be merely that of a kind of reserve-pouch, for it is found in fish-eating forms and in birds of prey. On the other hand, the glandular crop is a necessity for such birds as live on food which is so difficult of digestion as is grain.

Throughout the whole of the series we meet again and again with examples of a stomach only slightly, if at all, distinguished by its size from the rest of the tract; and this is not always due to the carnivorous habits of the animal, but rather, as we must suppose, to heredity, and to the fact that some other part of the intestine performs the more important part in the functions of digestion. Ceratodus is a striking example of this, for here the stomach is almost in a straight line with the general axis of the body, while the interior of the small intestine is elaborately 
developed. Two leading types of stomach have been distinguished in bony fishes; the so-called siphonal, in which the two halves of the stomach are bent upon themselves, as in the salmon, and the creal form, in which the upper or cardiac portion gives off a long blind sac. The walls of the stomach are richly provided with muscle in the mullets.

The simplicity of the œsophagus is found to extend to the stomach in most Amphibians and Reptiles, and the chief modification which we observe is an increasing tendency for the stomach to be set at right angles to the long axis of the body. In the crocodile the walls are very muscular, and call to mind those of some birds. In the latter group, the members of which are, it will be remembered, toothless, the socalled stomach is divided into two more or less distinct portions. The anterior of these (the proventriculus) has, as a rule, walls which are richly provided with glands that exert a chemical action on the food, while the posterior portion, or gizzard, has walls of considerable thickness, owing to the great development of its muscles; it seems to have only a mechanical action on the food. Two chief types of gizzard may be distinguished, the simpler, which is found in such birds as are carnivorous or insectivorous or live on soft fruits, has the walls much less thick than in the other type; the muscles radiate out from two tendinous centres, which are placed one on either side of the stomach, and the muscular fibres pass from one to the other. The crocodile also has such centra tendinea.

The complicated form of gizzard, or gizzard par excellence, is distinguished from the more simple by the great derelopment of its lateral muscles, and by the conversion of its lining wall into a strong horny layer, which is particularly thick, and may even form a hard pad on either side (Fig. 73). The tendinous patches, 
and the fibres that they give off; are very strong. We have already noted the presence of small pebbles in the gizzard ; the duty of these is to act as grinding stones. On the contraction of the muscles the cavity
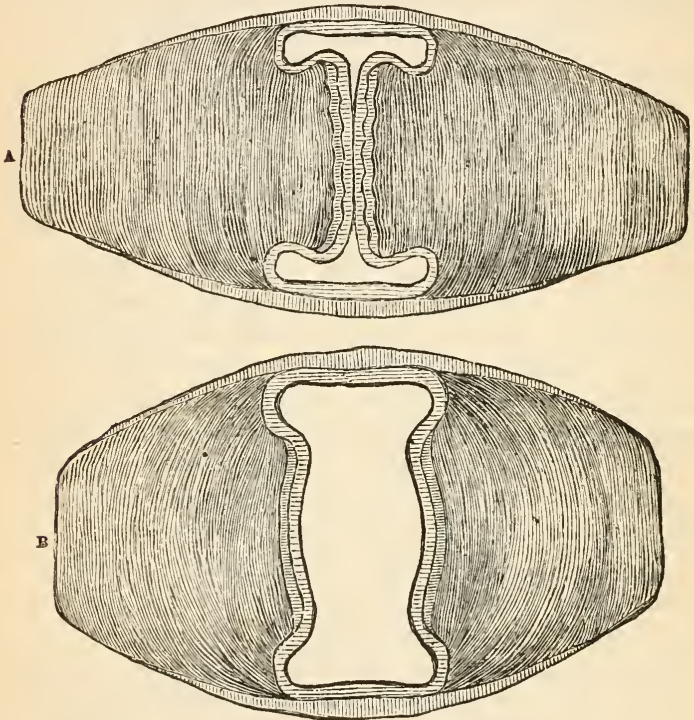

Fig. 73.- - Horizontal Sections of the Gizzard of a Goose, in contraction

(A) and relaxation (B). (After Garrod; Proceedings of the Zoological Society, 1872, page 527.)

of the gizzard is, of course, dininished in extent, and the food contained in it crushed against the stones. It sometimes happens that the lower end of one pad and the upper end of the other are respectively better developed than the rest; when this happens a slight sliding is added to the crushing movement, which must have considerable influence in breaking hard grains. 
In the heron, which lives especially on fish, which it swallows whole, the stomach is of great size and extent, reaching nearly to the anus, and occupying the greater part of the abdominal cavity.

In the Nammalia the stomach is often set more or less at right angles to the longitudinal axis of the body, and its upper is shorter than its lower curvature, which may, therefore, be distinguished from one another as the greater and the less; the enlargement of the cardiac side of the stomach is a little more marked in the dog and in man than in the insectivorous Gymmura, and very much more so in the rabbit. As the transverse axis increases in length; a division

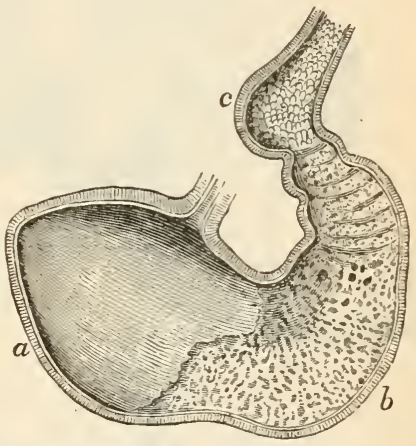

Fig. 74.-Inuer Face of the Wall of the Stomach of the Horse.

$a$, Cardiac; $b$, pyloric sac: $c$, duodenal dilatation. (After Chauveau.) into two parts becomes more or less well pronounced; this is best seen in the interior, and is very well marked in the case of the horse (Fig. 74), where the white-coloured cardiac portion, with its thick epithelium, is separated by a ridge from the redder pyloric sac, with its softer epithelium and its contained gastric glands. This separation of the stomach into a reservoir and a digestive portion is carried to an extreme in the ruminating Ungulates.

In the peccary the stomach may be divided into cardiac and pyloric regions, but the œsophagus is further remarkable for being continued on, in the form of a groove, into the pyloric division; in acklition 


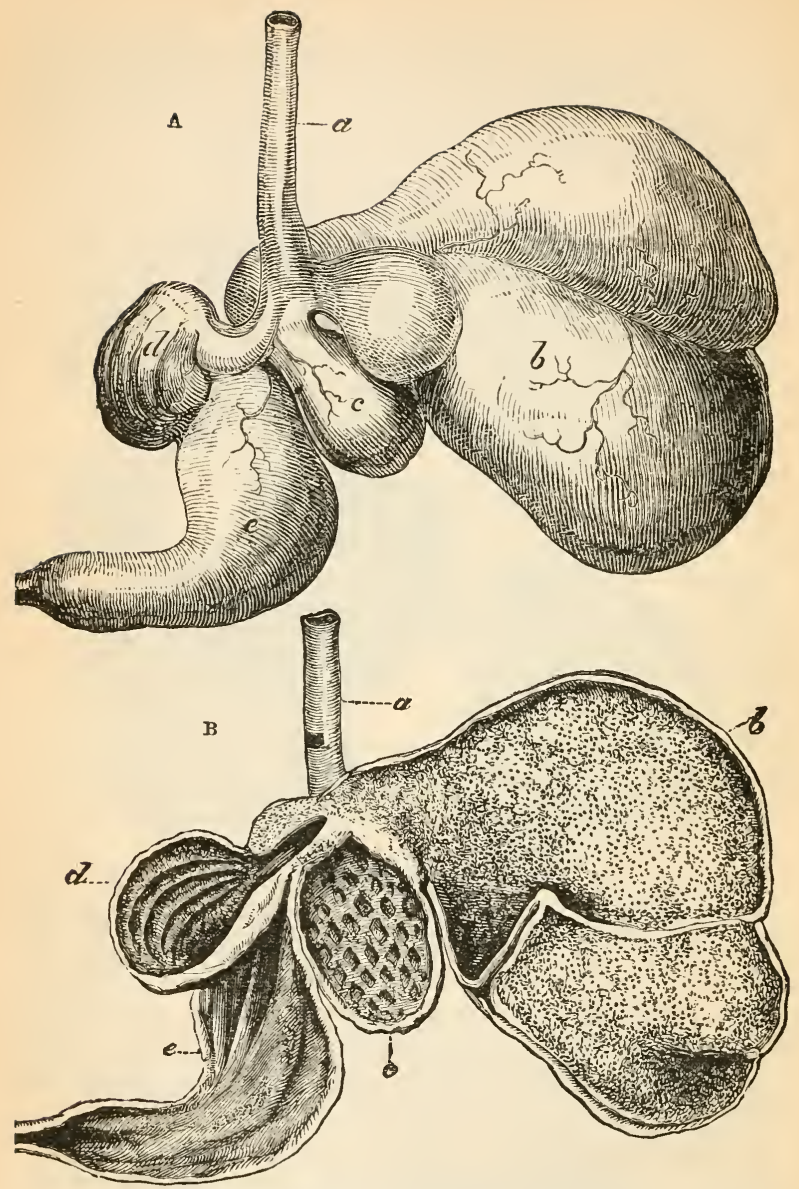

Fig. 75.-Stomach of a Ruminating Animal.

A, Exterior: B, interior ; $a$, œsophagus ; $b$, rumen or paunch ; $c$, reticulum or honey-comb bag; $d$, psalteriun or manyplies; $e$, abomasum or rennetstomach. 
to this, a well-marked ridge divides the cardiac part into two regions. In the chevrotain (Tragulus) the outer portion of the cardiac division forms a large paumch, and is incompletely separated from a portion lying just below the oesophagus, the inner sulfuce of which is raised up so as to form a honeycomb-like arrangement of ridges; from this the pyloric digestive portion opens by a narrow tube-like piece. In the horned ruminants (Fig. 75) this tube-like piece becomes more distinctly separated from the rest of the pyloric portion, and its inner surface becomes raised up into a number of folds of mucous membrane, which are closely appressed to one another, and permit only of the passage of the most finely comminuted food. All graditions in complexity are to be observed in the size and number of these lamellæ of the psalterium.

In the desert-dwelling camels, and in their allies, the llamas of South America, part of the cardiac region is converted into a number of pouches, which are provided with sphincter muscles, by which they can be shut off from the rest of the cavity; these pouches make up the so-called water-bag of these animals.

In the blood-sucking bat (Desmodus, Fig. 76), where little digestive secretion is required, on account of the nature of the food, the pyloric portion of the stomach is very short, but the cardiac is converted into a wide crecum, the length of which may be double that of the body of the animal, and which, no doubt, serves as a reservoir for the blood that is sucked in as food.

The region beyond the stomach is known as the intestine; it is characterised by having at its com. mencement the orifices of the bile ducts from the liver, and it is often sharply divisible into a narrower small, and a wider large intestine. The capacity of the internal surface is increased, as in the stomach, by the 
development of longitudinal and transverse folds; the most remarkable of these ingrowths is one that we cannot refrain from associating with the typhlosole of the earthworm and of the fresh-water mussel; when best developed, as in the elasmobranchs, this fold

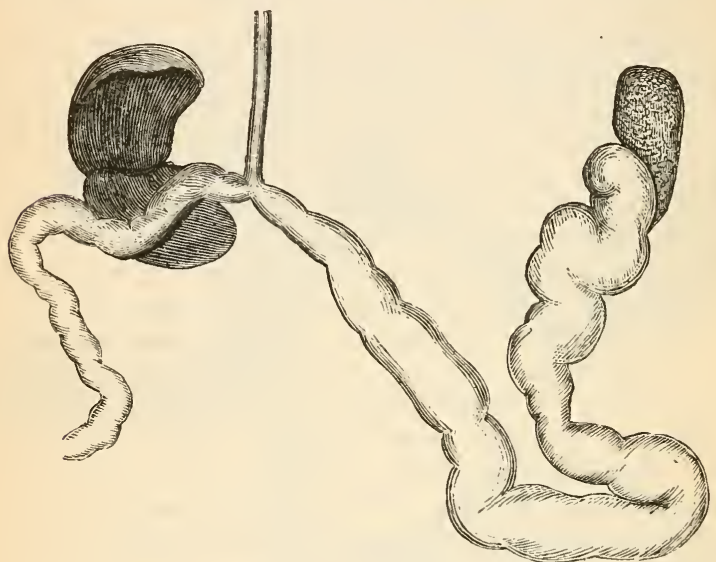

Fig. 76.-Stomach of Desmodus, in the form of a long cæcal process.

forms a spiral valve. In a more rudimentary condition it is presented as an incomplete spire in the lampreys, as consisting of thin whorls in the chimæra, or of varying degrees of complication in various ganoids, and as sometimes forming a closely appressed series of folds in the skate. Among the Teleostei it is very rarely developed, though a projection of this kind is certainly to be seen in some specimens of Chirocentrus, and has been expressly said to be found in Butirinus (Stamius). In the Teleostei there appear tubular outgrowths of the upper end of the small intestine, which may be supposed to take the place of the absent spiral valve ; these pyloric appendages, 
the number of which varies considerably in different forms, have been sometimes found to be full of food (Spatularia Wiedersheim), and are certainly developed in inverse proportion to the spiral valve itself. They are only one of the many means by which vertebrate animals increase the absorbing surface of their intestine without encroaching greatly on the space occupied by the other organs of the abdominal cavity.

In some Amphibia, as in Siren, the difference in calibre between the small and large intestine is not very well marked; in others, as the frog, there is a considerable difference. The same kind of difference is seen among the Reptilia; for the Ophidia and the Amphisbœna have the greater part of the tract of the same

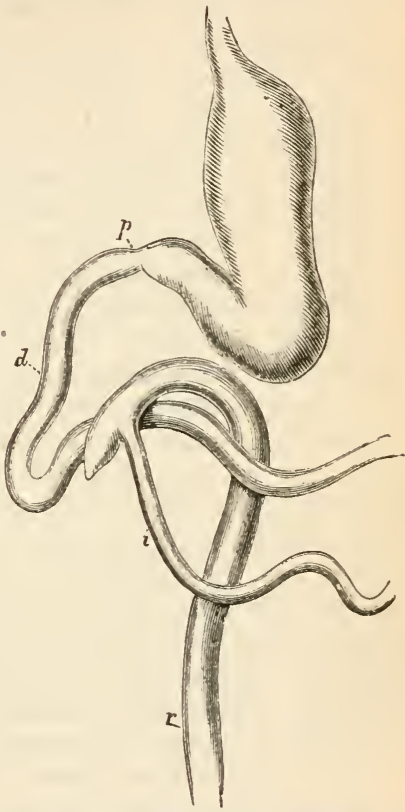

Fig. 77.-Diagram of the General Arrangement of the Abdomiual Portion of the Intestive of Mammalia, seen from in front; the small intestine is greatly abbreviated. (After Flower.)

$p$, Pylorus ; $d$, duodenum ; $i$, ilenm ; width, and the whole intestine is less coiled than in forms with a shorter body, such as the Chelonia or the Crocodilia. In Birds the first duodenal loop of the intestine always encloses the pancreas ; the intestine is proportionately long, but while nesting-birds, such as the 
sparrow, in which the yolk is almost or altogether used up before the bird leaves the egg, rapidly acquire the enteric proportions of the adult, those which leave the egg, like the chick, before the yolk material has been all used, are longer in acquiring the proportions of intestine which obtain in adult forms (Gadow).

In the Mammalia the small intestine is artiticially divided into a duodenum, a jejunum, and an ileum ; the large intestine is of greater length than in other Vertebrates, and the terminal portion only is straight or rectal (Fig. 77).

The rectum in many Fishes does not open into a cloacal pit, but lies in front of the urino-genital orifice ; in all other Vertebrata, except the Eutheria, the rectal and renal orifices open into a cloaca, while in the higher Mammals the anus lies behind the urinogenital opening. In the Chelonia, where the walls of the abdomen exert little or no influence on the movements of the intestine, part of the terminal portion of the gut may be enlarged, and its walls provided with abundant muscular tissue (elephant tortoise). The walls of the rectum are sometimes provided with glandular appendages, such as the bursa fabricii of Birds, and the bursae anales of Chelonia; the function of these organs is unknown.

The large is sometimes separated from the small intestine by a blind ingrowth or diverticulum, the caccum ; this is first seen in the Reptilia, where it varies somewhat in size in different forms, but it is never of any considerable extent. In most Birds the cacum is double, and the length of these outgrowths are in direct relation with that of the intestine, and therefore with the habits of the bird; they are, in other words, longer in herbivorous than in other forms; it has, however, been pointed out by Gadow, that when the intestine is narrow the tract is long and the cæca short, while other short cæca may also be 
associated with a short and wide intestine. With these cæca there must not be confounded the frequently present outgrowth on the small intestine, which is the curiously permanent remnant of the vitelline duct, by which food is obtained from the yolk.

The cæcum of Mammals presents some very remarkable variations; and we find many exceptions to the generalisation, that it is short in carnivorous and long in herbivorous forms. While its shortness or absence in the true Carnivora would seem to afford a support to the generalisation just indicated, it is more probable that its small size or absence in insectivorous forms, is rather to be associated with the danger's to which the hard chitinous coverings of their food might expose animals that fed on insects; the same explanation will apply to the insectivorous bats, and one of the same sort to the frugivorous species of Chiroptera, or to the fish-eating otter. At the same time, it is not to be thought that all frugivorous mammals are without cæca; not only has man a crecum, but the fruit-eating monkeys have one also. Herein we find one of the great arguments against prophesying as to the habits of an animal from what we can see as to its structure, and find a sufficient answer to those who assume that the parts of an animal are in accordance with its habits. The teleologist takes no account of that influence which, as we have shown again and again, is no less an important factor than adaptation, the factor of heredity.

It is clear enough that a cherry-stone impacted in a narrow cæcum may produce inflammation, and yet an animal that has been so successful in the struggle for existence as has man, has not only a crecum (which is about two or two and a half inches in. width), but this is continued into an appendix vermiformis, which is not so much as half an inch in width. So fir as man is concerned, we may well suppose that he 
has inherited this structure, for it is found also in all the anthropoid apes, while its wider distribution among the ancestors of the present Mammalia is spoken to by the presence of a vermiform prolongation to the cæcum in the rabbit. An appendix which is physiologically, even if it be not morphologically comparable to that of a man, is to be seen in the wombat among the Marsupialia.

Though it is not correct to say that the crecum is largest in herbivorous mammals, for it is absent in the bears, who are the most herbivorous of the Carnivora, yet in many cases there is a certain relation between the size of the cæcum and that of the stomach; for example, in the rabbit the stomach is simple, while the cæcum is enormous (more than 18 inches in length), and its absorbent surface is increased by the develop)ment in its interior of a large spiral valve; similarly, the horse has a very large crecum; on the other hand, the Ruminantia, in which the stomach is so complexly arranged, have a simple cæcum. It would, therefore, appear that when the absorbing surface of the stomach is not greatly increased by adaptive modifications, a special region of the intestine is entrusted with the functions that the stomach cannot perform.

In Hyrax there are two cæca.

In all Vertebrates the liver appears to arise as a bud or outgrowth from the wall of the enteron, and this embryonic condition is that which is seen in the lancelet, where, probably, the organ has no definite function; in most of the higher forms the secretion from the cells is stored up in a receptacle connected with the bile ducts; this is known as the gall bladder, and it is generally, though not invariably, attached to the right lobe. The primitive bud very early becomes double, though this is effected in different ways; in the chick the two diverticula are at first unequal, in sharks and Amphibians the primary 
outgrowth becomes bilobed, while in the rabbit two diverticula are developed, but not simultaneously.

The fat formed in the liver is, in many Fishes, Huid ; or, in other words, oil ; in these animals the organ is often of large size in proportion to the rest of the

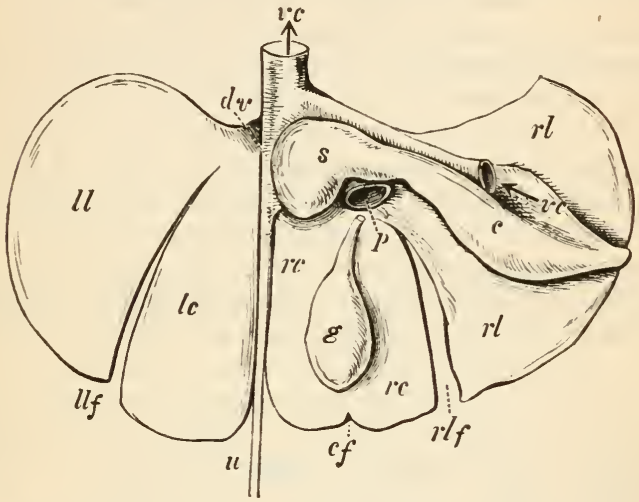

Fig. 78.-Diagramatic View of the Inferior or Visceral Surface of a Multilobed Liver of a Mammal extended transversely.

$v c$, Inferior vena cava; $p$, vena portæ; $u$, umbilical vein of the fœtus, represented by the round ligament in the adult, lying in the umbilical fissure; $l l$, left lateral lobe; $l c$, left central lobe; $r c$, right central lobe; $r l$. right lateral lobe ; $\delta$, spigelian lobe ; $c$, caudate lobe $g$, gall bladder; $d v$, remnant of ductus venosus : $l l f$, left lateral fissure; $c f$, central flssure; $r l f$, right lateral fissure. (After Flower.)

intestines, and much less firm in its consistency than in the higher divisions of the Vertebrata.

With regard to the liver of Mammals (Fig. 78), various attempts have been made to form a satisfactory system of nomenclature for its lobes, but it remained for Flower to suggest one which should gain universal acceptance.

We are taught by embryology that the liver ordinarily arises by two lateral outgrowths from the intestine, so that it is primitively bilobed; in the young (fœetus) the umbilical vein divides the liver 
into two parts, and this vein is retained in a rudimentary condition in the adult as the round ligament. It may, therefore, be taken as lying in the middle line of the liver; the parts or lobes that lie on one side are the right lobes, those that lie on the other are the left lobes. The fissure in which the remains of the umbilical vein lie is called the umbilical fissure, but it is not always the deepest; where a lateral fissure is as deep, or deeper, the liver appears to lose its bilobate character, and seems often to consist of three chief parts. The characters and relations of the umbilical fissure must, therefore, be carefully borne in mind if we desire to retain the proper morphological conception of the liver as an originally bilobed organ. A well-marked latera! fissure being frequently found on either side of the umbilical, it results that the organ is often found to consist of four chief lobes; these, from their topographical relations, may be spoken of as right central, left central, right lateral, and left lateral; while the whole mass of lobes on either side of the primitive middle line may be called respectively the right and left segments.

So far, then, we find that the liver is an organ consisting of two segments, each of which may be divided into two or more lobes. All the more important modifications of the liver affect its right segment; with the right central there is very frequently connected a reservoir or gall bladder; the right lateral often develops a prolongation on its lower surface, which is known as the spigelian lobe; another accessory to be developed from the right lateral is the so-called caudate lobe.

While all these parts are to be found in the human liver, we find some considerable variations exhibited in different mammalia; in some cases (Cetacea, Perissodactyla, and some other Ungulata, etc.) the gall 
bladder is absent, though the ducts may be enlarged at their extremity; sometimes (hippopotamus) it is present or absent, and, in the lemurs, it may be seen on the convex aspect of the liver. Sometimes the segments of the liver are greatly subdivided, and there are considerable differences in the depth of the fissures; thus, in the porpoises, the two segments are subequal and no further divided, while in the seal there are a number of minute notehes.

The liver is often adapted to the form of the body of its possessor, being elongated in elongated, truncated in shorter forms ; in the lower Vertebrates it largely retains its primitive bilobate character. The ducts by which its secretion passes into the intestine vary considerably in number and arrangement, and even closely allied forms may or may not be provided with the reservoil which is known as the gall bladder.

In Vertebrates with " hot blood" the bulk of the liver is, in proportion to the size of the animal, less than in the so-called cold-blooded orders; this, no doubt, is to be associated with the greater demand which is made by the former on the store of fat which accumulates in the liver, and which is more rapidly used up by them than by those animals in which oxydation is less extensive. The observations that have been as yet made on the "glycogenic" function of the liver have been directed rather to a study of the mode of production of this starchy compound than to the differences which obtain in different groups of Vertebrates.

A special outgrowth of the wall of the intestine gives rise in most Vertebrates to an important digestive or ferment-producing organ, the pamcreas. It is ordinarily connected with the duodenal region of the intestine, into which its duct often directly opens; in other cases, as in the frog, the duct opens into the bile duct. The details of the comparative physiology 
of this organ still await investigation, but sufficient is now known as to its importance to lead us to hope for much instructive information as to the action of its secretion in different animals.

Although it is absolutely certain that structural characters are profoundly modified by changes in function, or, in the words of John Hunter, "I dare say the different manner of living gives rise to the different formation of the viscera," it is, on the other hand, a fact beyond contradiction that in two purely herbivorous animals, such as, for example, the horse and the cow, or piscivorous forms as the seal and the porpoise, we find anatomical structures which are strikingly different ; to understand this we must again invoke the principle which, as we have already said, stands equal in value to that of the power of varying with varying circumstances; certain modifications of structure are impossible to certain animals, on account of the influence of heredity ; in other words, descent as much as environment has to be taken into account in the study of the morphological characters of the parts of any organism.

The first definite evidence as to the influence of food on the structural characters of the digestive canal was given by John Hunter, when he fed a sea-gull for a year on barley, and found that the muscular tissue of the gizzard became enormously developed.

It is stated that "this experiment is annually repeated by Nature; that the herring-gull, Larus tridactylus, of the Shetland Islands, twice every year changes the structure of its stomach according to its food, which consists luring the summer of grain and in winter of fish." Somewhat similar observations have been made on the raven and the owl, and the converse experiment, or that of converting the stomach of the grain-eating pigeon to the carnivorous type, has been effected by Holmgrén. 
The influence of the parasitic mode of life on the organs of digestion is exceedingly well marked. One of the most obvious and common results is the loss by endoparasites of a mouth; this, among the Protozoa, obtains in the Gregarines, which, living in organs or cavities of other animals (such as the intestine of the lobster, or the testicular reservoirs of the earthworm) that are rich in nutrient fluids, obtain their necessary nourishment through their cuticle by the merely physical process of osmosis. Anong the ciliated Infusorians, Opalina is mouthless. The same phenomenon is seen among the Metazoa in Echinorhynchus and the Cestoda, which in their adult condition live always in the digestive cavity of Vertebrates. What is certainly true of Tænia serrata (Frédéricq), namely, that no digestive ferment is to be found in any part of its body, is doubtless true also of other Cestoda, and is to be explained by the

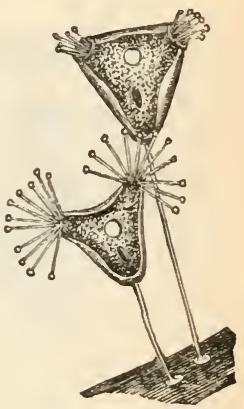

Fig. 79.-Acineta tuberosa with the pseudopolia extended and retracted. fact that these animals live in the midst of food which is being made ready to pass through animal membranes.

In another large set of cases food is obtained by suction; among the Protozoa this is seen in the ectoparasitic Acinetæ (Fig. 79), where elongated tubular processes of protoplasm arise from the surface of the body; these tentacles, as they are often called, are capable of very rapid protrusion; their knobbed ends widen into sucking discs, and are able to penetrate the cuticle of their prey, which are ordinarily ciliated Infusoria ; the semifluid endosare is then drawn up through the granular axis of the sucking tube. M-16 
Among the Metazoa sucking tubes are best developed in the Rhizocephala; these parasitic Crustaceans begin life in the shape of free-swimming naupliiform larvæ (see page 534), attach themselves to the bodies of higher Crustacea, and, losing all appearance of having true appendages, develop at their anterior end a
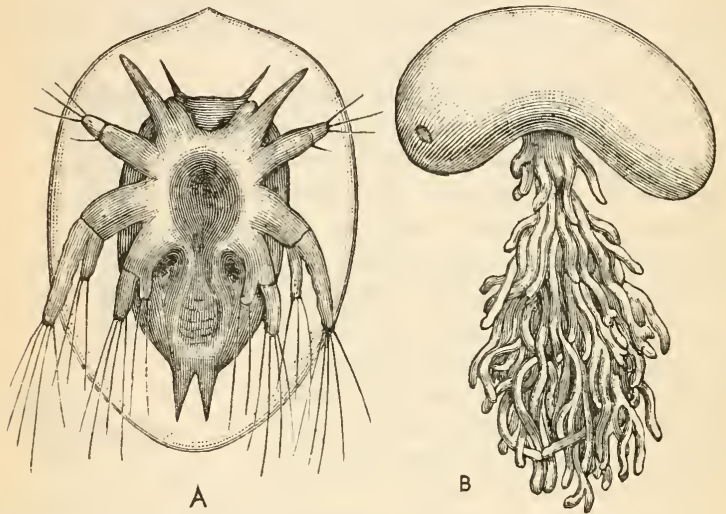

Fig. 80.-Sacculina carcini. A, Adult form showing the tuft of roots which it insert; into the bo ly of its host. B, The naupliiform larva. (After Haeckel.)

number of filamentar processes. These make their way into the body of the host, and by endosmosis take up nutriment, which they pass on to the shapeless body.

The mouth and the commencement of the digestive tract are often adapted for sucking, as in the liver-fluke, where the contractions of the protractor and retractor muscles of the pharynx effect this purpose; in the "Nematoid worms, where, as in the fluke, the intestine is complete, and is, moreover, provided with an anus, muscles set radially around the œsophagus extend to the walls of the body; 
on their contraction the cavity of the esophagus is greatly increased, and a vacuum is thereby formed; here, then, the tube asts as a sucking-pump. The great care needed in making any generalisations in comparative physiology is well spoken to by the curious fact that among the parasitic Nematoids a mouthless condition obtains only in the free-living stages; thus Gordius has a mouth when parasitic, but when it leads a free life the mouth is lost, and the worm is dependent on the store accumulated in its earlier stage; in its ally, Mermis, the peri-œsophageal muscles are lost in the free stage of existence, though the mouth remains. In the leech the sucking action is effected in essentially the same way as in the Nematoid. In the scorpion, where the mouth is excessively minute, the pharynx is pear-shaped, and has attached to its wall transversely set muscles, which, on contraction, increase the extent of the cavity, and so cause a vacuum which results in an up-flow of the fluids of the prey which it has stung to death. A large number of Arachnida have a distinct sucking apparatus.

The changes induced by parasitic habits on the conformation of external parts of the body are, as may be supposed, most striking in the Arthropoda, Among the Entomostraca a very instructive series of gradations may be made out. The gnathites of Cyclops are in Caligus, which is a temporary parasite on fishes, enclosed in a tube formed by the fore-andhind-lips ; the anterior pair, or mandibles, are alone well developed, and form piercing processes. In Corycæus the suctorial tube is not developed. In both of these there are swimming feet. In Lernæa, which may be found on the gills of the cod, to which the adult females are permanently attached, the swimming feet are small. In Achtheres, which is found on the perch, these feet are wanting, and a pair of gnathites 
unite to form a single sucker, or disc of attachment. As we pass from Cyclops to Lernæa or Achtheres, the form of the body becomes less and less obviously segmented, and more and more bizarre in appearance. In Argulus, the common parasite of the stickleback and other fishes, the changes are still more marked; the suctorial tube is large, and has within a pair of finely toothed mandibles and style-shaped maxillæ; in front of the mouth is a pointed spinous tube, containing the ducts of what are supposed to be poison glands; the anterior pair of maxillipeds (Claus) form large sucking discs on either side of the mouth.

Among the higher Crustacea the parasitic forms belong to the group of the Isopoda; the Bopyridæ liave a sucking proboscis, and their mandible is without a palp; some, like Entoniscus and Cryptoniscus, are ordinarily lernæoid in form, when adult; one species of the latter, which is parasitic on a Sacculina, which is parasitic on a Pagurus, has so peculiar a form as to have received the specific name of planaroides.

Among the Arachnida, many of the mites (Acarina) are parasitic, and the bases of the two anterior pairs of appendages form a sucking proboscis, as in Demodex, which dwells in the hair follicles of various mammals; the females of itch-mites are able to bore under the skin; in the blood-sucking ticks the proboscis is provided with a number of hooks. In Pentastomum, which has two hosts, and is endo-parasitic in both of them, the only signs of appendages to the body are the two hooks on either side of the month.

Parasitism is very rare among Mollusca ; Montacuta lives among the spines of Spatangus, Stylifer on sea-urchins, among corals, or in starfishes, but neither of these are specially modified. Entoconcha, parasitic in Holothurians, is merely known as an ovigerous sac. 
No Vertebrate is truly parasitic, for Myxine (the "Borer") penetrates the body of other fish for the direct purpose of feeding on their flesh; and the relation of Fierasfers to the Medusæ, Echinoderms, and Molluses, with which they have been found, is only that of a guest which makes use of the currents of water which the host intended for its own purposes (Symbiosis).

\section{CHAPTER V.}

THE BLOOD AND THE BLOOD-VASCULAR SYSTEM.

THE result of the process of digestion is the formation of a quantity of material which can be usefully taken up by the different cells of which the body is composed, and used by them for the purposes of repair, growth, and reproduction. In a majority of cases the material has yet another function, inasmuch as it becomes the vehicle for the oxygen which is constantly necessary to cell-activity; it is respiratory as well as nutrient.

This material takes the form of a liquid in which cells or corpuscles float; and these cells are either colourless, or tinged red by hamoglobin, and are either amoboid or constant in form. The liquid is known as the plasma, and it is either colourless, or tinged red, green, or blue.

The different characteristics of the various parts of this nutrient and respiratory medium are most clearly seen in the Vertebrata, with which, therefore, we will commence.

The blood is a fluid containing white and red corpuscles, a certain amount of dissolved albuminous and mineral bodies, and about half its own volume of 
gases ; the red would appear to be derived from the white corpuscles, and some, at any rate, of these last, owe their origin to the colourless amœboid corpuscles of the Iymph; this lymph, again, is finally dependent for the production of fresh corpuscles on the thicker milky fluid which is found in the lymplatics of the intestines (chyle); and this chyle is, of course, due to the metamorphosis of the food taken into the digestive tract, and there converted into peptones and other diffusible bodies.

The white or colourless corpuscles are amœboid in form, vary a good deal in size, but are constantly smaller in Mammals than in other Vertebrates, and while, on the whole, less numerous than the red corpuscles, they vary in number according to the state of fasting or repletion.

In all Vertebrates save Mammals the red blood corpuscles are provided with a nucleus; in all Mammals, except the camel and the llama, the red discs are circular in form, as they are also in the cyclostomatous fishes; in the remaining Vertebrates the discs are elliptical. These red corpuscles differ very greatly in size; largest in the urodelous amphibian Amphiuma, where they measure about $\frac{2}{10}$ millimetre by $\frac{1}{20}$; they are smallest in the Chevrotain (Tragulus), where they are only $\frac{1}{400}$ millimetre in diameter. The interesting researches of Gulliver have shown that, within the limits of any given natural group, the corpuscles are largest in the largest, and smallest in the smallest species of the group. The average number of red corpuscles in a cubic centimetre of human blood has been estimated at five millions; in the goat there have been found in the same quantity of fluid eighteen millions; in the rabbit, three and a half millions; in a cock, two to three millions or more; in bony fishes seren hundred thousand to two millions, and in various Elasmobranchs from one hundred 
and forty thousand to two hundred and thirty thousand (Malassez).

In Amphioxus and the Urochordata, there are no red blood corpuscles, and, as a rule, these are not found in what have been called invertebrates; they have, however, been observed in Solen (a Mollusc): Glycera (a Chætopod); Amphiporus (a Nemertean); and Phoronis (a Gephyrean).

In most nvertebrates the blood corpuscles are either limited to the fluid in the body cavity, or are found more or less numerously represented in the fluid contained in the ressels. In all these cases they are single cells, generally amœboid in character, and they vary considerably in size and number.

In Echinoderms, Arthropods, and Holluses, the corpusculated fluid is contained in a system of more or less completely closed walls (vide infira); in a large number of worms the fluid in the vessels is, on the other hand, said to be non-corpusculated, and, at any rate where corpuscles are found, they are often, as in the earthworm, rare, and of small size $\left(\frac{1}{3000}\right.$ inch; Lankester). It is, however, only quite recently that observations have been directed to the presence of corpuscles in the blood of Annulata, and since then they have been observed in several members of the group (Eunice, Nereis).

\section{BLOOD-VESSELS AND HEARTS.}

In all the forms already mentioned, part of the blood at least is contained in a system of more or less completely clcsed vessels, by means of which it is conveyed from part to part of the body; these vessels make up the blood-vascular system. When best developed this system has, on some parts of its course, a contractile organ, by means of which the fluid is pumped along; this is the heart. In the Vertebrata, the vessels given off from the heart (arteries) do not, 
as in the crayfish, open into spaces in the colom, thence to be taken up again by the vessels which pass to the heart (veins), but they are conveyed through networks of fine hair-like vessels (capillaries), which are completely closed. So, again, the chyle, or the direct result of the products of digestion, is contained in vessels which make their way into the veins (the more or less completely closed lymphatic system).

In the Mollusca and Arthropoda the bloodvascular system is not completely closed; in other words, the blood makes its way from the arteries into spaces or cavities in the body cavity, and from these incompletely closed spaces it is again taken up by the veins; it is clear, therefore, that no closed or proper lymphatic system is here needed; the results of the process of digestion make their way through the walls of the intestine directly into the colom, and thence into the sinuses, and in this way they replenish the store of corpuscles in the blood of the crayfish or the mussel.

In the Echinodermata the blood-vascular system would appear to be completely shut off' from the cœlom, and, as it would seem to be connected with the system of water vessels, it is, no doubt, diluted by sea-water; but the fluid in the cœlom contains characteristic corpuscles, some of which are coloured. Curiously enough, limoglobin has been detected in the water-vascular system of an Ophiuroid (Fœttinger).

In the Protozoa there is, of course, no blood, but even in the Amœba we observe currents within the protoplasm, and some of these are, no doubt, richer in nutriment than others, so that by their movement the distribution of nutritious material is equalised over the whole organism; in Paramœcium there is an advance on this, inasmuch as in it currents of definite directions are to be detected. In the Sponge the currents of water that traverse its walls 
bring in oxygen and food material. In the Coelenterata there are, as we know, out-growths of the enteric cavity, which, in reference to their functions, are spoken of as parts of the gastrovascular system; along these the digested material and the water taken in by the mouth pass to the different cells which line them. But the only agent in the propulsion of the material is the pressure due to the movements of parts of the body.

In the Turbellaria we observe no system of vessels ; the nutrient fluid either makes its way from cell to cell, or passes through the clefts and passages in the tissues of the body which so often indicate all that can be seen of a cœlom. In the dendrocœlous Turbellaria and in the Trematoda the absence of a system of blood-vessels is, no doubt, largely made up for by the branches of the gastric cavity (see page 114), which perform the same function as the gastrovascular system of the Colenterata. In the Tapeworms the only indication of a system of nutrient vessels are the delicate canals that lie internally to the longitudinal excretory vessels, and contain a homogeneous plasmatic fluid ; these are the plasmatic camals of Sommer. From the Rotatoria, on account of the small size of their bodies, a system of blood-vessels is wanting.

The origin of the closed system of vessels is involved in great obscurity, but it is, at any rate, to be partly ascribed to the increase in size of the organism; this increase demands the possession of a means of providing for the course of the circulating medium, and affords us another example of that division of labour which we constantly note as we ascend the scale of organisation. This explanation does not, at first sight, appear to apply to all of the Nemertinea, for in the smallest members of that group we find a comparatively elaborate system of not only closed but also contractile vessels; further investigation reveals, 
however, the important difference in the function of the contained fluid in the lower as compared with the higher Nemertinea. In the former hæmoglobin is distributed in the nerve tissue, but is absent from the blood, so that that fluid has only nutrient functions in the Schizonemertini, and not both nutrient and respiratory duties as in the higher Hoplonemertini. There are three chief longitudinal vessels, two lateral, which are connected with one another at the anterior end of the body, and one median, which is connected with the two lateral a little behind the region of the mouth. All these are contractile, but they are of the same calibre throughout, or, in other words, there is no special portion which is enlarged to act as a pumping organ or heart.

When we pass to those higher forms of Worms in which metarneres are developed, transverse branches or lateral vessels unite the median with a now ventrally placed trunk, and some of these lateral vessels become contractile (so-called hearts of Sænuris and others).

The dorsal vessel $(d)$ of such forms as, for example, the earthworm, is retained in the crayfish as the anterior (Fig. 81; $a a^{\prime}$ ) and posterior aortae $(p a)$; the transverse vessels are indicated by the short arteries at and $h p$, which supply the anterior regions of the body and the viscera; one transverse vessel is still complete, and forms the descending sternal artery (st.a) which opens into the backwardly and forwardly directed abdominal artery $($ si. $a$; $i a a)$ the representative of the ventral vessel of the earthworm. In the Anodon (Fig. $82 \mathrm{c}$ ) the spaces or sinuses are much more developed, and no indications of a ventral vessel are now to be seen ; the dorsal is, however, shown by the heart (H) with its anterior and posterior aortæ $\left(a \alpha^{\prime}, p a\right)$; while the terminal parts of the transverse vessels become enlarged to form the auricles of the heart or ventricle $(a)$. 
In the fish (Fig. $82 \mathrm{D}$ ) the enlargement for the heart(H) is found on the ventral vessel; passing forwardsitbranches on either side into the branchial vessels, and these unite and pour their blood into the dorsal $(b r)$ aorta $(d a)$.

The blood-vascular system of the Arthropoda is distinguished by the fact that the blood which comes to it to be pumped through the body does not

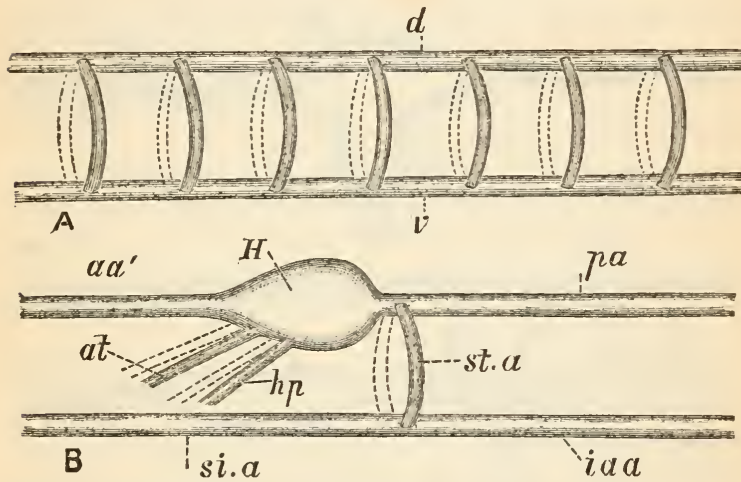

Fig. S1.-Diagrams to show the arrangement of the great Blood-vessels in the Earthworm (A); the Crayfish (B).

reach it directly by distinct vessels; the heart is surrounded by an imperfectly closed space, the pericardial sinus. When the contractile chamber which is called the heart dilates, the blood in the surrounding sinus flows into it through two or more spaces or holes in its walls. The heart may be short, as in Daphnia, and have only a pair of orifices; or it may be greatly elongated, as in Artemia, where there are twenty pairs; or it may be much more compact, as in the crayfish, where there are three pairs of large ostia, one superior, one lateral, and one inferior, which are guarded by valves that prevent 
the return of the blood to the sinus, as well as an irregular number of smaller holes. In the occasionally parasitic copepods (Corycæus) and the degenerated Cirripedes there is no heart.

The vessels arising from the heart likewise differ considerably in their arrangement; in the Entomostraca there is an anterior artery only, which may branch
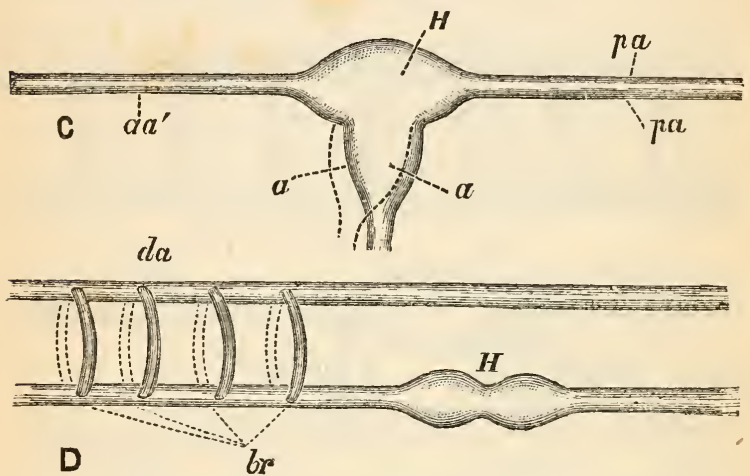

Fig. 82.-Diagrams to show the arrangement of the great Blood-vessels in the fresh-water Mussel (c); aud the Fish (D).

more or less at its free end; but the greater part of the blood makes its way through definite spaces without distinct enclosing walls, the so-called lacuma.* In the Malacostraca a posterior aortic artery is given off, in addition to the anterior; and in the crayfish, for example, we may further distinguish two pairs of anteriorly directed trunks; the antennary, which

* Our knowledge of the vascular system of Arthropoda, or Molluscs, is in an unsatisfactory condition; the "lacunar connection between the arteries and veins, which is confidently described and discussed by all zoologists, has never yet been demonstrated to exist in a manner satisfying the requirements of modern histology" (Lankester). 
supply the front part of the liead, and the hepatic, which go to the chief viscera. The posterior artery runs backward along the dorsal surface of the tail, and gives off on its course a downwardly-directed vessel (sternal artery), which on reaching the ventral region clivides into an anterior and a posterior abdominal artery. As these several vessels ramify, they break up into smaller vessels, and then finally open into spaces among the various organs of the body. The largest and most important of these is the great sternal sinus, which lies in the region of the entrance to the gills, into the spaces in which the blood passes to receive a fresh supply of oxygen (see page 224) ; thence the blood returns by the branchiocardiac veins or canals to the pericardial sinus, to again pass into the heart, and resume its journey through the body.

It will be observed that the blood goes to the organs of the body from the heart before it goes to the gills. Such a heart is known as a systemic heart, in contradistinction to the oramchial heart of fishes, for example, in which the blood pumped from the heart goes firstly to the gills, and secondly to the other organs of the body.

The vascular system of Peripatus is described by Balfour as consisting of a dorsal vessel shut off from the body cavity by a continuation of the endothelial lining of the latter. It has definite walls, but it is not clear whether they are muscular. It extends from near the hinder end of the body to the head, and is largest behind. Between the skin and the outer layer of muscles there is a very delicate ventral vessel.

In the Myriopoda the heart extends through the whole of the body, and is made up of a number of chambers separated from one another by valves provided with orifices for the entrance of the renous 
blood, and giving off in regular metameric fashion a pair of arterial vessels. Anteriorly the cardiac trunk is continuous with a vessel which lies on the upper surface of the ventrally placed nerve cord.

In the Iexapoda the rardiac tube is confined to the abdominal region of the body, and there is a smaller number of separate chambers. The anterior tube is known as the aorta; its further ramifications are not known. In them and in the Myriopoda the pericardiac sinus has connected with it several pairs of ordinarily fan-shaped muscles (alae cordis); as these are not directly attached to the cardiac tube, they cannot, as has been sometimes supposed, have any function in the way of dilating the heart; it is probable, however, that they enlarge the extent of the pericardiac sinus, and thereby assist or accelerate the flow of blood into it. The inner lining of the heart is elastic, and the outer muscular coat does not contract simultaneously, but from behind forwards (Lowne).

The blood-vascular system of the Arachnida, as represented by Limulus and Scorpio, is more complete than that of any other Arthropod ; fine vessels given off from the arteries form a true capillary system, and the veins are definite and distinct. The heart is elongated, and consists of eight chambers, each provided with a pair of apertures guarded by valves; it is continued forwards into an anterior, and, in the scorpion, backwards into a posterior aorta. In the scorpion each cardiac chamber gives off an artery on either side, and several pairs are given off from the posterior aorta. Anteriorly, the aorta forms a collar round the cerebral nerve-mass, and is continued into a ventral artery which lies above the ventral nervecord; this artery is intimately connected with the nerve-chain in the scorpion, and in Limulus it absolutely surrounds it.

In the spiders and other Arachnids the number of 
cardiac chambers is reduced, and in the mites appear to be altogether absent.

The circulatory system of the Mollusca presents a remarkable difference from that of the Arthropoda, in so far as the blood never passes into the pericardiac sinus. The heart is again formed from part of the dorsal vessel, and in the least modified forms, or such as still present a bilateral symmetry, a pair, or two pairs (Nautilus), of transverse vessels open directly into the central or axial portion of the heart; the ends of these vessels nearest to the axial portion are enlarged in size and modified to form auricles, while the altered part of the dorsal trunk serves as a ventricle, from which the blood passes forwards by an anterior, and backwards by a posterior, aorta.

A simple arrangement of this kind is well seen in the mussel (Anodon), or in the squid (Loligo). What is probably a still more primitive arrangement is presented by the Nautilus, in which there are two pairs of transverse vessels, and therefore two pairs of auricles. In the Octopus the aortic vessel, which in the mussel was directed backwards, now takes a forward course, or at first runs parallel to the true anterior aorta ; in those Gastropods that have suffered a more or less well-marked torsion of the chief viscera (see page 81 ), there is but a single auricle, and the great vessel arising from the front end of the ventricle early divides into two branches; of these one, like the anterior aorta of the mussel, supplies the front end of the body, while the other is, in like manner, distributed to the chief viscera.

The circulation is, to a large extent, effected in a manner which has been called lacunar; but, as has been already pointed out, our knowledge of these lacunæ is in a very elementary condition. The statement that water is taken up into the bloodvascular system by pores in the foot does not appear 
to rest on good foundation and is disproved by a number of observations. The system of vessels is better developed in the Cephalopoda than in other Molluscs; the definite arteries are more numerous, and their finer ramitications are more distinctly capillary in nature. The contractile power of the gills is, no doubt, of some aid in the propulsion of the blood; the walls of the vessels connected with them are, in the two-gilled Cephalopods, provided with muscles, and the name of branchial heart has been given to the enlarged portion of these arteries.

The three great divisions of the Chordates must be dealt with separately. The Urochordata are remarkable for an arrangement which, though not unique in the animal kingdom (for it has been observed also in the embryos of certain gastropods), is a very striking characteristic, and most instructive phenomenon. It has been observed that in them the pulsations of the heart, having resulted in the movement of the blood current in a forward direction, are, after a pause, reversed, so that the blood flows backwards instead of forwards. After this backward movement has obtained for a time there is another pause, and this is succeeded by a forward movement of the blood.

The heart of Tunicates has the shape of a tubular or fusiform sac, and gives off a large vessel at either end. In distinction to the forms already considered, and in agreement with what obtains in the Vertebrata, the heart appears to be an enlargement of a ventral, and not of a dorsal, vessel. The trunks which arise from it break up into vessels which, according to the area of their distribution, may be grouped as branchio-cardiac, cardio-splanchnic, or splancho-branchial; and, in addition to these, there are a number of anastomosing vessels in the test. When the heart contracts from behind forwards 
(that is, from its rentral towards its dorsal end) it contains almost pure arterial blood, and may, therefore, be regarded as a systemic heart; on the other hand, when the contractions are reversed in direction, the blood is nearly all impure, and, as it largely passes to the gills, the heart may now be said to be branchial or respiratory.

The cardiac tube is sometimes constricted at various points, but is never divided into distinct chambers. The most remarkable condition is presented, not only among the Tunicata, but among all known animals, by Appendicularia furcata. In it the heart consists of but two cells, which are connected with one another by from twelve to twentyfive processes, between which there are open spaces.

In the Cephalochordata we find an arrangement which reminds us of what obtains in the Annulata, inasmuch as there is no centralised contractile heart, but the blood is only moved forwards by the contractility of some of the great vessels. The vessel of largest calibre is found in the neighbourhood of the anterior gill-clefts; into this the blood passes from the gills, and from it it goes into a ressel which is connected with the right of the two so-called aortic trunks. These two trunks unite with one another behind the branchial area, and form a single dorsal vessel, or " aorta," which extends backwards along the body; at the hinder end it is continuous with a ventral ressel, which, on its way forwards to the gills, gives off some branches to the rudimentary liver (see page 161), and so forms a kind of rudimentary portal system. (See page 206.) The blood from the liver' returns to the great ventral trunk, and, with the rest, makes its way to the gills to receive a fresh supply of oxygen. The branchial vessels form dilatations on their course (bulbilli), and the contained blood either makes its way directly into one of the aortæ, or first $\mathrm{N}-16$ 
passes tirough the already-mentioned anterior enlargement.

A very definite system obtains throughout the Vertelprata ; there is always a centralised ventrally placed heart, which consists of at least two chambers, an auricle and a ventricle; from the latter, one, or a pair, or several pairs of arterial vessels (aortic arches) are given off; these divide into smaller and smaller arteries, which end in the capillaties found in all organs and parts of the body; the capillaries pour their blood into the small veins, and the small veins into larger ones, three, or less than three, of which open into the auricular region of the heart.

Where respiration is effected by gills the blood goes through the aortic arches directly to these organs, distributes itself in the fine gill-capillaries, and then, re-collecting, distributes itself through the body ; the heart, therefore, of a lowly Vertebrate is branchial, and not systemic like that of the gill-bearing crayfish; when lung-like structures are superadded to the gills, the heart becomes incompletely divided into two halves, and where lungs altogether take the place of gills there is a tendency, which in the higher forms becomes an accomplished fact, for the heart to become divided into two separate parts; one of these, that on the right side, collects the blood from the body, and sends it to the respiratory organ, or acts the part of a branchial heart, while the other (left side) receives the blood from the lungs and pumps it into the body, or, in other words, acts as a systemic heart.

The heart is placed in a membranous pouch or bag, the pericardium, and ordinarily hangs freely in it, though sometimes, as in the eel, the heart is attached to it hy fibrous bands; the successive chamhers are separated from one another by valves, and the ventricle is likewise separated from the aortic system 
by similar structures; these are numerous in the lower, but reduced to a single set in the higher forms. The blood, on returning from the body to the heart, is in the lower Vertabrata collected into an enlargement of the venous system which is known as the siuus venosus, and the walls of this chamber are, like those of the auricle and ventricle, contractile. Contractility, then, is not, as in the higher members of the group, confined to the centralised heart; this is well illustrated, on the one hand, by the Mrxinoids, in which the portal vein, and by the eel (IIcWilliam), in which the terminations of the jugular veins, are contractile; and on the other, by the Elasmoloranch fishes, the Dipnoi, and the Amphibia, in which the basal portion of the aortic system (conus arteriosus) is also contractile (Fig. 83). Here, as elsewhere, we have evidence of gradation in the division of labour.

The auricle, which is a single thin-walled sac in most fishes, becomes more or less divided into two in the Dipnoi; along the left-hand division of the heart there flows, in addition to the blood from the veins, that which has been returned from the rudimentary lung (see page 232); along the right side the rest, or purely venous, blood passes. Now, the arterial cone or trunk arises rather from the left than from the right side of the ventricle, which is incompletely divided into two halves, so that the blood which first leares it is the blood from the left auricle ; this will, of course, go to the farthest gill vessels, or those of the first and second arch; the last arch of all, the fourth, will, of course, receive the most impure or venous blood, and it is the one which, in Ceratodus, sends off a trunk to the lung.

This division of the auricle, which is hinted at even in Chimæra (Lankester), becomes complete in the forms which constantly breathe air by means of distinct lungs, and the sinus venosus, which brings the 
blood from the body generally, opens into the right, and the lung vein into the left compartment; in all the higher forms, however, the two halves are more or less connected during embryonic life, and just as the tadpole has only a single auricle, so even in man there is a communication between

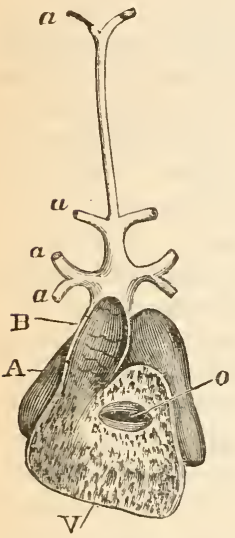

Fig. 83. - Heart of Squatina.

A, Auricle; $\mathbf{B}$, arterial cone; aaa, branchial arteries; 0 , orifice of veutricle, $v$. (After Gegenbaur.) the right and left sides (foramen ovale of the interauricular septum), which, in exceptional cases, remains open in the adult condition, and thereby produces the affection known as cyanosis. In the Mammalia the sinus venosus, which in Ceratodus (Lankester), though not in most lower Verte brata, is not sharply separated off from the auricle, becomes, when foetal development is over, completely merged into the right avricle (atrium or sinus venosus of human anatomy).

The ventricle remains an undivided chamber throughout the Amphibia and all Reptiles except the Crocodilia, so that it is clear that the presence of two ventricles in Crocodiles, Birds, and Mammals, is not a homogenetic, but a homoplastic arrangement. (Compare page 12.) An interesting example of the "falsification of the embryological record," is afforded by the development of the ventricles, inasmuch as in those forms where they are distinct, they become so before and not after the auricles; it is a case of what Haeckel calls cenogeny, and is, no doubt, dependent on the requirements of the organism.

The ventricular is separated from the auricular 
portion of the heart by nembranous valves, just as the auricle is shut off from the renous sinus by similar structures; these are in fishes ordinarily, though by no means always, two in number; and their function is clearly to close the way back into the venous system, and thereby to aid in forcing the blood forwards, on the contraction of the walls of the cavity. In the Amphibia (Fig. 84) the two valves are fibrous, and are connected by fibres with the wall of the ventricle, so that when this part of the organ contracts it draws down the valves; when the auricular chamber(atrium) becomes divided, each opening into the ventricle is provided with valves.

In the turtle the auriculo-ventricular valves are formed by the development of the rentricular edge of the auricular septum into two folds, which, on the contraction of the ventricle, meet a ridge on the correspondingly opposite side of the ventricle; in the crocodile these

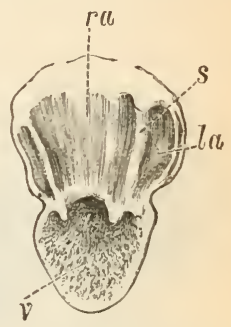

Fig. 81.-Heart of the edible Frog (Rana esculenta), to show the auricle and re tricle opened from the left side.

$s$, Septum atriorum : la, left auricle ; $r a$, right auricle ; $v v$, auriculoventricula: valves; $o$, orifice of arterial cone or trunk: $v$, ventricle. (After Echer.) folds are distinct valves. In the Bird we find a difference between the valves of the right and left side; on the right two folds of muscular tissue, close together at their anricular end, diverge from one another, and extend far down into the right ventricle; on the left the muscular is largely replaced by fibrous tissue which gives off fine tendons (chordae tendinea) to projecting muscular processes of the wall of the ventricle (musculi papillares) (Fig. 85); these tendinous chords are grouped into three masses, and there are three muscular elevations. Though it is possible to derive the arrangement of 
valves which is found in the bird from that which obtains in reptiles, no such comparison is possible in the case of the mammalian valves; in most of the Mammalia we find that the valves are membranous and not Heshy, and that there are three (tricuspid) valves in the right auriculo-ventricular orifice, and

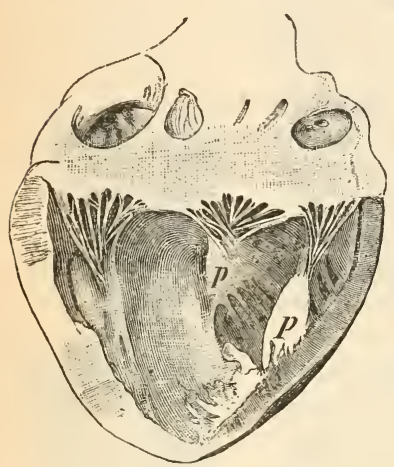

Fig. 85.-Left auriculo-ventricular valve of the Swan, shoring the chordæ tendineæ and the musculi papillares $(p p)$. (After Wiedersheim.) two in the left (mitral valves); as in the left side of the heart of the bird, there are chordæe tendineæ and musculi papillares, but the number of these is not confined to three. In the rabbit the valve of the right side is continuous, and not produced into three cusps. In the Ornithorhynchus, the valve of the right side is, as in the Sauropsida, muscular membranous tissue being only comparatively feebly developed in it.

As in the other parts of the heart, so in the ventricle, we find an instructive series of gradations. Single and undivided in all Fishes except the Dipnoi, it is always much stronger, and has much thicker walls, which are largely composed of muscular tissue, than has the auricular region; for while the office of the contraction of the auricle is merely to drive the blood into the adjoining chamber, the ventricle has the chief part to play in forcing it through the body. In the Teleostei and some Ganoids the wall of the ventricle is arranged in two layers, between which is a lymphatic space. 
An indication of a division of the ventricle into two parts is seen in the Dipnoi, but in the Amphibia there is no septum; in the uni-ventricular Reptiles (that is, in all but Crocodiles) there is no complete division of the eavity, but the muscular walls form internal projections which are functionally of some importance; the most valuable of these is the prominent fold which lies just beneath the entrance to the pulmonary artery, and almost separates off the part of the ventricular cavity which lies beneath it from the rest of the cardiac chamber ; in consequence of this being the region whence blood passes directly to the lungs by the pulmonary arteries (PA), it is known as the cavun puimonale (Fig. $86 ; C p$ ), and it occupies the right extremity of the heart. As the ventricle contracts, the blood in this carum is forced into the pulmonary artery, and as it is the blood which has entered the ventricle from the right auricle (RA), it is, of course, venous blood, or blood that requires oxygenation. As the contraction continues, the wall of the ventricle and the edge of the septum are brought closer together, so that the blood which is the last to leave the cavity is prevented from making its way into the cavum pulmonale; this blood is that from the left sicle of the heart, that is, from the left auricle (LA); in other words, it is blood which has just returned from the lungs, and requires no further oxydation, and it passes altogether into the systemic aortæ. An inspection of the figure of the heart will, however, show that some venous blood must pass into the same vessels, so that the blood in the systemic vessels of the tortoise is not pure arterial blood, but is a mixture of partly oxygenated blood and of blood that has already made a passage through the bocly.

In the Crocodilia, Birds, and Mammals there is a complete interventricular septum, so that within the 
heart itself the freshly oxygenated or arterial, and the impure or venous blood never commingle; in the Crocodile, where an aortic arch is in communication with each half of the ventricle, the arterial and venous blood commingle outside the heart at the point of union of their two vessels (the so-called foramen Panizzæ); in birds and mammals there is but

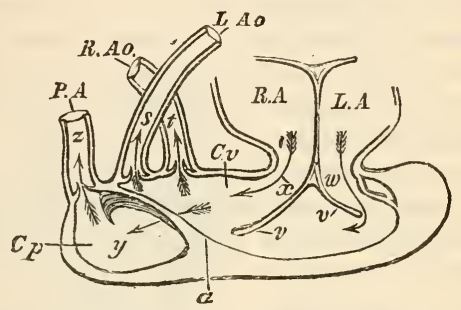

Fig. 86.-Diagram of the Ventricle and comnected parts in the Turtle ; showing the transversely elongated ventricle, with the right and left auricles (RA, LA) lying towards the left, the auriculoveutricular valves $(v v)$ formed by the inter-auricular and septum.

$\mathrm{RA}$, Right auricle; $\mathrm{LA}$, left auricle; $v$, the right; $v$, the left median auriculoventricular valves; $s \mathrm{~L}_{*}$, arrow showing the course of the blood in the left aorta; $t$, arrow showing the course of the blood in the right aorta; $x$, arrow showing the course taken by the blood from the left; and $w$, from the right auricle into the ventricle; $y$, showing the course of the blood from the cavum venosum into the cavum pulmonale; $z$, from the latter into the pulmonary artery ; $a$, the incomplete septum marking off the cavum pulmonale $(\mathrm{c} p) ; \mathrm{PA}$, pulmonary artery ; RAO, LAO, right and left aorta ; $v$, carum venosum. (After Huxley.)

a single aortic arch, which arises from the left ventricle, and the blood from the right never, therefore, passes into the aorta.

The differences between the arrangement of the auriculo-ventricularvalves have been already described, and we now need only point out that there must be a difference in the way in which these valves perform their office; in the Sauroid they are muscular, and therefore actively close the entrance to the auricles by contracting when the ventricles contract, while in the majority of Mammals the membranous flaps are 
floated upwards by the pressure of the blood contained in the ventricles, when acted on by the contraction of the walls of these cavities.

The peculiarities of the muscular tissue of the heart of vertebrates are dealt with in works on human or general physiology ; but it must be pointed out that this tissue is remarkable for the possession of hæmoglobin; that, under appropriate conditions of warmth and moisture, the heart of a frog or a tortoise will, after removal from the body, continue to beat automatically for a number of hours; and that minute threads of the tissue from certain regions possess the same peculiarity.

In the Mammalia the muscular tissue of the heart is supplied with proper blood-ressels (the coronary arteries), which arise directly from the aorta, and after branching elaborately, unite into the coronary veins which open into the right auricle. In some, especially Ungulates, a bone, which in the ox may be as much as an inch in length, is developed in the walls of the heart. An analogous development obtains in the penis, where a bone is sometimes present.

The ventricular portion of the heart gives off vessels which are known as the arteries; in the least modified Fishes, and in the Ganoids, the common trunk (conus or truncus arteriosus) is, like the venous sinus, contractile, but in the bony fishes this contractile power is altogether lost, and the bulbus aortae, as it is there called, becomes simpler in construction, while the valves which prevent the blood from flowing backwards are ordinarily reduced to two; the loss of the valves is clearly correlated with the loss of contractility, for there is not in the walls of this bulb any means by which the column of blood can be compressed, and thereby tend to be driven back into the ventricle. Where contractility is, on the other hand, retained, we find three (dog-fish) or 
more (in Lepidosteus eight or nine) longitudinal rows of pocket-like valves; in Lepidosteus there are four

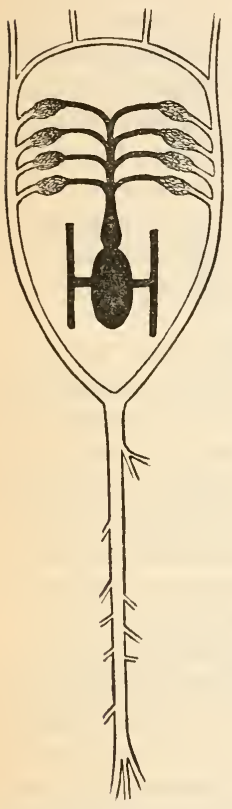

Fig. 87.-Diagram of the Arterial Circulation in Fishes. (AfterWiedersheim.) well-developed and four smaller valves in each of the nine planes, so that were they all complete there would be as many as seventy-two.

Among the Dipnoi, Ceratodus has one or more rows of welldeveloped pocket valves, but the fact that the number is inconstant shows that a change is impending; such a change is found in Protopterus, where the valves are few in number and minute in size, while their place is taken by a longitudinal fold, which extends down the greater part of the cone, and very possibly owes its origin to a fusion of a row of valves. By means of the valve the cone is divided into a right and a left half, and the blood that has just returned from the bocly is now carried to the third and fourth arches, the latter of which gives off a large pulmonary artery, or vessel which goes direct to the lungs.

The essential parts of this arrangement are seen among some of the Amphibia ; but, as may be supposed from what has already been said of the arrangement of the ventricle in the lower Reptilia, no functionally independent arterial cone is to be observed in them; nor is it seen in the adults of the higher Vertebrates, though even there it is at first a distinct part of the heart, and is undivided both within and without. 
From this cone or bulb cf the heart there proceeds a vessel which soon breaks up into a number of arches (Eig. 87); in Fishes the number of these is in correspondence with that of the gill clefts. Within the substance of the gill plate the artery (branchial artery) breaks up into a plexus of fine capillaries, and these become collected into a common trunk on either side which passes forwards to the brain and backwards to the rest of the body; behind the heart, the two trunks unite into a single median and dorsal aorta, whence vessels (arteries) are given off to the different organs and regions of the body.

When, as in the Dipnoi, a pair of lung sacs become developed, one of the branchial vessels (the fourth) gives off on its way from the gills a large trunk which passes directly to the lungs, whence the blood is returned directly to the lefit side of the heart. When the gills are lost altogether the branchial capillaries lose their function, and, for the greatest part, become aborted, though the frog retains in its so-called carotid gland the plexiform arrangement of the capillaries which was of use to it in its gill-bearing tadpole stage. As the arterial cone is retained by the Ampluibia, the general relation of the great vessels to the ventricle is the same as in Fishes, and the only differences that obtain are such as are due to the differences in function of difterent vessels, which influence their size and distribution.

In the Reptilia, as has been already explained, the orifices of the great vessels, which are ordinarily guarded by merely two semilunar valves, are brought into closer relation with certain parts of the ventricle; the arterial cone (Fig. 88 ; tr) becomes shorter, and is divided internally by septa.

In the lizard (Fig. 88) three arches arise from the heart; the two anterior are aortic, the third 
pulmonary. While three arches arise from the heart in many reptiles, only two are directly given off in Ophidia, one of which is aortic and one pulmonary. In the bird and mammal this reduction is

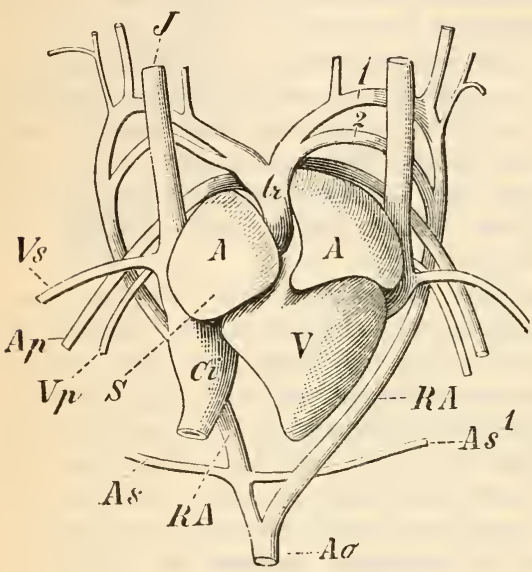

Fig. 88. Heart of Lacerta muralis. carried still farther, for in them the aortic trunk is $\operatorname{single}$ throughout its whole extent, the left half being reduced in the former, and the right in the latter. These reductions are best explained by a study of the figures of Pathke (Fig. 89).

The folanonymus): 1, 2, first and second arterial arches $\mathbf{R A}$, root of aorta; $\mathbf{A} o$, aorta; $\mathbf{A} s \mathbf{A} s^{\prime}$, suluclavian arteries; $\mathrm{A} p$, pulmonary artery ; $\mathrm{v} p$, pulmonary vein: J, jugular; $\mathbf{s}$, subclavian veins ; c $i$, vena cava inferior: these last three pass into the sinus venosus (s) which lies beneath the right anricle. (After Wiedersheim.)

distribution of the more important arteries:

lowing are the names and areas of

1. Carotids.-These may be double, when they are known as external and internal, or one or other may be reduced or disappear; in some Fishes the carotids are not direct continuations of branchial vessels, but the latter first unite to form a circulus cephalicus, by means of which the supply of bloor to the head is the better regulated; they supply the head and neck. 
2. Subclavian.-This is given off from the aortic arch, and supplies the fore-limb of either side.

3. Pulmonary artery (see Fig. 88), which supplies the lungs; this in the Amphibia, where
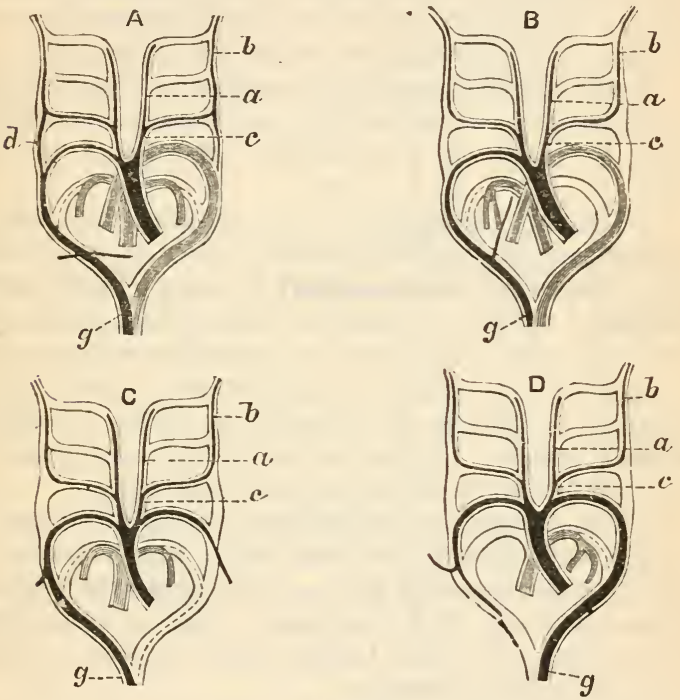

Fig. 89,-Diagrams to show the Metamorphosis of the Arterial Arches.

A, Yizard; B, Snake ; C, Bird : D, Mamnal. The five primitive arches are shown from helow. The first and second arches are alway's obliterated and their trunks carried on as the internal (a) and external (b) carotids. These are both continuous with the third $\operatorname{arch}(c)$ which forms the common carotid, and in $A$ arises directly from the arterial trunk; in A also the outer trunk lietween the third and fourth arch persists as the ductus Botalli $(d)$; in A and B the two arches of the fourth series are seen to he subequal, to cross one another just outside the heart, and to unite behind it into a dorsal aorta $(g)$; in c the left fourth arch l,ecomes the suliclavian artery, and takes no part in forming the dorsal aorta; in $D$ the same happens to the fourth arch on the right side. In all the primitive fifth arch supplies the lungs, but in nammals the right half disappears. (After Ratlike.)

respiration is largely cutaneous (see page 326 ), gives off a large cutancous branch, which is distributed in the skin. 
4. The aorta proper gives off large loranches, such as the coliaco-mesenteric, hepatic, renals to the viscera of the body cavity, and two large hinder (iliac) arteries which pass to the hinder limbs. The final termination of the aorta is the caudal artery, and the size and extent of this and its hranches are, of course, in direct relation to the size of the tail.

As the arterial vessels get smaller and smaller the blood from them flows into the capillaries, and thence hegins to make its way back to the heart by the veins.

1. The blood brought back by the hind-limb enters the pelvic vein, and then passes either by the iliac or the auterior abdominal into the vena cava inferior; in all Vertebrates, except Mammals and Birds, the blood that passes along the iliac veins breaks up again into a system of smaller veins within the substance of the kidneys, forming in them a renal portal* system. Again collecting, the renals, just as in mammals, pass into the inferior vena cava.

3 . The blood from the intestinal viscera is collccted into a portal* vein, which breaks up in the substance of the liver into a portal system; this hepatic portal system obtains in all Vertebrates. The hlood brought from the liver by the hepatic veins likewise passes into the inferior vena cava.

It is impossible to understand the arrangements of the collecting portion of the heart and of the superior veins without a knowledge of what obtains in all Vertebrates at an early period of development, and in Fishes throughout their lives. The unpaired vema cava is preceded by a single subintestinal vein, which collects the blood from the yolk sac, and this by

* The term PORTAL STSTEM owes its name to the fact that in man the so-called portal vein enters the substance of the liver by its fissure (or PORTA, as the older Latin-speaking anatomists called it). 
a paired system of cardina veins, of which the anterior pair collect the blood from the head, and the posterior from the body generally (Fig. 90; vC and HC). As these lie at the sides of the body the blood can only pass to the heart by a transverse vessel, the ductus Cuvieri (D). These two pairs of anterior and posterior cardinal veins are possessed by fishes, and the anterior pair remains throughout the

$\triangle A, A b d o m i n a l$ aorta : RA. RA, right and left roots of the anrta, connected by the collccting vessels (s $\left.s^{\prime}\right)$ with the branchial vessels $\mathbf{A} b ; c c^{\prime}$, carotids; $\mathbf{s} b$, sullelavian artery; $\mathbf{K L}$, gill clefts ; si, sinus venosus: A, atrium ; v, ventricle; $\mathrm{B}$, bullus arteriosus: vm, omphalo-mesenrer.c veins ; $A m$, nunlualonesenteric arteries; Ic IC, common iliac arteries: F. , extcrnal iliac arteries, All,allantoic arteries; Acd, eaudal artery: $\mathrm{vC}, \mathrm{HC}$ anterior and posterior cardinal veins; $\mathbf{s} b^{\prime}$, sul,clavian rein: $\mathrm{D}$, ductus Cuvieri. (After* Wiedersheim.)

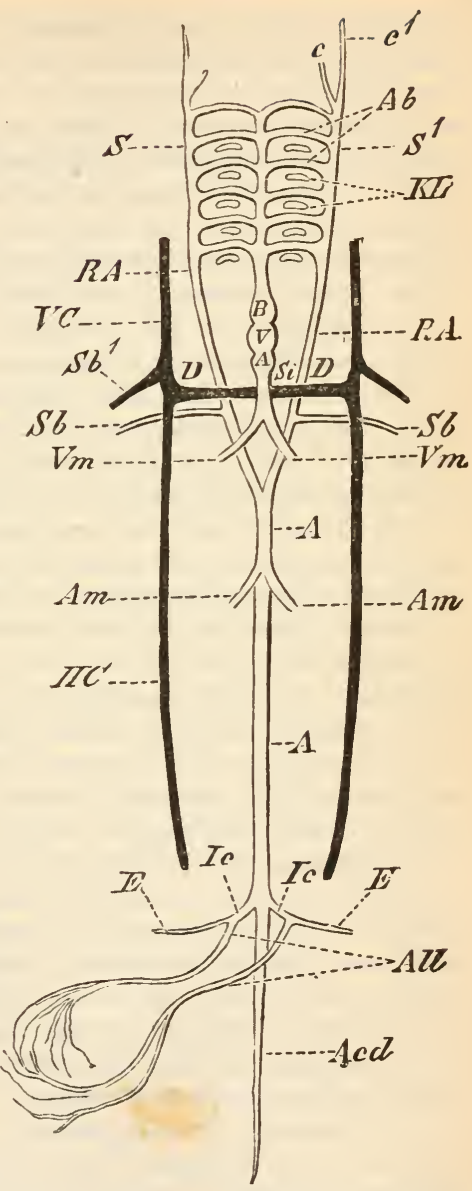

Fig. 90. -Diagram to explain the Arrange. ment of the Embryonic vascular System. 
vertebrate series as the jugular veins. In the pentadactyle vertebrates the chief afferent function for the hinder part of the body is undertaken by the just mentioned vena cava inferior, the posterior cardinals becoming the pelvic or hypogastric veins, while the Cuvierian ducts come to be the terminations of the jugular veins, and so lead into the sinus venosus whether that remains distinct from the atrium, or, as in higher forms, becomes a portion of the right auricle.

In addition to the important pulmonary veins which open into the left auricle, the vessel that brings the blood from the fore-limb (the subclavian) comes to be almost as important as the jugulars.

In the Mammalia the relations of the superior veins become considerably altered ; thus the left jugular, after having entered into an anastomosis with the right, becomes atrophied in various Ungulates and Rodents; in Man and the other Primates, in the Carnirora, and in Cetacea, the left jugular ceases to have, as a rule, any rudiment left in the adult condition. Rudimentary left ducts of Cuvier have, however, been occasionally observed in the human subject (Quain, Marshall).

Although there is a general body of truth in the statement that arterial vessels gradually become smaller, and veins larger, as the one leave and the other approach the central heart, yet, as we have already seen in the case of the portal circulation in the liver and kidney, veins do break up into smaller vessels to again unite into a.larger one; when this phenomenon obtains either with an artery or with a vein in any other part of the body than the organs just mentioned, such a plexus of vessels is ordinarily spoken of as a rete mirabile.

The function of such retia is not far to seek, the moment we remember the physical law that the passage of a fluid is slower through a narrow than a wide current; in other words, the exchange of gas or 
the escape of the blood corpuscles (diapcedesis), or, in general terms, the relation of the moving nutrient and respiratory currents to the surrounding cells is improved by such a slowing. This will explain the presence of a rete mirabile in the reduced anterior gill (pseudobranch) of many fishes, or in the walls of their air bladders, for by this means the exchange of oxygen is the more successfully effected ; a similar reason may be given for the great development of retia in the thoracic and costal regions of the Cetacea, or the very general distribution of small plexuses in the glomeruli of the kidney. (See page 258.)

On the other hand, the mere mechanical advantage of the slowing of the blood current must be of importance in forms such as the Ruminantia, in which the head is often for a long period at a lower level than that of the carotids, and by their presence the dangers of a flow of blood to the head may be averted; the same kind of explanation may, no doubt, be applied to the retia in the course of the abdominal ressels, the pressure on which must vary greatly with the extent of distension of the walls of the intestinal tract.

It is more difficult to explain the function of the retia mirabilia in the eyes of Fishes and Birds; or in the course of various vessels in monotremes and edentates. In the latter case the lowly position of these Mammals may, perhaps, be of significance.

The earlier division of Vertebrates into hot-blooded and cold-blooded forms disappeared before the progress of morphological discovery; in addition to the evidence that we now have as to the relationship of birds to reptiles, we have further to support us the now generally recognised difference between homoplasy and homogeny ; in other words, it is now clear to us that, with given structural arrangements, two forms, not closely allied, may, under similar external conditions, acquire a physiological resemblance; and we $0-16$ 
now see that Birds and Mammals have independently acquired the hot-blooded condition. In connection with this it is important to observe that they are the only Vertebrates in which the arterial and venous blood do not commingle at some point in the circulatory system. The term cold-blooded is so far inaccurate, that the blood is no colder than the surrounding medium, whether that be air or water; and, as its temperature varies, it is better to use the term "poikilothermic.".

\section{CHAPTER VI.}

\section{ORGANS OF RESPIRATION.}

THE essential object of the process of respiration is the taking in of oxygen either from the atmospheric air, which may be said to be oxygen dissolved in nitrogen, or from water, which holds in solution a larger quantity of oxygen than of nitrogen; for, whereas atmospheric air consists of twenty volumes of oxygen to eighty of nitrogen, water contains about 33 per cent. of oxygen. In the simplest cases (that of naked cells, such as Amaeba) the oxygen passes directly into the protoplasnic substance of the cell, and the chief product of the oxydation of the tissue, carbonic acid, passes freely out. In the Infusoria the oxygen has to make its way through the cuticle, and some, no doubt, enters with the drops of water that are taken in by the mouth; we are as yet altogether ignorant of the conditions under which animal membranes allow of the entrance of oxygen and the exit of carbonic acid. We have already seen that the cilia are of use in driving food particles towards the mouth, and it is clear that they are also of assistance in the respiratory process by producing currents around the cell, and thereby bringing fresh supplies of oxygenated water to its surface. 
The cilia of the flagellated chambers of the Sponge (Fig. 53) have clearly the same function among the Porifera, and the currents, which we have already learnt to be food-bearing currents, are the means also by which oxygen is brought to the cells that line the surface of the canals, and, while they bring oxygen, they carry away carbonic acid. Similarly, among the Coelenterata,* the necessary oxygen enters in the same way, and passes by the same passages as the food-currents. Among the lower worms, such as the Turbellaria, oxygen is, no doubt, obtained in the same way, but here in all probability the soft ciliated integurnent also affords a means by which oxygen may be carried to the cells.

It would be difficult to point to any part of the body of a Nematoid worm which could be reasonably supposed to have a respiratory function; on the other hand, such experiments as those of Oerley, who placed a number of specimens of Anguillula aceti (the vinegar paste-worm) in a small vessel and covered them with a layer of oil an inch thick, and found that after two months the greater number were still alive, prove that, in these worms at any rate, there is but a very feeble demand for fresh supplies of oxygen.

Where a definite blood-vascular system is developed, the consideration of respiratory problems is rendered easier; for, just as the currents of water in a sponge carry in oxygen as well as food, so does the blood of the higher Metazoa serve as an oxygen carrier as well as a store of food material for the different cells of the body. The oxygenating office is again rendered still more effectual when the blood

* It has been recently pointed out by Lankester that the socalled SUBGENITAL PITS of Aurelia have no connection at all with the genital glands. They are spacious cavities, opening to the exterior by comparatively small pores, and they serve, he thinks, as receptacles for respiratory water. They are four in number, and are set close to the mouth, one in each quarter of the disc. 
is impregnated with hamoglobin (see Power's "Human Physiology,"), which has a remarkable aftinity for oxygen. This hæmoglobin is either found in special corpuscles, as in the Vertebrata, some Annelids (Glycera, Capitella), some Gephyreans (Phoronis, Thalassema, Hamingia), some Lamellibranchs (Solen, Arca), or it is diffused in the liquid of the blood, as in most, though not all, Polychætous and Oligochætous Annelids and Hirudinea, some Nemertines, some Crustacea, the mollusc Planorbis, and the larva of the insect Chironomus.* It has been found in a special system of vessels in the Crustacean Lernanthropus and Clavella, and in the corpuscles of the water vascular system of Ophiactis virens. In various forms it is found diffused in muscular tissue. Its most remarkable position, however, is in the nerve tissue ; this has been observed in the sea-mouse (Aphrodite aculeata) and in a number of Nemertinea; in the latter it is absent from the nerve-tissue of those forms in which the blood is impregnated with it.

Among the higher worms in which no special respiratory apparatus is developed, it will probably be frequently observed, as has already been the case with the leech, that the epithelial covering of the body is interpenetrated by capillaries (Fig. 91); "the true respiratory organ of the leech is clearly this vascular epiderm, and amongst respiratory organs it stands alone in the nearness with which the absorbent bloodvessels succeed in bringing themselves through all structural obstacles into direct contact with the oxygenating medium" (Lankester).

When specialised respiratory organs are developed they may arise in various ways, either as in-pushings of the surface, which may become slits or tubes, or as

* The larger number of these cases have been observed by Ray Lankester. See the Proceedings of the Royal Society, 1873, No. 140. 
out-pushings of the body (external gills) ; or water may pass through or into the intestine and be pumped out of it again, or the walls of the intestine may give rise to cavities into which air is received; or, lastly, the body wall may give rise to an air chamber by folding over and becoming attached, for a more or less considerable extent, to the surface of the body, as is the case in the snail.

In a general way we apply the term gill to an

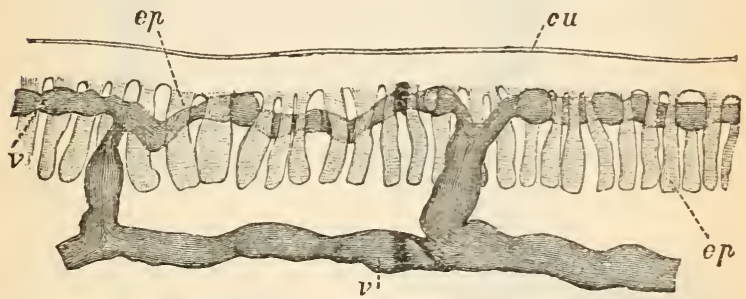

Fig. 91.-From a Trarsverse Section of a Leech; to show cu, cuticle ; $v$, intra-epithelial blood-vessel; $e p$, epithelial cells. (After Ray Lankester.)

organ which is fitted to take up the oxygen dissolved in water, and lung to that which breathes the oxygen of atmospheric air; but these terms can only be used in a very general sense.

The simplest form of in-pushing is seen in the Nemertinea, where the so-called side-organs or ciliated furrows are in Carinella annulata (Fig. 92 ; A) mere pits; this pit in C. inexpectata forms a more complicated groove, which leads into a ciliated duct (Fig. 92 ; B), which ends blindly among the cells of the brain; in both these species the nervous centres are quite close to the surface (page 398), and the tissue is, as we have just learnt, impregnated with hæmoglobin. In Polia, where the brain is more deeply placed, the ciliated duct is longer (Fig. $92 ; \mathbf{c}$ ). In the 
Schizonemertini (such as Cerebratulus) the transverse furrow of the Palæonemertine gives place to a deep longitudinal slit, which penetrates the muscular tissue
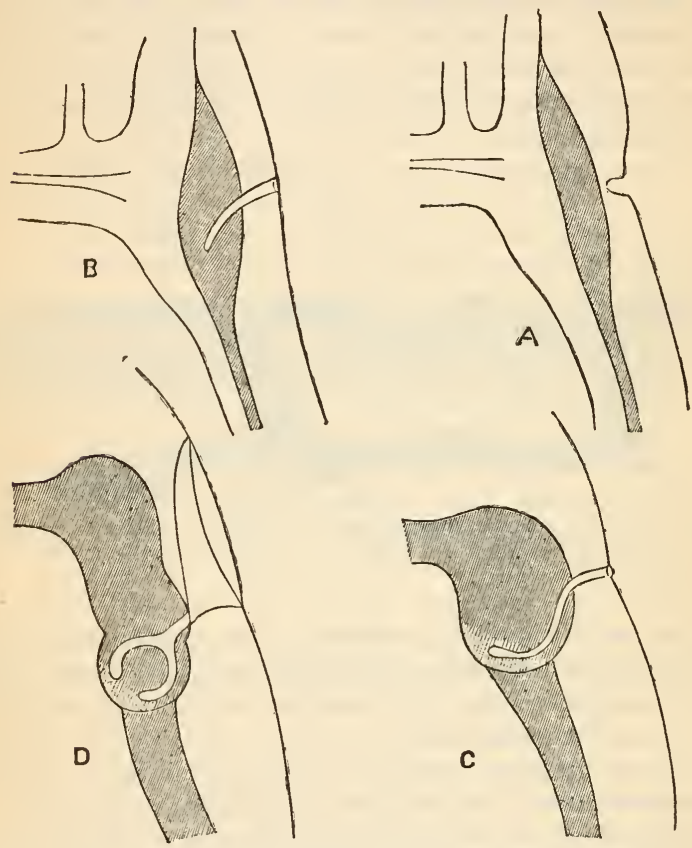

Fig. 92.-Diagrams of the Respiratory Ciliated Ducts of (A) Carinella annulata; (B) C. inexpectata; (C) Polia curta; (D) Cerebratulus. (After Hubrecht.)

of the head, and is continued below into the ciliated canal which penetrates the lobe of the brain (Fig. $92 ; \mathrm{D})$. The respiratory function of these slits has been pointed out by Hubrecht, who has made experiments in demonstration of his hypothesis, and who 
has directed attention to the deeper slits and larger amount of hæmoglobin in the Schizonemertini, as being correlated with their habit of dwelling in mud and other places in which the supply of oxygen is small; the ciliated cells of the groove clearly serve to drive in currents of sea-water.

In $\mathrm{C}$ and D (Fig. 92) it will be observed that the lower part of the ganglionic mass is shaded more lightly than the rest; the cells that form this portion are derived from the œsophagus, from the walls of which, however, they subsequently become separated; and we observe, therefore, that an out-pushing from the gullet goes to meet the epiblastic in-pushing from the surface.

An essentially similar phenomenon is to be observed in the Entero-

pueusti (Balanoglossus) and in the Chordata. page 231.)

In the tracheate Arthropoda we have examples of in-pushings of the surface adapted for

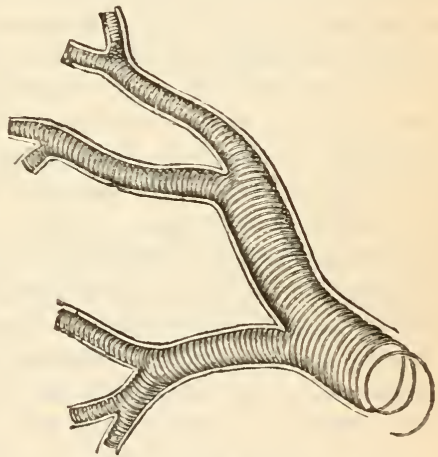

Fig. 93.-Tracheæ of Insect, showirg the Spiral Fibre. the entrance not of water, but of air ; they are seen at their simplest in Peripatus, where they are distributed over the whole of the body. The tracheal orifice leads into a pit, which traverses the dermis, and widens out at its inner end; from this the trachere arise as minute tubes, which rarely branch, and only have a faint indication of the presence of the spiral fibre, which, in higher Tracheates, gives so 
characteristic an appearance to these tubes (Fig. 93). These tachea are distributed to all parts of the body, running alongside the nerves and entering with them into the central nervous system; they are particularly well developed in the head.

In the higher forms the tracheal orifices, which are definitely known as stignanata, are not distributed over the whole body; they would appear to have been primitively arranged by pairs in each metamere, and in some Myriopods that condition is essentially retained. As the stigmata diminish in number, the tracheæ tend to branch, and in some Myriopods (such as Iulus) they unite with one another and form tracheal anastomoses of much the same kind as those found among Hexapod insects; in the higher members of the last-mentioned group the stigmata are reduced to two or three pairs, but, thanks to the anastomosing branches, all the parts of the body are still well supplied with air vessels, the thinnest and finest of which are without the spiral fibre. Just as in Birds (see page 239), we find that in flying insects the air passages or tracheal tubes often pass into swellings or enlargements, the so-called tracheal vesicles; these may be small and numerous as in some Coleoptera, or larger and less numerous as in butterflies and bees, or reduced to two, which are, as in the fly, of enormous size, and abdominal in position. The stignna or spiracle, by which the air enters, varies considerably in form and structure, and the same is true of the apparatus by which it can be closed. Little is known with certainty as to the mechanism of the respiratory movements of insects, but the high temperature of the bee-hive, and the activity of such restless creatures as the house-fly, speak clearly enough of a large amount of oxydation, and of waste of tissue ; in direct relation to the activity of the cellular organism is the amount of oxygen which it requires. It 
has been observed by Lowne that the blowfly makes vigorous movements with its legs from sixteen to thirty times a minute, and he judges that these are respiratory movements from the consideration that, as the valves of the anterior spiracles are closed for a short time, the air must be necessarily driven through the small tubes; these movements are accompanied by a contraction and a dilatation of the abdomen. If placed under an exhausted receiver of an air-pump and removed before death ensues, the refilling of the tracheal system is observed to be accompanied by violent movements of the legs and wings, so that here, as in the crayfish (see page 225) and elsewhere, the activity of the locomotor organs is seen to be in direct relation with an increased supply of oxygen. In the larva of some Insects the tracheal system is completely closed, or, in other words, there are tracheal tubes but no stigmata; in these cases the tubes are either placed not far from the surface of the body, when the respiration may be said to be vague, or the trachea form out-growths (the socalled tracheal gills) which project into the water (e.g. Culicilæe), and offer the exact converse of what is the essential point in tracheal respiration; in it the air comes to the organs by internal tubes, in such larvæ tubes go to the water in order to obtain the oxygen.

We may appropriately pass from these external tracheal tubes to the form of respiratory organ in which there is an out-pushing of the body wall to form a so-called external gill. Physiologically this condition is preceded by what obtains in the Starfish, where the respiration is said to be vague; from among the spaces left between the ossicles of the dorsal surface (Fig. 23) there project thin membranous out-pushings of the lining of the body cavity, and the fluid within is thus only separated from the 
oxygenated sea-water by a thin wall of membrane through which oxygen passes inwards, and carbonic acid outwards. In the Ophiuroidea, where the calcareous skeleton consists of continuous plates, a slit is to be seen on either side of the insertion of each arm into the disc; these so-called genital slits or bursal clefts, as they are more appropriately named by Ludwig, lead into membranous sacs (bursæ) into which sea-water is sucked, and from which it is again driven out; the thin walls of these sacs project into the body cavity, and here again the oxygenated sea-water is separated from the contents of the cœlom by nothing more than a thin wall. In the Echinoidea, where the test is, again, continuous, the membranous sacs are either internal as in Cidaris, where they lie at the apex of the lantern of Aristotle, or they form five pairs of sacculated projections which protrude from the five pairs of slits in the margin of the mouth. In some Echinoids the tube feet, or ambulacral suckers, take on a respiratory function. In the Holothuroidea, the respiratory organs, when specially developed, are connected with the intestinal tract. (See page 229.)

A simple condition of external gill obtains in some of the Polychatous Annelids, where, however, they are by no means always developed. In Nereis, for example, they are simple, short filaments ; in Cirratulus the filaments are simple, but are produced to an extraordinary length; in others, as the lug-worm (Arenicola), they are comparatively short but are elaborately branched (Fig. 94); in the tube-dwellers they are confined to the anterior end, where they form a pair of " respiratory plumes." In all cases these gills consist essentially of a thin wall, the epithelium of which is ciliated, and within which are bloodvessels more or less well developed. In the plumes of the Tubicolae supporting cartilages are not rarely 
developed. The mechanism of these gills is simple enough; projecting into the water they are moved about in it, and minor currents are produced around them by the action of the cilia which cover their surface.

A very simple type of gill is found in some of the Lamellibranchiata, where the Ctenidium (see page 79) consists essentially of two rows of hollow filamentar processes of the body wall extended along either side of the foot, and ciliated externally; these are the gill filaments; each filament, at its free end, bends upwards in such a way as to leave a space between the ascending and descending portions; the free end of the ascending portion of the outer filament may either be free, as in the sea-mussel (Mytilus), or become attached to the mantle as in the fresh - water mussel (Anodon); it is plain, then, that its as. cending lies externally to its des cending portion; the

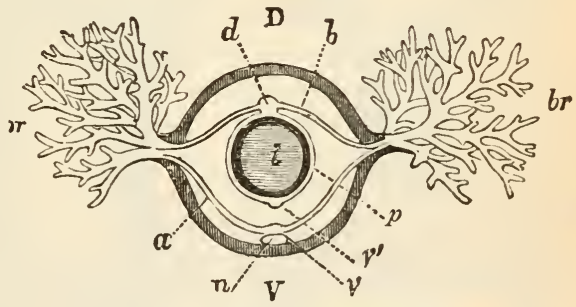

Fig. 94.-Transverse Section of Avenicola.

D. Dorsal ; $v$, ventral side; $n$, ganglionic chain ; $i$, intestine ; $b r$, gills; $v$, ventral vessel; $d$, dorsal ; $v$, visceral vessel : $p$, vessel around intestine; $a, b$, vesscls of gills. (After Gegenbaur.)

inner gill filament has its ascending portion internal to the descending, and so it results that in transverse section the two gill filaments have the form of a $\mathbf{W}$, the median upper point of which represents the point where the two filaments are inserted (or arise from) the body wall. The ciliated epithelial cells are often particularly well developed at certain spots; the cilia of these "ciliated jumctions" interlock with those 
of a corresponding junction on a neighbouring filament (Fig. $95 ; \mathrm{A}$ ); and in this way the several filaments are connected

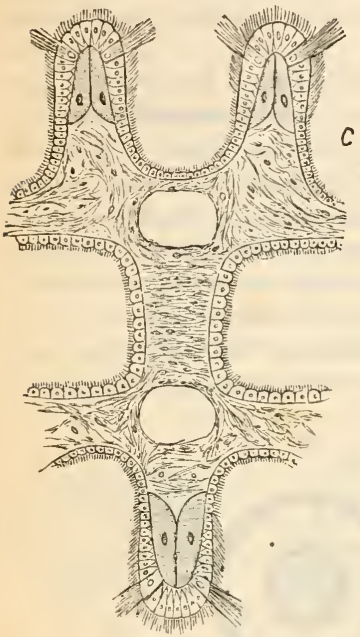
together. But the concrescence of the constituent parts of a gill does not end with the union of the neighbouring filaments, the ascending and descending portions likewise become connected with one another by interlamellar junc-
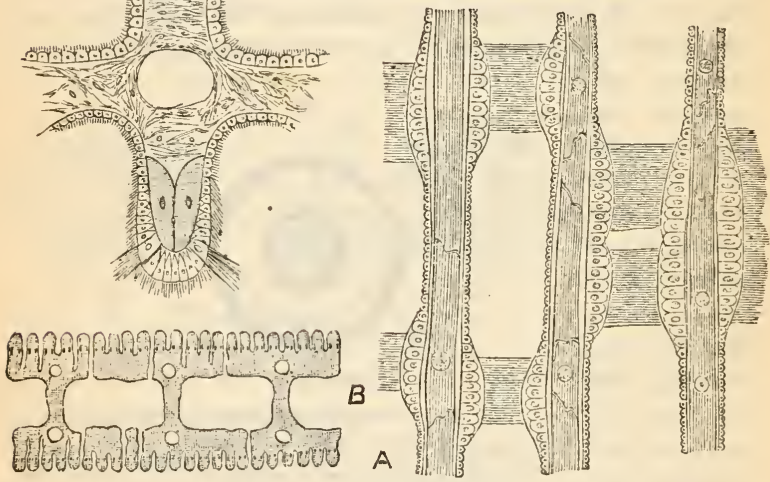

Fig. 95.-A, Part of three gill filaments of Arca, showing the large ciliated junctions; $\mathrm{B}$, transverse section of a portion of an outer gill plate, with solid interlamellar junctious and large vertical vessels of Anodon; c, a more highly magnified view of B. (After R. Holman Peck.)

tions (Fig. 95 ; в and c), and the bridges of union that were primitively ciliated become fibrous and solid, till at last we reach the continuous plate-like arrangements, which are channelled by spaces, or by definite vessels which lie outside the primitive blood-carrying hollow 
gill filaments, and which are now the means of passage for the circulatory medium. With this considerable alteration in structure there would seem to have come some change of function, and Peck is probably right in believing that the ciliated gill plates of the Lamellibranchs, by causing a constant current of water to pass over the animal, are as important aids to their nutrient as to their respiratory processes. The spaces between the gill filaments are sometimes used as incubatory pouches, in which the Glochidia, or young of the fresh-water mussel, lie during the early days of their development.

The branchial outgrowths (ctenidia) of the Cephalophora are, on the whole, simpler in structure than in the more highly developed members of the Lamellibranchiate group ; in most of the lowest forms they are arranged in a circle, as in Neomenia, where there is an oblong circlet of thirty filifor'm tubules, the Chiton, or the limpet; in Haliotis and others they are distinctly bilateral, and in the Anisobranchiata the left gill is, owing to the torsion of the body, much smaller than the right; in others, as the Heteropoda, the left gill disappears altogether, and in some the right gill has only one lamella developed; this is the so-called semi-pinnate gill. In other Gastropods, such as Lymnæus, or Helix, the gills disappear altogether, and a so-called lung is developed. (SBe page 228.) In a number of naked Pteropoda respiration becomes vague by a process of adaptative degeneration; or, in other words, the whole surface of the body takes on the function of the lost gills. Among the Cephalopoda the Tetrabranchiata (Nautilus) have two pairs, and the Dibranchiata (Octopus, Loligo) one pair of well-developed gills.

In the great majority of cases the gills of the Mollusca are covered in by the mantle, and come, therefore, to lie in a branchial chamber; into 
this chamber the air is, under the simplest conditions, drawn in by the action of the cilia which cover the surface of the gills or gill plates; in the Anodon, for example, the currents of water enter into the lower part of the chamber, which in the hinder region of the body is separated from the upper by the union of the gill plates of either side along the middle line; the water that enters by this lower inhalent passage passes out by the upper or exhalent one. In a number of Lamellibranchs the mantle which bounds these orifices is produced into a more or less long siphon; these siphons are best developed in forms that burrow in the sand, and which have the siphons directed upwards. A similar kind of gill chamber is formed in many Gastropods by the folding over of the mantle, and in a number of flesh-eating forms a pair of siphons are also developed. The absence of the mantle-fold in such forms as the Nudibranchs leads us, physiologically, to the vague respiration of the gynmosomatous Pteropoda, where the gills have become atrophied.

The most characteristic organ of the true Cephalopoda is the so-called funnel, which is a modification of part of the foot; in these highly developed molluscs we have again an example of the relation of the respiratory to the locomotor activity of the animal. When the muscles in the walls of the investing mantle relax they allow water to enter into the gill chamber on either side of this funnel; when they contract they not only press on the water in the cavity, but also close the orifices by which it entered; the only passage, then, by which the compressed fluid can escape to the exterior is by way of the funnel, the walls of which, by contracting, aid in the expulsion of the water; and the final result of this expulsion is, that, unless the Cephalopod is resting on the ground it is driven backwards ; the more often then, water is 
taken in and driven out, the more often is the animal mechanically helped on its course.

In no group are gills better or more characteristically developed than in Crustacea, and in none do we find better evidence of the association of locomotor with respiratory activity. sentatives of the group number of the appendages are nothing more than broadened thin plates within which the blood circulates, and outside of which is the oxygenated water in which they are batlied (Fig. 96).

In Squilla and its allies branched tufts of gill filaments are attached to the abdominal feet.

In the Decapoda, such as the crayfish or the lobster, the Among the lowest repre(the Branchiopoda) a

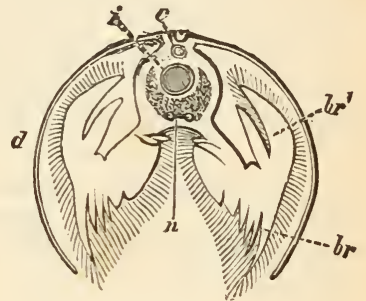

Fig. 96.-Transverse Section of a Branchiopod, showing the leaf-like (phyllopod) gills $\left(b r^{\prime}\right)$, which are appendages of the body.

$c$, Heart ; $i$, intestine $; n$, ventral nerrccord ; $d$, fold of the iutegument. (After Grube.)

gills are outgrowths of the sides of the body wall, but their relation to the locomotor function is still well marked; in this group the gills are placed in a gill chamber, which, as it is formed by lateral folds of the dorsal integument, reminds us, so far, of the simpler arrangements of the Branchiopod (Fig. 96; $d$ ); these gills are set in three sets, the lowest of which are (in the nomenclature of Huxley) podobramchs, for they are attached to the basal joints of the appendages (in the crayfish from the second maxilliped to the penultimate thoracic appendage); the next set, which are arranged in two rows, are called the arthobranchs, from the fact that they are attached 
to the membranous piece which connects the basal joints of the appendages with the walls of the thorax; the third and uppermost set consists of pleurobranchs, so-called from their attachment to the sides of the thorax. Among different members of the group we find a difference in the number of these gills, and here, as elsewhere, in scientific investigations, much time is saved, and intellectual operations considerably aided, by the use of formulæ. The following table, taken from Huxley, may be regarded as a type which is to be followed out when making the dissection of any one of the higher crustacea.

\section{Hypothetically Complete Branchial Formula.}

Somites and their appen-
dages.

$\begin{array}{cccr}\text { VII.* } & 1 & 1 & 1 \\ \text { VIII. } & 1 & 1 & 1 \\ \text { IX. } & 1 & 1 & 1 \\ \text { X. } & 1 & 1 & 1 \\ \text { XI. } & 1 & 1 & 1 \\ \text { XII. } & 1 & 1 & 1 \\ \text { XIII. } & 1 & 1 & 1 \\ \text { XIV. } & 1 & 1\end{array}$

Artholuranchs. Podobranchs. Anterior. Posterior. Pleurohranchs.

All these gills have essentially the same structure; they consist of an elongated stem, within which run two distinct canals, into one of which the blood passes from the body, and by the other of which it returns on its way to the heart; connected with these canals are a number of comparatively short hollow filaments with thin walls; the blood, therefore, on passing into them, is separated only by a thin membrane from the oxygenated water that is passing through the gill chamber, and an exchange of carbonic acid and

* There are many reasons for beginning to count the segments one farther back, and to call vi. what Prof. Huxley calls vii. 
oxygen is, consequently, easily effected. The podobranchs and pleurobranchs are more elaborately constituted than the simpler arthrobranchs.

When we remember the well-known fact that the Crustacea are altogether devoid of cilia, we find it at first difficult to understand how water is driven through the gill chamber; we have only, however, to make the experiment to see that a current of water does constantly enter at its hinder and pass out at the anterior end. The apparatus by which this current is produced is, again, a modification of one of the appendages for the exopodite and epipodite of the second maxilla (page 123) of either side is converted into a scoopshaped plate, the cavity of which is directed forwards, and which itself fits into the anterior orifice of the gill chamber; this so-called scaphognathite moves backwards and forwards about 200 times a minute, and with each backward and forward movement it scoops out water at the anterior, and causes a fresh supply of water to enter at the hinder end of the animal; moreover, the quicker the animal moves, the quicker the action of the scaphognathite, and, in consequence, the larger the inflow of oxygenated water. Within the gill chamber the waving plumes of the gills aid in the movement of the water, and the attachment of the podobranchs to the ambulatory (thoracic) and hinder mandibular appendages affords a certainty that the more these appendages work the greater will be the supply of oxygen that they will receiive.

A few Crustacea are modified to breathe air. (See below.)

Among the Arachnida, processes of the body projecting into the water are found in the only members of the group that are inhabitants of the sea; these are the King crabs, represented to-day by $\mathrm{Li}$ mulus. In these forms there is no protecting gill $\mathrm{P}-16$ 
chamber, and the gills project freely into the water, as in the lower Crustacea; they are attached to the five pairs of abdominal feet, and are broad, flattened, and provided with a number of secondary plates. These gills are essentially formed by a hard supporting axis, on which are placed some hundred and fifty flattened lamellæ (Fig. 97); these lamellæ are exposed to the surrounding water, and as they are hollow, and their cavities contain blood, we have only further to know that their walls are delicate to understand how it is that these "gill-books" are respiratory organs. Connected with these gills are the so-called "Iumgbooks" of the scorpion, which are adapted for aerial respiration, and the exact characters of which have been very carefully and ingeniously elucidated by Lankester. In that Arachnid the ninth to the twelfth segments bear appendages which are respiratory in function, the appendages of the eighth segment, or the first which is branchial in Limulus, being more especially modified as the so-called "pectines." These respiratory appendages, or "lung-books," are, like the "gill-books" of the king-crab, formed essentially by a hard supporting axis, and a number of lamellæ set on that axis (Fig. 97, B ; and in greater detail c); but they differ, at first sight, altogether from those of the king-crab in being no longer exposed freely, but placed in recesses, which open to the exterior by a narrow slit. This slit gives entrance not to blood but to air, and, as it communicates with the cavities in the lamellie of the lung-book, we expect to find that these do not, as in Limulus, any longer serve as blood passages ; the blood, indeed, is now found in the sac which invests the lung-book. Great as are the structural changes, the ultimate physiological arrangemient is the same as before; in other words, the lung-books no less than the gill-books are respiratory organs, but, instead of carrying the blood to the oxygen, they carry 
the oxygen to the blood. Among the Arachnida, the remarkable series of changes so far followed does not
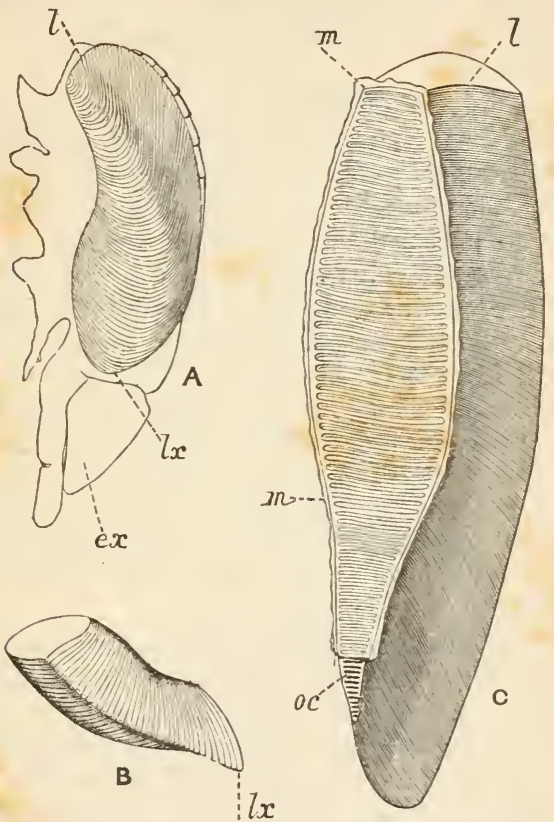

Fig. 97.-A. View of the lower Margin of the right lamelliferous Appendages of the eleventh segment of Limulus polyphemus.

A. $l$, Proximal lamella; $l x$, one hundred and fiftieth lamella ; $e x$, external lapjet of the bifid distal prolongation of the apluendages.

B. A similar view of the corresponding appendage of Buthus kochi. $l x$, One hundred and thirtieth lamella ;

c. A semi-diagramatic view of one of the respiratory Appendages of a Scorpion, to show

$l$, The bases of the lamellæ exposed by the removal of the integument of the axis, the remnants of which are seen at $m: o c$, the projecting portion of axis: $l$, proximal lamella. (After E. Pay Lankester.)

end with the scorpion; some, like Mygale, have but two pairs of lung-books, and other spiders have but 
one. In others, like the mites, there are no specialised respiratory organs, but a "vague respiration;" and, lastly, others, such as the pseudo-scorpions (Chelifer), have replaced the lung-books by true tracheal tubes.

A number of Mollusea have, like the common snail, replaced an aquatic method of respiration by one that is aerial ; this is effected by the large distribution of blood-vessels to a part of the mantle, which becomes so attached to the sides of the body as to leave only a comparatively small orifice by which air can enter; the moditied mantle chamber is called the "Iung." This arrangement is not separated by ary wide gulf from that which is found in the branchiate Gastropoda, for some of these have the walls of the mantle cavity more or less well provided with a lung; and others, like the marsh-snail (Paludina), have both gill and lung. On the other hand, the water-snail (Lymnæus) has no gill at all, yet constantly lives in water, and uses its air receptacle, as do some fishes (page 232), as a hydrostatic organ.

In some cases, as Semper has pointed out, certain Mollusca may be truly spoken of as amphibious; Ampullaria, an ally of Paludina, has been observed by him to use its gills and lungs in rapid alternation; "for a certain time they inhale the air at the surface of the water, forming a hollow tube by incurving the margin of the mantle, so that the hollow surface is enclosed against the water, and open only at the top. When they have thus sucked in a sufficient quantity of air, they reverse the margin of the mantle, opening the tube, into which the water streams. The changes are tolerably frequent, once or twice in a few minutes, depending, probably, on the temperature. No physiological explanation of these rhythmic alterations can, however, be at present assigned."

It is not only among the Mollusca that we have 
air-breathing forms closely allied to those that breathe oxygen dissolved in water; not only are there true amphipnous Vertebrates (see page 236), but there are among the Crustacea some terrestrial Isopods, in which some of the appendages are placed in a cavity of the abdomen, which is partly closed; the cavity of such of these appendages as are not rudimentary opens to the atmosphere by a longitudinal slit. Among the true crabs there are also some forms that constantly live on land, such as the robber crab (Birgus latro), the land crab (Gecarcinus), and others; the gills in the branchial chamber of these Crustacea are always small, but a quantity of air is to be found in the chamber; in Birgus this chamber is divided into a lower and smaller one, which contains small gills, and an upper larger one, which never contains any water, but always air, and which has its walls not only richly supplied with blood-vessels, but also produced into branched outgrowths, or villi, in which the blood-vessels are particularly well developed.

It is not in the lower Metazoa alone that the lining of the alimentary canal serves as a means of entrance for oxygen; even among the Vertebrata, where, in the higher forms, the respiratory organs (lungs) are really outgrowths of the enteric tract, we know of a loach (Cobitis) which swallows air bubbles ; among the Echinoderms, the surface of the mucous membrane of part of the intestine is, in Stichopus variegatus, so grooved as to display a large amount of vascular surface to the action of the inflowing water, or, as in many (Holothuria, Cucumaria), special branched organs, which extend throughout the greater part of the length of the body, are developed from the walls of the cloaca; in such pneumonophorous holothurians water is pumped in and out by the muscles at the hinder end of the body. Such a form of anal 
respiration is not confined to the Echinodermata, for it is very common among the Arthropoda; among the Entomostraca it has been frequently observed; in Leptodora, when the intestine is free of food, the water appears to pass in a continuous stream into the more anterior parts of the tract, and, when the stomach is full, water is taken in and expelled by the mouth; anal respiration has been seen by Lereboullet in the crayfish, and the rhythmical closing and dilatation of the rectum may always be seen in that animal, after the extirpation of the thoracic ganglia.

Amọng Worms, enteric respiration obtains in the Rotatoria, in some, if not all, Gephyrea, and in some of the aquatic Oligochrta; Dentalium is the only molluse in which it has been definitely observed.

In certain polychrotous Annelids, a somewhat complex arrangement has been detected by Eisig, which is of especial interest, both morphologically and physiologically, when it is compared with the function and structure of the respiratory organs of Vertebrates. 'Theobservation that number' of air bubbles constantly escape from the mouth or anus of Hesione sicula led him to detect the presence of distinct outgrowths of the intestine, which clearly serve as air reservoirs, and at the same time may be used as floats or hydrostatic supports; they are especially of use when the intestine is filled with food, and structural evidence in favour of their respiratory significance is afforded by their rich supply of blood-vessels. In connection with this it is very interesting to note that a fish will use up all the air in its air bladder before it dies of suffocation, and that, conversely, in the pulmonate Vertebrata the lungs have undoubtedly the power of acting as hydrostatic supports for the body, when immersed in water.

The Chordata present us with the most interesting and instructive series of arrangements, for while 
the lowest members of all three divisions are branchiate, the higher Vertebrata pass from an amphibious or amphipnous stage to one in which outgrowths of the enteric tract, or lungs, are alone the respiratory organs. In the Cephalochordata and Urochordata respiration is always effected by gills, and there are some very striking points of agreement between the two sets of forms.

In both, the gill slits are formed by an ingrowth from without, and an outgrowth from within; in both it is the anterior portion of the enteric tract which is so affected, and in both the water of respiration enters by the same orifice as the food. In those Tunicata that retain the chordate tail throughout life (Appendicularia), the water that passes in at the mouth passes out by a cylindrical tube on either side; but, on the other hand, water may enter by these "spiracula" and pass out by the mouth.

In the rest, as also in Amphioxus, an outgrowth of the body wall on either side gives rise to the formation of a peribranchial chamber, into which the water streams from the gills; the folds which form the walls of this chamber unite along the greater part of their length, but leave an orifice (atriopore) by which the water can escape to the exterior. This atriopore may either open, as in Ascidia, close to the incurrent orifice or mouth, or it may be at the aboral end of the body, as in Pyrosoma; in compound ascidians there is a single common excurrent orifice. In some the water is forcibly driven out, and then, just as in Cephalopods, the excurrent stream aids in locomotion. In Amphioxus the atriopore is on the ventral surface, and not far in front of the anus.

The ancestors of the present race of Vertebrata were aquatic forms that breathed the oxygen which was dissolved in the water in which they dwelt; or in other words, they had gills. This mode of 
respiration, the branchial, is retained to-day by the lowest of the Vertebrata, and gills are to be found in all Fishes, in all Amphibia at some period of their lives, and in some Amphibia throughout the whole course of their existence. None of the Sauropsida or of the Mammalia ever breathe oxygen dissolved in water, but are air-breathing forms with lungs; though the change of function has been completed, the remnants of gill clefts are observable in the earlier stages of development.

A most instructive series of gradations is to be detected in Fishes; all adult forms have the gills in pouches or. recesses, but the young of some (Elasinobranchs, some Ganoids), like the tadpole at an early stage, have protruding filaments or exterual gills; the lampreys have seven pairs of gill-clefts, as has the shark Heptanchus; Hexanchus, and most examples of Myxine, have six; most Elasmobranchs, five pairs; Chimæra has the first and fifth gill incomplete; most Teleosteans have four pairs of gills, but some have the fourth incomplete; the arigler (Lophius) has three pairs of gills, its ally Malthe has the third incomplete, while in Amphipnous all the three pairs of gills are more or less rudimentary.

Where gill respiration ceases to be effective, the blind outgrowth from the anterior portion of the intestine (the air bladder) may take on respiratory functions; Ania has a single sac lying on the dorsal surface of the intestine; in Lepidosteus (the gar-pike), the sac is divided internally, though it is single externally; in Ceratodus the opening into the single sac lies to the left of the ventral surface of the intestine, while in Polypterus the sac is double, and opens on the middle line of the ventral surface. As the air bladder becomes better developed, it becomes better supplied with blood. (See page 202.)

In the cyclostomatous Bdellostoma the ducts from 
the gill sacs open separately to the exterior, but in the hag the ducts unite and open by a common orifice on either side. A similar modification obtains in the gnathostomatous fishes, for in the shark-like elasmobranchs (sharks and rays) each gill cleft is open to the exterior, while in Chimæra and all other Fishes the clefts are covered over either by a fold of the skin merely, or by bony pieces (opercuIum), so that there is on either side but a single opening to the exterior.

The gills, when complete, consist of two folds of mucous membrane, which are ordinarily triangular in shape (Fig. 98), are supported by a branchial arch (b), and by cartilaginous rods, have a blood-vessel passing into them and bringing blood from the heart, which breaks up into capillaries; these capillaries unite into another ressel which carries the oxygenated blood back to the body. A gill is said to be incomplete when one of the two folds is alone developed.

In the Cyclostomata and the shark. like Elasmobranchs, the gills take the form of pouches, and the lamellæe form the transverse folds on the walls of the pouch; the septa which project from the branchial arches are as long as the gills, and each gill

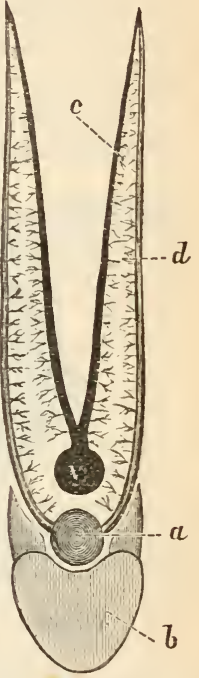

Fig. $98 .-$ Gill of Perch, to show the form of the gills and the arrangement of the blood-vessels.

a, Branchial artery ; $b$, branchial arch (seen in cross section); $c$, branches of the branchial vein $v ; d$, branches of branchial artery. chamber is, therefore, in a shark, completely separated from the one in front or behind it; as we pass through Chimæra and the Ganoids to the Teleostei, we find that these septa become more and more reduced, so that 
the gill is attached at its base only (Fig. 98), and the gill lamellie are free. With the disappearance of the septa we have, of course, the loss of the separate gill slits, and the whole of the gills of one side come to lie in a common chamber, which is covered over by the operculum, and has only one opening to the exterior.

The water which brings the necessary oxygen to the gills enters by the mouth; as the mouth opens

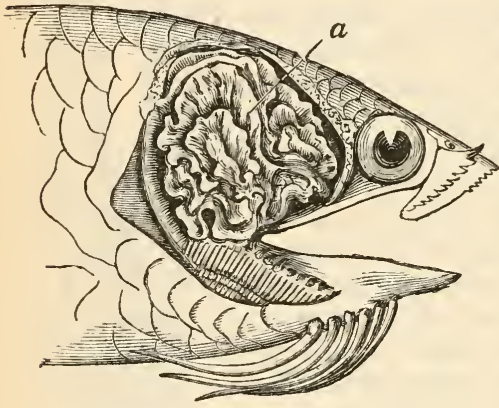

Fig. 99. -Suprabranchial organ of Anabas scandens.

$a$, Suprabranchial organ.

the opereulum rises, and the gills separate from one another, but the membrane which fringes the operculum acts as a valve to prevent the entrance of water through the opercular cleft (Bert). When the mouth closes, and the pharynx contracts, the water is forced through the pharyngeal clefts into the gill clefts owing to the presence of a valvular arrangement which shuts off the passage into the mouth.

In the already mentioned Amphipnous and in Saccobranchus, the true gills are rudimentary, and a sac with contractile walls is developed, which takes in water and expels it at intervals ; the walls of these sacs are richly supplied with blood-vessels, which are arranged as in a gill; that is to say, the blood that passes from them goes direct to the aorta; in the climbing perch (Anabas), the internal surface of the 
accessory sac is produced into a number of convoluted folds (Fig. 99), which retain their moisture, and are able to take up oxygen direct from the air, during the comparatively long periods that the fish lives out of the water. Its ally Ophiocephalus, Cobitis, and various fishes with spongy air-bladders, such as Sudis and Erythrinus, swallow air directly; so that it is not among the Dipnoi only that oxygen dissolved in nitrogen (atmospheric air), is used for the necessary oxydation of the tissues of fishes.

It is, however, in certain Ganoids and in the Dipnoi that we get the most certain proofs of aerial respiration; Lepidosteus has been observed to protrude its head from the water, to emit a bubble of air, and to make a swallowing movement, and a similar phenomenon lias been seen in Amia (B. G. Wilder); the noise made by Ceratodus is explained as being due to the swallowing of air, and the streams of Australia in which it lives are known to become liquid mud in the dry seasons of the year. Protopterus has been brought from West Africa to this country embedded in the mud balls in which it lives during the droughts, and has been revived by being placed in warm water.

Fishes differ considerably in the extent to which they are able to live on land; thus, an eel will live much longer than a gudgeon when taken out of the water. The careful experiments of Bert show that this difference is due not to a difference in gill arrangement, but to a difference in the demand made by the tissues of the body for their supply of oxygen. Here, again, we have an example of the danger of arguing from anatomical peculiarities where our hypotheses are not controlled by experiments. In any discussion of respiratory phenomena in animals it is necessary to bear in mind the fact that all living tissues are capable of absorbing oxygen, and that 
the tissues of different animals differ in the amount they require.

We may be especially convinced of the truth of this dictum of Bert's by the study of the respiratory arrangements of the Amphibia. If an adult frog is placed in a dry atmosphere it speedily dies ; in other words, respiration in a frog is cutaneous as well as pulmonary, and a frog may be deprived of its lungs and continue to live ; so, again, the axolotl may have both gills and lungs removed and yet continue to live. But if these experiments are made in summer death soon supervenes; in other words, the skin becomes more dry owing to the larger amount of moisture which can be taken up by an equal volume of warmer air, and is unable to take up enough oxygen to suffice for the needs of the organism.

In all Amphibia the gills are at first external, or project, under valious forms, from the sides of the body; there are ordinarily three pairs present, which are placed one above the other; among the Urodela, Menobranchus (Fig. 100) and Proteus appear to retain the gills throughout life; in Menopoma and Amphiuma the gills disappear, but one or two gill clefts per'sist; in the rest of the Urodela the gills disappear completely. In the Anura the external are soon replaced by internal gills, which, on the cessation of the tadpole stage, disappear, and the clefts, which had been covered by an opercular membrane, close up entirely. The bell-shaped gills of Notodelphys lead to the branchial vesicles which have been found in the Caeciliae (Peters).

In addition to or in place of the gills, all Amphibia have a paired outgrowth from the esophagus, which lies on the ventral surface, and is provided with special blood-vessels coming directly from and returning at once to the heart.

These outgrowths are known as the lungs, and 


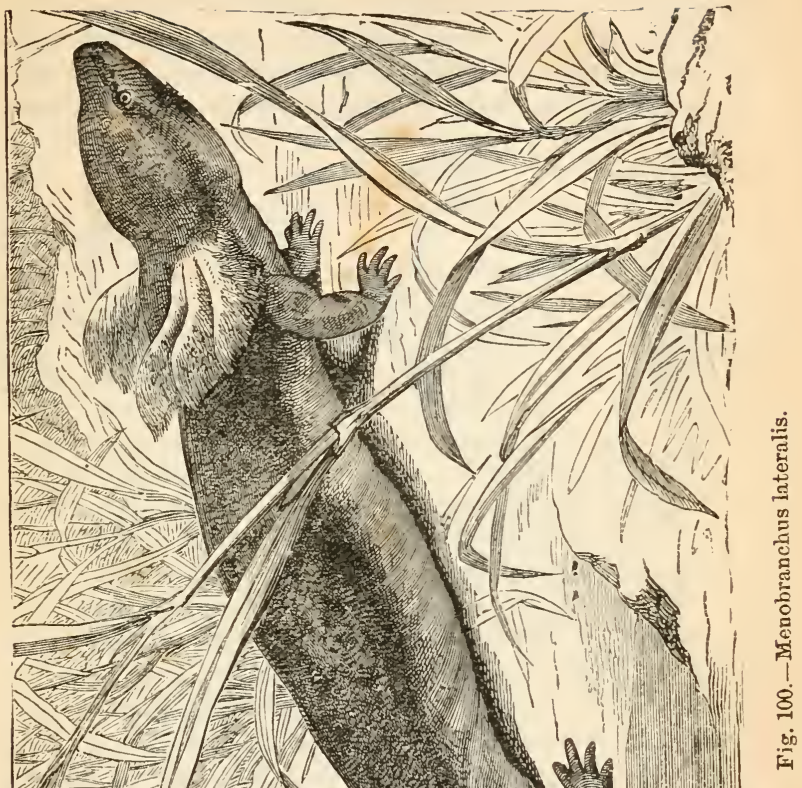


they seem to be the direct descendants of the swimbladder of fishes, which we have already traced from its position as a dorsal sac in A mia and Lepidosteus to a completely divided ventral sac in Protopterus.

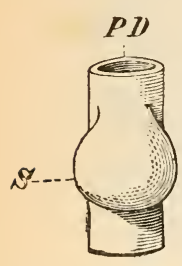

A

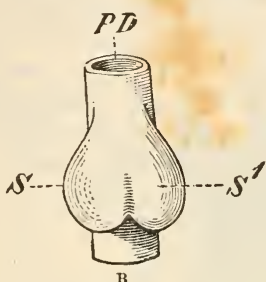

B

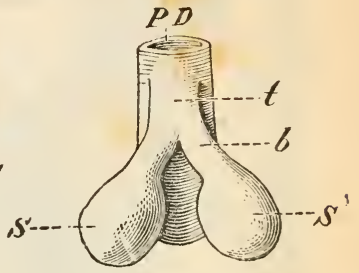

C

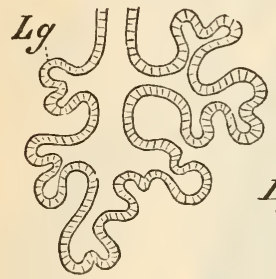

D

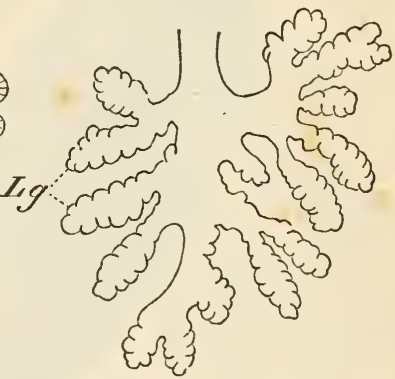

$\mathrm{E}$

Fig. 101.-Diagrams to illustrate the Development of the Lungs.

$\mathrm{PD}$, Prinitive intestine; $\mathrm{ss}^{\prime}$, lung sacs; $t$, trachea; $b$, bronchus (in $\mathrm{A}, \mathrm{B}$, and c) : $\mathbf{L} g$ (in $\mathrm{D}$ ), primitive; $\mathrm{L} g$ (in $\mathrm{E}$ ), secondary pulmonary vesicles. (After Wiedersheim.)

Comparable with these changes in the coarser details of its anatomy are the modifications suffered by its internal surface, which becomes more and more spongy and broken up into internal spaces; and the changes which bring its blood-vessels into direct relation with the heart. (See page 203.)

A similar set of changes affects the lungs, either as we trace them through the ascending scale of the 
pentadactyle Vertebrata, or through the developmental stages of a given individual. The earliest rudiment of the lung is a single outgrowth (Fig. 101; A), which soon divides at its blind end (B), while the unpaired portion remains to form the tube (trachea) by which the two sacs communicate with the œsophagus; each swelling gives rise to primary (D), and these to secondary (E) vesicles.

This series of changes ceases at various points in various forms, so that the lungs are smooth within in Menobranchus, provided with a few simple ridges in Siren, and with secondary as well as primary ridges in Amphiuma. The internal network in which the blood-vessels course is still more elaborately developed in the frog, but the lungs are, when looked at from without, apparently nothing more than simple sacs.

The same is true of the lower Reptilia; but there is this important advance, that the bronchus, or tube which brings the air into the lungs, does not, as in the frog, cease at the opening into the lung, but is continued into it, and gives off branches within it; in some chamæleons narrow blind outgrowths proceed from the hinder end of the lung, and in Chelonians and Crocodiles the common lung-chamber opens into a number of pouch-like sacs. The lungs of the former, like those of birds, are firmly attached on eitler side of the vertebral column, and the dorsal surface is marked by grooves which correspond in position to those of the superjacent ribs.

The lungs of Birds, in addition to their greater internal complexity, are more particularly remarkable for being continued into a number of air sacs, whence prolongations are given off in the form of air tubes and passages, which extend through all the organs, including even the bones, of the body. These air sacs play a very important part in the economy of the bird, for they not only diminish its specific gravity, 
but also warm the air. It has been calculated by Bert that, in a bird weighing 1,600 grammes, and having a volume equal to 1,230 cubic centimetres, or, in other words, a specific gravity of $1 \cdot 3\left(\frac{1600}{1230}\right), 200$ cubic centimetres of air can be introduced; as these 200 cubic centimetres weigh 22 of a gramme, it is clear that the specific gravity of the animal will be reduced to $1 \cdot 12\left(\frac{1600+0 \cdot 22}{1230+200}\right.$ or $\left.\frac{1600 \cdot 22}{1430}\right) *$ Birds that fly high must often take into their lungs air at a very low temperature, but with this cold air there is commingled that which returns to the lungs from the warm viscera, and by this means the temperature of the respired air is raised; yet again, such cold air, or, still more, the air of a desert, is often of great dryness, while that which returns from the air sacs has been moistened by the walls of these outgrowths.

The maximum of complexity is attained by the lungs of the Mammalia, which, occupying a comparatively smaller space in the body, have nevertheless a much larger area of respiratory surface ; externally the lungs are frequently subdivided into two or more lobes. It has been calculated by Aeby that the human lung contains from three to forr millions of pulmonary vesicles, and that in man the respiratory mucous membrane has, in a period of repose, a superficial area of 79.28 square metres, which can be extended to more than half as much again, or $129 \cdot 84$ square metres; the extent of respiratory surface in the female is rather less than that of the male.

The air is brought into the lungs from the nasal passages by the trachea, and that tube, as we know, divides into two bronchi, which, in the Amniota, lation.

* I have corrected what appears to be an error in Bert's calcu- 
extend into the cavity of the lung. The bronchi are short indeed in lizards and snakes, but in crocodiles and chelonians they extend for some considerable distance, and retain the cartilaginous rings by means of which the tube is kept open; these tubes give off smaller lateral tubes, and so give rise to the so-called bronchial tree, some of the branches of which lie above and some below the pulmonary artery ( $p$; Fig. 102 A) ; these may be conveniently distinguished as tlie eparterial and hyparteria! bronchi.

While this bronchial tree is comparatively simple in Reptiles, it becomes much more complicated in Birds, where both eparterial and hyparterial systems are well developed and give off lateral branches, some of which extend to the end of the lung.

The difference between the bronchial tree of a Bird and a Mammal does not lie in, as is ordinarily said, the dichotomous mode of division of the bronchial tubes of the latter, which never does obtain (Aeby), but in the great reduction in the eparterial bronchial system (Fig. 102 B), of which the right and left halves are but rarely both present; as a rule, the right is lost, while in Hystrix both right and left eparterial bronchi disappear.

The trachea varies greatly in the extent and characters of its development ; short in Amphibians, it is of a considerable length in Reptiles, but in them the cartilaginous rings are incomplete; in Mammals the rings are also always incomplete, but in Birds the separate rings are not only complete, but tend to undergo calcification, and in some cases, as in the Dinornis, even ossification. The trachea is of great length in. birds, and while this may be often seen to be of significance as an aid to the vocal organ (see page 391), it has clearly the not unimportant function of forming a long tube in which the air is slightly warmed before it enters the lungs. In birds the lower, and in other 
Vertebrates the upper, part of the trachea may be converted into a vocal organ.

In the skulls of certain Vertebrates, such as the crocodile and the whale, certain modifications of the

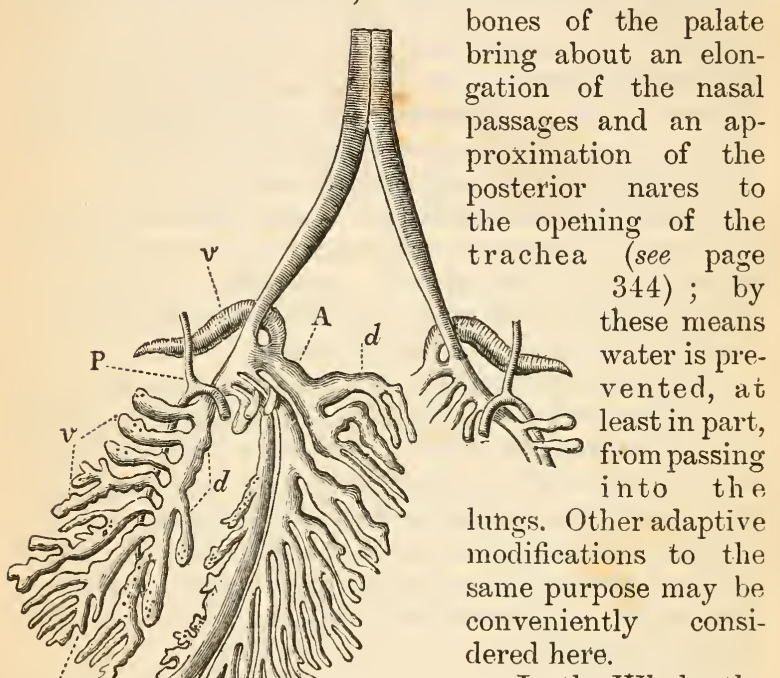

In the Whales the glottis, or opening into the trachea, is Fig. 102 A.-Bronchial Tree of a Bird.

P, Pulmonary artery ; A, elarterial; B, hyparterial bronchial systems; $v$, ventral ; $d$, dorsal branches.

embraced by its sides. By this means the trachea is brought into direct connection with the nasal passages, the air does not enter at all into the cavity of the mouth, and the water flows on either side into the gullet. A similar disposition of the glottis obtains in the young of the Marsupials, which, born at an 
age too early to allow them to actively suck the mother, hang on to a long nipple, and have the milk injected by the mother (by the contraction of the cremaster muscle, and the consequent compression of the mammary glands). Here, then, milk flows on either side of the air tube, and the latter is, as in the whale, a direct continuation of the air passages in the head. It is important to observe that there is no prolongation of the air tube in the Sirenia, but that their epiglottis is large, and capable of completely closing the entrance into the trachea; at the same time it will be remembered that the dugong and manatee are herbivorous.

So, again, the Sirenia differ from the Cetacea in the manner in which they obtain a large supply of air. In the former the diaphragm, in place of forming a more or less vertical par-

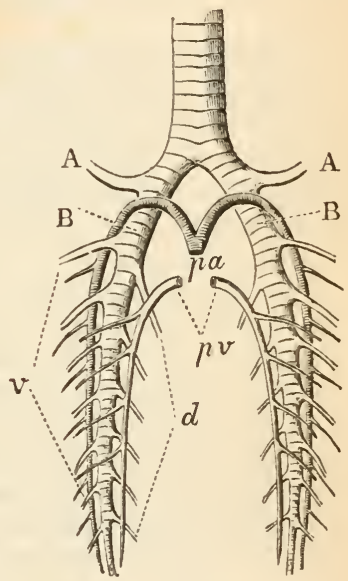

Fig. 102 B.-Brouchial Tree of a Mammal (Horse).

A, Eparterial : B, hyparterial ventral (v); (d) hyparterial dorsal bronchi $p a, p v$, pulmonary artery and vein. (After Aeby.) tition between the thoracic and abdominal cavities, slopes backwards and upwards, so as to largely increase the area of the thoracic cavity, the extension of which is occupied by the large lungs. In the dolphins and porpoises the nasal passages open into lateral sacs with elastic walls ; the possession of these sacs must, in addition to their air-containing function, diminish to a certain extent the specific gravity of the skull. The commonly received story that a whale "blows" water is due to the fact that a 
large quantity of warm air is rapidly expelled through the single spiracle (the homologue of the two external nares of other animals), or so-called "blow-hole," and that the moisture in this air condenses into water as it suddenly comes into a colder medium. A whale no more breathes water than does a man on a frosty day.

Pulmonary respiration, or the taking-in and the expulsion of air from the lungs, is effected in very various ways in different Vertebrates; the air tube being, as we know, ordinarily kept open by the cartilaginous or bony rings or supports which are found in its walls, it is clear that air may either be driven out or sucked in.

In the Dipnoi there is no cartilaginous trachea, and the air enters in and passes out by a longitudinal slit, the sides of which are separated from one another by the contraction of the muscle that surrounds it. In the Perennibranchiata there is no true trachea, but on either side of the slit there is a small cartilage with which a constrictor or a dilatator muscle is connected (Wiedersheim). In the rest of the Amphibia there is a true trachea of no great length, the opening into which is sometimes provicled with muscles, by means of which it can be enlarged or diminished in size. In the frog, whose physiology has been more fully studied, air is known to be forced into the lungs by the action of the muscles of the floor of the mouth; this apparatus, appropriately known as the buccal pump, acts in the following manner: the mouth is shut, and the floor of the mouth depressed by the contraction of the muscles connected therewith; the vacuum so formed is filled by the entrance of air through the nostrils and nasal passages; the nostrils are then closed, and the entrance to the gullet barred, while the floor of the mouth rises on the contraction of the muscles connected with the hyoid; the entrance 
to the air tube is widened by the contraction of the dilatator muscles, and the compressed air, finding there its only means of exit, enters the passage to the lungs. By the elasticity of the walls of the lungs themselves, and by the contraction of their muscles and those of the body wall, the air that has thus entered is soon afterwards driven out.

In the Chelonia, which, in accordance with their sluggish habits, execute respiratory movements only three times a minute (Bert), the thorax is dilated by a special inspiratory muscle, and the limbs only take part in the action when inspiration and expiration succeed one another with more than an ordinary rapidity. In the Ophidia the cavity of the thorax is increased by the movements of the ribs, and as these are also the locomotor organs of snakes, we have here again an example of the relation between respiratory and locomotor activity. In Lizards and Crocodiles, where the belly ordinarily touches the ground, the thorax is extended transversely much mole than from above downwards, for in all Amniota the enlargement of the cavity is effected by the movements of the ribs. The expulsion of the air is brought about by the contractility of the walls of the lungs.

In Birds the lungs are fixed to the back and sides of the thorax, the extension of which, in the movements of expiration, is much greater in the vertical than in the transverse direction. An inspection of the skeleton of a bird (Fig. 135) will show that the ribs connected with the spinal column are set at an angle to those which are connected with the sternum; on the contraction of the inspiratory muscles this angle becomes more open, the sternum is more widely separated from the back, and the thoracic region is increased in extent; there is, at the same time, a certain amount of transverse extension. When the thorax enlarges air is drawn in from the air sacs as 
well as from the outer world; and when the thorax contracts, in the act of expiration, air is driven into the air sacs as well as through the trachea outwards.

In MIammals the movements of the ribs are greatly aided by the flattening out, or curving upwards, of the diaphragm, or muscular partition which separates the thoracic from the abdominal portion of the body cavity. The respiratory movements of mammals have been fully studied in Man. (See "Human Physiology," chap. v.)

Bert has collected a large number of statistics with regard to the number of respiratory movements executed per minute by various animals. From this we learn that, on the whole, they are more numerous in Mammals than in Birds. A rat, for example, has been seen to make 320 movements a minute, while the canary gives the highest (100) number for birds. Rodents generally respire frequently; the dog and ox 15 times, the lion and horse 10 , and a hippopotamus was on one occasion observed to breathe only once in a minute; some large birds, such as the marabou, pelican, or condor, only 4 to 6 times a minute; a Crotalus 5 times, a lizard 12. An active sea-lamprey gave a number of 120 ; rays and dog-fishes from 40 to 50 , Limulus 12 , while Cephalopods varied between 14 and 65 times a minute. On the whole, carnivorous breathe less frequently than herbivorous forms, and both than rodents; smaller forms more frequently than larger members of the same group, and active more often than sluggish species. It is, however, to be carefully observed that these number's give us no information as to the quantity of air taken in, nor as to the number of times in which the heart was beating per minute. 


\section{CHAPTER VII.}

\section{ORGANS OF NITROGENOUS EXCRETION.}

VERY much doubt hangs over the function of the organs which are said to have a renal function in the lower animals, owing to the great discrepancies between the results attained to by those who have investigated the excreta of, or concretions in, these organs, and the very great difficulties which lie in the way of such chemical inquiries.

Nothing can be certainly said as to the renal organs of the Protozoa, if we may use the term renal organs in a general way, as applying to such parts of the organism as purify the body of its nitrogenous waste; this, however, is certain, that in the course of the molecular activity of a mass of protoplasm, nitrogenous products are formed which are in the nature of waste products, and which are injurious to the organism if not speedily removed from it. We know that in most Protozoa there are one or more spaces which, expanding, take up, and, contracting, drive out, water. Knowing, as we do, from our own experience, the value of water as a diuretic agent, it seems almost justifiable to suppose that, while this water has no doubt a respiratory function in the Protozoa, it acts also as an agent for removing waste. The supposition that the office of the contractile vesicle is to drive fluid out of the body is supported by the discovery of Vorticellids, in which the contractile vesicle is connected by a canal with the "vestibule" which lies beneath the mouth opening; on the contraction of the vesicle the contained water passes into the mouth-opening, and so, of course, makes its way 
to the exterior. In the same manner we may suppose that in the Sponges, which certainly do get rid of nitrogenous waste, the currents of water that pass through the canals of the body wall carry away with them waste nitrogenous formations; but here, as in the Protozoa, experimental evidence is still wanting. We are hardly better off for information as concerns the Coelenterata or the Echinodermata. Of the former class, indeed, the mesenterial filaments of Actiniæ, and a whitish layer on the lower side of the umbrella of Porpita, have been stated to contain guanin, which is a waste nitrogenous product; and the same compound has been said to be found in the rectal cæca of the starfish, and in the Cuvierian organs of certain holothurians; as to the last, however, it is doubtful whether the true Cuvierian organs were really examined, and, as to their function, the great balance of evidence is in favour of their being rather offensive than excretory organs.

In the Vermes we have the advantage of being able to detect organs which, by their position, relations, and homologies, afford considerable support to the view that they have a renal function. It will be most convenient to first examine the so-called segmental or kidney-like organs (Heplnidia) of so well developed a form as the earthworm.

In all but the first segment of the body we find on the ventral surface and on either side of the middie line, a convoluted tube, which opens by a funnelshaped orifice into the body cavity, penetrates the membranous wall which separates one segment from the next succeeding, and in the latter opens to the exterior by a small pore. The ciliated funnelshaped opening, and the thinner-walled portion of the coiled duct, may be looked upon as the receiving portion of the organ ; the true excretory activity is, no doubt, limited to the part where the walls are 
glandular, and these glands, we may suppose, act on the contents of the blood-vessels which are richly distributed to the nephridium. The terminal and wider portion, the walls of which are muscular, may be looked upon as analogous to a ureter.

Bearing in mind that we have in the earthworm to do with a form in which metameric segmentation is most markedly expressed, and that this metamerism has clearly affected the nephridia, we are prepared to find a very much simpler condition of things among the Platylelmintles, and, at the same time, to find an arrangement which is more diffused. In Monocœlis (Fig. 104), for example, there is a plexus of fine canals, which communicate, on the one side, with large principal canals, of which there are two pairs, one external and one internal, and on the other with funnel-shaped processes, the entrance to which is guarded by a long cilium; the principal canals are connected with one another by anastomosing branches. In the Den-

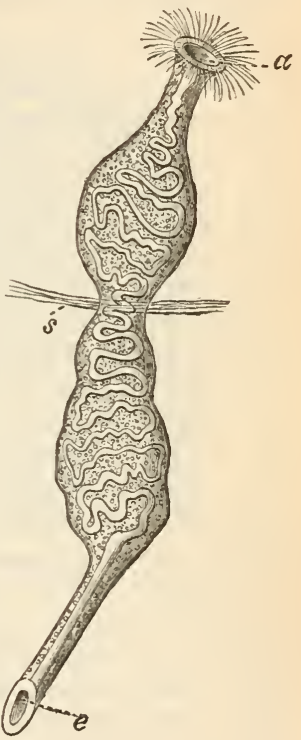

Fig. 103.-A single Nephridium of Anachata.

$a$, Internal orifice, funnelshaped and surrounded by cilia. It opens into one segment, passes through the septum (s) into the next segment, and opens to the exterior by $e$, external oriflee. (After Vejdorsky.)

drocala, as represented by

Polycœlis, the fine canals appear to be absent.

If we take the liver fluke as a type of the Frematoda, we again find that the system of excretory ressels is diffused throughout the whole 
body; the finest ducts are distributed through all parts of the organism, and they pass into collecting vessels, which, by the formation of anastomoses, give rise to a most complicated plexus; from these arise

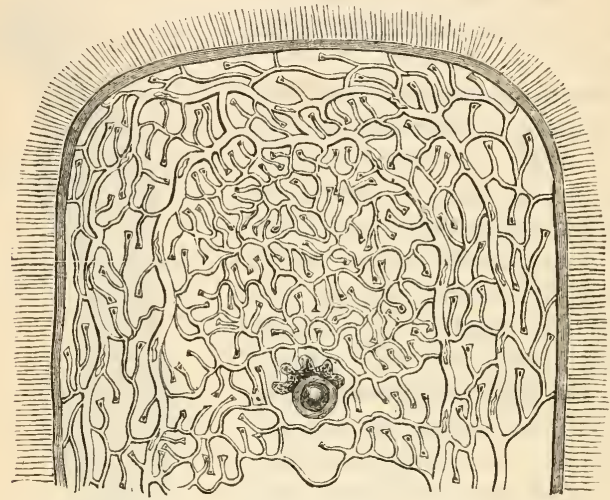

Fig. 104.-Excretory System of Monocelis fusca, showing the numerous Infuudibula, and the branching Tubes. (After Fraipont.)

the efferent ducts, which gradually unite into collecting vessels; these, again, form a plexus, and from these there again arise vessels which pass into a median longitudinal trunk, which opens at the hinder end of the body by an excretory pore. There are no valves or muscular walls by means of which the products are aided on their way to the outer world. The contents of the vessels are stated to be colourless, and to contain a number of small particles of high refractive power; Lieberkühn says that he has been able to detect the presence of guanin.

Among the Cestoda we find that, while the young of some forms have a complicated system of fine canals, the ordinary arrangement is that of two 
longitudinal vessels which extend through all the joints, which may or may not branch and form a plexus in the head, and which open to the exterior by a single excretory pore, which is placed in the terminal joint; sometimes the tubes open in the several joints by secondary foramina (Fraipont), and in such cases the terminal pore and vesicle become more or less atrophied. These secondary orifices in a tapeworm are not to be compared with the openings of the "segmental organs" in the earthworm. The calcareous concretions which are so frequently observed in tapeworms have not as yet been certainly shown to have the character of renal excretory products. The course of the fluid in these vessels is directed by the valves which are placed in the region of the head, and which are so arranged as to prevent the fluid from passing forwards; the canals themselves are devoid of cilia, and, as in the Trematoda, the propelling power is to be sought for in the muscles of the body wall. The fluid is said to contain substances which are chemically allied to xanthin or guanin (Sommer).

The simple unsegmented borly of the Rotatoria presents us with a correspondingly simple condition of the excretory organs, but their relations are here more easily made out, owing to the derelopment of a definite body cavity. There are several distinct ciliated and funnel-shaped openings into the colom, and these lead, by short and simple canals, into a longitudinal vessel on either side; this is more or less coiled on its course, and opens into the cloaca. (See page 119.)

Similar canals arising from the cloaca, and opening by ciliated infundibula into the body cavity, are found also in the Gephyrea; but these forms are most remarkable and interesting for having, in addition to these cloacal outgrowths, others which, by opening on one side into the body cavity and on the 
other directly to the exterior, recall the characters of the segmental organs of the earthworm; there may be one or a few pairs of these tubes, and their excretory nature is assumed from the presence in them of a brown concretion (as in the so-called "brown tubes" of Sipunculus); in certain forms they do, without doubt, lose their excretory, and take on the function of efferent ducts for the generative products, an arrangement which is by no means confined to the Gephyrea among animals ; in Bonellia, the tube which functions as the uterus is developed on one side only of the body.

It is of especial interest to observe that in the developing leech three pairs of canals are developed in the hinder end of the body, and are, at least, provisional excretory organs, even if they are in no way related to the cloacal outgrowths of lower worms. The permanent nephridia of the leech attain to a very high degree of complexity; it is possible to distinguish a vesiele and a gland, connected with one another by a vesicle duct (Bourne). The cells of the gland are all penetrated by ductules, and the central portion of each of its four constituent lobes is occupied by a duct which opens into the vesicle duct; a plexus of blood-vessels is found in the gland, each cell of which is surrounded by a loop of that plexus; the wall of the vesicle is muscular, and by its contractions the contents are expelled to the exterior. The marine ecto-parasitic leech Pontobdella is remarkable for the possession of a very primitive disposition of the nephridia; the organ is single and continuous, and consists of a highly complicated network of tubules; those on one side of the body are continuous with those of the other, and without developing any vesicle, they open to the exterior at regular intervals (Bourne).

In the lower Crustacea an excretory function is 
ascribed to the so-called "shell gland" which forms a looped organ in the dorsal middle line; but there are as yet no physiological facts which confirm this supposition. In the higher Crustacea, an organ which, in its essential relations, calls forcibly to mind the arrangement of the nephridia of the earthworm, is found at the base of the second pair of antennæ. This is the so-called "green gland" of the crayfish, where it presents the following characters.

An orifice, large enough to admit a fairly stout bristle, leads by a short canal into a wider sac, with very delicate walls, which lies in front of and below the anterior portion of the stomach. Below this wide thin-walled sac lies a smaller body, which is in communication with it by a narrow coiled passage ; this body consists of a yellowish-brown anterior portion, which ends blindly, and of a green portion, which lies between it and the duct. The former is spongy in character at its anterior end, and the rest has a number of lamelliform processes rising up from its floor; the green part, which is broader and flatter, has its walls produced into a number of small saccular outgrowths. On the inner surface of the cells of this green part, and of the succeeding white coiled tube, small highly refractive bodies are to be observed, which are no doubt of an excretory nature. The blood-vessels which bring to the gland the materials that are to be excreted by it arise from the antennary and sternal arteries, and break up into fine capillaries in the walls of the gland. The products excreted are stated to resemble guanin, but it will be understood that the small quantities which can be collected make any chemical investigation a matter of considerable difficulty:

Wassiliew, to whom we owe the latest description of the green gland, believes that three stages may be recognised in the differentiation of the renal organ of 
Crustacea. The simplest is that which obtains in many Copepoda, where there is merely a long smooth tube, of the same calibre throughout; in some Phyliopods the tube is enlarged at certain points, and more especially at its blind end; while the third and most complex stage is that which obtains in the crayfish, where the tube is widened at various points, has the constituent cells differing in structure and function, and is folded on itself. We may suppose that the lower terminal portion is glandular and excretory, and that the wide thin-walled sac acts as a reservoir.

The organ of Bojanus in the lamellibranch Mollusca offers many very striking points of resemblance to the green gland, but it differs most essentially in retaining the primitive character of having an opening into the body cavity. On the floor of the space which surrounds the heart (pericardium) we find, on either side of the ventricle, a small orifice which leads into an elongated chamber, with thick dark-coloured walls, and narrower at its hinder than at its front end; the walls give rise to spongy outgrowths, which project into the cavity, and which contain blood spaces, and are invested by the secreting epithelial cells; at its hinder and narrower end this thick-walled portion opens into a cavity which lies above it, and which has thin walls; this, which opens on either sicle into a cloaca, or directly to the exterior, is no doubt the portion of the organ which has the function of a reservoir. Here, then, we have again an arrangement which may be explained as that of a tube, folded on itself, and having part differentiated into a glandular secreting region and part into a collecting region or reservoir. The gland is said to secrete uric acid.

In the fresh-water mussel the products of the generative glands pass to the exterior quite independently 
of the ducts of the renal organ, but in others the latter are used as a means of passage for the genital products, just as are the brown tubes in the Gephyrea. In Spondylus the products are discharged into the renal cavity; in Mytilus (the sea nussel) there is a distinct genital duct, which opens, however, on the same papilla as the renal; while in Anodon and others the two ducts are completely separated. This use of the renal ducts by the generative glands is regarded by Hubrecht as a more primitive arrangement, but it was, he thinks, preceded by one in which the genital products first escaped into the pericardium, whence they were taken up by the renal organ.

In the lower Cephalophora the renal glands are paired, and either open separately, as in Dentalium, or, as in Proneomenia, the ducts unite posteriorly ; in the more differentiated Gastropoda we find that the organ of one or other side is affected by that torsion of the body, which has so pronounced an influence on the development of all the other organs of these molluscs. In the Pulmonata the external orifice is obscured by opening into the cavity of the air chamber, but as this is merely formed by the folding over and attachment of one edge of the mantle, there is no reason to suppose that there is any real change in its essential morphological characters. Sometimes the terminal portion of the gland has muscular tissue developed in its walls, and in some Heteropods and Pteropods the whole organ is capable of contracting.

In the Cephalopoda there are either one (dibranchiata) or two (tetrabranchiata) pairs of renal organs (Fig. 105; rr ). They are richly supplied with blood-vessels, which enter into the lamelliform processes that project into their interior; they open by a somewhat circuitous course into that portion of the body cavity which surrounds the heart, and 
communicate by ducts, or ureters, with the exterior. The chief product of these excretory glands is stated to be phosphate of calcium.

Among the air-breathing Arthropods we find that the excretory organs are outgrowths of the terminal portion of the intestine, which, varying more or less in size and number, extend some way

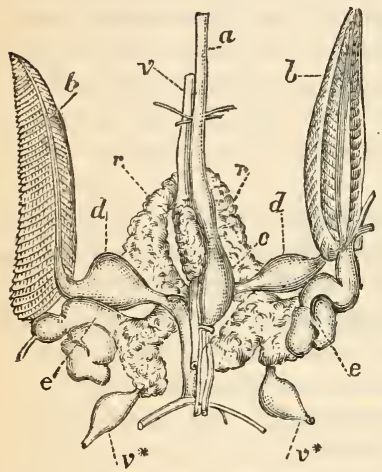

Fig. 105.-Respiratory and Renal Organs of Sepia.

$a$, Aorta ; $v$, vena cava ; $v *$, posterior ven:e cavæ, $c$, heart ; $d$, enlargements of the veins'(auricles); $e$, liranchial hearts ; $b b$, gills ; $r r$, kidneys. into the body cavity; they are the organs that are known as the MIalpighian tubes, and uric acid has been repeatedly proved to be found in them. It is possible, but it is by no means certain, that they are homologous with the rectal excretory organs which we have already found in the Gephyrea and the Rotatoria. They may be completely wanting, as in many of the Aptera and Pycnogonida; there may be two as in the harvestmen (Opilionida) where they are considerably branched ; or four, as in the blowfly, where they are very short; or six, as in the greater number of insects. Sometimes there is a much larger number, the cockroach having from twenty to thirty, and some Hymenoptera as many as one hundred and fifty. They are sometimes arranged in bundles, and where there is a common duct leading to the exterior, its walls are sometimes provided with muscular tissue, which aids in the expulsion of the contents.

The Malpighian tubules are often of great size in 
the larvæ of insects, and a large quantity of renal excretion is collected in the rectum during the pupal stage. This phenomenon may, as Gegenbaur has pointed out, be well brought into relation with the fact that it is at this stage that the "most intense plastic activity is going on in the organisn in connection with the development of the perfect body." The blowfly, when it first emerges from the pupa case, excretes a semi-solid mass of nearly pure uric acid (Lowne).

Periparus is remarkable for the possession of organs which have a general resemblance to the segmental organs or nephridia of the earthworm and other Annulata, and are like them found in all the segments of the body, but those in the three foremost pairs of legs are very rudimentary. A typical nephridium opens at the base of each leg; the tube leading to the opening is narrow, but is continued internally into a large sac, which appears to act as a bladder or collecting organ ; this sac is continuous with a coiled tube, which opens by a funnel-shaped orifice into the cavity of the body.

No definite information has been acquired as to the possession of a renal gland by Amphioxus. The Urochordata are remarkable for the fact that the uric acid secreted from their blood is not carried away to the exterior, but collected into spherical vesicles of large size, which lie in a mass round the intestine ; in Lithonephrya the cavity of the renal organ is almost filled by a single large concretion; in other Molgulidæ, where the presence of uric acid has been definitely proved by the colour reactions given with nitric acid and with ammonia ("murexide test"), the renal organ has the form of a sac, which lies close to the pericardium.

In the Vertebrata we find that, with a general resemblance to the nephridia of the ringed worms, the $\mathrm{R}-16$ 
excretory organs present some very complex characters as we ascend the series. In the examination of these organs it will be found convenient to make use of certain technical terms.

The Promephros (or head-kidney) is a small glandular body, with one or more funnel-shaped ciliated openings into the body cavity ; it is ordinarily placed far forwards, and is provided with a duct, the so-called segmental duct. Like many other renal organs, it is provided with a special blood-supply in the shape of a coil of vessels, or glomerulus.

The mesonephros (Wolfian body) consists of a series of glandular tubes which open by funnelshaped openings into the body cavity, and pour their secretion into the common segmental duct.

The metanephros (kidney of Amniota) consists of a complex of coiled tubes which open into a special duct, which is derived from that of the mesonephros.

All these three organs may be developed in one and the same individual, but they are not, in higher forms, in active function at the same time; the metanephros is developed in the Amniota only, though an indication of its existence is to be seen in Elasmobranchs.

In the adult Cyclostomata the mesonephros is found in its simplest condition, for it there consists of a segmental duct with tubes (Fig. 106; $a, b$ ) given off on one side, and ending in a blind enlargement; in this enlargement an artery $(d)$ breaks up into a plexus of fine vessels which form the glomerulus $(c)$, and thence the blood passes into the efferent artery (e). Anteriorly to this there is, in Myxine, a pronephros, which disappears in the adult Petromyzon, where the whole kidney is more compact.

In the Elasmobranchii the segmental tubes in the hinder part of the mesonephros unite with one 
another before they open into the common efferent duct, and the pronephros would appear to be absent even at the very earliest stages. In them, as in Fishes generally, the renal organs are of great length, as compared with those of the higher Vertelurata.

In the sturgeon, among the Gamoids, the kidneys extend from just behind the skull as far as the cloaca, and differ in width in different regions; in them, and
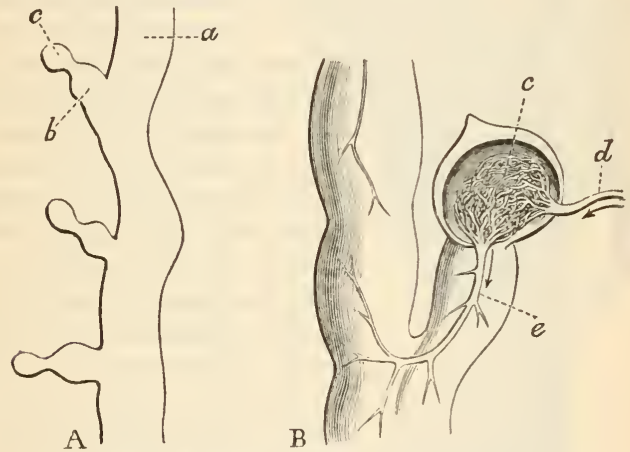

Fig. 106.-Mesonephrus of Bdellostoma.

A. $a$, Segmental duct: $b$, segmental tube $c$, glomerulus. B. A part more highly magnifeed, showing one duct with its afferent ressel $d$, and its efferent $e$. (After J. Atuiller.)

in the Teleostei, there is a great reduction in the number of separate ductules which pass from the substance of the kidney into the efferent duct.

In the Urodela the mesonephros is of considerable length, and gives off a number of ducts (Fig. 107); in the frog, which may be taken as a type of the Anura, the kidney is much shorter, and the efferent duct (ureter) is closely applied to the lower third of the kidney; if, however, we make an examination of a longitudinal section of the kidney under a low magnifying power, we shall see that the substance of that 
organ consists of a number of delicate and convoluted tubes, which, when mapped out in diagram, have

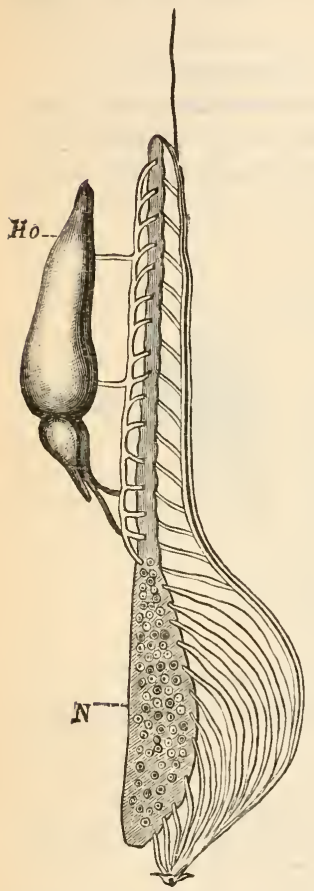

Fig. 107. - Diagram of the Mesunephros of an Urodele. Ho, testis ; N, kidney. (Modified from Sprengel.) that it becomes limited to the lumbar region of the body, while the ducts that open into the pelvis of the kidney are reduced in number and increased in size.

The more important macroscopic differences in the 
kidneys of the Amniota obtain in the relative position of the two organs; in Snakes, for example, not only are the kidneys elongated in relation to the general form of the body, but one lies a good deal in front of the other; this difference of level between the two kidneys, which is clearly an arrangement for more convenient packing, may be seen also in some Mammals (rabbit); secondly, the kidneys vary considerably in their external form ; thus, those of the lizard are only slightly, those of the Ophidia much more, broken up into lobes; this is a difference, also, which obtains letween young and old forms, for in the latter the number of lobes is much greater than in the former. In Bircls the lobes fit into the spaces

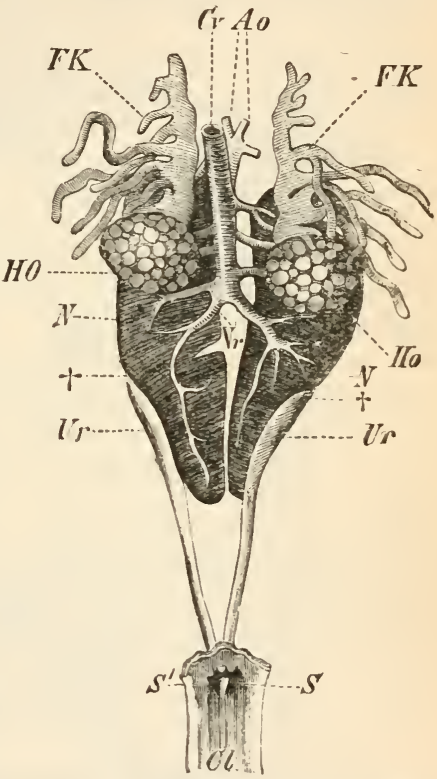

Fig. 108.-Urogenital Apparatus of a Male Frog.

$\mathrm{x} \mathbf{s}$, Kidneys : $\mathrm{c} r \mathrm{c} r$, ureters ; their point of origin ; $\mathbf{s} \mathbf{s}^{\prime}$, their opening into the cloaca $\mathrm{cl}$, H O, testes; FK, fat body : Ao, aorta ; $c r$; vena cava inferior; $\mathbf{v} r$, efferent veins. (After Wiedersheim.) between the transverse processes of the vertebræ of the pelvic region, The lobes of the kidney, after appearing, do, in many Mammals, again fuse with one another, so that while the Cetacea, in which this process does not obtain, may have as many as two hundred lobes, the 
outer surface of the kidney of a rabbit or of a man is quite smooth; this fusion affects also the inner sulstances of the lobes, and in man three, or only two, tubes open directly into the pelvis of the organ.

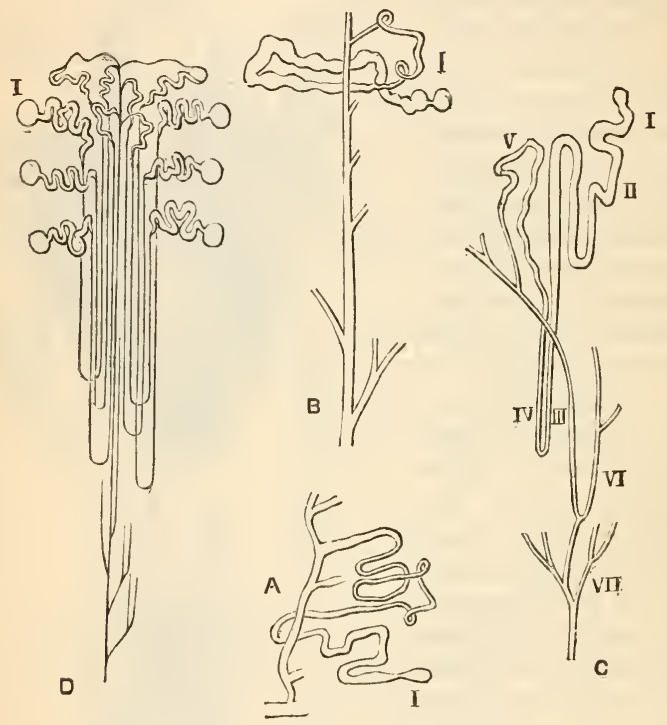

Fig. 109.-Diagrams of the Urinary Tubules of

A: The foog; B, tortoise: c, pigeon (after Hufner); D, man (after Ludwi 5 ); 1 , glomerulus; 11 . to vil., various regions of the tuhule.

The duct that carries to the exterior the secretion of the kidney is ordinarily known as the ureter; so long as the pronephros persists, the segmental dinct and the nreter are one and the same; when the mesonephros appears, the duct becomes divided into two, the Priillerian duct (which has no connection with the kidney, but forms the oviduct of the 
female, and undergoes more or less degeneration in the male), and the Wolfianu duct, which remains connected with the mesonephros, and carries away its products and those of the testes in the male. The ureter, like the collecting ducts of the metanephros, becomes developed from part of the Wolffian duct, which, when this ureter is present, only carries away the secretion of the testes.

In the Cyclostomata, the ducts that have the functions of ureters open to the exterior by a papilla (the urinogenital papilla), which is placed behind the anus; they first, however, open into a cloaca, into which also the generative products make their way hy the abdominal pores. Among the Ichthyopsida the renal and generative products ordinarily pass into a cloaca, which is common to them and to the rectal orifice of the intestine; but in the Teleostei the genito-urinary is distinct from and posterior to the rectal, and the urinary pore is, as a rule, separate from and behind the genital. The terminal portion of the ureteric ducts of fishes is often enlarged, to form a so-called bladder ; this, however, must not be regarded as the homologue of that of Amplibians, or of the Ammiota, where the bladder is an outgrowth of the ventral wall of the cloaca. In the Amphibia and in some Reptilia this bladder retains its primitive position, or, in other words, does not become part of the direct line of passage between the kidneys and the exterior; in the Ophidia, Crocodilia, and Aves, the bladder is atrophied.

Jt is in the Mammalia only that the bladder is found on the direct line of passage between the ureters and the exterior, and is not so found in the lowest division or Prototheria, where rather it occupies the same position as in the frog; in the Metatheria the ureteric ducts open into the base of the bladder; in the Eutheria they open at various points along its 


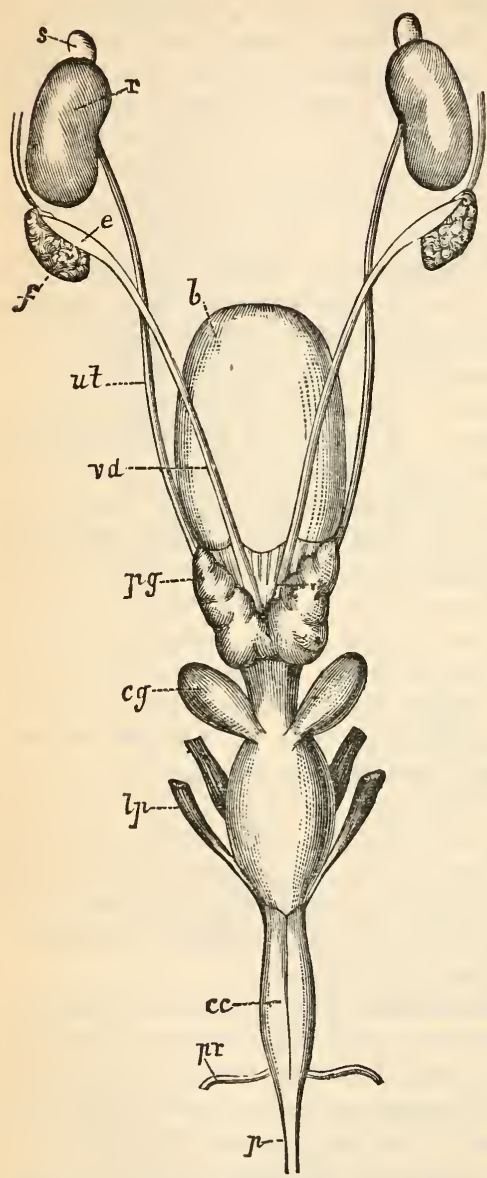

Fig. 110. - Renal and Generative Organs of Ericulus setosus. . course; thus in Gymnura they open into, and in Ericulusnear, the neck (Fig. 110); in man they enter the walls of the bladder at its base, but run in its walls for about threequarters of an inch before open ing into the cavity of the bladder; in the rab. bit they open far up on the hind wall, and in the coney at the top. Thebladderitself varies considerably in size and form; when, as in the higher forms, the cloaca disappears, the urino-genital orifice is in front of the anus. (See page 170.)

$r$ Kidneys ; $f$, testes ; $u t$, ureter $v d$, vas deferens ; $b$, bladder: $\mu g$, prostate gland: cg, Cowper's gland; $l p$, levator penis; $c c$, cystic uretlira: $p r$, prepuce, divided and reflected; $p$, penis. (After Dubson.) 
The two important constituents of the urine of the Vertebrata are urea and uric acid; the former is the preponderating constituent in the Mammalia, the latter in the Sauropsicla, and, as urea is readily soluble in water, while uric acid is very insoluble, we find that the renal products of the Sauropsida are ordinarily semi-fluid, and dry rapidly on exposure to the air. The urine of carnivorous marnmals is more concentrated and more acid than that of man; that of herbivorous forms is ordinarily alkaline, but when it is acid in reaction, uric acid is as abundant as in the lion or the tiger (Garrod); the herbivora have a large quantity of hippuric acid, which is only founct in small quantities in man.

\section{CHAPTER VIII.}

ORGANS OF SPECIAL SECRETIONS.

In addition to the various secretions, such as saliva and bile, or excretions such as the uric, there are others which, though dependent, of course, on the activity of protoplasmic cells, are special and peculiar to different animals, and are not a necessary result of protoplasmic activity ; such, for example, is the poison of the scorpion, or the ink of the cuttletish.

Poison or venom glands. - While in the Ophidia or the mad dog the poison is due to a modification of the proper salivary glands, we find special glands developed in various Arthropods. Among the Arachnida, the spider is provided with tubular glands placed at the base of the cheliceræ, or first pair of appendages, which open by a narrow duct at the orifice at the end of these organs; the two last joints are movable on one another, and are thus enabled to 
lite their victim before injecting the poison ; though, as in the case of the Tarantula, the ill effects of their venom have been somewhat exaggerated, there is no doubt that the paison of many spiders is capable of inflicting mortal injuries; the statement that the West Indian Mygale avicularia is able to catch and kill small birds appears to be true. In the Scorpions the poison glands, which are oval in form, and have sin outer layer of muscular tissue, are situated in the terminal segment of the body; their ducts open at the tip of the spinous process at the end of the tail, which is recurved when the animal strikes a blow. Among insects, many of the Hymenoptera are provided with racemose organs placed in the hinder part of the body, which secrete a fluid, the irritating effects of which appear to be due to the contained formic acid; the venom is injected by a sting, which consists of a median piece grooved longitudinally, and of two side pieces which, on becoming closely applied to it, convert the groove into a capillary canal along which the fluid flows. The venom is not always used merely as a means of offence, many Hymenoptera stinging other insects for the purpose of paralysing them while they carry them to their young, to which they will serve as food.

Various Fishes are provided with defensive organs possessing venomous properties; such are the dorsal spines of the weavers, which are deeply grooved and charged with fluid mucus. In Synanceia the free half of each dorsal spine bears a pear shaped bag in which the milky poison is contained. In Thalassophryne, from Panama, the sac is placed at the base of the spine, and as it is without any muscular sheath, the poison can only be ejected by the pressure exerted on the sac when the spine enters the body (Günther). The integument of many Amphibia is richly provided with glands, which secrete a viscid fluid possessed 
of more or less well-marked irritating properties; a familiar example of this is the common toad, the handling of which is often succeeded by inflammation of the eyelid. Experiments with subcutaneous injections of the dermal secretion of the Triton show that it appears to have an effect on the heart, and that of the salamander on the central nerrous system.

Silk organs. - The result of the secretion of the silk organs of Spiders is the well-known web; but the secreted product, when it first appears, is a viscous transparent liquid, which rapidly hardens on exposure to the air, and then forms threads. The silk is produced in various glands, which, however different in form, are always found distributed among the contents of the abdomen; the secretion makes its way to the exterior through the so-called "spinnerets," of which there are ordinarily three pairs; these have the form of obtusely conical papillæ, the tips of which are provided with a number of pores through which the silk escapes to the exterior. This silk is used in very various ways; some spiders make cells or tubes for themselyes, some scatter the threads about, with the obvious object of entangling an approaching prey, while many make nets for the purpose of entrapping victims. The so-called mason, or trap-door spiders, spin a number of successive webs, which unite to form a door for the pit in which they dwell. Clotho makes a net-like tent, in which the young are concealed. In many cases the webs are spun with considerable rapidity, the common English spiders being able to make one in about an hour.

Among the Insecta, silk-producing glands are hest seen in the larve of the Lepidoptera, where they have the form of two long creal tubes, placed one on either side of the intestine, and opening by narrow ducts at the base of a spinneret, which is dereloped on the labium. As in the spider, the silk is at first 
fluid, but soon hardens on exposure to the air. The silk thus secreted may be used as a kind of attaching rope, as in some moths (Tortrix), or it may form an investment for the larva, as is the ease with the silkworm. In the larvæ of the ant-lion (Myrmeleon) the silk is secreted by the rectum, and escapes by a spinneret which is placed near the anus.

A secretion of somewhat similar character is made by some of the Cameluibranchiata, where the foot secretes a soft substance, which becomes hard and chitinous on exposure to the air; this "hyssus" may consist of threads fine enough to be woven into gloves (Pinna), or of coarser filaments, as in the sea mussel, or they may form firmer chitinous plates. The function of these byssal threads, as may be well seen in the Glochidia, or young of the fresh-water mussel, is one of attachment,

Offensive organs of a somewhat similar character are to be found in certain Holothurians. Connected with and opening into the cloaca are a number of tubes, compacted together into a more or less large mass, and occupying in some cases a considerable portion of the body cavity. The secretion of these Cuvierian organs is expelled, on irritation, in the form of fine tubes, which are capable of considerable extension, and which also swell up in the water. These expelled threads have a remarkable power of adhering to any object which they may tolich, and of more or less completely entangling it and preventing its escape. An English example of a Holothurian thus provided is afforded by the so-called "Cottonspinner" (Holothuria nigra); the tubes are known to have an irritating effect on the human skin.

True electric organs are developed in Torpedo and other rays, in the eel (Gymnotus), and in the teleostean Malapterurus. They are either placed in the head (Torpedo), or in the tail (Gymnotus), or over 
the whole surface of the body (Malapterurus). They are very richly supplied with nerves, and appear to be modifications of muscular tissue, which they so far resemble in physiological activity that they are under the control of the fish; are exhausted after a certain period of activity; and are brought into a tetanic condition in which a number of discharges succeed one another involuntarily, when their possessor is treated with strychnine. In the Torpedo the organs are made up of a number of hexagonal bodies, each of which is divided into a number of cells by intervening septa, between which is a clear gelatinous fluid, or mucous tissue; the Torpedo has about a thousand electric prisms, and Gynnotus is said to have two hundred and forty electric cells in one inch of its electric organ. Though the effect of these bodies has no doubt been exaggerated by travellers, it is clear that they are capable of producing sufficiently remarkable results.

Curiously allied in the details of their structure to the organs just mentioned are the so-called eye-like spots found in various fishes (Argyropelecus, etc.), and best developed, apparently, in deep-dwelling forms. The special activity of these organs does not, however, exhibit itself in the production of electricity, but of light; they are phosphorescent organs. Kolliker, more than a quarter of a century ago, suggested that the luminous organs of insects, such as the Lampyridæ and Elateridæ, were allied to the electric organs of fishes. So far, however, as we know anything as to the mode of activity of these bodies, which are richly supplied with tracheæ, and appear to vary in brightness with the movements of expiration and inspiration, we are led to suppose that the oxygen taken in from the air is a factor of considerable importance.

Phosphorescence is exhibited by such simple 
forms as Noctiluca among the Protozoa; by many Medusæ, by the Pennatulidæ, by Beroe and Cestus; among the Annulata, it has been observed in the earthworm, where it appears to have its seat in the clitellum, and in various marine Polychrta; in Polynoe the light is of a greenish colour; in Polycirrus pale-blue; among the Tunicata, Doliolum has been observed to be phosphorescent; and the compound ascidian Pyrosoma is, as its name implies, remarkably so. As these animals float in great companies, they have been spoken of as a "shoal of miniature pillars of fire gleaming out of the dark sea, with an ever-waning, ever-brightening, soft bluish light" (Huxley).

The physiology of phosphorescence is incompletely known. Panceri observed in Pennatula that the activity was exhibited only by the eight longitudinal bands of fatty substance placed on the outer wall of the stomach; and these bands are luminous after removal from the body. They can be set in activity by various stimuli, mechanical, chemical, and so on. When exactly studied by electrical stimuli, there is found to be a latent period of $\frac{4}{5}$ ths of a second. The fact that many deep-sea forms are coloured points to the existence of light in great abysses of the ocean ; this can only be due to phosphorescent animals, as we cannot accept the supposition that sunlight can penetrate to any considerable depth.

The observations of Aubert and Dubois on Pyrophorus, one of the well-known phosphorescent beetles (Elateridæ), have revealed the remarkable fact that the most persistent of the rays of light are the green, and that, with increasing brightness, the last rays to appear are those that are least refractive, whereas, as a rule, they are the first to be seen. This light has been observed to have an action on sensitised paper.

The colou's of animals are due either to 
pigments, which are formed by protoplasmic cells, or to the minute structure of the surfaces of parts of their body, which variously affect the rays of which white light is composed; or to these two causes combined. Although, in most cases, the pigment is superficial, it is not always so; thus, the "colour" of a man's cheek is due to the hæmoglobin in the blood, as is shown by the yellow colour of those affected with jaundice, in which disease hæmoglobin is converted into bile pigment; or the staining of the skin in syphilis, the poison of which seems to be particularly destructive of the red blood corpuscles. Similarly, the red eye of an albino is due to the absence of pigment in the iris and the retina, in consequence of which the red blood is seen through the transparent tissues of the eye ; when the retina is pigmented, but the iris free of pigment, the red colour of the blood is, by interference, given a blue shade, and the eye is said to be blue. When pigment is laid down also in the iris, the red colour is more or less completely obscured, and we get lightbrown or dark-brown eyes.

No distinctive white pigment has yet been detected, and the whiteness of certain animals must be explained as caused by the presence of air-cells or spaces in which none of the impinging light is absorbed. Many of the colours seen in animals are due to the admixture of different pigments; red overlaid by yellow giving, for example, orange, or, when thinly spread out, pink of various shades, proportionate to the amount of colouring matter present.

Many colouring matters are soluble in alcohol, and not a few are fluorescent; in some cases they have been observed to present absorption bands when examined with the spectroscope, and these bands are definite and characteristic of the pigment. Among the Protozoa a blue colouring matter has been olserved 
in Stentor (stentoriu) ; in some corals and hydroids there is a red pigment (polyperythrin); chlorocruorin has been obtained from various Polychrta; pentacrinin from Pentacrinus; and antedonin flom Antedon and a Holothurian; the terms crus. taceorubrin, aplysiopurpurin, ianthinin, and bonellein explain themselves. Zooxanthin, zooerythrin, zoofulvin, and tmacin have been extracter from the feathers of various birds.

The question whether the characteristic colouring matter of plants (chlorophyll) is formed by animals is complicated by the undoubted fact that a number of lower organisms have associated with them green algæ, which are not so much parasitic as symbiotic, inasmuch as the oxygen which they evolve in the presence of sunlight is of advantage to the anima? with which they live; such are the so-called yellow cells of Anthozoa and Radiolaria. Where no cellnucleus is seen to be associated with the green corpuscles, as is the case in Spongilla and Hydra, we have no reason for refusing to suppose that the chlorophyll has been formed by the animal itself.

Some animals possess the power of changing more or less rapidly in colour ; as, for example, the cuttlefish or the chameleon. This property is due to the presence of chromatophores, or aggregations of pigment surrounded by an envelope; the latter is provided with radiating muscles, by the contraction or expansion of which the chromatophore becomes flattened out, and the contained pigment displayed or drawn into a denser mass, so as to appear merely as a dark spot. In the chameleon, where the play of colour is not so rapidly effected as in the cephalopod, there are no radial fibres. Similar structures are found less well developed in other lizards, and in some fishes.

The effects of structure are best shown by what are ordinarily known as metallic colours. These are 
well seen in the wings of various insects, the scales of which are marked by extremely delicate striæ, or covered by a thin membrane. The rays of white light suffering iuterference are broken up into their constituent parts, and different colours are produced in different positions. Similar phenomena are to be observed in the shells of Lamellibranchs. The causes of the metallic colours of birds has been carefully investigated by Gadow, who points out that if we look at a feather in a direction nearly parallel to its plane, having one eye between it and the light, it appears black, as it does also when placed between the eye and the light. If we keep the feather steady, and move the eye from one to the other of the just mentioned positions, we notice the gradual appearance of all the metallic colours that the feather is able to display. It is important to observe that these colours do not appear at random, but that the first to be seen are those that are nearest the red end of the spectrum, and the last those that are nearest the violet. No metallic feather ever exhilits a brown or grey appearance, or, in other words, any colour that is not spectral. These facts lead to the belief that the changeable metallic colours are due to a structure comparable to that of a prism; this structure is formed by a transparent sheath of remarkable thinness $(0.00085 \mathrm{~mm}$. in Sturnus, $0.0022 \mathrm{~mm}$. in Galbula), which is either perfectly smooth and polished, or has fine longitudinal ridges or numerous minute dots on its surface. Below the sheath there is a brown or dark pigment. As a very small part of the orbit of a curve may be treated as a straight line, the sheath may be regarded as consisting of a number of small prisins; the reason why colour is not seen when the eye is between the object and the light is that such a prism only produces colour on the side farthest from the light, and therefore refracts no light in the direction of the observer.

$$
\mathrm{s}-16
$$




\section{CHAPTER IX.}

\section{PROTECTING AND SUPPORTING STRUCTURES.}

WiтH the exception of such simple forms as Protamœba, even the lowest Protozoa exhibit some kind of difference between the outer parts of the cell that have to bear with the jars and dangers of external agencies, and the inner parts that are protected from them. In Amoeba itself we can recognise (Fig. 1) a difference between the outer ectosarc and inner endosarc. The former, from our present point of view, may be merely said to be firmer; but we have to note that the ectosarc of such Amœbæ as live in moist earth is much firmer than in those which live in water. But the group of which the Amœba is the simplest representative is not without parts which clearly form supports for the protoplasm of the cell : these are firmer structures, which may be called skeletons.

In the present chapter, then, we shall chiefly deal with skeletal structures, whether internal or external, but we shall have also to speak of other offensive and defensive organs.

The ectosarc of the Amœba leads to the definite cuticle of the Infusorian; but the Sarcodina are not without external defensive structures. The simplest condition may be found in such a form as Gromia (Fig. 111), where the ectosarc forms an organic layer of a substance like chitin, which, while it envelops the general body mass, may be itself flowed over by the contained protoplasm. In such a test as this there is a single large orifice at one end. This chitinous test varies considerably in thickness and consistency in 
various Rhizopods, and may take on the most different forms, and even become pigmented. In marine Rhizopods the test becomes much firmer, owing to the deposition in its substance of calcareous salts ; and as

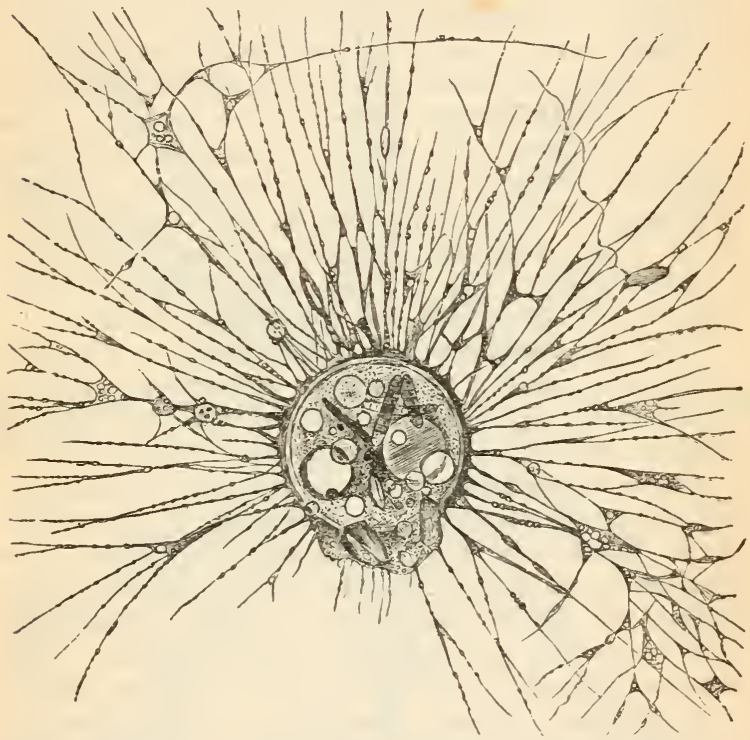

Fig. 111.-Gromia terricola, showing the Protoplasm extending round the chitinous test. (After Leidy.)

the test becomes traversed by pore canals, through which there pass processes of the protoplasmic body that has formed it, we get a structure which more easily falls in with our idea of a skeleton. This skeleton may be rounded and simple, or else it may give off fine projecting processes, or it may, as in Orbitolites and other Foraminifera, become 
very elaborately coiled, and attain, as in the fossil Nummulites, to a considerable size (more than four inches in diameter; or, as in some recent species, to a diameter of two inches). Otlıer Rhizopods build up their skeleton, as do many sponges, from the silica dissolved in sea-water, and others, like a number of sedentary worms, take up sand and other foreign products, and weld them into a consistent skeleton.

In the Heliozoa there may be a more or less gelatinous investment, whioh, as in the Rhizopoda, may appear at times only, or be permanent; or there may be a definite skeleton, which is in no case calcareous. It is most often formed of silex, and its parts are often discannected. In rare cases a shell is formed of sand only, or of sand and the tests of diatoms.

The Radiolaria are remarkable for the possession of a so-called "central capsule," which is membranous in structure, and is, like the test of Gromia, perforated at one point only, where there is a comparatively large space, or the membrane is perforated by several spaces, or a number of pore canals (as in the test of the perforate Foraminifera). In addition to this membranous central capsule, most, though not all, Radiolaria have also a skeleton which may or may not penetrate the central capsule. This skeleton is made up of spicules, which either consist of an organic substance, acanthin, as in the Acanthometridie, or of a siliceous compound. These spicules are primarily arranged in a radiating fashion, and are often connected by secondary spicules with one another, the result being forms of the utmost delicacy, and of great beanty (Fig. 112).

The great variety of skeletal structure which is seen in the Sarcodina does not obtain in the Infusoria, many of which are extremely active in movement. In various divisions, however, we find that the cuticle becomes particularly hard, and the so-called lorica (Fig; 
113) thus formed may be variously ornamented; the stalk, well known in Vorticella, is not contractile in Epistylis and others. The lorica may be produced

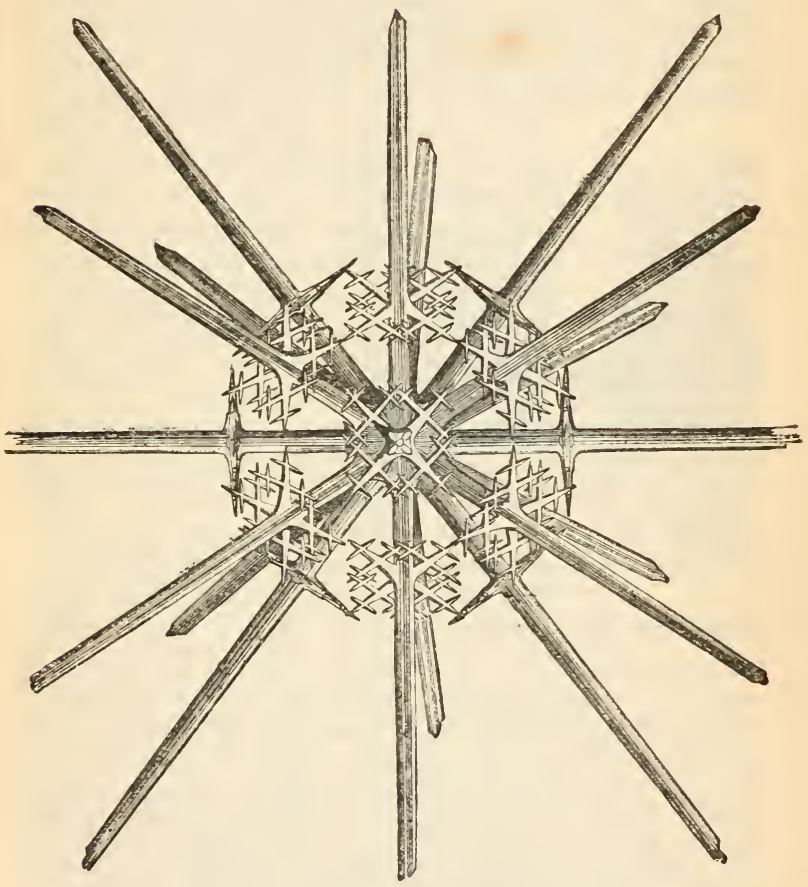

Fig. 112. -Xivhacantha murrayana. (After W 5 ville Thomson.)

into tooth-like or tail-like processes ; a shield-shaped test, or a bivalved carapace may be developed, or the body may become surrounded by a gelatinous capsule. Rarely, as in the Dictyocyrtidæ, the investing test becomes impregnated with siliceous bodies. 
Even naker Protozoa may become covered with a firm cyst formed by the ectosarc, at such times, as from choice or necessity they pass into a quiescent condition. This power of encystation is found also in the lowest members of the vegetable kingdom, and is a means of protection for the protoplasm at the time that it is undergoing the important changes that precerle the rejuvenescence of the indi-

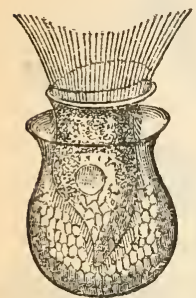

Fig. 113.-Tintinnus lagerula, showing the Lorica below, and the Crown of Cilia. vidual, or the production of progeny.

It is impossible to pass from the Protozoa without reminding the student of how large and important a part they have played and are playing in the formation of the earth's crust. The aphorism of Linnæus, "Petrefacta montium calcariorum non filii sed parentes sutnt, cum omnis calx oriatur ab animalibus," is silpported by our recently acquired knowledge that Diatoms and Globigerinæ live on the surface of the sea, and that their cases and tests sink to the bottom when their inhabitants and makers die. Some rocks, such as chalk-cliffs, are full of the tests of Globigerinæ, and the "Nummulitic Limestone" of Nummulites. Casts of Foraminifers have been found in greensand; a silicate of iron and alumina has been found filling casts of recent Foraminifera, so that as a matter of fact we at this present period find "greensand replacing and representing the primitively calcareo-siliceous ooze;" and, lastly, the researches of the Challenger show that at a depth greater than 2,500 fathoms a substance known as "red-clay" takes the place of the Globigerina ooze.

In all but the lowest Sponges (Myxospongix) skeletal structures have been observed, and these, as in the Protozoa, are of an organic nature simply (fibrous 
sponges), or the organic substance becomes impregnated with calcareous salts (calcareous sponges), or with siliceous (siliceous sponges). Considerable variations are, moreover, to be seen in the extent to which this impregnation takes place, so that while the fresh-water sponge (Spongilla) has but few and simple siliceous spicules, the Lithistidæ are quite hard and strong. In most cases the inorganic skeleton is spicular, and not continuous; but in some, as "Venus's Flower Basket" (Euplestella), a clelicate framework of siliceous particles is left after all the organic material has been removed (Fig. 114).

The spicules vary considerably in form, being uniaxial or needle-shaped, tri-

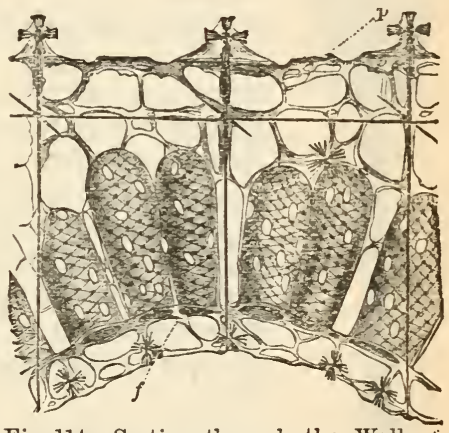

Fig. 114.-Section through the Wall of Euplectella $(\times 75)$.

$p$, Pores; $f$, flagellated chambers. (Aftcr Schultze.) axial (this is the characteristic form in the Calcispongiæ), or quadriaxial; connected with these are bi, tri, quadri, and sexradiate spicules, which may by the loss of some, and the greater development of other rays, take on the most different shapes. Some spicules are multi-radiate, and others curved. Some project beyond the body of the sponge, as in the glass-rope sponge (Hyalonema; Fig. 115), where anchoring spicules as much as eighteen inches long have been observed. In addition to these proper skeletal spicules, others which are smaller take an important part in giving firmness to the sponge body, and even, as in the case of the 
"gemmules" of the fresh-water sponge forming the "amphidises," which strengthen its protective coat during the periorl of quiescence. Sponges free from calcareous or siliceous spicules, and with

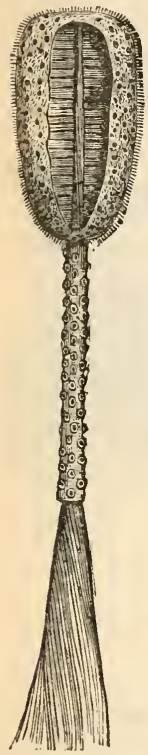

Fig. 115. - Hya. lonema sie. boldi. (After Schultze.) only a fibrous skeleton, have, in the present period, some commercial value, in consequence of their well-known use to man.

From the share that they have had in forming parts of the earth's crust, there is no division of the animal kingdom in which, from such a point of view, skeletal structures are of more importance than in the Colenterata, and both Hydrozoa and Anthozoa contain groups, members of which form the hard structures which we call coral; this consists essentially of deposits of carbonate of lime in the organic substance of the body.

The division of the Anthozoa contain the larger number of coral-forming animals, and may therefore be first dealt with. In the simplest forms, such as the common sea-anemone, there are no spicules at all, but the body wall is rendered more or less consistent by the development of fibrils of connective tissue in the mesoderm; this may be called the supporting lamella, and, as we may suppose, it is thinner in the tentacles than in the rest of the body, where it may become thrown into folds; from the body wall bands or septa, in the midst of which is a more or less thin supporting lamella, project inwards, and some of them reach the wall of the gastric cavity which lies in the central axis of the polyp. (See Fig. 54.) In rare cases the 
non-spiculate Anthozoa take up foreign bodies into, and thereby strengthen, their ectoderm.

The next stage isseen in Alcyonium, where definitely formed but scattered spicules are found in the layers of connective tissue. Where the skeleton becomes continuous it may be horny, and where, as in Gorgonia, a number of polyps are connected together, the skeleton of the common trunk forms a horny axis; in the mesodermal tissues of the polyp spicules with an
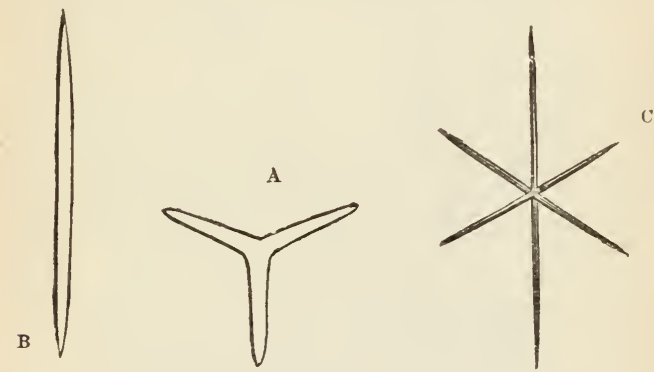

Fig. 116. -A, Triaxial spicule of Calcisponge (Ascetta blanca); B, Simple Acerate Spicule of Reniera; c, Six-rayed Spicule of the Hexactine!lidæ.

organic basis are developed, which, on the death of the animal, merely form a crust on the axis. In Isis the axis is calcified at certain points only; so that it is alternately horny and calcareous. In the red coral the whole of the axis is calcified (Fig. 117). In other cases, as in the organ-pipe coral, the hard deposits are laid down in the wall only of the polyp (Fig. $118 \mathrm{~A}$ ), and these tubes become connected with their neighbour by lateral outgrowths, and so form a continuous hard mass. In others, as in the only "coral" found on our own shores (Caryophyllia) the deposits in spicules is not confined to the wall, but extends also into the septa (Fig. 118 в); in others, as in 
282 Comparative Anatomy and Physiology.

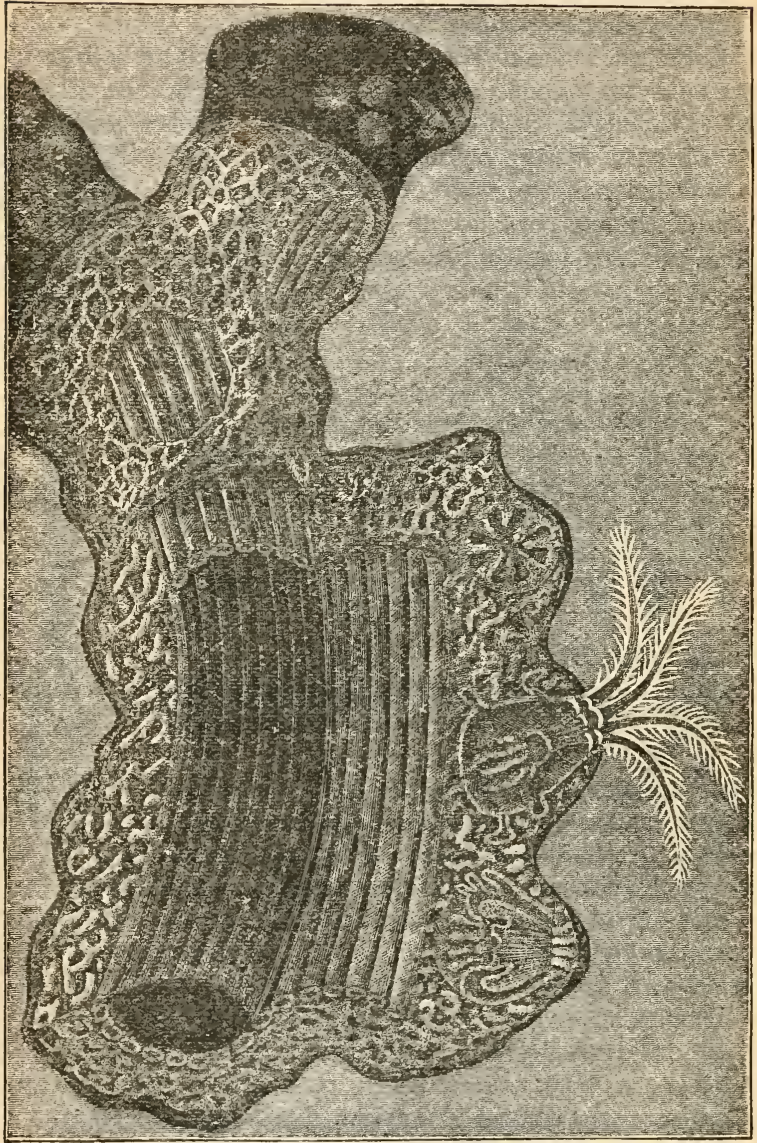

Fig. 117.-Section of Axis of the Red Coral, magnified. 
the common Fungia, the spicules are found in the septa only, while the body wall remains soft. Finally, the axis common to a colony of polyps may become calcified as well as the body wall and the septa (Fig. $118 \mathrm{c}$ ), and we then get large masses of hard stony-like structures which persist long after the polyps that formed them are dead and decayed (brain-coral).

In describing the skeletons of corals use is made of the following terms: the wall of the cup-like calcitication is called the theca, and consists sometimes of an exo- and endo- theca; where the theca is thin it is aided by an investing epitheca; the space between the calcified septa are the Ioculi; the septa may unite in the centre to form a pseudo-columella, or may be inserted into an axial hard part of distinct origin, which is the true columella; the ridges or outgrowths on this are the pali, and the symapticulae are the plates that project transversely and

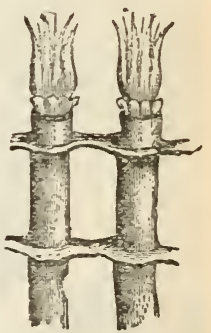

Fig. 118 A. - Coral. Two tubes of Tubipora musica, with their contained polyps.

connect one septum with another. The loculi are sometimes divided into chambers which rise one above the other, like storeys, and the floor of each of these is a tabula. The ridges on the exotheca are known as costae.

The hard connecting sclerenchyma may be compact, as in the stony corals, or traversed by canals, as in the red coral (Fig. 117).

Among the Hydrozoa continuous coralla are found only in the Hydrocorallina, where they are formed by the ectoderm which covers the canals that traverse and branch in the "cœenosarc," that is common to the compound stock of polyps; the 
gastric cavities of the separate polyps communicate with these canals. The coralla, though porous, are very hard and stony, and the canals are separated into storeys by tabulæ, and the upper chambers are alone living. The Millepores are common on coral reefs, the

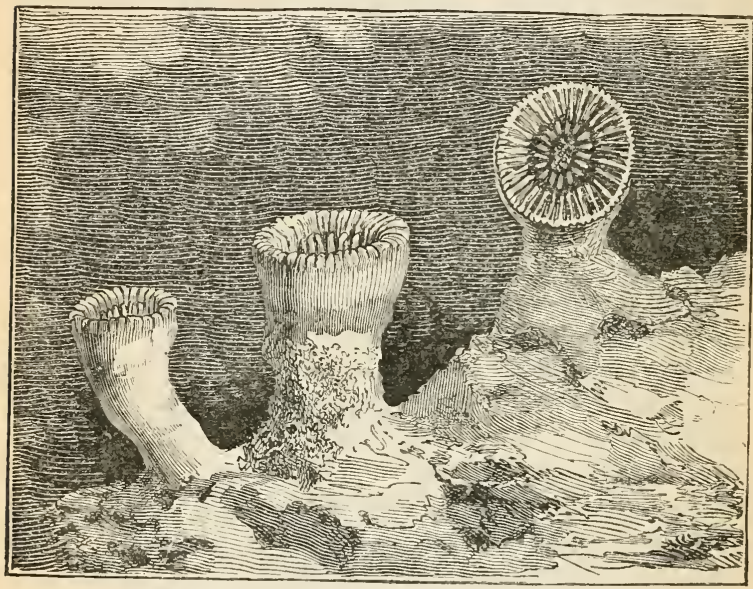

Fig. 118 B.-Coral. Caryophyllia cyathus.

Stylasters live in water from ten to seven hundred fathoms in depth.

In all the other Hydrozoa the supporting tissue is simply a supporting lamella mesodermal in position, as in the common Hydra, or there is an outer chitinous perisarc, as in many Hydroid polyps, which persists after the death of the animal as the so-caller coralline ; or, as in the Medusæ, the tissue lying between the ectoderm and endoderm becomes gelatinous (Fig. 119), or cartilaginous.

Spicular skeletons are not found among Vermes, where, when a protecting tube is developed, it is often 
largely composed of foreign material ; nor is there any complete internal skeleton. The cuticle may be soft

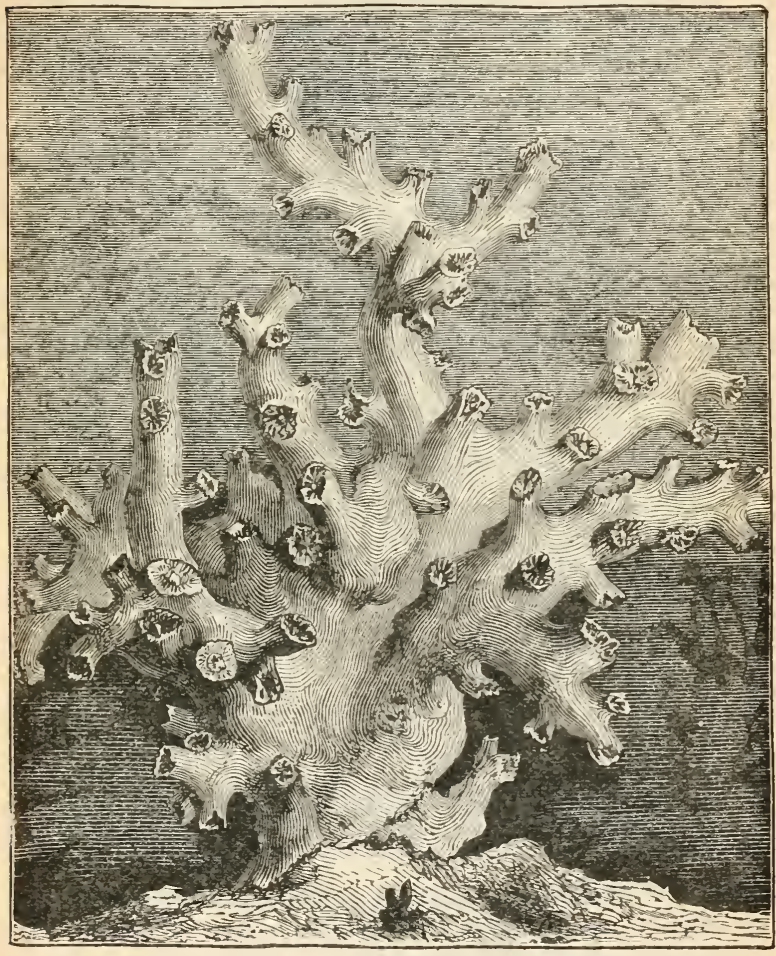

Fig. 118 c.-Coral. Dendrophyllia ramosx.

and ciliated, as in the Turbellaria, or become very firm and appear to be formed of a chitinous substance, as in the Nematoidea, or still more in the Rotatoria, where it may be jointed and have muscles inserted 
into it. In the Ammulata it often becomes of considerable thickness and is then traversed by pore-canals. In the sedentary marine Annelids a tube is developed as a means of protection; the inner portion, which is

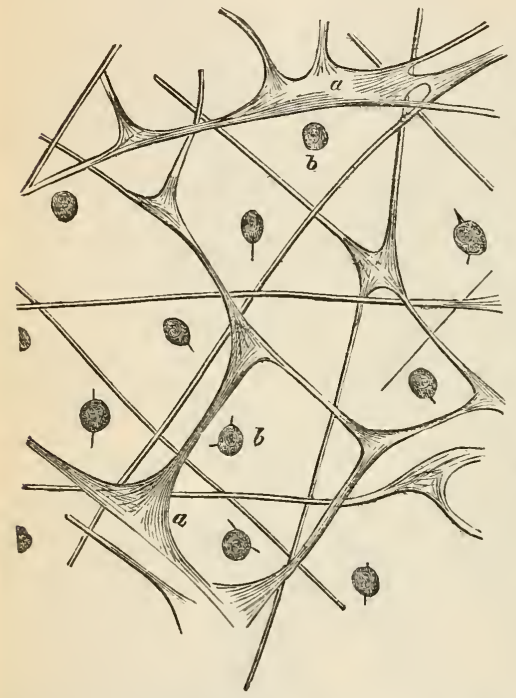

Fig. 119.-Gelatinous Tissue from the Disc of A urelia aurita; $a$, fibres; $b$, cells. (After M. Schultze.) partly membranous and partly fibrillated, is formed by special glands in the body wall ; outside this the tube is often rendered more resistent by the deposition of c a l c a r e o u s matter (as in Serpula), or of aggregations of sand, mud, and other foreign material (as in Sabella, or Amphitrite), which are taken up by the tentacles of the worm, and laid down on the tube by the animal itself. Withinthis tube the inhabitant may be retracted, and some (as Sabella) form an operculum by means of which the entrance to it may be closed.

In the Sabellidæ special cartilaginous supports are developed within the gill tentacles; this is not found in the Serpulidæ.

The cells of the integument often give rise to hard projecting structures, which may have the form of 
hooks, or of bristles. The former are well developed in some of the Cestoda, as in Tænia solium (the

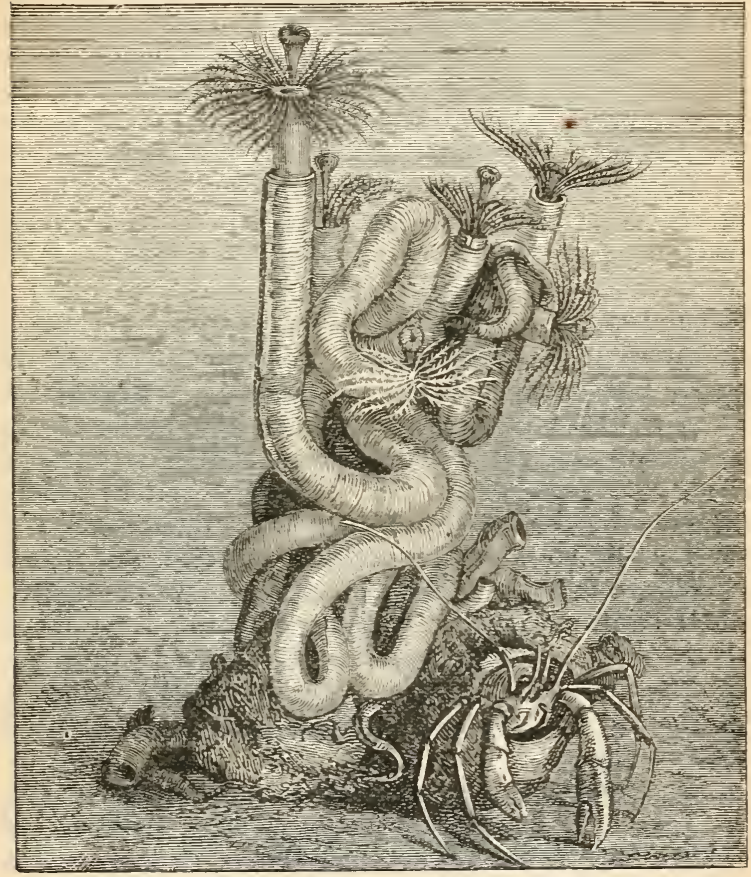

Fig. 120. - Serpula vermicularis, showing the coiled Tube, und the Animal protruded.

tapeworm!, where the head is surrounded by a circlet of recurved chitinous hooks, by means of which the animal fixes itself to the mucous membrane of the intestine of its host; the presence of these is the cause of the difficulty found by the practitioner in attempting to expel the parasites from the human intestine. 
Tapeworms with hooked heads are found in carnivorous mammals and in birds, where the cavity of the intestine is comparatively limited, but they have not yet been seen in such Cestoda as live in herbivorous inammals, where the intestinal tract is much more spacious. The group term Acanthocephali, and the generic name Echinorhynchus, refer to the presence of a number of hooks on the "proboscis" of other parasites.

In the higher Nemertimea stylets are developed at the base of the proboscis, and it is particularly interesting to observe that, where not present, their place is taken by stinging cells; a similar correlation is found among the Turbellaria, where the absence of nematocysts is often atoned for by the presence of small, rod-like structures, the so-called phabdites. In the Charopoda some of the gland-cells of the integument secrete hard chitinous bristles or setae of various lengths, which are protective and locomotor organs; in the Oligochata (e.g. Lumbricus, the earthworm) these setæ are few in number, and never exceed, so far as is known, eight in all ; in the marine Polychara they may be more numerous and much larger than in the earthworm; they may be variously denticulated or hooked at their free ends, and may, in the tube dwellers, aid the animal in raising itself up its tuke.

The Polyzoa are provided with an organ of protection, which is in all cases external or of tegumentary origin; it may be soft and gelatinous, or harder and chitinous, or calcareous. It has been, somewhat unfortunately, called a cell ; it invests only the hinder part of the body, but it may serve, in times of danger, as a refuge for the more anterior portion, which can be withdrawn into it.

All Echimoderms, with the exception of the Holothuroidea, have a well-developed skeleton, and such is found also in some Holothurians. It is formed 
of an organic basis, which becomes impregnated with calcareous salts, and, in thin sections, has a very characteristic reticular appearance.

It is particularly well developed in the Echinoidea, with the consideration of which it will be convenient to commence. In recent forms the test (corona) is made up of ten pairs of rows of plates, five of which are radial and five interradial in position; the former are perforated at the outer edge to allow of the passage of the ambulacral tubes or suckers; in the fossil Palæchinoidea the interambulacral plates were not paired, but as many as five or six took the place of the two which are now constantly developed in all known living species. These plates of the corona, which are covered by an epithelial lining and by the extracoronal portion of the peripheral nervous system, are ordinarily firmly attached to one another, so that no part of the corona is movable; in some, however, such as Asthenosoma, the plates are movable on one another, and the whole test is flexible.

The rows of pores may remain straight, as in Cidaris, or three or more primary may unite to form larger secondary plates, and the pores then become arranged in arcs; three pairs of pores go to form an are in an Echinus, and as many as twelve or thirteen in a Heterocentrotus. The plates carry tubercles of varying sizes, and on these tubercles (Fig. 121; B) are placed movable spines, which may be quite short, as in Echinus, longer than the long axis of the body, as in the piper (Dorocidaris), or very strong and massive, as in Heterocentrotus. Sometimes, as in Diadema, these spines are not only protective organs in virtue of their own strength and number, but are also capable of inflicting painful burning wounds in a manner which has not yet been satisfactorily explained. Sometimes, as in Spatangus or Echinocardium, the spines become very fine and silky. In most, though not in all cases $\mathrm{T}-16$ 
the larger primary are surrounded by smaller and more delicate secondary spines. On the lower
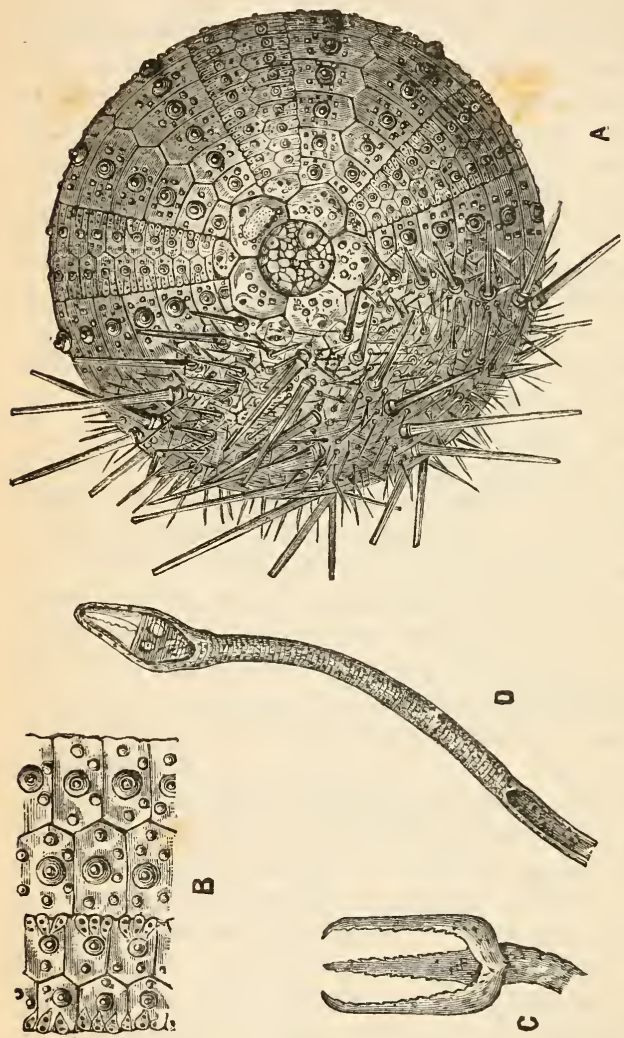

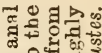

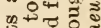
. $4500 \%$ 돈그응 융

$<$ \$

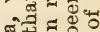
(1) की สㅋํ ฮำ

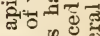
잉 영 † 0.72 00 का क्न है 羟入 그을 का ญे 다

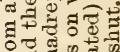
แ ㄷำ का की

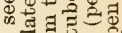
रैद्य क्रे

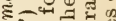
हิㅇำ क ई ใิ जิ ह잉 ¿. त. - .

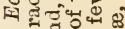
फै क ज्ञ

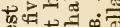
० $=$ ตि

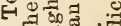
+े 4 क्षे 궁 $\sin$ 证

(actinal) surface of the corona there is an orifice which is the mouth, on the upper there is a special arrangement of plates which form the so-called apical area. 
This is best studied in a regular form such as the ordinary sea-urchin (Echinus), where it is found to consist of two sets of five plates (Fig. $121 ; \mathrm{A}$ ), one of which is radial and one interradial in position. The former are spoken of as the ocular plates, and are perforated by an ordinarily single orifice, through which a tentacle protrudes. The interradial plates, which are similarly perforated, and which are generally larger than the radial, are called the genital plates, from the fact that they have become secondarily modified to serve as the means of exit of the generative products ; for the comprehension of the morphology of this apical part of the test it is, however, best to strictly limit our nomenclature to the terms radial and interradial. One of these interradial plates, that which lies to the right of the anterior ambulacrum or radial plate, as seen in Fig. 121, is specially modified to serve as the entrance to the madreporic or stonecanal. It is distinguished by the name of madreporite, and is characterised by its larger size, and its perforation by a number of minute orifices.

Within the circlet of these radial and interradial plates of the apical area, there is a space which is ordinarily covered by a number of small irregularlyshaped calcareous plates, in or near the middle of which there is an orifice, the anal opening of the digestive tract; sometimes, as in Echinocidaris, the number of anal plates is much smaller, and in the genus just mentioned there are very often not more than four ; in Diadema the anal area is very nearly completely membranous, and the anal orifice is placed at the end of a projecting tube. Among the irregular echinids the anus leaves its apical position, and opens either some way posteriorly on the upper surface, as in Rhyncopygus, or at the margin of the test, as in Echinolampas, or on the lower surface and quite close to the mouth as in Echinoneus. 
The region of the anus in the regular echinoids is primitively occupied by a single large plate, the dorso-central, and, in the study of the morphology of the apical area of Echinoderms, it is necessary to always bear in mind (1) the dorso-central, (2) the radial, and (3) the basal plates, which are interradial in position.

Within the test of the Echinus are five calcareous arches (auriculae) which afford attachment to the "Lantern of Aristotle"; these auricles are, when present, radial in position in all Echinoids, except the Cidarida, where they are interradial.

In the adult Crinoid we distinguish a cup, or calyx, which may, as in Pentacrinus, be permanently fixed by a stalk, or, as in Antedon, be stalked in the larval stages only. In both cases the calyx gives off a number of arms, which consist of numerous small calcareous joints, and have jointed appendages, the pinmules, attached to them. However numerous these arms may be, and there may be almost one hundred, we find that, as we trace them back to the calyx, they form branches of one or other of its five rays. These rays ordinarily consist (the common Antedon of our own seas is an excellent example) of three radial joints ; all these joints unite to a common central piece, which is known as the centro-dorsal. In the stalked forms this centro-dorsal is placed at the top of the stalk, which consists of a large number of small ossicles, and is at various points along its length provided with jointed five-rayed outgrowths (cirri), which hare a claw at their free end. In Antedon and others, where the stalk is lost in adult life, the cirri, which vary a good deal in number, and are sometimes, after a certain age, completely lost, are directly attached to the centro-dorsal itself.

We apply the term centro-dorsal to the central plate of the crinoidal calyx to distinguish it from the dorso-central of the typical unaltered apical area of 
Echinoderms ; the plate is, in the Crinoids, modified by the large share in its formation that is taken by the topmost plate of the stalk. In the development of Antedon, the interradiallyplaced basals become obscured, but in other forms among the Crinoids they are evident throughout life. Careful investigation into the structure of the skeleton of Asteroids and Ophiuroicls
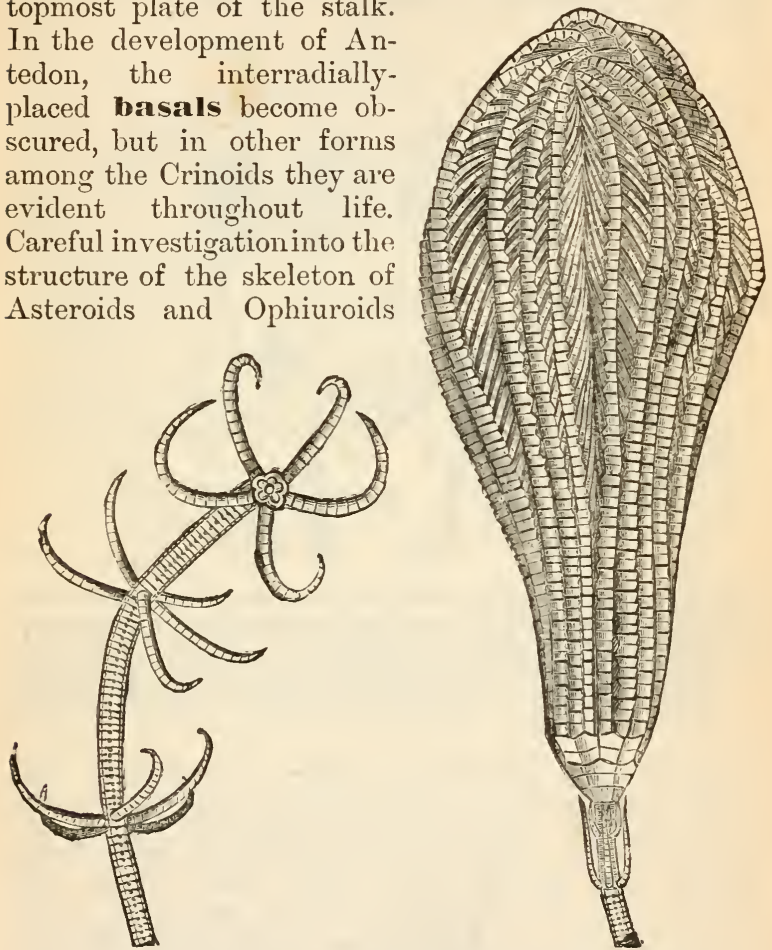

Fig. 122.-Pentacrinus Wyville-Thomsoni, (Natural size.) reveals the presence of the plates to which our attention has just been directed.

The following are the more important points in the structure of the skeleton of the Starfish; the arms, or rays, are made up of a number of ossicles 
set in regular paired rows, at a more or less acute angle to one another; these ossicles are not perforated like the ambulacral plates of an echinid, but the

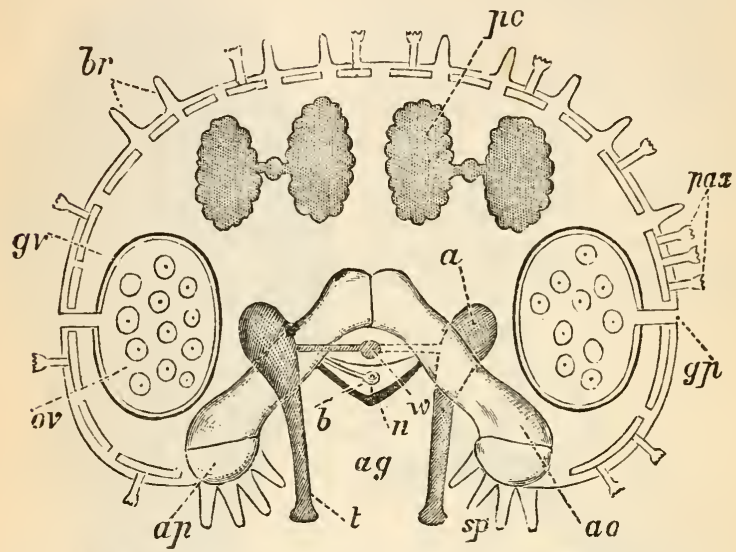

Fig. 123 A.-Cross Section of an Arm of a Starfich (Asterias rubens).

On the left side the section is supposed to pass between two of the ambulacral ossicles, but on the right side through one of them $(a o)$; $a g$, ambulacral groove; $n$, radial nerve; $b$, radial blood-vessel; $w$, radial water-vessel; $a$, ampullæ; $t$, tentacles or suckers ; $a p$, adambulacral plates; s.p, spines ; $p a x$, paxillæ, arising from limestone plates; $o v$, ovary; $g p$, genital pore; $y v$, genital blood-vessel ; $b r$, respiratory processes; $p c$, cæca of the intestine. (After P. H. Carpenter.)

tube-feet pass out between them; attached to each ambulacral ossicle is a smaller ad-ambulacral ossicle (Fig. $123 \mathrm{~A} ; a p$ ), which completes the side of the groove and carries spines; the rest of the wall of the arm is strengthened by irregular plates, which may be so formed as to leave considerable interspaces, as in the starfish, or they may be larger and more closely packed, and have only minute pores between them, as in Linckia; sometimes, as in Oreaster, the plates that form the margin of the arm form two regular rows of much stronger superoand infero-marginal plates. All, some, or none 
of these ossicles may bear spines of varying size and strength; where they are best developed we rarely find that any of the arms have suffered injury, and they are, no doubt, of very considerable importance as protective organs. The disc is formed chiefly of irregularly arranged intermediate plates, but the radials and basals are, in some cases, to be clearly detected in young specimens; near or at the centre of the disc there is an anal perforation which is rarely wanting (Astropecten). On the lower surface the large central mouth is to a slight extent aided in its work by the modification of the most central ambulacral ossicles, which project inwards at the angles of the mouth.

In the Ophiuroidea a cross section of the arms (Fig. 123 в) shows that the ambulacral ossicles $(a o)$ are covered in on all sides, so that no groove is apparent; pores in

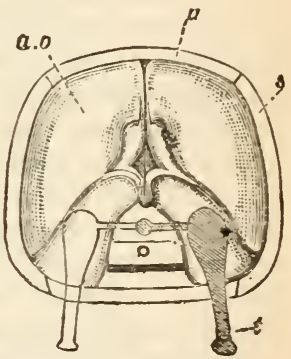

Fig. 123 B.-Cross Section of an Arm of an Ophiuroid. (after P. H. Carpenter.) the lower plate allow of the passage of the tube feet; the side plates $(s)$ ordinarily bear spines $(t)$, which are never of great length or much size, and can be of little use as organs of defence; above, a single plate $(u)$ roofs in the ambulacral ossicles, but this is rudimentary in Neoplax, and absent in Ophioscolex. The plates in the disc are proportionately larger than in starfishes, are ordinarily set in a close mosaic, and not unfrequently exhibit the essential parts of the typical calyx, the dorsocentral even being often apparent, owing to the fact that there has been no resorption of calcareous tissue to make room for an anal orifice. The plates around the mouth are so arranged as to give rise to five radially 
arranged slits; the edges of these slits often bear small spines, while the oral faces of the ossicles carry similar spines, the so-called oral papillae; this armature of fine spines serves no doubt as a filtering apparatus to the digestive cavity of these aproctous Echinoderms. We may correlate the injuries which the arms are often seen to undergo with the absence of defensive spines; the Ophiuroid leaves an arm with the foe from which it is mable to defend itself ; and we may compare with this the arrangements of the tail vertebræ of the harmless lizard. (See page 322.) Arms thus broken are in time renewed. While in the Oplniurida the arms are nearly always undivided, however long they may be, the Astrophytida exhibit various stages of division ending in the great complexity of the free termination of the arms which obtain in the basket-fish, or gorgon's head (Astrophyton, Gorgonocephalus); in the Astrophytida the spines are reduced to a minimum, and the integument is thick and leathery.

Though many 耳olothurians have a very thick skin, and a deposit only of spicules in their integument, we cannot suppose that this is a retention of the primitive condition, spoken to by the fact that in all Echinoderms the skeleton commences in the form of spicules, which gradually unite more or less with one another, so much as one that has been secondarily acquired. In some cases (Psolus) the calcareous plates are quite large, firm, and connected, and, on the other hand, the spicules sometimes disappear completely from old and large, even where they are present in younger and smaller, examples of some species of Cucumaria. In Synapta the spicules take on the form of anchors; in Chirodota, of toothed wheels. They are often turriform in shape, and the surface of the body is sometimes quite rough to the touch, owing to the large numbers which are present 
in and project from the integument. In these Echinoderms, where the defensive powers of the skeleton are slight or lost altogether, we again observe that the creature is prone to acts of self-mutilation, not unfrequently ejecting, when attacked, the whole of its viscera; these are in time repaired, if the animal is left to recover.

In the Echinoidea and Asteroidea a number of the spines are not unfrequently converted into stalked or sessile snapping-like organs, the pedicellariae, as they were called by those who believed them to be independent and parasitic animals; the sessile pedicellariæ are bivalve; the stalked have three or four valves; they are supported by the calcareous reticular tissue which is so characteristic of the hard parts of Echinoderms, and are moved by muscles. Their chief function appears to be that of holding on to objects that come into contact with them, or to such supports for the progression of the animal as waving fronds of seaweed, until the suckers are able to be brought into relation with the sbject; it has been observed that their prehensile power only lasts for ahout two minutes. In some cases it is probable that some of the pedicellarix are used for the purpose of cleansing the neighbouring spines of foreign or frecal material; but, if we are to judge from the great differences which obtain in their number, and their complete, or almost complete absence from some species, the close allies of which have a large number, we are led to believe that their function is not important, and that they have an inverse ratio of development to the size and number of the spines proper (Fig. $121 ; \mathrm{c}, \mathrm{D})$.

The Arthropoda are as definitely characterised by the development of a chitinous, as are the Echinodermata by that of a calcareous skeleton; this is 
likewise, in large part, external, so that while the endoskeleton of Vertebrates is characterised by having the muscles external to it, the exoskeletal parts of an Arthropod are moved by muscles that lie internally to them. The chitinous skeleton may be thin and soft, as in the simpler Entomostraca, or the parts of the different somites may fuse, to form, as in the Crayfish, a firmer cephalothoracic carapace ; or, as in the Ostracoda and other Entomostraca, give rise to two more or less dense lateral valves; in other cases certain parts may become very strong and thick, as is the case with the elytra, or wing-covers, of the Coleoptera (Beetles). The chitinisation of the epithelial layer is not confined to the surface, and, just as in Echinoderms, spicules or plates may be found in the walls of the digestive tract, or in the generative glands ; so, too, chitin may invade the stomodæal and proctodæal portion of the alimentary tract of Arthropods, or give rise to a definite series of internal supporting pieces, the

\section{endosternites.}

These chitinous layers are not formed of cells, but, like the cuticle of a protozoon, are shed out by cells, which they invest with a continuous layer ; the layer is often seen to be laminated, or made up of a number of superimposed secondary layers, laid down in succession. They are traversed by vertically-running porecanals, and are often strengthened, especially in the Crustacea, by the deposition of calcareous salts. ${ }^{*}$ A firm outer coating of this kind, moulded to the form of the body, would speedily limit the growth of an Arthropod, were it not for the process of shedding, or exuviation, which obtains during growth, and much more frequently in young and rapidly-growing forms than in those which have attained to their full size.

* In the Crayfish more than half of the whole weight of the exoskeleton is due to the presence of calcareous salts. 
In this exuviation, or ecdysis, the internal chitinous and calcareous parts are as much affected as the external ; when it is completed the integument of the animal is for a few days soft and moist, but a new exoskeleton is developed with comparative rapidity, while its function as a protective organ is spoken to by the temporary timidity of animals, which, when armed, are bold, and reacly to resent attack.

The integument is smooth in the lower forms only; in Peripatus, as in the larvæ of insects, it is soft, and in the latter it is sometimes very thin. It is generally stouter in Myriopods and Arachnida, and its degree of stoutness varies considerably in Insects. Among the Crustacea it is comparatively soft in Entomostraca, except where valves are developed ; these attain to their greatest hardness in the Cirripedia, which are fixed in the adult stages of their lives, and are therefore unable to escape from enemies; they are stronger and more compact in the sessile Balanus than in the stalked Lepas ; some Cirripeds have, however, lost their hard valves. In the Malacostracous Crustacea, where the carapace has more definite relations than in such Entomostraca as Apus, knobs, ridges, or immovable spinous processes, all of which are defensive in function, are very commonly developed. Among the Arachnicla, Limulus is remarkable for the long candal spine-like termination (Fig. 124) of its shield.

Internal hard pieces, which appear to have for their chief function that of protecting the central nerrous system, whereby they may be compared to the vertebral column of Vertebrates, are best developed in the higher Crustacea. Though topographically and functionally internal, these parts are morphologically external, and they share in the general moulting of the tegumentary skeletal parts; these ingrowths are known as the apodemes. In the crayfish, for 
example, four apodemes are well developed between every two thoracic somites; the inner pair unite above and below so as

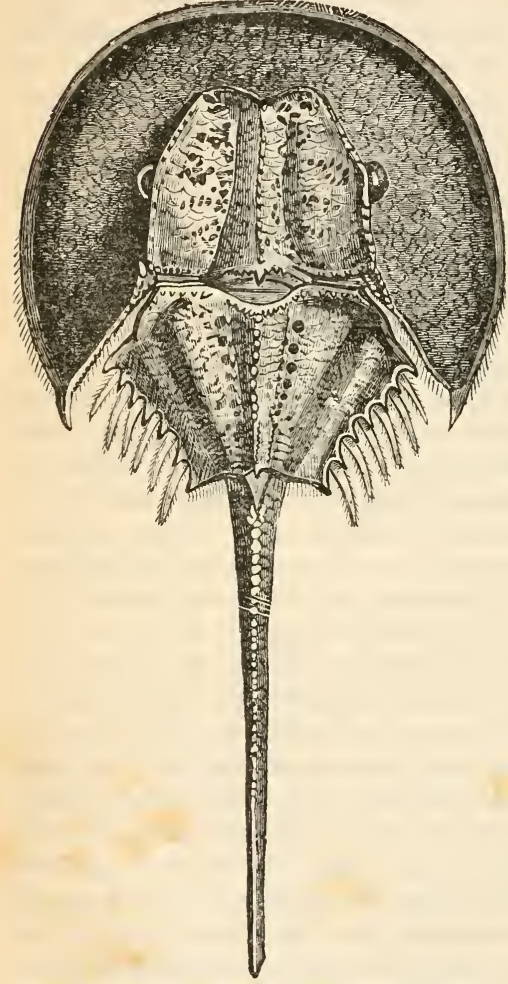

Fig. 124.-The King-Crab (Limulus moluccanus). to form a closed canal, the sternal canal ; with these, on either side, one of the outer apodemes becomes connected, and, as it also becomes connected with the apodemes behind it, the several parts are united into a continuous and substantial internal supporting and protective mass, which, in addition to its other functions, affords attachment to muscles.

The skeleton may gain in protective or defensive power by the development of spines, processes, or knobs, which resist the attacks of enemies, or are able to passively inflict injury upon them; sometimes, indeed, they almost come 
to be reckoned among active agents of offence, as when they are developed on the two terminal joints of the great chelæ or forceps, the last of which is movable on the last but one. The protective power of the hard exoskeleton is, inversely, spoken to by the softness of the hinder end of the body of the hermit-crab, which lives in an empty snail-shell, and protrudes only the anterior portion of its body.

The larvæ of various insects have often protective spines or warts ; those of Crustacea, in the Zoea-stage, have more or less long, anterior, dorsal, and lateral spines.

The several parts of which the skeleton is made up may be conveniently studied in one of the abdominal segments of a crayfish. We here see that there is a continuous ring, the convex dorsal region (tergum) of which is continued into two lateral (pleuraI) regions, which hang down on either side; beneath is a flattened ventral region (stemum), to which are articulated two jointed appendages; the piece between the articulation of the appendage and the pleuron of either side, is known as the epimeron. The appendage, when completely developed, consists of a two-jointed basal protopodite, with which are articulated an inner and an outer branch, which are known respectively as endopodite and exopodite; with these a third piece, epipodite, is sometimes connected. In the crayfish the appendages of the abdomen are either flattened to serve as swimmerets, or modified to act as accessory reproductive organs (see page 496); the last pair of appendages are greatly flattened out, and, with the last segment (telson), which is, in all known cases but that of Scyllarus, without appendages, forms the tail-fin. The four hindermost pairs of thoracic appendages are converted into walking limbs by a considerable increase in the size and strength of the endopodite, 
which constantly consists of five joints, known as the ischio-, meso-, carpo, pro-, and dactylo-podites. The pair next in front form the great "forceps" or chelae, the propodite of which is produced and articulated upon the dactylopodite, so as to form a most efficient seizing organ. The six pairs next in front form the Guathites, the modifications of which have been already described in connection with the organs of digestion (page 123). The two most anterior appendages form the antenna and the antenm mules; in the former the exopodite forms a flattened squame, and the endopodite is many-jointed; in the antennule both endopodite and exopodite consist of a number of joints. By some authors the eye-stalks are regarded as representing the protopodites of an appendage.

The paired appendages of the Arthropoda take on very various functions in different groups, and vary considerably in number; in the Phyllopoda, the Malacostraca, and the Myriopoda, all the segments of the body bear appendages; in the Copepoda and Arachuida they are absent from the hinder part of the body; and in the insects (Yrexapoda), there are but three pairs of definitely constituted appendages beliind the gnathites, and these are always attached to the thorax.

The appendages may be very simple, and may be nearly all similar in function, as in Peripatus, where the incompletely jointed appendages, provided at their free end with their two-hooked claw, are nearly all ambulatory in function; one pair alone forming gnathites, one oral papillæ, and the last of all the anal papillæ. In the Myriopoda, all behind the gnathites are ambulatory in function; in the Branchiopoda they form branchial swimmerets, and, as in other Entomostraca, there are never more than three pairs of gnathites; in the Copepoda and Ostracoda the second 
pair of antennæe retain the natatory function which they have in the Nauplius stage. In the Cirripedia the six pairs of appendages behind the gnathites have the exopodite and endopodite consisting of a large number of joints, and they form the filamentous cirri which are so characteristic of these animals. In the Arachnida there are no appendages in front of the head, antennæ being absent. In Peripatus the antennæ do rot belong to the series of ventral appendages of the segments of the body. In Myriopods and Insects there is a single pair of antennæ. In the Arachnida the basal parts of the circum-oral appendages alone take part in the service of the mouth; the most anterior pair are lincer-shaped at their free end (chsliceras); in some Myriopods one of the anterior pairs of appendages become poison-claws, as are the chelicere in spiders. In the parasitic Pentastomida all signs of appendages are reduced to two pairs of curved hooks in the region of the mouth.

The Hexapoda have only three pairs of gnathites (see page 128); and these, as has been already pointed out, present the most diverse modifications in different orders. The legs are almost always well developed on the three segments of the thorax, and are typically five-jointed ; the most proximal is known as the coxaand this is succeeded by the ordinarily smaller trochanter, by the longer femur, and the still longer tibia; the last joint or tarsus consists of several pieces, the most distal of which, or that farthest from the axis of the body, carries a pair of claws.

The number of legs (six) must be a great mechanical advantage to an insect, for three supports are necessary to maintain a stable equilibrium. They may become adapted to very various modes of progression through earth or air. In the digging forms, such as Gryllotalpa (the mole-cricket), the tibiæ of the first pair of legs are flattened, triangular, and toothed, 
and are supplied with well-developed muscles. In the aquatic forms, such as the water-beetles (Dyticus), the coxæ of the third pair of legs are flattened and oar-like. Such as float on the surface of the water have the contained air tubes enlarged to serve as float bladders, or the legs are greatly elongated so as to extend over a large surface of water. In climbing insects the claws may be cleft or pectinated so as to enable them to hold on to small objects; or an attaching lobule may be developed between the claws.

The tergal portions of several successive segments may unite with one another, and thus give greater firmness to the dorsal surface; this process may result in the formation of a free-projecting shell, as in Apus, or this shell may become divisible into two valves, as in the Ostracoda, or the fusion may extend far back, as in the crayfish, or the scorpion, where we have the so-called cephalothoracic carapace; in Limulus the sides of the carapace are produced, and we get the well-known large shield of these animals; the same phenomenon in the crayfish or the lobster results in the formation of a special wall for the branchial chamber.

The most remarkable modifications are exhibited by the Cirripedia, where the exoskeleton is ordinarily in the form of calcified valves, two on either side of the body, and in Lepas with a dorsal median piece ; in Balanus these valves are withdrawn into a special shell.

In the Mollusca the characteristic organ of support and defence is an external calcareous shell, which is formed by the mantle, and which, when aided by the operculum, which is developed on the base of the foot, becomes so completely an organ of protection that many snails hibernate in their closed shell; the tenant of an exotic shell has been bought, sold, and exhibited in a museum for the space 
of four years before giving any signs of vitality (Helix desertorum). The shell is sometimes, however, merely chitinous and internal, as in the slug or the squid, or it is, in earlier stages, rudimentary, and in adult life completely lost (Nudibranchs). In this phylum there is no arrangement comparable to the exuviation which obtains among the Arthropoda. The dependence of these calcareous shells on the nature of their surroundings is admirably spoken to by such facts as the absence of shelled forms from such districts as the Lizard, or parts of Asia Minor, where there is no lime (Forbes); while, on the other hand, the influence of the animal itself, and of other conditions, is expressed by the greater density of the shells of the mussel of the mountain streams of Westmoreland, as compared with the thinner shells of the Isis, which, at Oxford, is richer in salts of lime than the just mentioned more northern waters (Rolleston).

Shells vary considerably in texture and structure ; many are, as is well known, pearly within; these macreous shells owe their characteristic appearance to the alternate deposition of layers of thin membrane and of carbonate of lime, and to the irregular deposition of the thin layers, which, by slightly overlapping one another, diffract the light and so give rise to the iridescence of the internal surface. This explanation of the physics of the appearance of the shell may be applied also to the "pearls," whether formed naturally by the deposition of thin layers around an organic or inorganic nucleus, or artificially by the introduction of foreign material. Where the lustre is duller than in nacreous shells, the hard structures are said to be porcellanous; in Pinna and others the shell is said to be fibrous, owing to the fact that the separate parts of each layer correspond to one another, and fracture, therefore, results in a number of rertical pieces. The laminated 
arrangement, or disposition of the layers of the shell in horizontal planes, is well seen in the oyster. Where the possessor of the shell is in the habit of floating (Ianthina, Argonauta), the "shell" is comparatively thin, and of low specific gravity.

In the most primitive Mollusea the shell is merely spicular; in Neomenia the spicula are arranged in a single layer in the outer part of the integument, and protrude their pointed ends from its surface; in Proneomenia the spicules are set in several layers, placed in a chitinous interspicular substance. In both cases the spicules consist of carbcnate of lime. A higher stage is found in the Chitons, where the shell consists of eight plates which lie on the back of the animal, and have an arrangement which we can hardly resist from regarding as metaneric. In the Lamellibuanchiata the shell consists of two valves, which lie to the right and left of the animal, and are connected with one another by a chitinous ligament, which runs along the middle line of the back; this ligament is elastic, and in consequence of this property, the animal in a state of repose is able to keep its two valves slightly separated without incurring any expense of muscular activity. At the approach of danger the valves can be approximated so as to protect their possessor, by the contraction of two (freshwater mussel) or one (oyster) pair of adductor muscles. In the higher Cephalophora the shell is always single, whence they are often distinguished by the name of univalves from the Lamellibranchs, which are the bivalves. This shell may form a single conical cup, as in the limpet (Patella), or it may be slightly coiled, as in the cowry, or it may be greatly coiled and consist of a number of chambers, as in the nautilus. It is certain that many conchologists go too far in the trust that they put in the characters of the shell, but it remains as a matter of fact that in the great 
majority of cases the exact systematic position of a mollusc may be determined by the shell alone, so marked are the differences, and so deep - seated the essential characteristics. Geologists believe that there is no evidence more worthy of confidence than that which is afforded them by the shells of any given deposit.

The shell, which owes its growth to the activity of the outer cell-layers of the mantle, commences as a pit or invagination of the outer layer on the aboral surface of the larva; this pit is the shell gland of Lankester, and it secretes a viscid body which hardens on con-

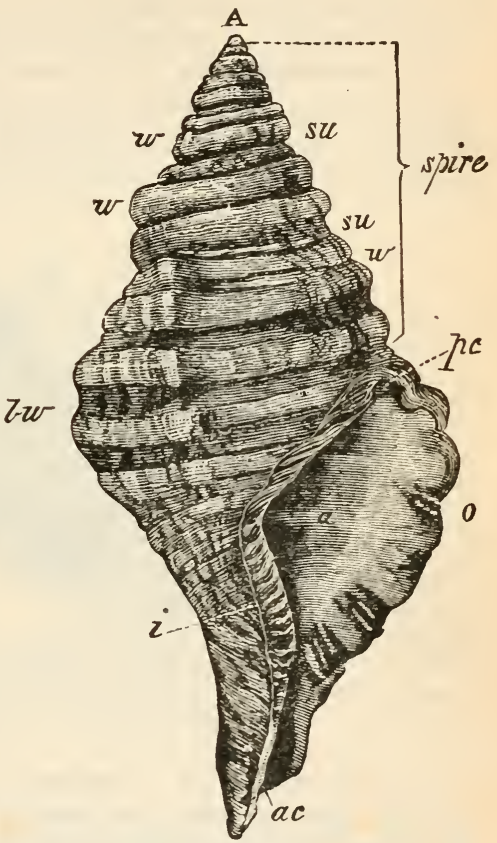

Fig. 125.-Shell of Triton, to explain the terms used in the descriptions of Shells.

The shell is fusiform in shape: its apex (A) is mammillated; it is made up of $u$ horls $(w)$, separated by sutures $(s u)$; bw, hody whorls There is an internal axis or columella (i), an outer lip (o), an aperture $(a)$, and an anterior $(a c)$ and posterior $(p c)$ canal. (After Woodward.)

tact with water ; this hardened substance is the earliest rudiment of the shell, and even in the bivalved forms it is at first a single saddle-shaped plate, which only later becomes divided into two bilateral halves. 
In many cases lines of growth can be made out, and the shell may continue to increase in size for so long a time that a single valve of a Tridacna will be found to weigh a hundred and fifty-six pounds.

In Nautilus the shell consists of a number of chambers (Fig. 126), each of which is larger than that which precedes it, and is formed by the animal as it increases in size; each of these chambers is separated

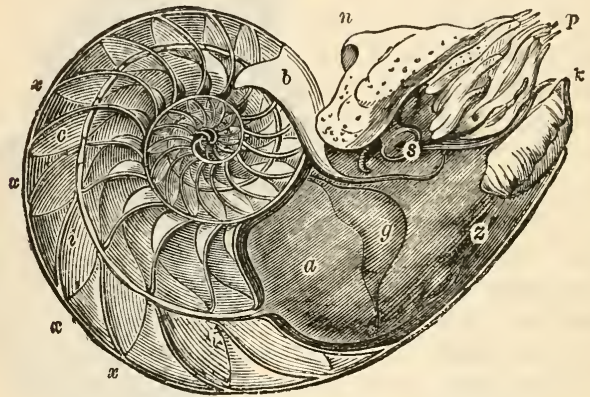

Fig. 126.-A Section of the Shell of the Pearly Nautilus, showing the successive Chambers occupied by the Animal.

$a$, Mantle; $b$, dorsal fold ; $g$, muscle; $i i$, siphuncle; $k$, funnel ; $n$, hood; $p$, tentacles; $s$, eye; $x$, septa ; $z$, last chamber.

from one another by a septum $(x)$, and the whole mass is spirally coiled on itself. The chambers are connected with one another by a tube or siphuncle (ii), the presence of which has given rise to the belief that the whole series forms a kind of float by means of which the animal is enabled to remain at will on the surface of the water; such definite observations, however, as have been made on living specimens, and the fact that though (like the shells of Spirula) the shells are common enough, but the animals very rare, lead us rather to believe that Nautilus is esser?tially a dweller at the botton of the ocean. Here, 
then, we have another example of the danger of arguing a priori as to function from structure. Physiology, like other branches of science, must proceed rather by observation and à posteriori arguments.

Nautilus is the only existing tetrabranchiate Cephalopod, but to that division belonged a number of extinct forms, whose shells are found fossil ; such are the Ammonites, with shells like those of the Nautilus, Gyroceras with discoidal, Trochoceras with spiral, and Baculites with straight shells.

Among the Dibranchiata, Spirula (Fig. 127; A), whose body is so rare and whose shell so common, alone has the shell coiled and clivided into chambers; it is not, however, an external shell, like that of the nautilus, but is internal. In the fossil Belemmite (Fig. 127; B) the proximal end of the shell (phragmocone) was divided into separate chambers, which were connected by a siphuncle. The distal end of the shell is dart-shaped and solid, and forms the so-called guard. In Sepia the shell is calcareous, straight, flattened out for the greater part of its length, with the apex only incompletely chambered.

In the squids, such as Loligo (Fig. 127; c), the shell, now ordinarily known as the pen, is merely horny, and consists of a shaft with two wings; in the Octopus the shell is lost; its ally Argonauta (Fig. 127; D) fashions for itself a shell which both morphologically and physiologically is a different structure from those we have hitherto been considering, for it is formed by a pair of the arms and not by the mantle cells, and is confined to the female, where it serves to carry the fertilised ova. A structure, the origin of which is unknown, but the function of which is likewise incubatory, is that which is known as the float of the Gastropod Ianthina.

The operculum is formed by the foot, is horny, 
and sometimes impregnated with calcareous salts; it is very generally distributed among the Gastropoda,

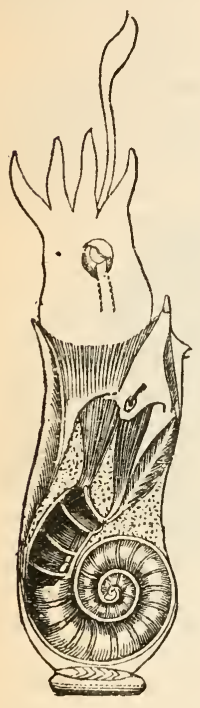

$\Delta$

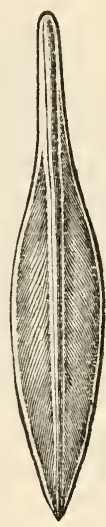

C

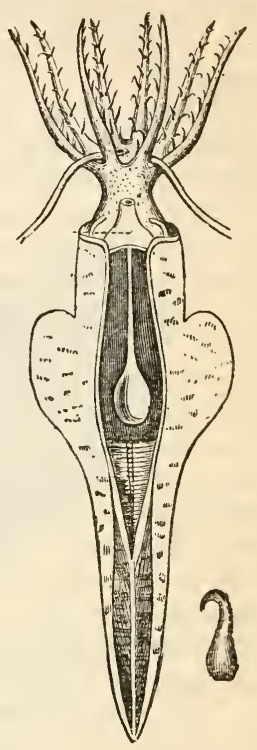

B

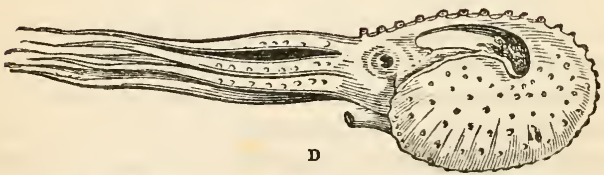

Fig. 127.-A, Section of Spirula australis, to show the internal shell ; B, Belemnite restored; c, Pen of the Loligo; 1 , Argonauta in Natural Position. (From Woodward.)

and may completely fit the mouth of the shell, as in the common snail, or close part only of it, as in Strombus; or, as in Dolium and other large-mouthed 
shells, it may be rudimentary, or absent. The operculum is not represented in the Lamellibranchs. In a few cases (e.g. the Lamellibranchiate Aspergillum) the protective function is not assumed by the shell, which may be quite small, but by the deposit of calcareous matter on the siphon-shaped prolongations of the mantle. (See page 80.)

Among the Gastropoda the shell is often greatly reduced, as in the slug, or completely lost, as in Doris and other Nudibranchs, where the integument is, however, richly supplied with calcareous spicules, and in Oncidium, where the integument is thick and leathery. One large division of Pteropods are without any shell, and in the thecosomatous forms it is always thin and glassy.

The internal skeleton of Gastropods consists merely of one or two pairs of cartilaginous plates, which are found in the region of the pharynx. It is better developed in the Cephalopoda, where it is represented by a median cephalic cartilage, which is pierced in the middle line by the œesophagus, and is produced on either side into plate-like supports for the eye and ear; in some cases the orbit is completely surrounded by cartilaginous pieces. In the Dibranchiata the muscles which move the fins, when those organs are developed, are inserted into special cartilages, and other cartilaginous pieces are more irregularly developed at the base of the funnel, on the dorsal surface, or in the neck.

The Brachiopoda have a hard external shell, which, though it consists of two valves, is not to be compared with that of the lamellibranchiate mollusc, for their valves are not right and left, but dorsal and ventral in position; they may be subequal, as in Lingula, or the ventral may be prolonged into the beakshaped free end, which has gained for these animals their familiar name of "lamp-shell;" in the latter 
the two valves are hinged on one another (Testicardines or Articulata). The dorsal valve may give off hard processes, which project into the cavity between the two valves, and which has a spiral or looped form (Fig. 128); they serve as a means of support for the highly-developed "arms" of the
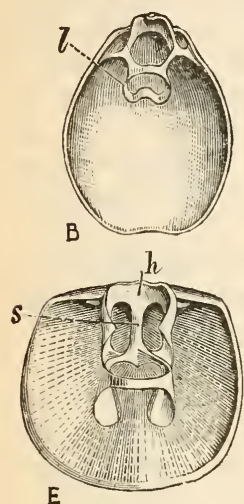

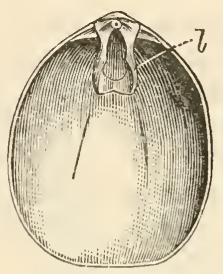

A

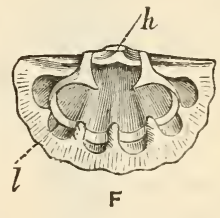

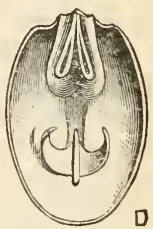

h

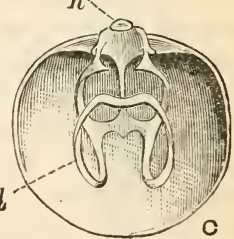

Fig. 128.-Dorsal Valves of various Brachropods, seen from within, to show the loop (l). A, Terebratula; B, Terebratulina; c, Terebratella; D, Bouchardia ; E, Megerlia; $F$, Argiope; $h$, Hinge; $l$, loop; $s$, septum. (After Davidson.)

Brachiopoda. In some (e.g. Terebratula) the substance of the shell is traversed by tubular prolongations of the contained mantle. Scattered calcareous spicules are to be found in the integument.

Among the Chordata, a well-developed skeleton appears only in the Vertebrata, where it attains to considerable complexity; the more characteristic is internal, but an external skeleton is sometimes also present.

All Vertebrata at some period of their lives, the 
Cephalochordata throughout their life, and the Urochordata either permanently, temporarily, or never, have an internal organ of support in the form of a rod, the so-called notochord or dorsal rod, which lies just beneath the central nervous system; the substance of which this rod is formed appears to be allied to cartilage; in Amphioxus it becomes much more complex in structure than in other Chordata, so that we have here an example of how an organ of an animal which remains at a certain grade in the scale of development, becomes more complex and elaborate under its conditions than does the same organ in a "higher animal," where it serves only a temporary purpose. In the Urochordata the notochord is only found in the tail ; it either is persistent, or is aborted when the free-swimming larva settles down to a fixed mode of life, or it is never cleveloped at all ; as in the rest of the division, it has a stout continuous sheath, and, as it is elastic, it brings the tail back into position when the organ has been bent by the muscles attached to it. In the Urochordata, therefore, the notochord, when present, may be regarded as having also a locomotor function.

Amphioxus has no external skeleton, nor have those Urochords that are tailed throughout life; in the rest, the "outer mantle," or test, may become very strong and rigid, so as to form a complete organ of protection; it is remarkable for containing cellulose, a starchy compound which, so common in vegetable organisms, is only known among animals in the Tunicata and the protozoic Cilio-flagellata; scattered calcareous spicules are not unfrequently deposited in the cells of the mantle, but never form a continuous layer. The tailed forms, such as Appendicularia, are able to rapidly secrete an investment, the so-called "house;" in this, however, they do not dwell permanently, but are described as 
leaving one after a few hours, and as forming a fresh one, when they again settle down.

In the greater number of the Vertebrata the notochord is very profoundly modified in character, and in the higher forms it disappears altogether from the adult, its place being taken by the jointed vertebial column. In the lowest stages, such as are found in the Cyclostomata, Chimaera among the Elasinobranclis, and the Dipnoi, the notochord remains unconstricted, but cartilaginous or calcareous deposits become aggregated around it, while above, and sometimes also below it, there appear arches of cartilage, which protect the overlying nerve-cord and the subjacent blood-vessel.

In more complete Vertebrae it is possible to distinguish a basal portion, or centrum, which grows round the notochord, from the overlying neural and the underlying lnamal arches, which enter into more or less close union with it. In many Fishes the notochord remains well developed between the separate vertebral centra, and these are, in the simplest cases, excavated both in front and behind, whence they are known as amphicalous vertebrae ; in better developed forms a smaller amount of notochord is persistent, and we then get either procalous or opisthocalous vertebræ, according as the excavation is on the anterior or the posterior face of the centrum ; sometimes, as in the frog, the invasion of the notochord by cartilage or bone is never complete, and in such cases a cross-section of the centrum of the vertebra reveals the presence of a central notochord (Fig. 129 ; ch). In the frog, as in the Amphibia generally, the neural arch and the centrum become firmly connected with one another, and from the centrum there are given off horizontal pieces of bone, which form the so-called taransverse processes. The sejarate vertebræ 
are articulated with one another by means of processes directed forwards and backwards, the zygapophyses, as these articulating outgrow ths are called. The shape of the faces of the centra of the vertebræ varies greatly, not only in different forms of the Sauropsida, but even in different parts of the vertebral column of the same individual. In the Ophidia these differences are seen to be associated with their mode of life; the anterior face is deeply hollowed, and the posterior rounded and convex; the convexity fitting into the concavity of the next succeeding vertebra, and being capable of rotation within it; in addition to this, the faces of the neural arch are modified, the anterior being produced into two wedge-shaped processes (zygosplienes), which fit into corresponding depressions (zygantra) on the hinder face of the arch, and

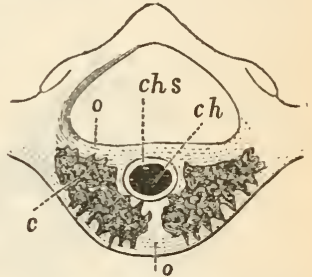

Fig. 129.-Section through the Vertebra of a Frog, magnified.

ch, Notochord: chs, its shenth: $o, c$, different kinds of boul. (After Ecker.) thereby form a kind of peg-andesocket joint (Fig. 130). Vertebræ of this kind are found also in the lacertilian Iguanæ, who are known to swim by the movements of their tails.

In Hatteria, the Geckos, and some fossil lizards, the notochord is persistent between the vertebræ, the centra of which are, therefore, amphicœlous. Among the Crocodiles a progressive loss of the intervertebral portion of the notochord may be made out, such forms as lived before the period of the Chalk having amphicœlous, while cretaceous and post-cretaceous crocodiles have procœlous, vertebræ. Among Birds, the fossil Archropteryx and Ichthyornis appear to have had anphicœlous vertebræ, but in all 
recent forms the centra of the vertebræ are exceedingly well ossified ; they have, especially in the region of the neck, an exceedingly characteristic form of surface, for they are saddle-shaped, being convex from side to side, and concave from above downwards on their anterior face; as exactly the opposite arrangement obtains on the posterior surface, it is obvious that the vertebræ are able to move on one another, and the neck capable of that mobility which is so notable and useful a possession of the bird, whose
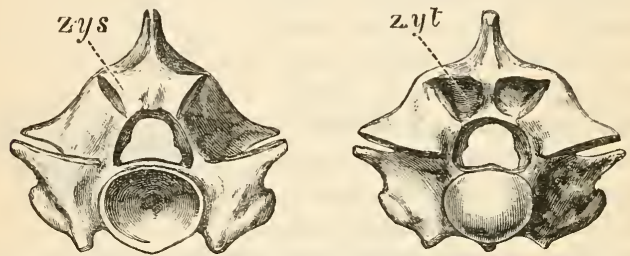

Fig. 130.-Anterior and Posterior Surfaces of the Vertebræ of a Snake, showing the form of the Centra, and the Zygosphenes (zys), and Zygantra (zyt).

anterior appendages are of no use for seizing food or other objects. An exactly analogous arrangement to this may be observed among the Ophiuroidea; in the larger number of these brittle stars the several ossicles have a certain power of movement on one another, but this is limited by the development of processes and pits analogous to the zygosphene and zygantra of the Ophidian vertebræ. In such Ophiuroids, however, as are, like Astroschema, capable of twisting or twining their arms round a straight Gorgonian, the saddle-shaped faces are well developed, but the limiting pits and processes are absent.

In the Mammalia the faces of the centra are often nearly plane, and from the intervening cartilage there is developed (except in the Prototheria, where 
there are only occasional rudiments in the tail, and, much more remarkably, in the Sirenia) disc-like plates of bone, the so-called epiphyses, which, on the arrival of maturity, fuse with the centra, and obscure the line of union (neuro-central suture) between the centra and the neural arches.

On the clorsal surface of these arches a spinous process (neuraI spine) is often developed, and from these muscles may have their origin ; forming only a feeble ridge in the Amphibia, though prominent in many fishes, they are often large in the Sauropsida, and are of considerable importance in many Mammals.

It is in the highest forms that we can best distinguish the several so-called regions of the vertebral column. In such a Mammal as the rabbit, it is, for example, possible to make out (1) a cervical region, in which the laterally placed ribs are never more than rudimentary; the vertebræ of this region, whether the neck is as long as in the giraffe, or as short as in the porpoise, is always composed of seven vertebræ, with the exception of the three-toed sloths (Bradypus) which have nine; of another Edentate (Manis), which has sometimes eight (W. K. Parker); and of one two-toed sloth (Cholœpus hoffmani), and the Manatee, which have six. (2) A thoracic region, with which are connected ribs that are movably articulated with them, and some of which join the ventrally placed sternum, and so form a kind of protecting cage for the thoracic viscera, and points of attachment for the important costal muscles. (3) A lumbar region, where the ribs are not movably articulated, but, being shorter, leave space for the coils of the intestine and the distension of the abdomen which occurs in gravid females of this group. (1) A sacral region, the definition of which is surrounded with considerable difficulties, but which is, perhaps, best defined, with Gegenbaur and A. Milne- 


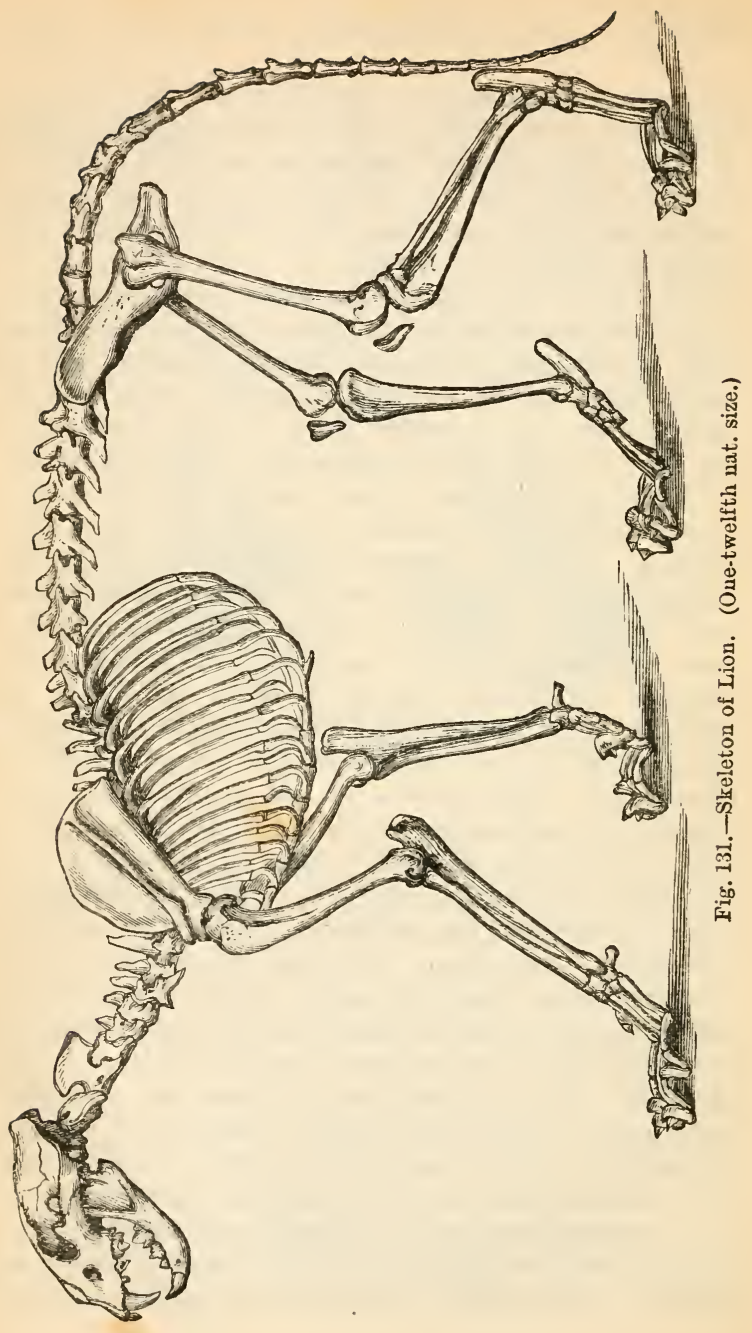


Edwards, as the region in which the vertebræ have additional (pleurapophysial) centres of ossification for the attachment of the ilium (Fig. 132), and which is defined posteriorly by the point of insertion of the ischio-sacral ligament. There are ordinarily two true sacral vertebræ, but with them there often becorne connected some of the (5) caudal or tail vertebræ; the whole fusing to form a single bone of great strength. (See page 321.) The caudal vertebræ vary greatly in number, according to the length of the tail. The greatest known number among mammals is found in the insectivorous Microgale longicauda, which may have as many as forty-eight; Manis has forty - six. Connected with and intermediate to the several candal vertebræ are V-shaped

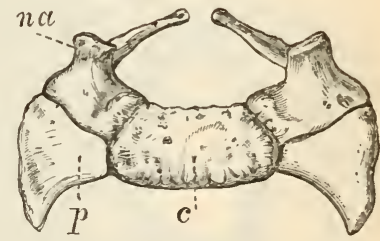

Fig. 132.-Anterior Surface of First Sacral Vertebra of Man.

$c$, Centrum ; na, neural arch; $p$, pleurali)physis.

(chevron) bones, which

protect the vessels of the tail, and afford a larger surface. of attachment for the muscles.

The neural spines and the transrerse processes vary very considerably in length and size, according to the functions and size of the muscles attached to them ; the transverse processes, for example, being long in the lumbar region of active jumping forms, such as the hare or the bandicoot.

The first vertebra, which in man supports the head, has been on that account called the atlas, while the second, on which the atlas moves, is distinguished as the axis; the centrum of the atlas is remarkable for either fusing with that of the axis to form the odentoid process, or, as in the Monotremata and many Reptiles. it persists as an independent bony piece. 
The importance of the vertebral column is well illustrated by the arrangements which obtain in the

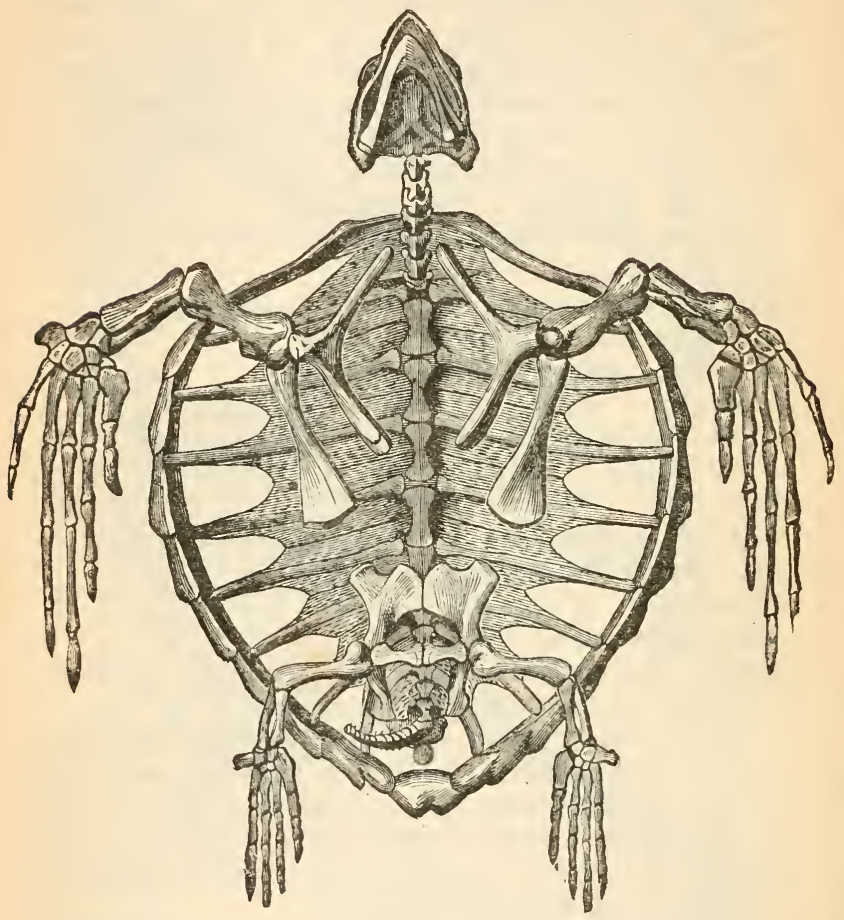

Fig. 133.-Skeleton and Carapace of the Loggerheaded Turtle (from below).

Mammalia. We find that not only does the bony tube afford a complete defence for the enclosed spinal cord, and that the several parts of which it is composed can be bent on one another; but that it is elastic in virtue 
of the cartilaginous discs that lie between the several vertebræ, and, in the more erect forms, by its sigmoid curvature; the bony outgrowths of the several parts may be elongated or broadened to serve as larger areas of attachment for the muscles.

The number of cervical vertebræ among the Sauropsida varies with the length of the neck; the swan, for example, having as many as twentyfive.* In all these hand-less Vertebrates the neck is of great mobility; freedom of movement to the vertebra on one another being allowed by the already described saddle-shaped form of their centra. In the Chelonia also, where much of the body is invested in the firm carapace, the neck is very flexible, and the shape of the centra varies greatly not only in different species, but in the different cervical vertebræ of the same animal; the neural spines are never well developed, and the head can be retracted or protruded. The succeeding vertebræ in the Chelonia have flattened centra, but most are more remarkable for the possession of a broad plate of bone, which is connected with the apex of the neural arch, and forms one of the median "neural plates" of the exoskeletal carapace; the vertebra of the tail can be moved on one another, and are, like most of the vertebræ of most Reptiles, procœlous. The most important exceptions to this law have been alreadly noted.

While in the Ampluibia only one vertebra enters into relation with the ilium, or can be spoken of as sacral, there appear to be two true sacral vertebræ in the Sauropsiala. In Birds, where the whole support of the body falls on the hind limbs, a number of presacral and post-sacral vertebræ fuse with the true sacrals, to form a firm mass of attachment and support. Where the bird has, like the ostrich, to depend

* Some of the extinct Plesiosauria had more than forty cervical vertebræe. 
entirely on its legs, not only for support, but also for means of locomotion, the number of vertebræ that so fuse together may be greater than twenty. Chevron bones are sometimes, as in lizards and crocodiles, developed in the caudal region, the length of which varies considerably among reptiles; but in flying birds, where a tail would seriously affect the centre of gravity, the caudal vertebræ are reduced in number, and unite to form the ploughshare bone, with which the so-called rectrices, or steering feathers, are connected (Fig. $135 ; c o$ ). An exception to the rule that the central portion of the vertebire is that which is most completely ossified is afforded by the caudal vertebra of many lizards. In these there is a central unossified region, where, of course, the tail is much weaker than at other points. If a lizard be seized by the tail it will ordinarily escape, thanks to the fracture of one of these centra, while the part of the tail left with the lizard will grow again. Here we have, no doubt, an example of a variation which has been seized upon, on the principle of natural selection, and has afforded these long-tailed but inoffensive forms with a satisfactory, though undignified, method of protection and escape.

In fishes the vertebral column can only be divided into that which belongs to the trunk and that which belongs to the tail. In some of the more generalised the notochord extends in a straight line to the hinder end of the boly, dividing the tail-fin into two equal halves. In most Elasmobranchs this notochord is bent upwards, and the lower half of the fin is much larger than the upper. In the Teleostei the notochord likewise becomes so bent up, but the rays which support the fin become so arranged as to give to the tail fin, when seen from the surface, the appearance of being composed of equal upper and lower halves, though, as a matter of fact, all the fin rays are 
inferior to the notochord, or the modified urostyle which has taken its place.

The unpaired dorsal fins of Fishes are connected with the vertebral column by means of spines, which are placed between the neural spines of the vertebræ, and are connected with the dermal spines or fin rays which support and make up the greater part of the fins themselves.

In many fishes there is very constantly developed a hæmal as well as a neural arch of bone in connectionwith the centrum, and these, like the superior, are produced into a spine; in the hinder region of the body interspinous bones are developed between
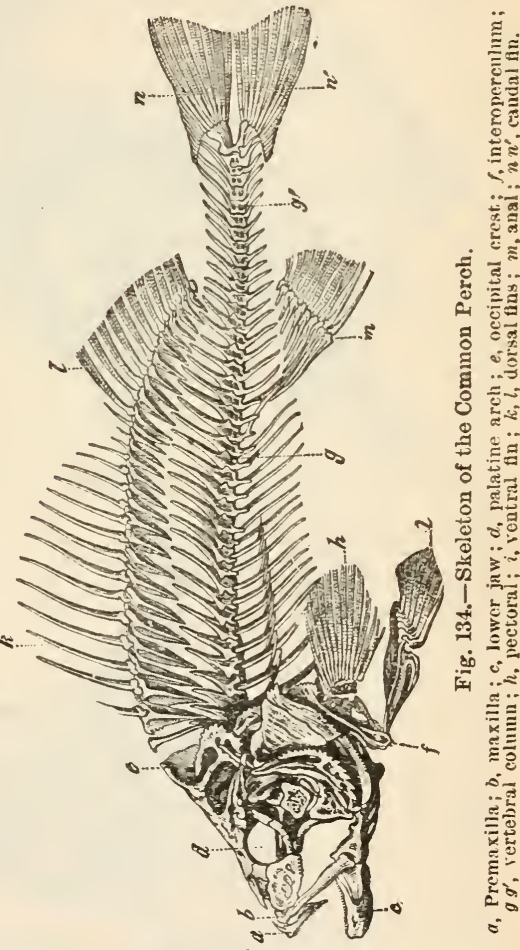
these so-called hamaphyphyses, and they serve to carry the fin rays of the anal fin.

Articulated to the atlas is the skull, which, in the first place, is the box or covering for the brain; this 


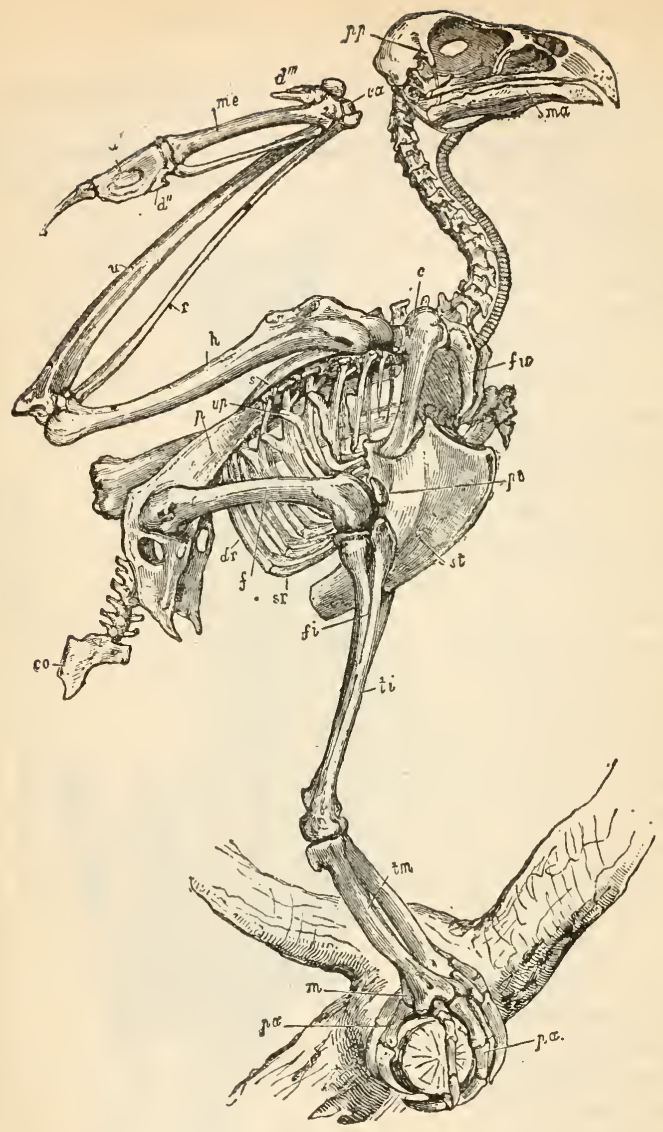

Fig. 135.-Skeleton of Eagle (reduced).

$c^{\prime}$ Coracold ; $c a$, carpus ; $d d^{\prime}$, phalanges of the chief digit of the wing; $d^{\prime \prime}$, phalanges of smaller digit ; $d^{\prime \prime \prime}$, pollex; $d r$, dorsal ribs; $f$, femur ; $f$, fibula; $f u$, furcula; $h$, humerus; $m$, metatarsus; $m a$, mandible; me, metacarpus ; $c o$, plonghshare bone $; p$, pelvis ; $p a$, phalanges of foot ; $p t$, patella ; $r$, radius; $s r$, sternal ribs; $s$, scapula ; st, sternum; $t i$, tibia, $t m$, tarsometatarsus ; $u$, ulna; up, uncinate processes of ribs. (After' Milne-Edwards.) 
is the true cranium. With this there enters into more or less complete union the cartilages or bones that form the framework for the mouth, and give rise, in higher forms, to the face.

The notochord extends forwards below the two hinder of the three primitive brain vesicles, and, on either side, there appear masses of cartilage, homologous with those that form the arches of the vertebral column. These parachordals unite with the notochord to form a continuous basilar plate, which serves as a floor for the two hind brain vesicles; this grows up on either side, and unites above to form a ring of cartilage which embraces the hindermost part of the brain. Posteriorly each half gives rise to a cartilaginous condyle, which articulates with the atlas. This hindermost portion of the cranium may be distinguished as the occipital region. In front of the parachordals there appear two bars, which unite behind, where they embrace the anterior end of the notochord, and in front also, leaving a space in the middle. These are the trabcculae, and they form the floor for the first brain vesicle, or fore-brain. As the plates unite to form a solid floor they grow up at the sides, but never form more than an imperfect roof in this region, which, therefore, is not cartilaginous, but membranous. This portion of the cranium may be spoken of as the sphenoidal region. As the cranium invests the brain, holes, or notches that will be converted into holes, have to be left for the passage of the cerebral nerves (Fig. $136 ; 5,9$ ).

In addition to these, the whole architecture of the skull is profoundly affected by another set of elements, which enter into more or less close contact with it. These are the capsules of the three higher senses, smell, sight, and hearing. At the anterior end of the sphenoidal region the olfactory cartilaginous capsule becomes connected with the cranium, the anterior wall 
(ethmoid) of which is perforated for the passage of the olfactory nerves from the brain. In the occipital region, on either side, the capsule for the ear (periotic capsule) early becomes connected with the cranial walls, and in the higher Vertebrata (see Fig. 136) the periotic cartilages are, at a very early stage in development, con-

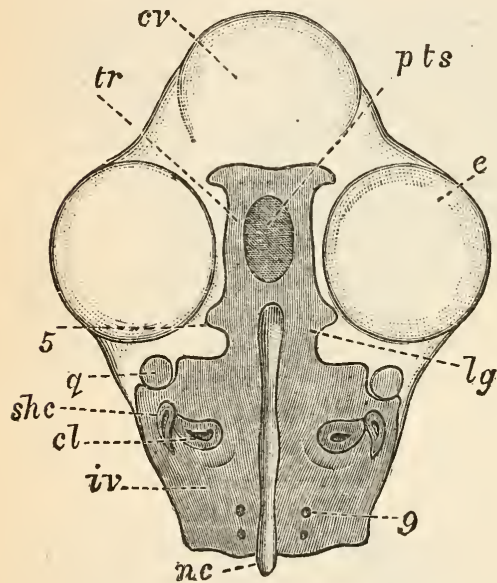

Fig. 136.- Carti'aginous Cranium of a Chick of the fourth Day of Incubation, showing the investing Mass (iv), and the Trabeculæ $\left(t v^{*}\right)$, with their Central space ( $p t s)$.

$c v$, Cerebral vesicle (sliced off) ; $e$, eve; $l g$, anterior end of investing mass formed from the parachordals ; 5 , notch for the passage of the fifth nerve; $q$, quadrata ; $c l$, cochlea: shc, semicircular canal of ear ; 9 , foramen of exit of the ninth nerve; $n c$, notochord. (After Parker.) tinuous with the basilar plate. The optic cartilage (sclerotic) lies in the sphenoidal region, but it never enters into direct union with the cranium, though the form of this part of the skull is greatly affected by the size of the eyeball.

In addition to the (1) cranial and (2) sensory cartilages which take so large a part in the formation of the skull, there is in all Gnathostomata yet a third element, which may be distinguished as the buccal. In the branchial and visceral clefts, which appear just behind the brain, cartilaginous bars are developed 
for their support. Throughout the series, whether gills are present or not, the first two take on, in addition or solely, quite another than a branchial function.

These (Fig. 137; $\mathbf{M} n, \mathrm{H} y$ ) send off from their upper end a process, which is directed forwards; the anterior arch becomes segmented into an upper and a lower piece, both of which, growing forwards, form the rudiments of the upper and lower jaws. The former $(\mathrm{P} l, \mathrm{P} t)$ may be called the pterygo-quadrate bar, the latter the Meckelian cartilage. The chief means of connection between these bars and the cranium is not the metapterygoidal region, or hinder and upper part of the first arch,

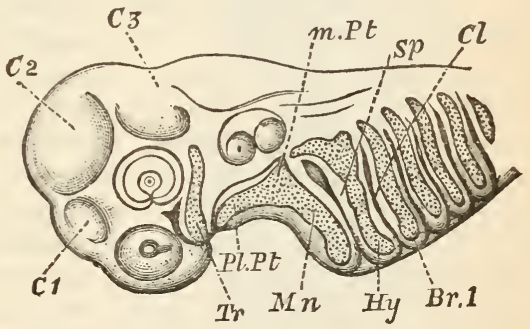

Fig. 137.-Head of Embryo Dogfish (11 lines long). $\mathbf{T} r$, Trabecula; $\mathbf{P l}, \mathbf{P} t$, pterygo-quadrate ; $m$, Pt, metapterygoid ; $\mathbf{s} n$, mandilbular cartilage ; $y$, hyoid arch ; Br 1, first hranchial arch, with four succeeding arches; $\mathbf{s} p$, mandibulohyoid cleft ; $\mathbf{c} l$, hyo-l)ranchial cleft ; $\mathrm{cl}^{2}, \mathrm{C}^{2}, \mathrm{C}^{3}$, cerebral vesicles. (After Parker.)

but the upper

part of the second arch (нy), which forms the hyo-

\section{mandibular.}

In such a skull, then, as that of the dogfish (which has formed the basis for this account), the attachment of the jaws to the skull is hyostylic (Huxley); in a large number of fishes this hyostylic arrangement obtains; in a few (Notidanus), however, the metapterygoid does enter into contact with the cranium, and the jaw is then supported by elements of both the mandibular and hyoid arches, or is amphistylic. On the other hand, in Chimæra, the Dipnoi, and all the pentadactyle Vertebrata, the hyoid takes no share in 
attaching the jaw to the skull, that attachment being effected solely by mandibular elements, and being, therefore, autostylic.

In the branchiate Vertebrata the number of branchial arches corresponds with that of the branchiæ, and the separate bars become segmented; all the visceral bars save the mandibular have a distinct median basal piece, which is known as the basibranchial; this passes on either side into the hypobranchial, which is succeeded by the ceratobranchial, epibranchial, and pharyngobranchial. When gills cease to be developed these bars undergo, as may be supposed, a certain amount of atrophy, but, in all, the first branchial arch is retained, white in tortoises and lizards two arches may be detected. These basal portions always fuse with those of the hyoid arch, and the coalesced pieces make up the so-called body of the hyoid, which forms a support for the tongue; the parts of the true hyoid arch form the interior, and those of the first branchial the posterior or lesser cornua of the hyoid of man.

We have hitherto regarded the skull as compounded of neural, sensory, and visceral portions, all of which are formed by cartilage; we have now to look at the same structure from another point of view. It has already been pointed out, that while the cartilage in the occipital region of the skull forms a complete ring in its hinder portion, the sphenoidai region is roofed in by membrane; this membranous roof is retained throughout life by Myxine (the hag). In other Cyclostomes and in Elasmobranchs the roof becomes more or less completely cartilaginous, and this cartilage, which never becomes ossified, though its outer layers may be calcified, is covered in by membrane.

In the more shark-like Ganoidei, the membrane, though not the cartilage, undergoes ossification, and a 
number of investing membrame bomes appear on the roof of the skull ; in the Holosteous Ganoids ossification commences in the occipital region of the cartilaginous cranium, while there are also membrane bones. From this point forward we have to clistinguish between bones that are preformed in cartilage (cartilage bomes), and those that are preformed in membrane (membrane bones).

At first, that is, in the lower Vertebrata, the membrane bones are numerous, and their relations are not so constant and exact as they are in the higher forms. When they become so we are able to recognise that the roof is formed by two pairs of more or less large bones, the parietals abutting on the occipital region, and the fiontals in front of the parietals. The base of the.

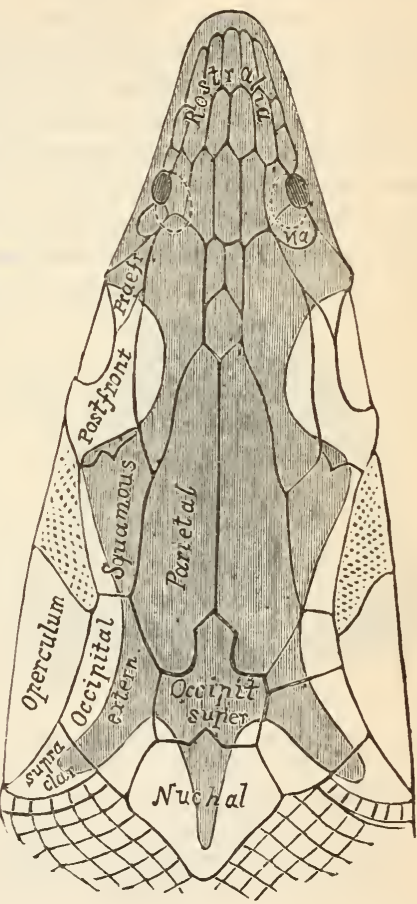

Fig. 138.-Head of Sturgeon, showing the Membrane Bones, and the Cartilaginous Cranium, which is shaded dark. (After Gegenbaur.)

skull is in the Ichthyopsida ossified in the occipital region only, and the sphenoidal portion is underlaid by a membrane bone, the parasphenoid 
(Fig. 139 ; par). The upper half of the mandibular arch becomes invested by membrane bones only, the jugal or quadratojugal, or both, which trend a little inwards as they pass forwards (Fig. 139; q). In front of these are two bones which, typically, carry teeth, the maxillae and the premaxillae.

Internal to this row of membrane bones is another, of which the most anterior, the vomer $(v)$, is formed from membrane that did not overlay cartilage, just like the maxillæe and the premaxillse, while the others, the palatines and the pterygoids $(p t)$, are

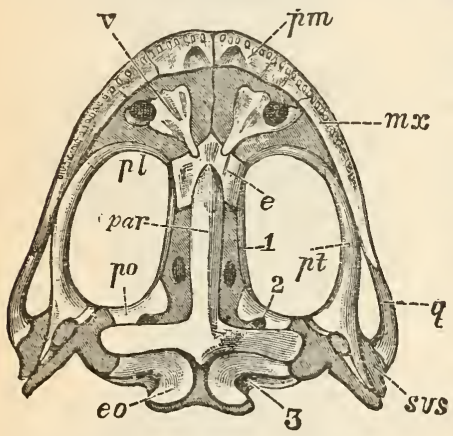

Fig. 139.-Sknll of Frog, from below; the Lower Jaw has been removed.

$e, 0$, Exoccipital ; po, prootic; par, parasphenord; $e$, sphenethmoid ; $v$, vomer: $p m$, premaxilla $m x$, maxilla; $q$, quadrato jugal ; $p t$, pterygoid ; sus, suspensorium ; palatine; 1 , optic foramen; 2 , foramen of fifth nerve ; 3 , foramen for ninth and tenth nerves. (After Parker.) formed from membrane which generally invested cartilaginous bars. Meckel's cartilage is likewise invested in bones of nembranous origin, the most important and constant of which is the tooth - bearing dentary. At the anterior end of the skull, above the olfactory capsule, there appear the paired nasals, with which a lachrymal is related in the higher forms.

In Fishes a series of membrane bones may become developed in connection with the branchial skeleton, and form the support for the opercular flap of the gills; such are the operculum, suboperculum, and interoperculum. The most anterior of the opercular bones is possibly the homologue of the 
membranous bone at the side of the skull, which is known as the squamosal in the abranchiate Vertebrata.

While in the Amphibia the posterior (occipital) and anterior (ethmoid) portions of the base and sides of the cartilaginous cranium undergo ossification, it is not till we reach the Ammiota that we find the central and lateral cartilaginous parts of the sphenoidal region becoming bony; when they do so we recognise a basisphenoid, with an alisphenoid on either side, and a presphenoid with corresponding laterally placed orbitosphenoids. Now, too, we can distinctly see an ossified basioccipital, two excccipitals, and a median supraccipital, all of cartilaginous origin, and surrounding the foramen magmum. In the Saurcpsida the exoccipitals unite with the basioccipital to form a single median occipital condyle; in the Mammalia the exoccipitals, as in the dog, alone form the condyles, or some share is taken by the basioccipital, but in either case the skull is articulated to the vertebral column by two condyles; it is for this reason that some writers speak of the Sauropsida as Monocondyla, and of the Mammalia as Amphicondyla.

At the anterior end, the cartilaginous plates which subdivide the nasal cavity may undergo more or less ossification, and give rise to the "spongy boues" of the nose; they enter into connection with the ethmoid in the middle line, and may become united with the nasals (naso-turbinals) or maxillæ (maxillo-turbinals) at the sides. (See Fig. 189, page 442.)

In the walls of the cartilaginous ear-capsule there appear centres of ossification, which are ordinarily three in number; of these the most constant is the prootic, which alone is found in the Amphibia, though in some fishes there are also epiotic and opisthotic 
ossiflcations. In Birds these fuse with one another and with the supra- and ex-occipital bones to an

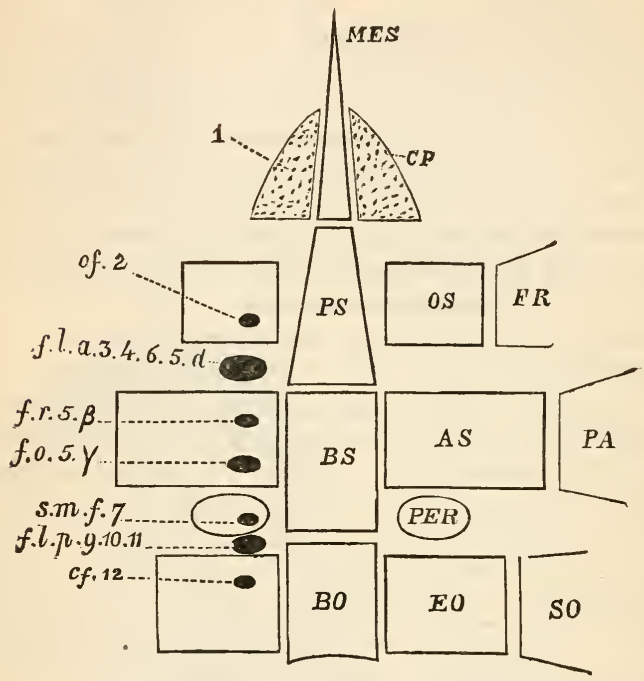

Fig. 140.-Diagram of the Cranial Bones of a Mammal, showing the

Foramina of exit of the several Cerebral Nerves.*

1, Olfactory nerve ; 2 , optic; of, optic foramen ; fla, foramen lacerum anterium, for the passage of the third, fourth, sixth, and first branch of fifth nerve $(3,4$, $6,5 a) ; f r$, foramen rotunduin, for the second branch of the fifth $(5 \beta) ; f o$, foramen ovale, for the third branch of the fifth $(5 \gamma) ; s m f$, stylomastoid foramen for the seventh nerve (7); $f l p$, foramen lacerum posterius, for the ninth, tenth, and eleventh nerves; MES, mesethmoid; $c f$, condylar foramen for the twelfth nerve; cP, cribriform plate: PS, presphenoid; Bs, basisphenoid; Bo, basioceipital; os, orbitosphenoid; As, alisphenoid ; Eo, exoccipital; PER, periotic ; FR, frontals ; PA, parietals ; so, supraoccipital.

extent of completeness which is greater than ordinarily obtains among Mammals.

In addition to the important relations which the cranium bears to the sense capsules, it has others even

* This diagram was, many years ago, shown to the author by Prof. Flower, F.R.S., and it is here, for the first time, published by his kind permission. 
more important to the brain, which it contains and protects ; of these the most important is its relation to the cerebral nerves and outgrowths that pass out from it. The distribution and arrangement of these nerves form, in disputed cases, one of the best criteria of the homologies of the different parts of the cranium. Seen in its most elaborated condition, as it is found in Mammals, the cranial bones and cerebral nerves have the following relations. The so-called olfactory nerve (Fig. 140 ; 1) perforates the cribriform plate of the ethmoid; the optic nerve passes through the optic foramen in the orbitosphenoid bone (os); the third, fourth, and sixth nerves, that go to the muscles of the eye, pass with the most superior division of the fifth through the irregular or jagged space $(f l \cdot a)$ that lies between the orbitosphenoid and the alisphenoid. The two other branches of the fifth (or trigeminal) pass through the round $(f r)$ and oval $(f o)$ foramina in the alisphenoid, while the seventh has a passage at the outer side of the periotic (PER), while between the periotic, basioccipital, and exoccipital there is a posterior foramen lacerum $(f l p)$ for the glossopharyngeal, vagus, and hypoglossal $(9,10,11)$ nerves ; lastly, the twelfth nerve passes through the condylar foramen $(c f)$, while, as we have already learnt, there is a great foramen at the hinder end of the cranium which serves as the means by which the medulla oblongata is allowed to be continuous with the spinal cord.

An examination of the interior of the cranium similarly reveals the close connection that obtains between the containing case and the contained brain; and, indeed, our knowledge of the characters of the brains of extinct forms is absolutely dependent on casts of the internal configuration of such skulls as have been preserved to us in the form of fossils.

Where, as in the lower Mammals, the cerebral hemispheres are of no great size, and do not overlap 
the hinder cerebellum, the upper surface of the cranium is straight and flattened; as we ascend the scale, howeves, we find that the cerebral hemispheres growing backwards come to overlap more or less the cerebellar region; concurrently with this the upper surface of the brain becomes more or less arched, and the cranial walls take on a corresponding form ; the most familiar example of this is, of course, the brain of man, but it is to be carefully noted that the skulls of the old-world baboons, and of some of the lower and smaller newworld monkeys, have the supraoccipital region thrown farther back and down than it is in man himself. As a result of this alteration in the position of the parts of the brain case we find that the foramen magnum looks downwards instead of backwards ; as a secondary result we find that the skull of man balances more or less completely on the occipital condyles, and, this being so, there is not the same need for the development of muscles and ligaments to support and hold up the back of the head as there is in the dog or the horse ; from this mechanical arrangement we get, further, a marked diminution in the extent of the bony ridges on the occiput to which these muscles are attached.

When a longitudinal section is made through the skull of a Mammal and the form of the internal cavity is revealed, it is seen that the bony ear-case projects into the hinder part of the cavity, and that the wall of the anterior boundary is perforated by the small holes which give passage to the fibres of the olfactory nerve (cribriform plate of the ethmoid) ; in the whales, where the olfactory sense is in a rudimentary condition, the holes in this plate are few and small; the region of the skull in which the olfactory lobes of the brain are contained is known as the olfactory fossa, and this is smaller or larger according to the size of the olfactory lobes themselves (see page 425 ) ; this cavity is bounded by the cribriform plate in front and below, and at the 
sides, and has behind it a ridge of bone on the orbitosphenoid, and frontal bones by which it is separated from the cerebral fossa, which, in all Mammals, occupies a larger part of the cranial cavity; this fossa is more or less feebly divided into two by a ridge of bone which corresponds to the sylvian fissure of the brain; in the more anterior division there lies the frontal lobe (see page 426) ; behind this comes the cerebellar fossa, marked off anteriorly by the tentorium. The flocculus of the cerebellum lies in a special depression on the inner face of the periotic, and the hypophysis cerebri on a pit (sella turcica) on the superior face of the basisphenoid, which, as we have already learnt, forms a portion of the floor of the brain cavity.

Such, then, being the general disposition of the parts of the skull in a well-developed Vertebrate, we have now to investigate the arrangements which obtain in various forms in relation to their habits of life and their zoological affinities.

In the Round-mouths, where no branchial rods are modified to form jaws, the sides of the buccal orifice are supported by cartilaginous pieces, the so-called labial cartilages; the mouth is surrounded by a circular lip, in the posterior region of which is placed the annular cartilage; into the cavity of the mouth there project a number of horny denticles; on the floor is the lingual cartilage, and in front of this is the median ventral cartilage, which, possibly, represents the basal median portion of the mandibular arch, which in other Vertebrates is only to be detected in early stages. It is very instructive to observe that there is a close resemblance between the mouth parts of a lamprey and those of a tadpole during the period when the latter has a suctorial mouth.

The labial cartilages of the Cyclostomata appear to be better retained by Elasmobranchs than by other 
Vertebrates, in which only those persist that take part in the formation of the nasal cavities.

In the voracious sharks the mouth is of large size, but the character of their food is related rather to the size of their teeth than to the extent of their mouth; when the mouth is not terminal but ventral in position, a shark has to turn on its side to seize its prey. In some Rays, such as Pristis (the saw-fish) the snout is produced into a long flattened weapon of attack, which is armed at the sides with spinous processes, and serves as an organ by means of which the body of its prey may be torn open. In the Teleostean sword-fishes, where maxilla and premaxillie are present, these bones are produced into a long stabbing-organ, not only strong enough to pierce the bodies of whales, but even the planks of wooden ships. In many Ganoidei, such as the sturgeon, the snout is of considerable length; the function of this organ is not completely understood, and the most plausible hypothesis is that of von Martens, who ascribes to the long snout of Polyodon the function of a tactile organ, the necessity for which is to be explained by the turbidity of the rivers in which it lives.

In the Teleostei the mouth may be very large, as in the Angler (Lophius), or exceedingly small, as in Chrtodon and Diodon; in Chelmo, a form allied to Chætodon, the mouth is prolonged into a snout which possibly serves as an apparatus for drawing from holes or crevices the small animals on which it feeds (Gunther). Where the teeth are of great size, and adapted, say, for crushing shells, as in the sea-cat, the jaws which carry them are of corresponding strength; in the wrasses, with somewhat similar habits, the upper pharyngeal bones are articulated with the basi-occipitals, and no doubt afford a firmer fulcrum for the jaws.

In bony fishes the eye-ball is sometimes provided with separate bony pieces for its protection. 
In the Amphibia the mouth is wide, and in some Anura the symphysis of the mandibles is strong, for it has to serve as the point of attachment of the tongue (see page 154); in some Urodela, as in some Reptiles and Birds, the sclerotic cartilage undergoes ossification, but presents only an advance on what is seen in the Teleostei.

Owing to our better knowledge of the habits of the higher Vertebrates, we are more easily able to associate the arrangements of parts of their skulls with the habits of their possessors. Nowhere do we find a better series of mechanical arrangements than among the Ophidia; in the python and those that swallow, without poisoning, their prey, the skull is wide behind, and the quadrates are at a considerable distance from one another (Fig. 14l; Qu). In other words, the lower jaw is wide at its point of attachment, and,

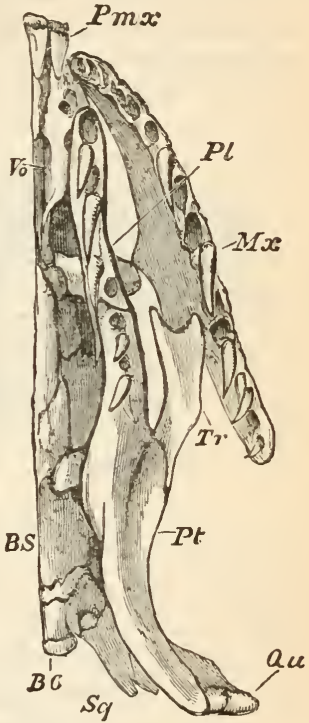

Fig. 141.-Lower Surface of Skull of Python.

P $m x$, Premaxillæ: $\mathbb{N} x$, maxillæ: vo, vonier; Tr, transverse bone; $\mathrm{Pl}$, palatine; $\mathrm{Pt}$, pterygoid: Qu, quadrate; sq, squanosal; Bs, basisphenoid; Bo, basioccipital. (After Huxley.)

as we have learnt already (page 96), the quadrate is movable upon the squamosal $(\mathrm{s} q)$, so that the width of the mouth behind can be very considerably increased.

Anteriorly, there is a corresponding arrangement, inasmuch as the lower jaws are not firmly $\mathrm{w}-16$ 
united by a symphysial suture, but are only connected by an elastic ligament. Thanks to this disposition of the separate parts in front and behind, the cavity of the mouth is capable of very considerable enlargement.

In the venomous snakes the arrangements are

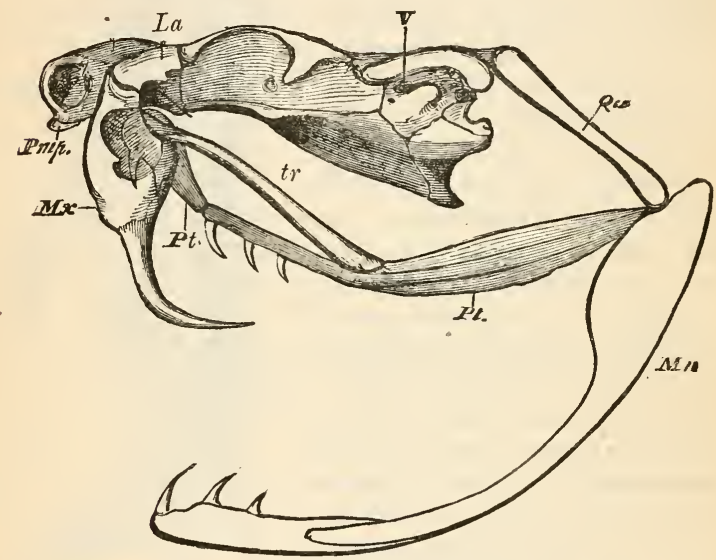

Fig. 142.-Skull of Crotalus.

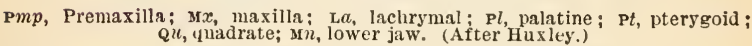

even more elaborate; the maxilla, instead of being elongated backwards, is shortened antero-posteriorly, so that its longer axis is directed downwards; it carries one long tooth, the "poison fang," and is excavated on its upper outer surface, where there lies the duct of the poison gland ; the maxilla moves freely on the lachrymal, which again can move on the frontal. The palato-pterygoid bar (Fig. 142: $l$, p $t$ ) is jointed, and the pterygoid is further connected with 
the maxilla by the transverse bone $(t r)$. The long quadrate is movable in a plane parallel to the lcng axis of the skull, and when the mouth is shut is directed backwards, so that the palato-pterygoid bar forms a straight line, while the palatine and transverse bones pull the maxilla backwards and upwards, and so cause the poison fang to lie along the floor of the skull. When the mouth opens, the point of attachment of the lower jaw is necessarily drawn upwards; this action forces the lower end of the quadrate forwards ; the quadrate acts on the pterygoid, and the pterygoid on the palatine and transverse bones, which, driving forwards what is before them, force the maxilla outwards and downwards; the poison fang is thus caused to become vertical, or in a position to inject the poison, which is simultaneously forced out of its gland through the chaniel in the tooth, and so into the body of the victim.

In the poisonous Mexican lizard Heloderma, the poison glands are modifications of sublingulal glands, and the lower jaw is traversed by the channels through which their ducts pass into the floor of the mouth. In Hatteria, the teeth are lost after a certain time, and their place is taken by the bones that bear them, the margins of which are sharp and of exceedingly dense structure, so that here the bones take the place of the teeth. (See page 146.)

While in the Ophidia the two halves of the lower jaw are connected by ligament, and in most Lizards and all Crocodiles by sutures, they become completely fused with one another in the Chelonia; the same phenomenon is to be observed in Birds, and in botl cases it is, no doubt, to be correlated with the loss of teeth and the acquirement of a horny investment or beak. In the turtles the fossa on either side of the skull, bounded externally by the jugal and quadratojugal, is roofed over by an outgrowth of the parietal; 
this remarkable arrangement is, curiously enough, found also in one species of the amphibian Pelobates, and in the African rodent Lophiomys.

In the voracious Crocodiles the teeth are confined to the maxillæ, premaxillæe, and lower jaw, as in Mammals, and these bones are, further, socketed for the reception of the strong teeth. In connection with their mode of life, which requires that they should, while breathing air, hide as much of their body as possible under the water, the anterior nares are placed at the end of their long snout; the eye, for the same reason, lies high up on the head, and the orbital cavity is seen, therefore, from an upper rather than from a lateral view of the skull; the hinder openings of the nasal passages, which, in the forms hitherto described, lie in the anterior region of the roof of the mouth, are in the crocodile placed very far back; this is effected by the development of transverse plates formed by the maxillæ, palatines, and pterygoids which unite into a long floor for the nasal passages.

In many Birds the upper jaw is capable of a certain amount of vertical movement, such as is carried to an extreme in the parrots; this freedom is due either to incomplete ossification between the ethmoidal and nasal regions, or to the formation of true articulations between the large premaxillæ on the one hand, and the frontals, jugals, and palatines on the other; these latter, as in a number of other birds, are not immovably connected with the basisphenoid, but can slide backwards and forwards, while the quadrate, with which the jugal is connected, is movable, as in lizards or snakes. When the quadrate is pushed forwards, as it is when the lower jaw is depressed, it pushes the jugal forwards, and that bone pushes the beak upwards. While the maxillæ are comparatively small, the three-rayed premaxillæ are of considerable size, and the processes by 
which they are connected with the frontal and with the palatines are very important factors in the attachment of the beak to the cranium; especially is this the case in those skulls in which ossification of the ethmoidal region is incomplete.

In the wood-peckers, where the head is "employed

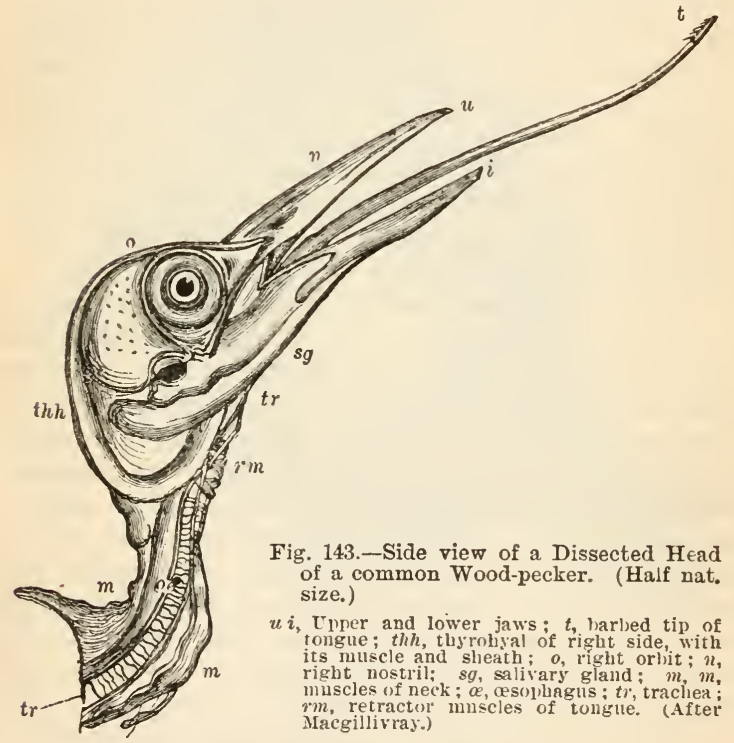

as a powerful hammer or axe, whose strokes can be heard at a considerable distance" (Garrod), the bones of the skull are thicker and stronger than in most bircls, and the upper jaw has its power of vertical movement considerably limited. The articulation of the palatine with the basisphenoid disappears, in consequence of the feeble development of the hinder 
end of the palatines. In correlation with the mode of action of the tongue (Fig. $143 ; t$ ), which is protruded into the recesses from which the bird extracts the insects on which it feeds, the hyoid bones that support it $(t h h)$ are greatly developed, the anterior cornua passing backwards and then curving forwards over the roof of the skull, in grooves of which they lie. From the ends of these bones or their sheath, there arises a muscle which is inserted into the lower part of the same bones; the contraction of this muscle straightens the curve of the thyrohyals, but this can only be effected by the protrusion of their free or lower ends; as the tongue is placed at this point, and is supported by the bones, it is clear that it is simultaneously protruded. (See page 156.)

In the Mammalia the quadrate, of which we have till now heard so much, is converted into one of the auditory ossicles, the malleus; the covering bones of the mandible are reduced to the dentary. Man, so far as is known, is the only animal, in addition to the frog and the sturgeon, in which the mentomeckelian cartilage is found on either side of the mandibular symphysis. The Marsupials are remarkable for having the angle of their lower jaw developed into a strong inflection, which is absent only in Tarsipes, and, among the Eutheria, has only been observed in the insectivorous Centetes (the Tenrec).

When we compare a carnivorous mammal, in which the lower jaw moves up and down, with a ruminant, in which it moves from side to side, we observe a difference in the characters of the glenoid cavity by which the mandible is articulated with the cranium ; in the dog, for example, this fossa is concave fiom before backwards, and the projections in front and behind limit the movements of the articular end of the mandible to such as can be effected in a vertical 
direction ; and this articular end or condyle is convex. In the sheep, on the other hand, the condyle is broad and flattened, and works upon a flattened or slightly convex glenoid facet.

When a large surface of attachment for the

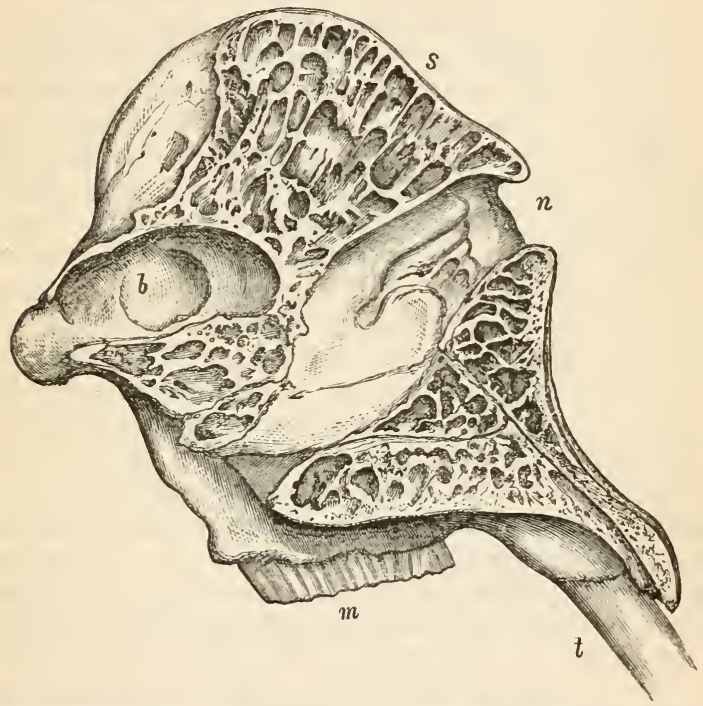

Fig. 144.-Section of the Skull of an Indian Elephant, to show the Air Carities.

$b$, Brain-case ; $s$, air sinuses; $n$, nostril ; $m$, molar ; $t$, tusk.

necessary muscles is required, as in the elephant, the skull is not composed of thick bone throughout, but a finer bony tissue with a number of intervening air cells is developed between the "tables" of the cranial bones; by these means a wider area is obtained without any proportional increase in the weight of skull to be supported (Fig. 144). 
In the dolphins, where the olfactory sense is greatly reduced or perhaps altogether lost, no olfactory fossa is to be seen in a longitudinal section of the cranium ; in correlation with their habits, and the large size of the mouth cavity, and the length of the premaxillæ and maxillæ which form its roof, the nasals are reduced in size and placed far up on the surface of the skull; the anterior nares consequently look upwards instead of forwards, and are therefore the first to appear above the surface of the water, when these pulmonate aquatic animals come up to breathe air. $J$ ust as in crocodiles, whose habits are so far essentially similar, the pterygoids develop transverse plates, the formation of which throws the posterior nares very far back on the roof of the mouth, and thereby approximates them to the opening into the trachea.

It is important to observe that quite a different set of arrangements obtains in the Sirenia, which, instead of being active or marine forms, are sluggish, and live much at the bottom of shallow rivers; here the bones are exceedingly dense, the anterior nares look forwards, but are of very large size, and no special plates of the pterygoid prolong the nasal passages backwards. When we compare the structural adaptations of the Sirenia and the Cetacea, it is impossible to avoid seeing, on purely theoretical grounds, which of the two has the advantage; and this consideration may be supported by the abundance of the species and specimens of the latter as compared with the former.

The ant-eater is another form in which the posterior nares are placed very far back owing to the development of pterygoidal plates to form a floor for the air passages ; in this case an explanation is possibly to be found in the fact that such a disposition, by means of which the nares and the glottis are brought into much closer proximity, would be an advantage in 
forms where a powerful inspiration might lead to an insect being carried from the tongue into the trachea.

In various Mammals the roof of the skull is in one way or another enlarged; in the sperm-whale, the nasals, maxillaries, and supraoccipital unite to form a large basin; as the contents of this basin are, however, of an oily nature, we may believe that the specific gravity of the bone is neutralised (even if no advantage is gained) by that of the spermaceti, the specific gravity of which is 843 at $50^{\circ} \mathrm{C}$. In the Pihinoceros and in the Ungulata the roof of the skull carries horns. (See page 369.) In the porcupines many of the upper cranial bones are expanded, and contain large air sinuses, as in the frontal region of the sloths.

The morphological characters and homologies of the ribs present a problem that is yet unsolved; the evidence as to their origin in the embryo being not a little conflicting. In a number of forms they undoubtedly arise in the tissue of the protovertebrie (see page 529) quite independently of the vertebræ themselves, their connection with which is only seconclary. In the Cyclostomata, Holocephala, and some rays, there are no ribs, and the supporting function of these absent rods is undertaken, as in Amphioxus, by the fibrous tissue which lies between the dorsal and ventral muscular layers.

Among the Amphibia and the Amniota, the ribs, when present, ard typically developed, are connected with the vertebræ by an upper and lower process ; in the Cæciliæ, where, among amphibians, ribs are best developed, these two processes are widely separated; in the Salamanders the proximal ends of the anterior ribs are forked, and of the hinder single; in the Anura the ribs are reduced or quite rudimentary.

In the Amniota the ribs have a greater functional importance, as is shown by the length of the more 
anterior, and their union in many cases with the sternum in the ventral median line. A definite thorax may henceforward be recognised, and the appearance of this cage associated with the complete absence of branchial respiration. In front of the thorax more or less well developed ribs may be developed, but these never become connected with the sternum; in the Chelonia there are no cervical ribs. The sternal ribs are jointed, and in Reptiles the sternal portion remains cartilaginous; where the sternum is short many of the ribs are connected with the cartilaginous rod that lies behind it. In Birds the connection between the ribs and the sternum is more complete, and the whole apparatus is firmer and stronger (see Fig. 135), while in them, as in crocodiles, the side walls of the thorax are strengthened by the development of backwardly directed processes from the ribs (uncinate processes) ( $\iota p)$. Cervical ribs are very rare among Mammals, though occasionally found, as in Bradypus. The thoracic ribs are so articulated as to be capable of a considerable amount of movement, thanks to which the thoracic cavity may be increased or diminished in size; they are either attached directly to the sternum, or connected with it by ligament, or are quite free at their distal end. In the Cetacea some of the hinder ribs lose even their attachment to the vertebræ.

In the Ophidia, where the primitive condition of a large number of similar ribs is retained, there is a single articular head for connection with the vertebral column; this is of a kind to allow of considerable freedom of movement, and the snake uses its successive pairs of ribs as stilts by which it may move along the ground.

In the Ammiota the ventral ends of the ribs become constricted off, and fuse with one another in the median line; the cartilaginous plate thus formed 
is known as the stermum. With the anterior end of this sternum there ordinarily comes into relation the ventral part of the anterior limb-arch (see infrà); and, farther back, we may find the rentral attachments of the ribs. In the Chelonia and Ophidia the sternum is lost, and this is to be correlated with the great development of the exoskeleton of the one, and the mode of life of the others of these orders of Reptiles. In the Carinate birds the median portion of the sternum is produced into a long and strong keel (Fig. 145 ; cs), to the sides of which are attached the powerful thoracic muscles which depress and elevate the fore limbs ; an analogous carination is to be seen in Bats. In the fossorial Insectivora, such as the mole (Fig. 146), the presternum is produced far forwards, is keeled, and widened out at the sides so as to afford a large surface of attachment for the muscles that move their digging limbs.

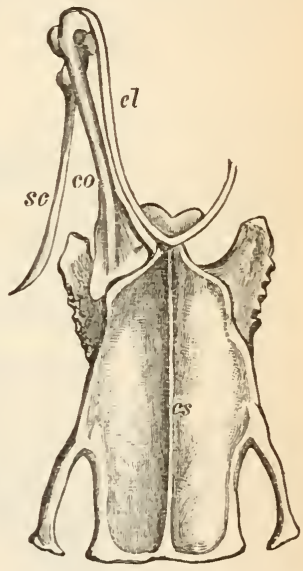

Fig. 145.-Sternum of Fregilupus varius.

$c l$, Clavicle ; $s c$, scapula ; co, coracoid ; $c s$, keel of sternum. (Aftér Murie.)

In all the gnathostomatous Vertebrata the body is typically provided with two pairs of lateral appendages, or limbs, one of which lies, as a rule, some distance in front of the other; these are the fore and hiud limbs. They are brought into connection with the axial skeleton by means of arches, the pectoral and pelvic arches.

The Pectoral arch consists essentially of a bar of cartilage, which undergoes division into a dorsal part, 
or scapula, and a ventral portion, the coracoid; at their point of junction the proximal end of the fore limb is attached. The pelvic arch is, similarly, a cartilaginous bar, which may be divided into a dorsal

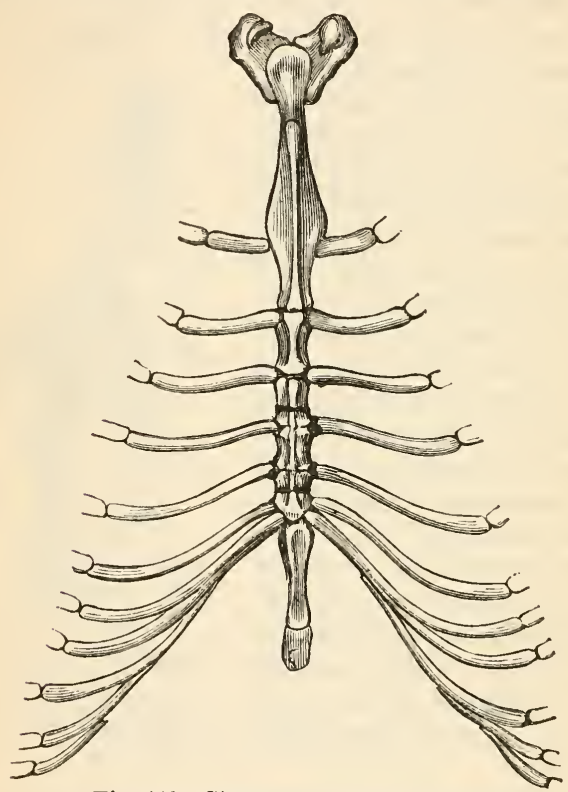

Fig. 146.-Sternum of common Mole.

iliac, and a ventral pubic piece; and the head of the hind limb is attached to the arch at the point where its two halves unite.

The coracoid divides into two processes, the praccoracoid and coracoid proper; the pubic bar is, sinilarly, in the higher forms, separable into an anterior pubis and a posterior ischium. In 
Fishes, where there is no sternum, the coracoids early unite in the ventral median line; where a sternum is present the coracoid of either side enters into connection with it. In the hind arch, where there is no bar corresponding to the sternum, the pubes and ischia may unite with their fellows at a symphysis, as in all Mammalia; in all Vertebrates above fishes, the ilia enter into a more or less firm union with the sacral region of the axial skeleton, or vertebral column. (See page 321.)

Just as in the case of the skull, when covering membrane bones are developed some enter into union with the cartilage or cartilage bones of the pectoral arch, but no such bones go to form part of the pelvis. The most important of these bones is the clavicle, with which in some fishes a supraclavicle, connected with the skull, and an infraclavicle, united with its fellow below, are added on; in the Amniota an interclavicle is sometimes developed. As we ascend the scale we observe a reduction in the coracoidal region; thus the precoracoid is absent in the crocodiles, and among birds is found in a rudimentary condition in the Ratitæ only ; in mammals it is never present, and the Prototheria alone have a fully developed coracoid; as a rule the scapular end of the bone is alone retained ; it is, indeed, from the hooklike form of its remnant in man that the bone has received its name. In a few (shrew, mouse) the sternal end of the coracoid is persistent (Gegenbaur).

In Chamæleons and Crocodiles the clavicle is lost, as it is also in many Ratitæ, where, if present, it is only rudimentary; in the Carinatæ the two clavicles unite to form a single bone, the furcula ("merrythought"), which becomes connected by ligaments with and strengthens the carina sterni (Fig. 145). Among mammals the clavicle may be well developed, as in man and the bat, bony in its median region 
only, as in the rabbit, and still more in the dog, or absent, as in bears and all Ungulates. The interclavicle is developed only in Prototheria.

In the 'Teleostei the pubic arch may be placed far forwards, and be thoracic, when the hind-fins lie below the fore-fins; or jugular, when they lie in front of them (Fig. 134). In the higher forms they always retain their position between the abdomen and the tail. In recent reptiles the ilium may extend far back, while in birds, and in certain extinct reptiles (Dinosaurs) it is developed anteriorly to the acetabulum, or cavity of articulation for the head of the hind limb. In the Sauropsida this cavity is never completely bony, and the same is the case in Echidna (though not in Ornithorhynchus); with this exception the acetabulum is always a completely bony cup in mammals.

In correlation with the posture or mode of progression, the ilium enters into more or less close union with the sacral region of the vertebral column, and the demands made upon the axis for further support are responded to by the fusion of presacral or postsacral (or both) vertebræ with those of the true sacrum to form a solid piece. Thus, in a bird (Fig. 147) the whole arch is of great size, while in the Cetacea it is at most represented by the ischia.

Just as there are very many striking and suggestive points of resemblance between the fore and hind arches, so are the fore and hind limbs arranged on essentially similar principles.

It will be most convenient to begin with what obtains in the Amphibia and Amniota, or the pentadactyle Vertebrata. Either limb may be divided into three regions : ( $\alpha$ ) arm, fore-arm, hand ; $(\beta)$ thigh, leg, and foot. In the arm, and in the thigh, there is a single bone: ( $\alpha$ ) humerus, or $(\beta)$ femur; in the fore-arm and leg two: $(\alpha)$ radius and HIma; $(\beta)$ 
tibia and fibula; the $(\alpha)$ hand (unamus) is divisible into wrist (carpus), palm (metacarpus), and digits; the $(\beta)$ foot (pes), into tarsus, metatarsus, and digits. The digits are typically five in number, and consist of a number of separate pieces, articulated on one another; the number of these phalanges is inconstant, but, as we ascend the

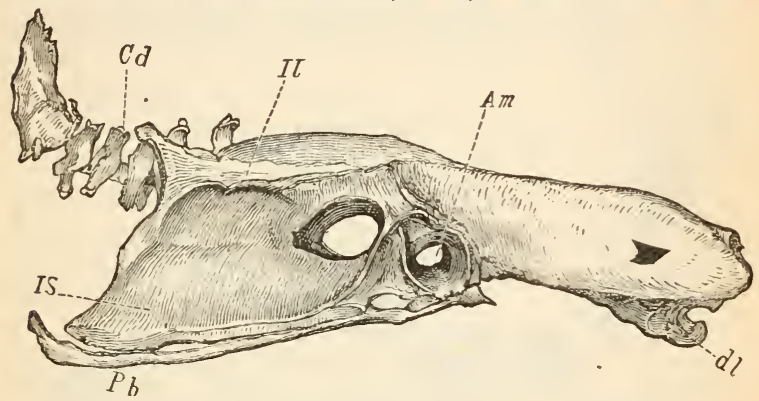

Fig. 147.-Side View of the Pelvis of an Adult Fowl.

Il, Ilium ; 18 , ischium ; $\mathrm{P} b$, puhis; $d l$, dorsal vertebre; $\mathrm{C} d$, caudal vertehræ; Am, acetalsulum. (After W. K. Parker.)

series, we observe a reduction; they are sometimes, though not always, provided with horny claws.

The humerus, which fits, by its anterior rounded head, into the glenoid cavity formed by the edges of the scapula and coracoid, acquires a greater freedom of movement when, as in the Mammalia, the coracoid is reduced in extent. It is generally characterised by the possession of a more or less strong bony ridge to which the deltoid muscle is inserted, the size of which is, of course, in proportion to the use to which the fore limb is put; and the ridge, therefore, is very pronounced in fossorial and flying forms. In the Carinatæ the muscle that elevates the wing lies, with those that depress it, in the pit formed by the sides of the keel of the sternum, and its tendon passes over 
the coracoid and scapula to be inserted into the humerus ; in other words, it works over a pulley.

While a flying organ is developed in the Carinatæ (Fig. 148) by the elongation of the humerus and of the radius and ulna, the latter of which is marked by the impressions of the secondary wingfeathers; while both are so articulated with the lower end of the humerus as to allow of little movement

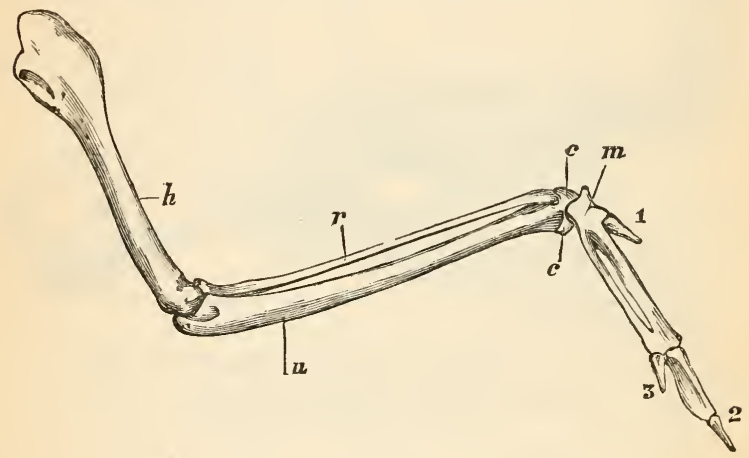

Fig. 148.-Skeleton of Fore Limb of a Flying Bird.

$h$, Humerus ; $r$, radius ; $u$, ulna ; $c$, carpal bones; $m$, metacarpus ; $1,2,3$, digits.

on one another, or, in other words, aid in the formation of a rigid rod; by the reduction of the carpus to two bones; and by the fusion of the second and third metacarpals and the reduction of the digits. a very different modification of the homologous parts is found in the bat. Here (Fig. 149) all the metacarpals, save that of the first digit (thumb), are greatly elongated, as are too the phalanges of the third, fourth, and fifth digits; between these and the body there extends a fold of thin membrane (the "wing membrane"), by the expansion of which these Mammals are enabled to float and move through the air. 
In Galeopithecus (the so-called Flying Lemur), the fore and hind limbs are both elongated, and there stretches between them, attached to the sides of the body, a fold of skin which, unlike the wing membrane of a bat, is hairy on either side. Among lizards a flying form is represented by Draco, where the support for the flying apparatus is afforded by the elongation of the ribs.

Another set of modifications is to be found in the aquatic pentadactyle forms, such as the turtles, crocodiles, and aquatic mammalia. Here the essential modification consists in the elongation of the manus or pes to form a fin-like organ; the simplest and first change is seen in river tortoises, where, as in the feet of wading birds, the digits are merely connected by a web; as this web extends, it gradually encloses the separate digits and converts the organ into a paddle, as in the marine turtles, where the fore are larger than the hind limbs, or the whales and Sirenia, in which the hind limbs are altogether aborted; the Sirenia have rudimentary nails, and agree with other mammals in never having more than three phalanges to their digits. The whales present a more

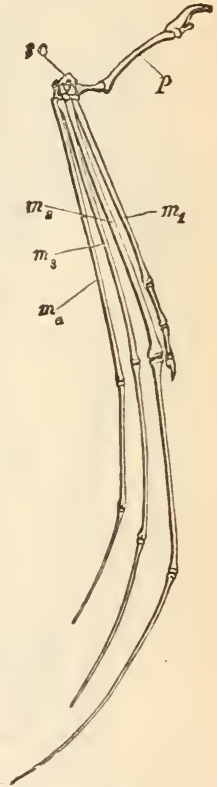

Fig. 149.-Manus of Bat.

$p$, Pollex ; sc, scaphoid : $m$ l to $m^{4}$, the elongated metacarpals of the second to flfth digits. extreme case, as all rudiments of nails are lost, and the phalanges of some of the digits may come to be as many as twelve or thirteen in number (Fig. 150).

In the Mammalia we observe that the limbs $\mathrm{x}-16$ 
ordinarily become organs of support for the borly,

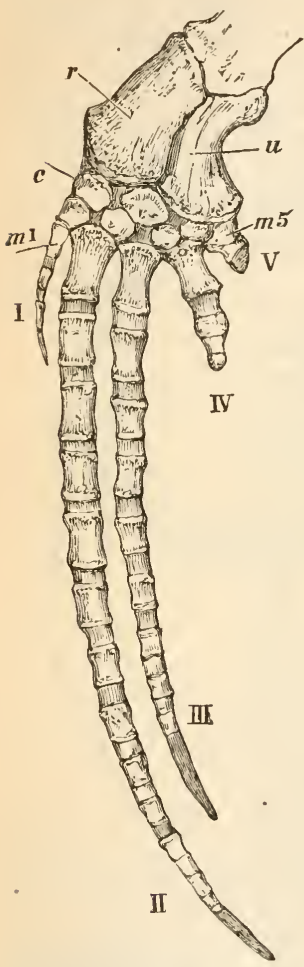

Fig. 150, - Fore-arm and Manus of the Round. headed Dolphin.

$r$, Radius ; $u$, ulna ; $c$, carpal bones ; $m 1$, first; $m$, fifth metacarpal; 1 to $\mathrm{v}$, digits. and that in them more than in other Vertebrates these appendages cease to lie alongsicle the body, or in a plane more or less parallel to its long axis, and come to be set in a vertical plane. This change having been effected, we note here, as elsewhere in the organs of the animal body, a reduction of superfluous parts, and a consolidation of what remains. In a large number of Mammals, the thumb (pollex) or great toe (hallux), which never have more than two phalanges, except in some, though not all, Cetacea, is completely lost. Among the Ungulata the tendency to a further reduction is seen in the sheep and ox on the one hand, where two digits persist, and in the horse, where the whole weight is carried by the micldle or third digit of each limb. The historical evidence as to the gradual reduction of the second and fourth digits in the horse may be regarded as complete. (Compare Fig. 151.) While reduction affects the digits, consolidation is more often seen in the metacarpal and metatarsal, and carpal and tarsal bones; the muscles that are 
connected with the lateral digits gradually disappear.

In the series of Artiodactyla (even-toed forms) we find, to take the foot, four toes, distinct metatarsal, and distinct tarsal bones (in the pig); in the Chevrotains (Tragulus), the second and fifth digits are still smaller, and while their metatarsals are distinct, the third and fourth metatarsals have united together, two of the tarsals have united together, and one of the rest has disappeared; in the muskdeer, as in the true deers, the outer digits are not directly articulated with the other bones of the foot, and the outer metatarsals have, as in
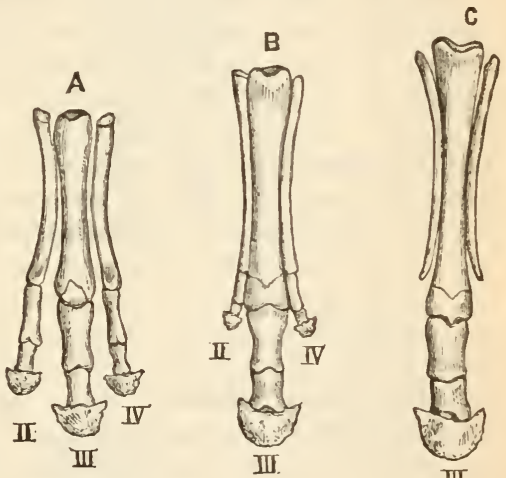

III

Fig. 151.-Foot of Anchitherium (A); Hipparion (B), and Horse (c).

II, III, IV, digits.

them, disappeared ; the musk-deer, however, retains what the deer have lost, the extensor muscle of the fifth digit.

While the large number of what are really or practically two-toed Ungulates is evidence that this reduction of the digits has not been associated with any diminution in the value of the limbs as locomotor or supporting organs, we have palæontological evidence of the disappearance of a group of even-toed Ungulates who tended to lose their lateral digits. When we examine the carpus of a deer we see that the carpal bones have fused with one another, and have not disappeared 
as the lateral digits, with which some of them were connected, have lost their function ; as the middle digits have grown larger and thicker they have seized on the carpal bones, and thereby gained "a better and more complete support for the body." In some fossil forms (Xiphodon, Anoplotherium), " the relation between the carpal and tarsal bones, and the remaining two middle metacarpals and metatarsals, remains just the same as it was in the tetradactyle ancestor"; the digits that remain do not, in other words, gain further support from the carpal or tarsal bones. Forms in which inheritance has been stronger than modification have disappeared, while in those which have lived on or left descendants, an adaptive modification has been effected (W. Kowalevsky).

As we ascend the scale of the Primates we find an increasing tendency to throw the support of the body on the hind limbs only; thus, all the manlike (anthropomorphous) apes are semi-erect; the Gibbon (Hylobates) uses the tips of his finger's much as an active man uses a walking stick (Huxley), the orang, the gorilla, and the chimpanzee, support themselves on their knuckles. Man is erect, and, in correlation with this position, the tuberosity of the os calcis of the foot is greatly broadened, the thigh and leg are in a straight line, the pelvis becomes an open basin separated by a wide space from the thorax, the vertebral column takes on a marked S-shaped or signoid curvature, the head is balanced on the atlas, and the spines of the cervical vertebræ, which have no longer to give origin to powerful muscles, are reduced in size. Owing to the monopoly of support enjoyed by the hind-limbs, the fore limbs become free to serve as prehensile organs, and in man, where there are no great canines (as in male gorillas) to serve as organs of attack, it is to the arms only that such an animal can look for offensive or defensive organs. 


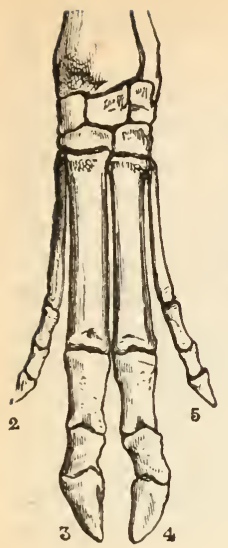

A.

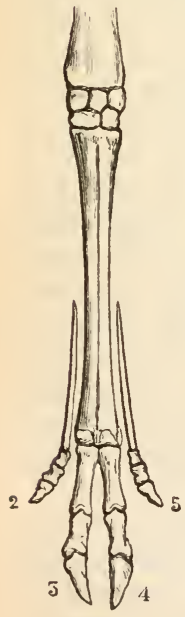

D

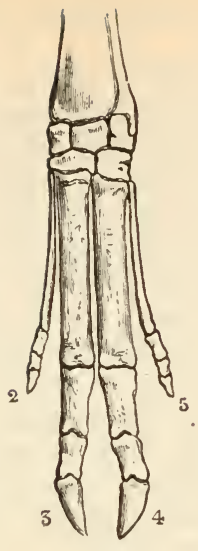

B

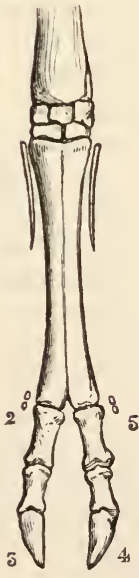

E
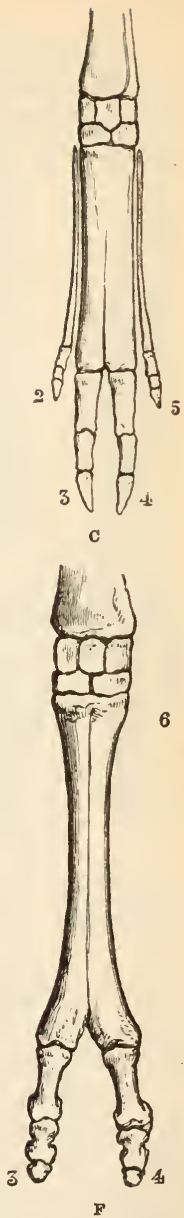

6

Fig. 152.-Skeleton of the Left Fore Limb of a Pig (A); Hyomoschus or African Deerlet (B); Tragulus or Javan Deerlet (C); Roebuck (D); Sheep (E); Camel (F). (After Garrod.) 
While the results of the erect position show that man has been able to adapt his altered mode of progression to the mechanical conditions of an organisation best suited for quadrupedal movement, it is to be

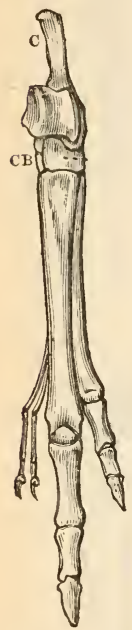

Fig. 153. -

Right Pes of Kangaroo.

noted that (1) the space between the thorax and the pelvis leads to, and is the cause of, prolapse and other affections of the uterus, and of hernia in both sexes; (2) the carotids which supply the most important of organs, the brain, have to carry their contents against the action of gravity, and, for this reason, they are of large size. Or, to put it in another way, the erect position entails certain positive disadvantages.

In other members of various divisions of Vertebrates, by far the most important part in support or locomotion is often undertaken by the hind limbs; this is especially well seen in hopping or jumping forms, as, for example, the frog, where the tarsal bones are greatly elongated and the digits of considerable length; in the jerboa, where the metatarsals are very long; or the kangaroo, where the calcaneum (c) is very long, the cuboid (CB) very strong, and the metatarsal of the fourth digit greatly elongated; in other words, we have here a continuous series of well-developed bones lying along one axis, and affording a firm support (Fig. 153).

When the extremities are used as seizing organs, the pollex of the manus and the hallux of the pes are apposable on the other digits; such an arrangement obtains in the higher Primates, but in man, where the foot has more of a supporting than of a prehensile function, this power of opposition is lost in many races 
by the hind limb, thongh it can be regained under the stress of necessity, or by education ; the saddle-shaped form of the articular surface of man's trapezium gives the mechanical reason for the power of apposition of the thumb, which he possesses in so marked a degree. In the tendons of the digits extra bones (sesimoids) are not unfrequently dereloped, and their presence is no doubt to be explained by a reference to the primitively multiradiate condition (see page 361 ) of the vertebrate limb; of such bones the most constant is the patella (knee-cap), which is found in all Mammals save a few Marsupials; another, which is very frequently found in the carpus, is the so-called pisiform (or pea-shaped bone of the human hand). The sesamoids are, as will be immediately explained, most commonly developed in association with the digits; thus, in the dog they are found on each metacarpal ; in the fossorial armadillos there is a large sesamoid on the palmar sicle of the metacarpus; two large palmar sesamoids are found in Ornithorhynchus ; while in the just-mentioned Monotreme, as to a less extent in Echidna also, there is a large sesamoid in the tarsus which supports the spur of the foot, that has so remarkable a likeness to what is found in the fowls and some other birds.

The paired fins of Fishes are, at first sight, difficult to bring into alliance with the pentadactyle limb of the higher Vertebrata. If we take the dogfish as a type, we find that the pectoral are larger than the pelvic fins, and more complicated in character. We will commence, therefore, with an account of the latter. They lie horizontally, and approach one another at the ventral median line. A long basal bar (Fig. 154; A, bp) is articulated to a process of the ilium, and bears on its outer side a series of rays, which are each divided into a larger proximal or basal and a smaller distal piece, almost parallel to one another; 

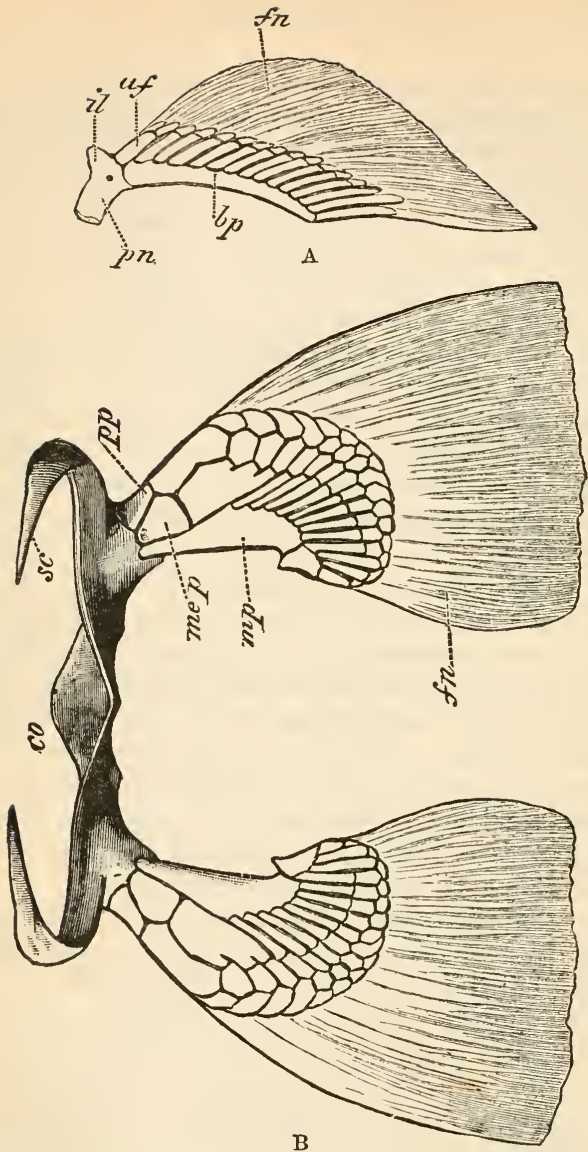

Fig. 154,-A, Right Pelvic Fin and part of Pelvic Arch of an Adult Female of Scyllium canalicula (nat. size). B, Right Pectoral Fin and part of Arch of an Adult Scyllium canilicula.

co, Coracoid; $s c$, scapula; $p p$, protopterygium; $m e p$, mesopterygium; $m p$, metapterygium; il, iliac process; $p$ p, pubic process, cut across below ; $b p$, basipterygium ; fu, anterior fln-ray ; fn, part of fin, supported by horny fibre. (After Balfour, P.Z.S., 18:1, p. 663.) 
the most proximal articulates directly with the ilium (il), and the most distal is, in the male, converted into the clasper. (See page 519.) The outer portion of the integument of the fin is supported by horny fibres $(f n)$. The pectoral fin (Fig. $154 ; \mathrm{B}$ ) is at least twice as large as the pelvic, and is placed horizontally, but the two halves do not approach one another ventrally; there are three basal cartilages, called respectively (Gegenbaur) protopterygium $(P p)$, meso- (mep), and metapterygium $(\mathrm{mp})$; the latter carries most of the cartilaginous rays, and these are divided into a larger number of pieces than the corresponding rays of the pelvic fin ; as with it, the greater part of the fin is supported only by horny fibres.

According to the observations of Balfour, the paired fins arise as ridge-like thickenings of the epiblast (see page 33); the mesoblast that invades the riclge gives rise to a cartilaginous bar, which, at first, lies parallel to the long axis of the body. On one side (the outer) of this bar a thin plate extends outwards, and this, by becoming clivided, gives rise to the primary fin rays; this simple condition is essentially retained in the pelvic arch; in the pectoral, however, the basal bar becomes rotated outwards, so that it is now only connected by its anterior end with the pectoral arch, and the bar, in place of being the basal portion, now forms the hinder border of the fin; the plate attached to the bar becomes imperfectly divided into a smaller proximal and a much larger distal piece; from the edge of each of these, rays are given off; the smaller piece undergoes a second division, by which we have, at last, the protopterygium $(p t)$ with one ray, and the mesopterygium with a few ; the rest of the rays are attached to the metapterygium, or larger distal piece.

On the supposition that a many-rayed limb of the characters just described is that from which the 
pentadactyle limb of the higher Vertebrata has been developed, we must suppose that the greater number of the cartilaginous pieces have undergone reduction, and that, in the Ichthyosauria for example, or in the frog, where there is a rudiment of a sixth digit to the foot, the number five is exceeded in consequence of the reduction not having been definitively impressed on the organism by inheritance; on the other hand, the possession by a Mammal (e.g. man) of more than five digits (polydactylism) must be regarded rather as an abnormality than as a return to an ancestral condition, and this because the gap between a man and a polydactylous ancestor is too wide for us to be able reasonably to believe in an "atavism" so far-reaching.

In the Ganoidei or Teleostei, the pterygial portions of the fins are reduced, but the reduction is atoned for by the replacement of the horny fibres by osseous tissue. In Ceratodus the fin takes the form of a central axis of cartilaginous pieces, with rays on both sides ; and in Protopterus it becomes filamentar, owing to the loss of the lateral rays. Gegenbaur regards the fin of Ceratodus as the most primitive arrangement (archipterygium); but, as Balfour has pointed out, this view of the matter is opposed by the facts that in Elasmobranchs there are indications of rays on one side only of the basipterygium, and that the supporting bar is, at first, basal, and not central.

Like the limbs of higher Vertebrates, the fins of fishes are, at first and in most cases, locomotor in function, wherein they are aided by the tail; just as the former are supporting organs, so, too, are the fins. This may be seen by removing the fins of one side, when the fish falls on to that side; or by cutting off both pectorals, when the body inclines forwards and downwards. In mud-dwelling fishes the pelvic fins are rudimentary or absent, disuse producing degradation. One of the most remarkable modifications of 
the fins is seen in Periophthalmus, which, thanks especially to its large pectorals, is able to hop over the mud. In sorne Gobies the ventral fins unite to form a kind of suctorial disc, by means of which the fish can attach itself to rocks. The sucking disc of Cyclopterus lumpus is supported by the rudimentary spines and rays of the ventral fins. In the flyingfish (Exocotus) the pectoral fins may extend as far back as the caudal, and can be spread out so as to act like sails. In cartilaginous fishes, where the edges of the fins are softer than in the bony fishes, these edges may perform an undulatory or screwlike movement. When the lateral fins disappear, the locomotor function falls altogether on the vertebral column and unpaired fins.

The External skeleton of Vertebrates is, in the simpler conditions, formed by seales, which are developed in the cells of the integument. The most generalised condition obtains among Elasmobranchis, where, as we have already learnt, the internal skeleton is throughout life cartilaginous; in such a form as the dog-fish the whole of the external surface is roughened, owing to the presence of projecting pointed processes, which have not inappropriately been called dermaI denticles, so close and striking is their resemblance to the processes which, when placed within the area of the mouth, are called teeth; like them, they consist essentially of dentine invested in a layer of harder enamel. In the huge basking shark the whole of the body is covered by denticles, which, taken separately, are small enough, but which en masse must be a very effective means of defence. In the spinous shark (Echinorhinchus) the diffused arrangement yields to one in which large spinous tubercles are scattered over the body, and the value of that diffused arrangement is very eloquently spoken to by the naked body of the torpedo, which has found a still 
better mode of protection in its well-developed electric organ. In various Elasmobranchs the more prominent fins are provided with strong spines.

The Ganoidei received their name from the possession by some of them of bright shining scales, which owe their appearance to the investing layer of enamel. Such "gamoid scales" are, however, found in perfection only in Lepidosteus and Polypterus among recent members of the group; in the sturgeon, for example, there are bony plates, and Spatularia is naked. In the two Ganoids first mentioned the scales overlap, and the whole body is protected by a closely and firmly set coat of mail. Among fossil forms we find the typical ganoid arrangement sometimes carried to a remarkable extreme, as in Pterichthys, where large bucklers are found not only on the dorsal but also on the ventral surface. The allied Dinichthys is thought to have reached a length of more than fifteen feet; and we see in it, as in other gigantic forms, such as the Irish elk, that individual protection has been only attained at the cost of the disappearance of the species.

The simpler smaller scales that are found in some Ganoids, and very commonly among the Teleostei, may be, when we look at extremes, classed under the head of cycloid scales, in which the free projecting margin is rounded, or as ctenoid, in which the margin, or part of the surface, is denticulated or comb-like; between these, however, there are a number of intermediate stages; the ctenoid scales may be supposed to have given rise to those in which part of the surface is continued into fine non-denticulated spines (sparoid scales of sea-breams). While some fishes, such as Stomias, have the scales deciduate, and others, not to speak of electric forms, are, like the eel, scaleless, the Teleostei, almost as much as the Ganoids, present us with examples of forms in 
which the whole or the greater part of the body is amply provided with a defensive armature. Such forms are Osteoglossum and its allies, in which the body is closely covered with hard scales, the "cofferfishes" (Ostracion), where the hexagonal scales fit like the pieces of a mosaic, or the globe-fishes (Diodon), where the whole of the globular body is covered by projecting and movable spines, which, standing out on erection, must most effectually protect their possessor.

The protective function of the exoskeleton of the true fishes is replaced in the Cyclostomata by the rich supply of mucous glands to the integument; in the hag this power is carried to so great an extreme that a single example placed in more than three cubic feet of water is able to shed out so much mucus that the whole becornes converted into a continuous viscid mass ; with this power of emitting a sticking secretion we may compare the "cotton-spinner," where, however, no observations have yet been made as to the amount of the secretion.

The Amphibia best known to us have a soft unarmed integument, but the Crciliæ, among recent forms, have small cycloid-like scales in their integument, a few Urodeles have flat bony plates, and the extinct Labyrinthodonta would seem to have had a plentiful supply of well-developed ventral plates.

Among the Reptilia we have thickenings which may merely form epidermic scales, as in snakes and lizards, or larger bony plates (scutes), as in crocodiles, or very extensive pieces, as in tortoises and turtles. In the Ophidia the separate scales are held together by the continuous epidermic covering to which they owe their origin, and the whole is ordina. rily shed in one piece; the most remarkable modifica. tion undergone by them is to be seen in the rattlesnake, where the cuticular scales at the hinder end of the 
body are converted into transversely oblong plates, which, when moved rapidly on one another, give out a rattling or vibrating sound. Lizards may be scaleless, like the chamæleon, which possibly makes up for the absence of the protective covering, such as it is, by the power of so adapting itself to the coloration of the neighbourhood in which it finds itself as to be almost invisible; or the Amphisbæna; or there may be thin scales, as in the true lizards; or, as in Cyclodus, bone may be deposited in the dermis, and the bony plates may, as in the skink, unite into a mosaic-like arrangement.

In the Crocodilia there are scutes as well as scales; that is to say, the dermis undergoes ossification; and the separate scutes are covered by an epidermic thickening or scale. In a few (as the Caiman), the scales on both the upper and lower surfaces become, respectively, so united with their neighbours as to give rise to a dorsal or a ventral shield; on the long tail the upper and lower ossifications unite to form continuous rings. In most crocodiles, however, the ventral shields are absent, and the dorsal scutes do not unite with one another to form such continuous pieces as can properly be called shields.

The differences between the homy epidermic hardenings and the osseous dermal thickenings are best exhibited by the Chelonia, where, as is well known, large continuous pieces, both of shell and bone, are ordinarily exceedingly well developed. The thinner epidermic plates form the so-called tortoiseshell, the thicker dermal bones the plates of the shield, or carapace, which enter into close connection with parts of the endoskeleton.

In Birds, the outer covering is in the form of feathers; a feather consists of a central quill, shaft, or scapus (Fig. 155 ; d), from which on either side there are given off flattened branches, or barbs; 
the latter similarly give off much finer radii or barbules, which, interlocking by "cilia" and hooklets with those that are found on neighbouring barbs,

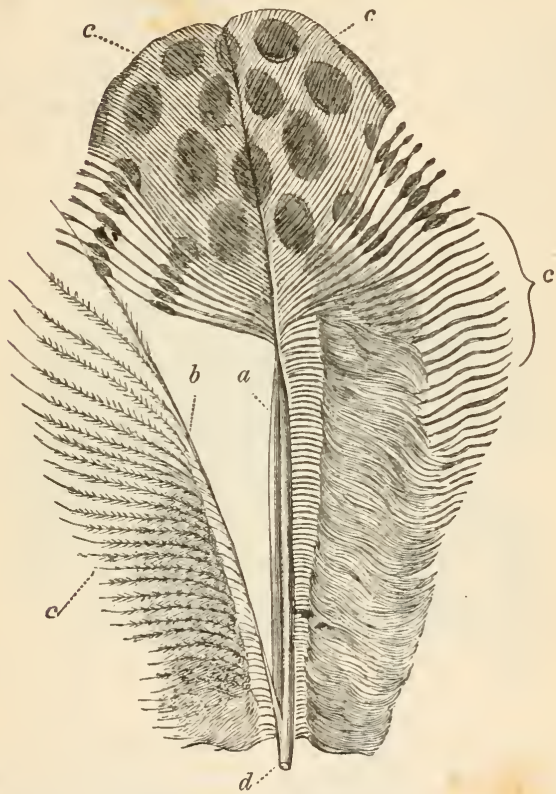

Fig. 155.-Feather from the Back of Argus giganteus.

$a$, Sbaft (rachis): $b$, aftershaft: $c$, branches to form the vexillum, removed from one side of both shaft and undershaft : $\bar{d}$, shaft (scapus). (After Nitzsch.)

form the connected vane or vexillum of the feather (c) ; the shaft, which in its upper portion is often called the rhachis, frequently gives off near its base a smaller feather or aftershaft $(b)$. It has been calculated (by Gadow) that the feather of an eagle contains about two thousand barbs, five millions and a 
half of barbules, and fifty-four millions of cilia and hooklets. These feathers are not irregularly arranged, but are set along definite tracts (feather tracts) the

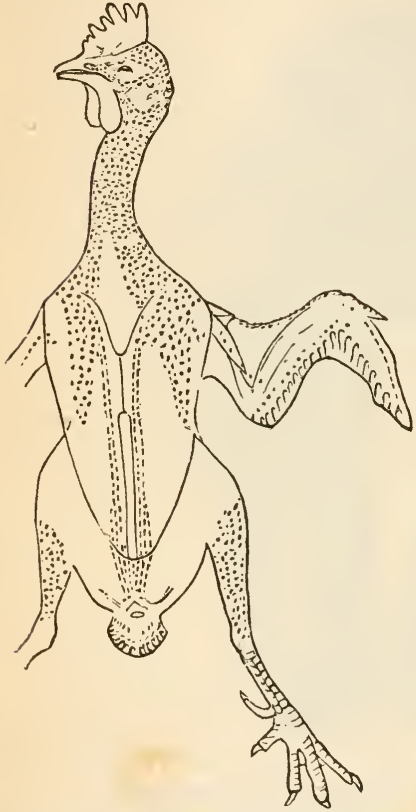

Fig. 156.-Pterylosis, or arrangement of Feather-tracts on the under surface of the body of a Cock (Gallus bankiva). (After Nitzsch.)

arrangement of which (pterylosis) varies in various birds, and has, since the time of Nitzsch, been made use of in classification (Fig. 156).

The function of feathers is not limited to the diminution of the specific gravity of the bird, which they effect by entangling air ; the same process is also of aid in preserving the high temperature of these creatures, in consequence of the feeble conductive power of air. So far as the former effect is concerned, we have to note that the Ratite birds, which never soar into the air, are without the barbules by means of which the barbs form a connected vane.

The hair's of Manmals, like the feathers of birds, are epidermic in origin, but their mode of development is somewhat different. As a general account of the structure of hair has already been given in chap. xxxiv. of Klein's "Elements of Histology," it is here only necessary to give some 
account of their arrangement in different forms. Hair is almost entirely absent from the body of adult Cetacea, and only scantily developed in the Sirenia; this common character must not, however, be regarded as any evidence of community of origin or closeness of relationship, but rather as the result of exposure to similar conditions. Sometimes, when the hair is

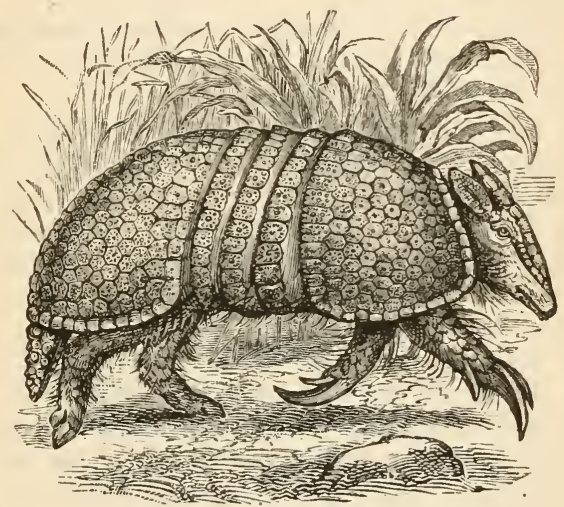

Fig. 157.-The Armadillo.

scanty on the body, as in the rhinoceros, a number of hair-like shafts unite to form a horn. In forms which live in very cold climates, like the musk-sheep (Ovibos moschatus), the hair is exceedingly long and thick, and serves as an efficient protection against the external cold ; the most striking example of this is afforded by the thick coating of the extinct mammoth, which lived in cold regions, whereas its allies, the elephants, which, in recent times, are confined to warm countries, have but little hair. The soft hair may be replaced by firm and strong spines, as in the porcupine or hedgehog, where, thanks to their power of $\mathrm{x}-16$ 
erection, they form very efficient organs of defence and protection.

Sometimes the hairs become specially endowed with a tactile function, as in the "whiskers" of feline and especially nocturnal carnivora; reminding us so far of the elongated delicate filaments of, no doubt, similar functions, which are found on the bodies of deep-sea fishes.

The hairs may be greatly elongated, and used, as in horses, for switches, by means of which their bodies are freed from offending insects.

The claws found on the digits of various lower Vertebrates are, as " nails," almost constantly present in Mammals, where they may be flat, as in man, sharp offensive claws, as in Carnivora, large protecting hoofs, as in Ungulates, or organs of support to arboreal forms, such as the bat or the sloth; they are wanting in the Cetacea.

The only Mammals in which long dermal scutes are now developed are the armadillos (Fig. 157), where three or more zones may be present, and form a more or less complete protective covering for these animals ; such scutes were present in enormous numbers in the extinct Glyptodon and Hoplophorus.

\section{CHAPTER $\mathrm{X}$.}

\section{ORGANS OF MOVEMENT.}

Is the Protozoa, where division of labour never proceeds so far as to lead to the formation of definite tissues, the function of Iocomotion, like all the rest, is simply performed by the protoplasm of the cell, which, as we have already learnt, is contractile. Thanks to this power of contractility, even an 
amorphous mass like an Amøba is enabled, by the withdrawal of one and the protrusion of another part of its substance, to move about from place to place. In the ciliated forms movement is due to the contractile action or play of those delicate processes of protoplasm which form the cilia; between the fine processes that we ordinarily call by that name, and the coarser, more lobate, processes that are distinguished as pseudopodia, the connection is very close, and under certain conditions one form may be observed to pass into the other. Among certain stalked Infusoria, such as Vorticella, we observe a mode of movement which is more rapidly executed than that of ordinary translation; a Vorticella, or its branched ally, Carchesium, may be seen to suddenly lower its bell, owing to the rapid contraction in length of its stalk; the agent by which this is effected is a modified portion of the protoplasm in the stalk (the so-called contractile band), which presents a striation that calls to mind that of a muscular fibre. Though agreeing with it functionally, the stalk differs from it morphologically, in that it is a modification of only part of a cell, and not of a whole cell, or of a set of cells. These bands are not confined to the stalked Infusoria, but are found in other forms both of the Ciliata and of the Gregarinida; without them, indeed, there can be but feeble movements in the latter endoparasitic organisms, which are withont either cilia or pseudopodia.

Among the lower Metazoa we find that the movements of the young are at first effected not by muscular tissue, but by cilia ; the free-swimming larva being provided with cilia, which may be scattered over the whole of the body, or confined to certain definite and characteristic tracts, such as circlets, one or more in number, or wavy bands (Fig. 158). In all groups, save that of the Porifera, the cilia are found on the outer surface of the body or epiblast, and in 
all but it, the members of which are always fixed when adult, a definite tissue, or collection of cells, becomes specially endowed with a contractile function,

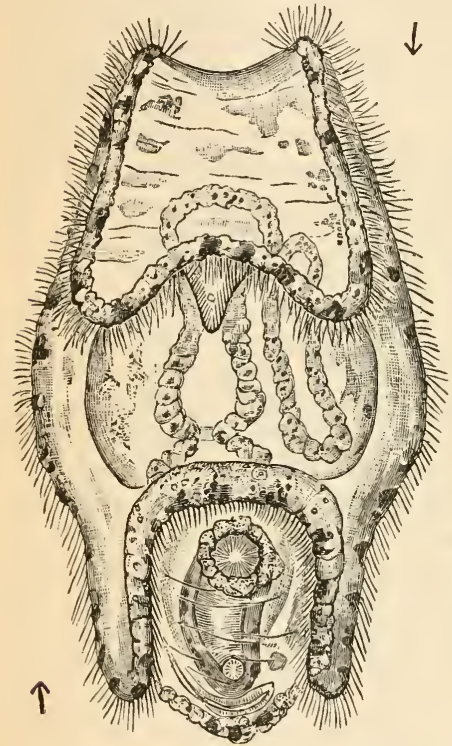

Fig. 158.-Larva of Holothuria tubulosa in its natural position.

The arrow indicates the axis of rotation, and the cilia are seen to be arranged in a sinuous band. (From Carpenter, after Selenka.) and forms muscular tissue, and a more or less regularly disposed muscular system. (For the minute structure of muscle see " Klein's Histology," chaps. viii. and ix.)

In Hydra, among the Coelenterata, the only indications of muscular tissue are the branched prolongations inwards of certain of the cells of the ectoderm (neuromuscular cells of Kleinenberg, or, more shortly, Kleinenberg's cells); in it the several cells of the body still retain their independent contractility. In higher forms the epithelialingrowths become more independent, and in the Medusæ they become transversely striated. In these last they form a sheet on the lower face of the disc or umbrella, which in living specimens is repeatedly opening and closing; they are continued into the tentacles, and when a velum is present they are largely developed in it. 
In the Actiniæ it is possible to distinguish a system of longitudinal from one of transverse muscular fibres, and the presence of these two explains how it is that a sea-anemone is able, when irritated, to diminish both in length and breadth; the longitudinal muscles are the best developed, and may be seen to be arranged in definite bundles; the transverse are strongest in the region of the base of the polyp (Fig. 54). The tentacles owe their contractility to the possession of muscular fibres.

In the Ctenophora, which retain an external investment of cilia along the lines of their "ctenophoral plates," the greater part in the production of movements of the body is not effected by the muscles, which are poorly developed in the ectodermal layer, but by the contractile fibres which are developed in the mesoderm, which is so richly developed in the Ctenophora; as seen in Beroe, these muscles are long cylindrical cords, which are not united into bundles, and are disposed radially, circularly, and longitudinally. The greater number are, like Cydippe (Fig. 15), provided with a pair of long tentacles, in addition to which other smaller or secondary tentacles may also be present; the axis of these is occupied by a cord of muscular fibre; their most important office is, no doubt, not one of locomotion, which is effected chiefly by the ciliated paddles, but of prehension, for where they are absent, the mouth is much wider than it is in those that possess them.

Many of the lower Worms move by the elongation of the anterior end of their body, which is succeeded by a contraction by means of which the hinder part is brought to its original point of distance from the anterior; in the performance of this operation they are sometimes aided by one or more cup-shaped suckers, by means of which a fixed point is gained; others, like the leech, fix themselves by their hinder 
sucker, and sway about or elongate their body so as to reach their prey. In the flat-worms and in the leeches there are longitudinal, circular, and transverse muscles. In all the rest of the Annulata, and in the Gephyrea, there are only circular and longitudinal bands in the body wall, the former of which are the more external ; but, in addition to these, there are smaller muscles which are of considerable importance in locomotion, as they are inserted into the base of the setæ, and are the means by which these processes are moved forwards and backwards, or used as parts of a locomotor apparatus, working either as mere stilts as in the earthworm ; or, as in the Polychrta, where they are numerous, like oars in the free-swimming forms, and as climbing hooks in those that live in tubes.

Among the Echinodermata the most important organs of movement are the contractile tube feet, which are most valuable when, as often happens in the Starfishes, or the Urchins, they are provided at their free ends with a sucker-shaped enlargement by means of which they can gain certain fixed points to which they can draw their bodies. When climbing up vertical, or almost vertical, heights, the Echinoderm converts its pedicellariæ (see page 297), which are provided with special muscles, into organs of locomotion, in so far that these pedicellariæ seize hold of waving fronds of sea-weed, which act, therefore, like the rungs of a ladder, up which one is climbing by the use of the hands only; it is of particular interest to observe that " the wonderfully tenacious grasp of the forceps is timed as to its duration with an apparent reference to the requirements of the pedicels (tube feet), for after lasting about two minutes, which is about the time required for the suckers (tube feet) to bend over and fix themselves to the object held by the pedicellariæ, if such should be a suitable one, this wonderfully tenacious grasp 
is spontaneously released" (Romanes and Ewart). Ordinary Ophiuroids, which, according to the authors just quoted, are able to move along at the rate of six feet a minute, have a certain wriggling power of their arms, which, in the Astrophytidæ, is converted into a power of coiling for the purposes of attachment, thanks to the fact that the faces of every one of their arm joints are convex in one direction, and concave in that which is at right angles to it. When the spines are long, as in the piper (Dorocidaris), where they are also of considerable stoutness, or in Spatangus, where they are much more delicate, they can be used as stilts, owing to the attachment of muscular tissue to their bases.

In the Arthropoda the function of locomotion, like so many other functions in that group, falls very largely upon the appendages, which may either act as walking or as swimming organs. In the Crustacea, where all but the first pair are typically biramose, this locomotor function is seen in the early Nauplius condition (see page 534), when even the antennæ take part in performing that duty; these appendages, being jointed and provided internally with muscles, are able to move in various directions. At first, and in the lower forms, they act more or less like oars, beating the water as they move backwards and forwards. In the higher forms, such, for example, as the crayfish, the more anterior of the locomotor appendages act as walking, and the more posterior as swimming organs.

In an appendage, which has been but little modified, and which may be regarded as typical, such as the pair formed on the third abdominal segment, we see a doubly-jointed basal piece or protopodite, bearing two terminal pieces, the outer exopodite and the inner endopodite. These pieces, which are fringed with long bristles, or setr, are flattened, and can act like oars. 
Those appendages of the thoracic region which are confined to a locomotor function have the form of an elongated jointed bar, consisting of seven joints, which have received the following names: the first two, which appear to correspond to the protopodite of the typical appendage, are called coxopodite and basipodite ; the remaining five, which may be supposed to

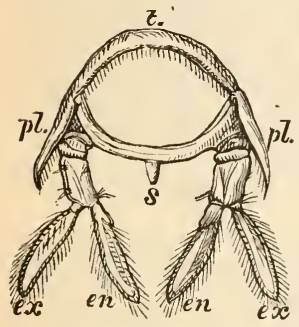

Fig. 159.-Third Abdominal Segment of the Lobster.

$t$, Tergum (dorsal piece); $s$, sternum (ventral piece); $p l$, pleuron; $p$, protopodite ; $e x$, exopodite ; $e n$, endopodite. represent the endopodite, are ischio, mero, carpo, pro, and dactylo-podites.

While these ambulatory appendages move in a plane which is parallel to the long axis of the body, those of the abdomen swing backwards and forwards, owing to the fact that the abdominal segments are, unlike those of the thorax, which is invested by the hinder part of the great carapace, capable of being moved on one another. This movement of segments is brought about by two great bundles of the muscle, which lie respectively above and below the intestine, and are attached to the tergal and sternal plates of the separate segments. It follows, from their mode of attachment, that the contraction of the upper muscles straightens out or extends the abdomen (tail), and that a contraction of the lower muscle tends to bend in or flex the same parts. An alternate contraction and relaxation of these muscles tends therefore to an alternate bending in and straightening out of the "tail," and therefore to repeated beats of the water, by means of which the crayfish or lobster is driven through it. In the performance of this locomotor action the "tail" is greatly aided by the modification of the appendages of 
the penultimate segment of the body, which, in place of being comparatively small parts, as in the typical third abdominal appendage, are widened out into more consiclerable plates, which have a backward instead of a downward direction; these unite with the terminal segment, which sometimes, though very rarely (Scyllarus), bears minute appendages, to form the powerful flapper of the Crayfish.

Peripatus, the species of which vary considerably in the number of appendages, have these organs only imperfectly jointed, and they move but slowly; in them, as in all Arthropods other than the Crustacea, the limbs are uni-, and not bi-ramose, but, as often happens, they are provided with a terminal claw.

The Myriopoda (Centipedes), as their name indeed implies, have a large number of walking limbs, each of which has essentially the same characters as that which precedes and that which follows it; in the Millipedes a number of segments carry two pairs of legs each. The Arachnicla have four pairs of walking limbs, which are completely lost in such endoparasitic forms as Pentastomum. The Insects, or as they are very appropriately called, the Hexapodan, have three pairs of walking limbs ; these are typically composed of a coxa, a trochanter, a femur, a tibia, and a six-jointed tarsus, which ends in a pair of claws; the larval or caterpillar forms have, however, a more or less larger number of walking appendages, or prolegs; these are best and most numerously developed among the Lepidoptera, but they are in all cases rudimentary as compared with the legs of the adult.

A large number of insects have yet another set of locomotor organs, in the shape of the dorsally-placed wings ; of these there are never more than two pairs, and of these both may be rudimentary, as in the female cockroach; or the anterior pair only may be developed as in the Diptera (flies), or the hinder alone 
be functional as in the Coleoptera (beetles). In no case are they developed except on the second and third segments of the thorax (meso- and metathorax).

A wing consists essentially of two flattened

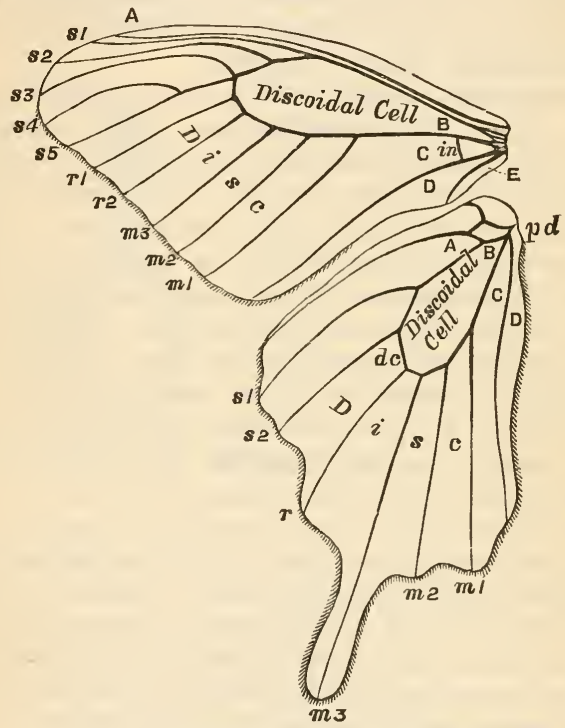

Fig. 160.-Skeleton of Butterfly's Wing.

A, Costalvein ; B, subcostal; $m^{1} m^{3}$, median branches ; $r^{1} r^{2}$, radial ; $s^{1} s^{5}$, subcostal branches; $\mathrm{C}$, median vein ; $\mathrm{D}$, submedian vein; $d c$. discocellular veinlet; in, internomedian veinlet; $\mathrm{E}$, internal vein. (After Butler.)

membranes, the presence of which is due to the organ arising in the form of a sac, which gradually becomes elongated and flattened out; through its substance there pass blood-vessels and air tubes, the walls of which are strengthened by chitin; the chitin may invade the rest of the wing, and convert it into a more 
or less horny body; this process, when carried to an extreme, ends in the stout wing-covers (Elytra) of the beetle. These tracheal tubes are the "veins" of entomologists, and the finer branches the so-called nervures.

These wings, when expanded, beat the air by being moved forwards and backwards on their point of articulation to the thorax; this is effected by special flexor and extensor muscles, the number of which is considerable, and each of which consists only of a few fibres; in considering, however, the causes which give their particular direction to the wings as they move in flight, due attention must be given to the effects of the resistance of the air which is beaten by the wing, which, as a matter of fact, follows a figure of 8 course. In studying the mechanism of the wing we have to bear in mind that the essential points are a rigid anterior nervure, and a flexible membrane behind (Marey).

Insects vary considerably in the number of movements of the wing per second, as may be seen by the following table, which we owe to Marey :

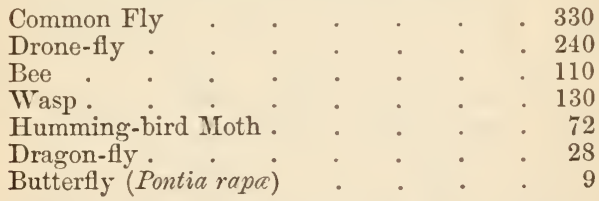

Among the Apterous insects, or those Hexapods in which wings have never been developed, and which must be carefully distinguished from those that have, owing to parasitic habits and so on, lost wings, which were possessed by their ancestors, the Collembola or Spring-tails are remarkable for the possession of a fork-like appendage to the hinder end of their abdomen, which can be bent backwards, and act like a spring. 
In the Mollusea the characteristic organ of locomotion is the foot, which is made up of muscular fibres, which are transversely striated, but are spindle-shaped cells, and so have the general form of unstriated muscular tissue. This foot, which can be withdrawn into the shell of such forms as Anodon by retractor muscles attached anteriorly and posteriorly, seems to be protruded or put into a state of erection by an increased flow of blood into its substance, and not, as has sometimes been supposed, by the intaking of water from without. While it has a somewhat conical or hatchet-shaped form in the fresh-water mussel, and in those Lamellibranchs which move about with some activity, it is very strong in boring forms such as Solen, and long and curved in Trigonia, where it is used as a leaping organ; on the other hand, it is very small in the scallop (Pecten), and quite inconspicuous in the still more sedentary oyster.

Among the Gastropoda the foot has often, as in the common snail, a broad disc-like lower surface, and is adapted for creeping or crawling. When the snail is in movement waves of contraction may be seen passing over the lower surface of the foot from behind forwards, and it has been found that smaller have greater locomotor power than larger forms. Within limits, snails are able to carry weights, and it follows, therefore, that unloaded snails do not make use of all the activity of which they are capable.

The foot may become modified in a most remarkable manner, as, for example, in the Heteropoda, which are forms found only on the surface of the ocean; the animal swims with its shell downwards, and its foot (Fig. $161 ; f$ ) is converted into a high crest-like fin, which is no doubt aided functionally by the fin-like prolongation of the hinder end of the body.

In the Pteropoda the sides of the foot become 
greatly enlarged, and form distinct epipodia, and these, either independently or in conjunction with the median part of the foot, become converted into powerful muscular fins. In the Cephalopoda the epipodia form a funnel, through which the water of respiration is expelled to the exterior; this expulsion of the water forwards results in a backward movement of the animal. In the Tetrabranchiata (Nautilus) the edges of the epipodia are not, as in th Dibranchiata, fused with one another, but merely folded over.

Among the Chordata locomotion is effected by swimming, jumping, creeping, walking, or flying, and all these activities are presented by marine as well as by terrestrial forms.

Swimming organs have the form of more or less broad plates, which may or may not be supported by bone. The simplest cases are presented by the mere flattening or expansion of an organ ; this, for example, obtains in the tadpole, the newt, or the insectivorous form Potamogale velox, where the tail is flattened from side to side and forms a powerful locomotor organ. In the Cetacea, on the other hand, which require to come repeatedly and rapidly to the surface of the water, the tail is flattened from above downwards.

In more complicated cases, as in many fishes, the tail, which is here also the most important organ of locomotion, and has a screw-like movement, is aided by the caudal fin when that is well dereloped; the paired lateral fins are in most cases rather organs of support and direction than of locomotion ; but in some 
cases, as in the Rays, movement is almost altogether effected by the undulation of the margins of the enormous pectorals. In flat-fishes and eels locomotion is due to the undulations or curvatures of the whole body.

In other aquatic Vertebrates, such as the marine turtles, the penguins, or the whales, where the limbs take some share in their movements through the water,

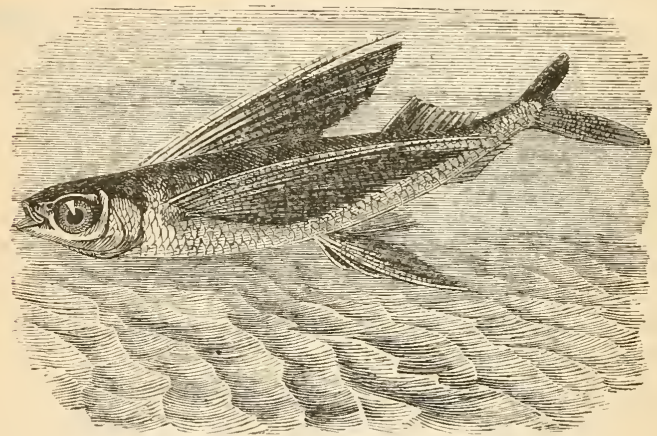

Fig. 162.-Exoccetus volitans.

the tendency is for the flipper to become a more or less rigid organ, movable only at its point of attachment to the body. The series of modifications which lead to this arrangement are very well seen among the Chelonia. In the marsh tortoises the digits are united by a web, but each digit has a claw; in the mud tortoises the limbs are flatter, and there are claws on only three of the digits, while in marine turtles the still more flattened digits are united by a common covering of skin into a more rigid paddle, and only one or two claws are found. In the penguin the wings are converted into firm paddles, movable only 
at their base. In the Cetacea all the bones of the fore limb are united in a common integument, and form the "flipper."

Some forms escape with rapidity by making bounds or jumps; of these we have examples in the frog, the kangaroo, or the Cape jumping-hare, in all of which the hind limbs are much stronger and longer than the fore limbs.

Creeping or crawling is best seen in the snakes, which move along the ground by the backward and forward movement of their ribs, which they use as stilts.

Flying organs are found among fishes in Exocœtus, where the pectoral fins are so greatly elongated as in some species to reach as far back as the caudal fin; the fins are not actively moved, and seem to have no power of turning the fish to the right hand or the left ; they cannot fly far at a time.

Similarly modified pectorals are found in Ditctylopterus.

Among recent Reptiles, Draco volans, the dragon, or flying lizard, is capable of short movements through the air, owing to the prolongation of some of its ribs, which, when covered with the skin, form a semicircular wing on either side of the body. The extinct Pterosaurians (Pterodactyle) had the outer digit of the manus as long or longer than the rest of the fore limb; and there is evidence that, as in the bats, the integument was produced on either side into a membrane, the outer edge of which was attached to this digit, and so formed an expansion, by means of which the creature was enabled to support itself in the air.

Among Mammals the organs of flight are best developed in the Chiroptera (bats) (Fig. 163), where they are formed by the modification of the skeleton, and especially of the fore-arm (see Fig. 149), and by the extension of the integument into the so-called 
384 Comparative Anatomy and Physiology.

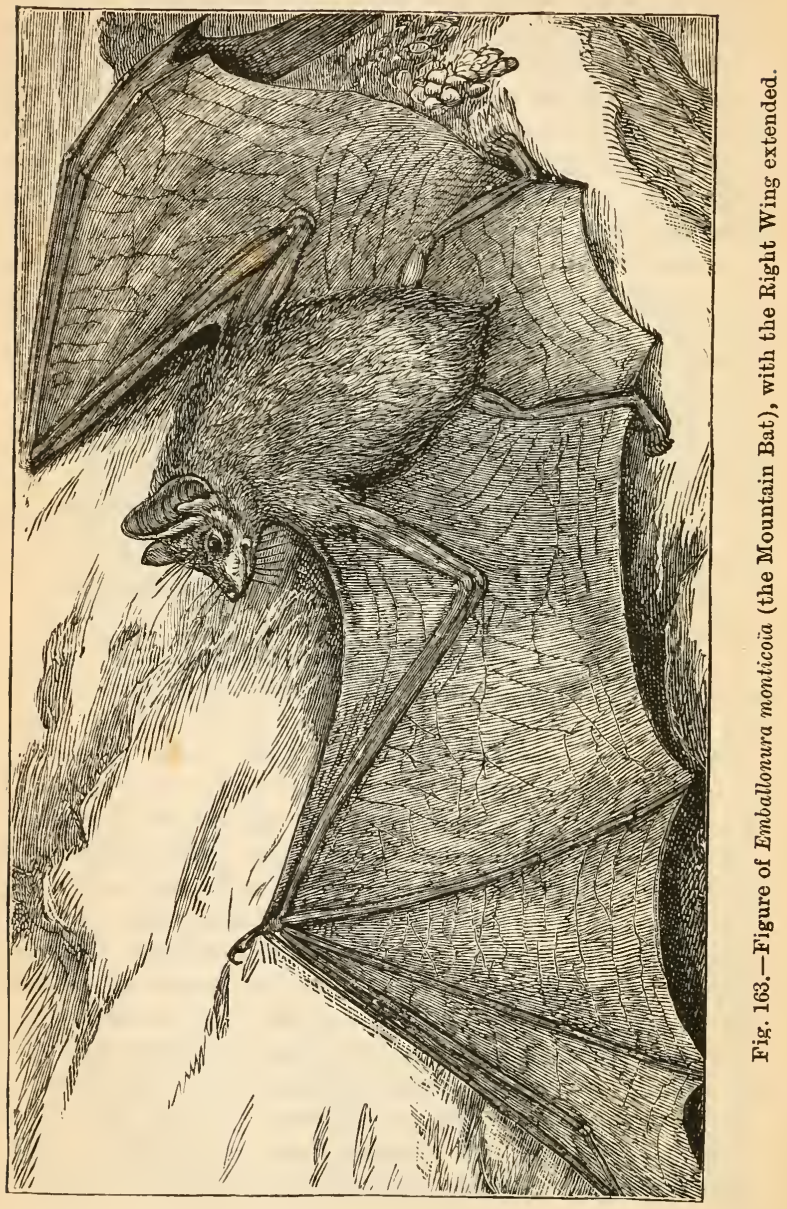


volar membranes. These, when best developed, consist of (1) an " antebrachial membrane," which extends from the shoulder to the base of the thumb; (2) the "wing membrane," which extends from the sides of the body along the fore-arm and between the elongated digits of the manus ; (3) an "interfemoral membranc," which is attached to the hinder end of the body, and to the sides of the leg as far as the heel, and in some as far as the phalanges of the foot. The relation of the antebrachial membrane to the power of flight is sjoken to not only by the extent of its devclopment in flying forms, but also by its reduction in such as are best fitted for terrestrial progression. The most important function of the interfemoral membrane would appear to be that of acting as a rudder; this power is greatest when, as in the Molossi, the bat is able to vary the extent of the membrane, for this "must confer upon them great dexterity in quickly changing the direction of their flight, as when obliged to double in pursuing their swiftly-flying insect prey " (Dolson).

Less well-marked powers of flight are possessed by the aberrant insectivore Galeopithecus (the so-called "flying lemur"), which has been observed to move through seventy yards of air, and in which the two pairs of limbs and the tail are connected together by an expansion of the skin, which forms a parachutelike enlargement; this is not, however, merely membranous, as in bats, but is hairy on either surface. Among the Rodents the flying squirrel (Pteromys), and among Marsupials the flying phalanger (Petaurus), have the fore and hind limbs connected by a fold of skin, which, when the limbs are extended, forms a similar kind of parachute, but it does not reach to the tail, nor is their patagium provided, like that of Galeopithecus, with any special muscles.

Organs of flight are, among the Vertebrata, best $\mathrm{z}-16$ 
developed, as we know, in certain Birds ; the skeleton of the fore-arm is specially modified (see page 352), and forms for the wing a firm anterior bar, comparable to the anterior nervure of the insect's wing; this bar is

moved by special muscles, which are attached near its base; but all of which lie on the ventral or lower surface of the body, and thereby enable the centre of gravity of the bird to be lower than it would be were the extensor muscles of the arm placed, as in other Vertebrates, on the dorsal surface. A large surface of attachment for the pectoral muscles is obtained by the great development in flying birds of the keel of the sternum (see page 347 ), and the extensor muscle works on a pulley. The greater portion of the wing is

Fig. 161.-The Common Swift.

not formed by membrane or integument, but by the development of those integumentary structures which we call feathers. These feathers overlap one another in such a way that the wing is convex above and concave below, and that pressure from below forces the feathers more closely together. From this arrangement it is clear that in the up and down movement of the wing in the air, much greater effect is gained by 
the down-stroke than by the up-stroke; for, in the first place, the pressure of air on a concave surface is always more effectual than that on a convex; an umbrella, for example, may be blown inside out, but never outside in; in the next place, the pressure of the air against the separate feathers welds them into a connected whole, while in the up-stroke the air not only meets with a convex surface from which it may flow away, but it is also able to escape between the separate feathers. The influence, therefore, of gravity is overcome by the greater value of the down-stroke, and by the diminution of the pressure of air in the less valuable up-stroke, which can be made more rapidly than the down-stroke. A further inquiry into the complicated question of the mechanism of flight would lead us beyond the scope of this work. In some cases the tail feathers, by being raised, depressed, or turned a little to one side, are able to give an upward, downward, or oblique course to the bird.

\section{CHAPTER XI.}

VOCAL ORGANS.

UNDER the head of vocal organs we may group all those which produce distinct and definite sounds to the human ear, or which may be supposed to similarly affect the auditory nerves of other animals.

These organs are never developed among the lower Metazoa; indeed, so far as we know at present, they are confined to the Arthropoda and the Vertebrata. Among the Crustacea they have been detected in Palinurus.

In several orders of Insects they are confined to the male sex, and appear, therefore, to be means, as 
they are also no doubt in birds, by which the male may attract the female.

They are so commonly developed in the Orthoptera (grasshoppers and crickets), that the arrangement which obtains in one member of this order may be conveniently taken as a type. In Macrolyristes
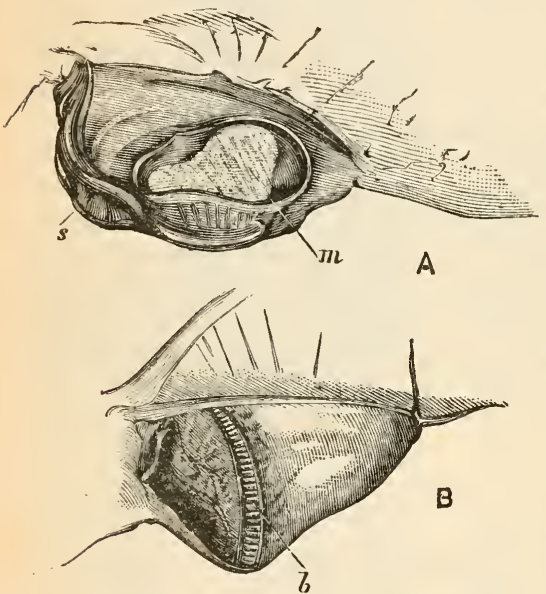

Fig. 165.-The Sound-producing Organ of the Orthopterous insect Macrolyristes imperator.

A, Upper view of right wing ; $s$, cord ; $m$, membrane ; $B$, lower view of left wing; $b$, roughened edge. imperator (Fig. $165 ; \mathrm{A}$ and $\mathrm{B}$ ) we observe that the hinder border of the right wing $(s)$ is thickened in such a way as to act as a cord, and that another part of the wing $(m)$ is converted into a tense membrane. The left wing (в) has its lower surface roughened like a file along one line; this file is brought to rub upon the thick cord $(s)$ of the right wing, and so sets the membrane $(m)$ in vibration; vibrations are, of course, conveyed to the air, and, being regular and definite, they set up vibrations in the air which, on-striking the auditory nerve, give rise to the sensation of more or less musical sounds. Somewhat similar structures are to be found on the wings of the locust, and in the field cricket; in the latter the two wings are similar in structure, and their movement on one another can, 
therefore, be reversed. In the grasshoppers the soundproducing organs are developed not on the wings but on the legs, the upper joints of which are provided with rather less than one hundred minute denticles which scrape on the wings; in the males of an allied form (Pneumora), the legs are rubbed against a notched ridge which is developed on either side of the abdomen, and the resonance is greatly increased by the whole body being distended with air. In most cases among the Orthoptera the males are alone vocal, and the object of the use of these organs is, no doubt, that of attracting the female.

In the hemipterous Homoptera, of which the Cicadas are members, and of which the males are alone vocal, the sound seems to be produced by the vibration of membranes, placed on either side of the stigmata of the metathorax, and set in motion by the respiratory air.

The Hymenoptera, among which are the bees that hum, would appear to produce sounds by the movement of the abdominal segments on one another; these, as Mr. Darwin has observed, are marked with very fine concentric ridges, such as are found also on the thoracic collar, with which the head articulates. Among the Coleoptera (beetles), there are forms such as the carrion beetles (Necrophorus), and others which make very distinct sounds; these are ordinarily produced by rasped ridges, which are placed on various parts of the body and worked against the edges of the elytra or wing-covers; or parts of the leg work against ridges on the abdomen; or the elytra are ridged, as in some of the water beetles; or, lastly, two of the seg. ments of the thorax may work on one another; in the latter case the ridges may be developed either on the upper or on the lower surface. The vocal or stridulating organs of Coleoptera appear to be equally or nearly equally developed in both sexes, and it is rare 
for the male to be much better provicled with them than the female.

Sound-producing organs are much less common among butterflies and moths, and where present, they seem to be due to the vibration of a membrane, and not to the movement of a rasping organ, as in beetles.

Among the Vertebrata, voice, or definite and more or less musical sounds, are ordinarily produced by the vibration of the column of air which passes down the trachea and sets in movement the membranes (vocal membrames), which lie on either side of that portion of the trachea which is distinguished as the larynx; they are supported by definite cartilaginous pieces (arytenoid cartilages), and bound a narrow cleft which is known as the glottis. While this simple condition is, for example, found, among the Amphibia, in some frogs, others have well-developed sacs connected with the larynx, which become swollen out and project on either side of the head; these sacs, which are often better developed in males than females, take an important share in increasing the noise made by their possessor, which may sometimes be heard at a great distance.

Among Reptiles, where the laryngeal apparatus is, on the whole, comparatively simple, the chamæleons are provided with air sacs, which do not appear on the surface of the animal as they do in the edible and some other, though not all, frogs.

Birds are remarkable for the fact that their vocal organ is not, as in other Vertebrates, formed at the top, but at the bottom of their trachea, and at the point where the trachea divides into the two bronchi; the syrimx, as the organ of voice in birds is called, is best developed in the Passeres, where a share in its formation is taken both by the trachea and by the bronchi (bronchio-tracheal syrinx). 
Some of the lower rings of the trachea unite to form a tympanic chamber; the tracheal orifices of the two bronchi are separated by a membranous septun, and on either side there is a tympaniform membrane formed on the inner side of the uppermost bronchial rings ; the air which passes through the bronchial clefts sets in vibration the membranes which bound them, and the character of the note produced is affected, on purely physical principles, by the position of the bronchial half-rings, and by the length of the column of air in the trachea. The position of these half-rings is not constant, owing to the fact that they are moved by proper muscles, which act on their ends, and so rotate them.

In Steatornis (one of the night-jars), the syrinx is completely bronchial, the fifteenth and sixteenth

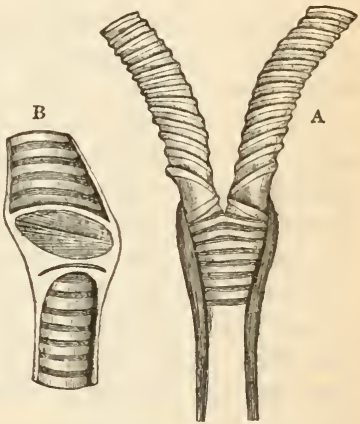

Fig. 166.-Larynx of Peregrine Falcon. A, Front view ; B, in section. bronchial rings being only half-rings, as are also some that follow them; the space thus formed is filled in with membrane, which can be rendered tenser by the contraction of the lateral muscle of the trachea, which is attached to the middle of the fifteenth ring. In those American crows in which the syrinx is completely tracheal, we have an arrangement which is essentially similar. Among the Ratite birds the syrinx is best developed in Rhea; in the American vultures the voice organ is found in its simplest condition.

It is obvious that the length of the trachea must have a very considerable influence on the character of 
the note or notes emitted by a bird; but as yet we have no definite information as to the meaning of those convolutions of the trachea which are so common in swans and ducks, and sometimes give to the tube the appearance of a French horn (Darwin). In some grouse resonance is aided by the development of air sacs which are capable of inflation; the great throat-pouch of the European bustard appears to have a similar function.

Among the Mammalia the larynx becomes remarkably complicated, a number of special cartilages being developed, which are connected together by ligaments, and moved on one another by special muscles ; the whole function of this apparatus is to alter the form of the slit of the glottis, and to increase or diminish the tension of the vocal cords. As this subject has been already dealt with in chap. xv. of the "Elements of Human Physiology," we have here only to point out that Mammals differ greatly in the sounds that they make, the dog barking, the cat mewing, the lion roaring, but that most agree in using the voice more at the breeding season than at any other; a few mammals, such as the American Hesperomys cornutus, and the gibbon (Hylobates), which, it is interesting to observe, is one of the anthropoid or man-like apes, may be distinctly said to sing. Man is remarkable for his capacity for producing not only sounds, but articulate speech, the wealth and extent of which is much greater in the higher than in the lower races of his species.

In Fishes, sounds, when produced, are of course but rarely associated with the passage into the air bladder; but Ceratodus has been observed to make grumting noises, which are possibly involuntary. Various Cyprinoid and Siluroid fishes are known to make sounds, and in Callomystax, Haddon has discovered that the agent by which they are produced 
are the anterior neural spines; these rub on the succeeding and more solid portion of the vertebral column.

\section{CHAPTER XII.}

\section{TUE XERYOUS SYSTEY AJD ORGAVS OF SENSE}

THE mervous system of an animal is the apparatus by means of which it becomes acquainted with what is going on around it, is enabled to distribute that information throughout itself, or to bring it to some central region, and to set itself in proper relation to the surrounding medium. In consequence of this relation to the outer world, we find that the system is, at first, superficial in position and diffused in arrangement, that is to say, it at first lies in the outer layer of the body, with which, indeed, it at all times remains closely connected; and that, primitively, the system is more or less equally distributed throughout the whole of the organism.

As we know, the Protozoa have no definite $x$ nervous system, but we have already leaint than an Amoba is so far sensitive that stimuli applied to its surface are followed by changes in the disposition of its protoplasm. Nor have we any knowledge of a nervous system in Sponges. (See page 431.)

$x$ In all other groups of the Metazoa we have evidence of the presence of cells set apart for the general function of informing the organism of what is going on around it.

When we inquire as to what are the essential constituents of a nervous system, we find that they are either central (ganglionic) cells or conducting fibres; and, as we advance through the scale of organisation, we observe that both cells and fibres 
\ undergo aggregation, so that a diffused or scattered arrangement makes way for one in which we have definite nerve centres and well-marked lines, along which, and along which only, nervous impulses will pass. The most important of the aggregations of nerve cells form the brain, or cerebrum, the most important of the fibres the merve cords; and just as nerve fibres going to or coming from the latter are associated with them, so there are secondary masses of ganglia which are connected with the former.

In the next place, information from without is gained from specially-modified cells, tsemse cells: + these belong to the epithelial region of the body, and are derivates of the epiblast.

The most generalised and widely-distributed sense cells are those which belong to the sense of touch, the so-called tactile cells; next we have those which, only a little more complex, are confined to the anterior region of the digestive tract; these are the gustatory cells, or those that subserve the sense of taste ; thirdly, we have the more complicated organs of the three higher senses, swell, sight, and hearing. When a brain is developed, all, or such of these organs as are present, send to it by the nerve fibres messages from the onter world; in it the messages are converted into more or less distinct sensations, and from it fresh messages are sent out to the different parts of the body.

The relations of the sensory cells to the epithelial layer are particularly well seen in some of the $t$ Coelenterata; for example, in the sea-anemones (Tealia; Fig. 168), some of the cells of the epithelial layer have their free end continued into a fine - stiff process, which projects outwards ; the inner or basal end of such cells breaks up into finer processes, which branch towards their ends. The free projecting process may be justly regarded as a 
Chap. XII.] NER VOUS SYSTEM OF CELenterata. 395

sense hair, which, acted on by movements in the water, and communicating with the body of the cell, is able to bring the animal into relation with the outer world.

In the sea-anemones the basal processes of the cells have been observed to be continued into a layer of

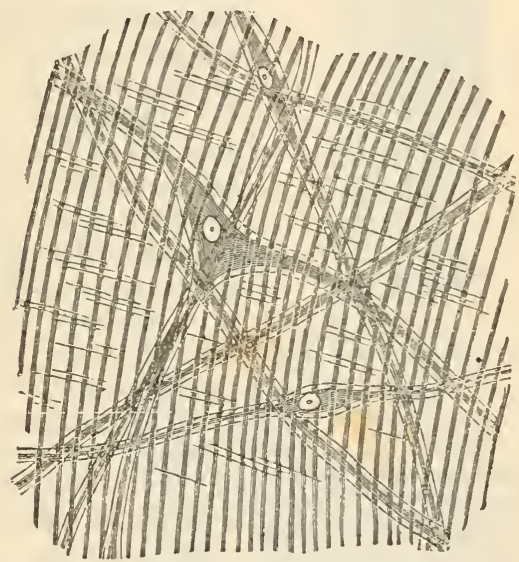

Fig. 167.-Part of the submuscular plesus of Aurelia aurita, showing ganglionic cells. (After Schäfer.)

fibres, which are, to all appearance, nervous in nature $x$ Well-developed ganglionic cells are to be found scattered in the layer of nervous fibres which surrounds the mouth.

While in Aurelia and other Acraspedote Medusæ the central part of the nervous system consists of isolated ganglia, ordinarily eight in number, the * Craspedote Medusæ, or those in which the edge of the bell is provided with a velum, have a more definite central system; the epithelial coverings of 
both the upper and lower surfaces of the velum have some of the constituent cells converted into sense + cells; the basal ends of these are of some length, and pass into a nervous ring which runs round the edge of the bell. The several sensory cells are thereby

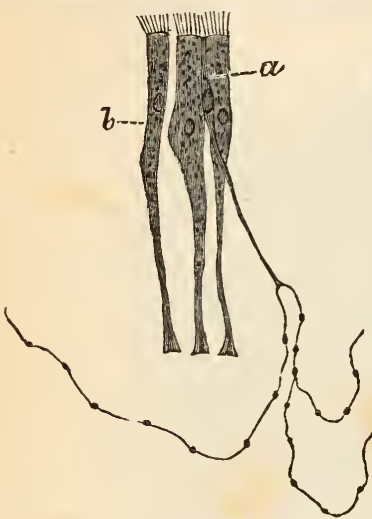

Fig. 168.-Transverse Section through a Tentacle of Tealia crassicornis; to show (a) Sensory Cells with their free Projecting Processes, and their Bases continued into the Nervous Layer; (b), supporting cells.

brought into connection with one another, and the insentaneous action of all parts of the jelly-fish is thus ensured.

Underlying the epithelium of the lower surface of the bell, and placed between it and the muscles, is a network of nerve fibres, among which there are scattered ganglionic $x$ cells (Fig. 167); this network is connected with the marginal nerve-ring. Here, then, we have a simple example of an aggregated central ner $x$ vous system, together with a periplneral $X$ system of fibres and cells, which is diffused over the whole of the under surface of the bell of the medusa. Some of the Craspedota (e.g. Carmarina) present us with an important advance in structural differentiation, for some of what, in all other particulars, resemble the sense cells, are found to have lost their free projecting process, and to be now moved a little away from the surface of the body. Here, then, we have nervous epithelial cells which are beginning to lose their superficial position, and sinking deeper into the substance of the organism. 
Experiments on Medusæ show that the seat of + spontaneous activity-is confined to the edge of the bellin the Craspedote Medusæ, and to the region of the marginal sense organs in the Acraspedote forms; if the extreme margin of the bell of the former be completely removed, there is immediately a total and permanent paralysis of the entire organ; in the latter, removal of the marginal bodies is sufficient to produce a similar effect. The results of these experiments are, then, in complete accordance with the anatomical facts. The diffused plexiform arrangement of the nerve fibres is, further, spoken to by the following experiment : if all the marginal sense organs but one be removed, and if deep

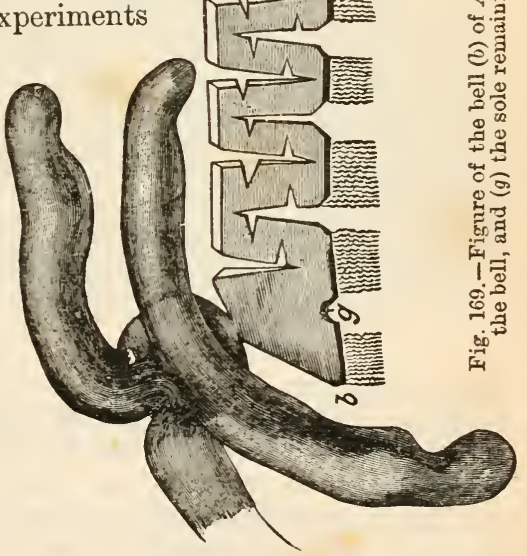
sections be made in the substance of the bell, so as to, at any rate, separate the nerve fibres at many points of their course, it is found that the bell is still capable of contraction; or, in other words, the stimuli sent out from the sole remaining 
centre are able to diffuse themselves over the whole substance of the jelly-fish.

We have, it is clear, to consider the nervous system $\downarrow$ as at first forming a difiused network over the whole body, and this truth must be constantly borne in mind, for it applies not only to the Coelenterata, but also to the lowest worms. At the same time,

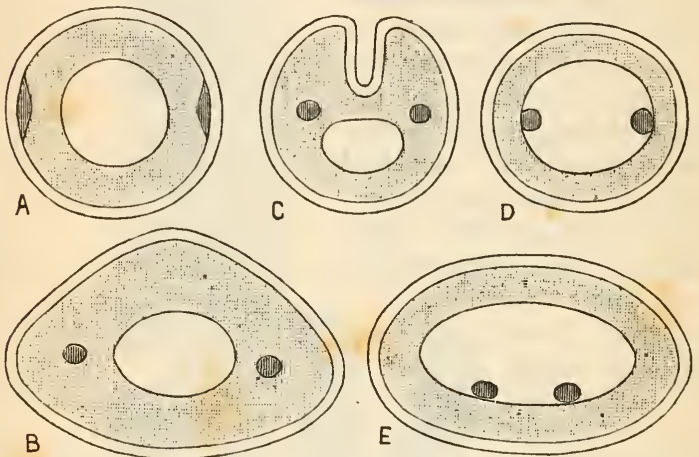

Fig. 170.-Diagrams to show the relative positions of the longitudinal Nerve Cords in different genera of Nemerteans. The epidermal tissues are left white, the muscles are darker, and the nerve cords are darker still. A, Cavinella ; B, Cerebratulus ; c, Langia ; D, Amphiporus; E, Drepanophorus. (After Hubrecht.)

$\downarrow$ we have to note the tendency of the nerve cells and fibres to seek a more sheltered position than that which can be afforded them by the surface of the body; nowhere, perhaps, are the various stages of $x$ modification better seen than among the Nemertean worms, of which Carinella is one of the lowest and simplest examples.

It will be seen that in the figure (Fig. 170) Carinella (A) has the longitudinal nerve cords just underlying the epidermal, and placed above the muscular tissues. 
In Cerebratulus and Langia ( $\mathrm{B}, \mathrm{c})$ they lie in the midst of the muscular tissue; while in Amphiporus and Drepanophorus they are internal to it, as they are in the greater number of invertebrate Metazoa.

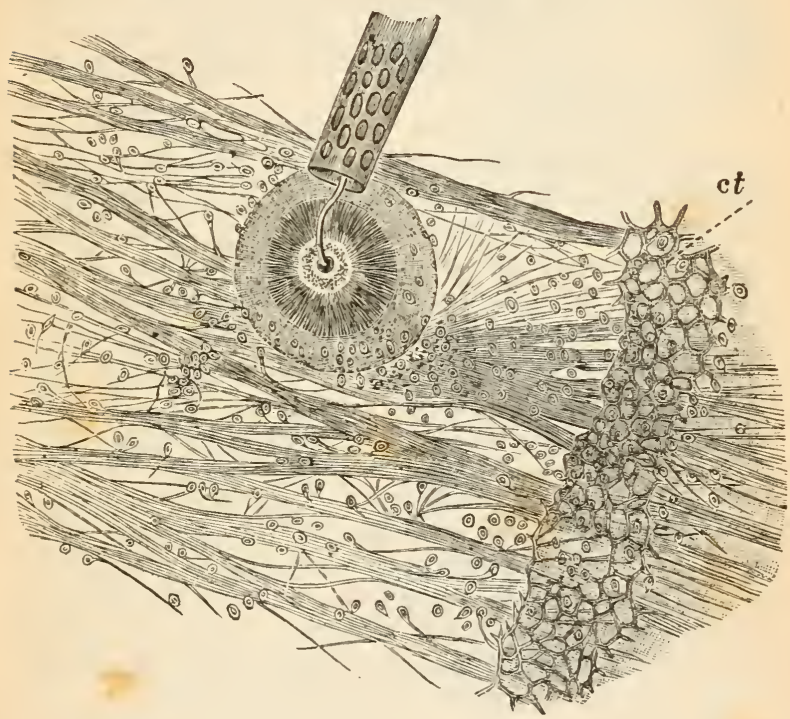

Fig. 171.-Outer surface of a decalcified Plate of the Test of Brissopsis lyvifera, from the greater part of which the connective tissue (ct) has been removed, to show the course of the Peripheral Nervefibres, and their ganglionic cells. Highly magnified. (After Lovén.)

Carinella is, moreover, remarkable for the fact that the centralisation of ganglia and nerve cords has proceeded to a small degree only. As in all Nemertines, the ganglia are distributed over the whole course of the longitudinal nerve trunks, and what, in other forms, is an anterior cerebral enlargement, is here merely represented by the enlargement of the front 
end of the lateral trunks. Connected, finally, with the two chief nerve trunks is a network of nervous cells and fibres, which lies just below the dermis, and forms a continuous layer over the whole of the worm.

In the Turbellaria we find also that the nervous system is superficial in position, and that the nerve fibres so branch as to be distributed widely over the surface of the body.

A similarly primitive condition obtains in the Echinodermata ; the epidermis consists not only of supporting cells, but of others which are sensory, and have their basal ends continued into nerve fibrils, which ordinarily run parallel to the surface of the body; with these fibrils small ganglion cells are connected (Hamann); as a result of this, we have a * continuous sheath of nerve tissue investing the body of a starfish or of an Echinoid (Fig. 171). In the Ophiuroid and the Holothurian, the superficial nerve plexuses have as yet been detected only on the tube feet. By far the greater part of the nervous system $x$ is superfieial in the starfish, for the nervous band that runs down the groove of every arm is placed just below the investing epithelium ; and, in addition to this, the more primitive histological condition is still x retained, for the ganglia are scattered among the nerve fibres, and not collected into separate masses.

Having now sufficient evidence of the truth of the statement that the nervous system is primitively superficial in position; that is to say, that at first the $x$ nerve cells lie side by side with the epithelial cells, and that they gradually come to lie just below the epithelial layer, we may return to that plexiform disposition $x$ of fibres which precerles the arrangement in definite strands or cords. Evidence as to this is afforded by the most primitive members now existing, both of the Arthropoda and of the Mollusca. Of the former, Peripatus is a striking example (Fig. 172). 
The ventral nerve cords are widlely separated from one a nother, but are connected together by a large number of commissures $\left(c o^{1}\right)$, of which there are from nine to ten for each segment of the body. From the outer borders of the cords nerve fibres are given off to all parts of the body, the whole of which is consequently surrounded by the nervous system; and we have here, therefore, what is essentially a plexiform arrangement, but one which has, so to speak, become regulated. A further advance is to be found in the fact, that while the cords are everywhere covered by ganglion cells on their ventral surface, the ganglia are more especially numerous at one point in every segment of the body,

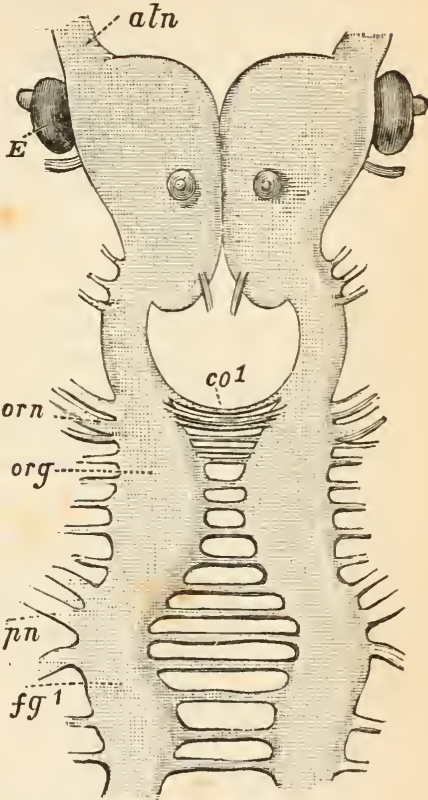

Fig. 172.-Anterior portion of the central Nervous System of Peripatus, show. ing the Anterior Cerebral Ganglia, with the Lateral Nerve Cords connected with one anot her by numerous commissures (co). (After Balfour.)

E, Eye ; atn, antennary nerve ; co 1, first commissure: orn, nerves for the mouth ; org, oral ganghon: $p n$, pedal nerves; $f{ }^{\prime}$, first ganglinnic enlargement for the pedal nerves.

where they form such an enlargement as that marked $\mathrm{fg}^{1}$ in Fig. 172.

Proneomenia may be taken as the simplest type of A A -16 


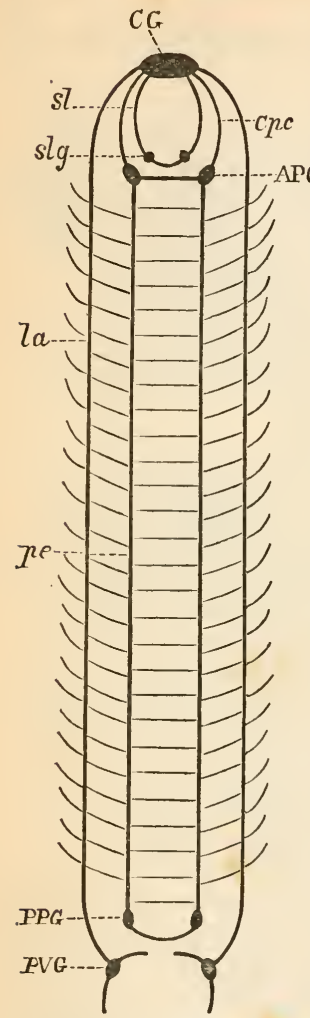

Fig. 173. - Diagram of the Nervous System of Proneo. menia.

CG, Cerebral ganglion; slg, sublingual ganglia ; A PG, Pl'G, PVG, anterior pedal, posterior $\mathbf{p}$ dal, posterior lateral (vi-ceral) yanglia ; sl, sublingual connectives: Cpc, cerebropedal connectives; pe, longitudinal pedal nerve trimks ; la, longitudinal lateral nerve trunks. (After Hubrecht.) the Mollusca, but it is important to note that along this phylum we have persisting a larger number of conditions than are at present, at any rate, known among the Arthropoda. A reference to Fig. 173 will show that, in Proneomenia, there are, on either side, two cords which run down the whole length of the body, and both of which terminate in a ganglionic swelling; the two inner cords are seen to be connected with one another by commissural fibres, and each of these with the edge of the cord that lies outside it; as these latter give off peripheral nerves it follows that here again we have a plexus of nerve fibres distributed through the body. In the case of Proneomenia we have ganglion cells not only accompanying the nerve fibres throughout the whole of their length, but they are also, as they are in some of the commissures of Peripatus, found on the commissures which connect these cords with one another. Here, then, we have yet another instance of the plexiform disposition of nerve fibres, and the diffused condition of ganglionic cells in a 
lowly and little differentiated representative of a large group of animals, in the higher members of which concentration is exceedingly well marked. (See page 411.)

With the exception, then, that in Peripatus and Proneomenia, the anterior end of the nerve cords is enlarged into a cerebral mass, we should appear to be able to see no essential difference between them and a Craspedote Medusa, save in the fact that the Medusa has a complete nerve ring. In so far, however, as there is in both the Arthropod and Molluse just named, a commissure at the hinder end of the body which connects the right and left corcls with one another, it is clear that the nerve system, if not a ring, is at any rate a closed system; that, in other words, it may be compared to a ring drawn out lengthwise (Balfour). If this comparison be a just one we are soon able to explain the reason why the anterior end of a Nemertime or Arthropod or a Xollusc is better developed than the rest of the nerve cord, for these animals are all bilaterally, in place of being circularly or radially, symmetrical; and it follows, therefore, that they do not advance in any direction indiscriminately, as does a jelly-fish, but that there is one end which is always directed forwards, and which first comes into contact with friends, foes, or food. It is at that end, naturally, that sense organs are first and best developed, and it is at that end, therefore, that the central portion of the nervous system comes to be largest and most highly developed.

In connection with this, the discovery by Kleinenberg of a nervous ring in the larvæ of certain Annelids is of great significance; for though the adult polychretous worm is bilaterally symmetrical, and has a central nervous system of the same character, the larva has a rounded head-disc.

After the disappearance of the diffused or plexiform arrangement of the nerve fibres the system may 
404 Comparatile Anatomy and Physiologi:

still retain a very close connection with the surface of the bocly; the Annulata, for example, present us with various arrangements of this kind, for while Chætopterus and Spio have the nerve cords outside the muscular layer of the body wall, and others, such as Hermella, have them between or even in the substance of these muscles, others again, like the earthworm, have them placed inside the muscular layers.

In the simplest condition of those forms which do not present the most primitive arrangements, we find

= a central ganglionic, or cerebral mass, with which there are connected a number of nerve fibres, which pass to different parts of the body; such a disposition is found in some of the Turbellaria, and in the Rotatoria.

The most important advance is seen in the appear$x$ ance of the main or longitudinal cords, such as we have already noted in Peripatus; but even when these do appear, we find that the cerebral mass still gives off a number of fibres, which pass to the different sensory organs that are situated at the anterior end of the body. The two main trunks that pass backwards are, more or less intimately connected with one another on the ventral surface of the gullet, so that we have now to distinguish the cerebral, or supracesophageal ganglia, the nesophageal nerve cords or commissures, and the subosophageal ganglia; these last are, in their most primitive conditions, similar to those that follow them (Fig. 174); at first they are not closely united with one another, but connected together by a pair of transverse commissural cords, as are the ganglia that follow them.

In the more primitive conditions, such as are presented by Apus among the Crustacea, the cerebral ganglia are merely formed by the nervous swellings in the anterior region (primitive cerelrum) 
- ("archicerebrum" of Lankester). Such an arrangement is found also among annulate worms.

In the greater number of the Arthropoda we not only see that the nerve trunks lie intermally to the muscular layers of the body wall, but also that the cerebrum is no longer primitive, but has other ganglionic cells used with it ; or, to use the words of Rathke, as applied to the developing scorlyion, the brain is "composed of several pairs of gandia $x$ lying one behind the other." Nor is this kind of fusion contined to the brain ; a longitudinal section of part of the nerve cords of a crayfish shows that the ganglionic cells in a segment have become closely united together, while, at the same time, the cords are still distinct. Nor is this all; while Apus has a distinct gang. lionic enlargement in every segment of its body, we find that in higher forms various ganglia become connected together, until at last, in the common

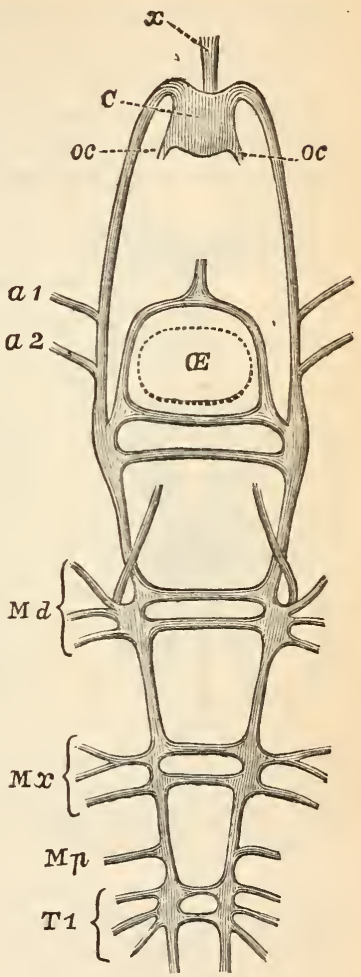

Fig. 174,-Diagram of the Anterior Portion of the Nervous System of Apus, showing the "archicerebrum" (c), and the Ganglia of the Lateral Cords. (From Lankester, after Zaddach.)

$x$, Frontal nerves; oc, optic nerves; E, nesophagus ; $a 1$, nerve for first antenna; $a 2$, nerve for second ditto: s $d$, nerves for mandible; $12 x$, for maxilla: $\mathrm{s} p$, for maxilliped; $\mathrm{T} 1$, for first thoracic apleudage. 
crab, all the ganglia behind the cerebral become fused into one large mass; which still retains evidence of its composite character by giving off a large number of separate nerve tibres (Fig. 175). A similar series illustrating the phenomenon of the fusion of nerve centres may be abserved in Arachnida and Insecta.

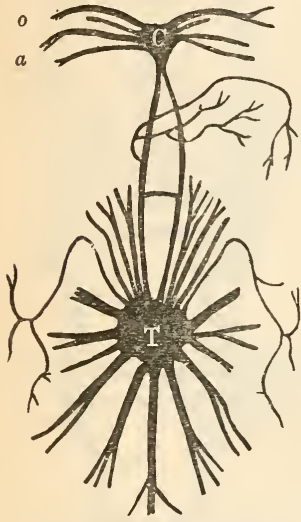

Fig. 175.-Nervous System of a Crab.

c, Cerebral ganglion; $o$, optic; a, antennary nerve; $c_{;}$ofso-
phageal commissure, $\mathrm{T}$, fused ventral ganglion.

We note, then, that the loss of that plexiform arrangement, of which we have spoken so often, is succeeded by an aggregation of ganglionic cells, which form distinct masses in every seginent of the body ; at first each mas: is composed of two distinct halves. The anterior regior becomes more and more predominant, and the "archicere. brum," or simple anteric enlargement, becomes a "syncerehrum," or compound one. As the segments of the body, which in the earthworm, for example, are all alike and have nearly all just the same functions, become arranged in groups which, as in the crayfish, take on different duties, or exhibit division of labour, the nervous centres likewise become affected, so that while Apus has a separate ganglionic mass for each of its sixty segments, the crayfish has the first six of its ventral ganglia fused together, and the short-tailed crab has all the ventral ganglia in a single mass (Fig. 175); so, again, the Myriopod has ganglia in every one of its segments, the scorpion has the first nine ventral ganglia united, and in the short-bodied spider there is only one ventral ganglion. 
We meet with the same phenomenon in Insects, but these Arthropods are of greater interest from the point of view that the changes undergone by them during their development afford support to the view that the more primitive forms have a larger, and the more complex a smaller, number of separate ganglia. While the worm-like larva has a ganglionic mass in nearly erery one of its segments, the adult insect has a varying number fused together

As has been already pointed out in speaking of the Echinodermata, the nervous system of a starfish is so far extremely primitive in character, that the nerve cord which runs down the ambulacral groove of each arm lies just below the integument; in the Ophiuroids this superficial position is lost, owing to the development of a calcareous plate, which forms a floor for the groove. The great development of the test in Echinoids leads to the same result; but here, as we have already learnt, a compensating arrangement is effected by the development of a plexus of nerve cells and fibres which is superficial to the test. In Holothurians the nerve cords are placed more or less deeply in various forms.

In all cases these radially disposed nerve cords are united with one another by a set of circular fibres, which form the circumoral nerve ring it is thanks to this that the apparently independent rays of a starfish or of a brittle star are enabled to act in concert; but, although the nervous system of an Echinoderm is hereby made a connected whole, it is important to observe that a single arm of a starfish, or even a segment of an Echinus (Fig. 176) is supable of exerting independent movements; for example, single rays of a starfish have been found to crawl as fast, and in as definite a direction as entire forms; if turned on their back they succeed in righting themselves, and sometimes, though not always, they attempt to move 
away from injuries inflicted on them. If the nerve ring be divided, without the separation of a ray from the rest of the organism, the ray whose nervous connection is so cut ceases to act with the rest of the star$x$ fish, but is capable, to a certain extent, of responding to stimuli on its own account.

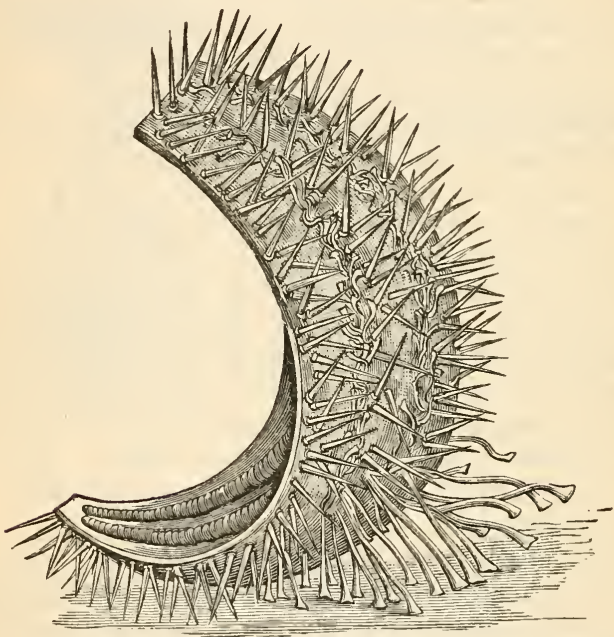

Fig. 176.-Separate Segment of an Echinus attempting to right itself after having been inverted. (After Romanes and Ewart.)

The Crinoidea must be dealt with separately from the rest of the Echinodermata, in consequence of the difficulties presented by the conditions and relations of their nervous system. When a transverse section is made of one of the pinnules which. hang down from the sides of an arm of a Crinoid, a nerve cord ( $n$; Fig. 177 ) is seen to lie just underneath the epithelium of the groove of the pinnule; this clearly corresponds to 
the nerve in the arm of a starfish, and it has similar relations to a nerve ring which runs round the mouth. If we now look at the opposite side of the section, we find another and larger cord which gives oft branches to the muscles of the arms $\left(a a^{\prime}\right)$; this cord, if it be followed up, will be found to end in an organ, the so-called "chambered organ," which lies in the centrodorsal piece (see page 292) of the Crinoid. Now, if the visceral mass, part of which is the circumoral nerve ring, be alone removed, the arms will continue to move as regularly as they did before, and the Crinoid will still be able to swim about in the water. If, on the other hand, the five-chambered organ be stimulated, then, as Dr. Carpenter has shown, there is a sudden and simultaneous flexion of all the arms. The ex-

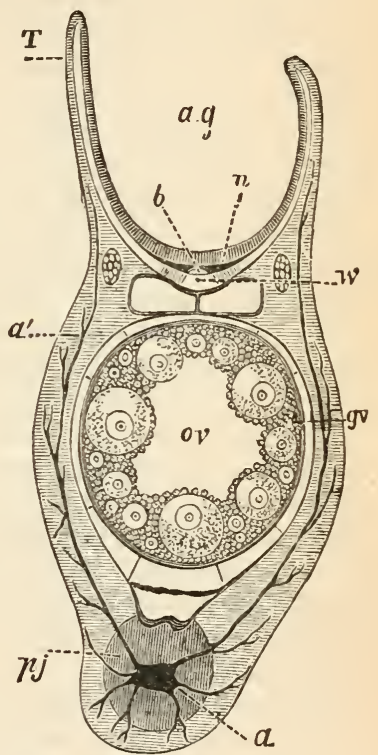

Fig. 177.-Cross Section of a Pinnule of the Arctic Featlerstar (Antedon eschrchti); $\times 75$.

$a$, Axial cord ; $a^{\prime}$, its branches; $a g$, ambulacral growve; $b$, radial bloodressel ; $g v$, genilal vessel ; ov, orary ; $n$, radial nerve; $p j$, pinnule joint : $w$, water-vessel; T, tentacle. (From Carpenter, altered from Ludwig.) istence of these two apparently independent nerve systems in a Crinoid is a difficulty which the morphologist has not yet been able to solve, but the anatomical and physiological evilence in favour of the nervous nature 
of the chambered organ and the axial cords appears to be complete. ${ }^{*}$

The greater number of the Mollusca present us with an arrangement of the nervous system which is very different from that which obtains in Arthropods; this is due to the want of metameric segmentation, and to the marked tendency of the ganglionic masses to fuse with one another. Indications of a more primitive condition of things are not, however confined to Proneomenia (page 402); commissures connecting the two chief longitudinal trunks, and so giving rise to a step-ladder-like kind of arrangement, are to be observed in Chiton and in Haliotis.

In the Camellibranchiata (e.g. Anodon), when the primitive bilateral symmetry of the body is retained, we find two supraœsophageal ganglia, whence nerve cords pass off on either side to the hinder end of the body; no ganglia are developed on the course of these trunks, but, as in Proneomenia, at their terminations only (visceral ganglia); these two ganglia are sometimes almost separate, in other cases more or less completely fused with one another, just as, at the other end of the body, is the case with the supraœsophageal ganglia.

These last also give off a pair of cords, which in the mussel extend some way down into the substance of the foot, where they end in the pedal ganglia ; but these pedal ganglia are not always so far clistant from the supraœsophageal as in the mussel, their size and position depending on that of the foot itself.

While the supracesophageal or cerebral ganglia of

* Prof. Milnes Marshall, who has lately repeated and extended the observations of Dr. Carpenter, has suggested that the antambulacral or dorsal portion of the nervous system of a Crinoid is modified from the antambulacral portion of the primitive nerve sheath, which in the starfish still invests the whole of the body. The "chambered organ," or "central capsule," still requires investigation from the morphological and embryological side. 
the Lamellibranchiata (Acephala) are always comparatively small, in consequence of the reduction of the head of these Molluses, they are always much larger in the Cephaloplora, which are prorided with eyes and powerful tactile tentacles. The two most important phenomena observable in the characters of the nervons system of this group are the fusion of the primitively separate ganglionic masses, and the twisting undergone by the nerve cords of some of the Gastropoda. The former attains its most marked development in the Cephalopoda, where the pedal fuse with the visceral ganglia, and are closely approximated to the cerebral mass ; the latter, which may be seen in the limpet (Patella), or the river-snail (Palndina), results in the nerves which connect the cerebral with the visceral ganglia passing from the right to the left, and from the left to the right-hand side.

From the ganglionic masses and from the cords that connect them together in the way that has now been clescribed, nerves are given off to various parts of the body. We have alrearly seen that in the lower forms the whole of the body is invested in a superficial plexus of nerve tibres and cells; as the cells became gradually aggregated into definite masses, the nerves that were given off from them became likewise arranged in a definite and regular fashion, and took on definite duties and functions. Those nerves that pass to muscles may be spoken of as the motor or efferent nerves, those that end in sensory organs, whether general tactile organs or organs of more especial sense, as sensory or afferent nerves; that is to say, they bring messages to the central system, while the efferent nerves carry messages away. The size and number of these nerves depend, therefore, primarily on the size of the parts to which they are distributed. Their general arrangement may be well seen in a segmented animal ; putting aside for a moment the nerves given 
off from the supraœsophageal ganglia, we find that in the earthworm, for example, several nerves are given off from the oesophageal commissures, and that each successive ganglion gives off two nerves on either side, while one nerve on either side is given off by the cords which connect the ganglia with one another. When we come to a more differentiated form, such as the crayfish, we find that no nerves are given off from the commissures, but that three pairs of nerves are sent off from each of the ganglia that belong to one segment only, while, when two or more ganglia have fused together, a large number of nerves are given off in order to supply more than one segment of the body.

In addition to the sensory and motor nerves there are others which are particularly related to the digestive and circulatory organs; these are the so-called visceral nerves, and, from a physiological standpoint, if not indeed also from a morphological, they are comparable to the system which, in Man and other vertebrates, is spoken of as the sympathetic system. While in the lower worms these visceral nerves are merely corls given off from the cerebral ganglia, they become more independent in the higher forms, owing to the development of ganglia along their course; a well-marked ganglion of this kind may be seen on the dorsal surface of the crop of the cockroach. The general arrangement of the "stomato-gastric" system of this animal will serve conveniently as a type, and may be thus described ; from the anterior part of the cerebral mass a cord arises on either side, which, after passing forwards for a short distance, bends on itself and unites with its fellow in a median ganglion. The single cord given off from this ganglion passes backwards beneath the brain to another median ganglion; with this last two lateral ganglia are connected; the second median ganglion gives off a cord which passes backwards above the digestive tract to a third ganglion 
or that already mentioned; from this there arise two trunks which give off nerve fibres to the anterior portions of the digestive tract. While the median ganglia and nerves form the unpaired system, the two lateral ganglia are the most anteriorly placed repre. sentatives of a paired system of stomato-gastric nerves and ganglia.

Other nerve cords connected with the sympathetic system supply especially the air tubes (tracher), and the muscles of their orifices (stigmata); from the fact that the nerve which runs above the ventral gangli. onic chain gives off lateral branches which pass outwards, the system is known as that of the nervi

transversi accessorii. In the crayfish the terminal ganglion of the ventral chain gives off nerve fibres which innervate the hinder portion of the digestive tract.

The function of the several parts of the nervous system have been investigated in so few of the Invertebrata, that it will be well to state at some length what is definitely known as to the physiology of the nervous system of the crayfish or the lobster.

We note in the first place that the presence of a comparatively large cerebral mass is associated with a large amount of influence orer the rest of the ganglia; thus, the limbs, which in ordinary circumstances move in due order in such a way as not to oppose, but rather to assist one another, cease to exhibit this harmonious activity when the cerebral ganglia are removed; in other words, they are no longer co-ordinated; but this is not all ; the cerebrum appears to be the centre of what, in our ignorance of all the circumstances of the case, we call spontaneous activity, and this is very pointedly spoken to by the loss of power in the selection of food, which follows on a removal of the cerebral centres. The separate condition of the œsophageal commissures which unite the brain with the chain of 
ventral ganglia is not only an anatomical fact, it has also a physiological significance, for when that of one sile is removed, it is only the organs on that side of the body which cease to react to stimuli, the appendages on the other side alone appearing to be affected.

The ganglia just below the œsophagus (the subosophageal) appear to have a considerable function as the centres of motor energy, for so long as they are present the appendages move with considerable activity, but when they are removed the chelæ "sprawl helplessly," and the legs are often found doubled up under the body. As might be supposed from the relations of their nerve fibres to the muscles of the gnathites, the same ganglia appear to be the centre for the feeding movements; after their extirpation, the chelæ or great forceps do not always carry the food to the mouth, as they do regularly in the uninjured animal; it is a curious fact that even when they do carry it there they do not give it up to be swallowed.

With regard to the general physics of the nerve fibres, we know from Frédéricq that motor excitations produced by electrical currents pass much more slowly along the motor nerve of a lobster than that of afrog, the proportion per second being as twenty-seven metres in the frog to six in the lobster:

The student of vertebrate physiology will best understand the leading differences between the activities of the nervous system of the frog and of the crayfish, by a comparative statement : "There is much less solidarity, a much less perfect consensus among the nervous centres in the crayfish than in animals higher in the scale. The brainless frog, for example, is motionless except when stimulated, and even then does nothing to suggest that its members have a life on their own account; whereas the limbs of a cray. fish, deprived of its first two ganglia, are almost 
incessantly preening, and, when feeding movements are started, the chelate legs rob and play at cross purposes with each other as well as four distinct individuals could do" (J. Ward).

This quotation will bring very forcibly to the mind the value and meaning of ganglionic masses in the separate segments.

So far as our present knowledge extends, we are led to the belief that the spinal cord of the lower Vertebrates (as represented by the frog) has much greater independence than that of the higher, as represented by the dog, or by man. For example, if the brain of a frog be removed, the animal will still execute movements, to which it is impossible to refuse the name of purposeful; in the Mammal, on the other hand, the movements which, under similar conditions, are similarly excited, are irregular and without order. Extirpation of the cerebral hemispheres of a Mammal results in death after a few hours, while the frog may be kept alive for an indefinite period, if suitable care be taken of it.

The general functions of the various parts of the brain have been cliscussed in the volume on "Human Physiology" (chap. xiv.).

The Chordata are to be distinguished practically, even if not morphologically, from the majority of the so-called Invertebrata by the fact that the nervous cord lies on the dorsal aspect of the body, and not on that on which the mouth is situated; at the same time it is to be borne in mind that in the Nemertinea the nerve cords often tend to lie dorsally, and that in Peripatus the two cords are, at the hinder end of the body connected together by a commissure which lies above or dorsally to the terminal portion of the intestine. Similarly, there are certain points in the anatomy of the vertebrate brain, too complicated to be here described, which afford some evidence in 
favour of the view that the anterior portion of the brain was once separated from that which lies behind it by the digestive tract.

In no known Chordate, however, does the œsophagus separate any one part of the nervous system from the rest, and the whole mass is superior to or dorsal in relation to it. In all Chordata also the nerve cord has a central canal, and occupies exactly the median axis of the body. The presence of this canal is not to be explained without a reference to the history of the development of the central nervous system; in this mode of development we find yet another important characteristic of the Chordata.

The median strip of epiblast which is to give rise to the nerve cord, instead of merely sinking away from the surface of the body, becomes grooved along its middle line; the sides of the groove grow up and unite with one another, so as to leave a central cavity ; in most cases the tube is first formed, and only later on separates off from the layer of epiblastic cells which forms the covering of the body ; in Amphinxus, however, the external layer covers over the so-called "medullary plate" which forms the nerve cord before the groove has become closed up. It will be seen that, owing to the formation and closure of this groove, the cells that were primitively external come to lie within those that were primitively internal.

In the Cephalochordata the central nervous system retains throughout life the form of a hollow tube, and there is no distinct enlargement at the anterior end which can be called a brain. In the Urochordata the typical arrangement is best seen in those which retain the tail during the whole of their lives (Appendicularia); in them we find an anterior swelling, which becomes divided into two vesicles, with the foremost of which an optic and an auditory organ become connected; the hinder vesicle is separated by 
a constriction from the cord that follows it, and from which three pairs of nerves have been observed to be given off. In this cord, as in that of the Vertebrata, we find that the nerve fibres lie externally to the ganglionic cells, an arrangement of the histological elements which is exactly the reverse of what obtains in "invertebrates."

With the loss of the tail, the nerve cord, which is found in the tailed larva in the same position as in the adult Appendicularia, undergoes atrophy, and the fixed or colonial Tunicate has a single ganglionic mass which lies between the mouth and the atriopore. (See page 231.) From this ganglion nerves are given off to the different parts of the body.

\section{In the Vertebrata a brain} is always present; the primitively single swelling at the anterior end rapidly becomes divided into three brain resicles, which may be distinguished as those of the fore-, mid-, and hind- brain. These vesicles are, of course, hol. low within, and their cavities have received distinct names, the reasons for which will certainly

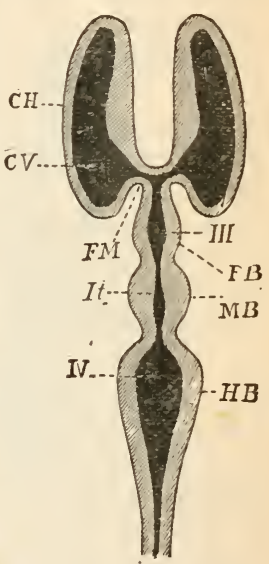

Fig. 178.-Diagram of the Ventricles of the Vertebrate Brain.

II 1 , third ventricle; It, jter; Iv, fourth ventricle; $\mathbf{C H}$, cereliral hemispheres; CV, their cavity ; FM, foramen of Munro; $F B$, forebrain; sB, mid-brain ; H B, hind-l)rain. be far from clear, unless we recollect that the terminology of the parts of the vertebrate brain is based on the nomenclature of anthropotomists. The cavity in the fore-brain (Fig. 178; III) is known as the third ventricle, and that in the hind-brain (IV) as the fourth ventricle; the often narrower cavity in the mid-hrain (It) is known as the iter a tertio B B -16 
ad quartum ventriculum, or more shortly as the iter.

The walls of these cavities undergo further changes; the hind-brain becomes divided into two parts, one of which lies behind, and at a little lower level than the other; this is the medulla oblongata, and it is directly continuous with the spinal cord. The anterior half, which in the frog is a narrow band, but in man forms a very conspicuous part of the whole mass, is the so-called little brain or cerebellum. The mid-brain does not undergo transverse division; its upper and lateral portions form the optic lobes, and the inferior portion the so-called crura cerebri. The most remarkable changes are undergone by the fore-brain vesicle, which buds out a vesicle on either side, the cavities in which are known as the lateral ventricles (cv) ; these lateral outgrowths always become of considerable size, and in the higher vertebrates form the chief mass of the brain. They are the cerebral hemispheres, and are the seat of the most important of the functions performed by the brain; they not only increase in size, but by the development of grooves, the presence of which permits an addition to the quantity of grey or ganglionic material altogether out of proportion to the increase in the area occupied, they come to have not only a more complicated surface, but also a much higher functional value.

The cerebral hemispheres are continued anteriorly into the olfactory lobes (Fig. 179 ; ol), and these into the so-called olfactory merves. More posteriorly, the fore-brain gives off another vesicle on either side, and this vesicle travels away from the brain, with which it only remains connected by its stalk; the vesicle forms the hinder part of the eye, and the stalk becomes the so-called optic nerve. The remainder of the fore-brain forms the thalamen- 
cephalon, or optic thalami, so called from the fact that when the brain is laid on its upper surface the optic nerves rest on them as on a couch (thalamus).

Connected with the upper surface of the thalamencephalon is the pineal gland, which is not
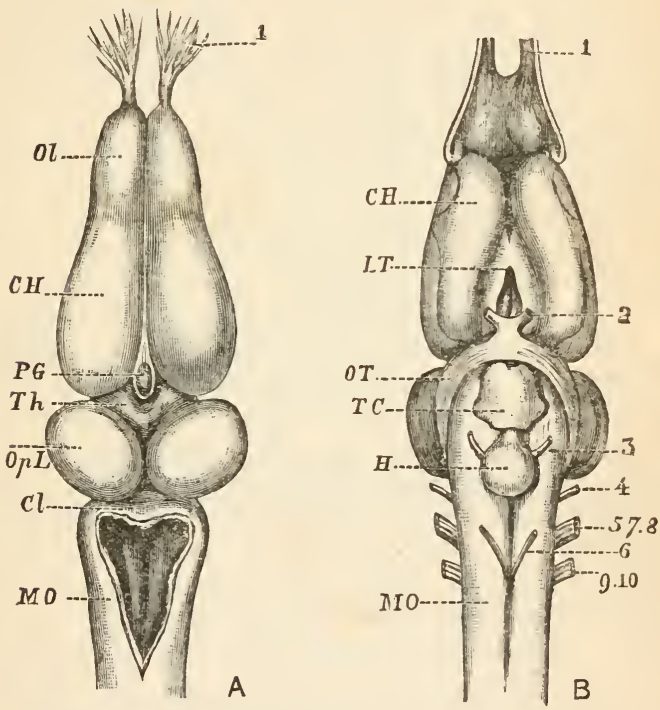

Fig. 179.-A, Brain of Frog from above; B, from below.

1, Olfactory nerves; Ol, olfactory lobes; $\mathrm{CH}$, cerehral hemispheres; LT, lamina terminalis; $\mathbf{T} h$, thalamencephalon with pineal gland $(\mathbf{P G}) ; 0 p \mathbf{L}$, optlc lohes; $\mathrm{cl}$, cerebellum; Mo, medulla ublongata; 2 , optic nerves; $0 \mathrm{~T}$, optic chiasma ; Tc, tuber cinereum; H, hypophysis cerebri ; 3-10, cerebral nerves. (After Ecker.)

nervous in nature, while the lower surface of the same region of the brain is continued into the funnelshaped tuber cimereum (Fig. 179 ; TC), with the base of which is connected the so-called pituitary body; this, like the pineal gland, is not nervous in 
nature, and is a structure which is not of cerebral origin at all, but is derived from the epiblast which lines the cavity of the mouth; in its primitive condition it forms an inpushing towards the lower surface of the brain; its base becomes solid, and then disappears, so that the ingrowth becomes completely separated off from the layer of cells from which it took its origin. In the lower vertebrates it does not, but in mammals it does, become structurally united with the brain.

In Fishes the brain is always small ; in the pike, for example, it is not more than $\frac{1}{130}$ th part of the weight of the whole body, whereas in Man it is about $\frac{1}{50}$ th of the total weight; nor does it grow proportionately with the growth of the body, or occupy the whole of the cranial cavity. In the Cyclostomata the walls of the cerebral hemispheres become greatly thickened, so much so, indeed, that in Myxine they become quite solid; the olfactory lobes are proportionately large, as is also the pineal gland; the region of the hind-brain is also of great size, proportionately to the rest of the organ. In the Elasmobranchs the olfactory lobes are often carried forwards on stalks, which are of great length in some sharks; these lobes may be broken up into smaller lobules. The cerebral hemispheres are proportionately large, and differ greatly in the size of the contained ventricles, or, in other words, in the thickness of their walls; the surface of these hemispheres is sometimes marked by a few shallow grooves. The cerebellum is of large size, and is often grooved transversely.

During the process of development the brain vesicles cease to lie in a straight line one behind the other; as a consequence of this "cranial fexure," the fore-brain lies at a lower plane than the mid-brain, and the long axes of the two are set at an angle to one another. A little later the 
wall between the two parts of the fore-brain becomes thinner, and a "primitive cerebral tissure" is apparent. This condition of things is retained by some Ganoids throughout life (Polypterus; Fig. 180) ; these fishes also possess the more primitive character of a large thalamencephalon.

In the Teleostei the brain is compressed, the cerebral hemispheres are almost completely solid, and the cerebellum is usually, though not always, of comparatively large size; it is often prolonged into the cavity of the mid-brain (valvula cerebelli); on the

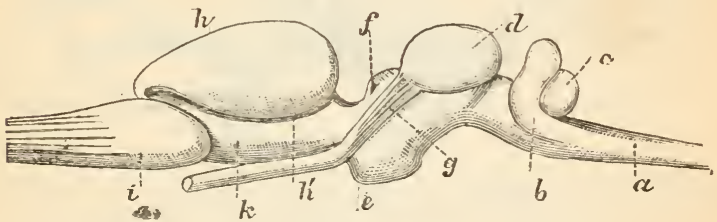

Fig. 150.-Brain of Polypterus seen from the Side.

$i$ Olfactory nerres; $h, k$, cerebral hemispheres ; $g$, optic nerve; $d$, optic lobes ; $e$, hypophysis; $f$, central fissure ; $b, c$, cerebellun; $a$, niedulla oblongata. (After J. Müller.)

whole, the brain of the Teleostei exhibits many resemblances to that of Ganoids, and especially of Lepidosteus.

In the adult Amphibia, as in the adults of most fishes, the several parts of the brain lie in the same plane; on the whole, the brain of the Anura is more highly organised than that of the Urodela; it is proportionately larger than that of fishes, but is still small. The brain of the Anura is different from that of all other Vertebrates, owing to the fact that the olfactory lobes of the adult are not separated from one another, and, like that of the Urodela, the cerebellum of the Anura is of extraordinarily small size. 
In the Amniota we find considerable advances in the characters of the brain, which are chiefly due to the angulation of its several parts, and the thickening undergone by the walls of the primary vesicles at various points.

In the Reptilia the cerebral hemispheres are always smooth on their surface, but they are now, and
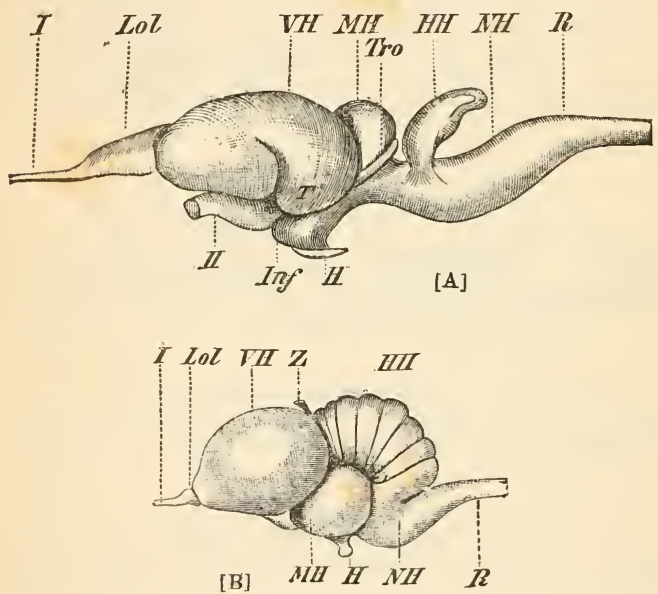

Fig. 181.-Side views of the Brain of a Tortoise (A) and a Bird (B).

1, Olfactory nerves; Lol, olfactory lobes; $\mathrm{vH}$, cerehral hemispheres: II, optic

nerves; Tro, optic tract; inf, infundibululu; $\mathbf{H}$, hypophysis cerehri; $\mathbf{T}$, temporal lobe; мн, optic lobes; $\mathrm{HH}_{\mathrm{H}}$, cerebellunı; $\mathrm{NH}$, medulla oblongata; R, spinal cord. (After Wiedersheim.)

henceforward, always large in proportion to the remaining parts of the brain ; the hemisphere of either side is united to its fellow by a transverse band of fibres (commissure), which lies just in front of the third ventricle; the optic thalami are similarly united by a transverse commissure; the cerebellum 
is not always a narrow plate, and in the Crocodilia the central portion forms a distinct "vermis."

Of the thickenings of the cerebral walls, the two most important are the corpora striata in the hemispheres, and the restiform bodies in the medulla oblongata; the former are the ganglionic masses which become developed on the floor of the

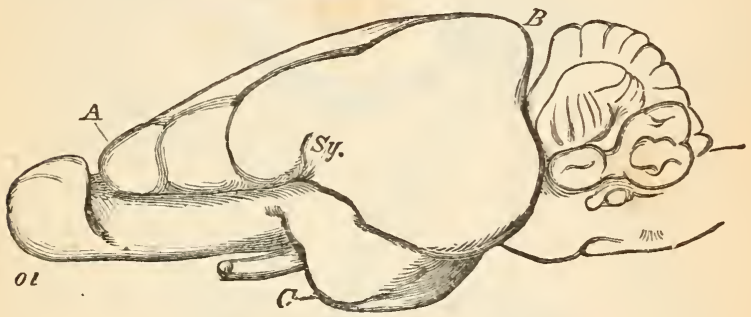

Fig. 182 A.-Lateral view of the Brain of Rabbit, to show the large olfactory lobes, and the termination of the hemispheres in front of the Cerebellum. (After Huxley.)

A, Frontal lobes; B, occipital lobes ; s $y$, sylvian fissure.

brain, and, as they extend inwards, they encroach on the carity of the lateral ventricle; as may be supposed, they are largest in the Crocodilia. The corpora restiformia in a similar manner encroach on the fourth ventricle.

In Birds the cerebral hemispheres are proportionately still larger in size, and, as the optic lobes, or so-called corpora bigemina (Fig. $181(\mathrm{~B})$; $\mathrm{MH}$ ) are now sot at the sides and base of the brain, the cerebral hemispheres so overlap them as to hide them when looked for from above. The cerebellum (Fig. 181 (в) ; нн) is much larger, and its lateral lobes, or flocculi, nay be distinguished from its central body, or vermis; while in section this division of the brain presents just the same appearance as the 


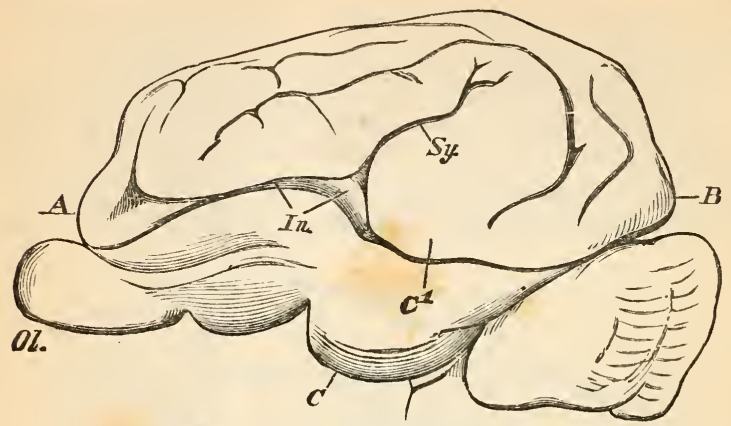

[B]

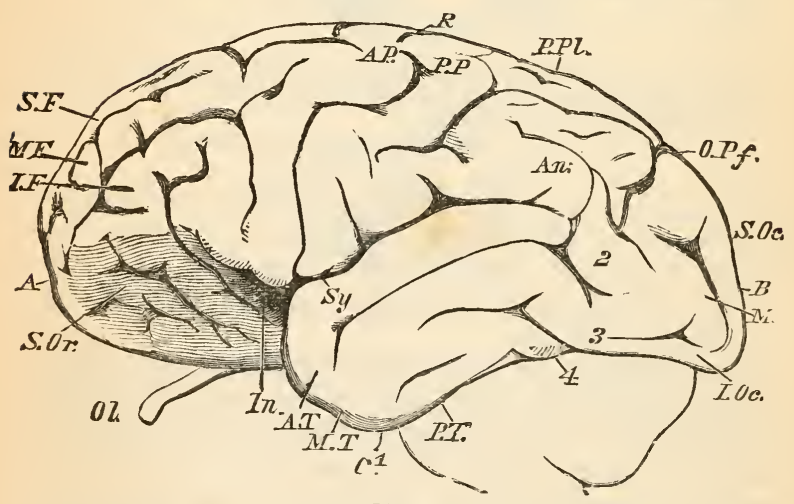

[C]

Fig. 182.-Lateral views of the Brain of : B, A Pig. c, A Chimpanzee, drawn of nearly the same absolute size,

ol, Olfactory ; A, frontal ; B, occipital; c, temp rral lohes; sy, sylvian flssure in, island of Rell; s.or, supraorhital; s F, superior: M F, middle ; I F, inferior frontal gyri : A P, antero-parietal ; P P, postero-parietal gyri: $R$, silcus of Rolando; P Pl, postero-parietal lobule; opf, occipito-tenporal sulcus; $\mathrm{A} n$,

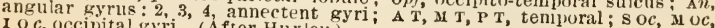
I o $c$, occipital gyri.' (After Huxley.) 
so-called "arbor vita" of the human brain, it is marked externally by fairly deep transverse fissures. The external surface of the cerebral hemispheres is smooth, but the corporate striata are very well developed.

The most important and instructive changes are to be seen in the brain of the Mammalia ; these depend chieflyon the great development of the commissures, which connect the two halves of the brain with one another, and on the gradually increasing sizeof the cerebral hemispheres which ends in their having an extraordinary predominance over the other parts of the brain; hand in hand with their increase in size and extent is the improvement of the intellectual faculties. But the cerebral hemispheres do not merely increase in bulk, their surface becomes marked by groores, and the amount of sur. face thereby developed is, as we have already said,

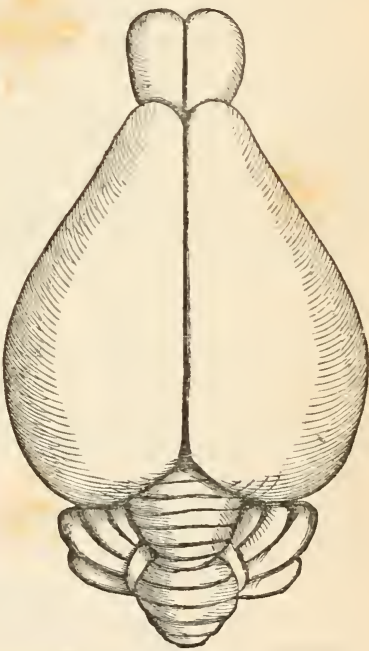

Fig. 183.-Brain of Tupain, to show the large Olfastory Lobe, the ungrooved Cerebral Hemi= spheres, and the large Cerebellum. (After Garrod. P.Z.S., 1879, p. 304.) greatly extended without any corresponding or proportionate increase in the size of the cranial cavity.

The olfactory lobes lie more or less below the cerebral hemispheres, and diminish in proportionate size as we ascend the series ; the cerebral hemispheres 
more and more extend backwards, and at last completely overlie the cerebellum. As they increase in size they become broken up into distinct lobes, frontal, occipital, and temporal. The cerebellum diminishes in proportionate size, and the flocculi cease to be conspicuous at its sides. (Compare ol, in Fig. $182 ; \mathrm{A}, \mathrm{B}$, and c.)

Transverse commissures are always richly developed, the corpus callosum connecting the two cerebral hemispheres, and the pons varolii, which brilges over the hind-brain, being parts which are developed in mammals only. The optic lobes are divided transversely, so that the "corpora bigemina" of the lower vertebrates are now the "corpora quadrigemina"; this mid-brain is proportionately small.

A very complete series of gradations of all these differential characters is to be observed as we pass up the scale of the Mammalia. This is to be seen, first of all, in the proportionate increase in the weight of the brain, as compared with the rest of the body, for, while that of the rabbit is about $\frac{1}{150}$ th part, that of man is $\frac{1}{50}$ th.

In the Prototheria the corpus callosum is always small, and the ceréral hemispheres, which are smooth, do not cover the cerebellum. The Metatheria differ a good deal among themselves. Among the Eutheria, the Insectivora exhibit a brain of very low character; the cerebral hemispheres are often quite smooth, the olfactory lobes are large, and project in front of the hemispheres, which only just, if at all, overlap the cerebellum behind (as in Tupaia; Fig. 183). This latter has a large vermis. The corpus callosum is thin and nearly straight, while the corpora quadrigemina are proportionately large. The pons varolii is very small. In the hedgehog there is a single simple groove (sulcus) on either hemisphere. 


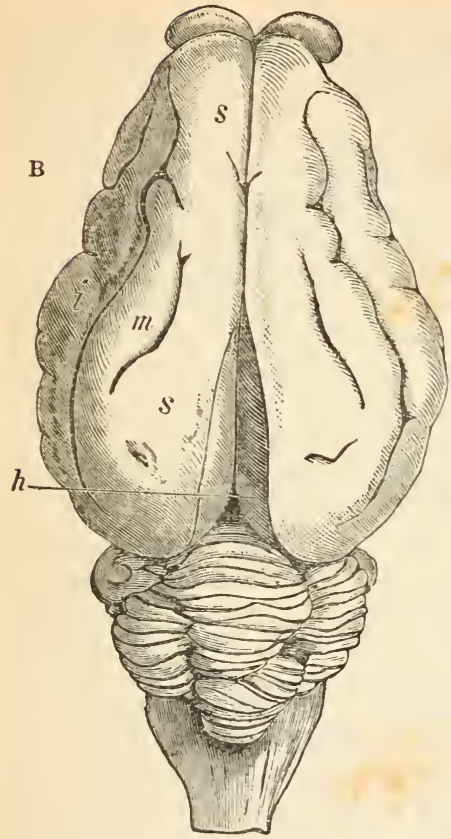

There early ap. pears a fissure at the side of the cerebral hemi. spheres, the sylvian fissure (Figs. 182 ; sy; and 184 (B); s), which separates the frontal from the occipital lobe; this, which is very shal. low in the rabbit or the musk-deer (Fig. $184 ; \mathrm{s})$, is deeper in the pig or the dog, and in man divides into an anterior and a pos. terior groove, between which is placed the island of Reil. The sulface of the hemispheres is next

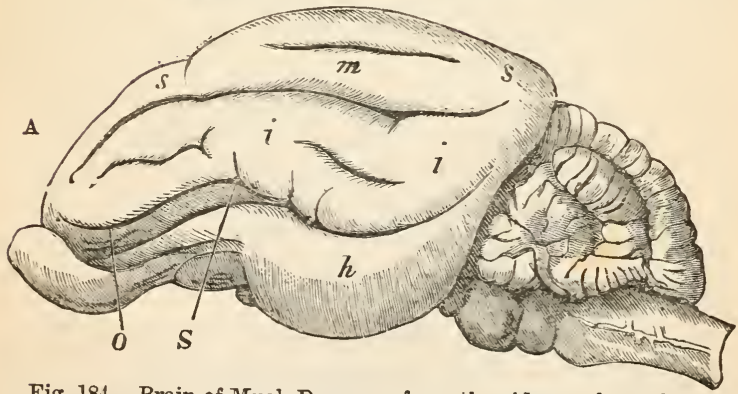

Fig. 184.-Brain of Musk-Deer. A, from the side; B, from above.

8 , Fissure of Sylvius ; $s s$, superior external gyrus ; $m$, middle ; $i$, inferior external gyrus ; $h$, hippocampal gyrus ; o, supraorbital gyrus. (After Flower, P.Z.S.,
$15 ; 5$, p. 175 .) 
broken up into simple folds or gyri, by the formation of intervening fissures; the arrangement of these is better studied in a small than in a large animal, for with increase in size the primitive pattern is obscured by the increase of the convolutions (Flower). These gyri may be distinguished as the superior; middle, and inferior external gyri (Fig. 184; $s, m, i)$; below is the temporal lobe, separated by the hippocampal sulcus $(h)$. To these other grooves may be added on, such as the supraorbital (Fig. 18t; o), and the complexity of the surface of the brain be increased by the development of annectent gyri between the primary folds of a simpler brain.

It is not, however, to the surface that the complexities of the brains of the higher Mammals are limited, the inner as well as the outer face of the cerebral hemispheres becomes convoluted. The corpus callosum, which is at first a thin straight band of connecting fibres, becomes thicker, especially in front and behind, and so curved on itself that anteriorly it forms the "genu" of humian anatomy. Behind and below this corpus callosum is the "formix," and these two structures are peculiar to mammalian brains; the former is developed from what is, morphologically, the inner portion of the surface of each cerebral hemisphere, and there is, therefore, a space left which is bounded on either side by a thin wall (septum lucidum); this space is known as the fifth ventricle, but the name is an unfortunate one, inasmuch as this fifth ventricle is not developed, as are the others, from the original cavity of the cerebrospinal axis, but is merely a space between two overgrown walls. The fornix is similarly derived from the hinder part of the walls of the cerebral hemispheres.

The thickening in the floor of the cerebral hemisphere of either side (corpus striatum) is much more prominent in the Mammalia than in other 
Vertebrates; behind this is a less conspicuous thickening (the hippocampus major), to which is added on in the higher Primates the hippocampus

\section{minor.}

The average weight of the human brain is, for males, between 46 and $53 \mathrm{oz}$, and for females between 41 and 47 oz., but the range of difference is much greater than this. As is well known, the brain of Cuvier weighed $64 \mathrm{oz}$., or 4 lbs., while that of an anonymous sane man was only $34 \mathrm{oz}$, or but little more than half that of the great anatomist; but the weight only must not be taken into consideration; the depth and extent of the convolutions must also be estimated, and Wagner has found a difference of as much as 15 per cent. in the extent of the surface of the cerebral hemispheres of two selected males. But that this, again, is not all is not only clear from the consideration that a small well-made watch often keel's better time than a kitchen clock, but by the following facts :

(1) The anterior portion of the cerebrum is fed by the carotid and the hinder by the vertebral arteries; as the former are much larger than the latter, it follows that the anterior portion of the brain is better supplied than the posterior, and that pro tanto the advantage lies not in the greater size of the cerebral hemispheres as a whole, but in the size of the anterior portion, or that which lies in front of the ear.

(2) Though absolutely the human brain is, on the average, heavier than that of all mammals except of the elephant, which weighs between 8 and $10 \mathrm{lbs}$, or of some whales, which may weigh as much as 5 , while the horse, for example, has a brain weighing only $23 \mathrm{oz}$, and an average-sized dog less than $7 \mathrm{oz}$., jet, in the apparently more important relation of brain weight to body weight, in which man presents the proportions of $\frac{1}{50}$, he is surpassed by some American 
apes, in which it varies from $\frac{1}{2} \frac{1}{8}$ to $\frac{1}{13}$, by the sparrow in which it is $\frac{1}{27}$, and the titmouse in which it is $\frac{1}{12}$ (Bischoff).

On the other hand, when we compare man with his nearest zoological allies, we find that not only is the capacity of his skull and the weight of his brain greater, but that there is a notable increase in the complexity of the secondary gyri of the surface of his cerebral hemispheres, as compared with those of the apes.

The spinal cord differs from its anterior enlargement, the brain, in having the grey ganglionic material placed internally to the white fibrous cords, which act as the conductors of nervous stimuli, but, like it, it is hollow internally, and the epithelium which lines it is temporarily or permanently ciliated. It is marked above and below by a median groove, and, in all vertebrates, has paired nerves issuing from it, each of which is connected with it by a superior and an inferior root. It is cylindrical in all Vertebrates except the Cyclostomata and Chimæra; not unfrequently it extends throughout the whole length of the neural canal formed by the spinal column, but in the sun-fish it is greatly shortened, so as to look indeed like a mere appendage to the brain, and in the anurous Amphibia, in Birds, and various Mammals (among which are the hedgehog and man), the terminal portion is filamentous, and is accompanied on either side by a number of nerves, thereby giving rise to the so-called cauda equina (horse's tail).

\section{SENSORY ORGANS.}

It has been already stated that all the organs of sense have their primitive seat in that outer layer of the body which, in the embryo, is called the epiblast or ectoderm; and we have already learnt that the nervous system itself does, in most cases, 
remain throughout the life of the animal in close local contact with the outer world. In tracing the history of the organs of sense we shall find that, whatever their final position, they too are essentially of epiblastic origin.*

Among the Hydroid polyps, where no nervous system has as yet been made out, we observe that the tentacles which surround the mouth are provided with fine hair-like projections, which look not unlike a trigger; these processes are seen to be in connection with cells which differ in character from their neighbours by the possession of a coiled up thread; when

* Since the above was put into type, Prof. Charles Stewart has favoured me with an account of his observations on sense cells in sponges, and with the accompanying illustrative figure (Fig. $184 \mathrm{~A})$. It is found that "the external orifices of the interradial canals of Grantia compressi are fringed with delicate hair-like processes of the soft substance of the sponge. At first sight these remind one of the palpocils of $\mathrm{Hy}$ dra, which they closely resemble in general form and size"; from these, however, they differ in important particulars. The processes or hairs vary in length from $\frac{1}{000}$ th to about $\frac{\pi}{400}$ th of an inch;

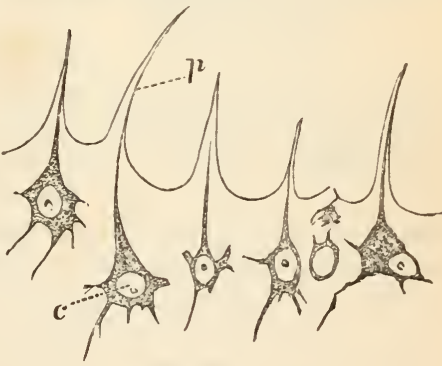

Fig. 184 A.

their base is from ${ }_{500}$ th to $\frac{1}{10000}$ th of an inch, and they taper to a fine point. All such as can be well seen are found to have a special relation to a subjacent branched cell ; this latter sends outwards a delicate filament which traverses the axis of the process. "Such an apparatus appears both by position and structure to be specially impressed by varying conditions in the inrushing water, particles in solution or suspension in this water inducing molecular changes in the cell at the base of the process, and perhaps leading to the contraction of neighbouring cells. In other words, these processes seem to act as part of an automatic mechanism for regulating the water-currents of the orgarism." 
the tentacle is stimulated we observe that these threads are expelled, and that they are barbed; it will be within the knowledge of most of us that these thread cells, as found in jelly-fishes, are efficient organs of offence. Their relation to the trigger-like process suggests that these projections are the first to feel the pressure of any foreign body, and that the pressure communicated by them to the thread-cell or nematocyst, results in the projection of the contained thread.

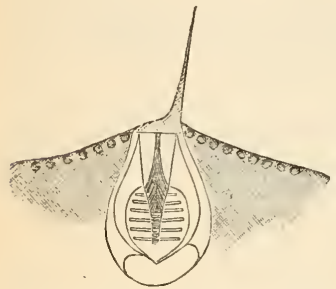

Fig. 185.-Tentacle of Hydra, showing the Trigger-cell and Nematocyst. (After F. E. Schultze.)

Here, then, we seem to have the earliest and simplest kind of automatic tactile orga n including, of course, in the term touch the general sensation of pressure from without. It is, at the same time, necessary to observe that, although these trigger-hairs appear to be the simplest sense organs of a multicellular or metazoic animal, yet that some of the unicellular Protozoa are not without organs of offence that are physiologically comparable to the threads of thread cells, for, if we add a drop of iodine to the water in which a Paramœcium is swimming, we find that it immediately thrusts out from its body fine stiff processes. If, then, these are comparable to the threads of a hydroid, it is clear that, functionally also, the ectosarc of an infusorian is comparable to the sensory parts of the epithelium of a hydroid, and is, like it, capable of responding to definite external stimuli in a definite way. It is important to observe that the first indication of tactile organs is associated with the protection of the individual, as much as with the function of paralysing the prey which is seizerl upon for food. As the sensory cells remain superficial 
in position in the Colenterata, the absence of special tactile organs in most of the members of the group is not to be wondered at, for the tentacles, as a whole, may be looked upon as having a general tactile sense.

Among the 'Turbellaria, trigger-hairs in connection with nematocysts have been observed; in many cases tufts of delicate hairs have been found scattered over the whole body, but more especially well developed at its sides. In some there are definite tactile organs in the shape of tentacles, which are best developed in the anterior regions of the body, and on which the sensory hairs are particularly numerous. Thysanozoon, which is remarkable for having the dorsal surface covered with villiform projections of the body wall, has a bundle of such hairs at the tip of each villus. In the earthworm, the whole body of which is very sensitive to tactile impressions, the anterior end is most remarkably so ; in the polychætous Annelids specially modified sense-cells are largely developed on the protruding antennæ and tentacles which are developed on the præstomium, and are supplied by nerves which arise directly from the cerebral ganglia; these, as well as those on other parts of the body, are, like the antennæe of the Arthropoda and of some Mollusca, very important aids to the organism, for they are capable of movement laterally, or of protrusion forwards, or of both; they are, in other words, able to feel about, and not, as is the case with the earthworm, compelled to wait for the arrival of food or foe.

In the IIiradinea the widely distributed organs of general tactile sense are purely of epidermic origin, and are known to be supplied with nerve fibres; at the anterior end of the body these cells are aggregated to form the so-called goblet-shaped organs. According to Whitman, special papilliform aggregations are to be found on every segment of the body.

c c -16 
When the outer surface of the body becomes hardened by the deposit in its wall of chitin, as in the Arthropoda, or of calcareous salts, as in the Echinodermata, or by the development of a shell, as in the Mollusca, the general tactile sense becomes more distinctly limited; this is, perhaps, least noticeable in the Echinodermata, where the superficial plexus of nerve filaments extends over the test and along the projecting suckers, while special nerve cells are developed in the highly sensitive pedicellariæ.

In the Arthropoda the special tactile organs are seen at their simplest in Peripatus; in it the dorsal surface is raised up into delicate imbricated papillæ, from the tip of which there projects a fine process. In others they take on the forms of projecting rods. As we all know, we have only to stroke lightly the hairs on our own arms to discover how easily tactile sensations are conveyed by more or less stiff processes to the sensory cells that lie at their base. Where the greater part of the integument is hardened it is clear that projecting rods or "hairs" will, if they be provided with nerve fibres, and continuous with sensory cells, convey to the underlying and protected nervous system any movement of their free ends; the movement, then, of these hairs becomes in an Arthropod a sense of touch; these rods are not confined to the antennæ, for they are developed on very various parts of the bodies of Arthropods.

Sagitta, in which there is likewise a chitinous cuticle investing the body, has a large number of bundles of stiff setæ scattered over the surface of its integument (Fig. 186).

Among the Chordata we find that little is definitely known as to the tactile organs of the two lower groups ; the only sensory cells that have as yet been recognised in Amphioxus are of a much simpler character than those which we have just been 
considering; these, which are most numerous on the cirri and in the neighbourhood of the mouth, lie side by side with the ordinary epithelial cells, from which they are to be distinguished by a stiff free process, and a basal connection with a nerve fibre, calling to mind again the simple sense cells of the Medusæ. A very ordinary character of tactile cells among the Vertebrata is their bulb-like arrangement (see "Elements of Histology," chap. xv.) ; they are, as may be supposed, widely distributed over the whole body, al. though, of course, they are much more richly developed in some parts than in others, and in some forms more than in others.

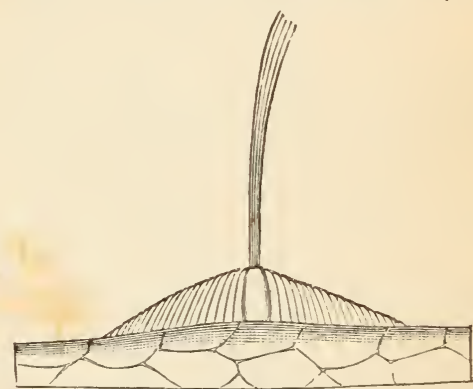

Fig. 186.-Tactile Organ of Sagitta bipunctata, showing the long stiff setæ. (After O. Hertwig.)

Organs of iaste.--Although we may well suppose that some sense of taste is possessed by the lower Metazoa, we have as yet very little definite information as to organs to which it is reasonable to ascribe such a function. In the Echinoidea (excepting Cidaris) Lovén has described, under the name of sphaeridia, organs to which he assigns a gustatory function. These are always set around and confined to the region of the mouth (actinostome), where they have the general appearance of transparent solid bodies invested by pigmented cells and a ciliated epithelial layer. Just as the auditory organs of some Cœlenterates appear to be modified tentacles, so do the sphæridia remind us in the most striking 
way of the structure of the spines of Echinids. Their small size and protected position, under large spines or in special cavities of the test, prevent us from regarding them as tactile organs, while their constant approximation to the entrance into the digestive tract justifies us, at present, in ascribing to them the function of testing the food which is found in the water in which their possessor lives.

Very little is definitely known as to the organs of taste in other Invertebrata, although, of course, most do, on observation, exhibit some kind of preference for certain fools ; this was seen by Mr. Darwin even in the omnivorous earthworm. In Insects the maxillary palpi are probably the seat of the organ, and Lowne has described those of the blowfly as having their cavity filled with cells, which are supplied by a branch from the great nerve trunk of the proboscis. Freely projecting epithelial papillæ, not unlike the gustatory organs of tadpoles, have been observed on the tentacles of various Molluses; the cells of which these papillæ are composed are ciliated, and appear to be well supplied with nerves ; their gustatory function seems to have been demonstrated.

Nothing is certainly known as to gustatory organs in the Urochordata or Cephalochordata. In Fishes, the organs of this sense are only feebly developed, and, as often happens with organs in a generalised condition, they are not so definitely localised as in the higher forms. The cup-shaped organs have at their edge long cylindrical cells, with more delicate cells in the central portion; they are not confined to the cavity of the mouth, but are found also on the skin (compare the account of the teeth of Elasmobranchs, page 141); those that are placed on the mucous membrane of the palate are supplied with branches from the glosso-pharyngeal nerve. In the carps they are described as being most largely developed 
on the palate, on the rudimentary tongue, on the mucous membrane which covers the inner side of the branchial arches, and the barbels ; around the mouth, on the skin of the head, and the rest of the body they are less numerously developed.

In the Amphibia the cells of this sense are grouped into discs, the so-called gustatory discs; those on the tongue are placed on elongated papillæ, but such as have been observed on the mucous membrane of the palate are not known to project above the surface, except in the region of the vomerine bones, where, as on the tongue, the papillæ that bear them may be distinguished as fungiform. The Amphibia exhibit a higher form of differentiation than the fishes, inasmuch as the gustatory cells appear to be confined to the region of the mouth. For the majority of the Samopsida it is impossible to affirm definitely the possession of a sense of taste, and it is very probable that in many, as in some (e.g. Birds) almost certainly, the sensations experienced are those of a foreign body only; are, in fact, mechanical, and not chemical. In Lizards and in Crocodiles there are, however, projections of the mucous membrane (papillæ) which are provided with goblet-shaped cells, and these may, by analogy, be reasonably supposed to have a gustatory function.

Just as the ant-eater, and other Mammals, prove to us that the tongue may be a seizing organ, and is not merely the bearer of the gustatory bulbs, so, in man at any rate, the gustatory function is not confined to the body of the tongue, for in ourselves the soft and part of the hard palate are also capable of taste. The greater number of gustatory sensations are, nevertheless, experienced through the tongue, and we may justly say that, in this particular, the fish stands at one, and the mammal at the other end of the series. The majority of the gustatory cells are 
set upon papillæ, and are most numerous on the circumvallate papillæe at the back of the tongue; in rabbits and hares a large supply of taste bulbs is to be found on an organ developed on either side of the root of the tongue, which is broken up into ten to fourteen valleys, in the recesses of which the bulbs are
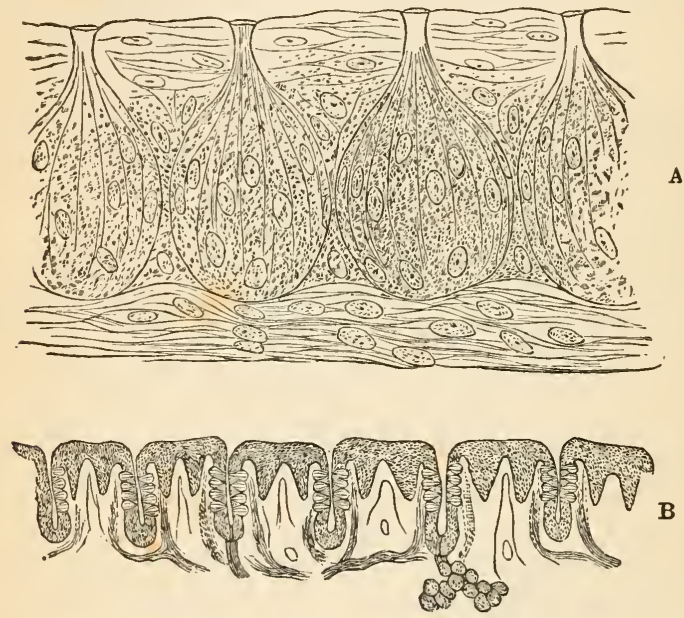

Fig. 187.-A, Taste Bulbs of Rabbit; B, Transverse Section through Taste Folds of Rabbit. (After Engelmann.)

placed. In this sense, then, as in others, we find that the terminal sense organs are withdrawn from the surface, protected from rough contact, and excited only by certain definite stimuli. This must not lead us to suppose that the gustatory sense organs offer any exception to the rule that all organs of sense have their origin in the epiblast of the embryo.

Onfactory organs.- Till we reach the Arthropoda and Mollusea we do not find any structures 
which can be definitely asserted to have an olfactory function. In the higher Crustacea we find organs in the antennules which, in the crayfish, are thus disposed ; the outer branch (exopodite) has attached to the greater number of its more distal joints tufts of short delicate bristles, flattened or papilliform at their free ends; these bristles have granular contents, and are supplied by fine nerve fibres. In the Insecta, where there is only one pair of antennæ, the olfactory organ is, to judge from the accounts of Braxton Hicks and Lowne, placed in the third joint of the antennæ of the blowfly; the surface of this joint is described as being "covered with minute hairs, between which are a vast number of pellucid dots, about 17,000 or 18,000 on each antenna, with about eighty large irregular spots of a similar character." The

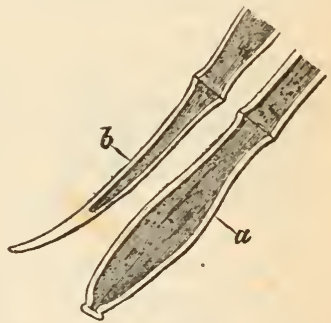

F'ig. 187 A.-Olfactory Appendage of Exopodite of antennulo of Craytish ; $\times 300$. a. Front. $b$. Side View. (After Huxley.)

smaller dots appear to be the optical expression of the orifices of minute sacculi, and the larger the common openings of compound sacculi. This third antennal joint is described as being filled with a cellular pulp, through which are distributed the fibrils of the antennary nerve.

In the Mollusea the olfactory organ ("osplaradium," Lankester) is remarkable for its constant relation to the neighbourhood of the respiratory orifice, and its as constant nerve supply from the visceral commissures ; it appears to be absent in air-breathing forms (e.g. the snail), and we may suppose, therefore, that it has a function in the way of testing the water which carries the oxygen necessary for respiration. It has ordinarily the form of a short 
canal, which either ends blindly, or is bifurcated at its free end; at this end, or at the point of bifurcation, there is a small ganglion. The cylindrical canal consists of a network of coiled fibrous bands, and is invested by elongated epithelial cells, which are directly continuous with the integument; these cells are very richly supplied with nerve fibres.

Among the Chordata no definite olfactory organ has been recognised in the Urochordata; in the rest it always stands in close relation to the respiratory orifice, but in nearly all fishes it is not directly continuous with the respiratory passages. The single pit at the anterior end of the body of Amphioxus, though lined with a ciliated epithelium, can by no means be certainly said to be an olfactory organ. The Cyclostomata have but a single pit, whence they have been distinguished from all other Vertebrata as the Monorruima ; notwithstanding the single condition of this pit the nerve supply is double, and we must not, therefore, yield to the temptation to regard this condition as being a primitive one; in this, as in many other points, the existing Cyclostomata show that they stand at some distance from the primitive rertebrate stock; their single nasal pit is, almost certainly, the result of the fusion of two originally separate sacs; this view is supported by the observation that, in the larval lamprey, the sac is more nearly divided into two internally than it is in the adult. The interior of the cavity is occupied by folds, some of which project farther inwards than others, and all of which are covered by a mucous membrane ; to this are distributed branches of the olfactory nerves. In the lampreys the sac is closed posteriorly, but in Myxinoids it opens into the cavity of the mouth.

In all the rest of the Vertebrata the olfactory organs arise from a pair of patches of epiblast in front of the mouth, which, as they thicken, give rise to a 
pit-shaped cavity; the epithelial cells that line this pit are the end organs of the olfactory sense, and the whole layer forms the so-called Schneiderian membrane, which gradually becomes more and more elaborately folded. The sac does not remain pit-like in fishes, but becomes connected by a groove with the angle of the mouth; this groove, which may become of some depth (rays), is covered over by a fold of the integument, the so-salled nasal valve (Fig. 188); so that we are able to distin. guish an anterior and a posterior orifice, the hinder of which is in close relation to, but is not within, the cavity of the mouth.

In the Dipnoi the hinder orifices come to lie within the buccal area, and the same is true of all the pentadactyle Ver. tebrata, in which, as we ascend the series, we find the posterior nares coming to lie farther and

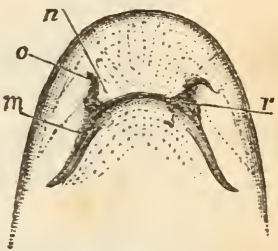

Fig. 188.-Nasal Groove of the Dog-fish.

$m$, MIouth; $n$, nasal valve; 0 , entrance to nasal pit; $r$, nasal groove. (After Gegenbaur.)

farther back, as the various bones of the roof of the mouth form outgrowths which serve as a floor for the nasal passages. We cannot resist the supposition that this movement in the position of the posterior nares is in relation, firstly, to the altered mode of respiration, the lungs taking the place of the gills; and, secondly, to the needs of the organism. If we may judge from the crocodile or the whale (page 242), the elongated passage has not essentially any relation to the olfactory sense; the true olfactory portion remains throughout the Vertebrata a closed pit, and the only advantage to it that results from the elongation of the passage is a mechanical one. The longer air passages allow of a more forcible inspiration, and, in consequence, of a more forcible taking in of odoriferous particles. 
The nasal sacs, then, of different Vertebrates, differ only in the extent of the complication of their internal walls, and of the membrane which covers them. This complication is chiefly effected by the development of

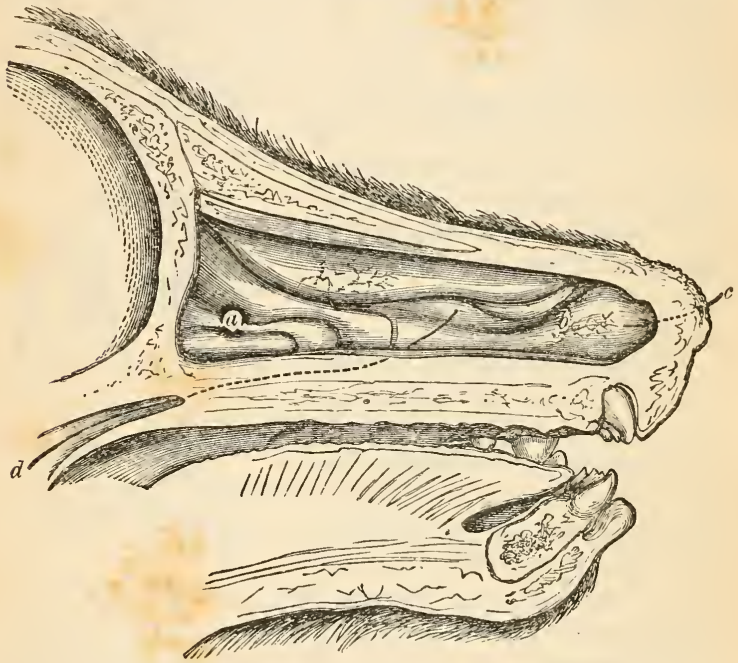

Fig. 189.-Longitudinal Section throngh a Dog's Nose, showing the Spongy Bones.

$a$, Region of the olfactory sense ; $b$, air chamber ("sneezing region "); $c$, a bristle passed throngh the nostril into the nasal chamber; $d$, a bristle from the nasal chamber into the passage by which the latter communicates with the mouth. (After T.J. Parker.)

cartilages, which may become more or less completely ossified, in the upper or olfactory region ; these arise from the side walls of the cavity, and project into it; such bones are known as the turbinate bones. While Reptiles and Birds have one only, Mammals have three (excepting the Cetacea, which have none); these vary greatly in form and in the extent to which they are developed, and, as they are covered by the 
olfactory membrane, we may estimate the comparative complexity of the turbinate bones by the acuteness of smell of their possessor. Many mammals, both those that hunt (Feliclæ), and those that are hunted (Cervidæ), have a much more acute sense, and more com. plicated turbinate bones, than has man (Fig. 189).

Like other specialised sensory organs, the olfactory apparatus of Vertebrates is provided with characteristic cells, which are to be found in the lamprey almost as well marked as in man. (See "Elements of Histology," Fig. 166.)

In the physiology of this sense it is necessary to distinguish between smelling, which is a more or less passive act, and scenting, which is an active operation. Although we cannot suppose that the latter power is well developed among Fishes, yet the fact that the nasal valve is provided with muscles, taken in connection with what we know as to the habits of sharks, for example, justifies in believing that some fishes, at any rate, are capable of scenting as well as of smelling. In the Sauropsida a more forcible inspiration of air must be the chief aid, but in Mammals the addition of external movable cartilages supplied with muscles results in a power to enlarge or diminish at will the size of the entrance to the nasal passages.

The external cartilaginous "nose" once formed may become adapted to duties altogether foreign to the olfactory sense; it may be prolonged into a snout which, as in the pig, may be of real use as a digging organ, or it may become, as in the elephant, greatly elongated, and have the functions of a prehensile trunk, or proboscis.

The sense of sight is at first a generalised property, many Protozoa showing themselves to be sensitive to light. The most primitive condition of an eye or optic organ is presented by patches of pigment which are more sensitive to light than is protoplasm generally. 
Such eye-spots are possessed by a number of the lower Invertebrata. They are, perhaps, found at their simplest condition in a starfish, where they occupy the ends of the arms ; and these ends are, by a muscle running along the upper surface of the arm, turned upwards so as to be exposed to the light. There are here (Fig. 190) a number of eye-spots, each of which is made up of several epithelial cells; these undergo a

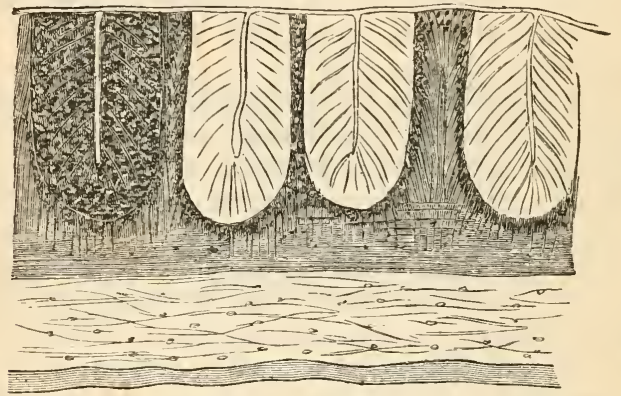

Fig. 190.-Four separate Eye-spots of a Starfish, showing the invaginated Epithelial Cells and the Central Cavity; below is the plexus of Nerve Fibres. (After Hamann.)

certain amount of invagination, and give rise to a central cavity in their midst; with these cells nerve fibres become connected, and in their substance a red pigment is deposited. Here, then, we have nothing more than a number of epithelial sensory cells, distinguished by the possession of pigment; the cuticle, it will be observed, is not thickened into a convex cornea, and there is no reason to suppose that the fluid in the central cavity has any refractive action on the rays of light.

The Medusae, or such of them as have eyes present us with a condition which is a little in advance of what obtains in the starfish; for, speaking 
generally, we observe a distinction between the pigmented and the sensory cells; the latter are not mere cylindrical bodies, but have their peripheral portion converted into an elongated process, not unlike a small rod, while they are continuous behind with ganglionic cells. In the simplest cases there is no comea or lens, or organ to concentrate the rays of light ; in the more complicated the investing cuticle becomes convex in shape, and has, no doubt, some such function; so that we have now to observe an apparatus which is composed of parts that are respectively refractive, light-absorbing, and light-perceiving. These eyes lie at the base of the tentacles, and have been proved by direct experiment to be really sensitive to luminous impressions ; specimens of Aurelia (the common jellyfish), which, when uninjured, were found to swim towards a beam of light flashed upon the water in which they were kept, were, when the eye spots were removed, observed to exhibit no change of manner on the application of a similar stimulus.

The earthworm is without any organs that can be called eyes, and, as a general rule, we find that burrowing forms are always less well provided with optic organs than their allies which live on the surface of the land; at the same time the worm is sensitive to light, and ordinarily withdraws from it; the sensitiveness is confined to the anterior region of the body. This cannot but be regarded as a very striking phenomenon, when correlated with the concentrated condition of their nervous system, and the fact that in Vermes with a more diffused arrangement of the nervous system, eyes are found in various regions of the body.

In the lower worms, simple eye-spots are not unfrequently present, and, as often happens with organs in a simple or indifferent condition, they are present in large numbers; some Turbellaria, for example, 
have several hundreds; they are, as a rule, best developed in the region of the cerebral ganglia, and, in some cases, even in these low forms, they are found on the tentacles; pigment cells are here also separate from sensory cells, and the latter are continued into nervous filaments, which pass to the optic nerve. They are turned towards all directions, but exhibit an advance in differentiation by lying below the epithelium which invests the body. Pigment spots are not confined to the adult forms, the larva of the liverfluke, for example, having on its back two curved patches, the convex sides of which are opposed to and placed close to one another.

In higher groups, the number of eyes ordinarily becomes reduced, but even among the Polychatous Anmelids we find a form (Polyophthalmus) in which a pair of eyes is developed on every segment, in addition to those on the head. This fact, especially when taken into consideration with the presence of eyes in the last segment of the body in Fabricia and some other worms, is very significant, as showing us that sensory organs, which are essentially of epiblastic origin, may be developed and retained on any part of the body in which their presence is useful to their possessor.

When the eyes become reduced in number, there may be several pairs in the more anterior region of the body, as in the leech, which has ten pairs; or they may be found on the tentacles, as in Branchiomma, or on the gills, as in Sabella. The next step in the reduction is seen in the scorpion and other Arthropods, where there are a pair of "compound" and several pairs of "simple" eyes ; and the final step is reached in the higher members of all groups, where the eyes are two in number only; in various Entomostraca (e.g. Leptodora) the two eyes become fused in the adult. 
The simplest condition of the final stage is to be found in the Nautilus, where the eyes retain the primitive condition of having their central cavity open to the exterior; the cells which line this cavity, and which are the direct continuation of the epithelial cells which invest the body, are converted into sensory (retinal) cells, and are connected by nerve filaments with the optic nerve which is given off from the cerebral ganglion. A higher stage than this is to be seen in the snail, for here the cup becomes closed up, and there is developed in its cavity a spherical body which has the function of a lens, while the outer wall of the cavity plays also a part in refracting the rays of light, owing to its having been converted into a cornea. Peripatus has an eye which does not essentially differ from that of the gastropodous Mollusca.

The typical eye of a well-developed Polychrtous Annelid presents an advance upon those of the just. mentioned Mollusca by the following characters; the lens does not occupy the whole of the cavity of the eye, but is placed anteriorly, while the rest is filled by a vitreous humour; the lens, therefore, is more distinctly convex, and has a greater influence on the impinging rays of light; the layer of rods which lines the cavity is bounded by a distinct and wellmarked layer of pigment.

Though the physiology of the eye of a crayfish offers some considerable difficulties which cannot as yet be satisfactorily explained, the morphological series is so complete that, from its point of view, much may be made clear.

The prime difficulty lies apparently in the large number of lenses that seem to be present in a com. pound eye physiologically, this arrangement is preceded by what obtains in the Chætognath Sagitta. In this worm, the eye, which is completely covered by the epidermis, consists of three biconvex lenses, each 
of which is embedded in a central pigment borly, and surrounded by fine cylindrical optic cells, which form
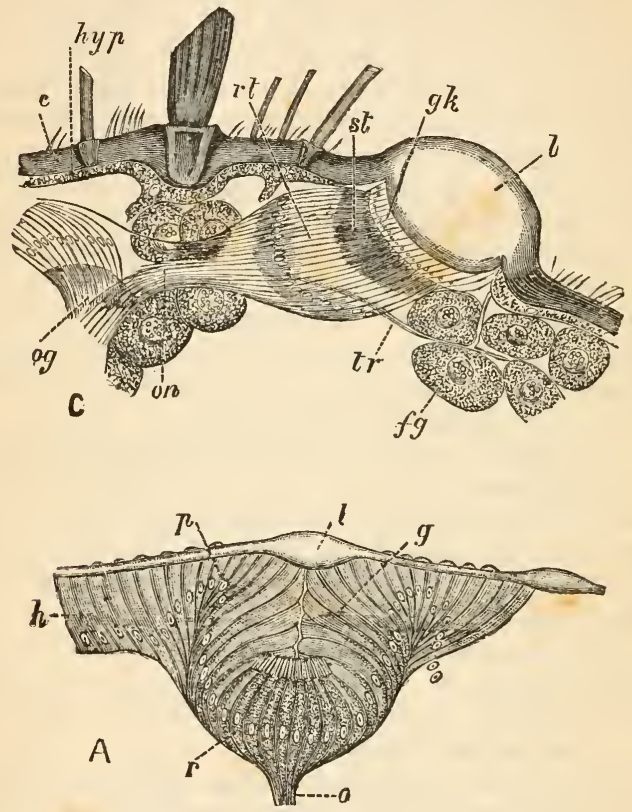

Figs. 191 A, 191 c.-Figures of Eyes of Arthropoda.

A, Eye of larva of Dytiscus, showing the simplest condition of a single layer of cells $(p, g, r)$, continuolis with those of the hypodermis $(h)$; each cell is distinct, and some $(r)$ are continuou's with optic nerve fibres $(o) ; l$, lens. (After Grenacher.)

c, Simple eye (stemma) of fiy, showing the layer $(g k)$ of vitreons cells distinct from the retinal layer $(r t) ; c$, cuticle; $h y p$, hypodermis ; $l$, lens ; $f g$, fat cells: tri, trachea; on, optic nerve; og, optic ganglion; st, rods of retina. (After Grenacher.)

a retina; each of these cells is sharply divided into two portions ; that which lies nearest the lens is rodlike, the rest is granular in character. As the lenses 
lie in different planes it follows that light passes to the rods from very various points.

Among the Arthropoda the simplest cases are seen in the larvæ of various insects (Fig. 191, A);
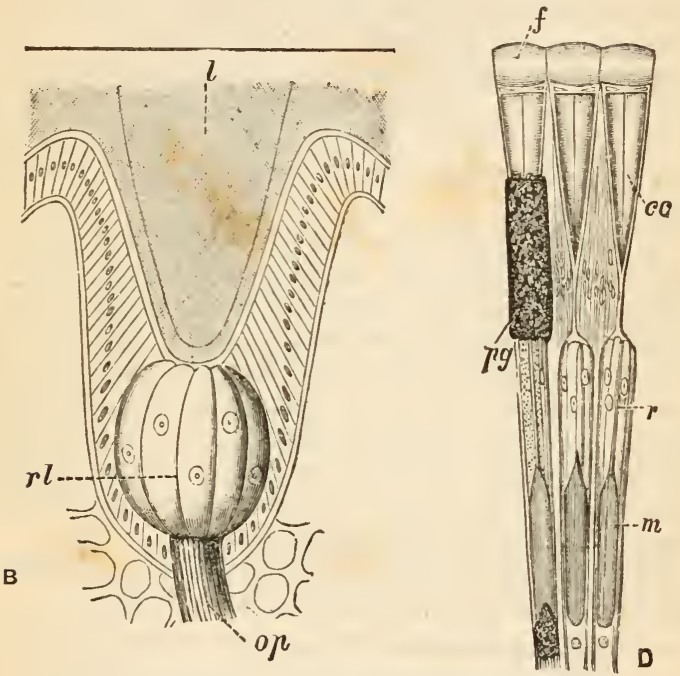

Figs. 191 в, 191 D. -Figures of Eyes of Arthropoda.

B, A single cuticular lens of Limulus, to klow the aggregation of cells to form a retinula $(r l)$. (After Lankester and Bourne.) $l$, lens; $r l$, retinula ; op, ontic nerve.

D, Part of the compound eye of Phryganen; the retinal cells are seen to he uniteil into a retinula $(r)$, which is differentiated into a rhabdom $(m)$ posteriorly; $c c$, crystalline cone ; $f$, facet of componnd eye; $p g$, pigment. (After Grenacher.)

there is a single lens, the hypodermic cells that form the sensitive elements, and some of which are continuous with filaments of the optic nerve, are simple and separate; these cells may be called the retinal cells. This condition may, as in Limulus (Fig. $191 \mathrm{~B}$ ), be complicated by the cells, instead of remaining separate from one another, becoming aggregated into D D -16 
definite groups, each of which may be known as a retinula. The next stage in complication is brought about by the cells of the sensitive layer becoming divisible into an outer (vitreous) portion, and an inner retinal part; this may be effected without the elements passing through the second stage, or that of segregation into retinulæ; as happens, for example, with the lateral eyes of the scorpion, and the more simple eyes of adult insects (Fig. $191 \mathrm{c}$ ). In the more complex cases the retinal cells form retinula (Fig. $191 \mathrm{D})$.

While the sensory parts thus become more complicated, the refractive element, or cornea, which is formed by the epidermis, may likewise lose its primitive simplicity as a continuous investment to the eye, and become divided into a number of facets, each of which is in connection with its proper set of sensitive cells; and of these lenses there may be several hundreds. We may distinguish, therefore, an eye with one lens from an eye with many by calling them respectively monomeniscous and polymeniscous.

The eyes of Arthropods (Fig. 191) are, therefore, in the classification of Lankester and Bourne :

A. Monostichous (formed by a single layer of cells).

a. Non-petimulate, as in the larvæ of insects.

B. Retinulate. i. Lateral eyes of scorpions. ii. Lateral eyes of Limulus.

B. Diplostichous (formed by a double layer of cells, one vitreous, and one retinal).

a. Non-retimulate.-Dorsal eyes of spiders, and simple eyes of adult insects.

B. Retinulate.-Central eyes of scorpions, compound eyes of insects and Crustacea.

i. Monomeniscous (with a single lens).

ii. Polymeniscous (with a number of lenses).

1. Separate vitreous bodies.

2. Aggregated vitreous bodies.

Among the Invertebrata the highest type of eye 
is to be found in the dibranchiate Cephalopoda, and it is remarkable for being protected by a cartilaginous orbit; the sicles of the eye are protected by a hard layer which has been called the sclerotic; this, which, in front, passes into the transparent cornea, is either entire, or perforated in its centre by a more or less large aperture. Beneath this is a chamber which is not so small as in the vertebrate eye, and which sends down a narrow process on either side. The hinder part of this chamber is, in the long axis of the eye, occupied by the lens, which is bounded on either side by the iris; the hinder part of the lens projects into the hinder or inner optic chamber, the posterior wall of which is formed by the retina. In this retina, as in those of nearly all Invertebrates, the sensitive portion or layer of rods is turned towards the impinging rays of light, and the connective elements are posterior to it. We shall shortly see that the reverse of this arrangement obtains among Vertebrates.

The eyes of the Vertebrata are constantly paired, and lie, as an ordinary rule, on either side of the more anterior portion of the head ; they are always divisible into tiwo portions, an anterior and a posterior chamber, and the hind wall of the latter, far away as it lies from the surface of the body, is the percipient portion of the optic organ, and has an epiblastic origin. In comparison with any other fact as to the vertebrate eye, this one fact stands out pre-eminently, and first deserves our attention.

We have already learnt that in the Chordata the central nervous system arises as an infolding of the epiblast, which gradually becomes separated from the surface of the body; as we know, the result of this infolding is to reverse the relations of the outer and inner strata of the epiblast, or, so to speak, to turn them inside out (Fig. 192; A, B). The nervous tube 
thus formed grows out at its anterior end into three brain vesicles; from the foremost of these an ontgrowth is given off on either side which forms the
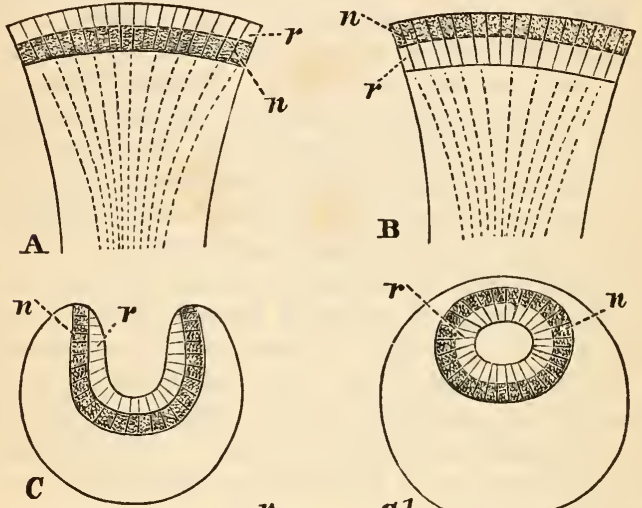

$\boldsymbol{n}$
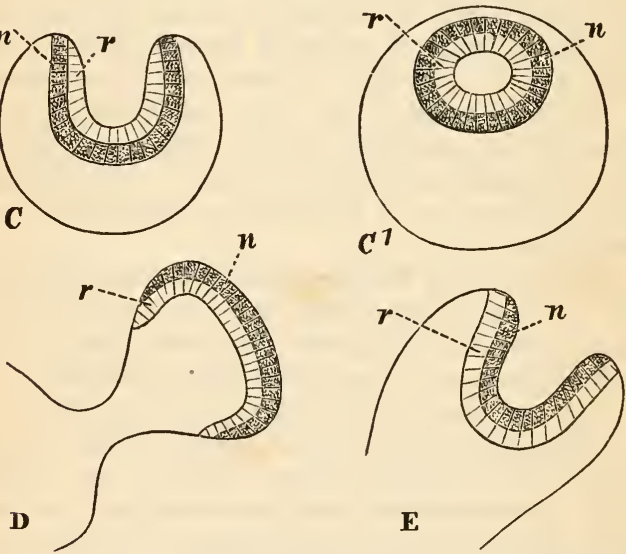

Fig. 192.-Diagrams to show $(\mathbf{A}, \mathbf{B})$ the relative position of the Rods and Cones $(r)$ and the Nerve Fibres $(n)$ in an Invertebrate $(A)$ and a chordate Eye (B). C shows the inpushing of the Cells from which $v$ and $n$ have their origin, $\mathrm{c}^{\mathrm{l}}$ the final result in a chordate Spinal Chord; D, the outgrowing Optic Vesicle from the Brain; E, the formation of the Optic Cup.

optic vesicle (Fig. 191 D); the outer wall of this vesicle next gets pushed in (E), but the layers retain the relations to one another that they had in the optic 
cup. The difference, then, in the position of the rods and nervous elements of a chordate as compared with that of an invertebrate eye is due to the primary alteration in position, caused by the mode of formation of the central nervous tube, and by the fact that the retina is an outgrowth from an anterior enlargement of this tube. The stalk of the vesicle forms the optic nerve.

The other or anterior half of the eye has a history which is essentially similar to that of the eyes of most invertebrates; the epiblast of the surface thickens and gives rise to the lens and cornea, while the mesoblast forms supporting and protective tissues.

The simple eyes of the Tunicata agree in the important point of the position of the sensory layers, with the typical eye of the Vertebrata; Amphioxus has no well-developed eyes, but eye spots have been observed in the larva; the eyes of the Cyclostomes remain in a condition which is embryonic as compared with that of higher forms ; a lens, for example, is absent. Throughout the rest of the Vertebrata the eye has essentially the same structure as in man (see "Elements of Histology," chap. xxxvi., and "Human Physiology," chap. xv.) ; such differences as obtain are of importance and interest as bearing on the adaptation of the different parts of the eye to the different media in which it is placed, or to certain differences in its duties.

In Fishes, where the aqueous and vitreous humours have but little effect in bringing to a focus the rays of light that have already entered the water, the antero-posterior axis of the eye is short, and the lens is very large and convex, while the cornea, owing to the small amount of vitreous humour that is present, is much flattened, and, inasmuch as it is without eyelids, it is thereby less liable to friction than if it projected outwards. The pupil is large, so as to admit a large quantity of light; in Anableps, which swims with 
its head half in and half out of the water, the cornea is divided into two halves by a horizontal line of conjunctival epithelium, and the pupil is sinilarly divided into an upper and a lower half. The eye is kept in shape and position by the cartilaginous or fibrous condition of the sclerotic ; in bony fishes plates of bone are not unfrequently deposited in this envelope or coat of the eye.

The eyes of the Urodela and Cæcilia are small, and this is especially the case in the latter group, the members of which are of burrowing habits; in both, the skin is completely continued over the eye, and in the Cæciliæ it is often quite thick. In Proteus, the skin which covers the lens is not at all transparent, and this cave-dwelling animal is so far blind that it is apparently only able to distinguish between light and darkness ; in much the same way, probably, as when a man turns his face to the light and closes his eyes, he is still able to perceive the passage of an opaque object, such as a hand, between himself and the light. Just as the cornea of fishes is flattened, so that of the amphibious newt and of the frog is provided with a muscle by which the eye-ball can be retracted when the animal is in the water.

In all Reptiles the eyes are small ; but, partly owing to the length of their bodies, we are especially struck with the smallness of the eyes of Snakes; in them the pupil is generally rounded, but in some nocturnal species it has the form of a vertical slit. There are no eyelids, or, in other words, the skin is continued over the eye, and this part of the integument is shed with the rest of the skin. In most other Reptiles there are two eyelids, in addition to the "nictitating membrane" which is found in some sharks and Amphibia, as well as in Birds, and which is drawn over the eye by special muscles. The eye of the crocodile is small. 
In Birds, even more than in Reptiles, we see the influence of the terrestrial mode of life, or rather of the different refractive powers of air and water, in the more convex form of the cornea. It is clear that the rarer the atmosphere the greater is the necessity for a convex apparatus to collect the rays of light, and we find an arrangement in the eyes of flying birds by which this convexity may be attained. By the contraction of the muscles at the sides of and behind the eye, the fluids in its two chambers, and thus the cornea, are pressed forwards; in some, pressure on the optic nerve is prevented, thanks to the possession of bony plates in the sclerotic. The crystalline lens is flattened, except in Apteryx and the owls that fly by twilight; the ciliary muscle, which is of such importance in the accommodation of the eye (see Power's " Human Physiology,"), consists in birds, as in reptiles, of striated muscular tissue, whereas in mammals the muscle is of unstriated tissue; owing to the difference in the property of these muscles, the eye of a swiftly-moving bird is more rapidly brought into focus than is that of the more slowly-moving mammal. It is not, however, unnecessary, perhaps, to point out that this possession of striated tissue in the ciliary muscle of the eye is not to be looked upon as a direct adaptation to the habits of a bird, inasmuch as it is possessed also by the more lethargic reptile; all we can say of it is that it is a very useful heritage. Projecting into the hinder chamber of the bird's eye is a folded membrane richly provided with blood-vessels; this pecten, which is found also in the eye of reptiles, has possibly a nutrient function, but nothing is certainly known as to the office which it fills. Compared with the size of their body, the eyes of birds are large, and the anterior chamber is remarkable for having its longitudinal axis as long as or longer than that of the hinder chamber. Bony 
pieces are found in the sclerotic of birds, as of reptiles.

The eyes of Mammals agree in essential points with those of man, no mammal above the Prototheria having a bony sclerotic; as we ascend the scale we observe that the eye becomes more and more completely protected, owing to the formation by the cranial bones of a bony orbit, which is to be seen in the dried skull. The eyes are reduced in moles and in burrowing rodents; in the mole-rat (Spalax) they are covered by the skin. In those that seek their prey by night or twilight, the cornea is larger and more convex, and the pupil broader than in the rest; in such, too, the lens is nearly spherical. In aquatic forms, just as in fishes, the cornea is much less convex than in their terrestrial allies; compared with the bulk of their bodies, the eyes of the Cetacea are exceedingly small.

While the body of an albino is perfectly white, it is often a matter of astonishment that the eyes are red; but a little reflection will show that this redness is due to the blood in the vessels of the eye, and that the colour is seen in the eye, though not in other parts of the boly, in consequence of the transparency of its tissues. It is not so frequently or so easily recognised, that the "colour of the eye" is dependent also on this blood. In light-grey or blue eyes no pigment is deposited in the iris, but there is pigment in the retina, the light reflected from which is, owing to interference, of a blue colour. When pigment is more thickly laid down in the retina, and becomes also deposited in the substance of the iris, we have dark-blue or brown eyes; and it is because this pigment is ordinarily laid down after birth that we have the somewhat strange phenomenon of the blue eyes of the babe becoming brown eyes in a child. 
IIovements of the eyes. - It is clear that when the number of eyes becomes limited, the power of sight of their possessor must either be very small, or the eye must acquire a power of movement. To obviate this inconvenience various means have been resorted to. The eye may, as in polymeniscous Arthropods, be provided with a large number of lenses, so that the whole corneal surface extends over more than half a sphere; in addition to this, the body may be provided with less useful lateral eyes, as in the scorpion; or, as in the crayfish or the crab, the eye may be placed at the end of a movable stalk. Phenomena of a corresponding kind obtain among the Mollusca; the Lamellibranchiata, which are without præstomial eyes, often have a number of small eyes (or pigment spots only) developed on the edges of the mantle, and these even are sometimes placed on stalks. In some Gastropods the eyes are placed at the ends of the tentacles, and as these tentacles are capable of protrusion and retraction, the optic nerve is of sufficient length to be quite straight only when the tentacle is protruded, while, when that organ is retracted, the nerve is looped. In Onchidium and some of its allies, a number of simple eyes, resembling in essential arrangement those of the Vertebrata, are developed on the surface of the back of these shell-less and slow-moving molluscs; Semper has counted as many as ninety-eight of these eyes on the back of an Onchidium.

In the Chitonidæ, Moseley has recently detected in some species more than ten thousand minute eyes, placed on the exposed surfaces of their shells; but it is remarkable that these eyes, unlike those of Onchidium, are on the type of the invertebrate, and not of the vertebrate, eye. Scattered among them are tactile organs, from which, it is supposed, the eyes have arisen by modification. In some of the heteropodous 
Molluses the optic bulb is moved by muscles, and this is the kind of mechanism which obtains in the Vertebrata, where four rectal and two oblique muscles are, as in man, almost always developed.

\section{Influence of light and daririess on the} fevelopment of the eye.-While our knowledge of such terrestrial forms as the earthworm, the proteus, or the mole, would lead us to think that a diminution of light is constintly associated with a degenerate condition or loss of the eye, it is very remarkable that among aquatic forms we find species which support, and others that unmistakably contradict this hypothesis. Among Crustacea we have, for example, Ethusa granulata, which in shallow water has eyes of the ordinary character, but, when taken from depths of 110 to 370 fathoms, is found to have the stalked eye replaced by a calcareous knob; it is a case to which the words of Darwin are altogether applicable: "The stand for the telescope is there, though the telescope with its glasses has been lost." Specimens of the same species, taken from a greater depth (500 to 700 fathoms), showed that the eye-stalk had undergone a change of function, and had become converted into a pointed rostrum, which probably serves as an organ of touch. On the other hand, species of Munida that were dredged at the same time as the Ethusa were found to have exceedingly large eyes. What is true of Crustacea is true also of fishes; at moderate depths the eyes are generally large, at greater depths they may be very large or very small. Where the eyes are small the fish has its tactile organs very largely developed. Fishes or Crustaceans, however, taken from very great depths (e.g. 1,900 fathoms), have been found to have both the eyes rudimentary and the special organs of touch absent. There is no reason to suppose that the so-called eye-like organs of 
some fishes (e.g. Scopelus) have any optic function. They appear, from the accounts given by those who have seen such fishes alive, to be phosphorescent organs.

The ear.-Definite auditory organs are wanting in various lower forms, which are, so far as we can tell, without any sense of hearing; an intermediate condition, between that of absolute incapacity to hear. and the possession of this sense, is, perhaps, presented to us by the earless earthworm, on which the vibrations of air which are heard by man are absolutely without effect, though the worms are very sensitive to vibrations conveyed along solid objects; in the experiments made by Darwin, "the vibrations, before reaching their bodies, had to pass from the sounding board of the piano, through the saucer, the bottom of the pot and the damp, not very compact earth on which they lay with their tails in their burrows;" though the connection was so slight, yet the result of striking a note on the piano was the immediate withdrawal of the worms into their burrows.

Definite auditory organs of a low degree of organisation are to be found in some Medusse, but it is a remarkable fact that, so far as we know at present, distinct auditory and optic organs are never developed in one and the same species. A very simple condition is found in such a jelly-fish as Euchilota or Tiaropsis, where the lower surface of the velum is, at various points, indented by open-mouthed pits; the sides and base of this pit are formed by the epithelial cells of the velum, and of these some on the inner face become provided with projecting auditory hairs, and so become special sense cells, while others develop within their contents the calcareous concretions which form the otolith; the sense cells are continuous by their bases with the lower nerve ring. The epithelial cells on the outer surface of the pit 
(which belong, of course, to the series of cells that lie on the upper surface of the velum) have thick membranes, and become filled with fluid. Mitrotrocha is provided with no less than eighty such open pits.

The next stage in advance is seen in Phialidium (Fig. 193), where the pit becomes closed. In other Medusæ the auditory vesicle appears to be a modified

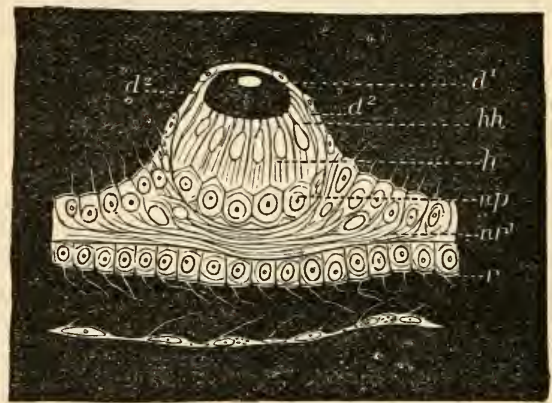

Fig. 193.-An Auditory Vesicle of Phialidium.

$d^{\prime}$, Epithelium of the upper surface of the velum; $d^{2}$, of the under surface ; $n^{\prime}$, upper nerve ring; $h$, auditory cells; $h h$, auditory hairs ; $n p$, nervous cushion formed by a prolongation of the lower nerve ring; $r$, circular canal at the edge of the velum. The; spot in the cavity represents an otolith. (After 0. and R. Hertwig.)

tentacle. In some cases the sense organs appear to be both eye and ear.

Throughont the whole of the Metazoa we find that the auditory organs have more or less the form of vesicles, which in lowlier forms, and in all primitively, are open to the exterior; within the vesicles one or more hard bodies are developed, which, on being agitated by the vibrations of the waves of sound, act on the sensory hairs of the sense cells, which are developed within the auditory cavity, and which are connected with the central nervous system by the fibres of the auditory nerve. 
Among the Echimodermata, auditory organs have only been satisfactorily observed in the deep sea-dwelling holothurian Elasipoda, where they are often present in large numbers, Kolga nana having no less than fifty-six auditory sacs; as in such Annelids as possess them, the sacs are set close to the nerve cords, and have a large number of contained otoliths or concretions.

We have more definite information as to the Arthropoda and Mollusea; in the former they are not always developed on the head; Mysis, just like Fabricia (among worms) with its posterior eyes, showing us that, inasmuch as sensory cells are distributed over the whole of the body, special sense organs may be developed at any part, and pointing the moral by having auditory organs in its terminal segment. As a rule they are, as in the crayfish, developed at the base of the antennules. Here the auditory sac is permanently open, though the setæ that protect it prevent the entrance of much foreign matter; within this sac part of the wall is raised up into a ridge, and the cells that form it are provided with delicate setæ at their free end, and with nerve fibres at their base and within. The sac is filled with a gelatinous fluid in which are to be found minute otoliths; these last, being set in motion by vibrations in the water which strike on the guarded open slit of the ear sac, affect the setæ; the setæ affect the cells on the acoustic ridge, and so the contained nerve fibres which are in direct connection with the brain.

While the sac of the Crustacea resembles in some respects the embryonic ear of the Vertebrata, that of Insects presents other points of similarity. Placed on the median segments of the body or on the legs, the ears of the Orthoptera are remarkable for the possession of a drum or tympanum; this is merely a modification of part of the chitinous integument of the 
insect, and the bow on which it is stretched is merely a part of the same integument that has become considerably thickened. Taking for an example the grasshopper, we find a number of small muscles which are inserted into the bow, and by their extension or contraction increase or diminish the tension of the tympanic membrane. The central portion of the membrane is occupied by a cavity which communicates with the exterior by an open tube, and within the cavity there is a ganglionic mass developed at the end of an auditory nerve. Here, then, we have the case of the sonorous vibrations impinging on a membrane, which is held tense; being conveyed to an air chamber, which is in relation with the outer air, and is therefore capable of adapting itself to any force that may be brought to bear upon it; and being carried thence to the termination of a sensory nerve.

In some insects, though not in the Orthoptera, rows of corpuscles have been observed on some of the nervures of the wing, and as these are supplied with nerve filaments, Braxton Hicks has suggested that they are auditory organs; somewhat similar organs found on the halteres of the Diptera have had the same function ascribed to them by Lowne.

In the ears, as in some other parts of the organisation of the Mollusca, we see arrangements which are simpler, and others that are more complex than those that obtain in the Arthropoda. The auditory organ is often a simple closed vesicle, surrounded by an investing membrane, and having in its cavity sensory cells provided with projecting hairs (Fig. 194); the central cavity is occupied by a single large concretion, otolith, or a number of smaller otoconia, as the smaller concretions may conveniently be called. In the Nautilus, the ears, as in most Lamellibranchs and Gastropods, are attached to the pedal ganglia, but in the Dibranchiata they are enclosed in the cartilage 
which protects the cerebrum and, as such portion of the cartilage forms a special investment for the ear, we have in these alone, among invertebrates, that distinction between the outer or cartilaginous, and the inner or membranous ear capsule to which we are accustomed in the ears of vertebrates ; in Cephalopods, as in Crustacea and Vertebrates, an acoustic ridge or crest is formed on which are set the auditory cells, and in some of them, as in some of the lower Vertebrates, it appears that the ear sac is permanently in communication with the outer world by a narrow open duct, the remnant of the primitive involution of the epiblast from which the organ was fashioned.

Amphioxus has no known auditory organ, and that which is found in the Urochordata would appear to have been independently developed within the limits of the group (Balfour). It lies on the

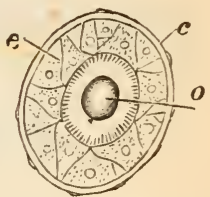

Fig. 194.-Diagram of the Ear of Cyclas. (After Simroth.) under surface of the anterior brain vesicle (Fig. $195 ; a)$; the cells of the brain form an acoustic ridge, the delicate hairs on whose cells hold an otolith which projects into the cavity of the brain, and is remarkable for being pigmented.

Though the sensory portion of the ear of higher Vertebrates is at some distance from the surface of the body, it is not to be supposed that it has not, like all other organs of sense, its primary seat of origin in the outer layer of the embryo or epiblast. In the lower vertebrates the auditory capsule is closed, and lies just below the skin, or sinks some way into the walls of the brain case, as in Elasmobranchs, where the duct either opens to the exterior by a minute pore (ray), or is closed over by the skin (sharks) ; in the higher forms a special auditory passage is developed. 
The first sign of the development of the ear is the formation, on either side of the hinder part of the head, of a pit or depression (Fig. 196 ; au v), which gradually deepens, and with which an outgrowth from the auditory nerve $(a u n)$ comes into contact. The pit becomes converted into an elongated sac, narrower above and below. The upper end grows out and gives rise to the recess of the membranous labyrinth, the lower

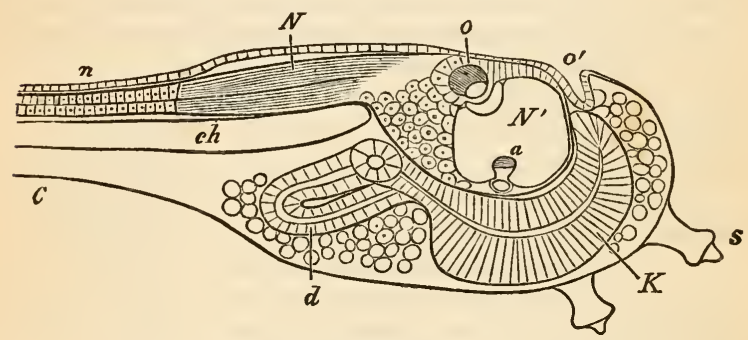

Fig. 195.-Larva of Ascidia mentula; the Anterior portion of the tail is alone represented.

$\mathbf{N} \mathbf{l}$, Anterior swelling of neural tube $\mathbf{N}$, anterior swelling of spinal portion of neural tube; $n$, hinder part of neural tube ; $c h$, notocliord: $\mathrm{K}$, jliranchial region of alimentary tract; $d$, its cesophageal and gastric region; $o$, eye; $a$, otulith; $o^{\prime}$, mouth; $s$, papilla of attachment. (After Kuppffer.)

end forms the cochlear canal, and the narrow duct (canalis reuniens) by means of which the cochlear canal communicates with the sacculus; the median portion of the auditory vesicles gives rise to the semicircular canals, and to the utriculus.

Fig. 197 (page 466) will make clear the relations of the just named and of other parts in the complex auditory organ of man.

External to the proper sensory portion in which the branches of the auditory nerves terminate in the special sensory cells, there is a median division of the ear, in which are developed one or more bones that convey the sonorous vibrations, and these are acted 
on by a membrane (the tympanic membrane) which is analogous to, though, of course, not homologous with, the membrane which we have already found in the ears of orthopterous insects. Externally to this middle ear is the outer portion, which forms the cxternal auditory meatus, and is in higher forms aided and protected by a conch, or so-called external ear.

Outer division of the ear, - The functions of

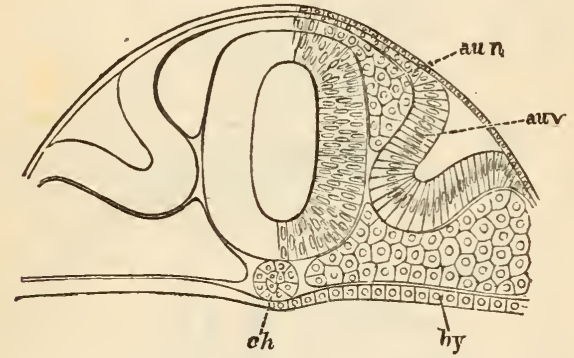

Fig. 196.-Section through the Head of a Lepidosteus, Six Days after Impregnation.

$a u v$, Auditory pit; au $n$, auditory nerve; $c h$, notochord ; $b y$, hypoblast. (After Balfour.)

the outer and middle portions is that of conveying the sonorous vibrations to the sensory region internal to them; they are but poorly developed in the lower forms for two reasons : first of all, the insinking of the sensory portion which is so marked in the higher forms is, as we may expect, less marked in the lower divisions of the Vertebrata, for it is a process which has only gradually been effected ; the second reason is to be found in the fact that the trumpet-shaped arrangements of the outer region, which are so useful in bringing to a focus the vibrations of air, are not so necessary when the animal lives in water. Evidence as to the influence of this denser medium is afforded us E E-16 
by the Cetacea, which, at most, have nothing more than an exceedingly rudimentary external ear (pinna), and this, when found in these mammals, is proportionately longer in the fotus than in the adult (Howse).

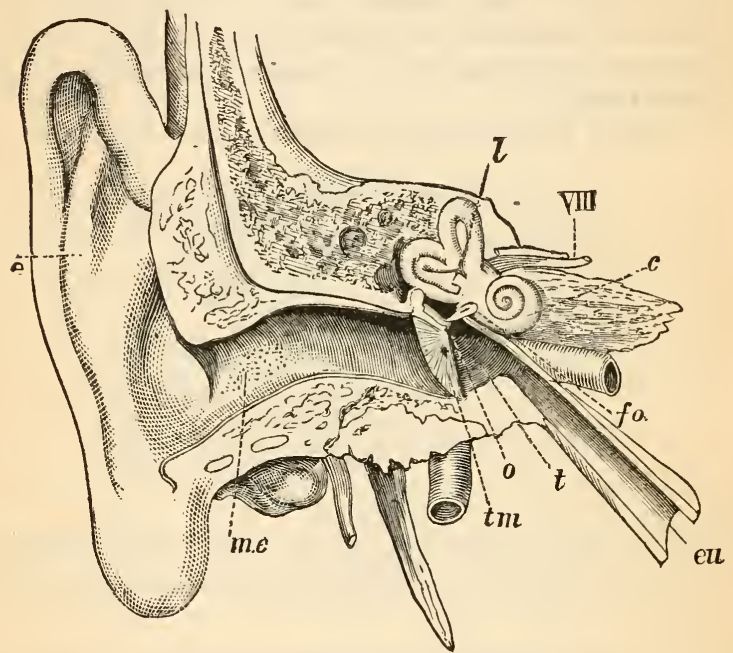

Fig. 197.-Representation of the Human Ear.

$e$, External ear: me, auditory passage (meatus anditorius externus); $l$, bony labyrinth; vil, anditory nerve; $o$, ossicles of the ear; fo, fenestra ovalis: $e u$, Eustachian tube, which opens into the pharynx; tympanum; $c$, bony cochlea ; tm, tympauic membrane.

Fishes are without any external ear or tympanic membrane, and, as has already been said, the Elasmobranchs have a canal which reaches to, and may open on, the outer surface of the skull ; in many Teleostei, where there is no such external opening, there are spaces in the skull which are only covered by skin or very thin bone in the neighbourhood of the ear; in some of the bony fishes there is an exceedingly 
remarkable arrangement, by means of which sounds are conveyed to the organ of hearing. The anterior ends of the air bladder are attached to membranes which close in spaces in the occipital region of the skull, and on the other side of these membranes is the ear of that side. This simple condition which obtains in the perch and its allies, is complicated in carps and others by the addition of three ossicles, which connect the air bladder with the auditory region, and convey such vibrations as affect the air in the air bladder.

In the lower Amphibia the ear cleft is merely closed by muscles, but in the Anura there is a distinct tympanic membrane, as there is also in most, though not in all, Reptiles. In the simplest condition this lies on the surface of the head, so that there is no external auditory meatus; but in the lizards we have a small pit external to the membrane, and we have, therefore, the commencement of an external ear passage.

In Mammals the tympanic bone of the skull takes part in forming the walls of this meatus. The pinna is represented by a fold of skin with combined muscular tissue in crocodiles, and by a movable membranous valve in some birds (owls). It is not found in the Prototheria, but in all other Mammals there is a well-developed outer ear, which becomes rudimentary or aborted only in marine forms. In many mammals the pinna can be moved by muscles, and directed, therefore, to different points from which sound is supposed to be coming. In the higher Primates these muscles are ordinarily rudimentary, but their possession by some men is spoken to by the power that such have of moving their ears.

Middle ear. - Associated with the development of a tympanic membrane is that of a contained tympanic cavity. This cavity is not a new formation, but is due to the modification of the, in the pulmonate 
Vertebrates, now useless visceral clefts. While on its outer side this cleft gives rise to the tympanic cavity (Fig. 197 ; $c t$ ) and part of the external meatus, on its inner side it continues to communicate with the pharynx, and so forms the Eustachian tube (eu), by means of which air can enter into the otherwise closed ear chamber. The vibrations of the tympanic membrane have to be conveyed to the inner ear, and this is effected by one or more bones, the outer end of which is fixed to the tympanic membrane, while the other impinges on the membrane which closes the entrance to the internal ear (fenestra ovalis, Fig. 197). In the Amphibia and Sauropsida there is but a single bone in the middle ear ; the origin of this columella is not satisfactorily established, but it is, probably, the upper end of the hyoid arch. (See page 327.) In the Mammalia this single bone is replaced by three, which are known respectively as the stapes, incus, and malleus ; the discussion of the homologies of these bones has been deep and protracted, but a consideration of it would be beyond our scope here. We must be content to say that, according to the latest views of Parker, the stapes is the uppermost element of the hyoid, and that the incus and malleus belong to the mandibular arch. According to these views it is the incus, and not, as is ordinarily taught, the malleus, that is the homologue of the quadrate bone of the Sauropsicla. In the Prototheria the stapes is not hollowed out at one end so as to have the form of a stirrup, nor is the incus of the "normal mammalian form"; Parker further finds that the malleus still forms the hinder part of the mandible.

We have in this history of the auditory ossicles (which must not by any means be confounded with otoliths) one of the most remarkable examples of the way in which parts useless for one are gradually appropriated to another function. The cleft between 
the hyoid and mandibular arches (the hyomandibular cleft) becoming useless as an organ of respiration has been seized upon by the ear; in Mammals, parts of the mandibular arch that lies in front, and of the hyoid arch that lies behind the cleft, are adapted to the use of one and the same organ.

Internal ear.-This, which is the essential portion, as those just described are the accessory parts, of the organ of hearing, consists primarily of the so-called membranous labyrinth, formed by the sacculus, utriculus, and semicircular canals; as we ascend the scale we find a bony labyrinth fashioned around this membranous one; the space between them contains lymph, and is known as the perilymphatic space or cavity, while the fluid within the membranous labyrinth is the endolymph.

The simplest stage obtains in the Myxinoid roundmouths, where there is only a single semicircular canal, at the base of which there is, on either side, a swelling or ampulla. In this, as in the underlying vestibule, special auditory cells are dereloped, which are supplied with filaments from the auditory nerve. In the other division of the round-mouths, that is, in the lampreys, there are two semicircular canals, and the vestibule into which they open has two blind diverticula arising from it, in each of which auditory cells are developed. In all the remaining Vertebrata there are three semicircular canals.

In the Elasmobranch fishes, and in the Dipnoi, no bony labyrinth is formed around the membranous, but a promise, as it were, is offered by the excavation of the cartilage around the labyrinth, in a form not unlike the membranous internal ear; in the bony fishes the labyrinth is protected by bone, but there is no proper bony labyrinth. A further point of advance is to be observed in the Ganoidei and Teleostei, for in them, as in Chimæra, the gradual insinking of the ear 
is expressed by the fact that the most internal portion now projects into the cranial cavity.

In no fish is there anything more than a rudiment of the cochlea (Fig. 198; A, c). The highest condition of the amphibian ear is seen in the Anura; though we cannot yet speak definitely of a bony labyrinth,
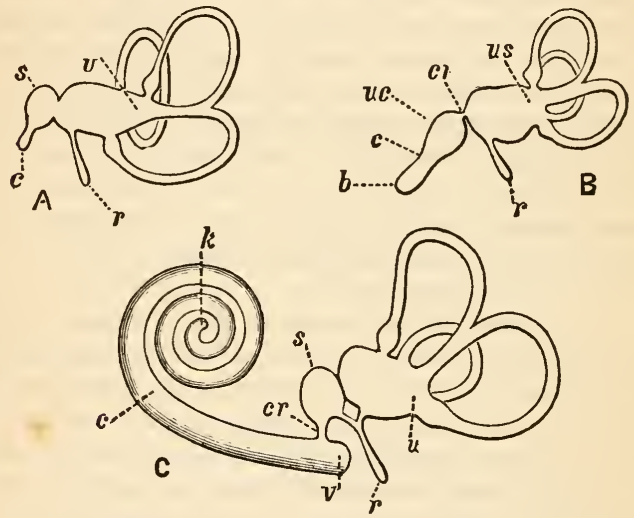

Fig. 198.-Diagrams to show the Relations of the Auditory Labyrinth in the Vertebrate Series.

A, Fish; B, bird ; c, mammal; $u$, utriculus, with the three semicircular canals : $s$, sacculus; $c$, cochlea; $r$, 'aquæductus vestibuli ; $b$, lagena; $c r$, canalis reuniens. In $\mathrm{c}, r$ is seen to divide into separate passages for the utriculus and sacculus; the vestibule is seen to have a cæcal sac at $\mathrm{v} ; k$, coil of the cochlea. (After Waldeyer.)

yet we can, in the frog, see that the membranous labyrinth within has an influence on the contour of the surface of its bony and cartilaginous capsule. Two foramina, the $f$. rotundum and the $f$. ovale, are now to be distinguished. Two tubular outgrowths are given off from the periosteum of the perilymphatic space; both of them end in blind sacs, and one of them (the ductus perilymphaticus) extends into the jugular canal, and part of the neck of the sac is 
continued into a tube which enters into connection with the subarachnoid cerebral cavity. Eight different sensory regions are now to be distinguished; the cochlear region has a commencing outgrowth or lagena, and within is a space which is covered over by a very thin membrane, the membrana basilaris.

In the Reptilia we observe several stages in the outgrowth of the cochlea, and these are most marked in crocodiles, which, in this character, as in so many others, stand nearest to the birds. In these last the lagena is quite prominent (Fig. 198; $\mathbf{B}, 6$ ), and begins to take on a spiral course.

With the exception of the Prototheria, all Mammals have their cochlea coiled into a heliciform spiral, the canal of which is wound round the bony axis or modiolus; the coil may be flat, as in the Cetacea, or very steep, as in some Rodents (guinea-pig) (Fig. 198 ; c). The internal structure of the cochlea has been fully described in the "Elements of Histology" (chap. xii.) ; here it need only be said that the scala vestibuli, the membrane of Reissner, and the rods of Corti are peculiar to the mammalian ear; as to the last, we have so far evidence that it has been developed within the limits of the mammalian series that we find them to be much more sinuply arranged in the Prototheria than in the higher mammals. The absence of this organ from the ears of birds, many of which are, as we know,

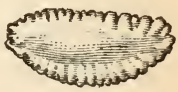
capable of being attracted by musical

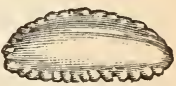

Fig. 199.-Otolith of Cod. sounds, makes it impossible for us at present to accept the doctrine that these rods are physiologically impor. tant as the means of distinguishing different notes of music.

The otoliths found in the lymph of the membranous labyrinth are ordinarily larger in fishes than in higher 
vertebrates: and their number is, of course, proportional to their size. Most bony fishes have two only, but these are rather to be looked upon as calcareous masses than as separate otoliths; in Elasmobranchs such otoliths are often grouped into masses of various sizes and forms. In the Teleostel they are crystalline, but in Chimæra and the sturgeons they are more chalky in character. Their function is, as in invertebrates, that of aiding the vibrating fluid in its action on the sensory cells of the auditory crest.

\section{CHAPTER XIII.}

\section{ORGANS OF REPRODUCTION.}

Is the preceding chapters we have considered the various organs of the body by means of which an animal is enabled to sustain or defend its own existence, to obtain information of whatis happening around it, and to adapt itself more or less successfully to the course of events. So far as an individual animal is concerned, no other organs than those with which we have already dealt are necessary for the maintenance of its own existence; indeed, there are, we know, individuals which do pass through the whole of their lives, are born, grow, and die, without once putting into active function the set of organs that remain to be considered.

Unimportant as they may be to the individual, they are of prime importance for the species to which that individual belongs; for they are the means by which individuals are enabled to reproduce their kind; and they are of the more importance inasmuch as, so far as we know, living matter never arises or is formed except from pre-existing living matter. In 
the performance of that part of his life-work which affects his race, the individual reproduces his kind.

This process of reproduction may be one of two modes, it may either be sexual or asexual; that is to say, two different cell elements may unite to form a single cell from which others arise, or one kind of cell element alone may form a new individual.

The latter is obviously a more simple method than the former, and it is the only one which is certainly known to obtain in the Protozoa. Here, too, as our previous studies wonld lead us to expect, there is no distinct differentiation of any special organ ;* we have the phenomenon, but not the organ.

As has been already pointed out in the case of the Amœba (see page 22), the simplest method of reproduction is that in which the mass of protoplasm under observation divides into halves of about the same size. Each of these halves is, save in size, a copy of the parent; which, ipso facto, has disappeared. This method of reproduction is known as Fission, and it is exceedingly common among the lower organisms. In some cases a process of non-nucleated protoplasm separates from the body of the Amœba ; and this budlike outgrowth, increasing in size and acquiring a nucleus, shortly comes to have the form and structure of its parent. This is the process by Gemmation.

Yet a third mode of reproduction, which may be called that of endo-spore formation, has been observed in some of the Protozoa; but it, like the methods of fission and gemmation, does not require the influence of another individual; like them, it is absolutely asexual. The protozoon, becoming quiescent, forms around itself an envelope or cyst, which is at first transparent, and which completely encloses

* The action and influence of the nucleus of a cell is so obscure that the part which it possibly takes in initiating cell-division cannot be discussed in an elementary work. 
the rounded cell. The nucleus at the same time becomes invested in a proper capsule. After a period of repose, the nucleus begins to break up into a number of smaller pieces, the wall now breaks, and each nuclear portion (spore) uniting itself with a certain quantity of the surrounding protoplasm, separates from the rest of the mass, escapes, and begins to grow up into the form of the parent cell.

Lastly, we sometimes observe that two individual Protozoa of the same species become connected with one another, the protoplasm of the two cells becomes commingled, the whole quiescent, and invested in a cyst. The enclosed contents break up into a number of spores, which, on the eventual bursting of the cyst, escape and begin to grow up into the form of their parent. Here, then, not only is spore-formation preceded by encystation, but also by conjugation. At the same time it is to be most carefully borne in mind that the two individuals are, to all appearance, essentially alike, and that there is no reason whatever for regarding this conjugation as being a sexual act.

The life-history of the Gregarina presents us with a case of development by spore formation, which may or may not be preceded by conjugation. A single Gregarine, or two conjugated forms, become spherical, and a firm structureless cyst is gradually developed around the protoplasm; the nucleus disappears, and the whole of the contained mass breaks up into a number of small separate bodies (spores); these are often spindle-shaped, and from their occasional resemblance to the diatom Navicula, have obtained the distinctive name of pseudonavicellae. This appears to be the most general mode of spore formation. The spores become each invested in a distinct envelope, within which the protoplasm is contained. The succeding stages of development have as yet been very insufticiently studied; in the large Gregarine of the 
lobster the following stages have, however, been observed.

The protoplasm, which has not been directly observed escaping from the spore, is first seen as a small amœbiform and apparently non-nucleated mass. Passing into a quiescent condition, it becomes differentiated into ectosarc and endosarc, and then gives rise

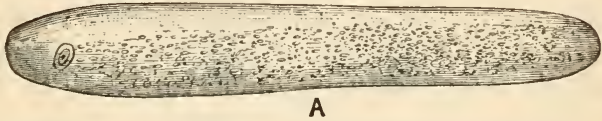

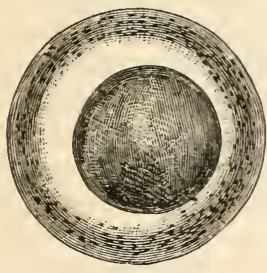

B

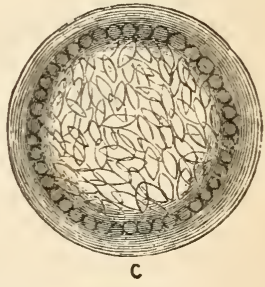

Fig. 200.-Figures of Giegarina of Earthworm.

A, Separate form ; B, encystment completed ; c, formation of pseudonavicellæ. (After Stein and Lieberkühn.)

to two processes, one of which is stiff, and the other actively motile; in the latter granules are richly developed, and it is the first to become elongated and to separate from the parent mass. It has now the form and something of the movement of a thread-worm, whence it has been called the pseudo-filaria; within this elongated mass a nucleolus and a nucleus become apparent, the tube shortens, becomes divided into protomerit and deutomerit, and, later on, develops a cuticle; so that we have here a minute example of the giant Gregarine. The stiff process has meanwhile absorbed the remainder of the parent 
protoplasm, has become motile, and been converted into a pseudofilaria.

The statement that a kind of sexual reproduction is observable among the Infusoria has, on account of the detailed characters of the reported observations, obtained considerable vogue. Put shortly, the account comes to this ; the substance of the nucleolus becomes converted into a number of curved rods, which represent the male element, while the nucleus breaks up into small spherical bodies, which have been compare l to ovules. The resulting young are said to be at first provided with knobbed tentacles and suckers (acinetiform embryos), and to become gradually converted into ciliate infusoria. Observations undertaken with the express view of examining into these results, have done anything but confirm them, for they have resulted in the conviction that the rod-shaped bodies of Balbiani are nothing but bacterioid parasites (Vibrios), and that the so-called embryos are also parasites ; these last, indeed, have, on direct observation, been seen to enter the body of one after escaping from another Infusorian. What really does happen appear's to be this ; two individuals (of Paramœcium) conjugate, and remain united for a day or longer ; the only result of this conjugation is that the nucleus becomes more finely granular, while the nucleolus breaks up into four oval capsules. Of these, two in each individual disappear, while the other two grow till they reach two-thirds the size of the original nucleus, which they then resemble in appearance; one of these remains as a nucleolus, and the other appears to fuse with the primitive nucleus.

The process, then, instead of being in any way sexual, falls rather under the head of rejuvenescence; the protoplasm, in other words, seems to undergo a kind of re-arrangement in much the same way as, in the political world, cabinets sometimes do. 
Where the method of reproduction becomes sexual, we find sets of cells or glands which have a different history and function; these are the male and female elements, and they may be found separately in different individuals of the same species, or they may both be formed in one individual; in the
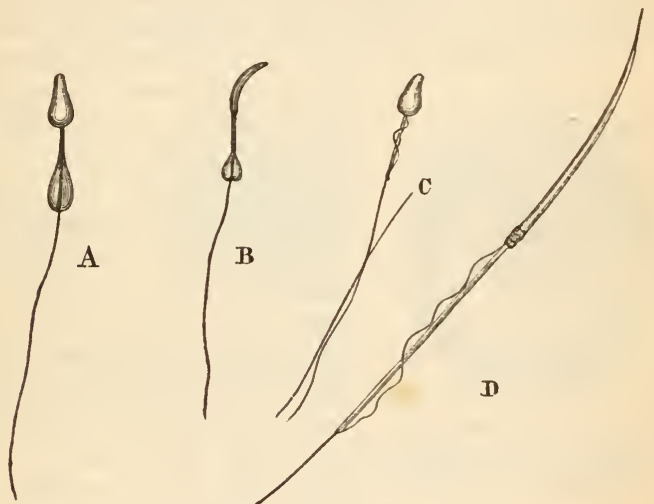

Fig. 201.-Figure of Spermatozoon of, A, Guinea-pig (not quite mature); B, the same seen sideways; C, Horse; D, Newt. (After Klein.)

latter case we have to do with hermaphrodite forms, and these may be only structurally hermaphrodite, as are the earthworm and the snail ; or they may also be physiologically hermaphrodite, as the tapeworm, the fluke, or the Ascaris nigrovenosa ; that is to say, the male elements of one individual sometimes impregnate the female cells of another individual, and in other cases the two kinds of sexual cells of one and the same individual come into union. It ordinarily happens 
that the set of cells which give rise to one are quite separate from those which give rise to the other sexual cells, but this is not always the case, as the hermaphrodite gland of the snail and the generative cells of the just-mentioned Ascaris are sufficient to bear witness.

The broad differences between a male and a female element may be easily apprehended; starting from cells which are essentially similar in character,

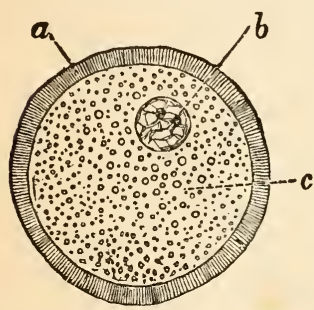

Fig. 202.-Ripe Ovum of Cat. $a$, Zona pellucida ; $b$, germinal vesicle : $c$, protoplasm. (After Klein.) those which are to become the male bodies subdivide, and each cell gives rise to a large number of smaller bodies, which typically, though by no means always, consist of a rounded head (which represents part of the nucleus of the original cell), and a more or less long, actively moving tail (Fig. 201). The female cell (Fig. 202), on the other hand, increases rather than diminishes in size, and often acquires considerable bulk from the large number of yolk cells that are aggregated around it ; it frequently also becomes invested in a membrane, the outermost portion of which may, as in the familiar example of the egg of the bird, form the basis for a shell, which may be calcareous or chitinous.

The generative cells are, in their simplest condition, nothing more than modified elements of the epithelial layer which lines the body cavity, and it is only with increasing differentiation of structure that they become aggregated into definite masses holding a certain topographical relation to the other parts of the organism. The influence of the male on the female element will be described shortly (page 482). 
We must first develop in detail the characters of the parts whose general morphology has just been sketched.

It is only lately that much attention has been given to spermatogenesis, or the history of the development of the spermatozoa, and it will be most convenient, therefore, to give an account of a common form (the earthworm) in which the process seems to
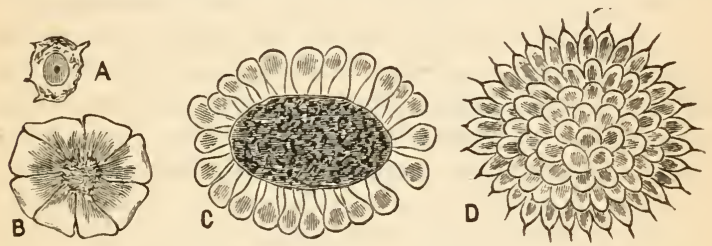

Fig. 203.-Figures showing the Mode of Development of the Spermatozoon of the Earthworm. A, Spermatospore; B, Young Spermatosphere, with eight Spermatoblasts; c, Spermatoblasts with Central Blastophore; D, Spermatoblasts with protruding Filament (After J. E. Blomfield.)

have been worked out (by Blomfield) with great exactness.

The testis of the earthworm is a body of irregularly quadrate form, which is about one-tenth of an inch in diameter, and is directly attached to, and seems to form a modified part of, the epithelium lining the body cavity; it consists of a mass of cells, each of which, breaking away from the common mass, makes its way into a special reservoir, there to undergo its further development. Each of these cells may be known as a spermatospore, and is distinguished by the comparatively large size of its nucleus, and its thin coat of surrounding protoplasm; the nuclei of these spermatospores undergo division, and the whole mass increases in size. When eight segments have been thus formed we get the spermatosphere, 
which consists of eight spermatoblasts, with a small central mass of inactive protoplasm (blastophore). Division of the cells still continues, until at last we get a spermatosphere, which consists of a number of elongated spermatoblasts supported by the blastophore (Fig. 203 ; c). The protoplasm around the nucleus of each spermatoblast next collects into a sinall cap, and then gives off a delicate filamentous process (Fig. 203; D), which, gradually increasing in size, comes to form the tail of the spermatozoon. Further changes in form are effected, and the constituent spermatoblasts of the sphere fall away from one another, to become, each of them, an actively motile spermatozoon capable of fertilising a female cell.

The essential points in this history have been detected by various observers in other animals, many of whom have, however, somewhat obscured the subject by the number of new technical terms which they have introduced.

Dogenesis, or the development of ova, has been more thoroughly studied than spermatogenesis, but the subject is rendered more complicated by the fact that the egg cell either absorbs in early periods, or is for a time surrounded by nutrient or yolk cells. The egg cells of the earthworm form a coherent mass, which occupies a similar position in the thirteenth to that occupied by the testes in the tenth and eleventh segments, and is only distinguished by the investment of firm membrane, which surrounds the mass of cells, or ovary, and separates it from the rest of the epithelium of the body cavity; the constituent cells of this ovary do not, however, undergo the segmentation which affects the male elements.

Consisting, in the simplest cases (e.g. Hydra), of a naked mass of protoplasn, the ovum, with its nucleus (here called germinal vesicle) and nucleolus (or 
germinal spot), brings to our mind the Amoba, with which our studies commenced; and, if we observe its early behaviour, we are the more struck with the resemblance, for we often find it seizing on and making part of itself the cells which surround it. In the great majority of cases the cell becomes so far differentiated that it develops around itself an investing (vitelline) membrane ; here, again, recalling to mind the next stage in protozoic differentiation in so far as protoplasmic pseudopodial processes pass through the pores in the membranous wall (Toxopneustes). In more elaborated stages the surrounding cells of the ovary give rise to more specialised membranes, and in some cases it appears to be necessary to leave an orifice (so-called " nuicropyle"), by means of which nutrient material or fertilising elements may be allowed to enter and come into contact with the substance of the egg.

The final act in the maturation of the ovum appears to be the extrusion of the two polar globules. The nucleus of the egg cell (the germinal vesicle) moves towards the periphery of the cell; as it does so its surrounding membrane becomes absorbed, and the contents altered in character. What remains of the germinal vesicle becomes spindle-shaped, and one end of the spindle is protruded from the edge of the cell. The projecting portion is next constricted from the rest, and so gives rise to the first polar globule. The process is again repeated, a second spindle being formed, and the projection being again constricted off to give rise to the second polar globule.

Whatever be the real explanation of this phenomenon, it is, in the first place, clear that it bears a very striking analogy to what happens in the male cell, where a portion of the original protoplasm becomes the inactive blastophor; and we can hardly F F-16 
help giving in our adhesion to so much of the doctrines of Sabatier as are contained in his thesis that all cells are originally hermaphrodite, and that some by losing one element, and some the other, become distinctively male or female cells. Balfour has enunciated the striking and bold hypothesis that the function of forming polar cells was acquired by the ovum with the object of preventing parthenogenesis ; the strongest support for this doctrine was found by Balfour in the reported absence of polar globules in the only two divisions of the animal kingdom (Rotifera and Arthropoda) in which we normally find development of ova without male influence. On the other hand, Billet, with a full knowledge of the facts, and of Balfour's hypothesis, has lately recorded the presence of polar globules in the Rotifera, and Grobben has given a less pointed account of the formation of the same bodies in some of the lower Crustacea.* The remaining portion of the original nucleus returns to the centre of the egg, where it forms the female pronucleus. The mature egg, or female element, requires the addition of the male element or spermatozoon, before it can set out on the course of its development. When brought into the neighbourhood of the male cell we find that an egg will receive one or more spermatozoa, but that, if fresh and uninjured, not more than two or three pass into it; if they do the future of the egg is endangered. As a rule, only one spermatozoon enters into and becomes a constituent of the protoplasm of the ovum ; the tail of the male cell disappears, but its head persists for a time as a distinct structure; this

* The student will not fail to observe that, at the present time, a well-conducted and carefully described series of observations on a selected form may affect very deeply the speculations of previous students. Conversely, philosophical speculations have a guiding influence on lines of study. 
may be call the male promucleus. Approaching the female pronucleus it gradually fuses with it, and thereby gives rise to a fresh structure, the so-called segmentation nucleus.

Pausing for a moment to consider how far the history now detailed has led us, we find that there has been a fusion of cells which, although different in final form, have arisen from parts which at first were exactly similar.

In the lowest forms the generative cells are not aggregated into any special masses, and though we can say that here there are male and there female cells, we cannot with accuracy speak either of testes or of ovaria ; here, as with various other organs, we find a diffused preceding a localised or concentrated arrangement.

The Sponges afford an example of this, the reproductive cells being, as a rule, scattered through the mesoderm (see Fig. 53, page 106); to this statement Myxospongia and Euspongia form exceptions; in the latter the ova are arranged in small groups, are embedded in connective tissue, and hold a definite topographical relation to the afferent canals. Here, too, the ova are naked and amœboid, and not yet enclosed in a distinct membrane, as they are in most of the higher Metazoa.

Asexual reproduction does obtain so far among the sponges that buds may be given off from an individual, and an increase in a sponge colony can be effected in a way which is of some commercial importance. The method here referred to has been tried in the Mediterranean, and in the Floricla sponge fishery with a certain measure of success, the greater completeness of which does not appear to depend on the sponge as much as on suitable fishery legislation. A piece of sponge, some two or three inclies high, is carefully cut off from the rest of the mass; owing, as 
it seems, to the injury done to the sponge by the operation, no growth occurs during the first four months, but during the next two months it will be found to have grown two or three inches.

Taking the groups in order, we find a higher grade of localisation in the Coelenterata than we should have been led to expect from what we know of the sponges. In Hydra, for example, the testes are always placed just below the circle of tentacles, and the ovary nearer the foot; in the sea-anemone the generative glands, or, as they may be more shortly called, the gonads, are developed on the sides of the primary septa; in the jelly-fishes they are found on the walls of the gastro-vascular canals. It is clear, then, that there is localisation, but this is still of a diffused nature; the generative elements are not, as in the crayfish or the fowl, limited to one aggregation, but there are several cell aggregates, each with a reproductive function.

This phenomenon is most striking in the case of a eolony of hydroid polyps, such as that presented by Syncoryne. Here we find that, of the numerous buds developed on the colony, some never attain to nutrient functions, and never have the oral cone or tentacles of a nutrient person (trophosome); instead thereof, they become gradually fashioned into the shape of bell-like Medusæ, separate from the colony, become free-swimming, and derelop gonads on the walls of their gastro-vascular canals. In other cases the medusoid buds or gonosomes become more or less completely developed, but never separate themselves from the rest of the colony; within such buds gonads become developed.

This method of division of labour, some persons of the colony undertaking nutrient and others generative functions, is, as may be supposed, particularly well seen in the Siphonophora, where special sets of 
persons, more or less medusoid in form, devote themselves solely to the duty of producing genital glands, and obtain the necessary food from the nutrient persons of the colony ; in a few cases these gonosomes become free.

The Platyhelminthes present an elaborate and somewhat difficult arrangement of their sexual organs; this is no doubt to be partly explained as due to their exhibiting an early stage in the consolidation of the diffused reproductive cells; we must, however, not fail to note that they present a distinct advance in the possession of accessory reproductive organs. The male is provided with a copulatory organ or penis, and the female, which may now have special ovarian ducts, has the terminal portion of the efferent tube modified into a special canal (vagina), into which the male organ may be received. Nor is this all; another portion of the duct is widlened out into a receptacle in which the ova may pass through the earlier stages of their development (uterus); and yet another is often converted into a pouch, in which the male elements may be stored till such time as the ova are ready for fertilisation (receptaculum seminis). The eggproducing and the yolk-producing cells are, however, still distinct, and the latter have not yet, as in the case of a bird, for example, taken their place on some part of the duct that leads from the ovaries.

This kind of arrangement is well seen in the Cestoid Bothriocephalus latus (Fig. 204; A B), where the testes $(t)$ are seen to be represented by aggregations of cells which are scattered through each segment; their proclucts pass by narrow ducts (ve) into a common coiled efferent vessel $(v d)$ which opens at the anterior end of the segment into the copulatory organ (cirrus, $c$ ). The ovarian region $(o v)$ occupies either side of the middle line in the hinder region of the segment, while the 
yolk-producing glands $(d)$ lie outside of these; from the latter there are given off a number of fine canals, which meet in the middle line $\left(d^{\prime}\right)$ towards the hinder end of the segment; these canals cormmunicate with

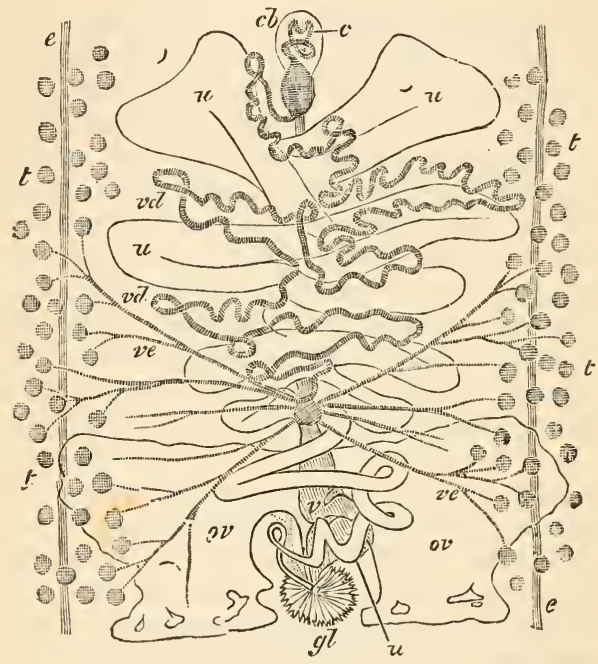

Fig. 204 A.-Male Apparatus of Bothriocephalus latus.

$t$, Some of the testes, with ( $(x)$ their ducts opening into $(v d)$ the vas deferens : $c$, cirrus; $c b$, cirrus sheath; $o v$, ovaries; $u$, uterus. (After sommer and Landois.)

the oviduct $(o d)$, which leads into a large coiled uterus (u), which opens near the anterior end of the joint $\left(u^{\prime}\right)$.

The liver Auke again presents us with a very complex arrangement of parts; there are two testes, one of which is placed in front of the other in the middle of the body; each consists of a large number of blind tubes of varying lengths, which open into 
three or four primary ducts ; these unite at a common point, one for each testis. Thence there pass forwards two deferent ducts, which open into a common seminal reservoir. The reservoir is continuous anteriorly with

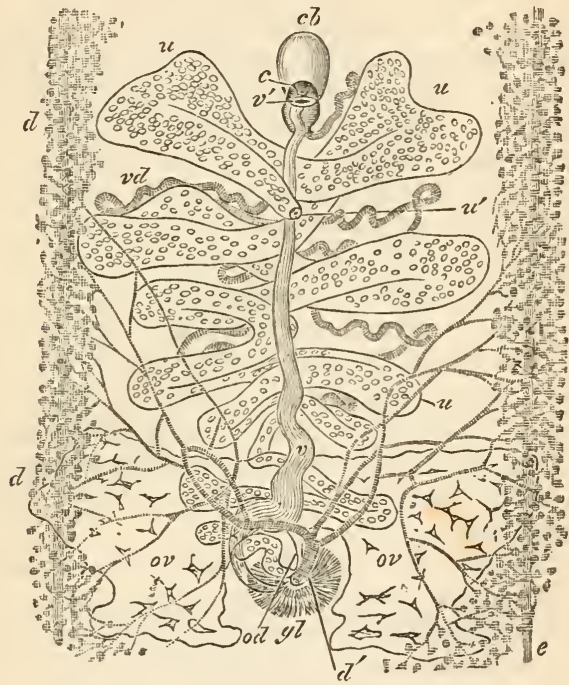

Fig. 201 B.-Female Apparatus of Bothriocephalus latus.

c. Cirrus; $c b$, cirrus sheath; ov, ovarles; $d$, vitellaria; $d^{\prime}$, their ducts; od, oviduct; $u$, uterus; $u$, its oriflce; $v$, vagina; $v$, its oriflce; $g l$, shellproducing glands. (After Sommer and Landois.)

a ductus ejaculatorius, which is coiled and looped, and which forms a papilliform projection at the base of the genital sinus, which is common to the male and female ducts, and is placed just behind the ventral sucker. The terminal portion is protrusible, and functions as a penis; it is ordinarily known as the cirrus. In the female organs the germ glands are quite distinct from the yolk glands; the former make 
up a single mass, which lies well forwards, and is composed of a number of blind tubes; the whole ovary is not very large. The yolk glands occupy the sides of the body, extend farther forwards than the ovary, and reach to quite the hinder end; they are racemose in character, each lobule being made up of a number of small vesicles, the ducts from which open into a large longitudinal duct, of which there is one on either side of the body. Just below the level of the ovary each of these gives off a transverse duct, which opens into a common median reservoir; the duct from this, after a somewhat irregular course, during which it gives off the fine duct of Laurer and Stieda which opens by a very minute pore on the dorsal surface of the body, opens into the genital sinus; the terminal part of the duct serves as a vagina. At the commencement of its course, where it unites with the short oviduct, it is surrounded by a complex of glands, the so-called shell glands, which are so called from their secretion serving to form a shell for the ova.

In the round worms (Nematohelminthes) the sexes are nearly always separate, and the generative products are developed in special tubes, which in the female are, however, of considerable length. Owing to their length, the female tubes are in most cases coiled, but this is the only character which presents any complexity; the blind end of the tube serres as the seat of production of the egg cells, and the remainder lias the function of an uterus, or of a vagina. Here, again, we find that while the blind ovarian portions of the tubes are double, the efferent portion (vagina) has undergone fusion, and the generative orifice is therefore single and median. The male tubes have essentially the same structure, and are only less complicated in character; the blind end of each tube is the seat of development of the 
male cells, while the rest forms merely an efferent duct, or has its distal portion widened out into a reservoir or seminal vesicle. The male orifice is, however, associated with that of the intestine, and two chitinous spicules are developed to serve as copulatory organs, and to aid in the entrance of the spermatozoa, which here are always amoboid in form, and have no specialised mobile tail.

The Acanthocephali are, again, examples of forms in which the sexes are separate and the males provided with a copulatory organ, but they exhibit so much advance in structure as is implied by the testes being two definite sacs; these, however, are not paired, but one lies in front of the other; the testes, like the ova, are developed on a special cord (Jigamentum suspensonium), the exact significance of which is very incompletely understood; a somewhat similar structure has been observed in the Bryozoa; in the Chrtognatha we find that the testes are developed in the anenterous or caudal segment of the body, and the ova in the segment in front; in the Rotifera the males are always without an intestine.

In the Nemertinea, the Gephyrea, and the polychaetous Chactopods the generative products are developed directly from the epithelial cells lining the body cavity, and there is no definite region of which one can speak as testicular or ovarian; in these cases, moreover, the sexes are, as a rule, separate; and we have herein some support for the view that the hermaphroditism of many worms has been secondarily acquired.

In the Hirudinea and the oligochatous Chaetopods we find, on the other hand, that the generative products are developed in certain segments only, and here, too, we find that the two sexes are united in the same individual. Taking as types of these 
two groups the leech (Hirudo) and the earthworm (Lumbricus), we have a striking example of the way in which more lowly and more specialised characters are often associated in the same individual. Starting with the proposition that the generative organs are at first irregularly distributed through the body cavity, we are led to suppose that the more these sexual cells are consolidated, or, in other words, the fewer the segments in which they are developed, the higher the grade of organisation. From this point of view we should assign the higher position to the earthworm, inasmuch as the testes are to be found in two segments only, while the leech has testes developed in nine segments; on the other hand, the arrangements for the safe disposal of the testicular products are no less indicative of superior organisation; from this point of view we should assign the higher position to the leech, inasmuch as it has, and the earthworm has not, a special intromittent organ, or penis, by means of which the male products are safely carried to the female.

Notwithstanding the absence of a penis in most Oligochætes, different individuals copulate with one another, and the male products of the one are received by the other into special pouches, whence they are expelled when the ova are mature and expelled also, while some of the setæe in the region of the body where the orifices are placed are specially modified to aid in copulation. The spermatozoa are often collected into masses or spermatophores, which may or may not be provided with a special investment.

While the generative products of the Nemertinea escape directly to the exterior, and those of the Gephyrea, and probably also of some Annelids, by means of the nephridial canals, the Hirudinea and some Oligochrta are provided with special ducts; in the earthworm the open funnel-shaped orifice of the efferent duct 
becomes greatly enlarged, and two pairs of large sacs (the already mentioned reservoirs), are developed, which completely obscure, and, indeed, have been very frequently mistaken for the true testes. The only explanation which has been given of the presence of nephridial canals and efferent ducts in the same segment is that of Lankester, who has suggested that each segment was typically provided with two pairs of segmental organs, the superior of which ordinarily become aborted. Some worms (Eudrilus), present indications of the presence of both sets of organs, and in others (Ocnerodrilus), the ordinary nephridia are not developed in the segments which carry the generative ducts.

While both the leech and the earthworm have but a single pair of ovaries, the former is provided with a single median vagina, in place of a duct opening directly to the exterior; in the leech, moreover, the ova, when set free from the ovary, are not taken up by the open mouths of the oviducts, and as the wall of the oviduct is directly continuous with the investment of the ovary, they do not, as in most rertebrates, for example, pass first into the body cavity; they make their way directly to the exterior.

As may be supposed from their radial symmetry in adult life, the Echinodermata have their generative organs radially disposed; in the more primitive forms, such as Brisinga, the glands are arranged by pairs, and extend along the whole length of each arm, while the generative pore is placed in the proximal region of each ray; as centralisation increases, the glands become less elongated, and the pores are placed within the area of the disc; in the Ophiuroids the glands are completely confined to the disc, where they form five racemose groups; in the Echinoids the interradially-placed pairs become fused, and only five sets of genital glands are to be made out. In the 
Holothurians reduction is carried still farther, the genital tubes finally uniting into a single tube which opens near the anterior end of the body.

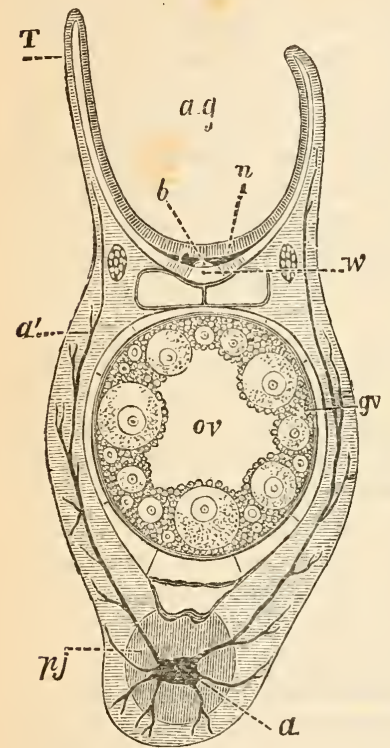

Fig. 205.-Cross Section of a Pinnule of the Arctic Feather-star (Antedon eschrichti) ; $\times 75$.

$a$, Axial cord; $a^{\prime}$, its branches ; $a g$, ambulacral or food groove; $b$, radial blood-vessel; $n$, radial nerve; $o v$, ovary ; $p j$, joint of pinnule ; $w$, watervessel; T, tentacles. (From P.H. Carpenter,slightly altered from Ludwig.)

. In keeping with their other primitive characters, the Crinoidea have a more diffused arrangement of the genital glands; these are situated in the axis of each arm, and make their way into the pinnulæ that are attached to it (Fig. $205)$.

It is ordinarily sup. posed that the generative products of all Echinoderms make their way into the water in a more or less casual manner; in Asterina, however, Ludwig has observed that the males twist their arms around those of the female, and so dispose themselves as to ensure the escaping spermatozoa meeting with the ejected ova. A somewhat similar mode of copulation has been observed by Jickeli in Antedon rosacea.

In addition to their power of sexual multiplication, the Echinoder. mata are distinguished by their remarkable capacity for repairing injuries, and of giving rise to new individuals from separated arms; in those cases in which the rays are very numerous (Brisinga, Labidiaster), 
it would appear that the arms often break off for the purpose of more effectually evacuating their genital products. In some cases, ordinary five-rayed forms, such as the common starfish, have been seen to, as it were spontaneously, break off an arm; from such a single arm several new rays are budded off, and as these only gradually grow, such a starfish has the appearance of a comet, or body with a long tail. In the case of the Ophiuroids, it is, owing to the centralisation of the organs, necessary that this mode of multiplication should be effected not by the separation of a single arm, but by the division of the disc, and Ophiuroids are not unfrequently to be seen in which there are three shorter, and two or three longer arms, the members of either set being subequal among themselves. The reproduction of arms is also to be frequently noticed among the Crinoids, but we have not yet sufficient information as to whether these arms have been directly broken off by enemies, or set free by their possessor in consequence of an inherited peculiarity, as observed by Jickeli in Antedon rosacea, or from fear of danger. This kind of reproduction has not been observed, as may well be supposed, among Echinoids, but it is well known that Holothurians will, if terrified, eject their viscera, and gradually redevelop what one must suppose to be important organs; the Crinoids will replace the whole of the viscera contained in their calyx (M. Marshall).

The various stages of reproduction and fusion which are to be observed among Echinoderms can be nearly all paralleled by what is to be - seen in different groups of the animal kingdom. An annelid of the southern seas (Palolo) is said to evacuate its genital products by completely breaking into pieces, when the ova and spermatozoa meet and unite in the water; the loss of a single arm may be compared to the gradual break-up of the organism which is seen in 
the common jellyfish (Aurelia, $c f$. page 541); the loss by reflex action on irritation of an arm is paralleled by the tail of the lizard; while the formation of buds by the injured arm or disc reminds us of the capacity for reproduction which is exhibited by the common Hydra.

Asexual reproduction in Echinoderms may, to sum up, be one of two things; there may be fission with repair, or a single arm may be separated off and give rise by external gemmation to a fresh zooid.

It is of interest to note that these phenomena are seen especially in those forms (Linckia) in which the ossicles of the arms are not protected either by strong spines as in Astropecten, or by well-developed marginal plates as in Pentagonaster.

A high grade of differentiation is reached by some of the Arthropoda, for the germinal glands are compact, and often, indeed, united into a single mass ; the efferent ducts are not unfrequently single, and their orifice median in position, while the distinction of the sexes is often to be demonstrated by the possession of secondary characters, such as differences in external configuration, or the characters of certain pairs of appendages. It is but seldom that the sexes are united in the same individuals, and the mode of life ordinarily allows us to find an easy explanation for this arrangement, when it does obtain.

On the other hand, there are some remarkable arrangements obtaining in various Arthropods which require immediate notice; in the Crustacean Apus, and in such insect forms as the bee (Apis), and the plant-louse, Aphis, we find that for a large number of generations the females are enabled to produce ova, which grow up to the adult stage without the interposition of any male influence; here, too, as in the case of the Rotifera (see page 482), the presence of polar globules in the maturing egg-cell have not yet 
quite been satisfactorily demonstrated. The distinctions between the various stages of what was originally called parthenogemesis will be considered later on.

To fix our ideas of the peculiarities of the Arthropod organisation, we may commence with an account of the generative organs of the crayfish ; the testes and ovary are respectively compact glands united along the middle line, and giving only indications of a primitively bilateral origin; they occupy a definite and constant position in the body, lying beneath or just in front of the heart, and having the enteric canal beneath ; they both give off a duct on either side, which opens to the exterior at the base of one of the paired appendages which are connected with the thorax; as the female orifice is placed two segments farther forward than the male, the oviducts are, as we may suppose, shorter than the vasa deferentia which carry away the products of the testes (Fig. 206).

The cells which line the walls of the ducts of the testes are, at the ends of the final canals, found to occupy swellings, the large cells of which undergo that division into smaller bodies which is so striking a characteristic of spermatogenesis; the products of these divisions are not, however, provided with merely one protoplasmic tail; in the Crustacea, as in the Nematohelminthes, we have a large development of chitin in various parts of the organism, and here, as there, we have spermatozoa developed which are without that protoplasmic flagellar process, which is to be likened to a cilium; in place of this there are a number of stiff processes, the disposition of which has gained for the spermatozoa the name of "radiate cells." In some Decapoda the rays retain so much of the character of the pseudopodia of an Amœba that they can be withdrawn into the nucleated portion of the cell (Owsjannikoff).

Immobile cells like these require some accessory 
organ by means of which they can be carried with

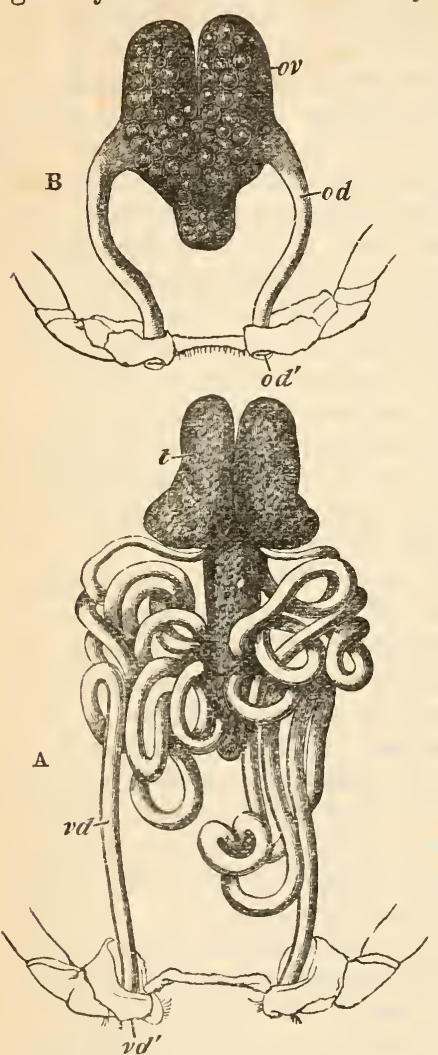

Fig 206.-Figures of the Male (A) and Female (B) Organs of Astacus fluviatilis.

$o v$, Ovary ; od, oviduct ; $o d^{\prime}$, its orifice ; $t$, test is : $v d$, vas deferens; $v d^{\prime}$, its oriflce. (After Huxley.) when this ovum escapes from the ruptured ovisac it safety to the body of the female, and here, as in so many of their other organs, we find the crayfish converting some of its appendages into a suitable apparatus ; the appendages of the first two segments of the abdomen, that is, of the two segments which lie immediately behind that on the base of the ap. pendages of which are placed the male orifices, have their terminal portions converted into styliform processes, with their edges so folded on themselves as to form each a halfcanal.

In the ovary we find here, as in so many other cases, that one cell in it special set (ovisac) grows to a comparatively large size at the expense of those that surround and form a coat for it ; 
passes into the oviduct, where it is perhaps fertilised, and, further, provided with a coat (comparable to that by means of which the spermatozon are aggregated into spermatophores), one end of which is drawn out into a short stalk; by means of this stalk the developing ova become attached to the small appendages of the abdominal region, with which they remain connected till they are converted into the likeness of the adult; a crayfish, or lobster, at this stage is said to be "in berry." There is, then, no free-swimming larval stage in the fresh-water crayfish.

In the cockroach, as in the earthworm, the true character of the testes proper has been misunderstood, owing to just the same causes; it is in young males only that the true testes, which have a dorsal position, can be detected; in the adult forms their products are found in the reservoir which forms the double head of the single short efferent duct, and as this reservoir is a complicated structure (the so-called mushroomshaped gland), formed of a number of short blind tubes, within which the spermatozoa go through the later stages of their development, it has, not unnaturally, been regarded as the true testis. The matured spermatozoa are thread-like bodies pointed at either end, which exhibit a wavy movement.

As has been pointed out by Waldeyer, structures are to be seen in the ovaries of the Arthropoda which correspond to the Graatian follicles of the Vertebrata (page 508).

Gegenbaur is strongly of opinion that the mass of generative cells in the Arthropoda is primitively single, and adduces many facts in support of this view; not only, however, is this arrangement contrary to that which obtains in all other bilaterally symmetrical animals, but it is further opposed by certain embryological facts; for example, the Lepidoptera (butterflies and moths) have, in the later stages of G $\mathrm{G}-16$ 
embryonic life, an organ on either side of the heart; and, lastly, it would be as easy to derive the single from the double, as the double from the single arrangement, when we bear in mind that so primitive a form as Peripatus has the two testes completely separated (Fig. 207).

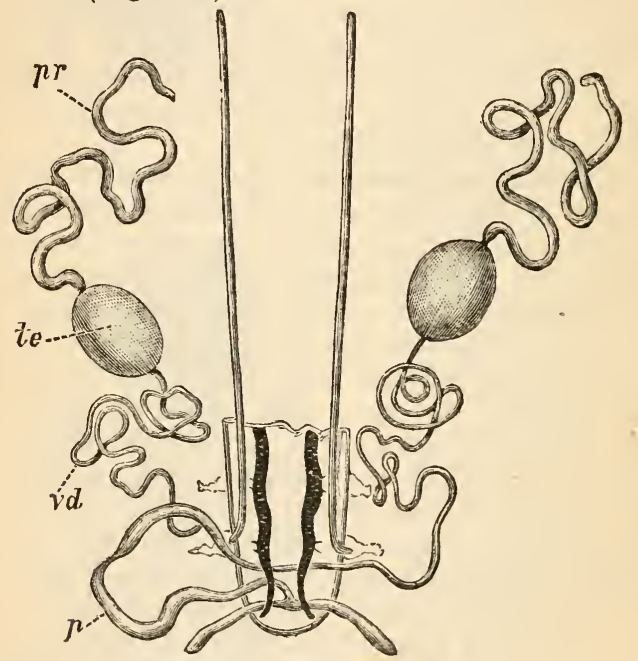

Fig. 207.-Male Organs of Peripatus.

te, Testes ; $v d$, vasa deferentia ; $p r$, prostates ; $p$, common duct of $v d$. (After Balfour.)

We find, then, that the generative glands are either distinctly double, united by an obvious bridge, or converted into a more compact single mass, which retains more or less obscurely indications of a primitively double arrangement.

The male glands are not always rounded off as in the crayfish ; in Squilla they are tubular, and from the sides of the walls short cxea, in which the generative 
epithelium is found, are given off; in Mysis the cæca are fewer and more distinct, and in Oniscus there are a few very long cæca.

In Iulus there are two testicular tubes united by a number of median branches, and provided at their sides with about as many rounded testicular follicles. In insects the testes are ordinarily found to consist of a large number of separate tubes, but the form of the compact mass varies very considerably, and no observations seem to have been made on these parts since the discovery of the character of the true testi-. cular organs of the cockroach.

While the spermatozoa of all Crustacea, with the exception of the parasitic Cirripedia, have no power of independent movement, those of the Insecta are wavy, and one end is often rigid, those of Myriopods may be rigid or motile, and those of the Arachnida, with which Limulus must be classified, are often actively motile.

The hermaphroditic arrangements which obtain in the Cirripedia are to be explained by their fixed mode of life, while the imperative necessity of avoiding the dangers of repeated self-fertilisation has in some cases been yielded to in the production of minute $\left(\frac{2}{25}\right.$ inch) and degraded males (complemental males) (Darwin), which, as in the case of the Gephyrean Bonellia, attach themselves to the body of the hermaphrodite, or simply female Cirriped.

In other epizoic Crustacean parasites (Achtheres percarum and other Siphonostomata) the male is constantly smaller than, and is generally found attached to, the female ; here, too, as in the case of the Rotifera, the number of males is much smaller than that of the females, and adult forms are often developed which arise from non-fertilised ova.

In some Isopoda (e.g. Cymothoa) a parasitic habit likewise obtains, and there is a curious mixture of 
structural and functional hermaphroditism; in the younger stages the testes are enormous as compared with the ovary, and two penes are seen to be developed; the spermatozoa developed in the glands of these Crustacea, with more highly differentiated ancestry than the Cirripeds, are, it is said, motionless. Later on, the testes diminish in size, and the ovarian region comes into functional activity. In the Cryptoniscidæ the male elements are matured during the larval stage, and male free-swimming larvæ copulate with females of fixed habit and a less high degree of organisation; the male larvæ subsequently become degraded, and take on the characters and develop the glands of the female (Kossmann). We have here to do with what may be called phenomena of pro-

\section{tandrous hermaphroditism.}

The differences between males and females are especially well marked in many groups of Insects; as an ordinary rule the males are smaller than the females, being, as it seems, developed more rapidly so as to be ready to fertilise their often short-lived mate; where, on the other hand, the males fight with one another, or carry the female through the air, they are the larger of the two sexes. In many cases (Cicadas, grasshoppers, etc.) the males are alone provided with sound-producing organs, or, as so often happens among butterflies, the males are much handsomer in appearance; sometimes, also, the females of one species are of two distinct forms (dimorphic females), and among the beetles we find that males of one species may vary very greatly in the size and character of their horns (Lucanidæ).

Differences in size obtain also among some Arachnids; the male spider, for example, being very much smaller than the female, and often exceedingly agile in escaping from her ferocity; in the spider, as in the crayfish, one of the appendages is modified to 
serve as an organ for conveying the sperm to the female.

'The cephalous Mollusca, such as the mussel or the oyster, retain the simple conditions of generative glands, being, as are so many marine forms for which the water serves, by its currents, as the carrier of the products of the male to the eggs or egg receptacles of the female, without any secondary sexual organs. In general character and appearance also the male glands closely resemble the female, and it is, no doubt, in consequence of this that so many discussions have arisen as to the monœcions or diœcious arrangements of certain Lamellibranchs.

As seen in ordinary cases, the glands are placed on either side of the body, and each has a separate orifice; with a continuous outer wall, each gland is broken up into a number of separate pouches, and some of the epithelial cells on their inner face become converted into ova or spermatozoa. Small at most periods of the year, they become greatly enlarged at the breeding seasons, when they occupy a large part of the spaces in the body ; the ducts are ordinarily short, and the ova, on escaping, make their way into pouches in the gill chambers, where they are fertilised by the spermatozoa which are brought in by the currents of the water of respiration. (See page 221.)

The elaborate investigations of Ryder seem to have settled the problem of the sexual characters of the oyster; one difficulty in the determination arises from the fact, that while the Portuguese and the ordinary American oyster have the sexes separate, the common edible oyster of Europe (Ostrea edulis) has the sexes united. By a magnificent effort of histological chemistry, Ryder has shown that if two colouring matters (safranin-red and methyl-green) are brought to bear on suitably-prepared sections of the body of an edible oyster, the red-staining fluid 
affects the ova, and the green the spermatozon. Before long we may hope to see this method of investigation applied to other problems of a like nature.

In the Gastropoda we not unfrequently meet with a hermaphrodite arrangement, and this even among the lowest forms; in Proneomenia Hubrecht has observed differences of colour in different parts of the elongated and double generative glind; in spirit specimens the light-yellow portions were found to be

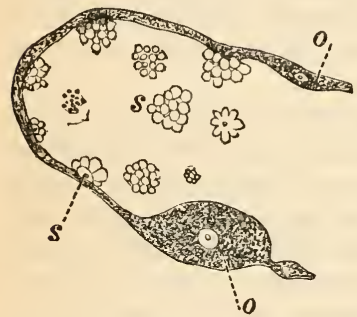

Fig. 208.-Follicles of the Ovotestis of Helix hortensis. $o o$, Ova; $s s$, spermatoblasts. ovarian, and the brownish-grey parts spermigenous. Here, again, we note just the same kind of development as we have seen before; the germinal epithelium gives rise to ova in one region, and spermatozoa in another.

In the higher Gastropods we again often find, as in the snail, a "hermaphrodite gland," and here, too, the male and female products are developed in different portions of the same genital area, from cells which were primitively similar in character; the spermatoblasts sometimes become free from the wall at an early stage (Fig. 208), and in some cases the wall of the gland is produced into a number of pouches. From the common generative gland, or ovotestis, there leads off a common duct.

In those Gastropods that are not hermaphrodite, and in the Cephalopoda, where, too, the sexes are separate, there is very generally a close resemblance between the male and fentale essential organs, reminding one altogether of what we have already noticed in the Lamellibranchiata. 
As in the Lamellibranchiata, we find that a simpler arrangement of ducts obtains among the Gastropoda with separate sexes, the secondary glands and copulatory organs, which are so well developed in the monœcious forms, being frequently altogether absent; this olservation does not, however, apply to the Cephalopoda, where we find several important and instructive complications.

As in some worms and nearly all Vertebrates, the oviduct is not directly continuous with the proper wall of the ovary, but the ova are set free into the cavity of the capsule which encloses the ovary, to le thence taken up by the open mouth of the oviduct. This is either single or double, and has a considerable extent, or only the terminal portion, of its walls provided with secreting glands. Near the orifice of the oviduct there open the ducts of two large glands, which lie on the branchial cavity, and which secrete a viscous substance, by means of which the ova are massed into groups; these are the so-called

\section{nidamentai glands.}

The vas deferens or duct from the testis, which may or may not be double, is, like the oviduct, not directly continuous with the gonad ; it is considerably coiled, and glands or pouches are developed along its tract; of these the most important is that which is ordinarily known as Needham's pouch, in which are collected the masses of spermatozoa that have been grouped together on their way down the duct (Fig. 209).

These spermatophores are tubular structures, which may be about half an inch in length ; the spermatozoa are grouped together, and the rest of the carity of the tube is occupied by a coiled body; when the spermatophore escapes by the penis into the water the external sheath becomes ruptured, and the coiled elastic band within being set free forces the sac of spermatozoa out of the containing sheath (Fig. 210). 
Though the germ glands of the higher Mollusca,

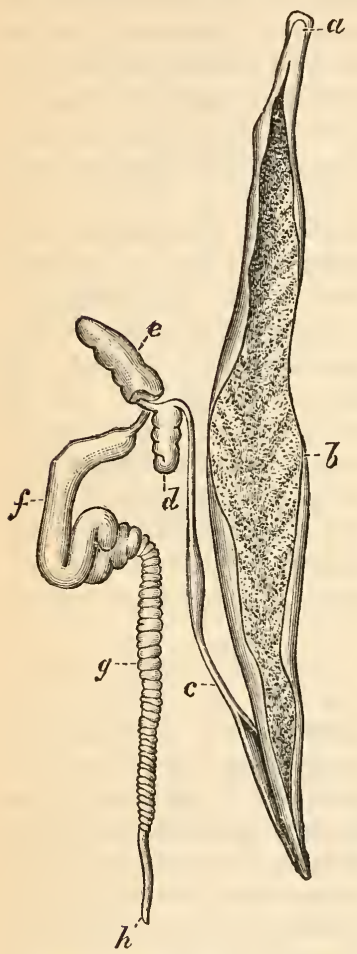

Fig. 209. - Male Duct of Loligo vulgaris.

a, Penis; $b$, pouch of Needham ; $c$, ras efferens : $d$, cæcum; $e$, prostate ; $f$, vesicula seminalis; $g$, vas deferens; $h$, its opening into capsule of testis. (After Brock.) are simple and similar in structure, there is in some a very complex system of accessory organs. In the hermaphrodite forms the duct remains common for a short distance only, and its tract becomes complicated by the development of glandular bodies, the secretion of which nourishes or protects the ova, and of pouches, in which the sperm received during copulation can be stored up till the ova are ready for fertilisation. The male portion has connected with it glands, by means of which the spermatozoa are massed into spermatophores, and the integument is invaginated to form a penis, which, when turned inside out, forms a duct for the sperm. In some cases also, as in the snail, each individual is provided with a gland which secretes a chitinous dart-like body (dart sac), which is thrown off from each snail at its mate in the preliminary stages of copulation.

In some Cephalopods there is a still more remarkable provision for the safety of the seminal products. 
Within the mantle cavity of a female Argonaut, Cuvier discovered an elongated worm-like body, provided with a number of suckers. This he regarded as a parasite, and in consequence of its appearance conferred on it the distinctive name of Hectocotylus Argonautae. This "ver bien extraordinaire," as Cuvier called it, is nothing more than one of the arms of the male Argonaut, which has undergone a remarkable alteration, become greatly elongated, and had conveyed within it the spermatophore. When fully developed it breaks away from the individual that has produced it and makes its way into the mantle cavity of the female.

There are various stages of "hectocotylisation" intermediate between this extreme form and the much more simple extrusion of the spermatophore which obtains in Loligo ; in the latter the fourth ar'm on the left side has its suckers ruclimentary; in Octopus it is the third on the right side, and in it the free end is provided with a spoon-shaped plate, to which the spermatophore is conveyed.

The general lessons as to the

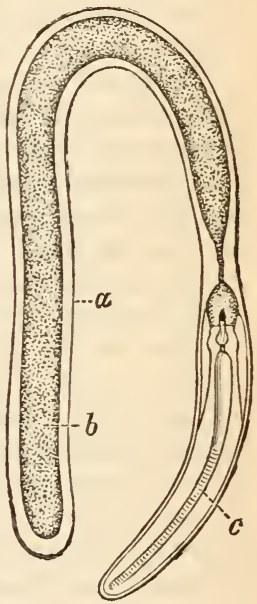

Fig. 210. - Spermatophore of Loligo pealii.

$a$, Sheath; $b$, spermatozoa ; $c$ coiled band. (After W. K. Brooks.) primitive origin of germinal cells may be well impressed on the mind by a consideration of what obtains in the Cramiate Chordata. Among the epithelial cells which line the body cavity, some become, at an early stage, sharply distinguished from the rest, but of these germinal cells it is not at first possible to say which are male and which female; later on they undergo their characteristic changes, the male cells 
gradually breaking up, and the female becoming surrounded with follicular cells and growing at their expense. The epithelial cells that are about to become germinal are, in the early stages of both sexes, formed on a genital ridge, or "sexual eminence"; but, while this ridge becomes more prominent in the female, it gradually disappears in the male. In other words, the distinction between the two sexes is, at this point, well marked at a very early period.

With the exception of Amphioxus, no Chordate presents any distinct indications of the metameric segmentation of its reproductive organs, and the consolidation which was observed in so many of the non-vertebrated forms is just as well marked in this phylum. The higher the vertebrate, the more compact its genital glands.

In Petromyzon the testis extends almost throughout the whole length of the body cavity; in the Elasmobranchs it is best developed in the anterior region of the body; and in most Ganoids it is rather smaller than in Elasmobranchs; in the Teleostei the glands are known to vary much in size at different times of the year, but they are generally of considerable length. In the Caciliæ the testes are broken up into a number (about ten) of separate parts, connected one with another by ducts, and having, on either side, the appearance of a string of pearls. In the Urodeles and Anura the testes are more or less elongated or rounded, but never form, externally, more than a single mass. As we pass through Reptiles to Birds we observe the same phenomenon, though it is necessary to note that the size of the organs varies very much with the conditions of virile activity; for example, the testes of the sparrow, which in January are only two millimetres long, are in April $15 \mathrm{~mm}$. long, and wider in proportion. 
The next important step in the differentiation of the testes is the great change in their topographical relations which is to be observed in the ligher Mammalia, a change which is of the more significance, as it is one that is never suffered by the ovaries. In the Monotremata the testes depart but little from their primitive position; in the porpoises they lie beneath the kidney; in the hedgehog they never leave the abdomen, though they descend as far as the inguinal ring; * in the horse they pass through the ring, which, however, remains permanently open, and they make their way into a sack which is formed by the integument, and is known as the scrotum. In man, finally, as in some other forms, the testes are permanently enclosed in a scrotum, although in individual cases of arrested development we have the atavistic arrangement of the testes being throughout life abdominal in position.

The ovaries, like the testes, become more compact as the scale of vertebrate organisation is ascended. In both sexes we may find that the gonad of one side projects farther forwards and that of the other farther back.

In rare cases, and in individual or specific variations (as in the toad, cod, herring), rudimentary testes are to be observed in females, and rudimentary ovaries in males. On the other hand, Serranus, among fishes, would appear to be ordinarily hermaphrodite, and in individual cases only to have the sexes separate.

The spermatozoa of Elasmobranchs have, as a rule, larger heads than those of Teleostean fishes; in the triton, salamander, and some other Amphibia a remarkable undulating membrane is developed on the

* The inguinal ring is the inferior or cutaneous orifice of the inguinal canal, or space in the abdominal wall by which the spermatic cord passes to the testis. 
tail of the spermatozoon; in some birds the head is not straight, but is twisted into a spiral (Canary). In the Mammalia there is nearly always a rounded head and a long tail.

The ova of Elasmobranchii and Teleostei, Amphibia and Sauropsida, are always of some size, the first and the last of these groups having much the largest ova, or eggs most richly provided with food yolk. In Amphioxus and in mammals * the eggs are very much smaller, and, in consequence of the absence of the disturbing element (the food yolk) the early stages of development are very different. In addition to the investing membranes, which are sometimes perforated by a micropyle, some eggs are provided with a calcareous coating or shell.

Calling to mind somewhat the arrangements which obtain in the Arthropoda, the eggs of vertebrates are enclosed in an envelope of cells which owe their origin to the primitive germinal epithelium; in the Mammalia this cellular investment becomes more than one layer deep, the cavity within enlarges, and the ovum projects into the fluid therein contained; this is the structure which is ordinarily known as the

\section{Graafian follicle.}

The numbers of ova formed within any one female vary enormously, and, as may be supposed, the largest numbers are found in the lowest forms, or, in fishes; thus the cod is credited with nine millions, the haddock and plaice with six millions; the Elasmobranchs have a very much smaller number, often less than ten; in the Amphibia there are often a considerable number, in the Sauropsida the number is smaller, and no mammal has more than about ten matured at the same time, while in many cases the birth of twins even is only an occasional phenomenon.

These ova become invested in membranes, of * The Monotremata have been lately stated to have large eggs. 
which the most common are the vitelline and the zona radiata; in some cases a third, more internally placed membrane, is also developed. In addition to these, there appear in the Sauropsida and Mammalia two very important fœetal membranes; the first of these forms an enveloping and protecting sac for the embryo, and is called the ammion; it owes its origin to two folds, which appear one at either end of the embryo, rise up, curve over, and finally unite in the middle line above. As each fold is double it follows that, when the ends of each unite, two envelopes are formed, and a cavity or space, which later on becomes filled with the liquor amnii, is developed between them. The inner of these envelopes forms the true ammion, and the outer the false amnion or subzonal membrame (Fig. 211) .

The other covering is the allantois, and it has a very different history. Early in the development of the intestine there is given off from in front of the region of the future anus a saccular outgrowth, which gradually extends beyond the body of the embryo, and over the greater part of it; during the period of fœtal development this allantois remains connected by a stalk with the body of the embryo, and over its surface there extends a rich supply of blood-vessels, the allantoic arteries and veins; so that it has a nutrient or a respiratory function, or both.

In the Sauropsida all the material for the development of the embryo is contained within the egg itself, which, at a very early period, becomes sharply divisible into a blastoderm, the seat of the future essential stages in development, and a yolk sac, or store of nutriment, the material from which is acquired by the embryo through the intermediation of the rich plexus of vessels which are rapidly developed within and around it. As the yolk sac diminishes, the allantois, for a time, increases in size, its vessels attain to 


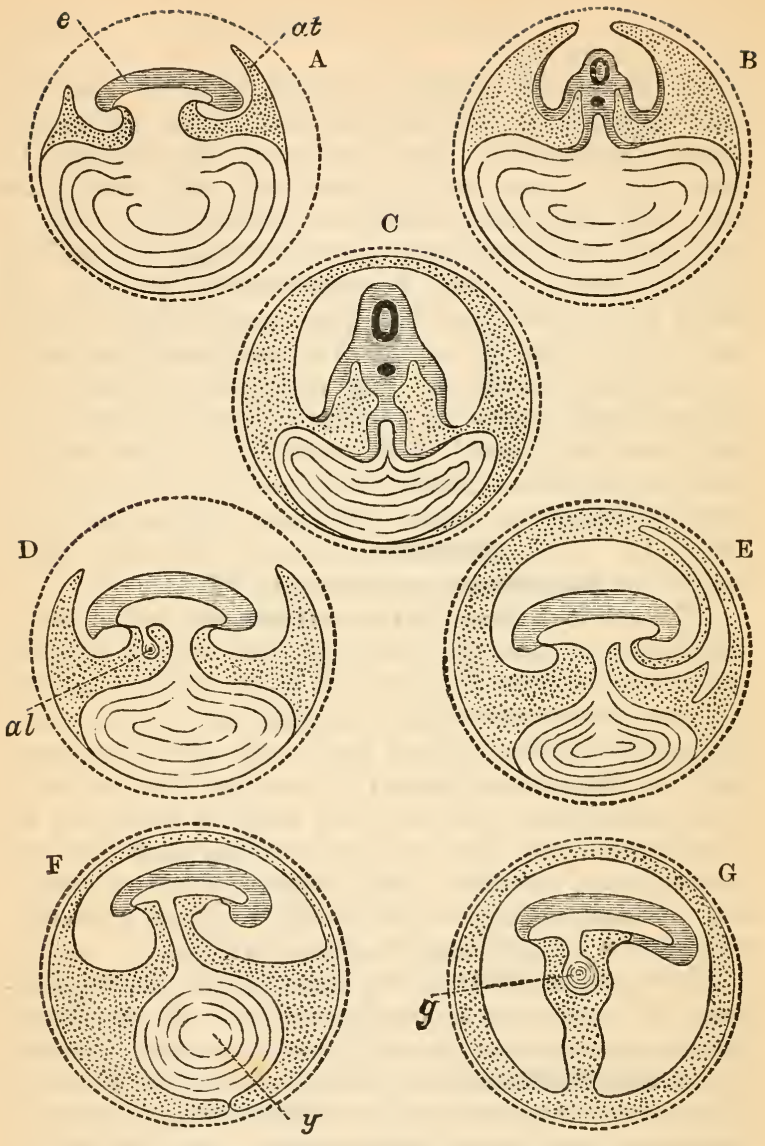

Fig. 211.-Diagrams to show the Development of the Amnion and Allantois. (After Foster and Balfour.)

In $\mathrm{A}$ the folds of the amnion (at) are to be seen rising un on either end of the embryo (e); in B they have nearly met, and in $c$ they have entirely coalesced. In $\mathrm{D}$ the allantois $(a l)$ is scen making its way ont of the body of the embryo, and in $\mathrm{E}$ it is seen at a later stage. In $\mathrm{F}$ the yolk sac is shown in position, and in $\mathrm{G}$ just before its flnal ahsorption. 
greater physiological importance, and give to this outgrowth the function of a respiratory organ.

The fate and functions of the membranes of the mammalian ovum will be considered a little later (page 515).

In the lower Vertebrates there are no special efferent ducts for the genital products; as in the Chætognatha, these fall into the colom, and make their way into the surrounding water through the two abdominal pores; in the Cyclostomata these pores represent, no doubt, the primitive mode of exit of the ova and spermatozoa, but in the higher Teleostei, where, again, they (or parts called by the same name) have the same function, it is to be distinctly borne in mind that proper ducts have been there developed, and have subsequently undergone atrophy.

The arrangement of oviducts which obtains in the frog is that which is most common, indeed almost universal, among Vertebrates; as in the earthworm, the ova escapes from the ovary into the body cavity, whence they are taken up by the open mouths of the paired oviducts. These two mouths are sometimes (Elasmobranchs, most Ganoids) fused into a common ostium, but the greater part of the ducts are distinctly separated from one another. As has been already pointed out (page 262) these ducts (IIullerian Iucts) are derived from the primitive excretory duct.

In Lepidosiren Hyrtl has described the abdominal orifice of each duct as being funnel-shaped, and this form of opening is commonly found in all the pentadactyle Vertebrata. As we ascend the scale we find the oviducts becoming more compact, in so far that the orifice, which in the Amphibia and in the lizard (Fig. 212; ot) lies far forward, and in front of the ovaries, becomes in snakes and mammals set much farther back; in the latter the oviducts are often spoken of as the Fallopian tubes. 


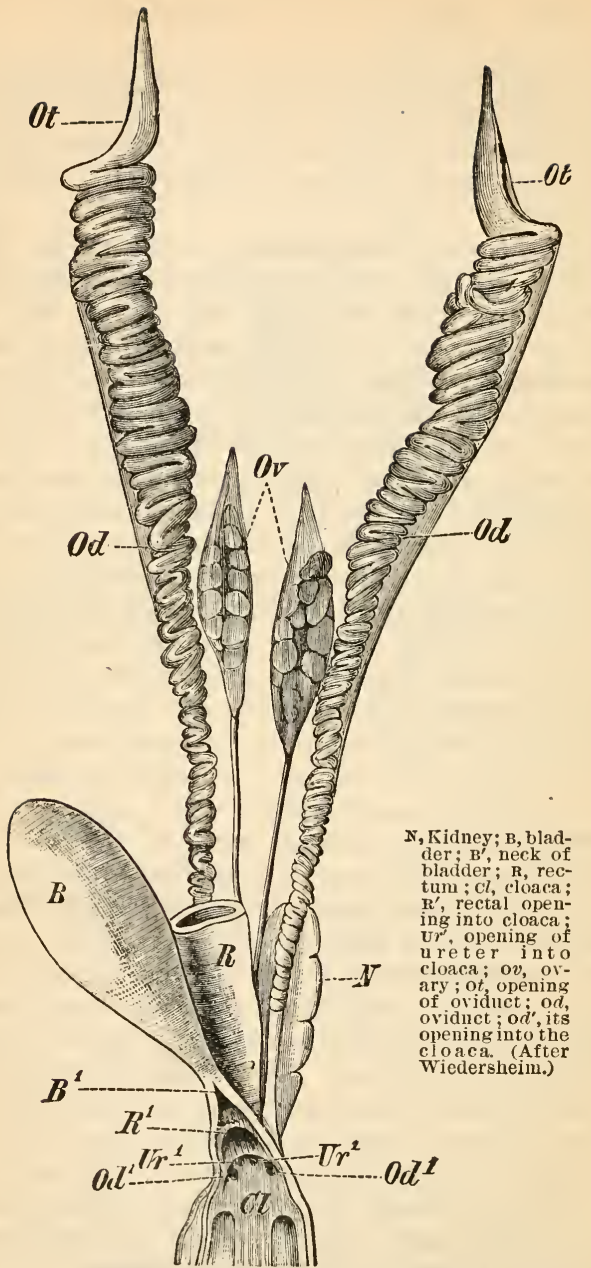

Fig. 212.-Urogenital Organs of the Lizard (Lacerta muralis). 
In the Teleostei, and the teleostean-like Ganoids, such as Lepidosteus, the oviducts have no patent abdominal mouths, but the walls of the tubes are continuous with those of the gland, or the ducts become more or less aborted; here it would appear that the oviduct is not the altered Mullerian duct, but sufficient information on this head remains to be acquired. When, as in eels and salmons, the ducts become completely aborted, the ova fall into the body cavity and escape to the exterior by the so-called

\section{abdominal pores.}

The different regions of the oviducal canal take on very various functions in various vertebrates; one important factor in determining the character of the ducts is the size of the ova which pass through it, and another is, of course, to be found in the different conditions of size and age in which eggs are laid or young brought forth. In the frog the whole of the canal, with the exception of the penultimate portion, is of the same calibre throughout; in the terminal enlargement the ova become grouped into masses, which are held together by the gelatinous substance secreted by the oviducal glands; the ova are fertilised outside the body of the female. In some Elasmobranchs, and in the Sauropsida, the ova as they pass down the ducts become not only invested by a layer of albumen, but surrounded by a shell; this may be horny, as in Elasmobranchs, Lacertilia, and Ophidia; or firmer and calcareous, as in other Reptiles and in Birds.

In the Ophidia the right ovary is always larger, and often much larger, than the left, and the left oviduct shorter than the right; in Birds, on the other hand, the right ovary and duct become aborted during development, though indications of their presence are, of course, retained by some forms.

Where the ova are not only fertilised within the H $\mathrm{H}-16$ 
body of the female, but also pass through the early stages of development within it, the ducts become much more elaborate than in the oviparous forms; Vertebrates in which this obtains are, somewhat improperly, spoken of as viviparous. The most prominent phenomenon is the enlargement of the distal portion of the duct into a cavity of varying width, the so-called uterus. In most of the viviparous fishes, in the few viviparous Lacertilia (Zootoca, Anguis fragilis), and in the viviparous Ophidia, the ova appear to continue to develop within the uterine cavity without any assistance or nourishment from the mother.

In a few Elasmobranchs, however, and in all the higher Mammalia, means are taken by which the young are brought into real relation with the parent, and are directly nourished by its blood; in the former (e.g. Mustelus lævis) the vascular walls of the yolk sac become raised into ridges which fit into corresponding depressions in the vascular uterine membrane. Here we have the lowest and simplest representation of a placenta.

Of the aplacental Mammals little is definitely known, and what information we have was long ago furnished by Owen, who observed in Ornithorhynchus that the ova lay free in the uterus, the lining membrane of which was highly vascular; in a fotal kangaroo there were folds on the investing membrane of the fœtus, and corresponding depressions on the walls of the uterus, but no organic connection was observed between the parent and the young.

In the placental Mammals outgrowths of the investing membranes of the egg become more or less closely united with vascular outgrowths of that portion of the oviduct which has the function of a uterus, and give rise to a characteristic organ.

To make such structures intelligible it is necessary, first of all, to give some account of the characters of 
these membranes; it will be remembered that, in speaking of the extra-uterine development of the embryo of the Sauropsida (the other division of the Amniota, as the Mammalia and Sauropsida are often collectively called) attention was directed to the amnion, the allantois, and the yolk sac. As in the other division, the embryo, notwithstanding the smallness of the mammalian egg, is early distinguished into an embryonic and a vitelline portion, but the yolk sac* is always smaller than in Sauroids; the false amnion, or subzonal membrane, has, moreover, an important part to play, which, from the nature of things, was impossible in the oviparous groups, and the yolk sac has, in some mammals, a certain relation to the uterine walls.

Dealing first with such a case (e.g. the rabbit) we find the developing embryo soon becoming attached to and embraced by the epithelium which lines the uterus; the epiblastic covering of the yolk sac separates from the subjacent layers and unites with the false amnion to form a layer beneath the zona radiata (page 509); a little later the latter and the subzonal membrane fuse together. Later on, this subzonal membrane fuses with the vascular walls of the yolk sac, to form a fresh investing membrane, the false chorion. The true chorion is formed by the fusion of part of the vascular wall of the allantois with part of the subzonal membrane. Into the substance of this chorion there extend bloodvessels, and from its surface there grow out a number of delicate processes which fit into corresponding vascular "crypts" which are developed on the inner wall of the uterus; the whole of the apparatus thus formed, partly by the mother and partly by the foetus, is known as the placenta.

* In mammals the yolk sac is generally known as the "um. bilical vesicle." 
As was first pointed out by Balfour, the types of mammalian placentæ fall primarily into two great groups; in one the yolk sac (or so-called umbilical vesicle) takes a share in the formation of the placenta; this arrangement, which is probably the more primitive, is retained by the Insectivora, Rodentia, and Chiroptera. The other type, which is seen in all the other forms, is characterised by the fact that the yolk sac ceases to take any important share in the nourishment of the fotus.

Placentæ, in which the fotal portion is derived chiefly from the allantois, and not from the yolk sac, fall again into two great divisions; in the simpler. forms the outgrowths (villi) of the chorion merely project into the pits which are developed in the uterus of the mother, and may, at birth, be drawn out from them without injuring the uterine vessels; these are the nou-deciduate placente. In the other the connection between the walls of the villi and those of the pits becomes so intimate that the vessels of the uterus are torn when the futus is born; such placentre are called deciduate. The former, again, belong to one of two groups; in the horse or the pig the chorionic villi extend over nearly the whole of the surface of the placenta, and we have a diffused placenta; in others, such as the sheep or the cow, the villi are collected into definite tufts or branches, which are distinctively known as cotyledons, and the placenta is said to be cotyledomary. The spaces between the cotyledons, of which the cow and the goat have from sixty to one hundred, but the deer only from eight to twelve, are left bare of villi.

In the deciduata the placenta is ordinarily said to be discoidal or zonary, but care must be taken in the application of the former of these two terms, for the placenta is disc-shaped in insectivores, rodents, and bats, as well as in man and the apes ; it is convenient, 
therefore, to follow Balfour in applying the term metadiscoidal to the disc-shaped placentr of such forms as have the placenta formed by the allantois, rather than by the yolk sac. From the diffused - or discoidal forms, or from both, there has been evolved another form of placenta, such as is seen in the Carnivora and some other mammals; in these the villi are confined to a broad girdle-shaped region of the chorion, and we have therefore an arrangement which may well be spoken of as zonary.

The oviducts of all vertebrates are typically paired, and in many cases, as in the Amphibia, they are completely separate from one another along the whole of their course, as they are also in the Reptilia, although in the Chelonia their terminal portion is invested in a common sheath.

In Teleostei and Elasmobranchs the two ducts unite at their termination to open by a common orifice; in the Teleostei they open to the exterior behind the anus; in Elasmobranchs, Dipnoi, and all the Sauropsida, they open into a pit or cloaca, which is common to them, the renal, and the rectal orifices.

In the Monotremata, in which there is a distinct, and the Marsupialia, in which there is a shallow, cloaca, the oviducts open separately; in the latter, but not in the former, the lower part of the oviducal tube is modified to form a vagina, which, however modified in various forms, is essentially double. In the higher Mammals, in which the common urinogenital orifice is placed in front of the anus, and separated from it by a more or less distinct perinam, the terminal portions of the two oviducts are always, at least externally, and in most cases also internally, single and united. As we ascend the scale of the Eutheria we find this confluence becoming more and more extensive. In the great ant-eater there is a remnant of the two walls of the separate tubes in 
the form of a longitudinal septum, which is about an inch in length and terminal in position, so that the vaginal tube opens by two separate orifices into the urino-genital canal. In some examples of, though apparently not in all, Indian elephants, the vagina and the uterus above are divided into two by a still
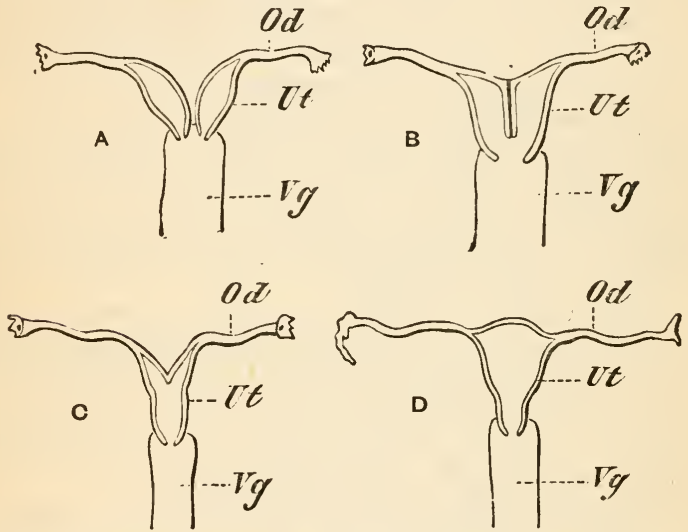

Fig. 213.-Diagrams to Show the Different Stages of the Mammalian Uterus.

A, Uterus duplex : B, uterus hipartitus: c, uterus bicornis ; n, uterus simplex ; $o d$, oviduct; $t$, uterus; $g$, vagina. (After Wiedershein.)

more complete longitudinal septum; in the rodent Lagostomus the septum is retained in the proximal or uterine, but is absent from the distal, portion of the vagina. As an occasional occurrence, a "vagina duplex" is found in the human subject.

In those Mammals in which the vagina is completely single we find (1) two quite distinct uteri, each opening by its own os into the vagina (Fig. 213; A); this condition obtains in the rabbit; (2) the undivided portion of the uterus is short, as in the 
hedgehog, and the remaining portions of the ducts, or so-called coruua uteri, are long; $(3)$ in the mare the cornua are proportionately shorter; and (4) in the highest forms, as in man, the short proximal portions of the oviducts ("Fallopian tubes") open directly into the large single uterus.

As has already been pointed out (see page 263), the male have a different origin to the female generative ducts of Vertebrates, arising, as they do, from the primitive Wolfian aluet. On the whole they present less important points of difference in rarious groups than do the oviducts; and they constantly remain separate along the whole of their course; where there is a terminal portion which appear's to be single, it is not part of the Wolffian duct.

In the ichthyoid vertebrates the seminal products always make their way through the kidney; in the lizard the testicular duct (vas deferens) and the ureter only unite just before they open into the cloaca. In Birds the two ducts run close to, but open separately from, one another. In the Monotremata the renal and seminal ducts open separately into the cloaca, and the common urino-genital passage is distal to it.

In the remaining Mammalia, where the ureters open separately into the bladder, there is, again, no relation between them and the Wolffian ducts; in place thereof, however, we find a common passage, the vasa deferentia, opening at some point on the course of the urethra, which is itself the narrowest proximal end of the allantois.

Copulation is not always effected among fishes, some only discharging their genital products into the water; in the Elasmobranchs the hinder pair of fins serve as organs for dilating the female orifice, and between them there is placed a papilla, on which the seminal ducts open, and this is inserted into 
the female. Union of the sexes is common among the Amphibia, but it is in the Cæciliæ only that an external copulatory organ is developed from the cloaca; this may be as much as five centimetres long (Wiedersheim). In Reptiles the penis is nearly always distinctly double; in the lizard the two halves ordinarily lie beneath the skin just behind the cloacal slit, but they are here, as they are also in the snakes, capable of protrusion and erection; a spiral groove runs along the inner face of each half, and serves as the duct by which the semen is conveyed from the vas deferens to the female. The penis of the Crocodilia and of the Chelonia is feebly, if at all, protractile, but an advance is to be noted in the greater union of the two halves, and the development of blood spaces or corpora cavernosa in its substance. Where a penis is developed in birds, it has (except in the ostrich) the form of a coiled protrusible tube, the groove on whose upper surface leads into a canal.

Among the Eutheria the penis always presents a certain number of common characters, in so far as the outgrowth of the cloaca from which it is formed always becomes separated by the perinæum from the rectal orifice, that the primitive groove always becomes a canal, and the basal or proximal end is continuous with the urogenital sinus, or portion common to the urethra and the vasa deferentia. This penis is erected by a median and two lateral corpora cavernosa, and at the free end, which is covered by a fold of the skin (prepuce), there is developed a glans. In addition to the corpora, an os penis may be found, and this is sometimes, as in the walrus, of great size. The portion of the urethra found in the penis is known as the penial urethra, and it sometimes, though by no means always, traverses the body of the glans before opening to the exterior. 
On the course of the urethra there are developed the prostate, and frequently also the Cowperian glands, the secretion of which appears to serve as a vehicle for the semen; the size of these, and especially of the former, varies not only greatly in various species, but also at different ages, being often much larger in advanced years. The glans itself is also provided with preputial glands, and is not unfrequently armed with spines. In Ornithorhynchus it has a kind of claw at its end, and its surface is covered with spiny hooks, which are directed backwards, and serve as organs of attachment.

The penis arises as an outgrowth of the wall of the cloaca, and is at first grooved along its upper surface ; the sides of this groove grow over and unite in the male. On either side there is a fold of skin, which, in males, unites below with its fellow to form the scrotum, in which the testes are carried in a number of mammals. In the female the just-mentioned parts remain as the clitoris and labia majora, and do not, as a rule, increase greatly in size ; in some, however, like the hyæna, they are as large as the corresponding or homologous parts in the male, so that the sexes cannot, externally, be distinguished from one another, and a belief in the hermaphroditism of the hyæna is consequently not uncommon. The clitoris is perforated by the urethra in some of the lemurs; and in the seal the female has an os clitoridis, the homologue of the os penis of the male.

Internally the male ordinarily retains a small portion only of the Müllerian duct. This uterus masculimus varies considerably in size; in the rabbit, for example, it is of considerable extent.

Of the organs connected with the care of the young, the most important are the mammary glands and 
the marsupial pouch. The former are found in all the Mammalia, but in the Monotremata they remain at a low or indifferent stage in so far as the ducts do not emerge to a common orifice, but open separately,
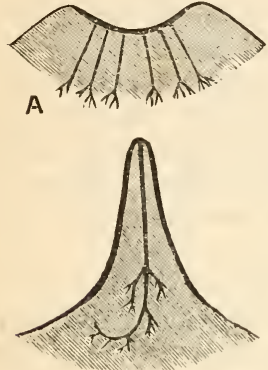

D

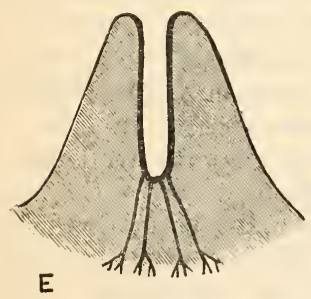

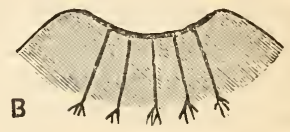

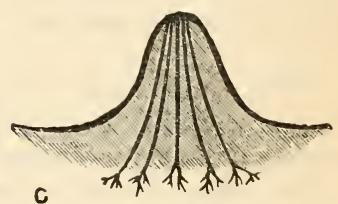

C

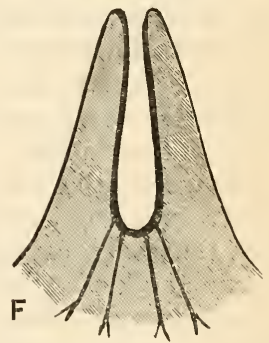

Fig. 214.-Diagrams of the Arrangements of the Ducts of the Mammary Glands in various Mammals.

A, Adult echidna; B, human embryo; c, adult Homo; D, adult mouse; E, embryo of Bos; F, adult Bos. (After Klaatsch.)

either on the surface of the integument (Ornithorhynchus), or in a special mammary pouch (Echidna) (Fig. $214 ;$ A). In all other mammals, "true" or "false" teats are developed, the former being found when, as in man, the ducts of the gland converge and open on an uprising projection (Fig. 214; c), or a 
single duct (as in Mus; D) traverses the projection. The false teat is found, for example, in the cow ( $\mathrm{T}$ and F), where the sides of the mammary pouch are drawn out to form a canal, at the pit of which the manmary ducts open.

Though the mammary glands are merely integumentary glands set apart for the secretion of a special fluid, milk, they are remarkable for being unlike any gland found in any other vertebrate. The character's of the secretion vary within limits; the milk of the mare, for example, being poor in fats, but so rich in sugar as to easily ferment, and form a spirituous liquor (koumiss); in other cases, e.g. the goat, the milk has the odour of the animal that secretes it. As a rule the glands are active in females only, but medical observer's have put on record a few cases of "male lactation."

In the lower Mammals the number of teats is much greater than in the higher forms, while their presence on the thorax in some (man, Sirenia), and on the groin (cow) only in other mammals, speaks to their having primitively extended along a large part of the ventral surface. The Centetidæ have twelve pairs of teats (Dobson), the rabbit and the hedgehog five. The teats are often found to correspond in number to the maximum number of young produced at a birth; in no known case do they exceed fourteen.

In the Marsupialia the teats are often arranged in a circle round a central larger teat, and the whole mammary area is enclosed by a fold of the skin, the marsupial pouch, into which the young, which are born in an altogether helpless condition, and at a period so early that they are unable to actively suck the mother, are conveyed. These helpless babes are fed by the mother, who forces the milk out of her mammary glands by the contraction of the cremaster 
muscle ; the young thus fed and fixed would, no doubt, soon be suffocated were their respiratory tube of exactly the same form as that of the adult; to prevent such a catastrophe the larynx is prolonged at its upper end into a conical projection, which is inserted into the cleft of the soft palate, and is thereby brought into direct connection with the nasal air passages. By these means the nutrient milk can pass with as much safety into the gullet as the water does in the case of the Cetacea. (See page 242.) Here we have an example of how in different groups the same result is attained to by the use of the same kind of means.

Very striking differences are to be observed among various Vertebrates as to their care of their young. Most Fishes lay their eggs in the water, where they are fertilised by the male and left to hatch; in very rare cases does the female exhibit the least care for them; indeed, but two are known; Aspredo, after depositing her eggs, is known to attach them to her belly, where they stay till they are hatched, and Solenostoma develops a pouch, within which are projecting filaments to which possibly the ova become attached. The male more frequently exhibits care for its young, the stickleback and others forming and guarding a nest in which the ova are deposited; others carry the ova in their pharynx, while the pipefish (Syngnathus), and the seahorse (Hippocampus) develop a subcaudal pouch in which the ova are carried till they are hatched. The female Surinam toad carries her young on her back, and the male Alytes obstetricans cuts the gelatinous cords by means of which the ova are attached to the body of the female, and twines the eggs round his legs. Pythons incubate their eggs, and during the process their temperature rises about $3^{\circ} \mathrm{F}$. (Forbes). Most Birds but the cuckoo and the American Cow-bird (Molothrus) incubate their own eggs, and in those cases where the young are unable, when hatched, 
to forage for themselves, provide them with food. All Mammals suckle their young, and the ascent in the series appropriately finds its termination in man, who alone has the idea of the family.

\section{CHAPTER XIV.}

THE DEVELOPMENT OF THE METAZOA.

THE organs described in the preceding chapter, whether essential, as the testes or ovaries, or accessory, as the ducts, glands, and intromittent organs, have in common the function of providing for the union of the male cell or spermatozoon and the female cell or orum. In all Netazoa, save those which multiply by budding or by the parthenogenetic development of the egg, this union of a male and female cell is the first step in the history of a new individual ; it may be effected either within the body of the female, as in Birds and Mammals, or it may be effected externally to it as in the frog, the perch, or the starfish. The ovum having freed itself of the polar globules, and received within itself the male or fertilising element, proceeds to undergo division or segmentation; this may regularly affect all the parts of the egg, and the several segments may be all of the same size, or, as in the egg of the hen, where there is an abundant supply of yolk, division may go on actively in a small portion only of the whole egg. It is particularly to be borne in mind that the absence or presence of yolk in small or larger quantities profoundly affects the character of the segmentation.

Regular segmentation, such as is seen in Amphioxus, obtains only in ova in which there is none or but little yolk (alecithal ova; Lankester); it is most common among the lowest Metazoa, such as the 
Sponges and Colenterata; it is found in some round and flat worms, and in Echinoderms, but is very rare in Insects, Molluses, and Chordates, Amphioxus, indeed, being the only representative in the lastmentioned phylum.

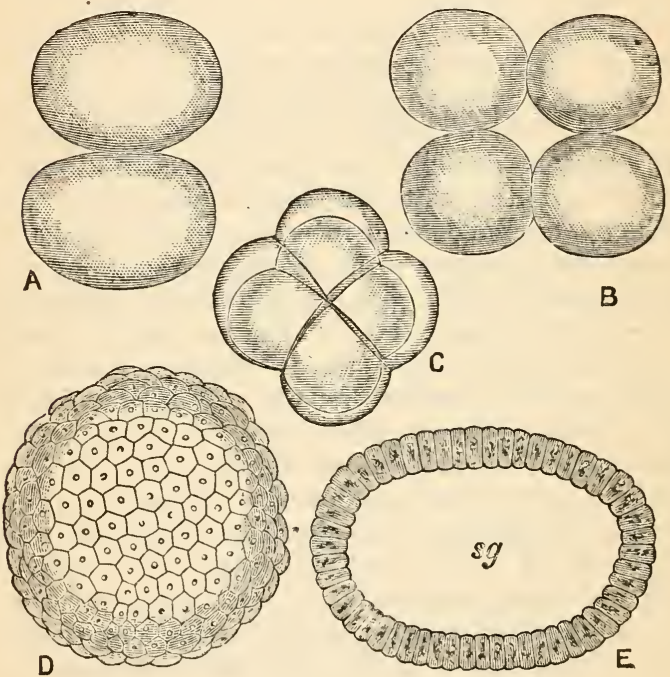

Fig. 215.-The Segmentation of Amphioxus.

A, Stage with two, B, with four equal segments. In c each of the four segments has been divided horizontally; $\mathrm{D}$, a later stage in which a single layer of equal cells encloses a central segmentation cavity ; $\mathrm{E}$, the cavity $(\boldsymbol{s g})$ is seen in optical section. (After Kowalersky.)

The influence of food yolk on the segmentation has been stated by Balfour in the following terms: "The rapidity with which any part of an ovum segments varies ceteris paribus with the relative amount of protoplasm it contains; and the size of the segments formed varies inversely to the relative amount of 
protoplasm. When the proportion of protoplasm in any part of an ovum becomes extremely small, segmentation does not occur in that part."

The yolk may be either concentrated in the centre of the egg (centro-lecithal ova) as in many Arthropods, or at one pole of the egg (telo-lecithal ova), as in the frog or the chick. In the former case the segments may be all equal, or some may be larger than others (unequal segmentation), or the segmentation may affect only the surface of the egg; in the latter the segmentation may be unequal, as in the frog, where there is not a large amount of yolk; or partial. as in the fowl, where, owing to the enormous quantity of yolk that is present, segmentation occurs only in the small area to which the protoplasm is confined; affording, that is, a proof of the validity of the law just quoted.

The mass of cells resulting from the segmentation of the ovum may remain closely packed together, and resemble a mulberry (morula stage), or they may separate from one another, and give rise to a central segmentation cavity (Fig. 215; E, $8 g$ ) (blastula stage). In the next stage, instead of a single we have two layers of cells, and this condition may either be brought about by the simple inpushing of some of the cells (invagination), or some of the cells may grow over the others, or the cells of the single layer may undergo transverse division (delamination), and the arrangement of the double layer be thus arrived at.

As we have already learnt, the two-layered stage with a central cavity is known as the Gastrula stage; the layers are known as the germinal layers (epiblast and hypoblast), and the cavity as the archenteron (Fig. 216). The opening into the archenteron is known as the blastopore, and appears, from what is known of the development of 
such primitive forms as Peripatus or Amphioxus to have been of considerable extent, just as is the mouth of a sea-anemone ; like it, it tended to close up in its middle, and to have an orifice at either end (A. Sedgwick); and these two ends would therefore represent the oral and anal orifices of the primitive intestine. The fate of the blastopore is very various ; it may remain as the permanent mouth, or as the

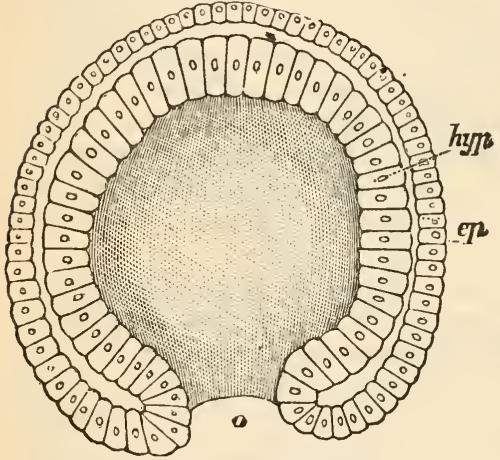

Fig. 216.-Diagram of a Gastrula. $o$, Blastopore; hyp, hypoblast ; ep, epiblast.

permanent anus; or it may close up, and the mouth or. the anus be subsequently formed at the point of closure, or itmay close up and apparently have no topographical relation to either the future mouth or the future anus.

In most, though not all (e.g. Hydra) Me-

tazoa, a third layer (the mesoblast) appears between the epiblast and hypoblast, and gives rise to the supporting tissues, the muscles, the connective tissue, and the blood and lymph; the epiblast covers the surface of the animal, and is the seat of origin of the nervous system and sense organs, the hypoblast lines the alimentary tract, and its appended glands. As has been already pointed out, a cavity (the coelom) appears in the midst of the mesoblast (see page 45) in all Metazoa above the Cœlenterata.

The epiblast becomes divisible in all forms above 
the Colenterata into two layers, the epidermic and the nervous; the former gives rise to a structureless cuticle, or undergoes hardening and becomes chitinous, horny, or calcified, thereby giving rise to the various forms of external skeletons; or its cells may undergo invagination, and give rise to the various forms of tegumentary glands, of which the mammary are the most specialised. In the region of the mouth the epiblast very ordinarily folds inwards to form the stomodaum, and in that of the anus to form the proctodaum.

The nerrous layer undergoes one of two kinds of modifications; its cells either become thickened along certain tracts, which in the more primitive forms remain permanently connected with the epidermic layer, or, as in all the Chordata, the nervous layer is grooved along its middle line, and, giving rise to the medullary canal, becomes separated from the epidermis. (See page 416.) Other parts of the layer become modified to form the organs of sense.

The mesoblast, the mode of development of which varies greatly in different forms, arises in such primitive forms as Peripatus or Amphioxus in the form of paired outgrowths of the enteron; in the segmented Metazoa, such as the earthworm, the insect, or Amphioxus, the mesoblast on either side becomes divided into a series of cubical masses, the mesoblastic somites. Where the mesoblast arises from the enteron, the somites are from the first hollow within; where, as in the earthworm, the somites arise from special cells, and are at first solid, a cavity is gradually developed within them ; and the cavities of either side becoming in time continuous with one another, give rise to the general body cavity (cœlom). The outermost portion of the mesoblast comes into contact with the epiblast, and gives rise to the dermis and the muscles of the body wall; the innermost layer comes into relation I I-16 
with the hypoblast, and forms the greater part of the wall of the permanent digestive tract. In the Vertebrata the upper dorsal portion of the mesoblast surrounds the notochord, and gives rise to the rudiments of the bodies of the vertebræ; the rest of the dorsal portion is converted into the so-called muscle plates. Other parts of the mesoblast give rise, in various ways, to the heart and blood-vessels, when such are present, to the blood itself, and to the renal and generative organs.

The hypoblast, in addition to forming the lining of a more or less large portion of the digestive tract, and of the organs (liver, lungs) which are developed as outgrowths from it, does, in the Cephalochordata and Urochordata at any rate, give rise also to the notochord, which arises as a diverticulum or outgrowth on the dorsal side of the primitive enteron.

We have, then,

(1) The epiblast giving rise to the epidermis, nervous system, stomodæum, and proctodæum.

(2) The mesoblast gives rise to the internal skeleton, the muscles, connective tissue, vascular, renal, and generative systems.

(3) The hypoblast forming the lining of the digestive tract and its appendages, and, in the lower Chordata, the notochord.

While in a large number of Metazoa the fertilised ovum, by a regular and steady series of differentiations, gives rise to forms which essentially resemble their parents, there is a not inconsiderable number of cases in which the young live for a time an inde-

- pendent life under a form very different to that of the adult. Such forms are known as Iarvae; a few only can be here dealt with.

Among the Chordata the best known is the tadpole stage of the frog ; instead of a tailless fourlimbed animal with a large mouth, no gills or gill 
clefts, we have a creature with a long tail, a sucking mouth with horny jaws, and two suckers below, and with external gills. In a later stage of metamorphosis the gills become covered by an operculum (o); two buds between the body and the tail are the rudiments of the future hind limbs; later on the signs of fore
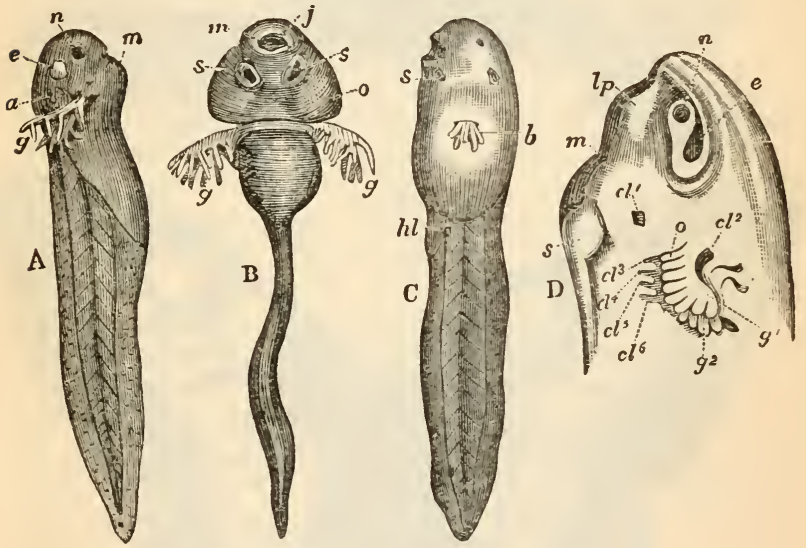

Fig. 217.-Structure of the Tadpole.

A, From the side : B, from below ; c, a later stage ; $\mathbf{D}$, head of tadpole; $g g^{\mathbf{l}} g^{2}$, gills ; $m$, mouth; $j$, jaws; $n$, nasal sac $: e$, eye $; a$, ear ; $o$, operculum ; $h l$, rudument of hind limbs; 8 , sucker; $l p$, upper lip; $c l$ te $c l 6$, visceral clefts.

limbs become apparent, the gills are lost, and their clefts disappear, while the tail gradually undergoes atrophy, and the larva is converted into a small quadruped tail-less frog, which breathes air by means of lungs. A similarly tailed larval stage obtains in some of the Urochordata, which, in adult life, are fixed.

Among the Arthropoda, Insects, as we well know, present, when their metamorphosis is "complete," three distinct stages ; in the earliest stage, or that of the "larva" (Fig. 218; A), the product of the 
532 Comparative Anatomy and Phisiology.

developed egg has a more or less worm-like shape ; it may be headless and legless (maggot), or have a head, but no legs (grub), or be provided with head,

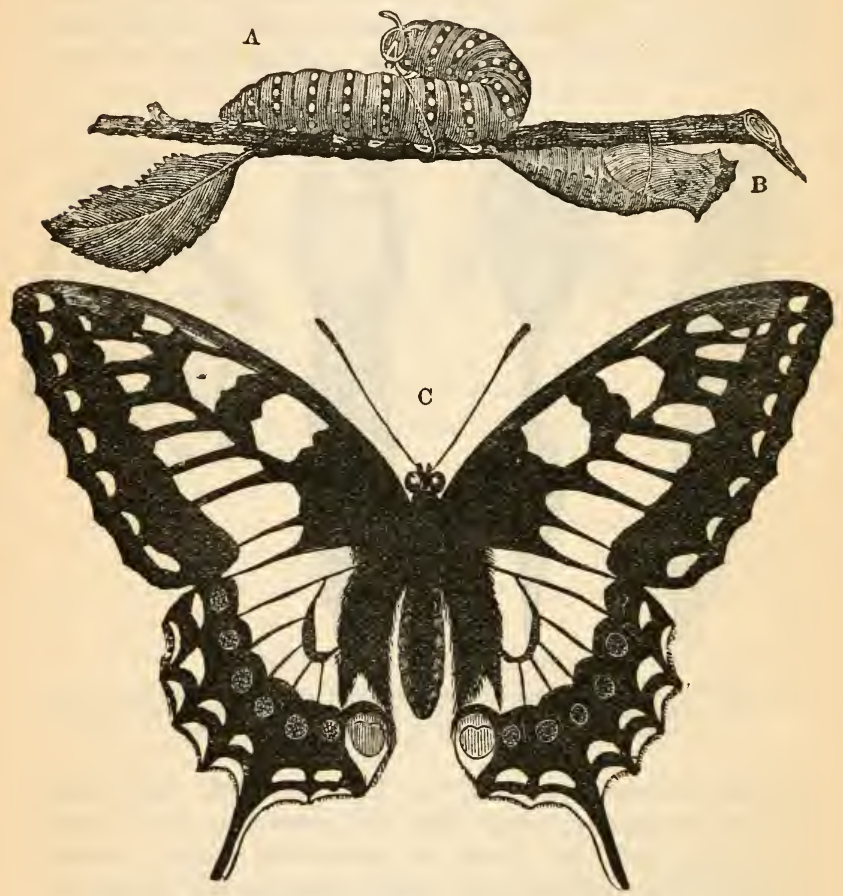

Fig. 218.-A, Larva ; B, Chrysalis ; c, Imago of Papilio machron.

legs, and fore-legs (caterpillar). The larva grows, and moults its skin as it grows; after a time it ceases from this active mode of life, and passes into a more quiescent condition, as in the case of the butterfly, or, 
even in this pupal stage, it continues to move about actively; during the pupa stage a number of changes occur within the body, and organs, such as the wings, which were absent from the larva, are developed from masses of indifferent cells, the so-called imaginal dises. The most complete series of changes during the pupal period obtain in the Flies; all the organs of the larva,except the generative, undergo degeneration, while the abdomen of the imago is derived from that of the larva; the imaginal discs, which are formed of minute cells, and enclosed in a structureless
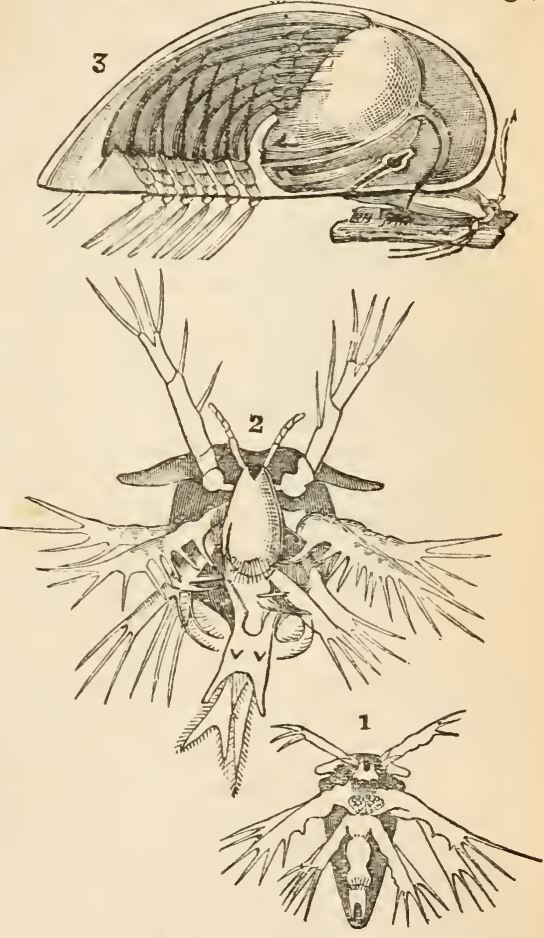
capsule, g row Fig. 219.-Larval form of Cirripedia. 1, Nauplius of rapidly; those Balanus; 2, Larva of Chthamalus stellatus; 3 , Older in the lower

portion of the thorax become united by pairs, and give rise to the legs; those in the upper portion become converted into the wings and halteres; the cephalic 
discs similarly give rise to the head and its appendages.

In the developmental history of the Crustacea there are two larval forms or stages which are very widely distributed among the different orders; the appearance of these has been of very considerable assistance in determining the real zoological position of such forms as the barnacle and the parasitic Copepoda, which, when adult, have an appearance altogether unlike that of Apus or Astacus (Fig. 219).

Like many other larvæ, these free-swimming forms were, when first observed, thought to be distinct animals, and received in consequence distinctive names. The first is the stage known as that of the Nauplius. In this the larva has an unsegmented body and three pairs of appendages of which thetwo posterior are biramose, a single median eye, and a distinct digestive tract. In the lowest forms, the Phyllopoda, this nauplius passes gradually into the adult stage, the body becoming segmented, and fresh appendages appearing as the crustacean grows in size, and undergoes its periodical ecdyses, or sheddings of the outer skin.

Among the higher Crustacea (Malacostraca) the larvæ are hardly ever found freely swimming in the Nauplius stage; they more frequently make their appearance at a more advanced period, or that which is known as the Zoca. Here we have a cephalothoracic shield, which is often, though not always, provided with long spiniform processes, the iongest of which projects upwards from the middle of the back ; the tail region is developed, but, like the hinder part of the thorax, it is without the appendages that are already developed in the anterior region of the body ; lateral eyes are present in addition to a median one. This Zoea stage is often succeeded by others, in which certain characters are greatly exaggerated, or in which there are presented arrangements which are permanent 
in less highly developed forms, but only transitory in the higher ; these, however, cliffer in different orders, and are beyond our consideration here.

Finally, it is to be borne in mind that some Crustacea leave the egg in a form essentially similar to that of their parent; of such forms the crayfish is an example.

Some remarkable larval forms obtain among the

Echinodermata, and the wide distribution of species which, when adult, are capable of but a slight amount of locomotion, must be ascribed to their possession of free-swimming ciliated larvæ. The most instructive examples are presented by the Comatulicle, which are members of the group Pelmatozoa, but are stalked in their larval stages only, during which, therefore, they have a certain resemblance to the permanentlystalked Pentacrinus. After passing through a short period of free existence, in which the cilia are arranged in four transverse bands (Fig. 220), and during which two sets of

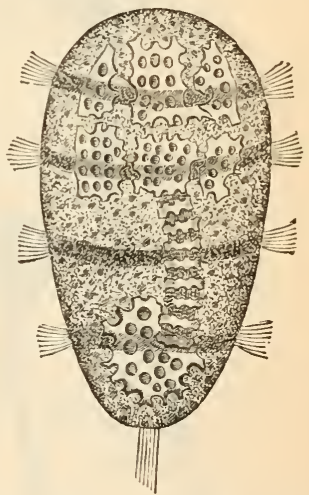

Fig. 220.- Torsal view of the Larva of the Common British Feather-star ( $A n$ tedon rosacea); $\times 20$. (After Wyville-Thomson.) five plates and a short calcareous stem become developed, the larva loses its ciliated bands, and becomes fixed by the stalk (Fig. 221 ; A) ; at the free end of this stalk the arms become developed, and below the cuplike portion (calyx) there appear the jointed processes which are known as the cirri. The calyx and the top joint of the stem break away from the rest, and we get the Comatulid which is capable of a certain amount of locomotion. 


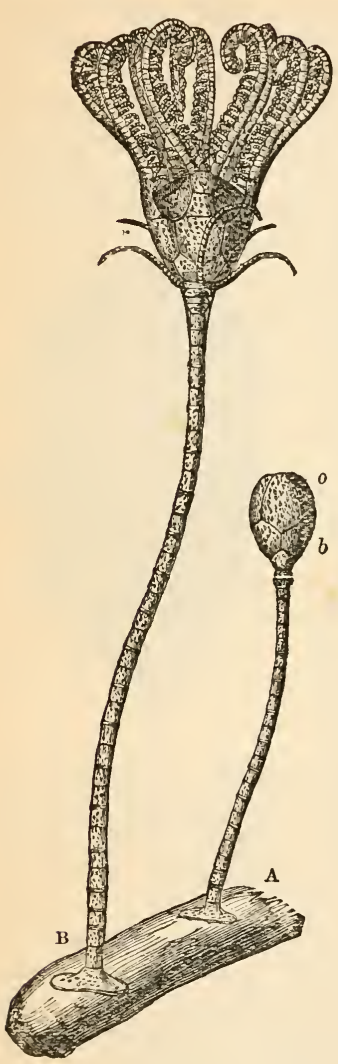

Fig. 221.-Pentacrinoid Larvæ of the Feather - star (Antedon rosacea).

A, Quite young, before the opening of the cup, and the appearance of the five radial plates: $B$, nearly uxture; $b$, hasal; $o$, orals ; $r$, first radials. (After Carpenter.)

Among the Echinozoa we often find arrangements which exhibit more completely the characters of a true metamorphosis, and which are of especial interest because they present a bilateral symmetry, such as is ordinarily obscured in the adult. The simplest conditions obtain in the Holothurians. After passing through the early stages of development, the body, which was originally covered with cilia, has these processes arranged in a sinuous band at its edges.

The anterior portion of the enteric tract, before uniting with the hinder involution, the orifice of which forms the permanent anus, buds off a vesicle, which becomes completely separated from the enteric tract, and the cavity of part of which forms the body cavity. The vesicle elongates, and sends outwards a process which comes into contact with the dorsal surface of the body, or that which is opposite to the surface on which the mouth opens; this process, or diverticulum, has an opening 
to the exterior (Fig. $222 ; w p$ ). The vesicle then breaks up into three parts, the most anterior of which gives rise to the water-vascular ring and its appended canals, while the two more posterior (Fig. $222 ; r p, l p$ ) give rise to the general body cavity, the lining of which is formed by their walls. In Holothurians generally, though not always, the connection between the vascular system and the body wall becomes broken, and the madreporic canal hangs freely in the body cavity.

Among other Echinozoa the amount of difference between the larval and the adult stage is much greater than it is in Holothu. rians; the larvæ are more elaborately de. veloped, and present distinct evidences of secondary adaptations to their free mode of life. The sides of the

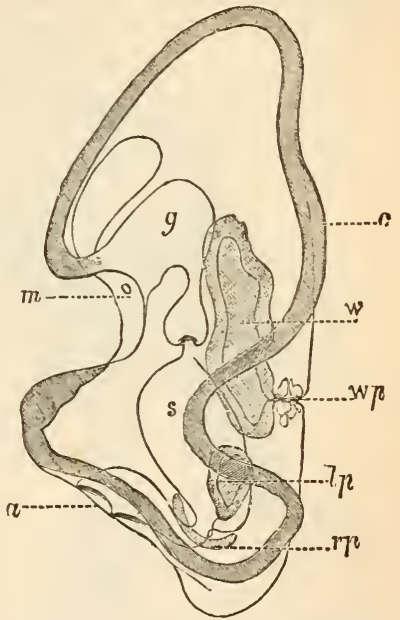

Fig. 222.- Dingrammatic View of the $I$ arva of a Holothurian (from the side).

$m$, Mouth ; $g$, gullet; $\delta$, stomach; $a$, anus; $c$, longitudinal ciliated band; $w$, rudiment of water-vascular ring; $w p$, water-pore; $r p, l p$, right and left peritoneal cavities, from which the hody cavity is developed. (Frum P. H. Carpenter, after Selenka) body are not unfrequently produced into free arm-like processes, the interior of which may (Pluteus larvae, Fig. 223), or may not (Brachiolaria), be supported internally by delicate calcareous rods. Part only of the body of such larvæ passes directly into the substance of the adult; the rest is either absorbed by the growing echinozoon, or shrivels up and disappears. The 
connection between the peritoneal vesicle and the outer world is permanently retained, and forms the so-called madreporic canal.

A few Echinoderms (Hemiaster, Ophiacantha vivipara, Chirodota rotifera) do not pass through any

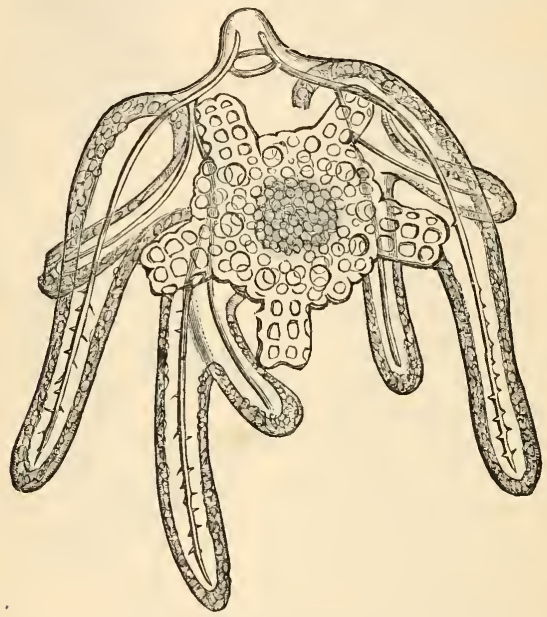

Fis 223. - Pluteus paradoxus, the Larva of an Ophiuroid, at a late stage, in which both the Larval Arms with their supports and the rudiments of the Disc and Radial Skeleton of Adult are to be seen. (After J. Müller.)

larval stages; the eggs are received into incubatory pouches, or are developed in the cœlom without passing through any larval stages, or leading a freeswimming independent existence.

A very common form of free-swimming larva is that which is known as the Trochospliere, and which essentially resembles the adult condition of a Rotifer; it is found among the marine Chætopoda, some of the Gephyrea and Mollusca, and in the 
Bryozoa. It is characterised by the possession of a circlet of long cilia, which separates the anterior portion of the body of the larva (preoral lobe) from that which lies behind it (Fig. 224); this ciliated circlet is retained throughout life by the Rotatoria. In addition to it, other circlets may become developed. The most common of these is that which appears in the region of the anus (telotrochal larvae); in others several bands of cilia are formed (polytrochal), and these sometimes encircle the whole body, and are sometimes dorsal and sometimes ventral in position. The banded condition is preceded by one in which the cilia are equally distributed over the whole body.

The Trochosphere is provided with a definite digestive tract, the lining of which is ciliated; has a fairly well developed nervous system and a sensory apparatus in the præoral

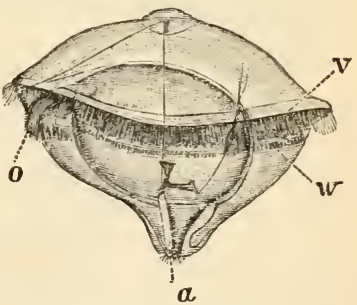

Fig. 224,-Larval Chætopods.

$o$, Mouth ; $r$, anus ; $v$, præoral ; $v$, postoral ciliated band. (After Hatschek.)

lobe; there is also a paired excretory organ, which opens into the body cavity by several funnel-shaped orifices. As the postoral portion increases in length the bands of mesoblastic cells undergo segmentation, and the præoral portion becomes proportionately smaller. Later on it develops the tentacles characteristic of the Chætopod, and loses the band, or bands of cilia.

All the Mollusca have not a free-swimming larva which can be referred to this type; in the common fresh-water mussel the ova are developed under the shelter of the gills; here they become provided with a bivalved shell, the free edges of which are toothed; the larva cloes not fix itself to its parent by these hooks, 
but by the byssus-threads, which are secreted by a gland at the hinder end of the body. After a time the Glochidium, as the larva at this stage is called, breaks away from the parent, and makes it way to some of the fish that live in the same water. To the gills or other part of these hosts it fixes itself by its toothed shell, while the byssus gland becomes aborted, as do also the sense organs with which the larva is provided. Attached to and covered by the epidermis of its host, the young mussel undergoes a series of further changes and takes on the characters of the adult.

When the Molluscan larva is referable to the trochosphere type, it has, as Lankester was the first to point out, two distinctive characteristics; on the ventral surface, between the mouth and the anus, there is a projection which is the rudiment of the foot, and on the dorsal surface there is an epiblastic ingrowth which forms the shell gland. The larva of Chiton is remarkable for having the posterior dorsal region segmented.

The simplest of all known larvæ are found in the Colenterata, where they have the form of a twolayered oval or elongated body, covered externally with cilia, and provided with a central gastric cavity, but without a mouth. In the simplest cases this Planula becomes fixed by one end, loses its cilia, and begins to develop tentacles at its free end. In the common jelly-fish (Aurelia) and in the vast majority of the Acraspedota a very remarkable metamorphosis obtains. The free-swimming planula having settled down and become fixed (Scyphistoma stage) in the form of a polyp with a central mouth (Fig. $225 ; \mathrm{A}$ ), begins to undergo division into a number of saucerlike rings set one below the other; each of these Strobila contains a portion of the gastric cavity, and, as development proceeds, the edges of the saucers 
become produced into eight lobes into which prolongations of the central cavity extend. After undergoing some further development, each saucer in turn breaks away from the common stock, and, as an Ephyra, with a disc of gelatinous tissue, a layer of muscle, and eight bifid tentacular lobes, swims about freely, increases in size, and becomes gradually converted into an adult sexually mature jelly-fish. Here, then, we have an example of "alternation of generations"; the fertilised ovum gives rise, through the planula, to the Hydra-tuba, the parts of which undergo by constriction a serial multiplication, and each part gives rise to a sexually mature form.

AIternation of generations. - This complex process has, from various eauses, been considerably obscured, and various

A

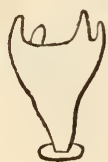

B
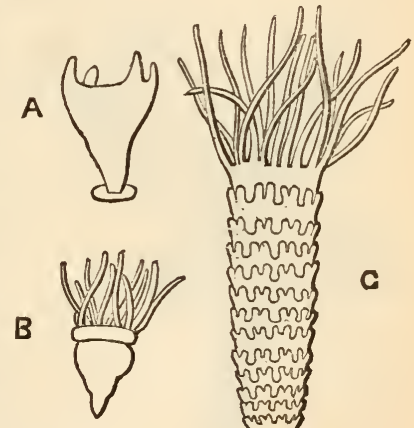

innom

C

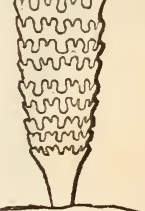

Fig. 225. - Development of Aurelia aurita.

A, Polyp stage ; B, commencement of transversc cleavage: $c$, completion of the same so-called Hydra-tube stage. (After Sar8.) terms have been applied to the various ways in which this phenomenon has been observed. As seen among the hydrozoic Cœlenterates, Annelid worms, and Tunicata, it may be thus described in the words of Balfour: "The simplest cases are those in which an individual which produces by sexual means gives origin to asexual individuals differently organised to itself, which produce, by budding, the original sexual form, and so complete a cycle .... In all these cases the origin of the phenomenon is easily understood. It appears, as is 
most clearly shown in the case of the Annelida, that the ancestors of the species which now exhibit alternations of generations originally reproduced themselves at the same time both sexually and by budding, though probably the two modes of reproduction did not take place at the same season. Gradually a differentiation became established, by which sexual reproduction be-

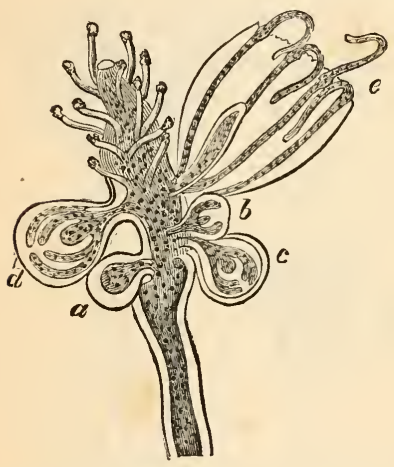

Fig. 226.-Figure of Syncoryne with a number of Budding Medusæ on it at Different Stages ( $a$ to $e$ ) of Development. (After Desor.) came confined to certain individuals, which in most instances did not also reproduce asexually. After the two modes of reproduction became confined to separate individuals, the dissimilarity in habits of life necessitated by their diverse functions caused a difference in their organisation; and thus a complete alternation of generations became established. The above is no merely speculative history, since all gradations between complete alternations of generations and simple budding combined with sexual reproduction can be traced in actually existing forms."

When alternation of generations is fully expressed among the Hydrozoa we find that the sessile hydriform colony gives rise to buds which gradually break away from their colony and become free-swimming (Fig. 226). Differing in some details from the structure of the Medusa already noted, these forms are still more interesting in that between them and the ordinary hydroid polyp we find a series of stages which 
have been variously regarded as grades of development or of degradation.

We find, that is, that the medusiform buds do not always become separated from the stock that has produced them; and while in some cases (e.g. Syncoryne itself, towards the end of the breeding season, or Tubularia) the buds are fully formed medusæ, in others, though still bearing the sexual organs, they are nothing more than projections from the sides of the body, in which the medusoid characters are hardly, if at all, apparent (Hydractinia). These stages of difference in the medusoid buds are allied, on the one hand, to the condition which obtains in the common Hyclra, where ova and spermatozoa are developed in one and the same individual, and in which the young do not pass through any larval stage; and on the other, to what is seen in Geryonia, for example, where the hydriform condition is altogether suppressed, and the larva, after a certain amount of metamorphosis, passes into the medusoid condition of its parent. In both of these cases there is no alternation of generations.

A series of very interesting conditions are exhibited by different Annelids. In Lumbriculus there may be simple transverse division of the body, one half of which acquires a new tail, and the other a new head; in Ctenodrilus it has been observed that the anterior half of the body may again divide; in Syllis the generative products are developed in the posterior half only of the body; in Myrianida the same products are confined to the forms that arise by budding, so that from a simple case of transverse division we have come to a complete example of alternation of generations.

In some cases (e.g. the fresh-water Nais) there is not simple transverse division, but the formation first of all of a so-called "zone of gemmation;" here the zone becomes converted anteriorly into an anal zone, 


\section{Comparative Anatomy and Physiology.}

and posteriorly into a fresh head; several zones of gemmation may appear before the zooids break awhy from the parent, and begin to develop generative organs. In Protula, the parent reproduces sexually, as well as the buds, but in Autolytus the genital glands are confined to the zooids that have been developed by budding.

The most complicated alternations are found among the Urochordata,* a large number of which multiply by budding; a simple case is presented by those forms in which the bud arises as an outgrowth of the body wall, together with a prolongation of part of the intestine. From this outgrowth the organs of the bud are fashioned, and the bud, breaking away, gives rise to fresh buds. Both bud and parent develop generative organs and reproduce themselves sexually.

In Botryllus the product of a fertilised ovum gives rise to a single bud; this gives rise to two, each of which again develops two buds; the four buds arrange themselves round a common cloaca, then give rise to two or three buds, and these again to others. These last, which may go on budding, are the first that are provided with sexual organs.

In Pyrosoma the product of a fertilised ovum gives rise, while still an embryo, to four zooids; these reproduce sexually, and so give rise to fresh colonies, or multiply by budding, and so increase the size of the colony.

The height of complexity is reached by Doliolum, the embryo of which is at first tailed, but becornes cask-shaped in form, like its parent. From its dorsal surface there grows out a process or Stolon, at the sides and along the dorsal middle line of which buds appear. The former become converted into the spoonlike forms of Gegenbaur, and become free; their

* The account given by Balfour ("Comparative Embryology," vol. ii.) has been closely followed here. 
further history is as yet unknown. The dorsal buds take on the form of the parent with sexual organs, but do not themselves become sexually mature; they develop a stolon from their ventral surface, on which appear buds that grow up into the sexual forms.

The relations of these different stages is shown by the following table :

Sexual generation.

First asexual form with dorsal stolon.

Spoon-like forms developed as lateral buds (future history unknown).
Second asexual forms developed as median buds with ventral stolon.

Sexual generation.

A somewhat different condition of things is found among the endo-parasitic forms, where, as a rule, the animal passes through its different stages in two different hosts; we may take as typical the histories of the common tapeworm, and of the liver-fluke which causes the "rot" in sheep (Distomum hepaticum).

Tania solium is sexually mature in the intestine of man, and the final joints of the tapeworm consist merely of fertilised ova, which have already passed through the earlier stages of development; when the joints become free and escape to the exterior, they break up, and the contents escape in the form of embryos contained in a thick chitinous shell. If these are now swallowed by a pig, the shell is digested by the gastric juices of the new host, and a rounded embryo, which is provided with three pairs of hooks, is set free; by means of these hooks the guest makes its way through the wall of the stomach or intestine, and finally settles down in the muscles of its host. The embryo now loses its hooks and gradually acquires a bladder-like form, the central cavity of which is filled with fluid, while circular and J J-16 
longitudinal muscular fibres are developed in its walls. This bladder-worm (cysticercus), now has its outer wall pushed inwards at the anterior end, and on the involution so formed hooks and suckers become developed, in such a way that when, as next happens, the involution is turned inside out, these hooks and suckers lie on the outer surface of the so-called "head."

We have now a narrow head and neck with an attached bladder (Fig. 227), the head being at this time hollow, and having in it a

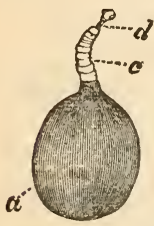

Fig.227.-Cysticercus cellulosa (after Von Siebold), showing the Head $(d)$, Neck $(c)$, and Vesicle $(a)$. circular vessel which communicates with four longitudinal fibres.

If, during the long time that these "bladder-worms" remain alive, the pig is killed for food, and afterwards insufficiently cooked, they are, when the pork is eaten, conveyed into the human stomach. Here the bladder-like termination becomes absorbed, and the neck, increasing in length, becomes divided into joints which are constantly produced at the anterior end; the oldest joints (proglottids) are, in other words, farthest from the head. In them sexual organs are developed, and the cycle recommences.

Distomum hepaticum, of which several hundreds may occupy the liver of one sheep, is of extraordinary fecundity, producing at least as many as one hundred thousand ova; these only pass through their earliest segmentation phases in the warmth of the mammalian body, but when they escape and reach a moderately warm and moist place, the egg commences to develop rapidly within its firm shell. When ready to escape as an elongated ciliated larva, the embryo bursts the cap of its shell, and begins to move about freely. If the pasture on which it has fallen is moist, the larva soon finds a stream of water along which 
it may pass to the neighbourhood of its next host; this has been shown by Thomas to be the small airbreathing snail which is known as Lymmaeus truncarulus. Provided at its anterior end with a papilla which acts as a most efficient boring-organ, the larva forces its way between the cells of the wall of the lung of the Lymnæus, and makes its way into the lung cavity. In this position it loses its elongated and acquires a rounded form, giving rise to the so-called sporocyst stage. The cells within the body which have not yet been used up in the formation of any tissue, arrange themselves in clefinite groups, each of which gives rise to an elongated larval form not unlike a gastrula (Fig. 228), save that it is provided with a definite pharynx, has an "annular ridge," and two short blunt processes behind. We have now the Rédia stage. The Rédia, becoming free, may make its way into other organs of the snail's body; within this Rédia fresh Rédiæ may be again developed, or the germinal cells within it may, instead, give rise to yet another form. At any rate, the final product of rédiæ, or daughter-rédiæ, is a

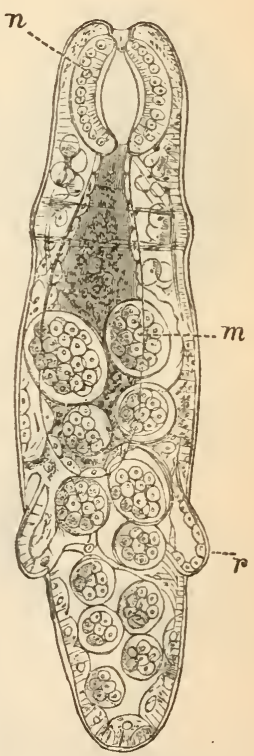

Fig. 228. - Rédia of $D$. Hepaticum. (After Thomas.)

$n$, Pharynx ; $m$, contained germs ; $r$, posterior processes.

body of rounded form with a long tail (Fig. 229), to which the name of cercaria has been long since applied. The parasite in this stage makes its way to the exterior, and, becoming enclosed in a firm cyst, loses its tail; these cercarian cysts take up their 
position at the roots of the grass, and so on, and in time either die down, or are eaten by a sheep. When the latter misfortune happens, they pass into the stomach, and so to the gall ducts and liver, to grow

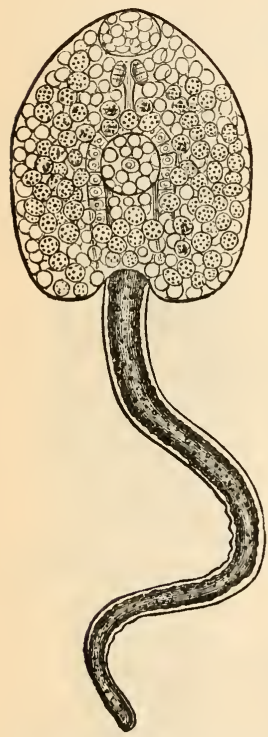

Fig. 229.-Cercaria of $D$. hepaticum. (After Thomas.) up afresh into the likeness of the liver-fluke from which they started.

Histories not unlike those of these two divisions of the Platyhelminthes are presented by the round-worms or Nematohelminthes, and by the Echinorhynchi. The thread-worm of the human blood (Filaria sanguinis hominis), which appears to be the cause of chyluria and of some other diseases in the countries of the Eastern Old World, has been found to have an intermediate host in the mosquito, from whom it passes into water; when this water is drunk the young return to the human intestine. Dracunculus medinensis lives in its adult condition in the subcutaneous tissue of the human leg and foot; its larval stages being passed, as it seems, in a fresh-water crustacean. Trichina is an example of a form which appears to have had its history modified; in societies that may be called cannibal (e.g. rats) no intermediate host would appear to be necessary; in the case of civilised man, the adult worms are obtained from the flesh of incompletely-cooked pigs. 


\section{N D E X.}

Acanthocephala, 51; hooks, 283; gonads, 489

Acanthometra, 27 ; skeleton, 276

Acarina, 74 ; respiration, 228

Achæta ; cilia, 56

Achtheres; gnathites, 179

Acineta, 31; suckers, 177

A cipenser, 91 ; skull, 326

Acraspedota, 42 ; nervous system, 395

Actinophrys, 27

Ærobranchiata, 73

Alcippe, 69

A mblystoma; oral glands, 158

Amia, 92

Ammothoa ; figure, 72

Amniota, 93

Amœba; structure, 18 ; zoological position, 27 ; respiration, 210 ; ectosarc, 274

Amphibia, 89, 93 ; teeth, 145 ; tongue, 154; oral glands, 158 ; heart, 195, 202 ; respiration, 232 , 236 ; kidneys, 259; glands, 266 ; vertebral column, 314, 321 ; skull, 330; mouth, 336 ; scales, 365 ; brain, 421 ; sensorv organs, $436,454,467$; gonads, 506

Amphioxus; segmentation, 32, 87

Amphipoda, 70

Amphiuma, 93; blood corpuscles, 182

Amphonyx; proboseis, 132

Ampullaria; respiration, 228

A nabas, 93 ; suprabranchial organ, 234

Anguillulidæ ; oral bristles, 114; respiration, 211

A nisopleura, 81

Annulata, 54; digestion, 117 ; gills, 218; skeleton, 286; eyes, 446 ; gonads, 489

Anodon, 80; blood-vessels, 191.

Anoplophrya; figure, 104

Antedon, 63; nervous system, 402 ; copulation, 492

$$
\mathrm{J} \mathrm{J}^{*}-16
$$

Anthozoa, 43; mouth, 110 ; siphonoglyphe, 111; figure, 112; yellow cells, 272 ; skeleton, 280 ; muscles, 373; gonads, 481

Anthropoidea, 100

Anura ; respiration, 236 ; kidneys, 259 ; testes, 506

Aphrodite, 5t; cæca, 118

Aplysia, 81; intestine, 137

Appendicularia, 87 ; heart, 193 ; house, 313

Aptera; zoological position, 75 ; gnathites, 128 ; spriugs, 379

Apus; nervous system, 405 ; ova, 494; carapace, 299

Arachnida; organisation, 72 ; parasitic, 180 ; heart, 190 ; respiration, 225 ; limbs, 377 ; gonads, 499

Arca; gills, 220

Arenicola; gills, 219

Argonauta; shell, 309

Argulus ; gnathites, 180

Arthropoda, 64; gnathites, 122 ; blood-vessels, 187; tracheæ, 215 ; stigmata, 216; renal organ, 256 ; skeleton, 291; locomotion, 375 ; nervous system, 405 ; sensory organs, $434,438,418,461$; gonads, 494

Artiodactyla, 99 ; limbs, 357

Ascaris, 51

Ascetta; figure, 35

Ascidia, 88; atriopore, 231

Ascon, 35

Asiphoniata, 80

Aspidogaster, 49

Asterias, 63; figure of arm, 61 ; skeleton, 294

Astropecten, 63 ; figure, 59 ; loss of anus, 121

Atlanta, 82

Aurelia, 42 ; figure, 42 ; respira. tion, 211; gelatinous tis:ue, 286 ; nervous system, 395

Axolotl ; oral glands, 158

Azygobrancliata, 82 
Balanoglossus ; figure, 86

Balanus, 69

Balistes ; teeth, 144

Bdellostoma ; kidneys, 259

Reroe ; mouth, 113

Birds, 97; tongue, 151; oral glands, 159 ; erop, 162 ; gizz.rd, 163 ; intestine, 169 ; bursa far bricii, 170 ; vitelline duct, 171 ; arterial arches, 205 ; lungs, 239 ; kidueys, 261 ; metallic colours, 273 ; vertebræ, 316,321 ; jaws, 340 ; fureula, 349 ; limbs, 352 ; feathers, 366 ; wings, 336 ; voice, 390 ; brain, 423 ; spinal co.d, 430 ; sensory organs, 437, 412, 455,$470 ;$ gonads, 506

Boltenia, 88

Bonellia; proboscis, 118

Bothriocephalus; joiuts, 50 ; gouads, 455

Botryllus, 88; development, 514

Brachionus, 52

Brachiopoda, 100 ; shell, 311

Branchiopoda, 67 ; figure, 63 ; respiration, 223

Brissopsis ; nervous system, 390

Bryozoa, 101 ; intestine, 120 ; cell, 288; gonads, 489

Buccinum, 82

Bugula ; figure, 101

Butirinus, 20 ; intestine, 168

Caducichordata, 87; senfe-cells, 431

Cæciliæ, 93 ; penis, 520

Calcispongiæ, 35

Caligus ; gnathites, 179

Camels; water-bag, 167 ; foot, 357

Cardium, 80

Carinella, 85; nervous system, 398

Carmarina ; nervous system, 396

Carnivora, 99 ; jaws, $3 \pm 2$

Caryophyllæus, 50

Centetes; lower jaw, 342; teats, 523

Centrogonida; organisation, 69

Cephalochordat:, 86 ; digestive tract, 138; vascular system,193; respiration, 231; renal organ, 257; gonads, 506

Cephalopoda ; ink-bag, 138 ; brancbial hearts, 192; gills, 221; funnel, 222 ; renal organ, 255 ; ear, 463 ; gonads, 503

Ceratodus ; teeth, 14t; heart, 195, 202 ; fin, 362

Ceratospongix, 36 ; skeleton, 278
Cestoda, 49 ; nitrogenous waste, 250 ; hooks, 287 ; gonads, 485

Cestus, 45 ; figure, 46

Cetacea, 99; teeth, whale-bone,153 ; salivary glands, 160 ; retia mirabilia, 209; respiration, 242; kidneys, 261; skull, 34t; tail, 381

Cetochilus; figure, 68

Chalina, 36

Chamæleon ; tongue, 154 ; chromatophores, 272

Chætodermatidæ, 81

Chætodon, 93 ; teeth, 144

Chætognatha, 101

Chelonia, 96 ; fins, 97 ; intestiue, 169 ; bursæ anales, 170 ; $\mathrm{fiu}$, 353,384 . See Tortoise.

Chirocentrus, 90; intestine, 168

Chiroptera, 99

Chitonidæ, 81 ; shell, 306 ; eyes, 457

Chordata, 86; digestive tract, 138 ; vascular system, 192 ; respiration, 230 ; skeleton, 312 ; nervous system, 415 ; eye, 452 ; gonads, 505 ; larvæ, 530

Cicada; vocal organ, 389

Ciduris, 63

Ciliata, 30

Cirripedia, 69; shell, 299, 301

Clione, 82

Clypeaster, 63

Cockroach; zoological position, 76 ; figure, 76 ; gnathites, 130 ; intestine, 133 ; gonads, 497

Colenterata, 36,40 ; trophosomes, 109 ; gastro-vascular canals, 185 ; respiration, 211; nitrogenous waste, 248; gonads, 484. See also Medusæ.

Coleoptera; characters, 77 ; gnathites, 131; stomach, 133 ; elytra, 298; vocal organ, 389

Copepoda, 68

Corallium ; coral, 282

Cordylophora, 40

Crania : figure, 100

Craspedota, 40

Crayfish ; mouth organs, 123 ; gastric mill, 125; heart, 187 ; respiration, 223; scaphognathite, 123, 225; green gland, 253; skeleton, 301 ; nervous system, 413 ; sensory organs, 439, 449, 451 ; gonads ; 45

Crinoidea; organisation, 58 ; digestion in, 121 ; skeleton, 292 ; nervous system, 408; gonads, 492 
Crocodile, 97 ; stomach, 163 ; vertebræ, 315 ; skull, 340 ; scales, 355

Crotalus ; skull, 338.

Crustacea; organisation, 65; gnathites, 128 ; respiration, 223; branchial formula, 224; nitrogenous waste, 253 ; skeleton, 298 ; locomotor organs, 376 ; gonads, 499 ; larvæ, 534

Cryptocarpa, 40

Cryptoniscidæ; gonads, 500

Ctenophora, 45 ; cilia, tentacles, 373 ; gastric cavity, 113

Cucumaria, 61; lungs, 229

Cyamus, 72

Cyclodus, 96 ; scales, 366

Cyclops ; zoological position, 68 ; figure, 68 ; gnathites, 179

Cyclostomata, 88; mouth, 140 ; gills, 223 ; kidney, 258 ; skeletou, 314, 328 ; gonads, 506

Cymbulia, 82

Cymothoa; hermaphroditism, 500

Cyprœa, 82

Cytozoa, 24

\section{Demodex, 180}

Dendrocœlum, 49

Ventalium ; figure, 82

Desmodus; stomach, 167

Didelpbia, 99

Diodon, 92 ; exoskeleton, 385

Diphyes, 41

Dipnoi, 90 ; heart, 195 ; puluonary vessels, 203 ; lungs, :235

Diptera, 77 ; gnathites, 132 ; stomach, 13\%; imaginal disks, 533

Distomum, 49; digestion, 114; gonads, 486

Dog ; tongue, 157 ; salivary glands, 160

Dogfish ; teeth, 141 ; fins, 360

Dolium, 82 ; salivary glands, 137

Dolphin ; fore-limb, $35 \pm$

Doris, 81

Draco, 96 : flying organs, 383

Dytiscus ; eye, 450

Earthworm; digestion in, 115; typhlosole, 117; blood, 183; spermatozoa, 479 ; gouads, 490

Echidua, 98 ; teats, $5 \div 2$

Echinanthus, 63

Echinodermata, 58; digestion in, 120 ; respiration, 218,229 ; renal waste, 248 ; skeleton, 288 ; pedicellariæ, 297, 374; movements,
374 ; nerrous system, 400,407 ; sensory orgaus, $424,435,444,461$; gonads, 491 ; development, 535

Echinoidea; organisation, 63 ; skeleton, 289 ; sphæridia, 435

Echinometra, 63

Echinorhynchus ; figure 50

Echinozoa, 63

Echinus; zoological position, 63 ; test, 290 ; nervous system, 408 ; gonads, 491

Edentata, 99

Elasmobranchs, 90 ; heart, 195 ; labial cartilages, 335; brain, 420 ; taste-organs, 436 : gonads, 506 ; placenta, 514

Elephant; molars, 15 t ; skull, 343

Entoconcha, 180

Łntomostraca; parasitic, 179 ; blood - vessels, 188; skeleton, 298

Ephemeridæ; gnathites, 133

Ericulus; kidneys, 264

Euplectella; zoological position, 36 ; skeleton, 279

Eurystomata, 96

Euspongia; zoological position, 36

Eutheria, 99. See Mammalia

Euthyweura, 81

Exocœetus, 93 ; figure, 382

Fierasfer, 181

Filaria, 51

Firuloides, 82

Fishes; teeth, 142 ; spiral valve, 168 ; heart, 201 ; circulus cephalicus, 205; gills, hair-bladder, 232 ; operculum, .233; kidneys, 258 ; poison glauds, 266 ; eyelike spots, 269; vertebræ, 314; skeleton, 323 ; fins, 359 ; branchial bars, 328 ; mouth, 336 ; sounds, 392 ; brain, 420 ; spinal cord, 430; seusory orgaus, 4:36, $410,453,466$; eye-like organs, 458; gonads, 506 ; oviducts, 513 ; copulation, 519 ; care of young, 521

Flagellata, 30

Fluke; digestion, 178; neplridia, 248 ; gonads, 406

Fowl; pelvis, 351

Frog, 93; beart, 197; carotid gland, 203 ; vertebræ, 315 ; skull, 230 ; brain, 419 ; gonads, 506

Galago ; tongue, 157

Galeopithecus ; flight, 385 
Granoidei, 90; snout, 336

Gastropodx; divisions, 80 ; digestive tract, 135; blood-vessels, 191 ; gills, 221 ; lungs, 228 ; renal organ, 255 ; foot, 380 ; gonads, 502

Gephyrea, 56 ; digestion, 118 ; respiration, 230; nephrida, 251 ; gonads, 489

Glossophora, 80 ; odontophore, 135

Gnathopoda, 58

Gnathostomata, 88; mouth, 140

Goose ; gizzard, 164

Gordius, 51 ; moutll, 114, 179

Gorgonia ; zoological position, 44 ; figure, 44 ; skeleton, 281

Grantia, 36 ; sense-cells, 431

Gregarina, 25; reproduction, 474

Gromia, 27 ; figure, 26 ; test, 275

Gymuosomata, 82

Gymnotus ; electric organs, 269

Gy mnura ; teett, 150 ; stomach, 165

Hæmatobrauchiata, 73

Haliotis, 81

Halis : rca, 35

Hatteria, 96 ; teeth, 146 ; vertebræ, 315 ; jaws, 339

Hanstellata, 77

Hedgehog ; teeth, 151

Hedriophthalmata, 70

Helicidæ; teeth, 134 : gonads, 502

Heliozoa, 27, 29 ; skeleton, 276

Helix, 81

Heloderma ; oral glands, 159

Hemiptera, 77 ; gnathites, 132

Hesione; air sacs, 230

Hesperornis, 98

Heteropoda, 82

Hirudinea, 56 ; sensory organs, 433 ; gonads, 489

Histozoa, 24; nephridia, 252

Holopus, 121

Holothuria, 64; lungs, 229 ; cuvie. rian organs, 268 ; skeleton, 296 ; lurva, 372 ; gonads, 492

Homo, 100 ; erect position, 356 ; brain, 429 ; scrotum, 507 ; oviducts, 519 ; teats, 522

Horse; teeth, 153; stomach, 165 ; foot, 355

Hyalea, 82

Hyalonema ; spicules, 279

Hydra ; figure, 36, 40 ; digest:on, 105 ; chlorophyll, 272; sensecells, 432 ; gonads, 484

Hydractinia, 40

Hydrocorallinæ, 40

Hydromedusæ, 40; coral, 283
Hvmen $>$ pter 1,77 ; gnathites, 130 ; vocal organ, 389

Hyomoschus ; foot, 357

Hyrax, 99 ; сæca, 172

Ichthyopsida, 89

Infusoria, 29; digestion, 103 ; respiration, 210 ; lorica, 278 ; cilia, 371 ; reproduction, 476

Insecta; gnathites, 128 ; enteron, 133 ; salivary glands, Malpighian vessels, 134; heart, 190 ; respiration, 216 ; poison glands, 266 ; silk glands, 567 ; appendages, 303 ; wings, 378 ; vocal organs, 388 ; nervous system, 406 ; sensory organs, 436, 449, 439, 461; gonads, 497, 500 ; larvæ, 531

Insectivora, 99 ; brain, 426

Isopleura, 81

Isopoda, 70 ; parasitic, 180 ; respiratiou, 229 ; gonads, 499

\section{Lacerta, 96}

Lacertilia, 96 ; orel glands, 159

Læmodipoda, 72

Laganum, 63

Lamellibranchiata, 79 ; gills, 219 ; glochidia, 221 ; renal organ, 254; byssus, 268; shell, 306 : foot, 380 ; nervous system, 410 ; eyes, 457 ; ear, 462 ; gonads, 501

Lancelet. Ses Cephalochordata

Leech; mouth, 179; respiration, 212 ; nephridia, 252 ; movements, 373

Lemuroidea, 100

Lepidoptera, 77; gnathites, 131; stomach, 134

Lepidosiren, 90 ; teeth, 144

Lepidosteus, 92 ; teeth, 144; air sac, 235 ; ear, 465

Lepisma, 75

Leucon, 36

Ligula, 50

Limax, 81 ; shell, 305

Limulus, 70 ; respiration, 225; carapace, 299 ; eye, 451 ; spermatozoa, 499

Linckia, 63; comet form, 494

Lineus, 85

Lion ; skeleton, 318

Lipobranchiata, 74

Lipocephala, 79

Lizard; heart, 204 ; arterial arches, 205 ; gonads, 512

Loligo, 83; shell, 309 ; spermatophore, 505

Lophius ; teetb, 112 
Lumbricus, 56. See Earthworm.

Lymnæus, 81; lung, 228

\section{Mactra, 80}

Malacostraca, 69

Mallophaga ; gmathites, 133

Mammalia, 98; teeth, 148; tougue, 157 ; salivary glands, 159 ; stomach, 165 ; intestine, 170 ; cæca, 171 ; liver, 173 ; blood-corpuscles, 182 ; heart, 198; arterial arches, 205 ; jugulars, 208; lungs, 240 , 246; kiduey, 261 ; bladder, 263 ; vertebial column, 316; skull, 332 ; jaws, 342 ; hairs, 368 ; nails, 331 ; flying organs, 383 ; laryux, 392 ; brain, 425; spinal cord, 430 ; sensory organs, 437, 413, 456,471 ; gonads, 507 ; placenta, 514; vagina, 517 ; penis, 520 ; teats, 521

Mandibulata, 76

Manis, 99 ; vertebræ, 317

Macrolyristes; vocal organ, 358

Marsupials; respiration, 243 ; bladder, 263 ; lower jaw, 342

Medusæ; gastro-vascular canals, 110 ; nervous system, 395 ; eyes, 414 ; ear, 459 ; gonads, 484

Menobranchus, 93 ; gills, 236

Menopoma, 93; gill clefts, 236

Mesostomum, 49; digestion in, 107

Metatheria, 99

Metazou, 31

Millepora, 40 ; coral, 283

Mole; sternum, 348

Mollusca, 77 ; odontophore, 134 ; parasitic, 180 ; intestine, salivary glands, 136; heart, 191 ; respiration, 219; lungs, 228; renal organ, 254; byssus, 268; skull, 30 ; foot, 380 ; nervous system, 410 ; sensory organs, $439,447,449$; gouads, 501

Monera, 27

Monocœlis ; nephridia, 248

Monodelphia, 99

Monotremata; retia mirabilia, 209 ; bladder, 263

Musk-deer; feet, 355 ; brain, 427 ; cloaca, 517

Mussel; gills, 219; organ of Bojauus, 255 ; byssus, 268

Mya ; figure, 80

Myodora, 79

Myriopoda, 74; gnathites, 127 ; heart, 189 ; respiration, 216 ; appendages, 377 ; gonads, 499

My xine, 88, 181
M y xospongiæ, 35 ; ova, 483

Myzostomum, 102

Nais, 56

Nautilus ; figure, 83; gills, 221 ; sliell, 308; funuel. 381

Nematoids, 50; digestion, 114, 178 ; respiration, 211 ; gonads, 488

Nemertinea, 81; blood-vessels, 186 ; respiration, 213 ; gonads, 489

Neomeniidæ, 81

Nepa; guathites, 132

Nereis, 54

Neuroptera, 77; gnathites, 181 ; stomach, 133

Notacanthus, 92

Nudibranchs ; respiration, 222

Nummulites, 27, 28 ; test, 276

Oceania, 40

Octactiniæ, 43

( dontopteryx; jaw, 146

Odontornithes, 98 ; teeth, 146

Oligochæta, 56

Opalina ; digestion in, 104

Ophideres ; proboscis, 132

Ophidia; vertebræ, 314 ; skull, 337 ; scales, 355 ; oviducts, 513

Ophiocephalus, 92

Ophiocoma, 63

Ophiothrix, 63

Ophituroidea, 63: respiration, 218 ; skeleton, 295 ; gonads, 491

Orchesella, 75

Ornithodelphia, 98

Ornithorhynchus, 98 ; heart, 198 ; pelvic arch, 350

Orthoptera, 76; gnathites, 129 ; vocal organs, 388

Orycteropus, 99

Ostracocla, 69

Oyster, 79; foot, 380 ; gonads, 501

Paludiua, 82 ; gill, 228

Pangonia; proboscis, 132

Paramœcium ; figure, 29

Parrots ; tongue, 157 ; skull, 340

Patella, 81; gill, 221

Peachia ; mouth of, 112

Peccary ; stomach, 165

Pedipalpi, 74

Pelmatozoa, 63

Peltogaster, 69

Pennatula, 70; phosphorescence, 270

Pentacrinus; figure, 60,63 ; skeleton, 293

Pentastomum; hooks, 180 
Perenuichordata, 87

Perigonimus ; tigure, 37

Peripatus; figure, 64 ; guathites, 127; blood-vessels, 189; tricheæ, 215 ; nephridia, 257; skin, 299 ; appendages, 302,377 ; nervous system, 401; sensory organs, 434, 447; gouads, 498

Perissodactyla, 99

Petromyzon, 88

Pholas, 80

Physaliu, 41

Physoklisti, 92

Physophora ; figure, 41

Physostomi, 92

Pipa; tongue, 153

Pl.uaria, 49

Platyhelminthes, 49 ; gonads, 485

Pneumodermon, 82

Podophthalmata, 70

Podura, 75

Polia, 85

Polychæta, 54; larva, 539

Polynoe, 54

Polyodon, 91

Polyplacophora, 81

Polypterus, 92 ; brain, 421

Porifera, 35

Primates, 100 ; limbs, 356

Pristis ; teeth, 142

Proneomenia; nervous system, 401 ; gonads, 502

Proteus, 93; gill, 236

Prototheria, 98; vertebræ, 317

Protozoa, 25; disestion, 103 ; parasitic, 177 ; contractile vacuoles, 247; phosphorescence, 270 ; movements, 371 ; reproduction, 473 ; skeleton, 274

Protracheata, 65

Pteropoda, 82

Pycnogonoidea, 71

Pyrophorus; phosphorescence, 270

Pyrosoma, 88; phosphorescence, 270

R.bbit ; cæcum, 172 ; brain, 424 ; taste-bulbs, 433 ; placenta, 51.5

Radiolaria; yellow cells, 272; skeleton, 276

Ratitæ, 97 ; feathers, 368

Reptiles, 96 ; teeth, 145 ; salivary glands, 159; œesophagus, 162; intestine, 169 ; heart, 196 ; lungs, 239 ; respiration, 245 ; kidneys, 261 ; brain, 422; sensory organs, $437,454,467,471$; gonads, 512

Rhizocephala, 69

Rhizocrmus, 63
Rhizopoda; skeleton, 276

Rhyncopygus; auus, 121

Rodents, 99 ; teeth, 150

Rotatoria, 50 ; digestion, 118 ; re. spiration, 230; nephridia, 251

Ruminants; stomach, 166; retia, 209

\section{Sabella, 55}

Sacculina, 69; uutrition, 178

Sagartia, 39 ; section of, 111

Salamaudra, 93 ; ribs, 345

S.lmon ; teeth, 141

Salpa, 88

Sargus; teeth, 142

Sar'sia, 40

Sauropsida, 95 ; uric acid, 265 ; vertebral column, 314, 321; skull, 331

Scaphopoda, 82

Scarus ; teeth, 142

Scorpion; guathites, 127 ; mouth, 179 ; lung-books, pectines, 226 ; poison, 266

Sea-gull; gizzard, 176

Sełachoidei, 91

Sepia, 83

Serpula, 55

Sinupalliata, 80

Siphonopliora, 41

Sirenia, 99 ; respiration, 213 ; vertebræ, 317; limbs, 353

Snakes; teeth, 146; arterial arches, 205

Solen, 80; hæmoglobin, 212

Sprtangiảæ, 63

Spider; poison glands, 265; silk organs, 267

Sponge, 31 ; digestion, 106 ; respiration, 211; nitrogenous waste, 248 ; skeleton, 278 ; sensecells, 431 ; gonads, 483

Squatina ; heart, 196

Squilla ; figure, 69 ; testis, 498

Steatornis ; syrinx, 391

Steganophthalmata, 42

Stenostomata, 96

Stentor, 30 ; stentorin, 272

Strepsiptera, 77

Streptoneura, 81

Stylasteridæ; dactylozooids, 109

Suctoria, 31; digestion in, 104

Sun-birds ; tongue, 156

Sycon, 36

Synapta, 64 ; spicules, 296

Tænia, 49 ; digestion in, 177 ; plasmatic canals, 185 ; development, 545 
Teleostei, 90 ; teeth, 142

Teleostoidei, 92

Terebella; figure, 55

Termitidæ, 77 ; gnathites, 133

Tetrabranchiàta, 82

Thecosomata, 82

Theriumorpha, 95

Torpedo; electric org : ns, 269

Tortoise; shell, 366 ; brain, 4-2

Toxotes, 93

Tracheata, 74

Tragulus ; blood corpuscles, 182

Trichina, 50, 548

Trichoptera, 77 ; gnathites, 131

Tridacna, 80 ; shell, 308

Triton, 93 ; shell, 307

Tubicolæ, 55 ; setæ, 288

Tubifex, 56

Tubipora; figure, 43 ; skeletun, 283

Tunicata, 86 ; eye, 452 ; ear, 464

Tupaia; brain, 425

Turbellaria; digestion, 107, 113 ; circulation, 185 ; respiration, 211; nephridium, 249 ; nervous system, 400 ; tactile organs, 433 ; eyes, 415

Turtle; heart, 197 ; skeleton, 320 ; skull, 339

Typhlops, 96

Ungulata, 99 ; feet, 355

Urochordata, 86; digestive tract,
139 ; rascular system, 192 ; respiration, 231 ; renal organ, 257 ; yotochord, 313 ; larva, 544. See Tunicata.

Urodela, 93 ; respiration, 236 ; kidneys, 259 ; gonads, 506

Uropeltis, 96

Vagantia, 55

Velella, 41

Vertebrata, 88; digestive tract, 140 ; teeth, 141; tongue, 157; intestine, 161 ; liver, 175 ; blood, 181 ; vessels, 194 ; retia mirabilia, 208 ; hæmoglobin, 212 ; respiration, 231; renal organ, 257; vertebral column, 314; skull, 323; limbs, 347; vocal organ, 390 ; brain, 417 ; spinal cord, 430 ; sensory organs, 435, 437, 440, 453, 463; gonads, 505

Viper; fang, 147

Vorticellids, 30 ; contractile vacuoles, 247 ; movements, 371

Whales ; see Cetacea, 99

Wolf ; teeth, 152

Woodpecker; tongue, 156 ; skull, 341

Xiphacantha ; figure, 28 ; skeleton, 277

ZJgobranchiata, 81 



10686 
11. 3

$5 t^{\circ}$

8

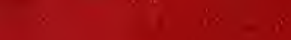

s

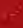

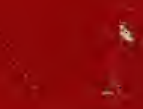

it
18

\&

$-1$ 